\title{
Mechanistic Analysis of Reductive Boracarboxylation Using Low Valent Copper and $\mathrm{CO} 2$
}

\author{
Notashia Nicole Baughman \\ West Virginia University, nnbaughman@mix.wvu.edu
}

Follow this and additional works at: https://researchrepository.wvu.edu/etd

Part of the Inorganic Chemistry Commons

\section{Recommended Citation}

Baughman, Notashia Nicole, "Mechanistic Analysis of Reductive Boracarboxylation Using Low Valent Copper and CO2" (2020). Graduate Theses, Dissertations, and Problem Reports. 7940.

https://researchrepository.wvu.edu/etd/7940

This Dissertation is protected by copyright and/or related rights. It has been brought to you by the The Research Repository @ WVU with permission from the rights-holder(s). You are free to use this Dissertation in any way that is permitted by the copyright and related rights legislation that applies to your use. For other uses you must obtain permission from the rights-holder(s) directly, unless additional rights are indicated by a Creative Commons license in the record and/ or on the work itself. This Dissertation has been accepted for inclusion in WVU Graduate Theses, Dissertations, and Problem Reports collection by an authorized administrator of The Research Repository @ WVU.

For more information, please contact researchrepository@mail.wvu.edu. 
Notashia Nicole Baughman

Follow this and additional works at: https://researchrepository.wvu.edu/etd

Part of the Inorganic Chemistry Commons 


\title{
MECHANISTIC ANALYSIS OF REDUCTIVE BORACARBOXYLATION USING LOW VALENT COPPER AND CO2
}

\author{
Notashia N. Baughman \\ Dissertation Submitted to the Eberly College of Arts and Sciences \\ at West Virginia University \\ In Partial Fulfillment of the Requirements for the Degree of \\ Doctor in Philosophy in \\ Chemistry
}

\author{
Brian V. Popp, Ph.D., Chair \\ Carsten Milsmann, Ph.D. \\ Jessica M. Hoover, Ph.D. \\ Brian S. Dolinar, Ph.D. \\ Werner Geldenhuys, Ph.D. \\ Department of Chemistry
}

Morgantown, West Virginia

2020

Keywords: Boracarboxylation, cooperative secondary ligand effect, mechanistic elucidation

Copyright 2020 Notashia N. Baughman 


\title{
ABSTRACT \\ Mechanistic Analysis of Reductive Boracarboxylation using Low Valent Copper and $\mathrm{CO}_{2}$
}

\author{
Notashia Baughman
}

The synthesis of organoboron compounds is of contemporary importance in the chemistry community given their utility in subsequent functionalization reactions as well as their growing therapeutic potential in the treatment of human disease. This, coupled with the ubiquity of carboxylic acid functional groups in pharmaceuticals and fine chemicals, has led to interest in onepot difunctionalization reactions using $\mathrm{CO}_{2}$ and a boron source. An (ICy)copper(I)-catalyzed boracarboxylation reaction was recently developed wherein $\mathrm{CO}_{2}$ and a pinacolboryl group is added across the double bond of vinyl arenes was recently developed, providing access to $\alpha$-aryl- $\beta$-boryl propionic acid derivatives. A subsequent publication detailed the addition of $\mathrm{PPh}_{3}$ as a secondary ligand, which permitted boracarboxylation of previously inaccessible styrene derivatives while also reducing catalytic loading.

An extensive experimental and computational mechanistic study has been conducted to validate the proposed mechanism and to understand the electronic considerations and the additive effects on the system. More stable analogs to catalytically relevant complexes were synthesized using the bulkier $\operatorname{IPr}$ NHC ligand. The rates of carboxylation for $\operatorname{IPrCu}^{\mathrm{I}}\left(\beta\right.$-borylbenzyl $\left.{ }^{\mathrm{X}}\right)$ complexes with varying electronic properties were examined, and results indicated the strong preference for electron rich vinyl arene substrates originates in the carboxylation step of the mechanism. $\mathrm{PPh}_{3}$ and exogenous alkene additives enhanced the rates of carboxylation for severely electron deficient $\operatorname{IPrCu}\left(\beta\right.$-borylbenzyl $\left.{ }^{\mathrm{CF}} 3\right)$, suggesting alternative pathways for $\mathrm{CO}_{2}$ incorporation are operative.

Complementary computational studies were performed using density functional theory (DFT) to explore the effects of electronics of the vinyl arene and the inclusion of additives for carboxylation. Further, the effect of the Lewis acidity of the boron moiety on $\mathrm{CO}_{2}$ insertion was evaluated using boron valence deficiency. Analyses of these data corroborate conclusions drawn about an alternative mechanism determined experimentally and provided evidence of a Lewis acid/base cooperative interaction between the boron center and $\mathrm{CO}_{2}$ that promotes carboxylation. 
Dedicated to Judith Spencer and Loretta Fazenbaker 


\section{ACKNOWLEDGEMENTS}

I would like to thank my family and loved ones, friends, and colleagues for their support and encouragement during my time at West Virginia University. Many thanks to my advisor Dr. Brian Popp, who through his instruction and guidance has inspired me to learn as much as possible while under his tutelage. He has been remarkable in allowing me to explore new ideas while also keeping me on track. Additionally, I appreciate his demonstration of extraordinary patience. I have the tendency to be stubborn, but he never stopped pushing me, and I am appreciative of that. He has been a truly great advisor, and moreover he is a kind and respectful person. Thank you so much

for maintaining a relationship with me and the rest of the group that is inclusive and has helped us flourish as researchers and as well-rounded people.

I would also like to thank my committee members Dr. Carsten Milsmann, Dr. Jessica Hoover, Dr. Brian Dolinar, and Dr. Werner Geldenhuys. I appreciate that you each took the time and energy to not only attend my oral presentations but also for the numerous times I have asked for help with academic endeavors as well as life matters. I would like to especially thank Carsten, who I constantly sought out for questions when Dr. Popp was unavailable. Dr. Jeffrey Petersen has also played an invaluable role in my experience at WVU. Thank you for continuing to push me and being supportive when I struggled. You really are one of the best professors I have ever had the pleasure to interact with. I would like to thank Dr. Novruz Akhmedov for his assistance with numerous NMR studies, as they were invaluable to understanding the complexities of our chemistry. More importantly, he is genuinely excited about the success of all students and is a joy to be around. He is greatly appreciated.

The staff at WVU also deserves great thanks, as it takes so many people to keep a department moving forward, and they have played no small part. Thanks to Becky Secrist, who always had the interest of the students at heart, and Brenda Prentiss, who is so generous with her time to assist. Randy Eaglen and Allen Burns kept our lab up and running until their retirement and were an instrumental piece of the department! A special thanks to Sherman Adams, who is a great glass blower and an even better conversationalist. If you want a good discussion about anything, he is the man for the job! We as a department are lucky to have him.

I also want to thank the Popp group members, past and present. When I came to WVU in 2015, it was Dr. Trina Perrone and Dr. Brian Nichols that got me started. They were patient with 
me and taught me everything I needed to know to be successful. I owe them a great debt of gratitude. Thanks also to Dr. Jessica Rogers and Rachel Pickens, past Popp group members. To the current group members Steven Knowlden, Randika Abeysinghe, Alexa Martin, Carly Gordon, Stephen Long, and Mason Hamilton, I also owe a lot. I have had the profound privilege of having my great friend and a fellow West Virginia Wesleyan alum, Dr. Brett Hakey, nearby (across the hall) for the past several years. I think it is rare to find a group of people that you can work with seamlessly, but it is rarer still to find a support system so strong. It has truly been a joy to experience graduate school alongside you folks, and I wish each of you all the best in life.

Finally, I would like to thank my loved ones. Thank you to my friends and those nearest to my heart for giving me your unwavering support. I am very fortunate to be surrounded by people who care about me. A special thanks is owed to my parents, Matthew and Jeanie Spencer and Nathan Baughman. Despite the challenges that life presented, each of you were instrumental in getting me to this point, no matter the circumstances. Thank you for always being proud of me. 


\section{TABLE OF CONTENTS}

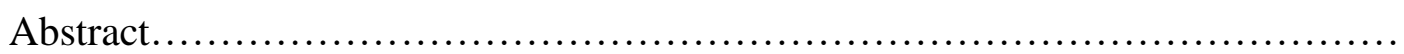

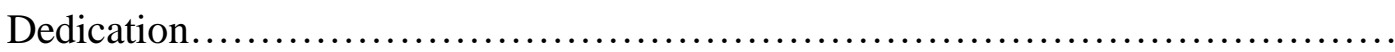

Acknowledgements........................................................

Table of Contents .............................................................

List of Abbreviations........................................................

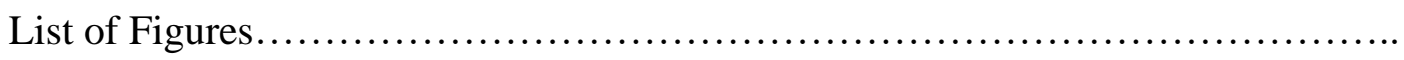

List of Tables...........................................................

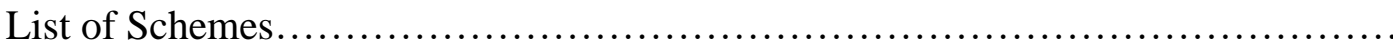

page

ii

iii

iv

vi

viii

ix

xiii

xiv

CHAPTER I. Carbon Dioxide Utilization by Transition Metal Complexes

1.1. Ubiquity of Carbon Dioxide

1.2.1 Stoichiometric $\mathrm{CO}_{2}$ Fixation via Cyclometalation...........................

1.2.2. Stoichiometric $\mathrm{CO}_{2}$ Fixation via Insertion Reactions ....................... 13

1.3. Catalytic Carboxylation of Organoboron and Organohalide Compounds......... 15

1.4. Catalytic Reductive Carboxylation of Unactivated Olefins.................... 20

1.5. Catalytic Hetero(element)carboxylation of Unsaturated Compounds.............. 25

1.6. Concluding Remarks.................................................. 28

\section{CHAPTER II: Mechanistic Investigation of Copper(I)-Catalyzed Boracarboxylation of Vinyl Arenes}

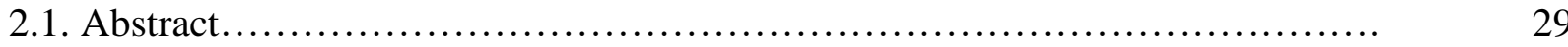

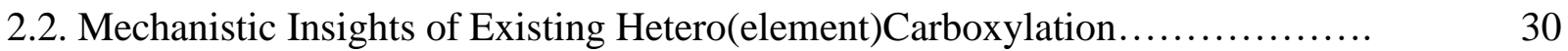

2.3. Isolation of Catalytic Intermediates................................... 35

2.4. Synthesis of Spiroboralactonate-Copper(I) Complexes..................... 38

2.5. Characterization of Spiroboralactonate Complexes........................ 41

2.6. Characterization of Salt-Metathesis Product............................... 51

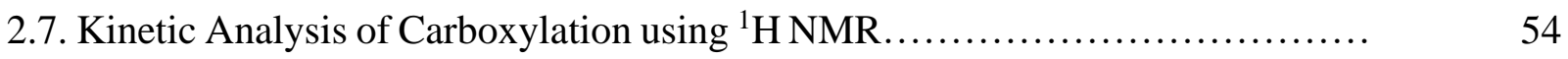

2.8. Computational Analysis of Carboxylation................................. 58

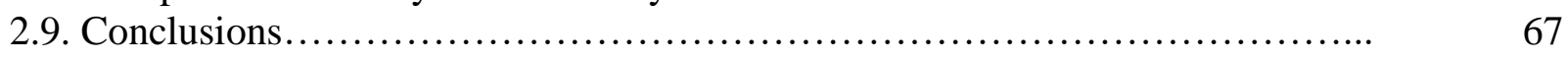

2.10. Experimental.................................................. 68

CHAPTER III: Experimental and Computational Analysis of Additive Effects in Copper-Facilitated Boracarboxylation of Vinyl Arenes

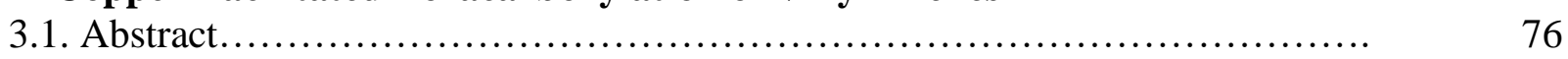

3.2. Additives in Catalysis............................................. 77

3.3. Stoichiometric Carboxylation of $\mathrm{CF}_{3}$ and ${ }^{\mathrm{t}} \mathrm{Bu}$ Complexes with $\mathrm{PPh}_{3} \ldots \ldots \ldots \ldots . . . \quad 81$

3.4. Computational Exploration of Carboxylation with Phosphine Additives......... 86

3.5. Stoichiometric Carboxylation of $2 \mathrm{i}$ with 4-tert-butylstyrene.................. 91

3.6. Computational Exploration of Carboxylation with Alkene Additives............. 94

3.7. Conclusions ....................................................... 96

3.8. Experimental.................................................. 98 
CHAPTER IV: Evidence of Boron Assistance for $\mathrm{CO}_{2}$ Activation during Copper-Catalyzed Boracarboxylation of Vinyl Arenes

4.1. Abstract................................................................ 100

4.2. Cooperative Activation in Nature..................................... 101

4.3. Cooperative Activation of $\mathrm{CO}_{2}$ at Transition Metal Complexes................ 103

4.4. Boron as a Second-Sphere Activator................................... 106

4.5. Computational Analysis of $\mathrm{ICy}^{\mathrm{I}} \mathrm{Cu}$-Facilitated Carboxylation................... 112

4.6. Computational Analysis of IMe ${ }^{\mathrm{I}} \mathrm{Cu}$-Facilitated Carboxylation-Exploration of 114

$\mathrm{BX}_{2}$ Moieties.

4.7. Second Order Perturbation Analysis of Lewis Acid/Base Interaction............. 124

4.8. Exceptions to the Model................................................ 125

4.9. Conclusions.................................................... 126

4.10. Computational Methods................................................ 128

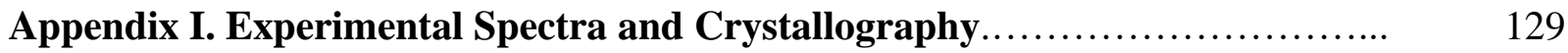

NMR Spectra........................................................... 130

IR Spectra................................................................ 157

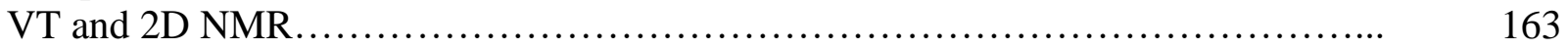

X-Ray Crystallographic Data.......................................... 166

Appendix III. XYZ Coordinates of Optimized Structures................... 167

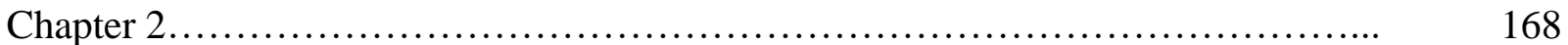

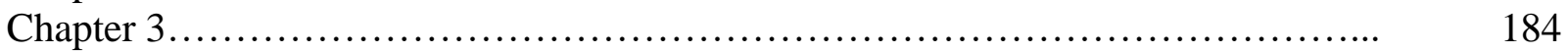

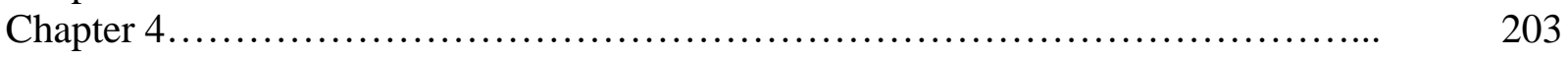




\section{LIST OF ABBREVIATIONS}

$\begin{array}{ll}\text { B }_{2} \text { pin } & \text { bis(pinacolato)diboron } \\ \text { Bpin } & \text { Boronic acid pinacol ester } \\ \text { atm } & \text { atmosphere } \\ \text { NHC } & \text { N-heterocyclic carbene } \\ \text { ICy } & 1,3 \text {-dicyclohexyl-imidazol-2-ylidene } \\ \text { IPr } & 1,3 \text {-bis(2,6-diisopropylphenyl)-imidazol-2-ylidene } \\ \text { IMe } & \text { 1,3-dimethyl-imidazol-2-ylidene } \\ \text { THF } & \text { tetrahydrofuran } \\ \text { VT } & \text { variable temperature } \\ \text { DFT } & \text { density functional theory } \\ \text { BVD } & \text { boron valence deficiency } \\ \text { eg } & \text { ethyleneglycato } \\ \text { en } & \text { ethylenediamino } \\ \text { IRC } & \text { intrinsic reaction coordinate } \\ \text { DCM } & \text { dichloromethane } \\ \text { HOMO } & \text { highest occupied molecular orbital } \\ \text { LUMO } & \text { lowest unoccupied molecular orbital } \\ \text { FLP } & \text { frustrated Lewis pair } \\ \text { PPh } & \text { triphenylphosphine } \\ \text { WGSR } & \text { Water-Gas Shift Reaction }\end{array}$




\section{LIST OF FIGURES}

\section{Chapter I:}

1.1. FDA-approved drugs that possess carboxylic acid functional groups..............

1.2. Structural representations of the active sites in aerobic carbon monoxide

dehydrogenase $(\mathrm{Mo}, \mathrm{Cu}-\mathrm{CODH})$ and the anaerobic carbon monoxide dehydrogenase enzymes (Ni, Fe-CODH).

1.3. HOMO and LUMO of $\mathrm{CO}_{2}$ as they apply to metal binding as well as common

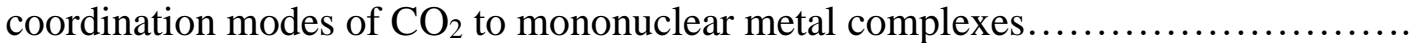

1.4. Synthesis of Aresta's Complex, $\left(\mathrm{Ni}\left(\mathrm{PCy}_{3}\right)_{2}\left(\eta^{2}(\mathrm{C}, \mathrm{O})-\mathrm{CO}_{2}\right)\right) \ldots \ldots \ldots \ldots \ldots \ldots \ldots . . . \ldots \ldots$

1.5. Transition metal- $\mathrm{CO}_{2}$ complexes featuring different binding modes of $\mathrm{CO}_{2} \ldots \ldots$

1.6. Stoichiometric carboxylation of 2-butyne with $\mathrm{CO}_{2}$, (cdt)Ni and TMEDA..........

1.7. Stoichiometric carboxylation of ethylene to generate carboxylic acids facilitated by a dbu-ligated $\mathrm{Ni}^{0}$ complex

1.8. Incorporation of $\mathrm{CO}_{2}$ into $\left(\mathrm{h}^{5}-\mathrm{Cp} *\right)_{2} \mathrm{Ti}\left(\mathrm{h}^{2}-\mathrm{C}_{2} \mathrm{H}_{4}\right)$ to generate

$(\mathrm{Cp} *)_{2} \mathrm{Ti}^{\mathrm{I}}\left(\mathrm{OC}(\mathrm{O}) \mathrm{CH}_{2} \mathrm{CH}_{2}\right)$.

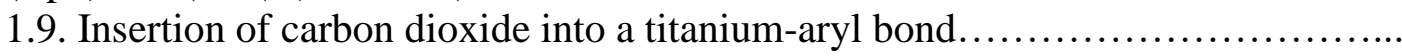

1.10. Ring expansion reaction via $\mathrm{CO}_{2}$ insertion into Ni-aryl bond.................

1.11. Examples of the carboxylation of organoborane substrates...

1.12. Representative examples of base metal catalyzed carboxylation of aryl and

alkyl organohalides.

1.13. Ni-catalyzed hydrocarboxylation of styrene and Fe-catalyzed

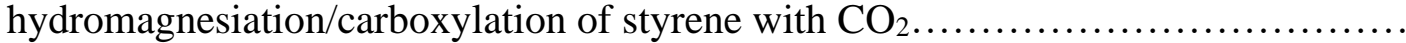

1.14. Nickel-catalyzed carboxylation of aryl and alkyl olefins using water as

hydride source and site-selective carboxylation of mixture of alkenes yielding single isomer.

Chapter II:

2.1. Extent of hetero(element)carboxylation reactions with unsaturated substrates....

2.2. Proposed mechanism of the tert-butoxide-catalyzed carboxylation of vinyl

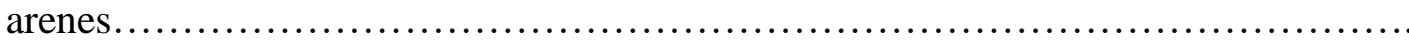

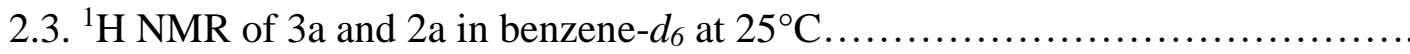

2.4. Comparison of ${ }^{11} \mathrm{~B}$ NMR chemical shifts for $3 \mathrm{a}$ and $2 \mathrm{a}$ at $25^{\circ} \mathrm{C} ;{ }^{13} \mathrm{C}$ NMR of $3 \mathrm{a}$

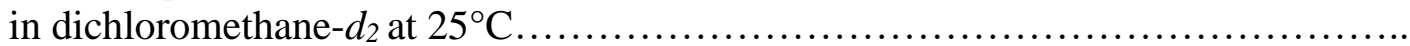
2.5. ${ }^{1} \mathrm{H}-{ }^{1} \mathrm{H}$ gradient-COSY (gCOSY) spectrum of $3 \mathrm{a}$.....

2.6. A) Molecular structure of 3a; Molecular structure of $\alpha$-aryl carboxylic acid product $(\mathrm{Ar}=$ para-tert-butylphenyl)....

2.7. VT ${ }^{1} \mathrm{H}$ NMR spectra of $3 \mathrm{a}$, collected from $+25^{\circ} \mathrm{C}$ to $-90^{\circ} \mathrm{C}$ in

2.8. Comparison of ${ }^{13} \mathrm{C}$ NMR data at $-90^{\circ} \mathrm{C}$ and $+25^{\circ} \mathrm{C}$ in dichloromethane- $d_{2} \ldots \ldots \ldots$

2.9. Interconversion of the binding of copper to each oxygen of the pinacol ring, including the carboxylate-bound intermediate, derived computationally

2.10. Formation of a salt metathesis product from the starting spiroboralactonate structure with the concomitant generation of $\mathrm{IPrCuO}^{t} \mathrm{Bu}$.

Figure 2.11. ${ }^{1} \mathrm{H}$ NMR spectrum of $\mathrm{IPrCuOtBu}(4)$ as a product of the salt metathesis reaction. 
2.12. ${ }^{1} \mathrm{H}$ NMR spectrum of $3 \mathrm{a}$, spectrum demonstrating the production of $1^{\operatorname{IPr}}$ upon the addition of $\mathrm{NaO}^{\mathrm{t}} \mathrm{Bu}$ to a $40 \% \mathrm{THF} /$ benzene- $d_{6}$ solution of $3 \mathrm{a}$ and ${ }^{1} \mathrm{H}$ NMR in $40 \% \mathrm{THF} /$ benzene- $d_{6}$ solution of $\mathrm{B}_{2}$ pin $_{2}$ addition to reaction, generating IprCuBpin

2.13. ${ }^{1} \mathrm{H}$ NMR array depicting conversion of $\mathrm{IPrCu}\left(\mathrm{CHPhCH}_{2} \mathrm{Bpin}\right)$ (2a) to $\operatorname{IPrCu}\left(\left(\mathrm{CO}_{2}\right)\left(\mathrm{CHPhCH}_{2} \mathrm{Bpin}\right)\right)$ (3a) at $25^{\circ} \mathrm{C}$ in benzene- $\mathrm{d}_{6}$ under an atmosphere of

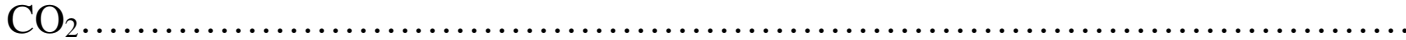

2.14. Kinetic traces for the growth of $3 \mathrm{a}$ and the concomitant loss of $2 \mathrm{a}$ with respective observed rate constants $\left(k_{\mathrm{obs}}\right)$ based on integration of ethenyl resonance. Data collected via ${ }^{1} \mathrm{H}$ NMR spectroscopy in benzene- $d_{6}$ at $25^{\circ} \mathrm{C}$.

2.15. Hammett plot of relative rates of carboxylation of $\mathrm{Cu}^{\mathrm{I}}(\beta$-borylbenzyl $)$ complexes $2 \mathrm{a}-2 \mathrm{~h}$.

2.16. Direct insertion carboxylation transition state structures for $4 \mathrm{a}-4 \mathrm{i}$ optimized at M06 (4x.TS)....

2.17. Free energies derived from experimental data; free energies of solvation obtained from single point calculations using the gas-phase minimum structure optimized without dispersion corrections (optimized using M06); free energies of solvation obtained from single point calculations using the gas-phase minimum structure optimized with dispersion corrections.

2.18. Comparison of experimental $\Delta \Delta G^{\ddagger}$ values for carboxylation of $2 \mathrm{a}-2 \mathrm{~g}$ (blue) and computational $\Delta \Delta G^{\ddagger}$ values for carboxylation of $4 \mathrm{a}-4 \mathrm{i}$ (red). Theory: rm06/6-

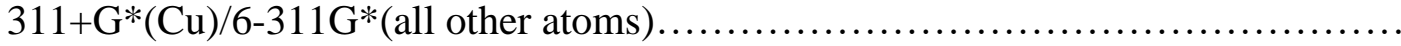
2.19. IRC calculation of $3 \mathrm{a}$ to demonstrate the reverse and forward reaction........... 2.20. Visual representations of the highest occupied molecular orbital (HOMO) for the $\mathrm{IMeCu}(\beta$-borylbenzyl) structure $4 \mathrm{a}$ as well as the transition state for the cooperative carboxylation (4a-TS) obtained at the M06 DFT level. NC represents

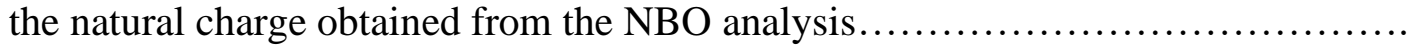

\section{Chapter III:}

3.1. Asymmetric addition of $\mathrm{EtMgCl}$ to cyclic acetals..............................

3.2. Select catalytic examples wherein exogenous $\mathrm{PPh}_{3}$ plays a role in enhancing reactivity.....

3.3. Rates of carboxylation for $\mathrm{p}-\mathrm{CF}_{3}$ complex $2 \mathrm{i}$ with varying amounts of $\mathrm{PPh}_{3}$ and tBu complex $2 \mathrm{~d}$ with varying amounts of $\mathrm{PPh}_{3}$.

3.4. Plots depicting the initial rates of carboxylation of $2 \mathrm{i}$ at $25^{\circ} \mathrm{C}$ with various amounts of $\mathrm{PPh}_{3}$. Table contains the \% yields and \% conversion after 200 minutes. 3.5. Initial rates of carboxylation of $2 \mathrm{i}$ using electronically differing phosphine additives.

3.6. Reaction coordinates for $\mathrm{Cu}^{\mathrm{I}}$-catalyzed boracarboxylation via 1) cooperative insertion (blue), 2) unassisted $\mathrm{S}_{\mathrm{E}} 2$, and 3) $\mathrm{PMe}_{3}$-assisted pathways calculated at the M06 level of theory

3.7. IRC calculation starting from the TS. $\mathrm{PMe}_{3}{ }^{\mathrm{SE} 2}$ using rm06 level of theory.....

3.8. Visual representations of the highest occupied molecular orbital (HOMO) for the $\mathrm{IMeCu}(\beta$-borylbenzyl) structures as well as the transition states for the unassisted electrophilic substitution ( $\mathrm{TS}^{\mathrm{SE2}}$ ) and the $\mathrm{PMe}_{3}$-mediated (TS.PMe ${ }_{3}{ }^{\mathrm{SE} 2}$ )

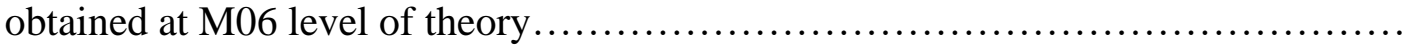
913.9. Alkene competition experiments for copper(I)-catalyzed boracarboxylation... 
3.10. Rates of carboxylation for $p-\mathrm{CF}_{3}$ complex $2 \mathrm{i}$ with varying amounts of 4tertbutylstyrene...

3.11. Visual representation of deinsertion of 4-trifluoromethylstyrene and subsequent insertion of 4-tert-butylstyrene into $\mathrm{Cu}$-Bpin bond....

3.12. Initial rates of carboxylation of $2 \mathrm{i}$ with varying $p$-substituted styrene

3.13. Reaction pathways for carboxylation of styrene a) under a cooperative regime without additive (blue trace); b) under an $\mathrm{S}_{\mathrm{E}} 2$ mechanism with 4-tert-butylstyrene as an additive (black)...

3.14. Renderings of the HOMOs for electrophilic substitution pathways as well as structural parameters and natural charges $(q)$ for relevant fragments obtained from NBO analysis.

\section{Chapter IV:}

4.1. Depiction of classical catalysis and cooperative catalysis, wherein transformation is aided by the ligand.

4.2. Second-sphere cooperative $\mathrm{H}_{2}$ scission in the active sites of [Fe,Fe]-and

$[\mathrm{Ni}, \mathrm{Fe}]$-hydrogenases

4.3. Molecular structure of the inactivated Ni,Fe-carbon monoxide dehydrogenase (CODH II) cofactor from the anaerobic bacterium Carboxydothermus hydrogenoformans. Visual representation of the $\mathrm{Ni}-\mathrm{Fe} \mathrm{CODH}$ cofactor binding carbon dioxide, which was characterized crystallographically.

4.4. Tungsten-oxo complexes with frustrated-Lewis pair ligands synthesized by Mankad, et. al to mimic the behavior of the aerobic carbon monoxide dehydrogenase (CODH). A visual representation of the conversion of $\mathrm{CO}$ to $\mathrm{CO}_{2} \ldots$ 4.5. Examples of $\mathrm{CO}_{2}$ activation and functionalization using secondary sphere effects.

4.6. Activation of hydrazine by $\left({ }^{\mathrm{BBN}} \mathrm{NN}^{\mathrm{tBu}}\right) \mathrm{FeBr}_{2}$

4.7. The activation of hydroxylamine by iron and zinc complexes bearing a bidentate $\mathrm{N}$-based ligand with an appended Lewis acid.

4.8. Cross coupling achieved selectively through neighboring group stabilization of the transmetalation transition state.

4.9. Rare example of a one-pot diboration/cross-coupling through neighboring group activation . ......................................................... 4.10. The $\mathrm{Cu}^{\mathrm{I}}$-catalyzed boracarboxylation of vinyl arenes. Close-contact interaction in the $\mathrm{CO}_{2}$ insertion transition state.

4.11. $\mathrm{O}-\mathrm{H}$ bonding interactions between ancillary $\mathrm{NHC}$ ligand and $\mathrm{CO}_{2}$ computed by Lu et. al. ...

4.12. Depiction of optimized ground state- and transition state structures containing the ICy ligand; Computed molecular structure of $\mathrm{ICyCu}(\mathrm{I})$-benzyl carboxylation (TS $\left.{ }^{\text {direct }}\right)$, illustrating an interaction between the boron atom of the ethyleneglycato (eg) boron ester and the proximal oxygen of $\mathrm{CO}_{2}$. Relevant natural bond orbitals illustrating a non-covalent Lewis acid/base interaction........................... 4.13. Reaction coordinates of hydrocarboxylation of styrene using $\mathrm{Cu}-\mathrm{H}$ (black trace) and boracarboxylation of styrene using $\mathrm{Cu}-\mathrm{B}(\mathrm{eg})$ obtained at rm06 level of theory 
4.14. Geometry optimization of structures relevant to carboxylation using

IMe model ligand.

4.15. Based-promoted carboxylation of benzylic boronic esters

4.16. Reaction coordinate for carboxylation of $\mathrm{Cu}^{\mathrm{I}}(\beta$-borylbenzyl) species and the various boron substituents employed....

4.17. Comparison of the enthalpic barrier for carboxylation of $\mathrm{Cu}^{\mathrm{I}}(\beta$-borylbenzyl) complexes to the average electronegativity of the varying boron substituents; Comparison of the average substituent electronegativity to the boron valence deficiency calculated for each boron substituent.

4.18. Effect of boron valence deficiency on the enthalpic (left) and free energy (right) barriers of the $\mathrm{CO}_{2}$ insertion

4.19. Computed ground state $7 \mathrm{a}$ (left) and transition state $8 \mathrm{a}$ (right) structures annotated with relevant physical information.

4.20. Stabilization energies from NBO analysis of analogous oxygen- and nitrogencontaining boron fragments (black trace) and the relationship to the corresponding B-O interaction distances (red trace). Molecular structures featuring computed NBO

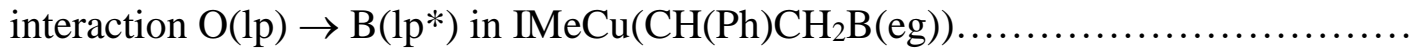
4.21. Comparison of $\mathrm{BVD}$ and the average electronegativity of $\mathrm{BX}_{2}$ Fragments, including sulfur variants; Comparison between BVD and a linear combination of both electronegativity and atomic radius for $\mathrm{BX}_{2}$ fragments, including several sulfur variants. 


\section{LIST OF TABLES}

\section{Chapter I:}

1.1. Boracarboxylation of alkynes developed by Hou and colleagues................ 25

2.2. Silacarboxylation of alkynes developed by Tsuji and colleagues................. 26

1.3. Boracarboxylation of vinyl arenes developed by Popp and colleagues............ 27

\section{Chapter II:}

2.1. Series of electron deficient and sterically hindered $\mathrm{Cu}^{\mathrm{I}}(\beta$-borylbenzyl $)$ complexes.

2.2. Carboxylated copper(I) complexes isolated through stoichiometric boracarboxylation of vinyl arenes.

2.3. Summary of relevant IR data and ${ }^{11} \mathrm{~B}$ NMR chemical shifts for the series of $\mathrm{Cu}^{\mathrm{I}}$ (spiroboralactonate) complexes.

2.4. Relevant bond distances $(\AA)$ and angles $\left(^{\circ}\right)$ for 3 a and $\alpha$-aryl carboxylic acid product shown in Figure 2.6.

2.5. Gibbs free energy of carboxylation using different functionals and dispersion corrections

2.6. Computationally derived Gibbs free energy barriers associated with direction insertion $(\mathbf{4} \times \mathbf{T S})$ and electrophilic carboxylation $\left(\mathbf{4} \times \mathbf{T S}^{\mathbf{S E 2}}\right)$

2.7. Metrical parameters and natural charges of $\mathbf{4} \cdot \mathbf{T S}$ from natural bond orbital analysis

\section{Chapter III:}

3.1. Representative examples of accessible substrates for boracarboxylation upon addition of $\mathrm{PPh}_{3}$

3.2. Computationally derived free energies associated with carboxylation of substituted $\mathrm{Cu}^{\mathrm{I}}$ benzyl complexes

\section{Chapter IV:}

4.1. The Ru-catalyzed hydrogenation of alkynes assisted through secondary sphere interactions with a pendent boron on an NNN

4.2. Boron valence deficiency (BVD), natural charge on boron, thermodynamic parameters for $\mathrm{CO}_{2}$ insertion, and the distance between the boron and oxygen of the $\mathrm{CO}_{2}$ molecule in the carboxylation transition state.

4.3. Comparison of thermodynamic information of $\mathrm{CO}_{2}$ insertion into $7 \mathbf{a}$ using different levels of theory. 


\section{LIST OF SCHEMES}

\section{Chapter I:}

1.1. Routes for $\mathrm{CO}_{2}$ transformations into fuel and fine chemicals $\ldots \ldots \ldots \ldots \ldots \ldots \ldots \ldots$

1.2. A qualitative reaction coordinate diagram illustrating the energy barrier associated with non-catalyzed and catalyzed transformations of carbon dioxide.

1.3. Generalized description of the three most common pathways for carboxylation at a metal center.

1.4. General mechanism for carboxylation of organoboron compounds..................

1.5. Rhodium-catalyzed hydroxycarbonylation of alkenes using $\mathrm{CO}_{2}$ and $\mathrm{H}_{2}$ gas......

1.6. Ruthenium-catalyzed hydroxycarbonylation of alkenes

\section{Chapter II:}

2.1. Catalytic reaction and proposed mechanism for the copper(I)-catalyzed boracarboxylation of vinyl arenes............................................

2.2. Stoichiometric reduction of $\mathrm{CO}_{2}$ to $\mathrm{CO}$ via copper(I)-Bpin. Stoichiometric insertion of vinyl arenes into copper(I)-Bpin.

2.3. Stoichiometric studies of the boracarboxylation of alkynes presented by Hou et al.

2.4. Methods to synthesize spiroboralactonate-copper(I) complexes utilizing $\mathrm{CO}_{2}$ and boron reductant ..........................................................

2.5. Potential pathways for the carboxylation of $\mathrm{Cu}^{\mathrm{I}}(\beta$-benzylboryl) complexes........

\section{Chapter III:}

3.1. Ligand-accelerated diastereoselective hydroxytrifluoromethylation of dienes by

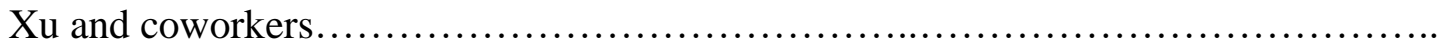

3.2. Proposed competitive pathways for carboxylation with $\mathrm{PPh}_{3}$ additive............. 


\section{CHAPTER 1}

\section{Carbon Dioxide Utilization by Transition Metal Complexes}

\subsection{Ubiquity of Carbon Dioxide}

Coinciding with global conversation of greenhouse gas reduction, the synthetic utility of carbon dioxide $\left(\mathrm{CO}_{2}\right)$ has garnered interest from the scientific community. ${ }^{1}$ The quantity of carbon dioxide in the atmosphere has been steadily increasing approximately $2.5 \mathrm{ppm}$ every year for the last 20 years. ${ }^{2}$ This rate, relative to all recorded $\mathrm{CO}_{2}$ concentration data, has generated concern about the sustainability of life on Earth. Significant advances have been made in $\mathrm{CO}_{2}$ sequestration technology in both research and industrial scale applications. However, while there is continued enthusiasm regarding $\mathrm{CO}_{2}$ capture, its storage on a large scale presents issues financially ${ }^{1 \mathrm{c}}$ as well as ecologically, with disruptions in the carbon cycle resulting from removing significant quantities from the atmosphere. ${ }^{1 a}$ Utilization of $\mathrm{CO}_{2}$ in synthesis has emerged as an alternative to sequestration solely, both industrially and in a research capacity.

The synthesis of urea through the Bosch-Meiser process is the largest source of $\mathrm{CO}_{2}$ consumption in an industrial setting, using approximately 112 million metric tons of the gas annually to produce approximately 153 million tons of urea for the manufacture of agricultural fertilizers. ${ }^{1,3,4} \mathrm{CO}_{2}$ gas is combined with gaseous ammonia $\left(\mathrm{NH}_{3}\right)$ at high pressures and high temperatures to produce the intermediate ammonium carbamate $\left(\mathrm{H}_{2} \mathrm{~N}-\mathrm{COONH}_{4}\right)$ (Equation 1.1), followed by its decomposition to urea $\left(\left(\mathrm{NH}_{2}\right)_{2} \mathrm{CO}\right)$ and water (Equation 1.2).

1. (a) Artz, J.; Müller, T. E.; Thenert, K. Sustainable Conversion of Carbon Dioxide: An Integrated Review of Catalysis and Life Cycle Assessment. Chem. Rev. 2018, 118, 434-504. (b) Liu, Q.; Wu, L.; Jackstell, R.; Beller, M. Using Carbon Dioxide as a Building Block in Organic Synthesis. Nat. Commun. 2015, 6, 5933-5948. (c) Aresta, M.; Dibenedetto, A.; Angelini, A. Catalysis for the Valorization of Exhaust Carbon: from $\mathrm{CO}_{2}$ to Chemicals, Materials, and Fuels. Technological Use of $\mathrm{CO}_{2}$. Chem. Rev. 2014, 114, 1709-1742. (d) Tsuji, Y.; Fujihara, T. Carbon Dioxide as a Carbon Source in Organic Transformations: Carbon-Carbon Bond Forming Reactions by Transition-Metal Catalysts. Chem. Commun. 2012, 48, 9956-9964. (e) Peters, M.; Köhler, B.; Kuckshinrichs, W.; Leitner, W.; Markewitz, P.; Müller, T. E. Chemical Technologies for Exploiting and Recycling Carbon Dioxide into the Value Chain. ChemSusChem 2011, 4, 1216-1240. (f) Sakakura, T.; Choi, J.; Yasuda, H. Transformation of Carbon Dioxide. Chem. Rev. 2007, 107, 2365-2387.

2. Global Climate Change: Vital Signs of the Planet. https://climate.nasa.gov/vital-signs/carbon-dioxide (accessed October 5, 2020).

3. Meesen, J. Urea Synthesis. Chem. Ing. Tech. 2014, 86, 2180-2189.

4. Behr, A. Carbon Dioxide Activation by Metal Complexes. VCH: Weinheim, 1988. 


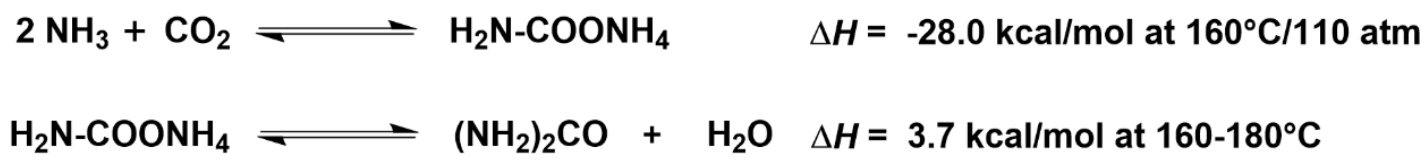

Other industrial applications of note include the production of methanol $\left(\mathrm{CH}_{3} \mathrm{OH}\right)$ and other synthetic fuels through hydrogenation catalysis. Hydrogenation of $\mathrm{CO}_{2}$ also gives synthesis gas through the reverse water-gas shift (RWGS), which is a precursor to liquid hydrocarbons and alcohols via the Fischer-Tropsch process. In addition to industrial applications using $\mathrm{CO}_{2}$, several promising synthetic uses have been recognized, including the synthesis of methanol, molecular and polymeric carbonates, and other small molecules (Scheme 1.1). ${ }^{5,6,7,8,9}$

Scheme 1.1. Routes for $\mathrm{CO}_{2}$ transformations into fuel and fine chemicals. Adapted from Ref. 9.

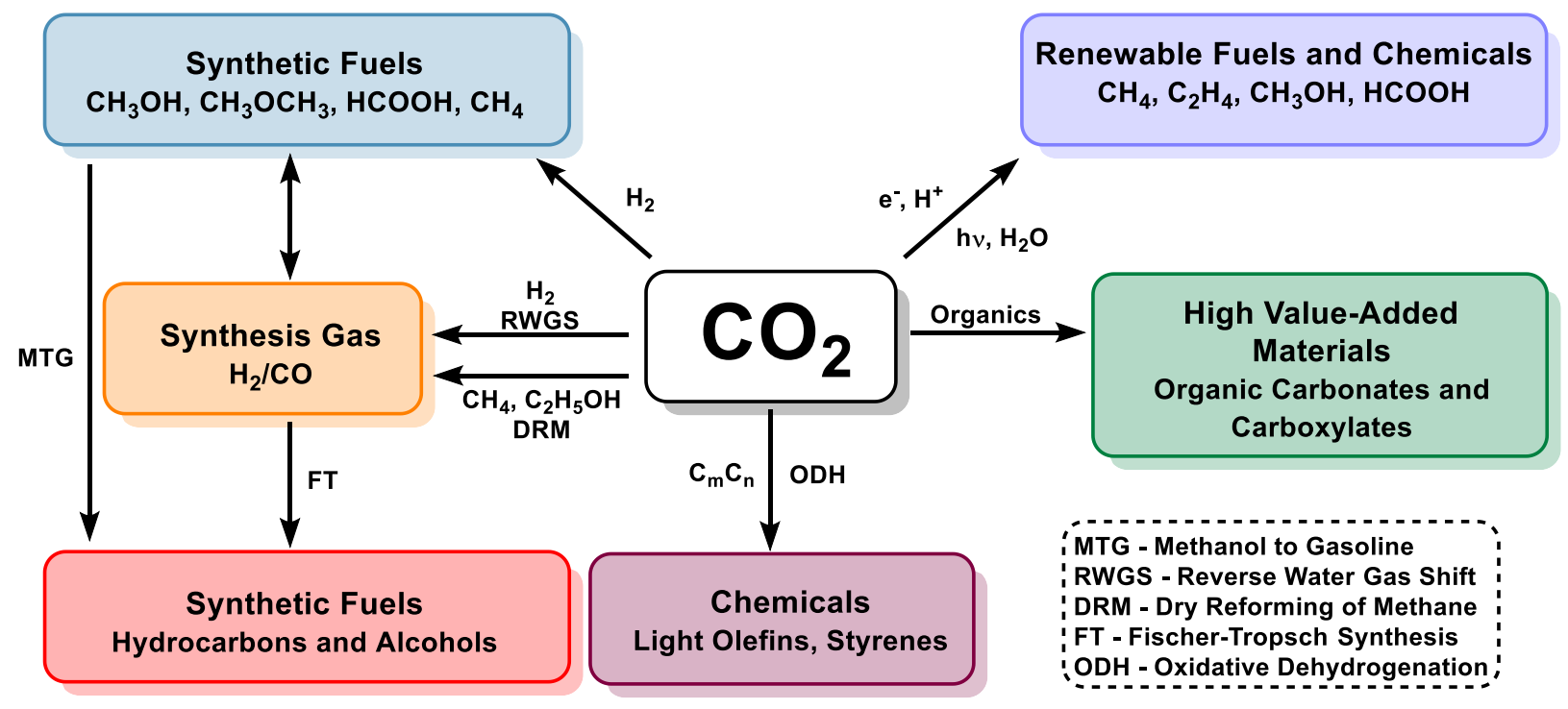

5. Burkhart, M. D.; Hazari, N.; Tway, C. L.; Zeitler, E. L. Opportunities and Challenges for Catalysis in Carbon Dioxide Utilization. ACS Catal. 2019, 9, 7937-7956

6. Jessop, P. G.; Joó, F.; Tai, C. C. Recent Advances in the Hydrogenation of Carbon Dioxide. Coord. Chem. Rev. 2004, $248,2425-2442$.

7. Solmi, M. V.; Schmitz, M.; Leitner, W. Chapter 6: $\mathrm{CO}_{2}$ as a Building Block for the Catalytic Synthesis of Carboxylic Acids, in Studies in Surface Science and Catalysis; Elsevier: Amsterdam, 2019.

8. Maeda, C.; Miyazaki, Y.; Ema, T. Recent Progress in Catalytic Conversions of Carbon Dioxide. Catal. Sci. Technol. 2014, 4, 1482-1497.

9. N. Homs, J. Toyir, P.R. de la Piscina, Chapter 1-Catalytic Processes for Activation of $\mathrm{CO}_{2}$, Suib, S. L., New and Future Developments in Catalysis, Elsevier, Amsterdam, 2013, pp. 1-26. 
Incorporation of $\mathrm{CO}_{2}$ into existing organic and organometallic frameworks is also of interest, as it provides a direct route to the production of carboxylates and carboxylic acids as well as other interesting valued-added products. ${ }^{10}$ This is attractive from a pharmaceutical standpoint, as there are many existing bioactive molecules that possess the carboxylate functional group (Figure 1.1). ${ }^{11,12}$
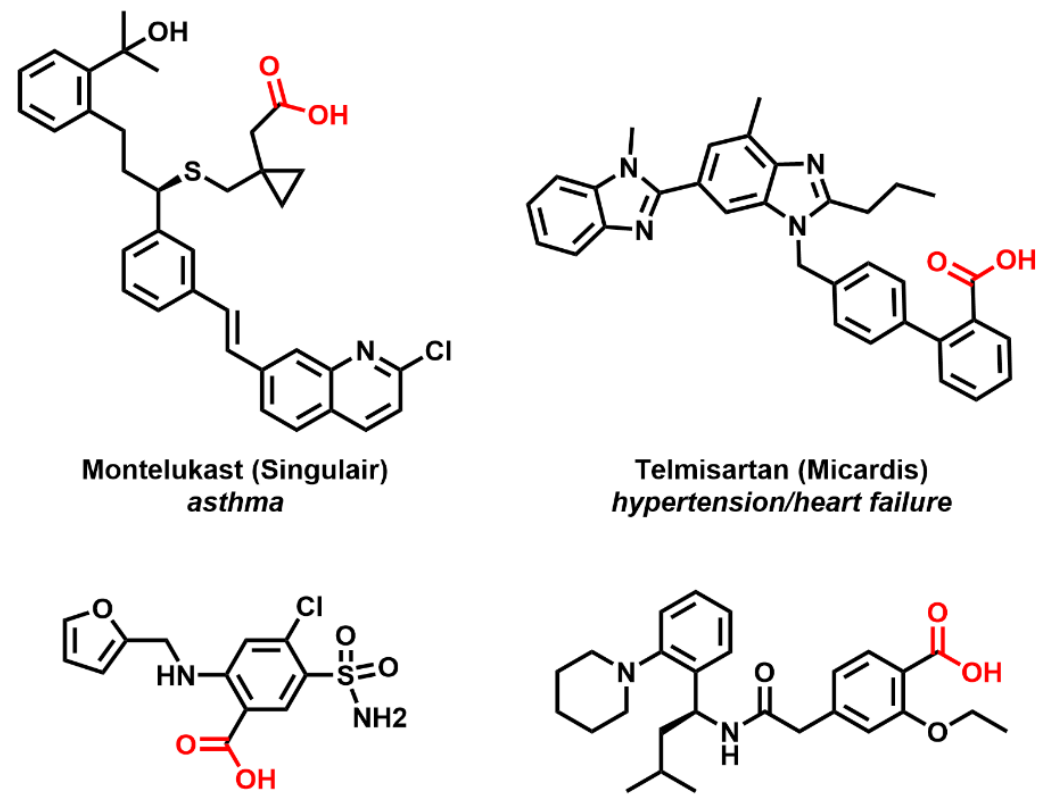

Furosemide (Lasix) edema due to heart failure

Repaglinide (Prandin) type II diabetes

Figure 1.1. FDA-approved drugs that possess carboxylic acid functional groups.

The use of $\mathrm{CO}_{2}$ as a $\mathrm{C}_{1}$ feedstock, however, comes with a collection of challenges. Activation of $\mathrm{CO}_{2}$ poses an issue due to its high stability and inertness, with carbon in its most oxidized form (+4). Additionally, as a linear molecule, carbon dioxide is nonpolar, despite its ambiphilic character. $^{13}$

Nature can circumvent these challenges in highly efficient ways. There are two well-studied naturally-occurring enzymes that are able to overcome the inertness of $\mathrm{CO}_{2}$ : aerobic carbon

10. Tortajada, A.; Julía-Hernández, F.; Börjesson, M.; Moragas, T.; Martin, R. Transition-Metal-Catalyzed Carboxylation Reactions with Carbon Dioxide. Angew. Chem. Int. Ed. 2018, 57, 15948-15982.

11. Carboxylic Acid Compound Classes: Pharmaceuticals and Agrochemicals. Wiley-VCH: Weinheim, 2016.

12. Maag, H. Prodrugs of Carboxylic Acids; Springer: New York, 2007.

13. Aresta, M.; Dibenedetto, A.; Quaranta, E. Reaction Mechanisms in Carbon Dioxide Conversion; Springer-Verlag, Berlin Heidelberg, 2016. 
monoxide dehydrogenase $(\mathrm{Mo}, \mathrm{Cu}-\mathrm{CODH})$ and anaerobic carbon monoxide dehydrogenase $(\mathrm{Ni}, \mathrm{Fe}-\mathrm{CODH})$ (Figure 1.2). ${ }^{14}$ These two enzymes are responsible for carbon fixation in the organism as well as for its energy source through the reversible oxidation of carbon monoxide (CO). Both are found in carboxydotrophic bacteria, which are organisms that thrive in a concentrated CO atmosphere. ${ }^{15}$ The bimetallic molybdenum/copper active site in the former cooperatively binds carbon monoxide at the $\mathrm{Mo}^{\mathrm{IV}}$-oxo center to gain an additional oxygen atom, with stabilization of the molecule by the copper center as well as the surrounding amino acid residues that comprise the cavity of the active site. ${ }^{16} \mathrm{Ni}, \mathrm{Fe}-\mathrm{CODH}$ operates in a similar fashion with an iron-sulfur cluster, a motif found regularly in nature, that replaces the $\mathrm{Mo} / \mathrm{Cu}$ system aside an integrated nickel center. ${ }^{17}$

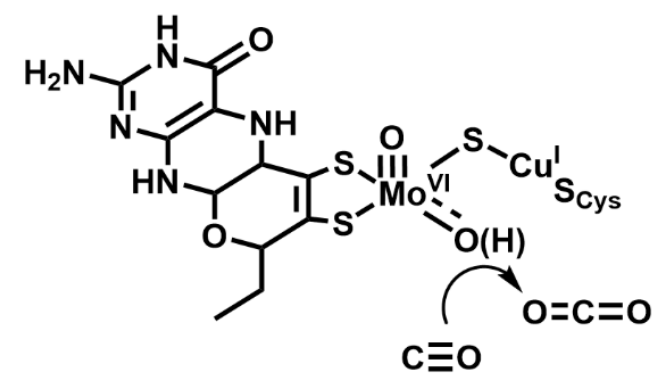

Aerobic Carbon Monoxide Dehydogenase (Mo,Cu-CODH)

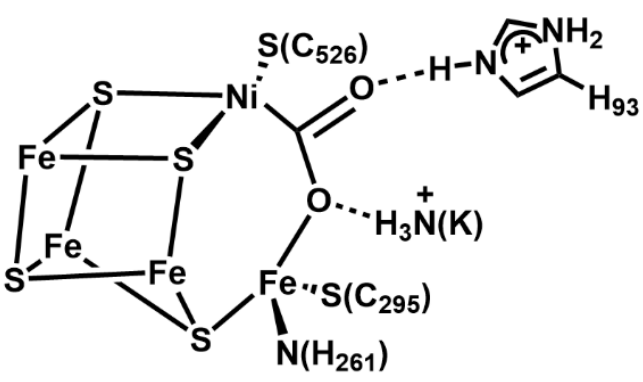

Anaerobic Carbon Monoxide Dehydogenase (Ni,Fe-CODH)

Figure 1.2. Structural representations of the active sites in aerobic carbon monoxide dehydrogenase (Mo, $\mathrm{Cu}-\mathrm{CODH})$ and the anaerobic carbon monoxide dehydrogenase enzymes

(Ni, Fe-CODH).

14. (a) Jeoung, J. H.; Dobbek, H. Carbon Dioxide Activation at Ni,Fe-Cluster of Anaerobic Carbon Monoxide Dehydrogenase. Science 2007, 318, 1461-1464. (b) Amara, P.; Mouesca, J. M.; Volbeda, A.; Fontecilla-Camps, J. C. Carbon Monoxide Dehydrogenase Reaction Mechanism: A Likely Case of Abnormal $\mathrm{CO}_{2}$ Insertion into a Ni-H Bond. Inorg. Chem. 2011, 50, 1868-1878.

15. Williams, E.; Colby, J. Biotechnological Applications of Carboxydotrophic Bacteria. Microbiol. Sci. 1986, 3, 149153.

16. (a) Dobbek, H.; Gremer, L.; Meyer, O.; Huber, R. Crystal Structure and Mechanism of CO Dehydrogenase, a Molybdo Iron-Sulfur Flavoprotein Containing S-Selanylcysteine. Proc. Natl. Acad. Sci. 1999, 96, 8884-8889. (b) Dobbek, H.; Gremer, L.; Kiefersauer, R.; Huber, R.; Meyer, O. Catalysis at a Dinuclear $[\mathrm{CuSMo}(=\mathrm{O}) \mathrm{OH}] \mathrm{CO}$ Dehydrogenase Resolved at 1.1-Å Resolution. Proc. Natl. Acad. Sci. 2002, 99, 15971-15976.

17. Dobbek, H.; Svetlitchnyi, V.; Gremer, L.; Huber, R.; Meyer, O. Crystal Structure of a Carbon Monoxide Dehydrogenase Reveals a [Ni-4Fe-5S] Cluster. Science 2001, 293, 1281-1285. 
Both take advantage of the water-gas shift reaction (WGSR) to provide either $\mathrm{CO}$ or $\mathrm{CO}_{2}$ to the organism (Equation 1.3). However, unlike the WGSR, which requires temperatures of 400$900^{\circ} \mathrm{F}$ depending on catalyst employed, ${ }^{18}$ the enzymes facilitate this transformation under ambient conditions.

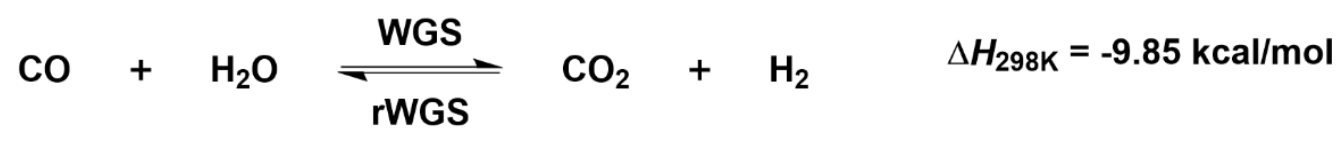

Researchers have gained inspiration from these enzymes to design effective transition metalligand complexes that allow for the reduction of $\mathrm{CO}_{2} \cdot{ }^{19}$ Manipulating the electronic properties of the metal center has been a useful synthetic method for controlling its reactivity. As stated above, carbon dioxide is an ambiphilic molecule, therefore electron deficient early transition metals generally prefer to bind $\mathrm{CO}_{2}$ through the nucleophilic oxygens (eg. $\left.\eta^{2}-\mathrm{O}, \mathrm{O} ; \eta^{1}-\mathrm{O}\right)$. Alternatively, more nucleophilic late transition metals, such as copper and nickel, generally bind to the electrophilic carbon of $\mathrm{CO}_{2}\left(\right.$ eg. $\left.\eta^{1}-\mathrm{C}\right)\left(\right.$ Figure 1.3). ${ }^{13,20,21}$

18. National Energy Technology Laboratory. Water Gas Shift \& Hydrogen Production. Accessed September 1, 2020. 19. Bullock, R. M.; Chen, J. G.; Gagliardi, L.; Chirik, P. J.; Farha, O. K.; Hendon, C. H.; Jones, C. W.; Keith, J. A.; Klosin, J.; Minteer, S. D.; Morris, R. H.; Radosevich, A. T.; Rauchfuss, T. B.; Strotman, N. A.; Vojvodic, A.; Ward, T. R.; Yang, J. Y.; Surendranath, Y. Using Nature's Blueprint to Expand Catalysis with Earth-Abundant Metals. Science 2020, 786, 1-10.

20. Huang, K.; Sun, C. L.; Shi, Z. J. Transition-Metal-Catalyzed C-C Bond Formation Through the Fixation of Carbon Dioxide. Chem. Soc. Rev. 2011, 40, 2435-2452.

21. Aresta, M.; Nobile, F. Carbon Dioxide-Transition Metal Complexes. III. Rhodium(I)- $\mathrm{CO}_{2}$ Complexes. Inorganica Chimica Acta 1977, 24, L49-L50. 


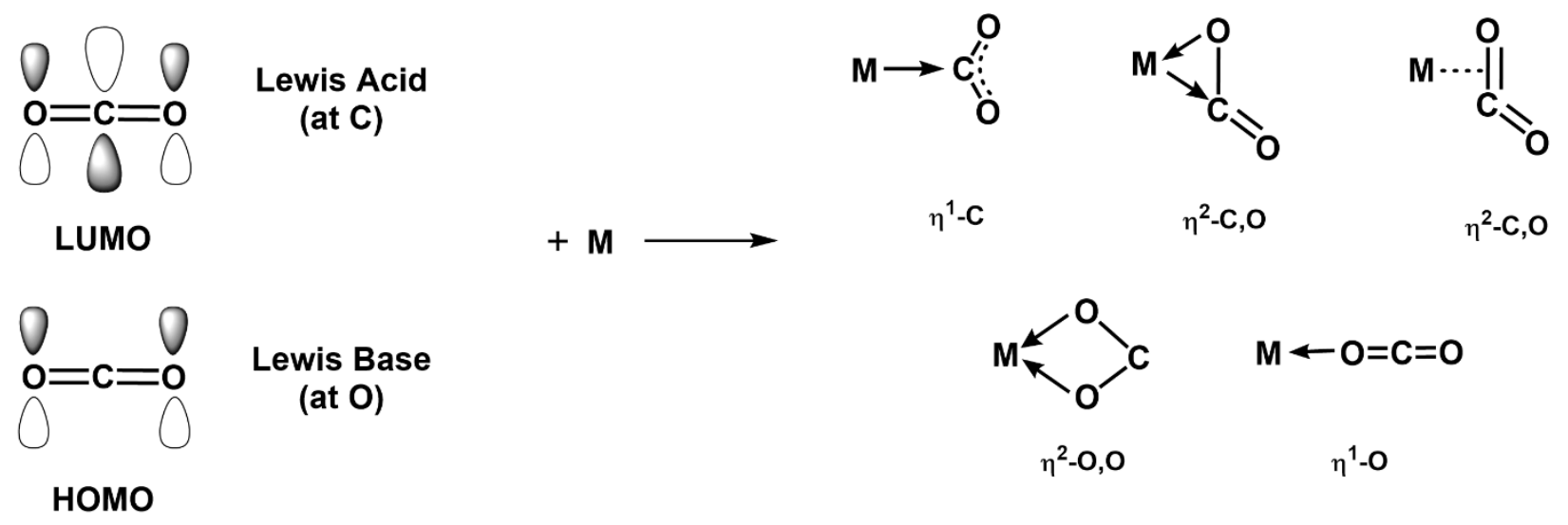

Figure 1.3. HOMO and LUMO of $\mathrm{CO}_{2}$ as they apply to metal binding as well as common coordination modes of $\mathrm{CO}_{2}$ to mononuclear metal complexes.

Coordination of carbon dioxide to the transition metal complexes is widely accepted to be a key step in its catalytic conversion. Therefore, many carbon dioxide-appended transition metal complexes have been characterized, with the objective of studying their structure and reactivity. ${ }^{22}$ Arguably, the most notable example of a metal-bound $\mathrm{CO}_{2}$ complex is $\mathrm{Ni}\left(\mathrm{PCy}_{3}\right)_{2}\left(\eta^{2}(\mathrm{C}, \mathrm{O})-\mathrm{CO}_{2}\right)$, also known as Aresta's complex (Figure 1.4). ${ }^{23}$ This square planar compound was synthesized by treating $\mathrm{Ni}\left(\mathrm{PCy}_{3}\right)_{3}$ or $\left\{\mathrm{Ni}(\mathrm{PCy})_{2}\right\}_{2} \mathrm{~N}_{2}$ with gaseous $\mathrm{CO}_{2}$ at ambient temperature. The results of

22. For selected works on the activation of carbon dioxide at transition metal complexes, see: (a) Alvarez, R.; Carmona, E.; Gutierrez-Puebla, E.; Marín, J. M.; Monge, A.; Poveda, M. L. Synthesis and X-Ray Crystal Structure of $\left[\mathrm{Mo}\left(\mathrm{CO}_{2}\right)_{2}\left(\mathrm{PMe}_{3}\right)_{3}\left(\mathrm{CNPr}^{\mathrm{i}}\right)\right]$ : the First Structurally Characterized Bis(Carbon Dioxide) Adduct of a Transition Metal. J. Chem. Soc. Chem. Commun. 1984, 1326-1327. (b) Komiya, S.; Akita, M.; Kasuga, N.; Hirano, M.; Fukuoka, A. Synthesis, Structure and Reactions of a Carbon Dioxide Complex of Iron(0) containing 1,2Bis(diethylphosphino)ethane Ligands. J. Chem. Soc. Chem. Commun. 1994, 1115-1116. (c) Hirano, M.; Akita, M.; Tani, K.; Kumagai, K.; Kasuga, N. C.; Fukuoka, A.; Komiya, S. Activation of Coordinated Carbon Dioxide in $\mathrm{Fe}\left(\mathrm{CO}_{2}\right)(\text { depe })_{2}$ by Group 14 Electrophiles. Organometallics. 1997, 16, 4206-4213. (d) Gong, J. K.; Wright, C. A.; Thorn, M.; McCauley, K.; McGill, J. W.; Sutterer, A.; Hinze, S. M.; Prince, B. From Carbon Dioxide to C2 Organic Molecules Mediated by Aresta's Nickel Carbon Dioxide Complex. Adv. Chem. Conv. Mitigating $\mathrm{CO}_{2}$ 1998, 114, 491-494. (e) Yin, X.; Moss, J. R. Recent Developments in the Activation of Carbon Dioxide by Metal Complexes. Coord. Chem. Rev. 1999, 181, 27-59 and references therein. (f) Yaung, C. S.; Dong, V. M. Beyond Aresta's Complex: Ni- and Pd-Catalyzed Organozinc Coupling with $\mathrm{CO}_{2}$. J. Am. Chem. Soc. 2008, 130, 7826-7827. (g) Grice, K. A. Carbon Dioxide Reduction with Homogeneous Early Transition Metal Complexes: Opportunities and Challenges for Developing $\mathrm{CO}_{2}$ Catalysis. Coord. Chem. Rev. 2017, 336, 78-95. (h) Mascetti, J. Metal Coordination of $\mathrm{CO}_{2}$. Encyclopedia of Inorganic and Bioinorganic Chemistry. 2014, 1-17. (i) Chiou, T.; Tseng, Y.; Lu, T.; Weng, T.; Sokaras, D.; Ho, W.; Kuo, T.; Jang, L.; Lee, J.; Liaw, W. [Ni $\left.{ }^{\mathrm{III}}(\mathrm{OMe})\right]-M e d i a t e d$ Reductive Activation of $\mathrm{CO}_{2}$ affording a Ni( $\left.\kappa^{1}-\mathrm{OCO}\right)$ Complex. Chem. Sci. 2016, 7, 3640.

23. (a) Aresta, M.; Nobile, C. F.; Albano, V. G.; Forni, E.; Manassero, M. New Nickel-Carbon Dioxide Complex: Synthesis, Properties, and Crystallographic Characterization of (carbon dioxide)-bis (tricyclohexylphosphine) Nickel. J. Chem. Soc. Chem. Commun. 1975, 15, 636-637. (b) Aresta, M.; Gobetto, R.; Quaranta, E.; Tommasi, I. A BondingReactivity Relationship for $\mathrm{Ni}\left(\mathrm{PCy}_{3}\right)_{2}\left(\mathrm{CO}_{2}\right)$ : A Comparative Solid-State-Solution Nuclear Magnetic Resonance Study $\left({ }^{31} \mathrm{P},{ }^{13} \mathrm{C}\right)$ as a Diagnostic Tool to Determine the Mode of Bonding of $\mathrm{CO}_{2}$ to a Metal Center. Inorg. Chem. 1992, 31, 4286-4290. 
crystallographic analyses demonstrated that $\mathrm{CO}_{2}$ is bound in an $\eta^{2}-(\mathrm{C}, \mathrm{O})$ fashion to the nickel center. This complex is described best as a binding motif in which the nickel center is not oxidized, with the $\mathrm{CO}_{2} \mathrm{C}-\mathrm{O}$ bond retaining most of its double bond character. ${ }^{13}$ However, modifications to the phosphine ligands can lead to more X-type behavior from the bound oxygen atom of $\mathrm{CO}_{2}{ }^{24}$

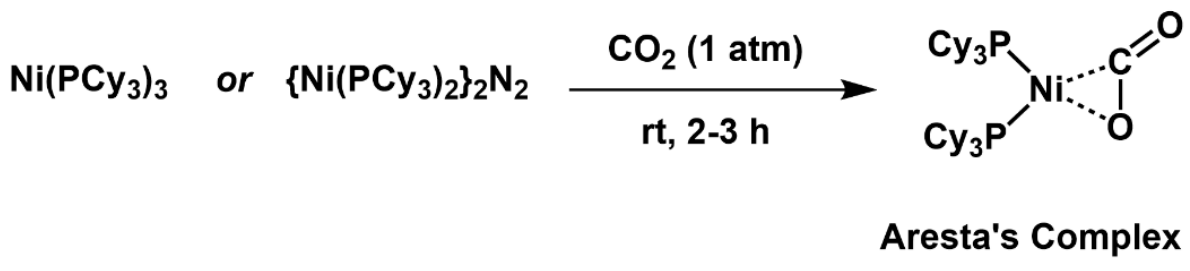

Figure 1.4. Synthesis of Aresta's complex, $\left(\mathrm{Ni}\left(\mathrm{PCy}_{3}\right)_{2}\left(\eta^{2}(\mathrm{C}, \mathrm{O})-\mathrm{CO}_{2}\right)\right){ }^{23}$

Analogues of Aresta's complex have been synthesized with different ancillary phosphine ligands to probe the reactivity as a result of their stereoelectronic properties. For example, in 2010, Hillhouse synthesized a (dtpbe)Ni $\left(\eta^{2}-\mathrm{CO}_{2}\right)$ complex (where dtpbe = 1,2-bis(di-tertbutylphosphino)ethane) by treatment of $[(\mathrm{dtpbe}) \mathrm{Ni}]_{2}\left(\eta^{2}-\mu-\mathrm{C}_{6} \mathrm{H}_{6}\right)$ with $\mathrm{CO}_{2}$ gas. ${ }^{25}$ Crystallographic characterization confirmed the $\eta^{2}-(\mathrm{C}, \mathrm{O})$ binding mode (Figure 1.5.A). Chiou and Law demonstrated one of few examples of a discrete end-on $\eta^{1}-\mathrm{O}$ coordinated $\mathrm{CO}_{2}$ complex using a tripodal tetradentate S/P ligand and nickel (Figure 1.5.B). ${ }^{22 \mathrm{i}}$ Also rare are $\eta^{1}$-C-bound $\mathrm{CO}_{2}$ complexes, ${ }^{26}$ as they require a nucleophilic metal center to enhance complex stability. A $\mathrm{Co}$ (salen) $\mathrm{CO}_{2}$ example of this compound class (where salen $=\mathrm{N}, \mathrm{N}^{\prime}-$ ethylenebis(salicylideneaminato)) is shown in Figure 1.5.C. ${ }^{27}$

24. Paparo, A.; Okuda, J. Carbon Dioxide Complexes: Bonding Modes and Synthetic Methods. Coordination Chemistry Reviews 2017, 334, 136-149.

25. Anderson, J. S.; IIuc, V. M.; Hillhouse, G. L. Reactions of $\mathrm{CO}_{2}$ and $\mathrm{CS}_{2}$ with 1,2-Bis(di-tert-butylphopshino)ethane Complexes of Nickel(0) and Nickel(I). Inorg. Chem. 2010, 49, 10203-10207.

26. (a) Oren, D.; Diskin-Posner, Y.; Avram, L.; Feller, M.; Milstein, D. Metal-Ligand Cooperation as Key in Formation of Dearomatized $\mathrm{Ni}^{\mathrm{II}}-\mathrm{H}$ Pincer Complexes and Their Reactivity toward $\mathrm{CO}$ and $\mathrm{CO}_{2}$. Organometallics 2018, 37, 2217-2221. (b) Yoo, C.; Lee, Y. Carbon Dioxide Binding at a Ni/Fe Center: Synthesis and Characterization of $\mathrm{Ni}\left(\eta^{1}-\mathrm{CO}_{2}-\kappa \mathrm{C}\right)$ and $\mathrm{Ni}-\mu-\mathrm{CO}_{2}-\kappa \mathrm{C}: \kappa^{2} \mathrm{O}, \mathrm{O}$ '-Fe. Chem. Sci. 2017, 8, 600-605. (c) Calabrese, J. C.; Herskovitz, T.; Kinney, J. B. Carbon Dioxide Coordination Chemistry. 5. The Preparation and Structure of $\mathrm{Rh}\left(\eta^{1}-\mathrm{CO}_{2}\right)(\mathrm{Cl})(\mathrm{diars})_{2}$. J. Am. Chem. Soc. 1983, 105, 5914-5915.

27. Gambarotta, S.; Arena, F.; Floriani, C.; Zanazzi, P. F. Carbon Dioxide Fixation: Bifunctional Complexes Containing Acidic and Basic Sites Working as Reversible Carriers. J. Am. Chem. Soc. 1982, 104, 5082-5092. 
A. $\left(\eta^{2}-\mathrm{C}, 0\right)$ : Hillhouse, 2010
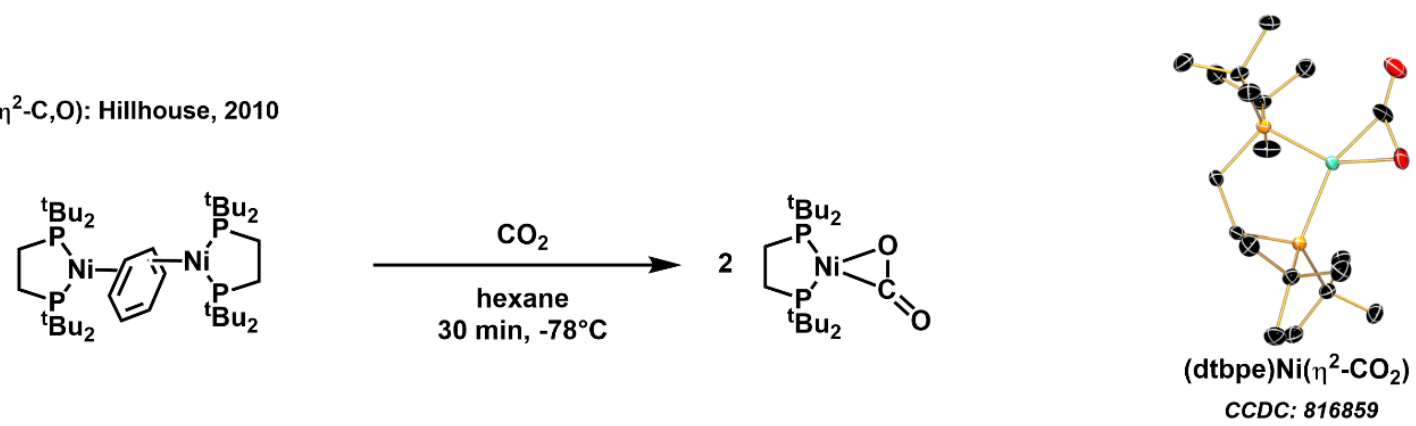

B. $\left(\eta^{1}-0\right)$ : Chiou and Liaw, 2016

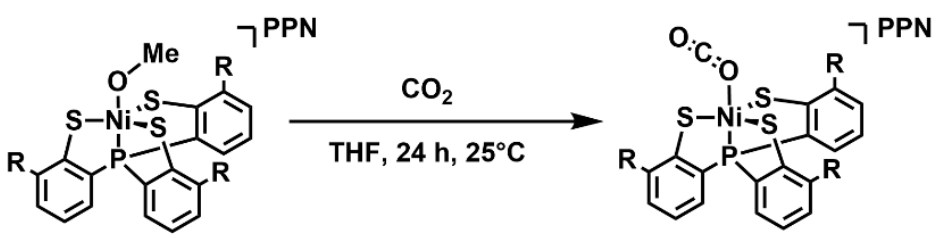

PPN=bis(triphenylphosphoranylidene)

C. $\left(\eta^{1}-C\right)$ : Floriani, 1982

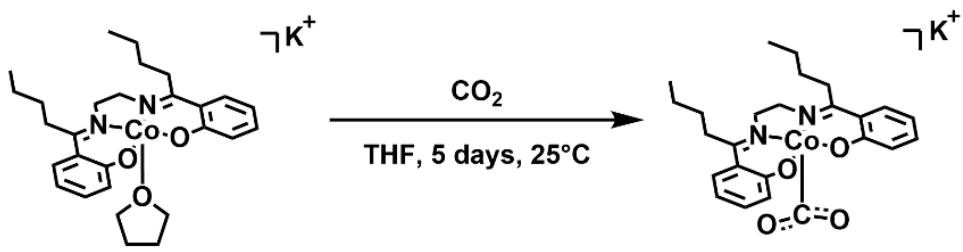

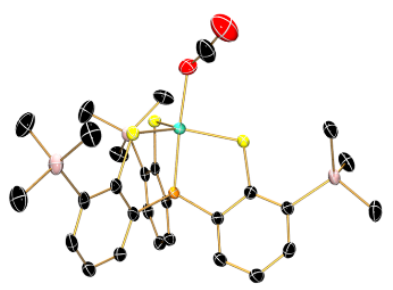

[PPN][Ni( $\left.\left.\kappa^{1}-\mathrm{OCO}\right)\left(\mathrm{PS}_{3}\right)\right]$

CCDC: 785531

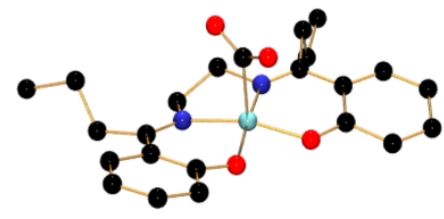

[Co(n-Pr-salen) $\left.\mathrm{K}\left(\eta^{1}-\mathrm{CO}_{2}\right)(\mathrm{THF})\right]$ CCDC: 1148378

Figure 1.5. Transition metal- $\mathrm{CO}_{2}$ complexes featuring different binding modes of $\mathrm{CO}_{2}$.

A number of these discrete complexes have demonstrated stoichiometric and catalytic reactivity toward carboxylation. ${ }^{22}$ Early examples involve application of Aresta's complex for production of acetaldehyde upon treatment with phosphine ylide via a nickel ketene species. ${ }^{28}$ Dong and colleagues also demonstrated catalytic production of organocarboxylates using $\left[\mathrm{Ni}\left(\mathrm{PCy}_{3}\right)_{2}\left(\eta^{2}-\mathrm{CO}_{2}\right)\right]$ coupled with organozinc reagents. ${ }^{22 \mathrm{f}}$

\subsection{Stoichiometric C-C Bond Formation using $\mathrm{CO}_{2}$}

As described in previous sections, utilizing carbon dioxide as a synthetic feedstock requires a reaction strategy to overcome the associated energy barrier. This can be achieved both by introducing starting materials that are considered 'high-energy' relative to $\mathrm{CO}_{2}$, such as

28. Wright, C. A.; Thorn, M.; McGill, J. W.; Sutterer, A.; Hinze, S. M.; Prince, R. B.; Gong, J. K. A First Example of a "Wittig Reaction" on a Coordinated Carbon Dioxide Nickel Complex. J. Am. Chem. Soc. 1996, 118, 10305-10306. 
unsaturated hydrocarbons, and the introduction of an effective catalyst (Scheme 1.2.). Further, the application of Earth abundant metal catalysts in this context would offer sustainable alternatives to precious metal systems that are routinely used in catalysis. ${ }^{19}$

Scheme 1.2. A qualitative reaction coordinate diagram illustrating the energy barrier associated with non-catalyzed and catalyzed transformations of carbon dioxide. ${ }^{1 \mathrm{e}}$

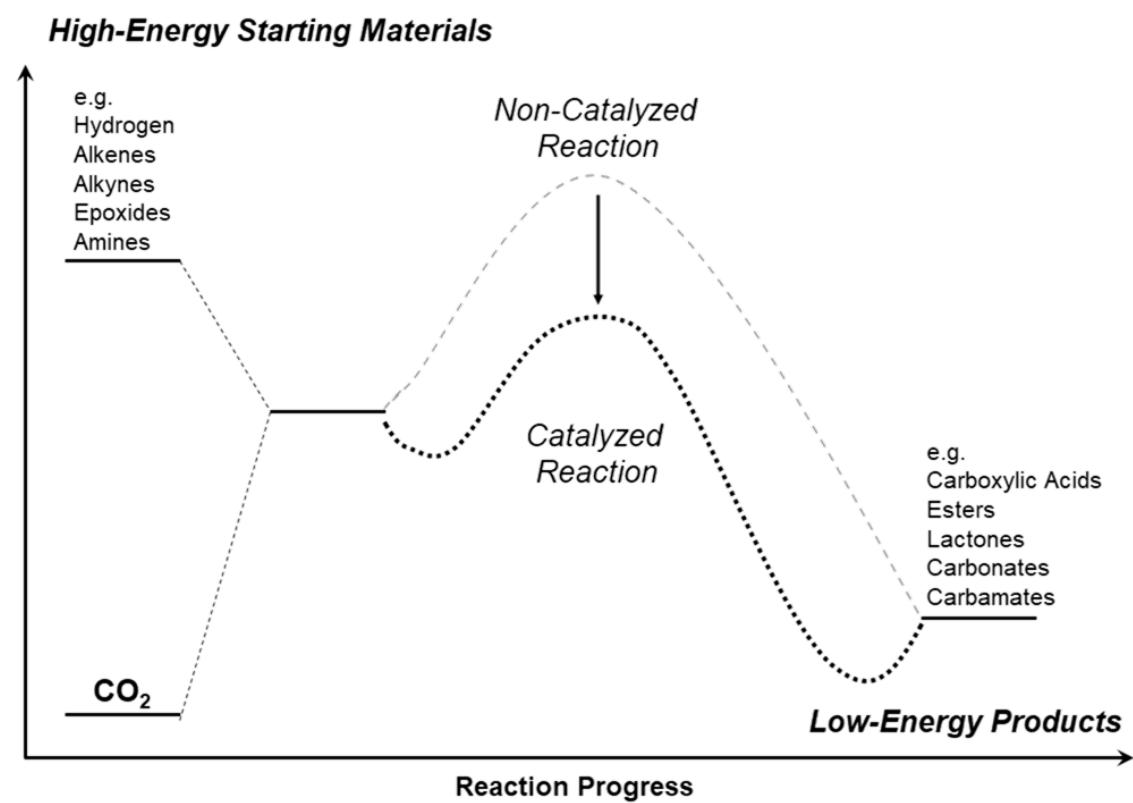

Three pathways are commonly cited for carboxylation of organic substrates (Scheme 1.3.): 1) insertion of a substrate into an existing $\mathrm{M}-\mathrm{CCO}_{2}$ bond; 2) insertion of $\mathrm{CO}_{2}$ into a preformed M-E bond of a substrate; and 3) a simultaneous reaction where both $\mathrm{CO}_{2}$ and substrate react with the metal, followed by reductive elimination. Transient intermediate species resulting from one of these pathways have been proposed and, in some cases, have been isolated. 
Scheme 1.3. Generalized description of the three most common pathways for carboxylation at a metal center.

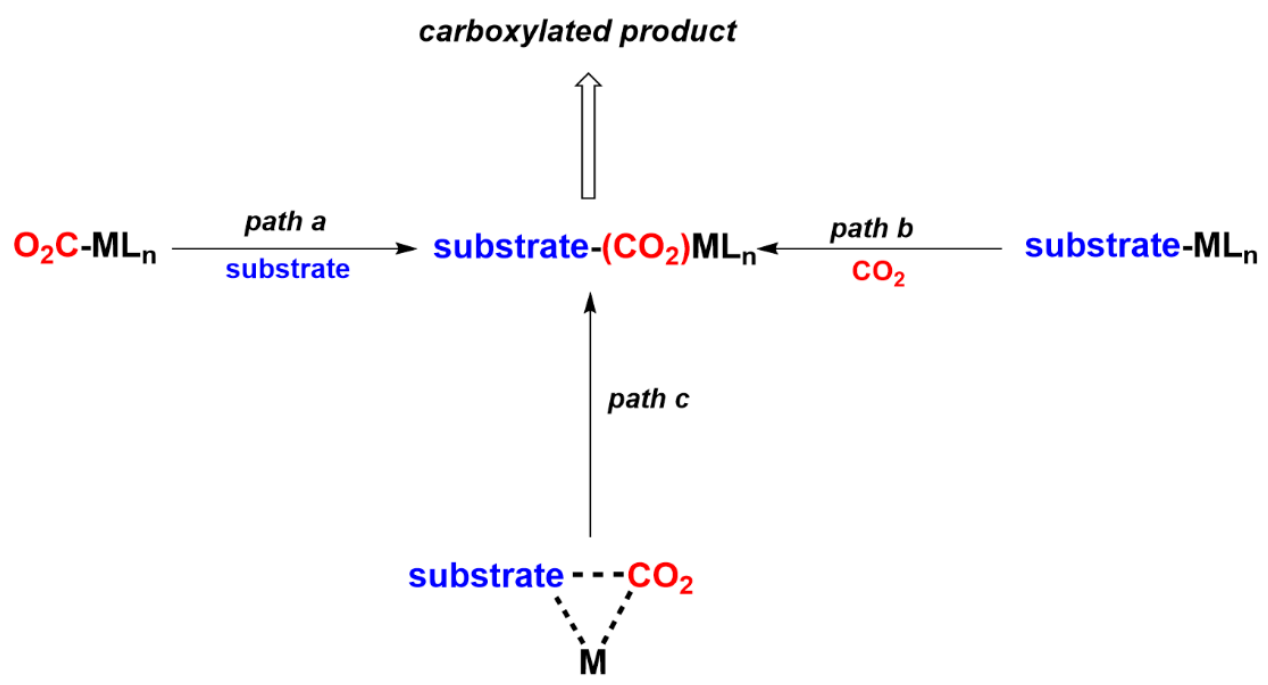

\subsubsection{Stoichiometric $\mathrm{CO}_{2}$ Fixation via Cyclometalation}

Following the synthesis of Aresta's complex in 1975, interest in developing similar metal complexes to introduce $\mathrm{CO}_{2}$ to unsaturated organic compounds grew. Much of this work was performed using nickel complexes with significant contributions made by Hoberg and coworkers in the following decade. The first instance of oxidative cyclization, or oxidative metalation, with carbon dioxide was reported by Burkhart and Hoberg. Oxanickelacyclopentene was formed through treatment of $\mathrm{Ni}(\mathrm{cdt})$ (cdt=1,5,9-cyclododecatriene) with 2-butyne, TMEDA (TMEDA = $\mathrm{N}, \mathrm{N}, \mathrm{N}^{\prime}, \mathrm{N}^{\prime}$-tetramethylethylenediamine), and $\mathrm{CO}_{2}$ (Figure 1.6). ${ }^{29}$

29. Burkhart, G.; Hoberg, H. Oxanickelacyclopentene Derivatives from Nickel(0), Carbon Dioxide, and Alkynes. Angew. Chem. Int. Ed. Engl. 1982, 21, 76. 


\section{Hoberg, 1982}

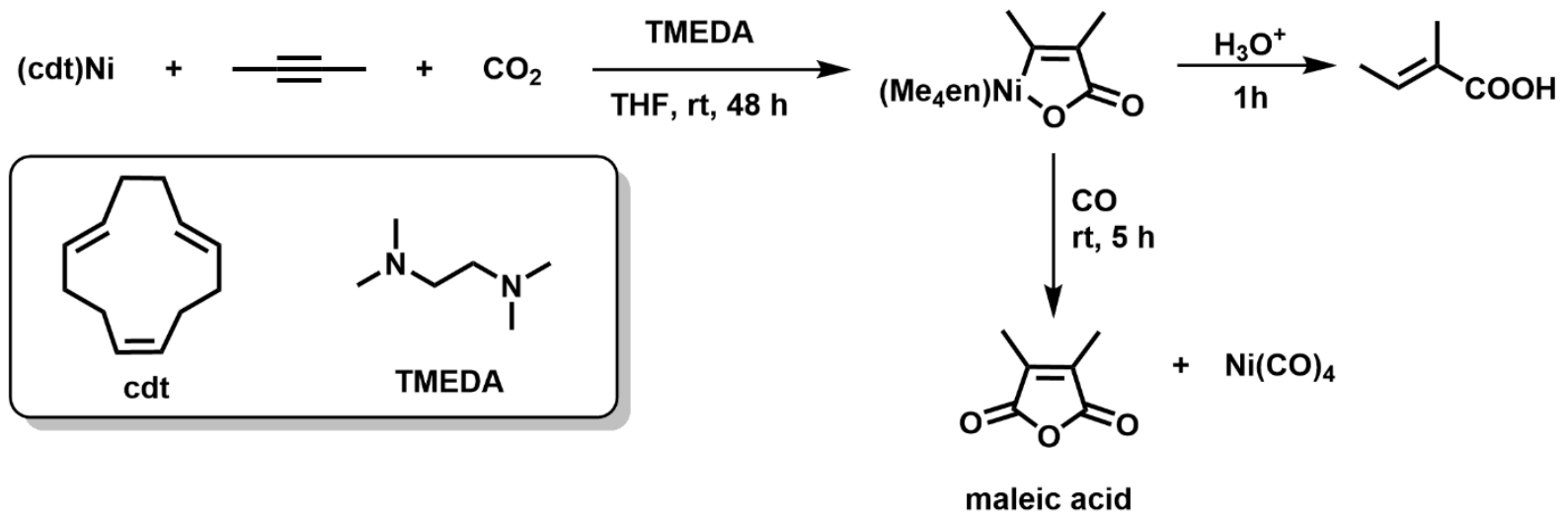

Figure 1.6. Stoichiometric carboxylation of 2-butyne with $\mathrm{CO}_{2}$ with (cdt)Ni and TMEDA. ${ }^{29}$

In a subsequent report, $\mathrm{Ni}(\mathrm{COD})_{2}(\mathrm{COD}=1,5$-cyclooctadiene $)$ in the presence of 1,8 diazabicyclo[5,4,0] undec-7-ene ( $\mathrm{dbu}$ ) facilitated the oxidative coupling of ethylene and $\mathrm{CO}_{2}$ to form a 5-member nickelacycle that under acidic workup conditions yielded either propionic acid or 4-pentenoic acid (Figure 1.7). ${ }^{30}$

Hoberg, 1987

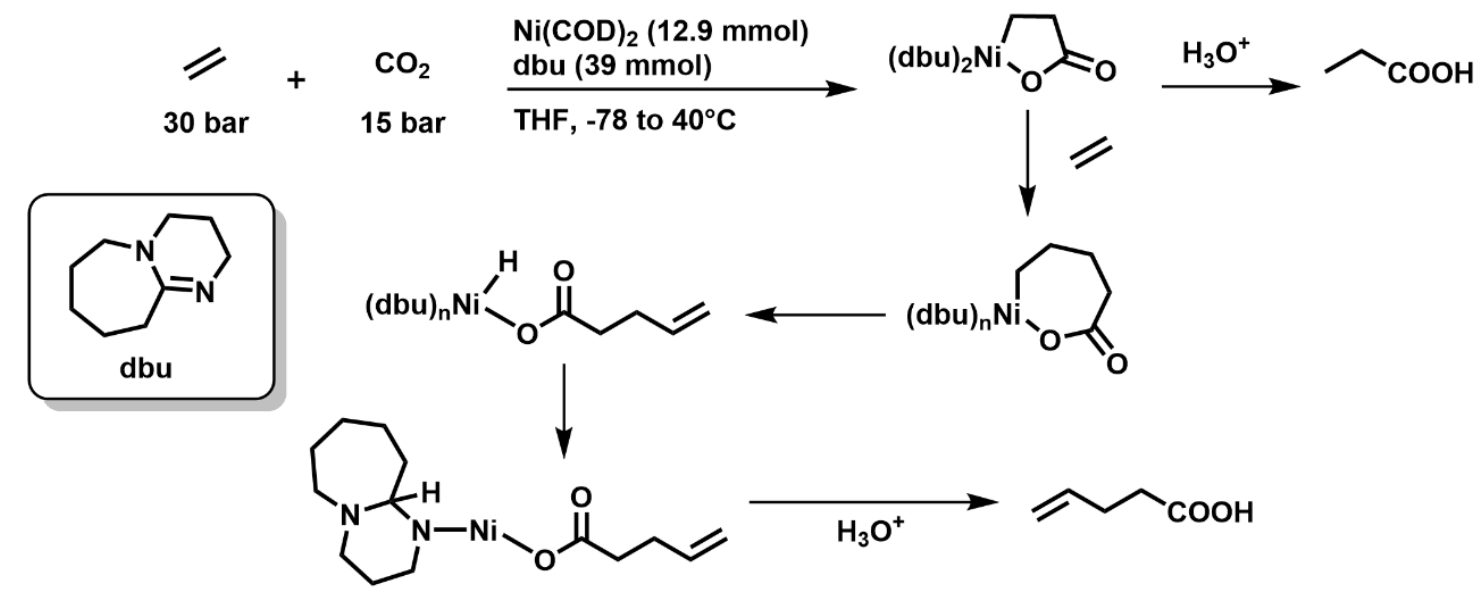

Figure 1.7. Stoichiometric carboxylation of ethylene to generate carboxylic acids facilitated by a dbu-ligated $\mathrm{Ni}^{0}$ complex. ${ }^{30}$

30. Hoberg, H.; Peres, Y.; Kruger, C.; Tsay, Y. H. A 1-Oxa-2-nickela-5-cyclopentanone from Ethene and Carbon Dioxide: Preparation, Structure, and Reactivity. Angew. Chem. Int. Ed. 1987, 26, 771-773. 
This methodology was expanded to other alkenes including cyclooctenes, ${ }^{31,32}$ styrenes, ${ }^{33}$ and dienes $^{34}$ as well as imines ${ }^{35}$ and aldehydes. ${ }^{36}$ Early base transition metal complexes are also competent in the oxidative coupling of ethylene and $\mathrm{CO}_{2}$. For example, Bercaw et al. demonstrated that $\left(\eta^{5}-\mathrm{Cp}^{*}\right)_{2} \mathrm{Ti}\left(\eta^{2}-\mathrm{C}_{2} \mathrm{H}_{4}\right)\left(\mathrm{Cp}^{*}=\right.$ pentamethylcyclopentadiene $)$ and 1.0 equivalent of $\mathrm{CO}_{2}$ gas at low temperature produces the titanalactone $\left(\left(\eta^{5}-\mathrm{Cp}^{*}\right)_{2} \mathrm{Ti}^{\mathrm{IV}}\left(\mathrm{OC}(\mathrm{O}) \mathrm{CH}_{2} \mathrm{CH}_{2}\right)\right.$ (Figure 1.8). ${ }^{37}$ Analogous reactions are possible at several other late transition metal centers such as Pt, Ir, and $\mathrm{Pd}^{38}$

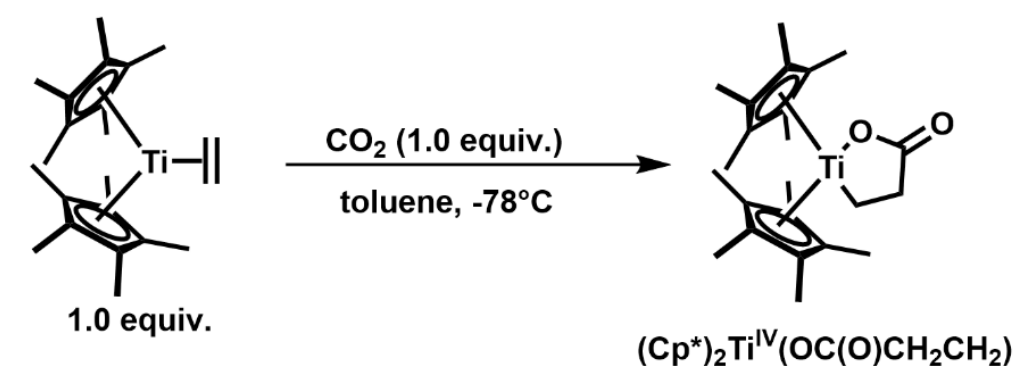

Figure 1.8. Incorporation of $\mathrm{CO}_{2}$ into $\left(\eta^{5}-\mathrm{Cp}^{*}\right)_{2} \mathrm{Ti}\left(\eta^{2}-\mathrm{C}_{2} \mathrm{H}_{4}\right)$ to generate $\left(\mathrm{Cp}^{*}\right)_{2} \mathrm{Ti}^{\mathrm{IV}}\left(\mathrm{OC}(\mathrm{O}) \mathrm{CH}_{2} \mathrm{CH}_{2}\right){ }^{37}$

31. Hoberg, H.; Ballesteros, A. Nickel(0)-Induced Formation of Cyclic C8 Carboxylic Acids from Cyclooctenes and Carbon Dioxide. J. Organomet. Chem. 1991, 411, C11-C18.

32. Hoberg, H.; Ballesteros, A.; Sigan, A.; Jegat, C.; Baerhausen, D.; Milchereit, A. Ligand Promoted Ring Contraction of Nickel Five-Membered Ring to Four-Membered Complex - New Synthon for Preparative Chemistry. J. Organomet. Chem. 1991, 407, C23-C29.

33. Hoberg, H.; Peres, Y.; Milchereit, A. C-C Coupling of Alkenes with Carbon Dioxide and Nickel(0). Preparation of Cinnamic Acid from Styrene. J. Organomet. Chem. 1986, 307, C38-C40.

34. Hoberg, H.; Jenni, K. $\eta^{4}$-1,3-Butadienetris(triethylphosphine)iron(0): A Complex Useful for the Complexation of Alkenes or Alkynes. J. Organomet. Chem. 1986, 301, C59-C61.

35. Ceneni, S.; Porta, F.; Pizzotti, M.; Crotti, C. Insertion of Carbon Dioxide, of $\mathrm{CO}_{2}$-Like Molecules, and of Other Unsaturated Compounds into the Platinum-Nitrogen Bond of $\left[\mathrm{Pt}\left(\mathrm{PPh}_{3}\right)_{2}(\mathrm{PhNO})\right]$. J. Chem. Soc., Dalton Trans. 1985, 163-168.

36. Kaiser, J.; Sieler, J. Braun, U.; Golic, L.; Dinjus, E.; Walther, D. Activation of Carbon Dioxide at Transition Metal Centers: Crystal and Molecular Structure of 2,2'-dipyridylnickela-5-methyl-2,4-dioxolan-3-one, a Coupling Product of Carbon Dioxide and Acetaldehyde at the Central Atom Nickel(0). J. Organomet. Chem. 1982, 224, 81-87.

37. Cohen, S. A.; Bercaw, J. E. Titanacycles Derived from Reductive Coupling of Nitriles, Alkynes, Acetaldehyde, and Carbon Dioxide with Bis(pentamethylcyclopentadienyl)(ethylene)titanium(II). Organometallics 1985, 4, 10061014.

38. Braunstein, P.; Matt, D.; Nobel, D. Reactions of Carbon Dioxide with Carbon-Carbon Bond Formation Catalyzed by Transition Metal Complexes. Chem Rev. 1988, 88, 747-764. 


\subsubsection{Stoichiometric $\mathrm{CO}_{2}$ Fixation via Insertion Reactions}

$\mathrm{CO}_{2}$ fixation by direct insertion into a metal-E bond $(\mathrm{E}=\mathrm{H}, \mathrm{C}, \mathrm{N}, \mathrm{O}, \mathrm{P}, \mathrm{Si}$, etc. $)$ is also possible. $^{22 \mathrm{~g}}$ The most pertinent to this discussion are the $\mathrm{C}-\mathrm{C}$ bond forming reactions. Stoichiometrically, this has been achieved with transition metals that span the d block.

One of the earliest examples of stoichiometric $\mathrm{CO}_{2}$ fixation used diphenyltitanocene complexes. Kolominkov and colleagues noted that upon treatment of $\left[\left(\mathrm{Cp}^{*}\right)_{2} \mathrm{Ti}(\mathrm{Ph})_{2}\right]$ with $\mathrm{CO}_{2}$, a 5-membered metallacycle was formed following insertion into the Ti-aryl bond (Figure 1.9). ${ }^{39}$ Methyl benzoate was isolated upon treatment with $\mathrm{MeOH} / \mathrm{BF}_{3}$. 1,2-benzenedicarboxylic acid (also known as phthalic acid) arises from insertion of an additional $\mathrm{CO}_{2}$ equivalent into the $\mathrm{M}-\mathrm{C}_{i p s o}$ bond of the titanacyclolactone complex, followed by acidification.

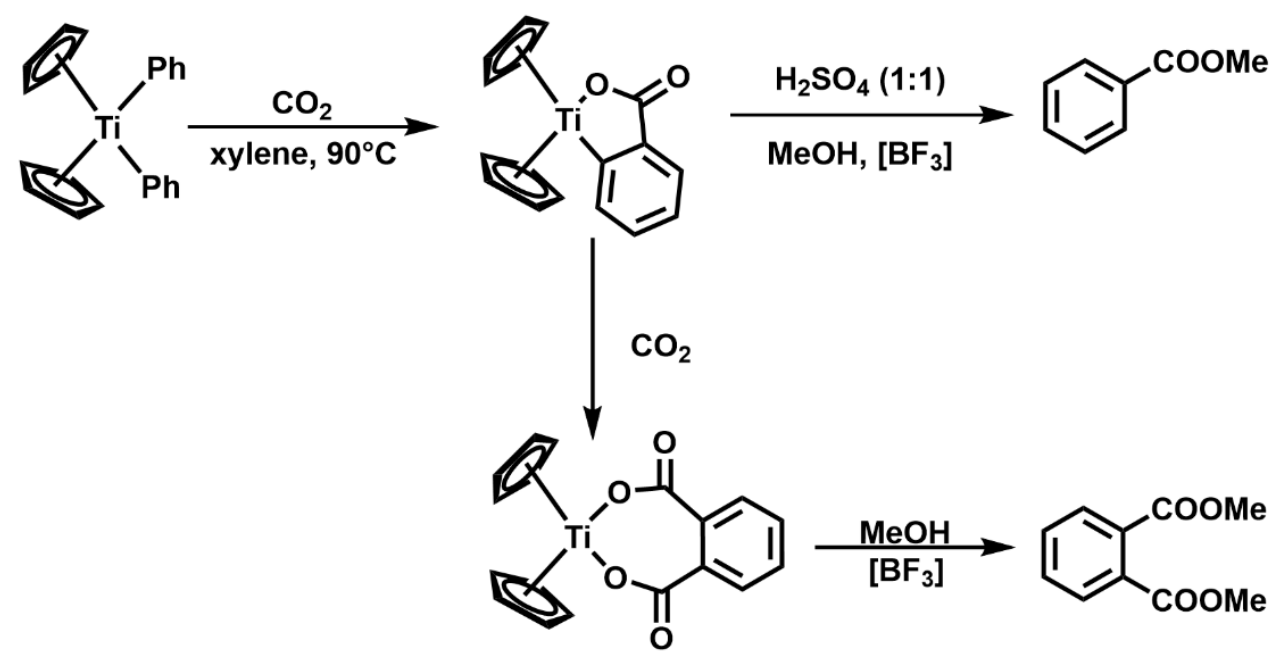

Figure 1.9. Insertion of carbon dioxide into a titanium-aryl bond. ${ }^{39}$

39. Kolomnikov, I. S.; Lobeeva, T. S.; Gorbachevskaya, V. V.; Aleksandrov, G. G.; Struchkov, Y. T.; Vol'pin, M. E. Reaction of Carbon Dioxide with Diphenyltitanocene and X-Ray Crystal Structure of the Product. Chem. Commun. 1971, 972-973. 
A similar reaction was reported using nickel ligated with a series of heteroleptic bidentate ligands, yielding the same carboxylic acid products after workup. ${ }^{40}$ Other instances of stoichiometric $\mathrm{CO}_{2}$ insertion reactions using nickel include the ring expansion of a nickelacyclobutabenzene complex to form a 6-membered nickelalactone (Figure 1.10). ${ }^{41}$ Copper has also been used for insertion of $\mathrm{CO}_{2}$ into activated alkanes, such as malonodinitrile and ethyl cyanoacetate, yielding interesting carboxylated products. ${ }^{42}$ While many of the complexes are not suitable for catalysis, mechanistic study of the stoichiometric reactions has provided insights into the informed design of successful $\mathrm{CO}_{2}$ functionalization catalysts.

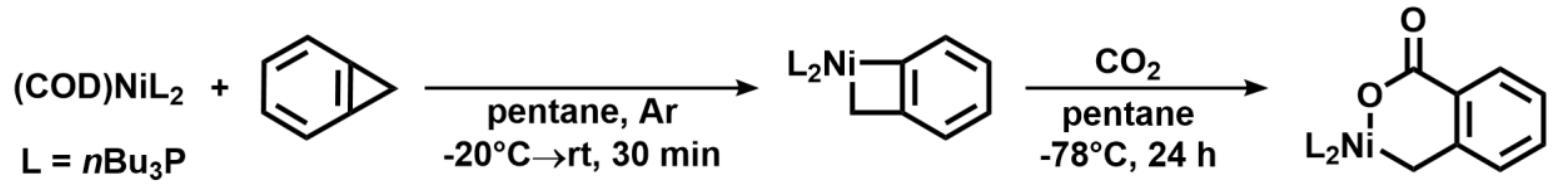

Figure 1.10. Ring expansion reaction via $\mathrm{CO}_{2}$ insertion into $\mathrm{Ni}$-aryl bond. ${ }^{41}$

40. Behr, A.; Keim, W.; Thelen, W. Stoichiometric Insertion of Carbon Dioxide and Ethylene into Nickel-Carbon Bonds. J. Organomet. Chem. 1983, 249, C38-C40.

41. Neidlein, R.; Rufinska, A.; Schwager, H.; Wilke, G. Nickelacyclobutabenzene Compounds by Oxidative Addition of Cyclopropabenzene to Nickel(0) Compounds. Angew. Chem. Int. Ed. 1986, 25, 640-642.

42. Monica, G. L.; Angaroni, A.; Ardizzoia, G. A. C-C Coupling of Activated Alkanes with Carbon Dioxide by $\left[(\mathrm{phen})\left(\mathrm{Ph}_{3} \mathrm{P}\right) \mathrm{Cu}\left(\mathrm{O}_{2} \mathrm{COH}\right)\right]$. J. Organomet. Chem. 1988, 348, 279-284. 


\subsection{Catalytic Carboxylation of Organoboron and Organohalide Compounds}

Incentive to couple $\mathrm{CO}_{2}$ with other readily available organic materials via catalytic carboxylation has led to significant advances in the field. Many carboxylation strategies rely heavily on the use of transition metal complexes ${ }^{43}$ to gain access to desirable products such as complex carboxylic acid derivatives through a variety of $\mathrm{C}-\mathrm{E}\left(\mathrm{E}=\mathrm{B}^{44}\right.$ and $\left.\mathrm{Sn}^{45}\right), \mathrm{C}-\mathrm{H},{ }^{46}$ and $\mathrm{C}-\mathrm{X}^{47}$ bond transformations. ${ }^{22}$ Organoboron reagents are common carboxylation substrates, providing access to several interesting compounds. Iwasawa demonstrated the first transition metal catalyzed carboxylation of organoboron reagents using $[\mathrm{Rh}(\mathrm{OH})(\mathrm{cod})]_{2}$ and the bidentate ligand 1,3-

43. For selected reviews on transition metal-facilitated carboxylation chemistry, see: (a) Zhang, L.; Li, Z.; Takimoto, M.; Hou, Z. Carboxylation Reactions with Carbon Dioxide Using N-Heterocyclic Carbene-Copper Catalysts. Chem. Rec. 2019, 19, 1-20. (b) Yang, Y.; Lee, J. Toward Ideal Carbon Dioxide Functionalization. Chem. Sci. 2019, 10, 39053926. (c) Cokoja, M.; Bruckmeier, C.; Rieger, B.; Herrmann, W. A.; Kühn, F. E. Transformation of Carbon Dioxide with Homogeneous Transition-Metal Catalysts: A Molecular Solution to a Global Challenge? Angew. Chem. Int. Ed. 2011, 50, 8510-8537.

44. For select examples of C-B bond carboxylation, see: (a) Kuge, K.; Luo, Y.; Fujita, Y.; Mori, Y.; Onodera, G.; Kimura, M. Copper-Catalyzed Stereodefined Construction of Acrylic Acid Derivatives from Terminal Alkynes via $\mathrm{CO}_{2}$ Insertion. Org. Lett. 2017, 19, 854-857. (b) Juhl, M.; Laursen, S. L. R.; Huang, Y.; Nielsen, D. U.; Daasbjerg, K.; Skrydstrup, T. Copper-Catalyzed Carboxylation of Hydroborated Disubstituted Alkenes and Terminal Alkynes with Cesium Fluoride. ACS Catal. 2017, 7, 1392-1396. (c) Duong, H. A.; Huleatt, P. B.; Tan, Q. W.; Shuying, E. L. Regioselective Copper-Catalyzed Carboxylation of Allylboronates with Carbon Dioxide. Org. Lett. 2013, 15, 40344037. (d) Ohishi, T.; Nishiura, M.; Hou, Z. Carboxylation of Organoboronic Esters Catalyzed by N-Heterocyclic Carbene Copper(I) Complexes. Angew. Chem. Int. Ed. 2008, 47, 5792-5795; and references therein.

45. For select examples of C-Sn bond carboxylation, see: (a) Feng, X.; Sun, A.; Zhang, S.; Yu, X.; Bao, M. PalladiumCatalyzed Carboxylative Coupling of Benzyl Chlorides with Allyltributylstannane: Remarkable Effect of Palladium Nanoparticles. Org. Lett. 2013, 15, 108-111. (b) Franks, R. J.; Nicholas, K. M. Palladium-Catalyzed Carboxylative Coupling of Allylstannanes and Allyl Halides. Organometallics 2000, 19, 1458-1460. (c) Shi, M.; Nicholas, K. M. Palladium-Catalyzed Carboxylation of Allyl Stannanes. J. Am. Chem. Soc. 1997, 119, 5057-5058.

46. For selected examples of C-H bond carboxylation utilizing $\mathrm{CO}_{2}$, see: (a) Takimoto, M.; Gholap, S. S.; Hou, Z. Alkylative Carboxylation of Ynamides and Allenamides with Functionalized Alkylzinc Halides and Carbon Dioxide by a Copper Catalyst. Chem. Eur. J. 2019, 25, 8363-8370. (b) Sahoo, B.; Bellotti, P.; Juliá-Hernández, F.; Meng, Q.; Crespi, S.; König, B.; Martin, R. Site-Selective, Remote sp ${ }^{3}$ C-H Carboxylation Enabled by the Merger of Photoredox and Nickel Catalysis. Chem. Eur. J. 2019, 25, 9001-9005. (c) Ishida, N.; Masuda, Y.; Imamura, Y.; Yamazaki, K.; Murakami, M. Carboxylation of Benzylic and Aliphatic C-H Bonds with $\mathrm{CO}_{2}$ Induced by Light/Ketone/Nickel. $J$. Am. Chem. Soc. 2019, 141, 19611-19615. (d) Saini, S.; Singh, H.; Prajapati, P. K.; Sinha, A. K.; Jain, S. L. Nickel/Nickel Oxide in Combination with a Photoredox Catalyst for the Reductive Carboxylation of Unsaturated Hydrocarbons with $\mathrm{CO}_{2}$. ACS Sustainable Chem. Eng. 2019, 7, 11313-11322. (e) Hong, J.; Li, M.; Zhang, J.; Sun, B.; Mo, F. C-H Carboxylation with Carbon Dioxide. ChemSusChem 2019, 12, 6-39.

47. For selected examples of $\mathrm{C}-\mathrm{X}$ bond carboxylation utilizing $\mathrm{CO}_{2}$, see: (a) Charboneau, D. J.; Brudvig, G. W.; Hazari, N.; Lant, H. M. C.; Saydjari, A. K. Development of an Improved System for the Carboxylation of Aryl Halides through Mechanistic Studies. ACS Catal. 2019, 9, 3228-3241. (b) Yan, S.; Wu, D.; Ye, J.; Gong, L.; Zeng, X.; Ran, C.; Gui, Y; Li, J.; Yu, D. Copper-Catalyzed Carboxylation of C-F Bonds with $\mathrm{CO}_{2}$. ACS Catal. 2019, 9, 6987-6992. (c) Bhunia, S. K.; Das, P.; Nandi, S.; Jana, R. Carboxylation of Aryl Triflates with $\mathrm{CO}_{2}$ Merging Palladium and Visible-Light-Photoredox Catalysts. Org. Lett. 2019, 21, 4632-4637. (d) Ma, C.; Zhao, C.; Xu, X.; Li, Z.; Wang, X.; Zhang, K.; Mei, T. Nickel-Catalyzed Carboxylation of Aryl and Heteroaryl Fluorosulfates Using Carbon Dioxide. Org. Lett. 2019, 21, 2464-2467. 
bis(diphenylphopshino)propane (dppp) (Figure 1.11). ${ }^{48}$ The reaction was robust, with a large library of aryl- and alkenylboronic esters undergoing carboxylation efficiently.

Iwasawa, 2006 - Aryl and Alkenylboronic Esters

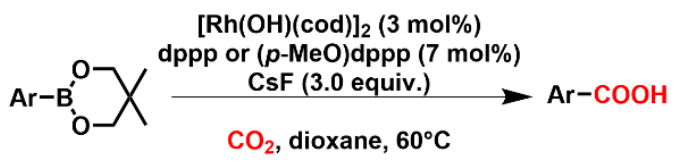

Iwasawa and Hou, 2008 - Aryl and Alkenylboronic Esters

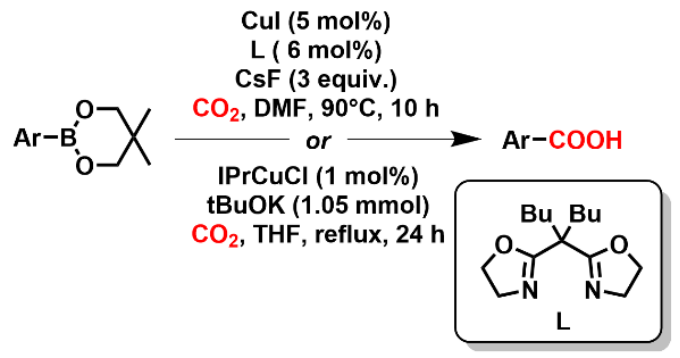

Sawamura and Hou, 2011 - Tandem Hydroboration/Carboxylation

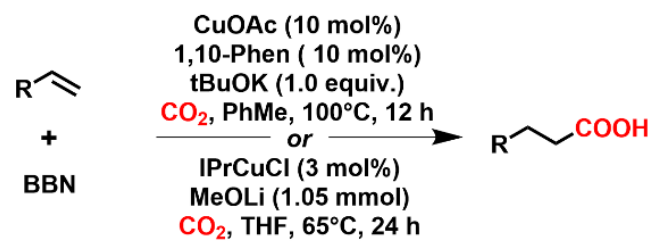

Skrydstrup, 2017 - Tandem Hydroboration/Carboxylation of Disubstituted Alkenes and Terminal Alkynes

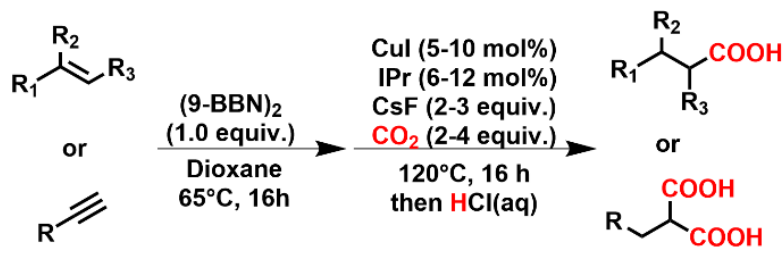

Figure 1.11. Examples of the carboxylation of organoborane substrates. ${ }^{50-53}$

This work was expanded to copper complexes by Iwasawa with the carboxylation of arylboronic esters catalyzed by a copper(I)-bisoxazoline complex (Figure 1.11). ${ }^{49}$ The reaction was tolerant of several electron deficient and electron rich arylboronic esters, all giving good to excellent yields of the carboxylate product. Alkenylboronic esters bearing $\mathrm{B}(\mathrm{nep})(\mathrm{B}(\mathrm{nep})=5,5$ dimethyl-1,3,2-dioxaborinane) were also carboxylated under mild conditions, demonstrating the robustness of the reaction.

In the same year, a reaction developed by $\mathrm{Hou}$ employing $\mathrm{IPrCuCl}$ ( $\mathrm{IPr}=1,3-\mathrm{Bis}(2,6-$ diisopropylphenyl)imidazol-2-ylidine) under basic conditions demonstrated carboxylation of heterocyclic substrates, such as 2-thienylboronic ester and indole derivatives in addition to several

48. Ukai, K.; Aoki, M.; Takaya, J.; Iwasawa, N. Rhodium(I)-Catalyzed Carboxylation of Aryl- and Alkenylboronic Esters with $\mathrm{CO}_{2}$. J. Am. Chem. Soc. 2006, 128, 8706-8707.

49. Takaya, J.; Tadami, S.; Ukai, K.; Iwasawa. Copper(I)-Catalyzed Carboxylation of Aryl- and Alkenylboronic Esters. Org. Lett. 2008, 10, 2697-2700. 
substituted aryl substrates. ${ }^{50}$ One-pot reactions that negate the pre-installation of a boron moiety were independently reported by Sawamura and Hou with 9-borabicyclo(3.3.1)nonane (BBN) as the boron source, using $\mathrm{CuOAc} / 1,10-\mathrm{Phen}$ (phen= phenanthroline) and $\mathrm{IPrCuCl}$, respectively. ${ }^{51,52}$ Disubstituted alkenes and terminal alkynes were added to accessible substrates in 2017 by the Strydstrup group using cesium fluoride salts rather than alkoxide bases (Figure 1.11). ${ }^{53}$

Each of these reactions is thought to follow a similar generic mechanism (Scheme 1.4). The active alkoxide or halide catalyst (A), following its generation, undergoes transmetalation with an organoboron reagent that was previously activated by a base (Step I). The metal-alkyl or -aryl compound (B) then undergoes insertion of $\mathrm{CO}_{2}$ into the M-C bond (Step II), generating metalcarboxylate species $\mathrm{C}$. An additional transmetalation step (III) with base (alkoxide or fluoride salt in these examples) yields a carboxylate salt, which is subsequently protonated via acidic workup.

50. Ohishi, T.; Nishiura, M.; Hou, Z. Carboxylation of Organoboronic Esters Catalyzed by N-Heterocyclic Carbene Copper(I) Complexes. Angew. Chem. Int. Ed. 2008, 47, 5792-5795.

51. Ohmiya, H.; Tanabe, M.; Sawamura, M. Copper-Catalyzed Carboxylation of Alkylboranes with Carbon Dioxide: Formal Reductive Carboxylation of Terminal Alkenes. Org. Lett. 2011, 13, 1086-1088.

52. Ohishi, T.; Zhang, L.; Nishiura, M.; Hou, Z. Carboxylation of Alkylboranes by N-Heterocyclic Carbene Copper Catalysts: Synthesis of Carboxylic Acids from Terminal Alkenes and Carbon Dioxide. Angew. Chem. Int. Ed. 2011, 50, 8114-8117.

53. Juhl, M.; Laursen, S. L. R.; Huang, Y.; Nielsen, D. U.; Daasbjerg, K.; Skrydstrup. Copper-Catalyzed Carboxylation of Hydroborated Disubstituted Alkenes and Terminal Alkynes with Cesium Fluoride. ACS. Catal. 2017, 7, 1392-1396. 
Scheme 1.4. General mechanism for carboxylation of organoboron compounds. ${ }^{10}$

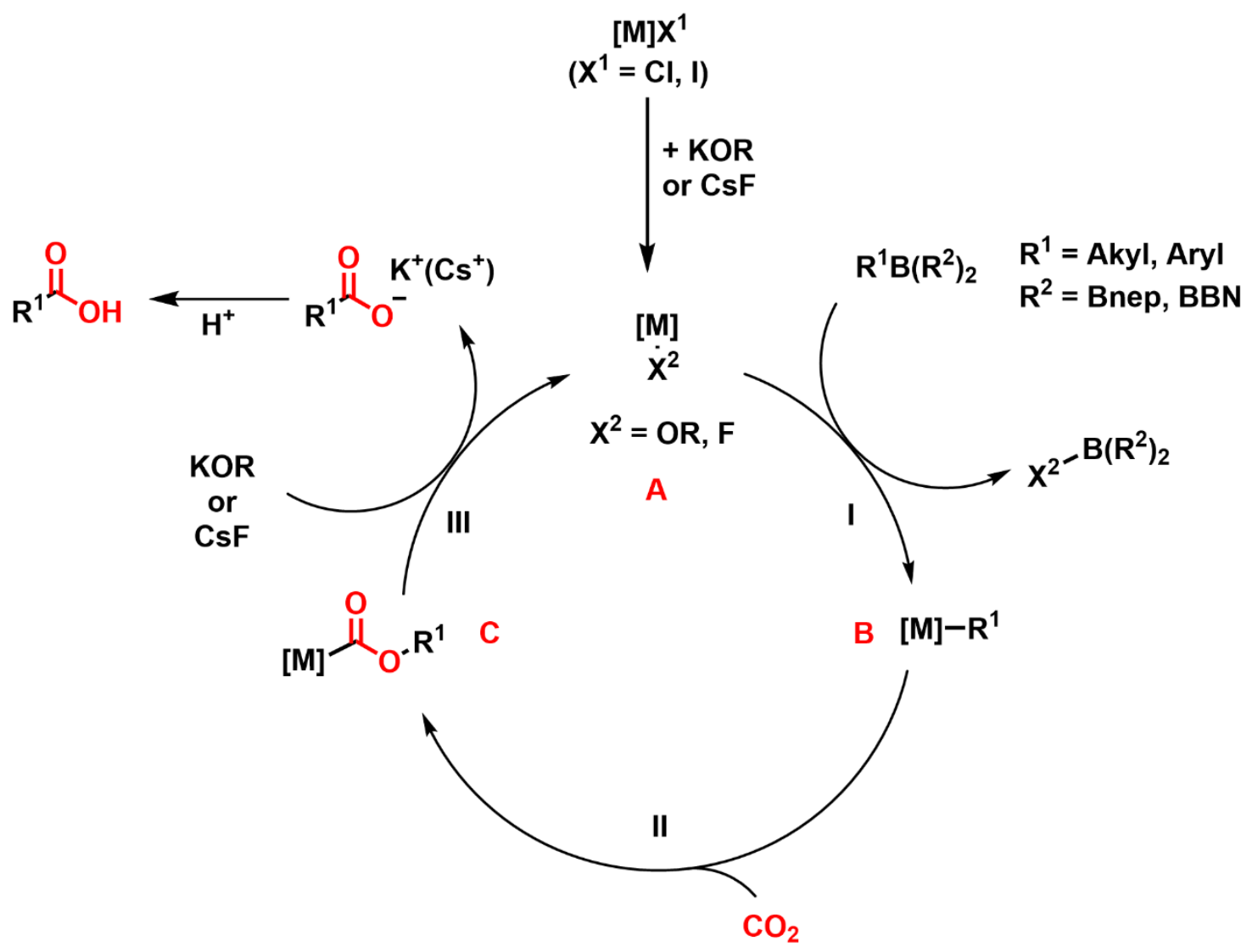

Significant progress has been made in the carboxylation of organohalide compounds following the first stoichiometric example reported by Osakada and Yamamato in $1994 .{ }^{54}$ Initially, $\mathrm{Pd}^{\mathrm{II}}$ and $\mathrm{tBuXantPhos}$ ligand (tBuXantPhos = 9,9-dimethyl-4,5-bis(di-tertbutylphosphino)xanthene) were used catalytically in the carboxylation of aryl bromides with various substituents. ${ }^{55}$ However, the need for pyrophoric diethyl zinc $\left(\mathrm{ZnEt}_{2}\right)$ coupling with high $\mathrm{CO}_{2}$ pressures required leaves safer and more user friendly alternatives to be desired.

In the last decade, powerful reducing agents have been largely replaced by $\mathrm{Zn}$ and $\mathrm{Mn}$, and most of examples demonstrate excellent reactivity with base transition metals such as nickel rather

54. Osakada, K.; Sato, R.; Yamamoto. Nickel-Complex-Promoted Carboxylation of Haloarenes Involving Insertion of $\mathrm{CO}_{2}$ into $\mathrm{Ni}^{\mathrm{II}}-\mathrm{C}$ Bonds. Organometallics 1994, 13, 4645-4647.

55. Correa, A.; Martin, R. Palladium-Catalyzed Carboxylation of Aryl Bromides with Carbon Dioxide. J. Am. Chem. Soc. 2009, 131, 15974-15974. 
than using precious metals. Tsuji reported the first base metal catalyzed carboxylation of aryl chlorides using $\mathrm{Ni}^{\mathrm{II}} \mathrm{Cl}_{2}\left(\mathrm{PPh}_{3}\right)_{2}$ with additional $\mathrm{PPh}_{3}$ as an additive (Figure 1.12. top). ${ }^{56}$

Tsuji, 2012 - Carboxylation of Aryl Chlorides

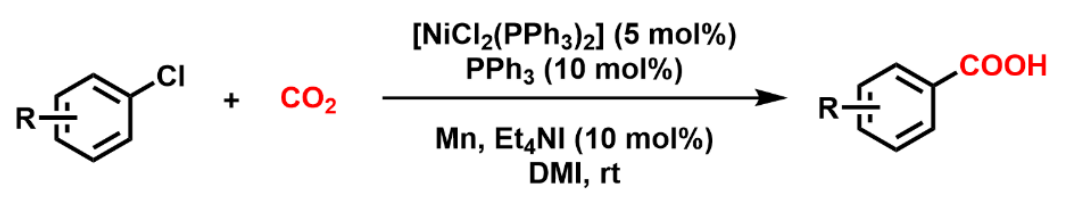

Martin, 2013 - Carboxylation of Benzyl Halides

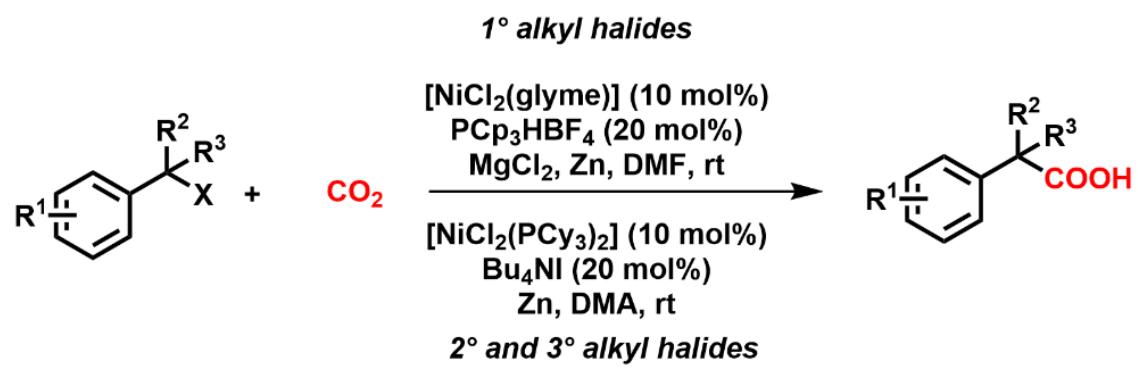

Martin, 2014 and 2016 - Carboxylation of Benzyl Halides
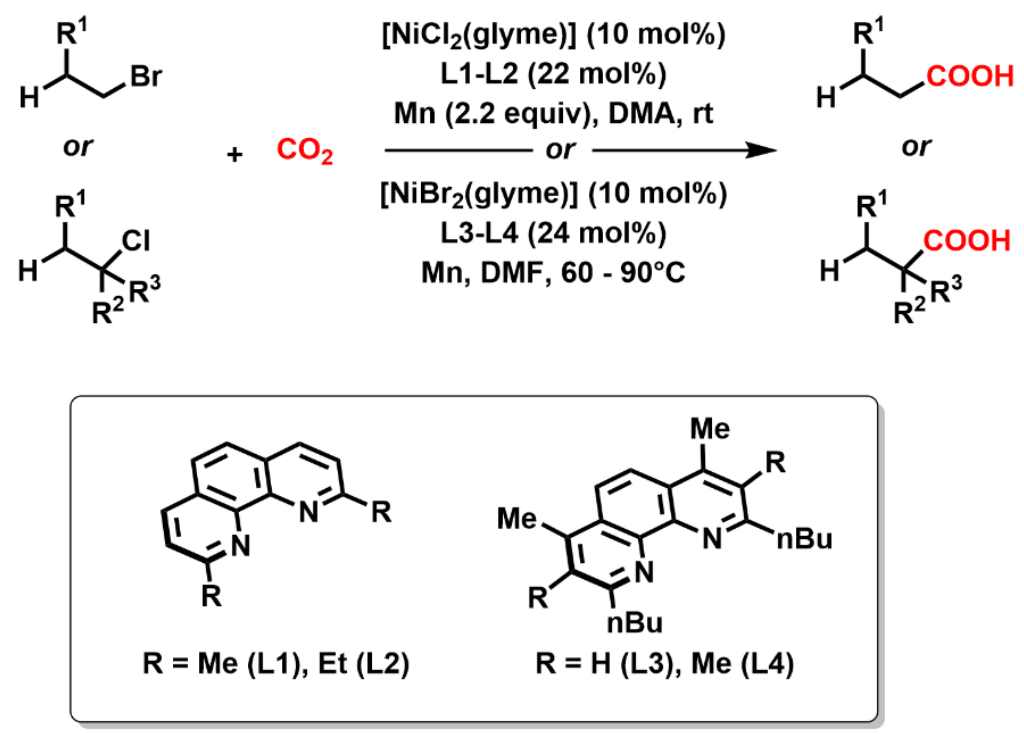

Figure 1.12. Representative examples of base metal catalyzed carboxylation of aryl and alkyl organohalides. ${ }^{56-59}$

56. Fujihara, T.; Nogi, K.; Xu, T.; Terao, J.; Tsuji, Y. Nickel-Catalyzed Carboxylation of Aryl and Vinyl Chlorides Employing Carbon Dioxide. J. Am. Chem. Soc. 2012, 134, 9106-9109. 
Several para-substituted aryl chlorides with diverse electronic properties were accessible in good yields under mild conditions. Martin subsequently reported the Ni-catalyzed carboxylation

of primary, secondary, and tertiary benzyl halides (Figure 1.12, center). ${ }^{57}$ The ligand dictates the identity of benzyl halides that are amenable to the reaction conditions. If $\mathrm{PCp}_{3} \mathrm{HBF}_{4}(\mathrm{Cp}=$ cyclopentadienyl) is added to reaction, selectivity for primary alkyl halides is observed. However, switching to pre-isolated $\mathrm{NiCl}_{2}\left(\mathrm{PCy}_{3}\right)_{2}\left(\mathrm{PCy}_{3}=\right.$ tricyclohexylphosphine $)$ as the precatalyst leads to the preferential carboxylation of secondary and tertiary alkyl halides. Expansion of the scope to incorporate aliphatic alkyl halides has also been achieved through similar Ni-catalyzed reactions (Figure 1.12. bottom). ${ }^{58,59}$

\subsection{Catalytic Reductive Carboxylation of Unactivated Olefins}

The carboxylation of organoboron and organohalide reagents is a significant step forward in $\mathrm{CO}_{2}$ functionalization chemistry; however, the need for prefunctionalized substrates limits the usefulness of catalytic carboxylation. Thus, methods in which unsaturated substrates such as alkynes and alkenes can be carboxylated directly have been developed.

The catalytic direct reductive carboxylation of alkenes was first reported by Rovis and colleagues, in which carboxylation of styrenes was accomplished using $\mathrm{CO}_{2}$ as well as $\mathrm{Ni}(\mathrm{acac})_{2}$ and $\mathrm{Et}_{2} \mathrm{Zn}$ (Figure 1.13. Left) ${ }^{60}$ The reaction proved to be tolerant of a variety of electron deficient and electron neutral styrene derivatives. Based on mechanistic investigations, carboxylation was proposed to precede a formal transmetalation/ $\beta$-hydride elimination with $\mathrm{Et}_{2} \mathrm{Zn}$ to afford carboxylic acids (following acidic workup) rather than proceeding through the anticipated nickelalactone species (see Section 1.2.1). A similar transformation was reported using iron(PDI)

57. León, T.; Correa, A.; Martin, R. Ni-Catalyzed Direct Carboxylation of Benzyl Halides with $\mathrm{CO}_{2}$. J. Am Chem. Soc. 2012, 135, 1221-1224.

58. Liu, Y.; Cornella, J.; Martin, R. Ni-Catalyzed Carboxylation of Unactivated Primary Alkyl Bromides and Sulfonates with $\mathrm{CO}_{2}$. J. Am. Chem. Soc. 2014, 136, 11212-11215.

59. Börjesson, M.; Moragas, T.; Martin, R. Ni-Catalyzed Carboxylation of Unactivated Alkyl Chlorides with $\mathrm{CO}_{2} . J$. Am. Chem. Soc. 2016, 138, 7504-7507.

60. Williams, C. M.; Johnson, J. B.; Rovis, T. Nickel-Catalyzed Reductive Carboxylation of Styrenes Using $\mathrm{CO}_{2} . J$. Am. Chem. Soc. 2008, 130, 14936-14937. 
complexes $(\mathrm{PDI}=$ pyridinediimine $)$ and various Grignard reagents; however, the reaction was only successful with electron-rich and electron-neutral substrates (Figure 1.13. Right). ${ }^{61,62}$

Rovis, 2008
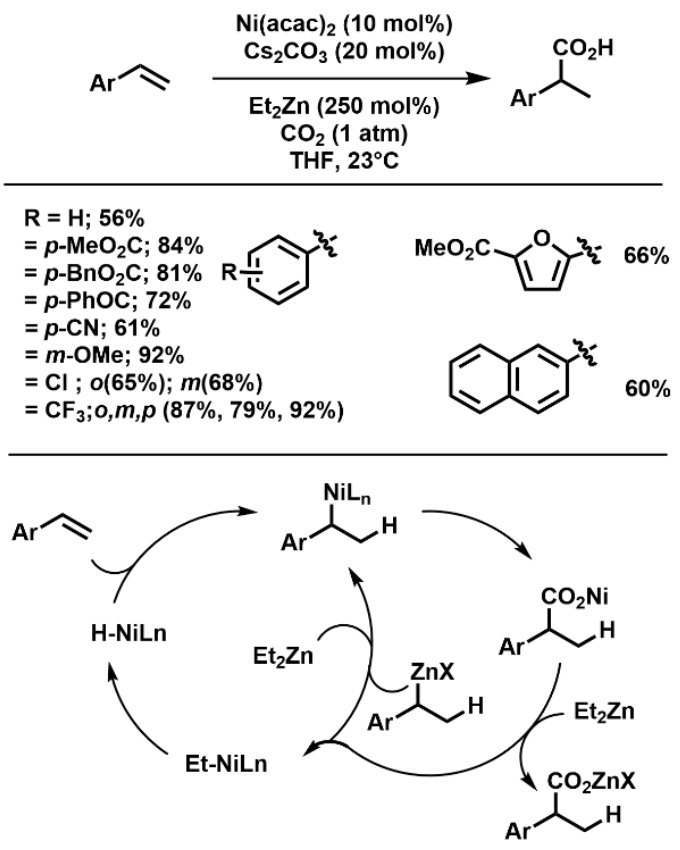

Thomas, 2012
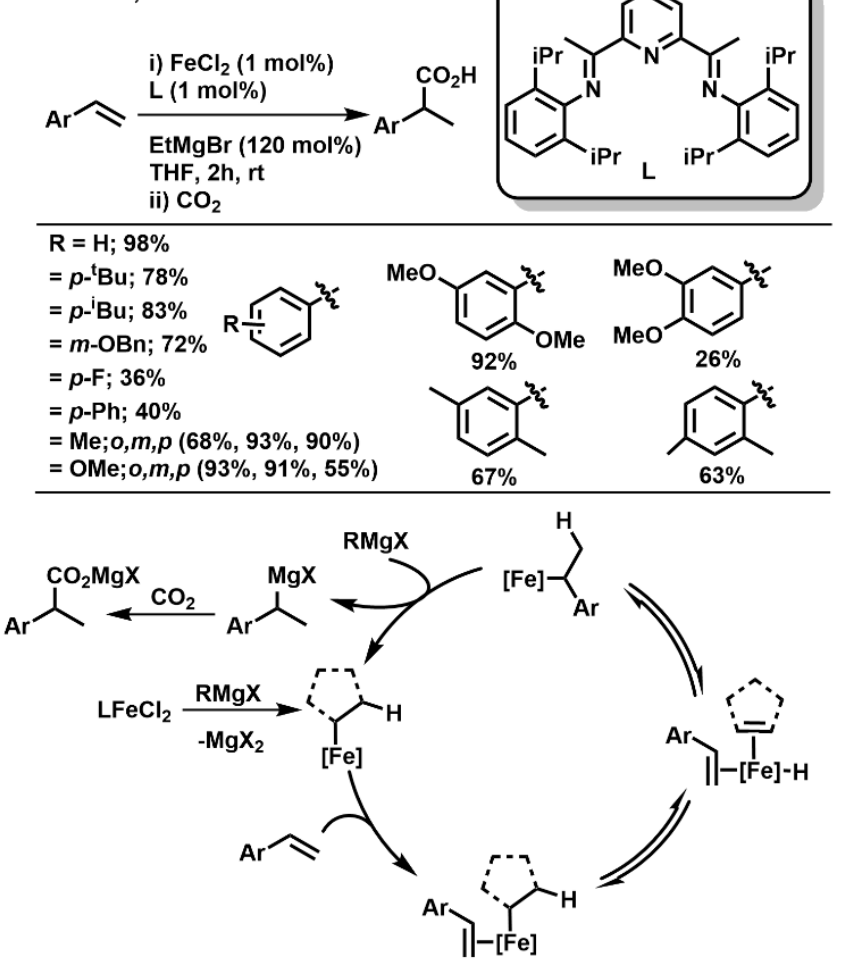

Figure 1.13. Left: Ni-catalyzed hydrocarboxylation of styrene. ${ }^{60}$ Right: Iron-catalyzed hydromagnesiation/carboxylation of styrene with $\mathrm{CO}_{2} \cdot{ }^{61}$

Multimetallic ${ }^{63}$ and early transition metal ${ }^{64}$ catalysts have also been identified that are capable of carboxylation of unactivated alkenes as well; however, both necessitate the presence of strong

61. Greenhalgh, M. D.; Thomas, S. P. Iron-Catalyzed Highly Regioselective Synthesis of $\alpha$-Aryl Carboxylic Acids from Styrene Derivatives and $\mathrm{CO}_{2}$. J. Am. Chem. Soc. 2012, 134, 11900-11903.

62. Recent computational studies found the mechanism of Fe-catalyzed hydrocarboxylation of vinyl arenes to be more complex than originally proposed by Thomas et al. For details, see: (a) Rogers, J. A.; Popp, B. V. Operando Infrared Spectroscopy Study of Iron-Catalyzed Hydromagnesiation of Styrene: Explanation of Nonlinear Catalyst and Inhibitory Substrate Dependences. Organometallics 2019, 38, 4533-4538. (b) Neate, P. G. N.; Greenhalgh, M. D.; Brennessel, W. W.; Thomas, S. P.; Neidig, M. L. Mechanism of the Bis(imino)pyridine-Iron-Catalyzed Hydromagnesiation of Styrene Derivatives. J. Am. Chem. Soc. 2019, 141, 10099-10108.

63. Shirakawa, E.; Ikeda, D.; Masui, S.; Yoshida, M.; Hayashi, T. Iron-Copper Cooperative Catalysis in the Reactions of Alkyl Grignard Reagents: Exchange Reaction with Alkenes and Carbometalation of Alkynes. J. Am. Chem. Soc. 2012, 134, 272-279.

64. Shao, P.; Wang, S.; Chen, C.; Xi, C. $\mathrm{Cp}_{2} \mathrm{TiCl}_{2}$-Catalyzed Regioselective Hydrocarboxylation of Alkenes with $\mathrm{CO}_{2}$. Org. Lett. 2016, 18, 2050-2053. 
reducing agents. The use of highly reactive reducing agents poses challenges, such as erosion of selectivity and limited substrate scope. Methods circumventing the requirement of highly reducing organometallic reagents while expanding the available scope of substrates are known.

One way of avoiding reactive organometallic reagents is to manipulate the water-gas shift reaction (WGSR). Leitner demonstrated in 2013 that formal hydrocarboxylation of several aliphatic linear and cyclic alkenes was possible with a rhodium-tricarbonyl/ $\mathrm{PPh}_{3}$ catalyst system and the inclusion of $\mathrm{H}_{2}$ gas. ${ }^{65}$ Initial reduction of $\mathrm{CO}_{2}$ by $\mathrm{H}_{2}$ generates $\mathrm{CO}$ gas, which is then inserted into the Rh-alkyl bond. Subsequent reaction with water releases the carboxylic acid products, and the cycle is completed (Scheme 1.5.).

Scheme 1.5. Rhodium-catalyzed hydroxycarbonylation of alkenes using $\mathrm{CO}_{2}$ and $\mathrm{H}_{2}$ gas. ${ }^{65}$

Leitner, 2013
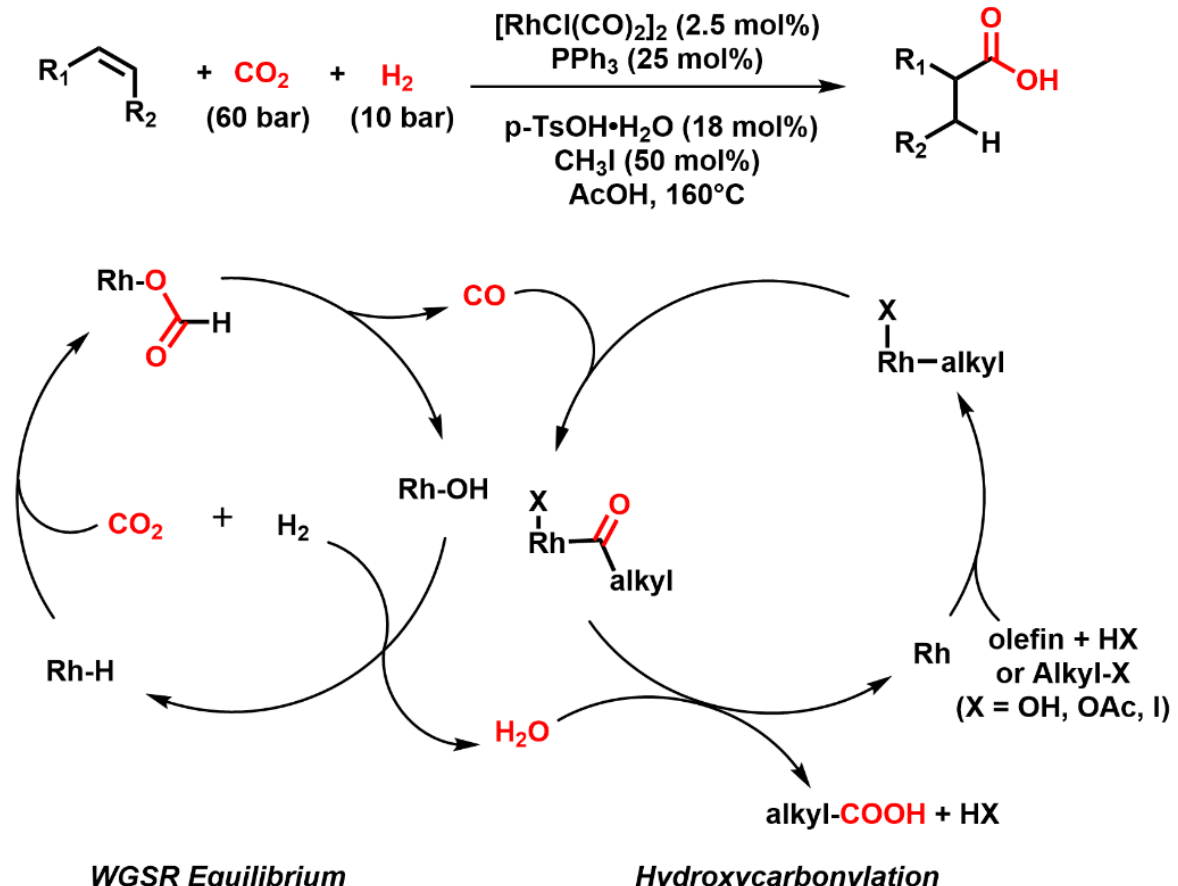

The same concept was explored by Beller in 2014 to generate carboxylic acid esters from a large scope of aliphatic and styrenyl alkenes using a multimetallic ruthenium complex and an NHC

65. Ostapowicz, T. G.; Schmitz, M.; Krysof, M.; Klankermayer, J.; Leitner, W. Carbon Dioxide as a $\mathrm{C}_{1}$ Building Block for the Formation of Carboxylic Acids by Formal Catalytic Hydrocarboxylation. Angew. Chem. Int. Ed. 2013, 52, 12119-12123. 
salt (Scheme 1.6) ${ }^{66}$ Similar to the Leitner work, this reaction too harnessed the WGSR with an alcohol providing the source of hydrogen through "hydrogen-borrowing." However, use of the endothermic WGSR often leads to, as in this example, a mixture of products.

Scheme 1.6. Ruthenium-catalyzed hydroxycarbonylation of alkenes. ${ }^{66}$

Beller, 2014
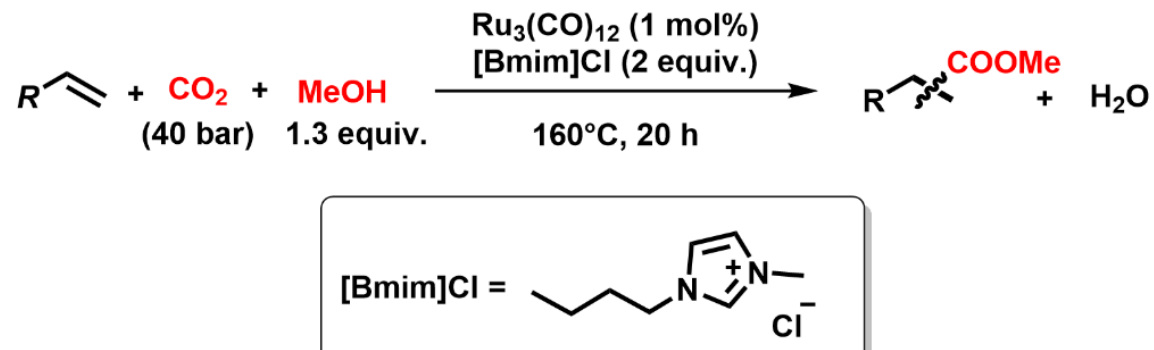

Possible Pathways

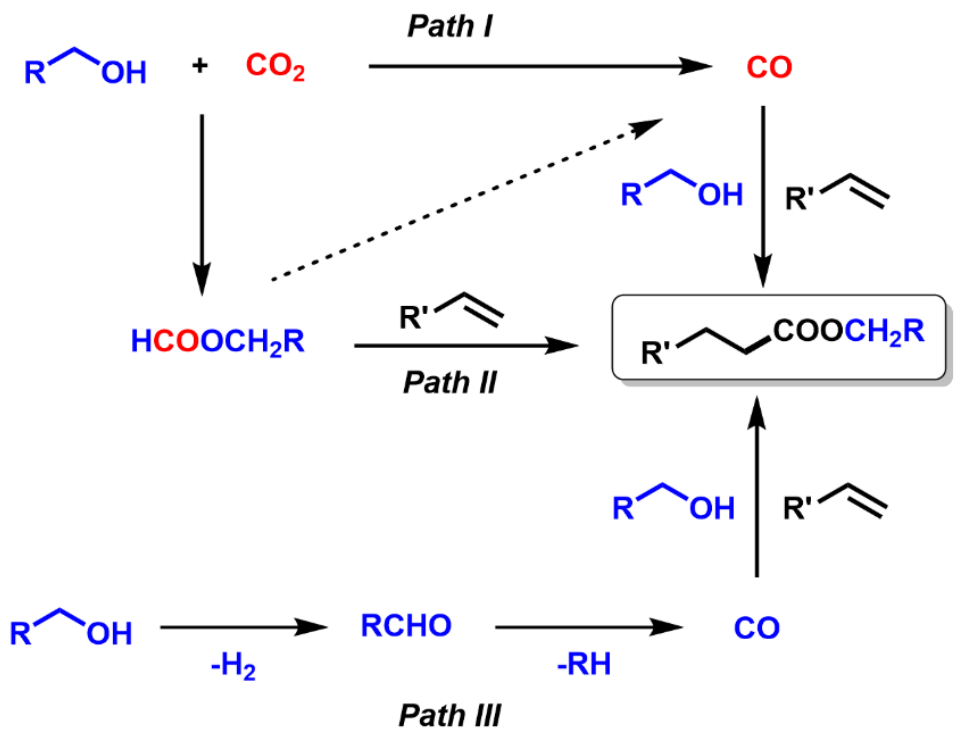

Other avenues of alkene carboxylation have garnered success. In 2017, Martin described carboxylation methodology amenable to both aliphatic and aromatic substrates (Figure 1.14). ${ }^{67}$ Using a derivatized bipyridyl ligand (L1) in conjunction with inexpensive nickel halide hydrate salts and water as the source of hydrogen, a series of aromatic alkenes were carboxylated.

66. Wu, L.; Liu, Q.; Fleischer, I.; Jackstell, R.; Beller, M. Ruthenium-Catalyzed Alkoxycarbonylation of Alkenes with Carbon Dioxide. Nat. Commun. 2014, 5, 1-6.

67. Gaydou, M.; Moragas, T.; Julía-Hernández, F.; Martin, R. Site-Selective Catalytic Carboxylation of Unsaturated Hydrocarbons with $\mathrm{CO}_{2}$ and Water. J. Am. Chem. Soc. 2017, 139, 12161-12164. 
Compounds such as fenoprofen and ibuprofen, commonly prescribed non-steroidal antiinflammatory drugs (NSAID), were produced in moderate yields. By switching the ligand to bathocuproine (L2), aliphatic terminal and internal alkenes as well as cycloalkenes were readily carboxylated (Figure 1.14.A). Carboxylation of remote sites on the $\alpha$ - and internal olefins is achieved through iterative $\beta$-hydride elimination/migratory insertion events known as chain walking (Figure 1.14.B). This work is a rare instance of carboxylation of unactivated alkenes with the added benefit of a "green" solvent choice with water as well as low pressures of $\mathrm{CO}_{2}$.

A.
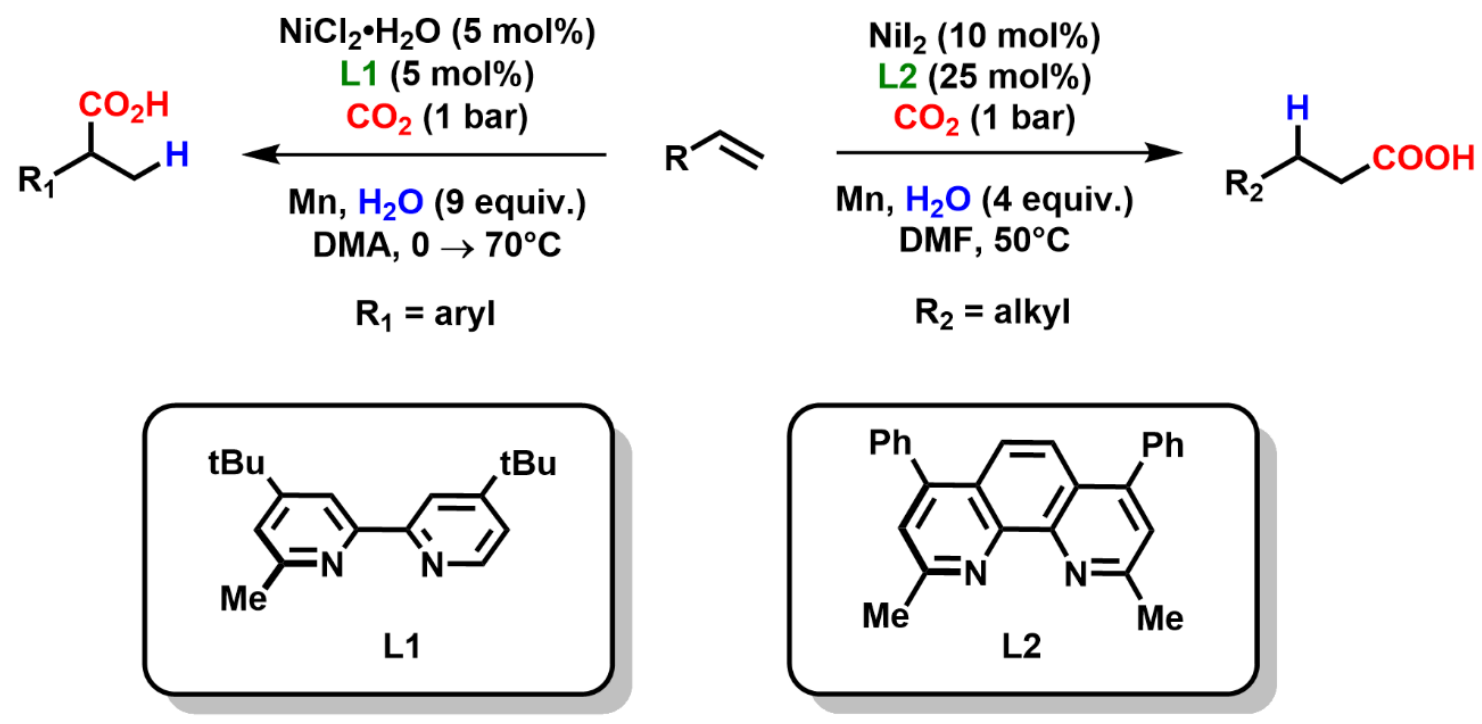

B.

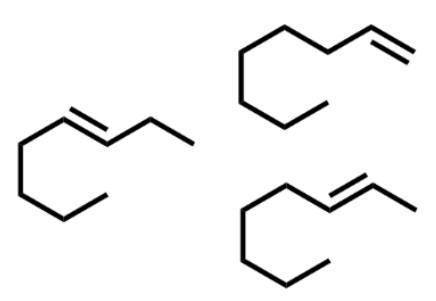

(1:1:1)

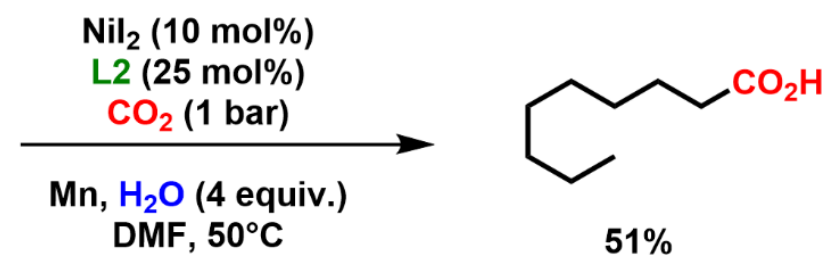

(linear: branched = 99:1)

Figure 1.14. A) Nickel-catalyzed carboxylation of aryl and alkyl olefins using water as hydride source. B) Site-selective carboxylation of mixture of alkenes yielding single isomer. ${ }^{67}$ 


\subsection{Catalytic Hetero(element)carboxylation of Unsaturated Compounds}

Another recent achievement in carboxylation chemistry is hetero(element)carboxylation, wherein the reductant is not a hydride equivalent, but rather a heteroatom moiety (such as silicon, boron, nitrogen, etc.). The first example of hetero(element)carboxylation of unsaturated compounds was reported by $\mathrm{Hou}$ in 2012. $\mathrm{CO}_{2}$ was used in the presence of an SIMescopper(I) catalyst (SIMes = 1,3-Bis(2,4,6-trimethylphenyl)-4,5-dihydroimidazol-2-ylidene) and $\mathrm{B}_{2} \mathrm{pin}_{2}$ as a reductant to functionalize both positions of terminal and internal alkynes. Varying electronic and steric properties were tolerated and yielded a series of $\alpha, \beta$-unsaturated boralactonate salts under mild conditions (Table 1.1). ${ }^{68}$

Table 1.1. Boracarboxylation of alkynes developed by Hou and colleagues. ${ }^{68}$

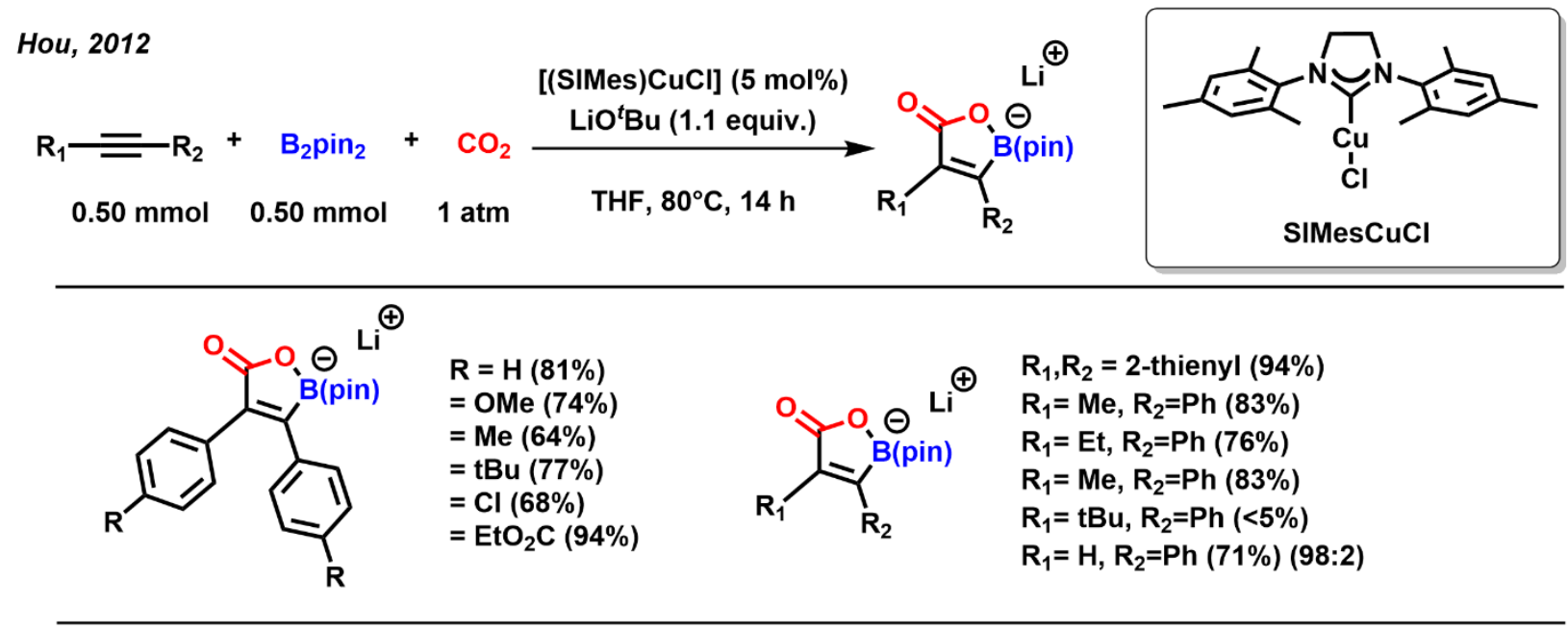

This report was followed shortly after by a silane-based analogue developed by Tsuji (Table 1.2). ${ }^{69}$ Silane and a carboxylate group were added across the triple bond of a series of internal alkynes using $\left[\mathrm{PCy}{ }_{3} \mathrm{CuCl}\right]$, providing moderate to good regioselectivity in a few cases.

68. Zhang, L.; Cheng, J.; Carry, B.; Hou, Z. Catalytic Boracarboxylation of Alkynes with Diborane and Carbon Dioxide by an N-Heterocyclic Carbene Copper Catalyst. J. Am. Chem. Soc. 2012, 134, 14314-14317.

69. Fujihara, T.; Tani, Y.; Semba, K.; Terao, J.; Tsuji, Y. Copper-Catalyzed Silacarboxylation of Internal Alkynes by Employing Carbon Dioxide and Silaboranes. Angew. Chem. Int. Ed. 2012, 51, 11487-11490. 
Several other substrates have been identified as competent for hetero(element)carboxylation. Notable examples include the silacarboxylation of allenes ${ }^{70}$ and the boracarboxylation of imines, ${ }^{71}$ and azacarboxylation of alkynylanilines, to name a few. ${ }^{72}$ Transition metal-free phosphonocarboxylation of alkenes with $\mathrm{CO}_{2}$ has also been recently disclosed. ${ }^{73}$

Table 1.2. Silacarboxylation of alkynes developed by Tsuji and colleagues. Ratio reflects the two possible insertion products. Major isomer drawn. ${ }^{69}$

Tsuji, 2012

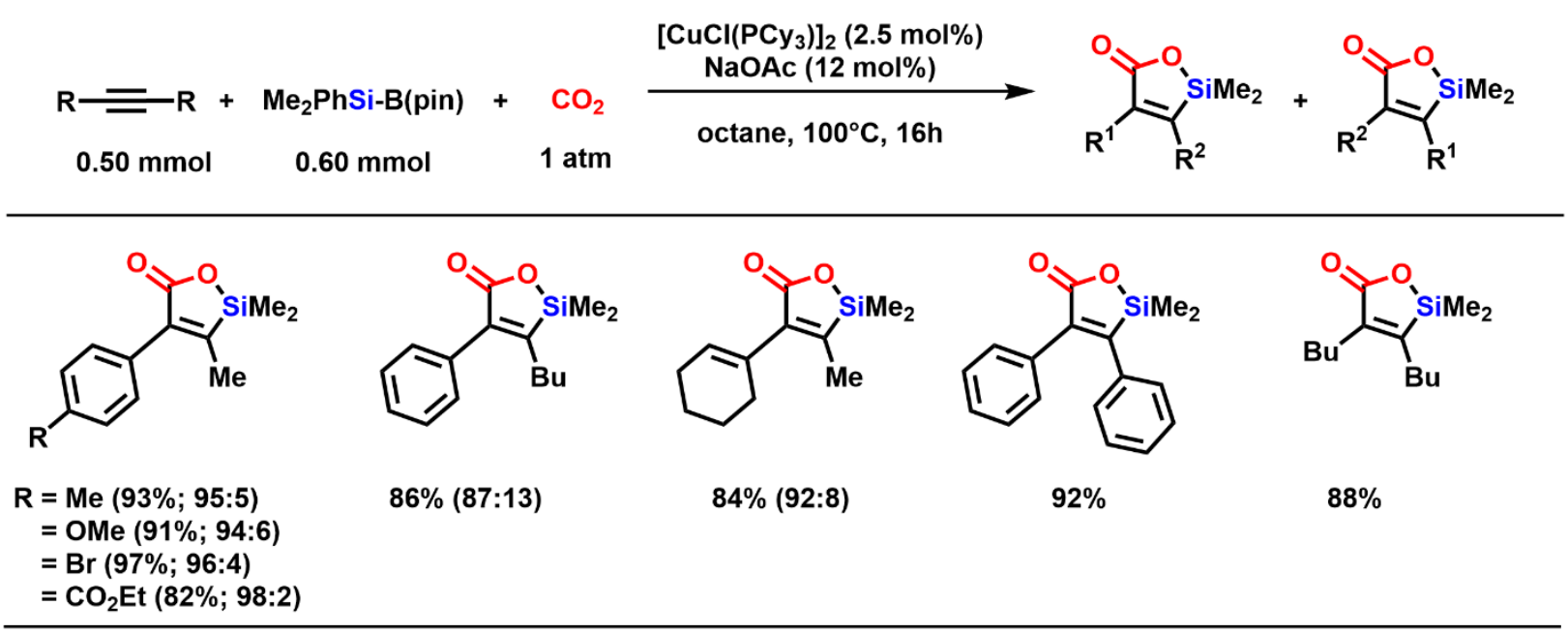

In 2016, Popp and colleagues extended boracarboxylation to vinyl arene substrates, a previously inaccessible reactant class. ${ }^{74}$ This reaction is proposed to proceed via in situ generated $\mathrm{Cu}^{\mathrm{I}}$-alkoxide complex ligated by the NHC ligand dicyclohexyl-2H-imidazolylidene (ICy) (Table $1.3)$.

70. (a) Tani, Y.; Fujihara, T.; Tsuji, Y. Copper-Catalyzed Regiodivergent Silacarboxylation of Allenes with Carbon Dioxide and a Silylborane. J. Am. Chem. Soc. 2014, 136, 17706-17709.

71. (a) Li, Z.; Zhang, L.; Nishiura, M.; Luo, G.; Hou, Z. $\mathrm{CO}_{2}$ Activation by Lewis Pairs Generated Under Copper Catalysis Enables Difunctionalization of Imines. J. Am. Chem. Soc. 2020s142, 1966-1974.

72. (a) Miao, B.; Li, S.; Li, G.; Ma, S. Cyclic Anti-Azacarboxylation of 2-Alkynylanilines with Carbon Dioxide. Org. Lett. 2016, 18, 2556-2559. (b) Li, S.; Ma, S. Quadri-Synergetic Effect for Highly Effective Carbon Dioxide Fixation and Its Application to Indoloquinolone. Adv. Synth. Catal. 2012, 354, 2387-2394.

73. Fu, Q.; Bo, Z. Y.; Ye, J. H.; Ju, T.; Huang, H.; Liao, L. L.; Yu, D. G. Transition Metal-Free Phosphonocarboxylation of Alkenes with Carbon Dioxide via Visible-Light Photoredox Catalysis. Nature Commun. 2019, 10, 1-9.

74. Butcher, T. W.; McClain, E. J.; Hamilton, T. G.; Perrone, T. M.; Kroner, K. M.; Donohoe, G. C.; Akhmedov, N. G.; Petersen, J. L.; Popp, B. V. Regioselective Copper-Catalyzed Boracarboxylation of Vinyl Arenes. Org. Lett. 2016, $18,6428-6431$. 
Table 1.3. Boracarboxylation of vinyl arenes developed by Popp and colleagues. ${ }^{74}$

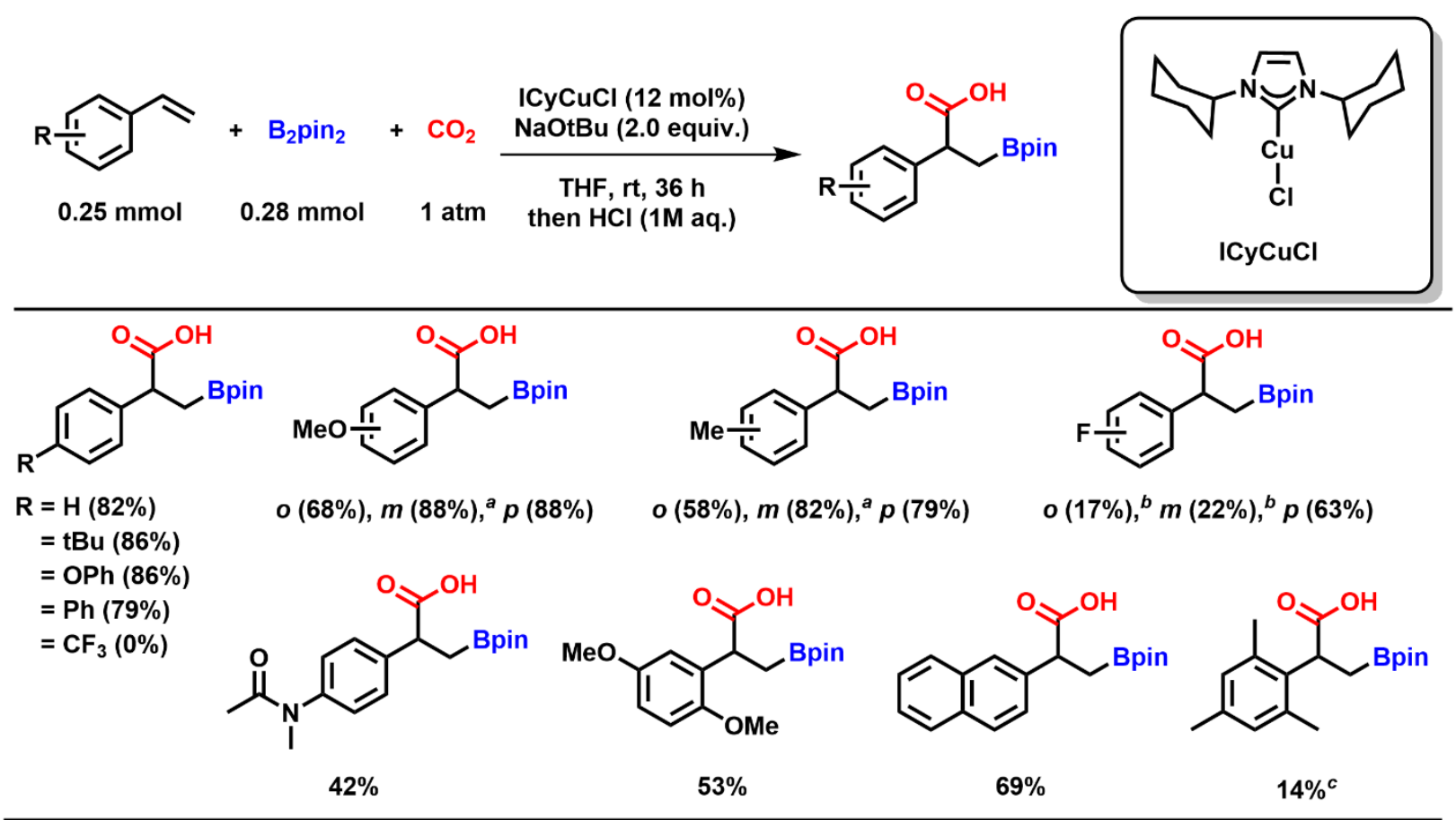

a. $40^{\circ} \mathrm{C}{ }^{b .} 50^{\circ} \mathrm{C}$

The substrate scope of boracarboxylation encompassed several electron rich and electron neutral vinyl arenes as well as some with extended $\pi$-systems. Even more interestingly, novel NSAID derivatives, such as ibuprofen, with a boronic ester group in the $\beta$-position were accessible using this methodology, offering a handle for further functionalization. However, optimized reaction conditions were not amenable to substrates bearing electron deficient aryl rings nor to aliphatic/non-benzylic alkenes. While more recent studies have provided access to some of these more challenging substrates (see Chapter 3), ${ }^{75}$ there are still many unknown aspects of this reaction. A concrete understanding of the mechanism may identify opportunities to extend the scope of the reaction.

75. Perrone, T. M.; Gregory, A. S.; Knowlden, S. W.; Ziemer, N. R.; Alsulami, R. N.; Petersen, J. L.; Popp, B. V. Beneficial Effect of a Secondary Ligand on the Catalytic Difunctionalization of Vinyl Arenes with Boron and $\mathrm{CO}_{2}$. ChemCatChem 2019, 11, 5814-5820. 


\subsection{Concluding Remarks}

This chapter has presented a brief overview of current carboxylation chemistry as it pertains to alkenes with the advantages and disadvantages to each system, culminating with an overview of hetero(element)carboxylation up to the report by the Popp group on the boracarboxylation of vinyl arenes. Given that hetero(element)carboxylation is relatively new, there are still many general aspects of the process to understand. The following chapters describe analysis of the stoichiometric synthesis and characterization of relevant intermediates of copper(I)-catalyzed boracarboxylation of vinyl arenes. Reactivity studies pertinent to understanding the mechanism of carboxylation are also presented. Chapter 3 discusses stoichiometric and computational experimentation regarding the use of additives to enhance the reactivity of boracarboxylation of electron deficient vinyl arenes and the implications that has on the active metal species. Chapter 4 explores the possibility of Lewis-acid/base characteristics that may aid in facilitating carboxylation via activation of the $\mathrm{CO}_{2}$ moiety. This study was conducted using density functional theory (DFT) and natural bond orbital analysis (NBO), where it was discovered that carboxylation becomes more energetically accessible as the Lewis acidity at the boron increases. 


\section{CHAPTER 2}

\section{Mechanistic Investigation of Copper(I)-Catalyzed Boracarboxylation of Vinyl Arenes}

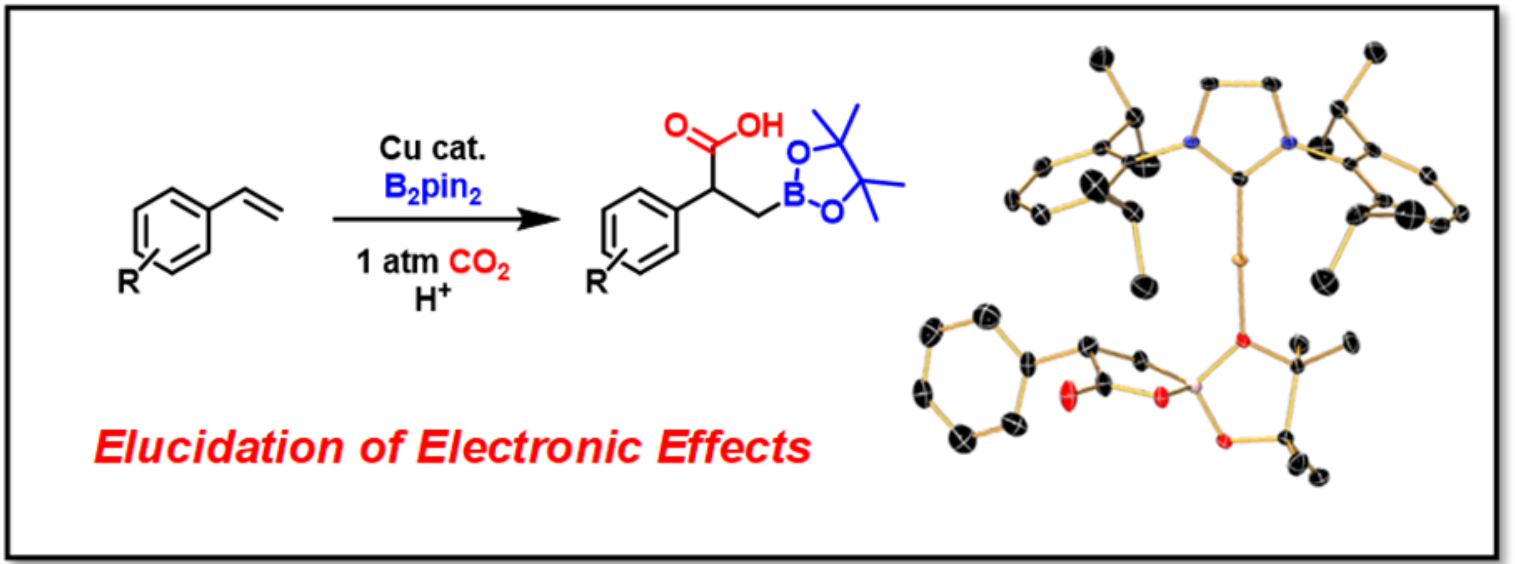

\subsection{Abstract}

Herein is presented an experimental and computational mechanistic investigation of the key carboxylation step in the copper(I)-catalyzed boracarboxylation of vinyl arenes. Catalytically relevant intermediates with electronically diverse vinyl arenes, stabilized by the NHC ligand IPr (IPr = 1,3-Bis(2,6-di-isopropylphenyl)-imidazol-2-ylidine), were isolated and characterized. In situ ${ }^{1} \mathrm{H}$ NMR timecourse studies and subsequent Hammett analysis $\left(\sigma_{p}\right)$ of $\mathrm{CO}_{2}$ addition to $(\beta$ borylbenzyl)copper(I) complexes (benzyl $=\mathrm{CH}_{2} \mathrm{Ar}^{\mathrm{p}-\mathrm{X}}$ ) revealed a linear correlation with a negative rho $(\rho)$ value. Density functional theory (DFT) calculations support direct $\mathrm{CO}_{2}$ insertion as the primary mechanism for electron rich benzyl-copper carboxylation. 


\subsection{Mechanistic Insights of Existing Hetero(element)carboxylation}

Incentive to couple $\mathrm{CO}_{2}$ with other readily available organic materials, such as unactivated alkenes and other unsaturated compounds, via reductive carboxylation has led to significant advances in the field. In recent years, a new class of carboxylation termed hetero(element)carboxylation, wherein the reductant is not a hydride equivalent, but rather a heteroatom moiety (such as silicon, boron, nitrogen, etc.), has been developed. This has been achieved predominately with copper(I) catalysis for the boracarboxylation of imines and alkynes, ${ }^{76}$ silacarboxylation of allenes and alkynes, ${ }^{77}$ and azacarboxylation of alkynylanilines (Figure 2.1). ${ }^{78,79}$

76. (a) Li, Z.; Zhang, L.; Nishiura, M.; Luo, G.; Hou, Z. $\mathrm{CO}_{2}$ Activation by Lewis Pairs Generated Under Copper Catalysis Enables Difunctionalization of Imines. J. Am. Chem. Soc. 2020, 142, 1966-1974. (b) Zhang, L.; Cheng, J.; Carry, B.; Hou, Z. Catalytic Boracarboxylation of Alkynes with Diborane and Carbon Dioxide by an N-Heterocyclic Carbene Copper Catalyst. J. Am. Chem. Soc. 2012, 134, 14314-14317.

77. (a) Tani, Y.; Fujihara, T.; Tsuji, Y. Copper-Catalyzed Regiodivergent Silacarboxylation of Allenes with Carbon Dioxide and a Silylborane. J. Am. Chem. Soc. 2014, 136, 17706-17709. (b) Fujihara, T.; Tani, Y.; Semba, K.; Terao, J.; Tsuji, Y. Copper-Catalyzed Silacarboxylation of Internal Alkynes by Employing Carbon Dioxide and Silaboranes. Angew. Chem. Int. Ed. 2012, 51, 11487-11490.

78. (a) Miao, B.; Li, S.; Li, G.; Ma, S. Cyclic Anti-Azacarboxylation of 2-Alkynylanilines with Carbon Dioxide. Org. Lett. 2016, 18, 2556-2559. (b) Li, S.; Ma, S. Quadri-Synergetic Effect for Highly Effective Carbon Dioxide Fixation and Its Application to Indoloquinolone. Adv. Synth. Catal. 2012, 354, 2387-2394.

79. There is one report of phosphonocarboxylation of alkenes that does not require a transition metal catalyst. Fu, Q.; Bo, Z. Y.; Ye, J. H.; Ju, T.; Huang, H.; Liao, L. L.; Yu, D. G. Transition Metal-Free Phosphonocarboxylation of Alkenes with Carbon Dioxide via Visible-Light Photoredox Catalysis. Nature Commun. 2019, 10, 1-9. 


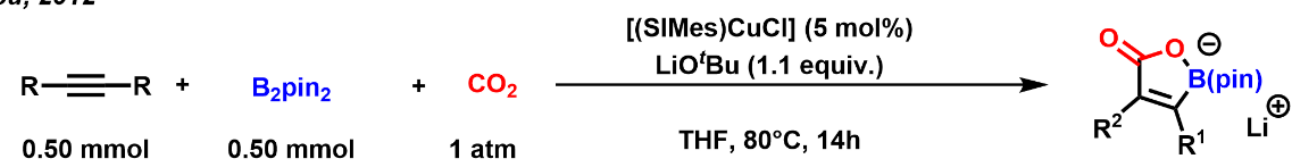

Hou, 2020

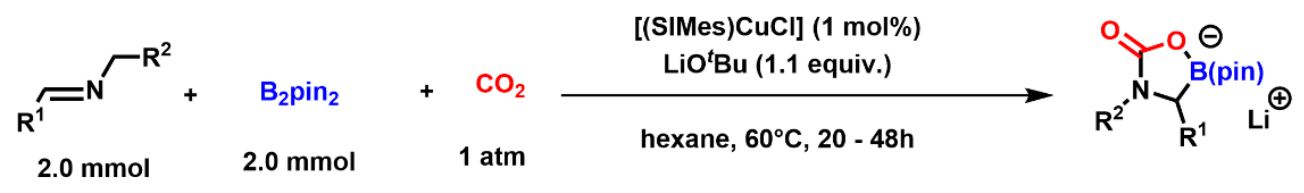

Tsuji, 2012

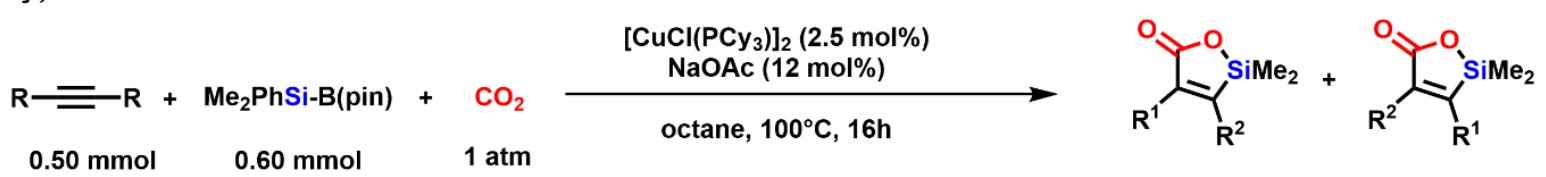

Tsuji, 2014
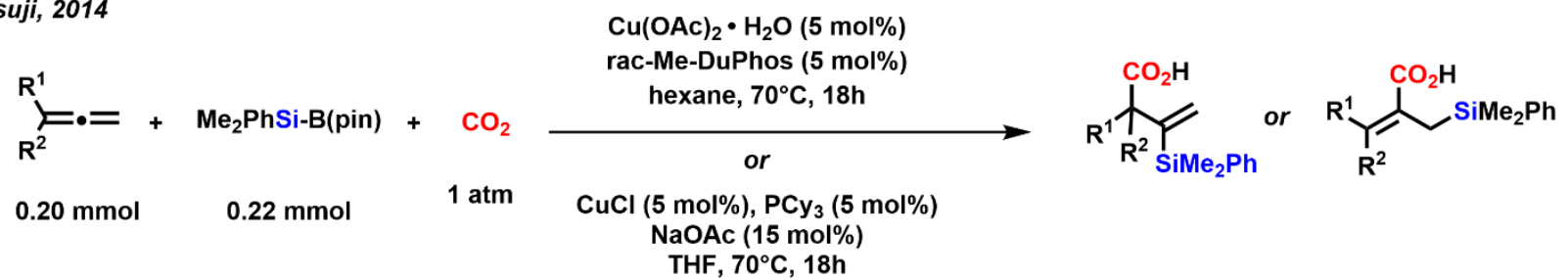

$0.20 \mathrm{mmol} \quad 0.22 \mathrm{mmol} \quad$ NaOAC (15 mol\%)

Figure 2.1. Extent of hetero(element)carboxylation reactions with unsaturated substrates.

As discussed in Chapter 1, vinyl arenes became accessible to boracarboxylation conditions developed by the Popp group in 2016 (Scheme 1). ${ }^{80}$ Subsequently, more effective catalysis through the inclusion of additives such as triphenylphosphine $\left(\mathrm{PPh}_{3}\right)$ provided access to electron deficient vinyl arenes as well as permitted lower catalyst loading. ${ }^{81}$ However, the role of the additive is not yet well understood. Further, despite the general success using a variety of unsubstituted vinyl arene derivatives, these methodologies are not applicable to a wide scope of other alkene substrates. This lack of an in-depth mechanistic understanding has hindered progress in generalizing the method.

80. Butcher, T. W.; McClain, E. J.; Hamilton, T. G.; Perrone, T. M.; Kroner, K. M.; Donohoe, G. C.; Akhmedov, N. G.; Petersen, J. L.; Popp, B. V. Regioselective Copper-Catalyzed Boracarboxylation of Vinyl Arenes. Org. Lett. 2016, 18, 6428-6431.

81. Perrone, T. M.; Gregory, A. S.; Knowlden, S. W.; Ziemer, N. R.; Alsulami, R. N.; Petersen, J. L.; Popp, B. V. Beneficial Effect of a Secondary Ligand on the Catalytic Difunctionalization of Vinyl Arenes with $\mathrm{Boron}$ and $\mathrm{CO}_{2}$. ChemCatChem 2019, 11, 5814-5820. 
Scheme 2.1. Catalytic reaction and proposed mechanism for the copper(I)-catalyzed boracarboxylation of vinyl arenes.

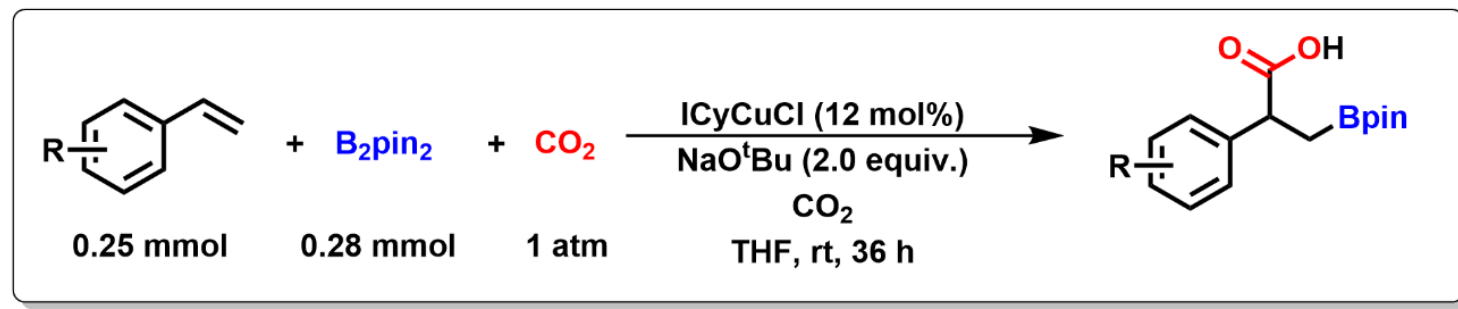

Transmetalation

Migratory Insertion

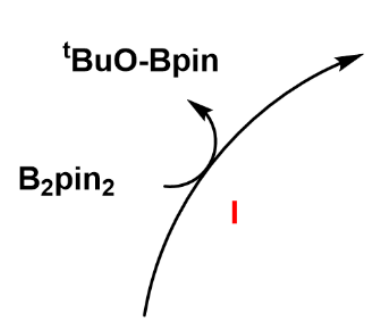

[Cu]-Bpin
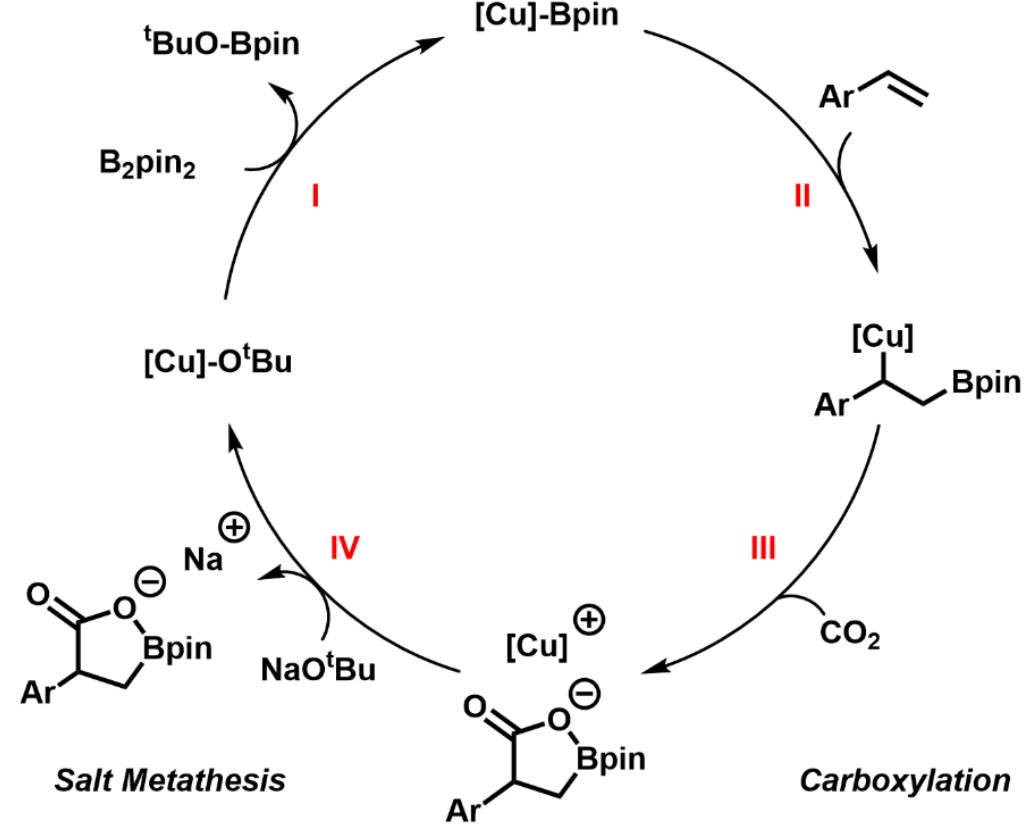

Several previous studies support the proposed mechanism for the boracarboxylation of vinyl arenes. Sadighi and colleagues reported the synthesis and reactivity of $\operatorname{IPrCu}^{\mathrm{I} B p i n}{ }^{82}(\mathrm{IPr}=1,3-$ bis(2,6-di-isopropylphenyl)-imidazol-2-ylidine) as well as the resulting boracupration product ${ }^{83}$ upon treatment with a series of alkene substrates (Scheme 2.1, Steps I and II, respectively) (Scheme 2.2).

82. Laitar, D. S.; Müller, P.; Sadighi, J. P. Efficient Homogeneous Catalysis in the Reduction of $\mathrm{CO}_{2}$ to CO. J. Am. Chem. Soc. 2005, 127, 17196-17197.

83. Laitar, D. S.; Tsui, E. Y.; Sadighi, J. P. Copper(I) $\beta$-Boroalkyls from Alkene Insertion: Isolation and Rearrangement. Organometallics 2006, 25, 2405-2408. 
Scheme 2.2. (A) Stoichiometric reduction of $\mathrm{CO}_{2}$ to $\mathrm{CO}$ via copper(I)-Bpin. (B) Stoichiometric insertion of vinyl arenes into copper(I)-Bpin. Thermal ellipsoids set at $50 \% .{ }^{82,83}$

\section{A. Sadighi, et al., 2005}
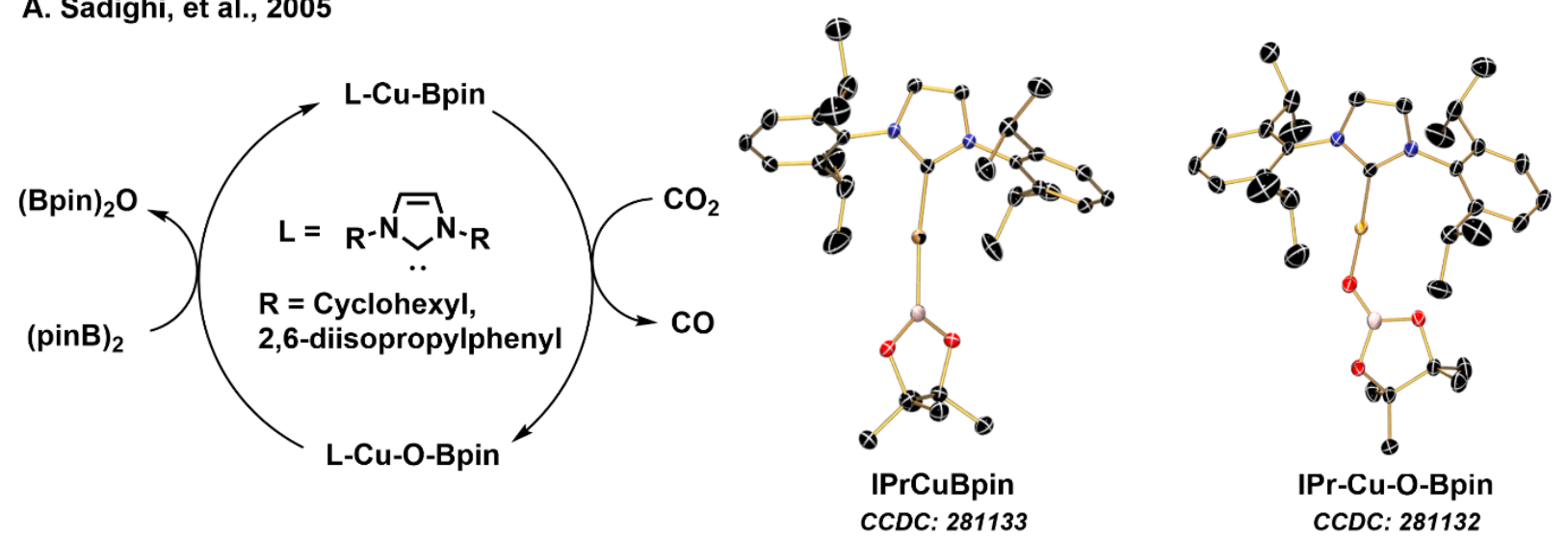

B. Sadighi, et al., 2006
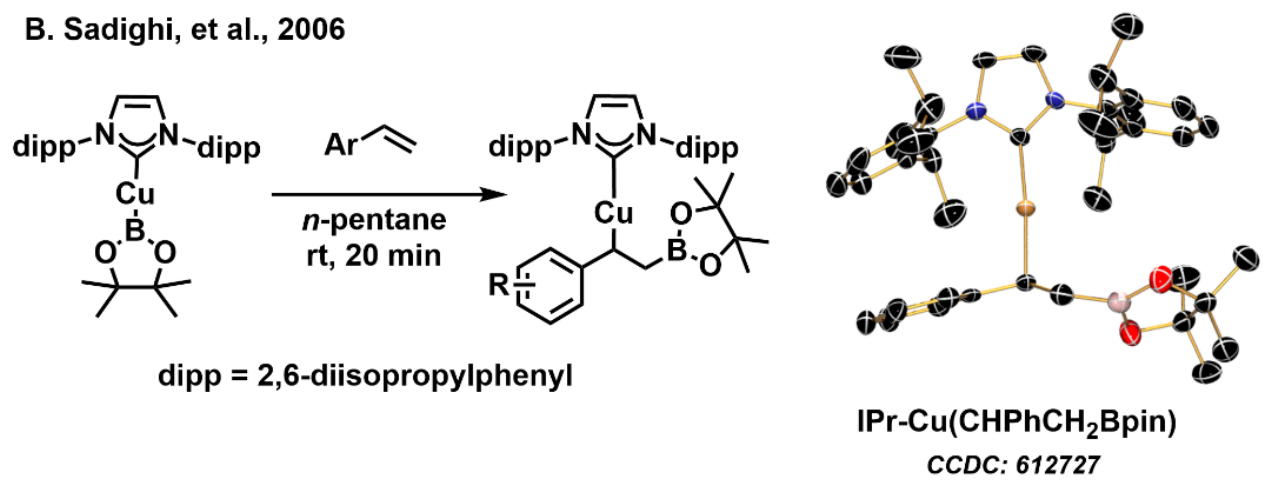

Despite the demonstration of $\mathrm{CO}_{2}$ insertion into a number of $\mathrm{NHC}-\mathrm{Cu}^{\mathrm{I}}$ complexes, ${ }^{84,85}$ carboxylation of the $\mathrm{Cu}^{\mathrm{I}}(\beta$-borylbenzyl) species relevant to the current study was not reported. Carboxylation of alkynes, however, has been demonstrated by Hou, following an analogous stoichiometric insertion of the substrate into a $\mathrm{Cu}^{\mathrm{I}}$-Bpin bond (Scheme 2.3). ${ }^{68 \mathrm{~b}}$ Several independent computational studies have detailed specific aspects of the proposed cycle, such as the role of sodium tert-butoxide $\left(\mathrm{NaO}{ }^{t} \mathrm{Bu}\right)^{86}$ and the stereoelectronic contributions of the ancillary

84. Mankad, N. P.; Gray, T. C.; Laitar, D. S.; Sadighi, J. P. Synthesis, Structure, and $\mathrm{CO}_{2}$ Reactivity of a TwoCoordinate (Carbene)copper(I) Methyl Complex. Organometallics 2004, 23, 1191-1193.

85. Bhattacharyya, K. X.; Akana, J. A.; Laitar, D. S.; Berlin, J. M.; Sadighi, J. P. Carbon-Carbon Bond Formation on Reaction of a Copper(I) Stannyl Complex with Carbon Dioxide. Organometallics 2008, 27, 2682-2684.

86. Lin, S.; Lin, Z. DFT Studies on the Mechanism of Copper-Catalyzed Boracarboxylation of Alkene with $\mathrm{CO}_{2}$ and Diboron. Organometallics 2019, 38, 2, 240-247. 
ligand ${ }^{87}$ and the boron moiety. ${ }^{88}$ Nevertheless, direct experimental evidence in support of the proposed mechanism remains lacking.

Scheme 2.3. Stoichiometric studies of the boracarboxylation of alkynes presented by Hou et al. Thermal ellipsoids set at $50 \% .{ }^{68 \mathrm{~b}}$
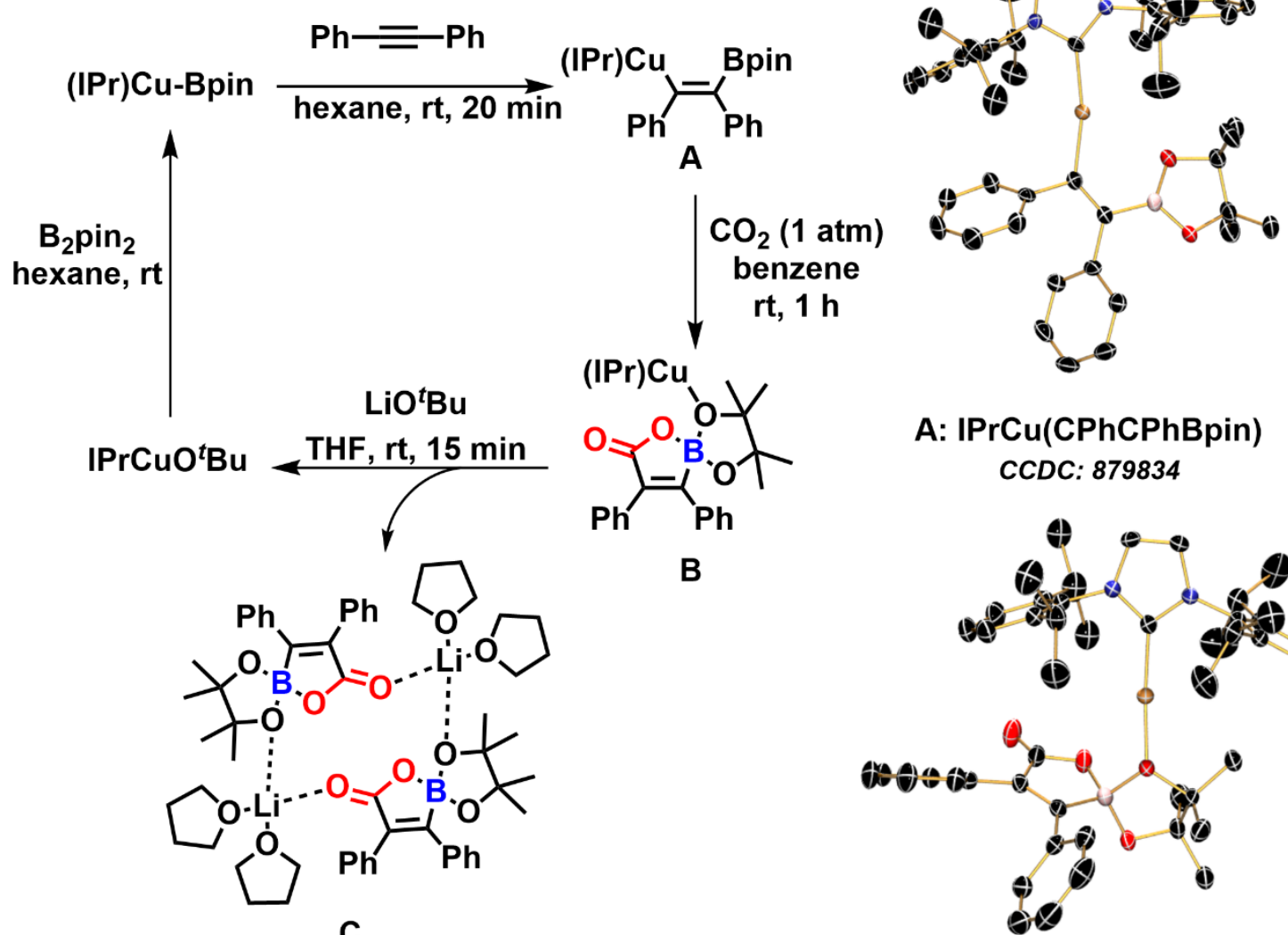

A: IPrCu(CPhCPhBpin) CCDC: 879834

B

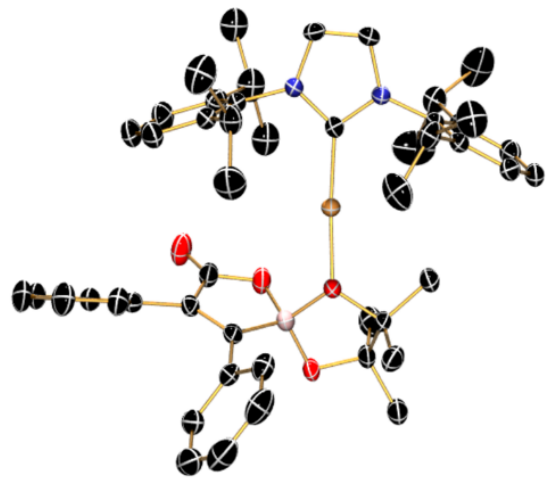

B: $\mathrm{IPrCu}\left(\mathrm{O}\left(\mathrm{C}\left(\mathrm{CH}_{3}\right)_{2}\right)_{2} \mathrm{OB}\left(\mathrm{CH}_{2} \mathrm{CHPhOCO}\right)\right.$ CCDC: 879835

In this chapter, the experimental study of copper(I)-catalyzed boracarboxylation of vinyl arenes complemented by DFT is discussed, wherein a series of $\operatorname{IPrCu}(\mathrm{I})$-spiroboralactonate complexes were generated from vinyl arene substrates. Additionally, rate studies of the

87. Lv, X.; Wu, Y. B.; Lu, G. Computational Exploration of Ligand Effects in Copper-Catalyzed Boracarboxylation of Styrene with $\mathrm{CO}_{2}$. Catal. Sci. Technol. 2017, 7,5049-5054.

88. Baughman, N. N.; Popp, B. V. Evidence of Boron Assistance for $\mathrm{CO}_{2}$ Activation during Copper-Catalyzed Boracarboxylation of Vinyl Arenes: A Synthetic Model for Cooperative Fixation of $\mathrm{CO}_{2}$. Comm. Inorg. Chem. 2020, $40,159-175$. 
carboxylation step indicated that increasingly electron deficient vinyl arenes undergo carboxylation at substantially slower rates.

\subsection{Isolation of Catalytic Intermediates}

The studies of the mechanism of boracarboxylation began with attempted isolation of reactive intermediates using the catalytically competent $\mathrm{ICyCuCl}$ precatalyst. The proposed catalytic cycle (Scheme 2.1) is initiated by the generation of an active copper(I)alkoxide complex from $\mathrm{ICyCuCl}$ in the presence of $\mathrm{NaO}^{t} \mathrm{Bu} .{ }^{74,81}$ Only $\mathrm{ICyCuO}^{t} \mathrm{Bu}^{89}$ has been definitively characterized, while catalytically relevant $\mathrm{ICyCu}{ }^{\mathrm{I}} \mathrm{Bpin}$ and $\mathrm{ICyCu}^{\mathrm{I}}(\beta$-borylbenzyl) (Scheme 2.1, step II and III, respectively) have not been isolated. $\mathrm{ICyCuO}{ }^{t} \mathrm{Bu}\left(\mathbf{1}^{\mathrm{ICy}}\right)$ was synthesized following the literature from treatment of $\mathrm{ICyCuCl}$ with $\mathrm{NaO}^{t} \mathrm{Bu}$ (1 equiv.). ${ }^{89}$ Following this, attempts were made to isolate $\mathrm{ICyCuB}\left(\right.$ pin), a presumed intermediate during catalytic reduction of $\mathrm{CO}_{2}$ to $\mathrm{CO}$ (Scheme 2.2). ${ }^{82}$ Similar to previous reports, rapid decomposition of $\mathrm{ICyCu}$-species was observed, ${ }^{82,90}$ rendering isolation of $\mathrm{ICyCu}{ }^{\mathrm{I}}$-boryl complex and subsequent reactivity studies impossible. In lieu of isolation, addition of vinyl arene to a mixture $\mathrm{ICyCuO}^{\mathrm{t}} \mathrm{Bu}$ and $\mathrm{B}_{2}$ pin 2 led to a complicated spectrum featuring an intractable mixture of products. Given these difficulties, attention was turned to the well-known IPr-copper system. ${ }^{68,82,83}$ Notably, the IPrCuCl precatalyst proved ineffective in the original boracarboxylation methodology catalyst screening, yielding only $17 \%$ of the desired product. ${ }^{74}$ This diminished reactivity made the IPr ligand a suitable candidate for potential isolation of more stable, catalytically relevant intermediates.

To understand the reactivity of $\mathrm{Cu}^{\mathrm{I}}(\beta$-borylbenzyl) carboxylation, generation of the insertion products that were reported by Sadighi was necessary (Scheme 2.4). ${ }^{83}$ Following literature protocol, ${ }^{91}$ IPrCuOtBu (1 $\left.{ }^{\mathrm{IPr}}\right)$ was treated with bis(pinacolato)diboron (B2pin 2$)$ (1.1 equiv.) in $n$ pentane under an inert atmosphere of dinitrogen to form $\operatorname{IPrCuB}($ pin) in situ, after which vinyl arene was added. The generation of $\operatorname{IPrCu}\left(\beta\right.$-borylbenzyl) complexes directly from $\mathbf{1}^{\operatorname{IPr}}$ was possible, providing moderate to excellent yields.

89. Laitar, D. S.; Tsui, E. Y.; Sadighi, J. P. Catalytic Diboration of Aldehydes via Insertion into the Copper-Boron Bond. J. Am. Chem. Soc. 2006, 128, 11036-11037.

90. Herron, J. R.; Russo, V.; Valente, E. J.; Ball, Z. T. Catalytic Organocopper Chemistry from Organosiloxane Reagents. Chem. Eur. J. 2009, 15, 8713-8716.

91. Mankad, N. P.; Laitar, D. S.; Sadighi, J. P. Synthesis, Structure, and Alkyne Reactivity of a Dimeric (Carbene)copper(I) Hydride. Organometallics 2004, 23, 3369-3371. 
Scheme 2.4. Methods to synthesize spiroboralactonate-copper(I) complexes utilizing $\mathrm{CO}_{2}$ and boron reductant.

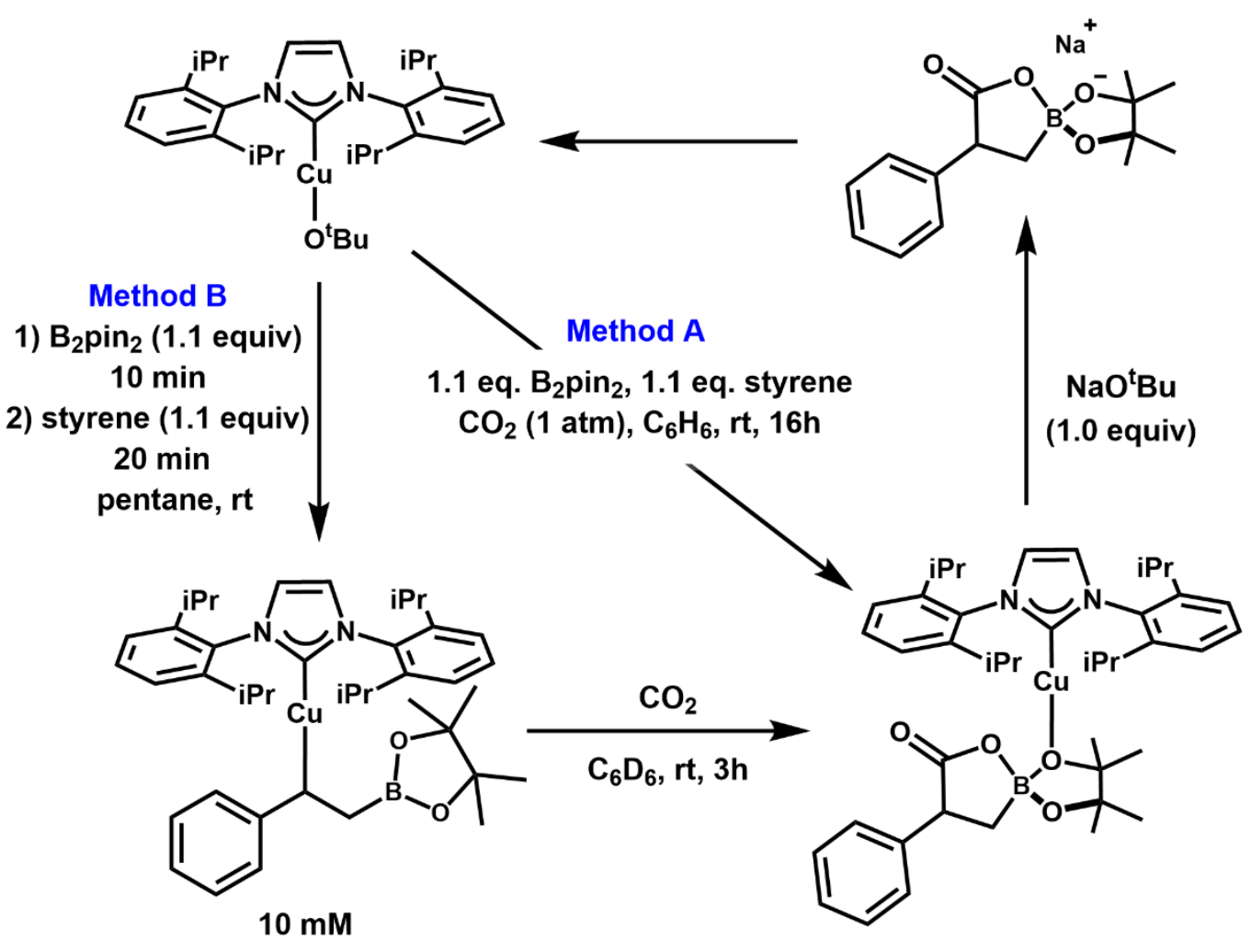

This synthetic route avoided isolation of more reactive, less stable $\operatorname{IPrCu}^{\mathrm{I} B p i n}$ and circumvented the decomposition observed when using the ICy ligand. Consistent with Sadighi's reported insertion rates of vinyl arenes into the $\mathrm{Cu}$-Bpin bond, the more electron deficient substrates, such as para-fluorostyrene, reacted more quickly than more electron rich substrates, such as $4-N, N$-dimethylaminostyrene. Some of the electron deficient vinyl arenes that were employed did not yield the desired complexes, such as $\mathrm{p}-\mathrm{Cl}$ and $\mathrm{p}-\mathrm{Br}$, which led to unproductive side reactions with no discernable product formed. The same was true in the case of $p$ cyanostyrene, findings consistent with previous literature. ${ }^{83}$

Despite this, electron deficient $\mathrm{Cu}^{\mathrm{I}}\left(\beta\right.$-borylbenzyl $\left.{ }^{\mathrm{X}}\right)$ complexes $(\mathrm{X}=$ acetoxy $(\mathrm{AcO}-\mathbf{2 g})$, methoxycarbonyl $\left(\mathrm{CO}_{2} \mathrm{Me}-\mathbf{2 h}\right)$, and trifluoromethyl $\left(\mathrm{CF}_{3}-\mathbf{2 i}\right)$ substitution in the para position of the arene ring) were synthesized as yellow powders in yields ranging from $44 \%$ to $67 \%$ (Table 2.1). Additionally, sterically hindered trans- $\beta$-methylstyrene and trans-stilbene were used to generate the sterically encumbered $\mathbf{2} \mathbf{j}$ and $\mathbf{2} \mathbf{k}$, and an example of a complex featuring an extended$\pi$ system was synthesized using 4-vinylbiphenyl in $\mathbf{2 1}$. Given that the alkene is incorporated via a 
$[2,1]$ insertion into the $\mathrm{Cu}^{\mathrm{I}}$-boryl bond, functionalization of the $\beta$-position led to substantially slower reaction times (15 hours). However, the products were isolated in $67 \%$ yield and $75 \%$ yield, demonstrating the robustness of the insertion step of this reaction, even with increased steric bulk about the reaction site. Extension of this scope was imperative to subsequent kinetic studies, as the series of complexes allowed for a wide variety of electronic and steric properties (see below).

Table 2.1. Series of electron deficient and sterically hindered $\mathrm{Cu}^{\mathrm{I}}(\beta$-borylbenzyl $)$ complexes.

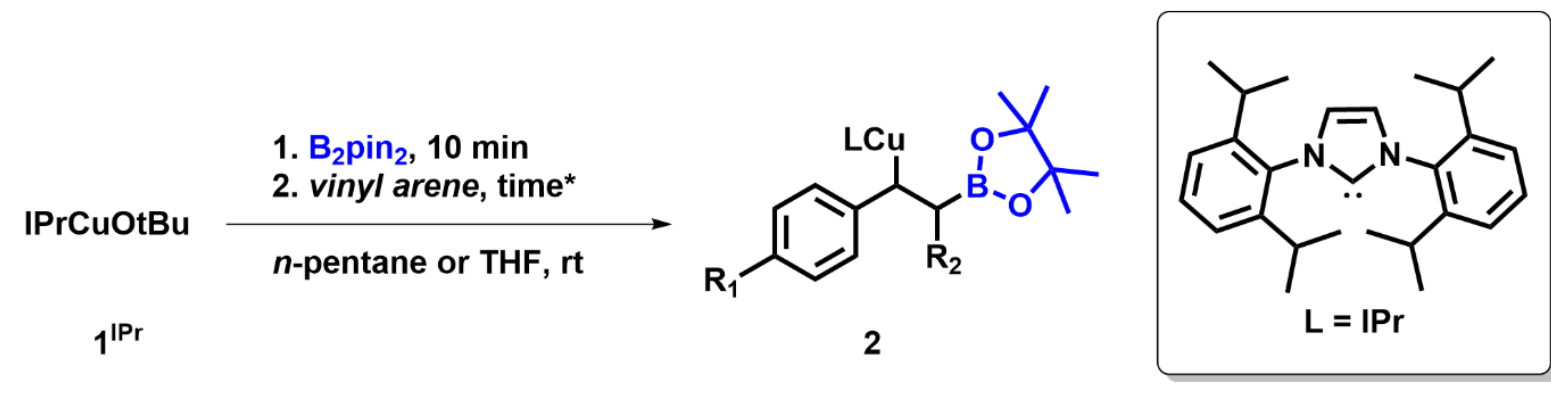<smiles>CC(=O)Oc1ccc(C(CB2OC(C)(C)C(C)(C)O2)C(Cl)(Cl)C(C)(C)C)cc1</smiles><smiles>COC(=O)c1ccc(C(CB2OC(C)(C)C(C)(C)O2)C(Cl)(Cl)Cl)cc1</smiles><smiles>CC1(C)OB(CC(c2ccc(C(F)(F)F)cc2)C(Cl)(Cl)Cl)OC1(C)C</smiles><smiles>CC(B1OC(C)(C)C(C)(C)O1)C(Cl)c1ccccc1</smiles>

$2 \mathrm{j}(67 \%)^{b}$<smiles>CC1(C)OB(C(c2ccccc2)C(Cl)C(Cl)(Cl)Cl)OC1(C)C</smiles><smiles>CC1(C)OB(CC(c2ccc(-c3ccccc3)cc2)C(Cl)(Cl)Cl)OC1(C)C</smiles>

$2 \mathrm{k}(75 \%)^{b}$

21 $(70 \%)^{c, d}$<smiles>CC1(C)OB(CC(c2ccc(Br)cc2)C(Cl)(Cl)Cl)OC1(C)C</smiles>

$2 \mathrm{~m}(0 \%)^{a}$<smiles>CC1(C)OB(CC(c2ccc(Cl)cc2)C(Cl)(Cl)Cl)OC1(C)C</smiles>

2n $(0 \%)^{a}$<smiles>CC1(C)OB(CC(c2ccc(C#N)cc2)C(Cl)(Cl)Cl)OC1(C)C</smiles>

$20(0 \%)^{a}$

${ }^{a}$ time $=1 \mathrm{~h} .{ }^{b}$ time $=3 \mathrm{~h} .{ }^{c}$ time $=15 \mathrm{~h} .{ }^{d}$ previously synthesized, see ref. 22. 
The initial report by Sadighi demonstrates this insertion is possible in $n$-pentane, in which all starting materials aside from IPrCuOtBu are soluble. Additionally, the product remains insoluble, making isolation very simple via filtration and collection on a glass fritted funnel ${ }^{83}$ However, upon the synthesis of $\mathbf{2} \mathbf{i}-\mathbf{2} \mathbf{I}$, it was noted that the starting copper(I) complex remained at the end of the reaction. This issue was attributed to the insoluble starting material; thus tetrahydrofuran (THF) was used in place of $n$-pentane. This led to much better conversion, and no starting $\mathrm{IPrCuOtBu}$ was detected in the NMR spectrum of the product.

\subsection{Synthesis of Spiroboralactonate-Copper(I) Complexes}

Previous reports indicate carboxylation occurs following insertion of alkynes into the $\mathrm{Cu}-\mathrm{E}$ group $\left(\mathrm{E}=\mathrm{SiR}_{3}, \mathrm{~B}(\mathrm{pin})\right) .{ }^{69 \mathrm{~b}, 78 \mathrm{~b}}$ Thus, attempts were made to validate a similar carboxylation pathway from $\mathrm{Cu}^{\mathrm{I}}(\beta$-borylbenzyl) complexes, $\mathbf{2}$. A solution of $\mathrm{IPrCuOtBu}$ was treated with a slight excess of $\mathrm{B}_{2} \operatorname{pin}_{2}$ (1.1 equiv.) and the appropriate styrene to generate the $\operatorname{IPrCu}(\beta$-borylbenzyl) in situ. $\mathrm{CO}_{2}$ gas was then added to the reaction flask following evacuation. After 16 hours, products were isolated as white solids (Scheme 2.4). Consistent with catalytic data, ${ }^{74}$ electron rich vinyl arenes allowed facile access to $\mathrm{Cu}^{\mathrm{I}}$-spiroboralactonates in good yields, ranging from $68-83 \%$ yield. Electron-withdrawing 4-fluorostyrene $\left(\sigma_{p}=+0.06\right)$ was met with a diminished yield comparatively, reactivity opposite of that observed in the initial alkene insertion reaction. ${ }^{83}$ Further, complexes bearing significantly more electron deficient aryl substituents (i.e. 3g-3i) were not accessible under the standard conditions outlined in Table 2.2. However, increased reaction times (48 hours) and inclusion of $\mathrm{PPh}_{3}$ as an additive circumvented these issues (Chapter 3). $\beta$ methylstyrene and trans-stilbene (3j-3k) were used to provide instances of sterically hindered spiroboralactonates. 
Table 2.2. Carboxylated copper(I) complexes isolated through stoichiometric boracarboxylation of vinyl arenes. ${ }^{a}$
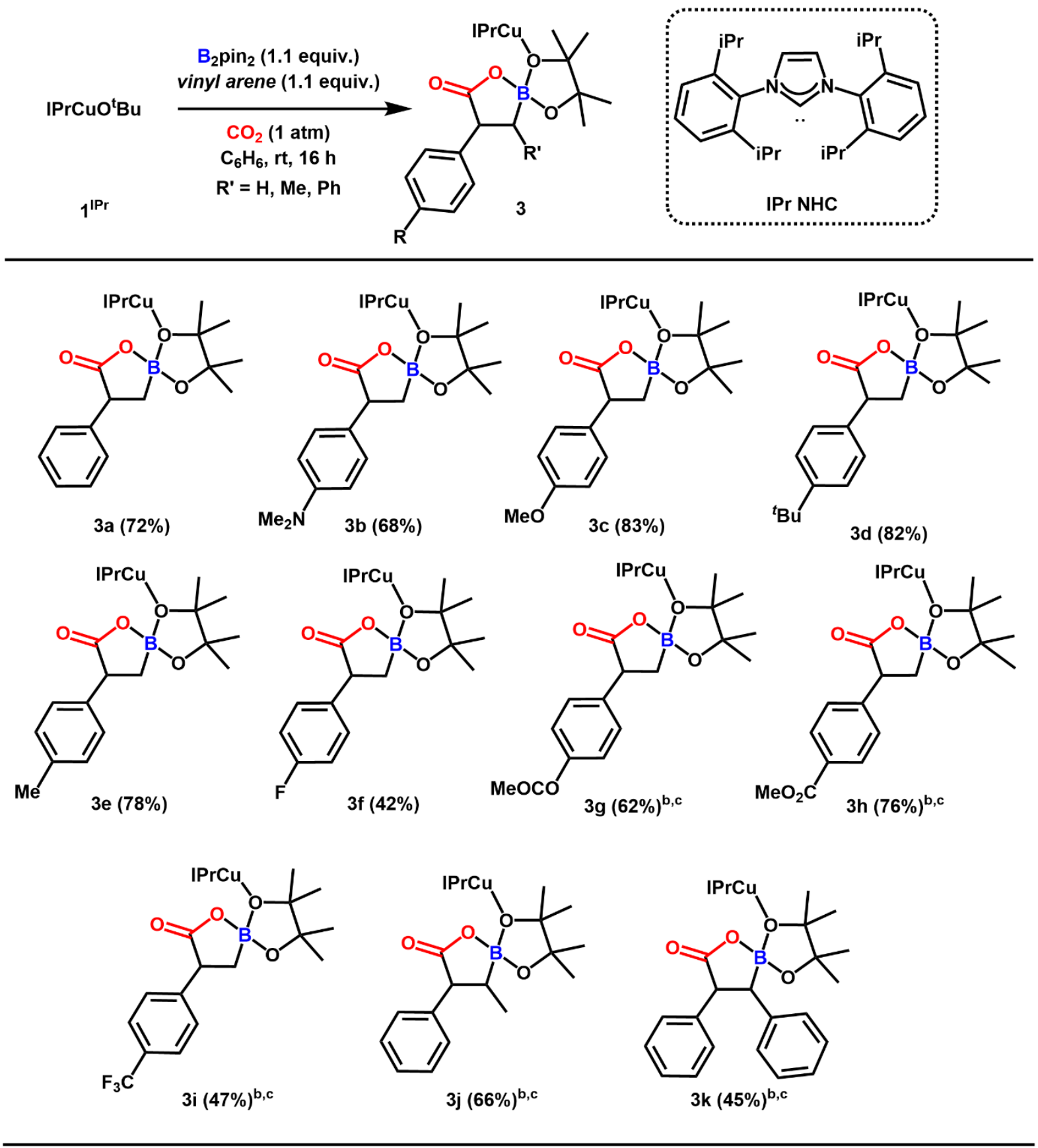

${ }^{a}$ All spiroboralactonate complexes are represented as neutral for clarity. Formal charges are presumed to reside on the copper center (+1) and on the tetracoordinate boronate (-1). ${ }^{b} 48$ hour reaction time. ${ }^{c} \mathrm{PPh}_{3}$ additive (1.0 equiv.). 
Carboxylation of vinyl arenes can occur through a tert-butoxide-catalyzed pathway unaided by copper (Figure 2.2). ${ }^{92}$ To determine whether this type of reactivity is operative in boracarboxylation of styrene derivatives, the requisite $\mathrm{Cu}^{\mathrm{I}}(\beta$-borylbenzyl $)$ complexes were isolated and purified following the protocol reported by Sadighi ${ }^{83}$ (Scheme 2.4, Method B).

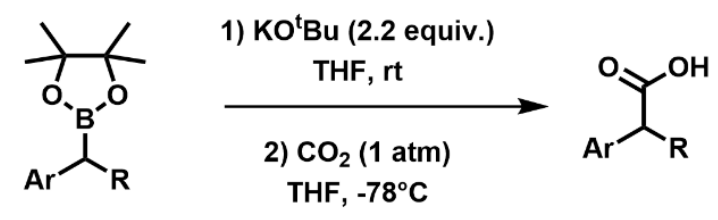

Proposed Mechanism

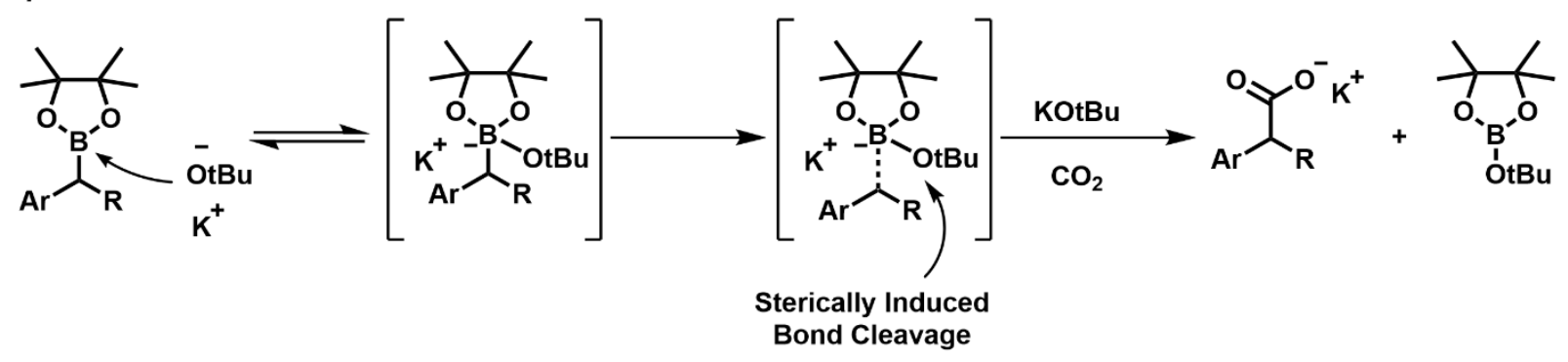

Figure 2.2. Proposed mechanism of the tert-butoxide-catalyzed carboxylation of vinyl arenes. ${ }^{92}$

Carboxylation was achieved by exposing benzene solutions of $\mathbf{2 a - 2 \mathbf { i }}$ to $\mathrm{CO}_{2}$ gas $(1 \mathrm{~atm})$ at room temperature. Following the reaction, white solids were isolated and characterized as 3a-3i, thus providing strong support for the role of copper in the carboxylation reaction. Interestingly, complex $2 \mathbf{i}$ bearing the strongly electron deficient $p-\mathrm{CF}_{3}-$ benzyl moiety was carboxylated at a prohibitively slow rate such that only low yields of $\mathbf{3 i}$ could be obtained for characterization purposes.

92. For example, see: Grigg, R. D.; Rigoli, J. W.; Van Hoveln, R.; Neale, S.; Schomaker, J. M. Beyond Benzyl Grignards: Facile Generation of Benzyl Carbanions from Styrenes. Chem. Eur. J. 2012, 18, 9391-9396. 


\subsection{Characterization of $\mathrm{Cu}^{\mathrm{I}}$-Spiroboralactonates}

Carboxylated complexes 3a-3i were characterized using ${ }^{1} \mathrm{H}$ - and multi-nuclear NMR techniques as well as IR spectroscopy. The parent complex 3a, for example, revealed a strong feature at $1711 \mathrm{~cm}^{-1}$ in the IR spectrum, consistent with the $\mathrm{C}=\mathrm{O}$ stretch of a carbonyl functionality. Comparison of ${ }^{1} \mathrm{H}$ NMR spectra of $\mathbf{2 a}$ and $\mathbf{3 a}$ in benzene- $d_{6}$ and dichloromethane- $d_{2},{ }^{93}$ respectively, revealed separation of the methine proton of the alkyl fragment from the IPr-NHC methine protons $(\mathbf{2 a} \Delta \mathrm{ppm}=0.07 ; \mathbf{3 a} \Delta \mathrm{ppm}=0.23)$ as well as a downfield shift of the ethylene protons of the ligand N-heterocycle from $6.21 \mathrm{ppm}$ to $7.21 \mathrm{ppm}$, owing to decreased electron density upon the incorporation of $\mathrm{CO}_{2}$ (Figure 2.3). The diastereotopic methylene group adjacent to the boron shifted upfield from $1.64 \mathrm{ppm}$ to $0.50 \mathrm{ppm}$, suggesting that the electronic environment about the boron changed following $\mathrm{CO}_{2}$ insertion.

Additionally, a similar effect was observed in the ${ }^{11}$ B NMR spectra of $\mathbf{2 a}$ and $\mathbf{3 a}$. The shift of the $\mathrm{B}$ (pin) resonance from $34.7 \mathrm{ppm}$ to $13.9 \mathrm{ppm}$ was consistent with formation of a fourcoordinate boronate species rather than an open, tricoordinate $\kappa^{1}$-carboxylate complex (Figure 2.4). ${ }^{33}$ This observation aligns well with ${ }^{11} \mathrm{~B}$ NMR spectra reported for analogous spiroboralactonates generated $^{68 \mathrm{~b}}$ as well as other examples of non-coordinating arylspiroborate ligands. ${ }^{94}$ This behavior in the ${ }^{11} \mathrm{~B}$ NMR spectra was observed for complexes $\mathbf{3 b - 3 k}$ as well, suggesting the formation of the spiroboralactonate ring in all cases (Table 2.3).

93. Copper(I)-spiroboralactonate complexes $3 \mathrm{a}-31$ are sparingly soluble in benzene- $d_{6}$, therefore their NMR spectra were collected in dichloromethane- $d_{2}$. Despite differences in solvents, the features relevant to the discussion here do not shift substantially when a 1:1 mixture of benzene- $d_{6}$ : dichloromethane- $d_{2}$ is used (See Appendix 1).

94. (a) Lee, G. M.; Bowes, E. G.; Vogels, C. M.; Decken, A.; Westcott, S. A. Cyclisations of Alkynoic Acids using Copper(I) Arylspiroborate Complexes. Tetrahedron 2019, 75, 2106-2112. (b) Riddlestone, I. M.; Kraft, A.; Schaefer, J.; Krossing, I. Taming the Cationic Beast: Novel Developments in the Synthesis and Application of Weakly Coordinating Anions. Angew. Chem. Int. Ed. 2018, 57, 13982-14024. 


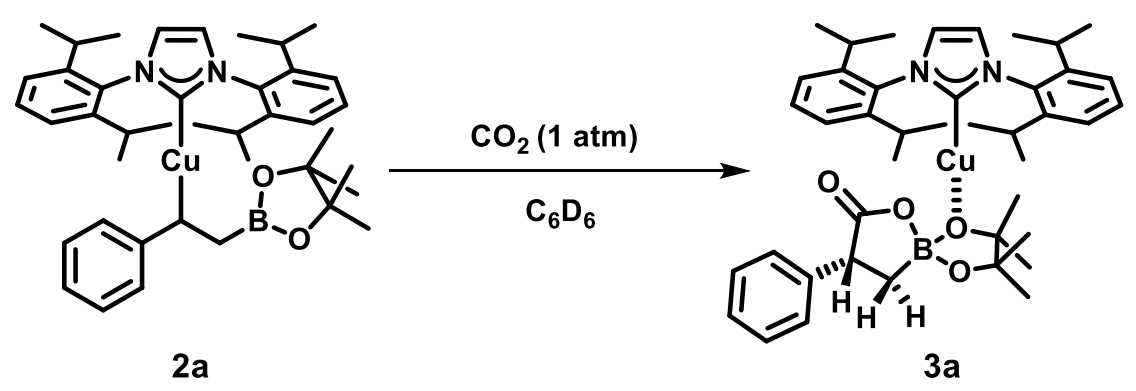

3a: IPrCu(CO2(CHPhCH2Bpin))
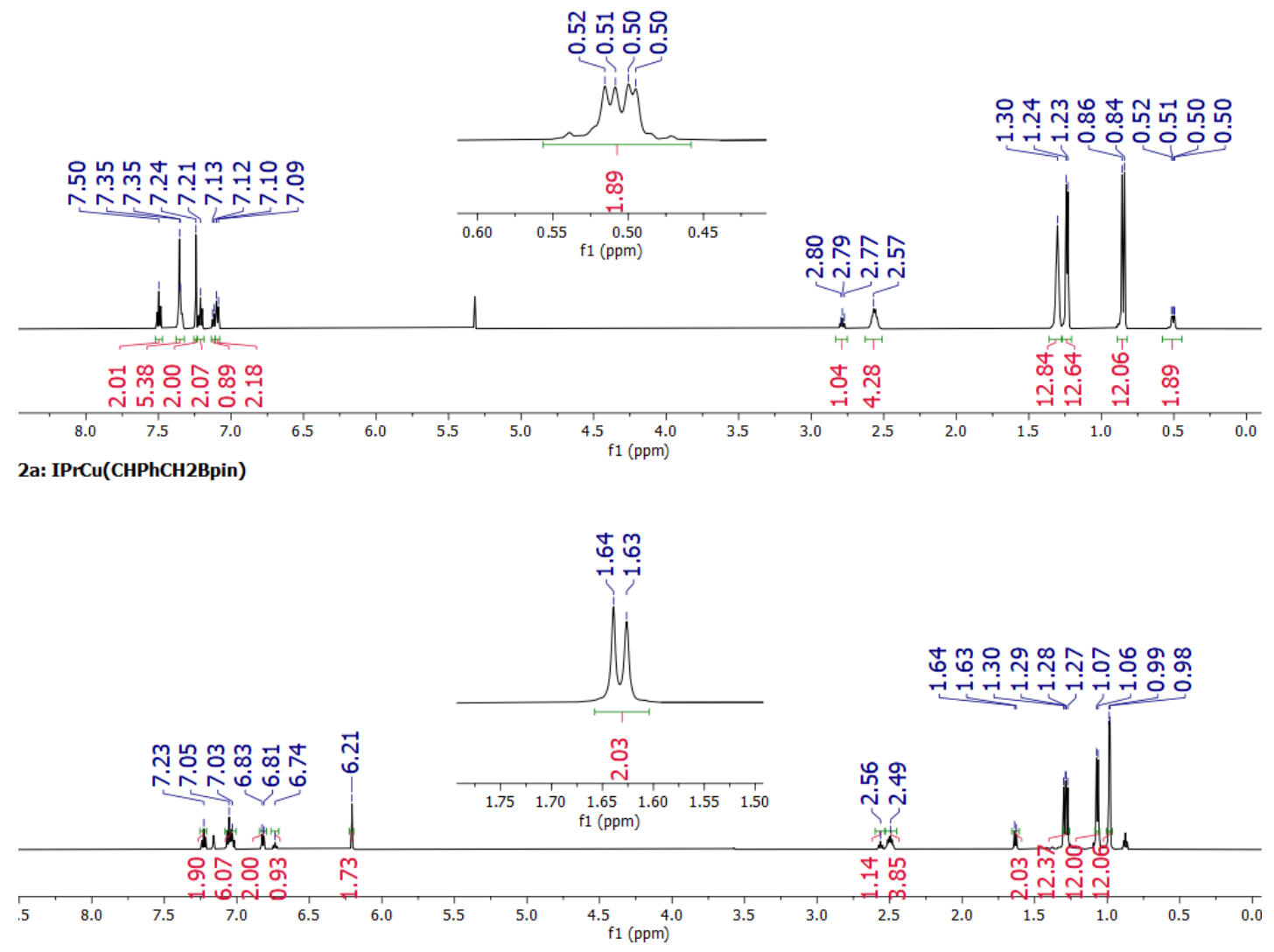

Figure 2.3. ${ }^{1} \mathrm{H}$ NMR of $\mathbf{3 a}$ (top) in dichloromethane- $d_{2}$ and $\mathbf{2 a}$ (bottom) in benzene- $d_{6}$ at $25^{\circ} \mathrm{C}$, with inlays featuring the methylene protons adjacent to the boron ester substituent in both cases. 


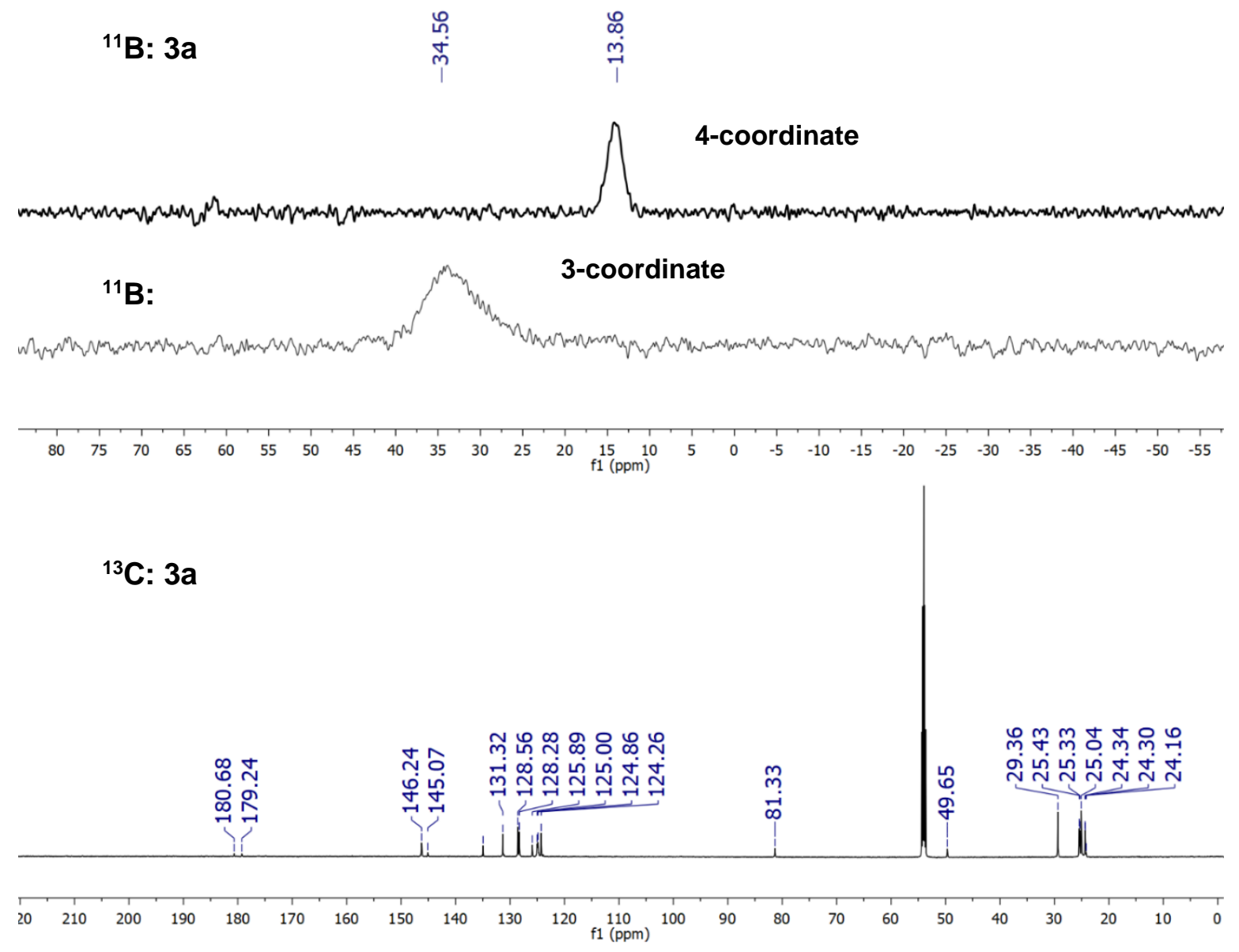

Figure 2.4. Top spectrum: Comparison of ${ }^{11} \mathrm{~B}$ NMR chemical shifts for 3a (top dichloromethane- $d_{2}$ ) and $\mathbf{2 a}$ (bottom - benzene- $d_{6}$ ) at $25^{\circ} \mathrm{C}$. Bottom spectrum: ${ }^{13} \mathrm{C} \mathrm{NMR}$ of $\mathbf{3 a}$ in dichloromethane- $\mathrm{d}_{2}$ at $25^{\circ} \mathrm{C}$. 
Table 2.3. Summary of relevant IR data and ${ }^{11} \mathrm{~B}$ NMR chemical shifts for the series of $\mathrm{Cu}^{\mathrm{I}}$ (spiroboralactonate) complexes.

\begin{tabular}{|c|c|c|}
\hline Complex $^{a}$ & Relevant IR Features $\left(\mathrm{cm}^{-1}\right)$ & ${ }^{11}$ B NMR Chemical Shift (ppm) \\
\hline 3a: H & 1711 & 13.9 \\
\hline $3 b: \mathrm{NMe}_{2}$ & 1699 & 13.7 \\
\hline 3c: OMe & 1709 & 14.3 \\
\hline $3 \mathrm{~d}:{ }^{t} \mathrm{Bu}$ & 1707 & $17.55^{c}$ \\
\hline 3e: Me & 1717 & 13.85 \\
\hline 3f: $F$ & 1709 & 14.55 \\
\hline $3 g: A c O$ & $1710\left(\mathrm{CO}_{2}\right), 1762(\mathrm{AcO})$ & $11.23^{c}$ \\
\hline $3 \mathrm{~h}: \mathrm{CO}_{2} \mathrm{Me}$ & $1719\left(\mathrm{CO}_{2}, \mathrm{CO}_{2} \mathrm{Me}\right.$ overlapping $)$ & 12.20 \\
\hline $3 i: \mathrm{CF}_{3}$ & 1708 & 12.50 \\
\hline $3 \mathbf{j}: \boldsymbol{\beta}_{-} \mathrm{CH}_{3}{ }^{b}$ & 1701 & 11.20 \\
\hline $3 \mathbf{k}: \boldsymbol{\beta}_{-} \mathbf{h}^{b}$ & $\mathrm{~N} / \mathrm{A}$ & 8.94 \\
\hline
\end{tabular}

$\overline{{ }^{a} \text { All substituents are featured in para position on the aryl ring unless otherwise specified. }{ }^{b} \text { The } \beta}$ carbon of the alkyl chain is substituted. ${ }^{c}$ The solvent in which ${ }^{11} \mathrm{~B}$ NMR spectra were collected was a 1:1 mixture of benzene- $d_{6}$ : dichloromethane- $d_{2}$. All other examples were collected in dichloromethane- $d_{2}$.

2D NMR techniques were also employed to determine the connectivity of the molecule in solution. The ${ }^{1} \mathrm{H}-{ }^{1} \mathrm{H}$ gCOSY revealed correlation between the resonance at $2.8 \mathrm{ppm}$ and $0.5 \mathrm{ppm}$, which were determined to be the methine $(\mathrm{Cu}-\mathrm{CH})$ and the methylene $\left(\mathrm{Cu}-\mathrm{CH}-\mathrm{CH}_{2}\right)$ protons, respectively (Figure 2.5.). Other confirmational 2D NMR spectra are in Appendix I. 


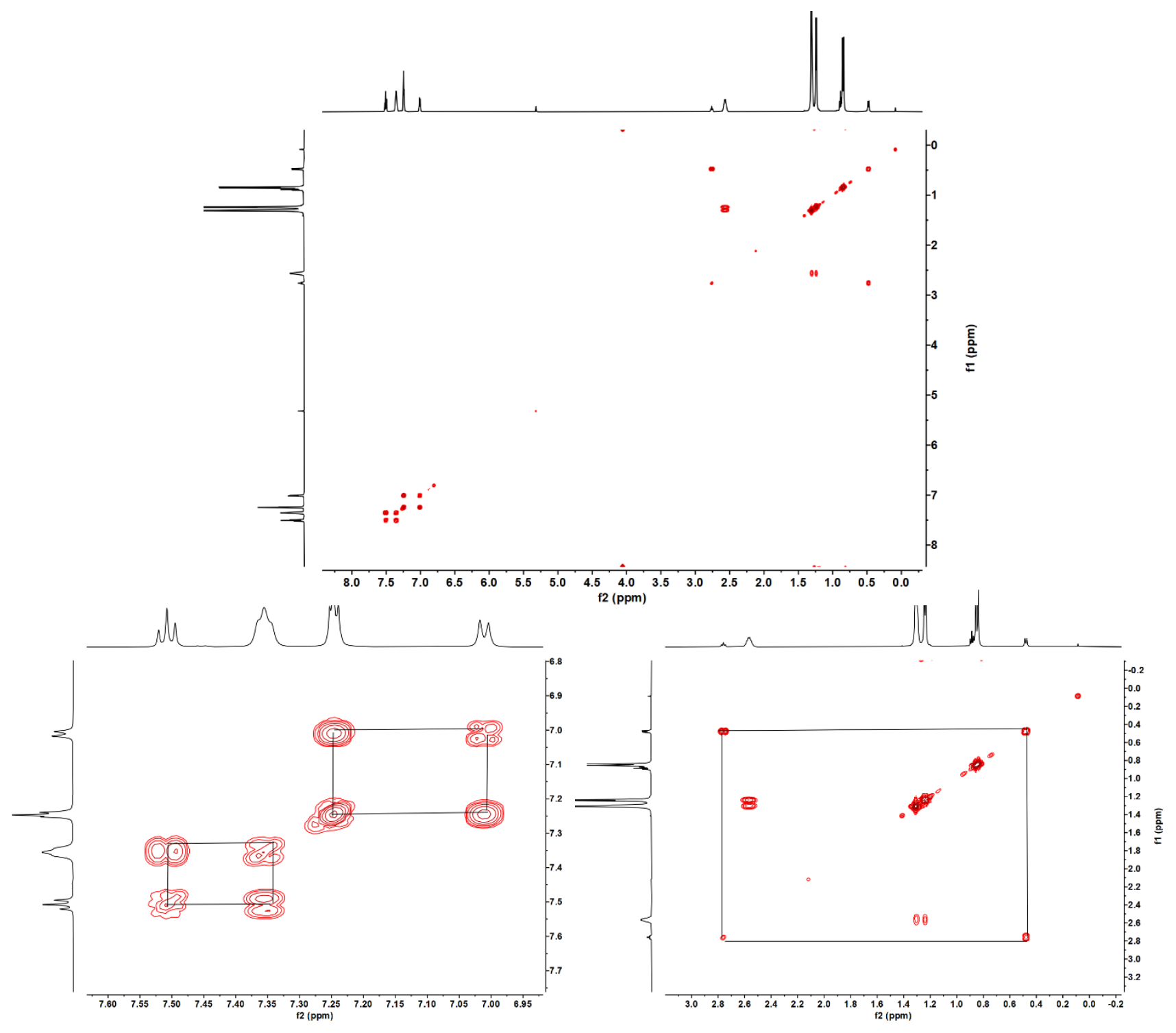

Figure 2.5. ${ }^{1} \mathrm{H}-{ }^{1} \mathrm{H}$ gradient-COSY (gCOSY) spectrum of 3a, with two enlarged regions of the alkyl and aromatic resonances. Collected at $25^{\circ} \mathrm{C}$ in dichloromethane- $d_{2}$.

The solid state spiroboralactonate structure was confirmed by X-ray crystallographic analysis of 3a (Figure 2.6.A). The structure features a bond between a pinacol oxygen of the pinacolboryl substituent rather than through an oxygen of $\mathrm{CO}_{2}$, suggesting a rapid shift of the copper following insertion. An elongated B-O bond of $1.537 \AA$ from the carboxylate oxygen supports a bicyclic structure (Table 2.4). Further, the formation of the boralactonate ring imposes an $\mathrm{sp}^{3}$-hybridization 
to the boron center, confirmed by the average bond angles of $107^{\circ}$ that make up the tetrahedral arrangement (Figure 2.6.A, enlargement). This contrasts with crystallographic data of a boracarboxylic acid reported by Popp et al. ${ }^{74}$ in which the average bond angles of $120^{\circ}$ suggest the boron is $\mathrm{sp}^{2}$-hybridized (Figure 2.6.B, enlargement). This assignment of the anionic tetracoordinate boron was also supported by the analogous copper complexes generated via the boracarboxylation of alkynes. ${ }^{68 \mathrm{~b}}$

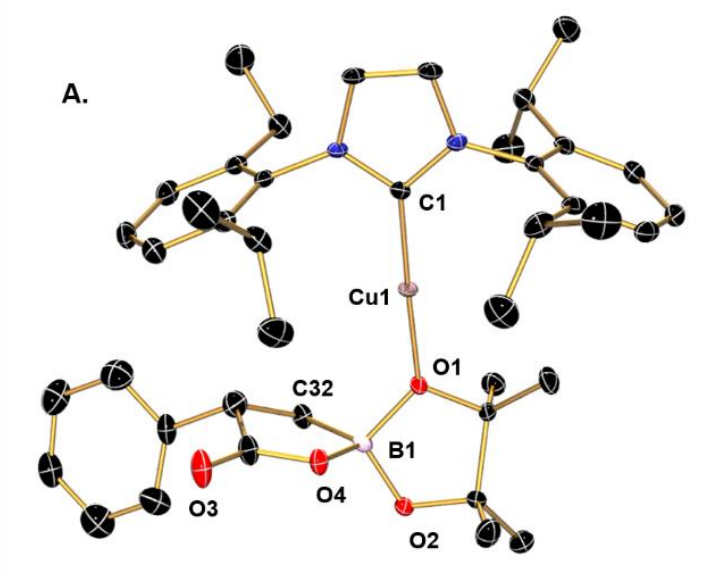

B.

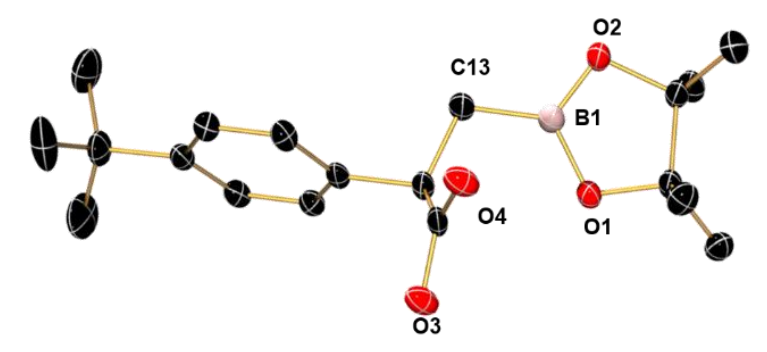

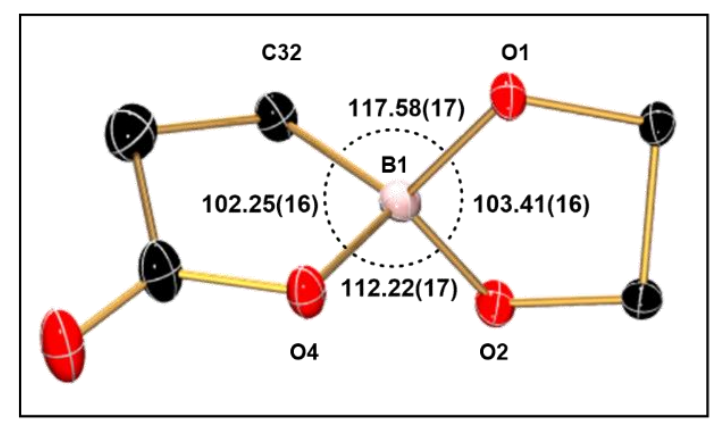

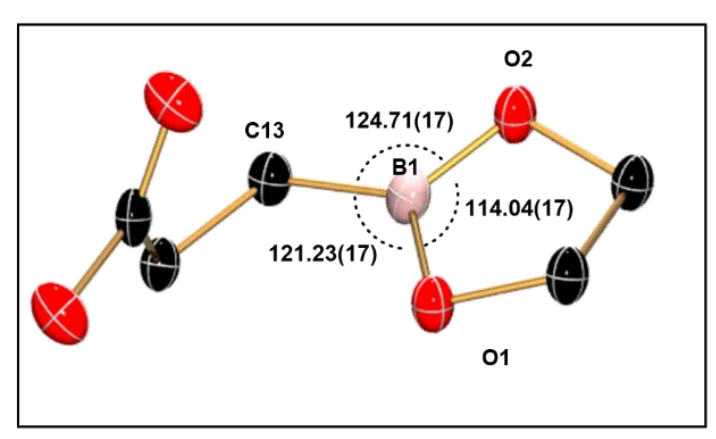

Figure 2.6. A) Molecular structure of 3a with thermal ellipsoids set at 50\% probability. $\mathrm{H}$ atoms have been omitted for clarity with an enlarged image of the environment around the boron atom. B) Molecular structure of $\alpha$-aryl carboxylic acid product ( $\mathrm{Ar}=$ para-tert-butylphenyl) from the original report of boracarboxylation of vinyl arenes for source of comparison of the boron environment. ${ }^{74}$ 
Table 2.4. Relevant bond distances $(\AA)$ and angles $\left(^{\circ}\right)$ for 3 a and the $\alpha$-aryl carboxylic acid product $^{74}$ shown in Figure 2.6.

\begin{tabular}{|c|c|c|c|}
\hline \multicolumn{2}{|c|}{$3 a$} & \multicolumn{2}{|c|}{$\alpha$-aryl carboxylic acid } \\
\hline \multicolumn{2}{|c|}{ Relevant Bond Lengths $(\AA)$} & \multicolumn{2}{|c|}{ Relevant Bond Lengths $(\AA ̊)$} \\
\hline Cu1-O1 & $1.8568(14)$ & C13-B1 & $1.572(3)$ \\
\hline O1-B1 & $1.508(3)$ & O1-B1 & $1.366(2)$ \\
\hline O2-B1 & $1.437(3)$ & O2-B1 & $1.360(2)$ \\
\hline O4-B1 & $1.531(3)$ & & \\
\hline $\mathrm{B} 1-\mathrm{C} 32$ & $1.618(3)$ & & \\
\hline \multicolumn{2}{|c|}{ Relevant Angles $\left(^{\circ}\right)$} & \multicolumn{2}{|c|}{ Relevant Angles $\left(^{\circ}\right)$} \\
\hline O2-B1-O4 & $112.22(17)$ & O1-B1-C13 & $121.23(17)$ \\
\hline O2-B1-C32 & $114.96(17)$ & O2-B1-O1 & $114.04(17)$ \\
\hline O4-B1-C32 & $102.25(16)$ & O2-B1-C13 & $124.71(17)$ \\
\hline $\mathrm{O} 2-\mathrm{B} 1-\mathrm{O} 1$ & $103.41(16)$ & & \\
\hline O1-B1-O4 & $106.37(16)$ & & \\
\hline O1-B1-C32 & $117.58(17)$ & & \\
\hline B1-O1-Cu1 & $129.31(12)$ & & \\
\hline
\end{tabular}

Variable-temperature (VT) ${ }^{1} \mathrm{H}$ NMR experiments were conducted to determine whether coordination of the copper center to the pinacol oxygen was maintained in the solution state. As the temperature was decreased from $+25^{\circ} \mathrm{C}$ to $-90^{\circ} \mathrm{C}$, the spectrum of $\mathbf{3 a}$ became more complex (Figure 2.7). The doublet resonance at $0.80 \mathrm{ppm}$ corresponding to the methyl protons on the pinacol ring splits into four distinct singlet resonances, implying dynamic solution behavior at ambient temperature. 

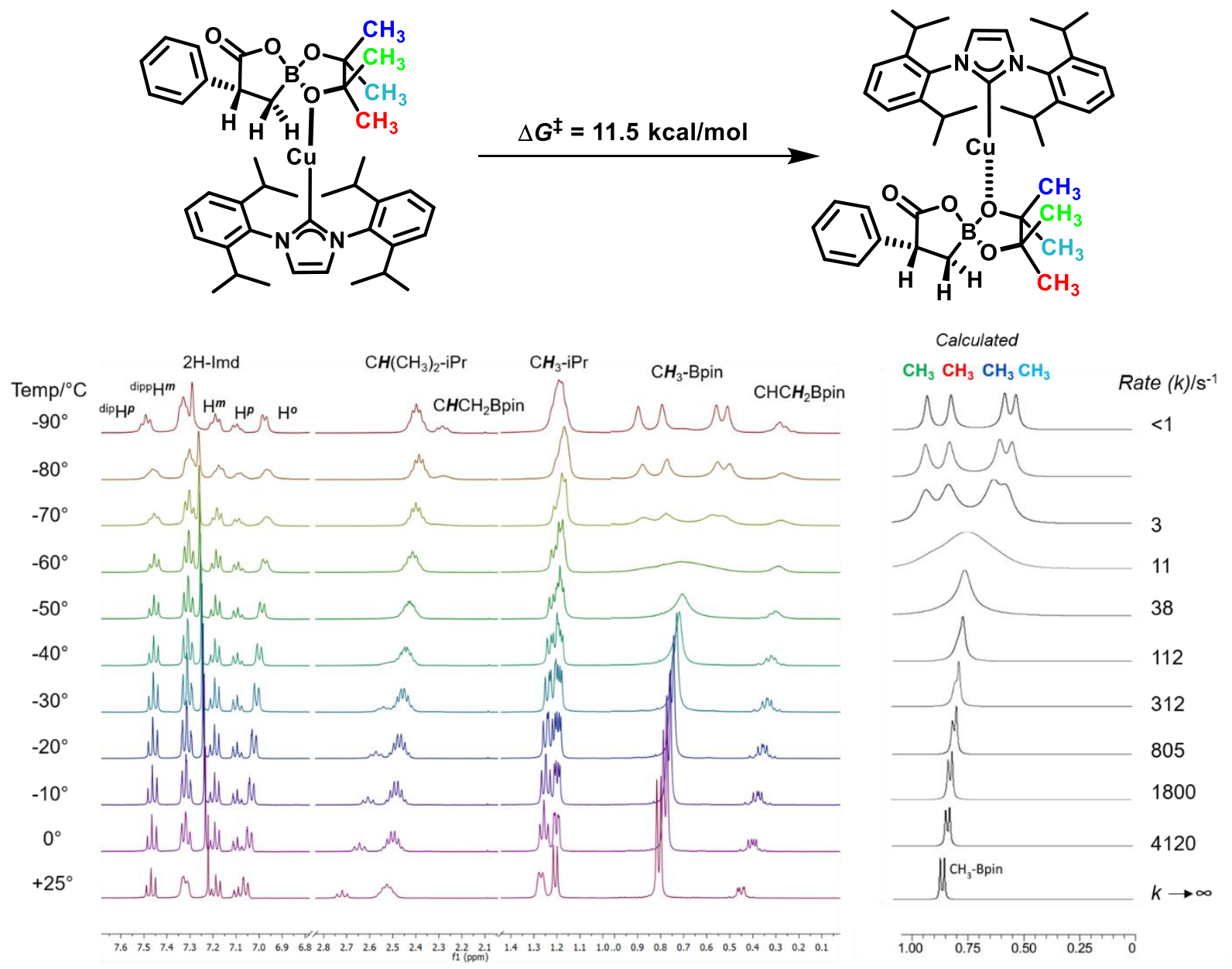

Figure 2.7. Dynamic behavior of spiroboralactonate 3a with experimentally determined free energy barrier of conversion. Left: Full spectrum of VT ${ }^{1} \mathrm{H}$ NMR experiments of 3a, collected from $+25^{\circ} \mathrm{C}$ to $-90^{\circ} \mathrm{C}$ in dichloromethane- $d_{2}$. Right: Calculated spectrum of the region that contains the Bpin methyl groups with their respective calculated rate of interconversion.

A similar effect was observed in VT ${ }^{13} \mathrm{C}$ NMR experiments, wherein inequivalent tertiary pinacol carbon resonances at $-90^{\circ} \mathrm{C}(83.4$ and $77.0 \mathrm{ppm})$ collapse to a single resonance at $+25^{\circ} \mathrm{C}$ (81.3 ppm) (Figure 2.8). Conformational 2D NMR experiments support the desymmetrization of the pinacol ring upon copper binding (Appendix I). Geometry optimization of the solid-state structure for 3a using DFT and subsequent natural bonding orbital (NBO) analysis revealed natural charges on the relevant oxygens (see Figure 2.6. for atom labels) that are consistent with copper binding at the more basic oxygen moiety. The natural charge on pinacol oxygens (O1: $-0.89 \mid \mathrm{O} 2$ : -0.83) was noticeably larger than the charges on carboxylate oxygens (O3: -0.65 | O4: -0.74), reflecting higher basicity. 


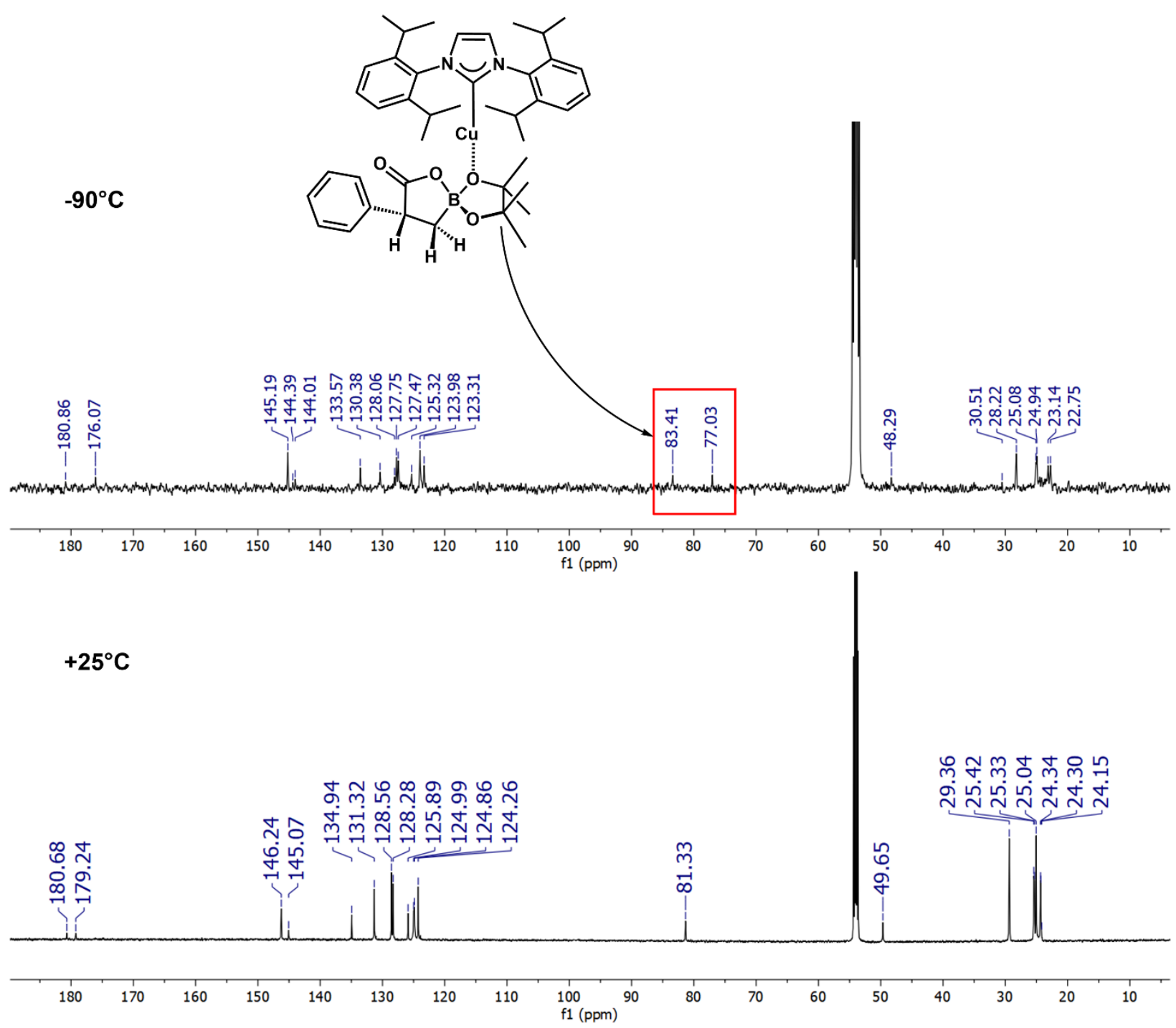

Figure 2.8. Comparison of ${ }^{13} \mathrm{C}$ NMR spectra at $-90^{\circ} \mathrm{C}$ and $+25^{\circ} \mathrm{C}$ in dichloromethane- $d_{2}$.

The dynamic behavior observed during ${ }^{1} \mathrm{H}$ VT-NMR studies of complex 3a was further explored computationally. Close inspection of spiroboralactonate 3a shows that two sets of diastereomeric structures are possible because the 5-membered borapinocolate ring can adopt two unique conformations. Thus, four ground-state structures for 3a were identified from DFT geometry optimization, with the most energetically feasible diastereomeric pair shown in Figure 2.9 (full analysis in Appendix I). Notably, the solid-state structure of 3a led to the second most stable isomer $\left(\mathbf{3 a}^{\mathbf{D F T}}\right)$ while the diastereomer $\mathbf{3 \mathbf { a } ^ { \mathbf { D F T } }}$ was most stable. Interconversion between 
diastereomers $\mathbf{3} \mathbf{a}^{\mathbf{D F T}}$ and $\mathbf{3} \mathbf{a}^{\text {'DFT }}$ proceeds by an inner-sphere mechanism via less-stable $k^{1}$ carboxylate intermediate $\operatorname{Int}\left(\mathbf{3 a - 3} \mathbf{a}^{\prime}\right)^{\mathbf{D F T}}$.

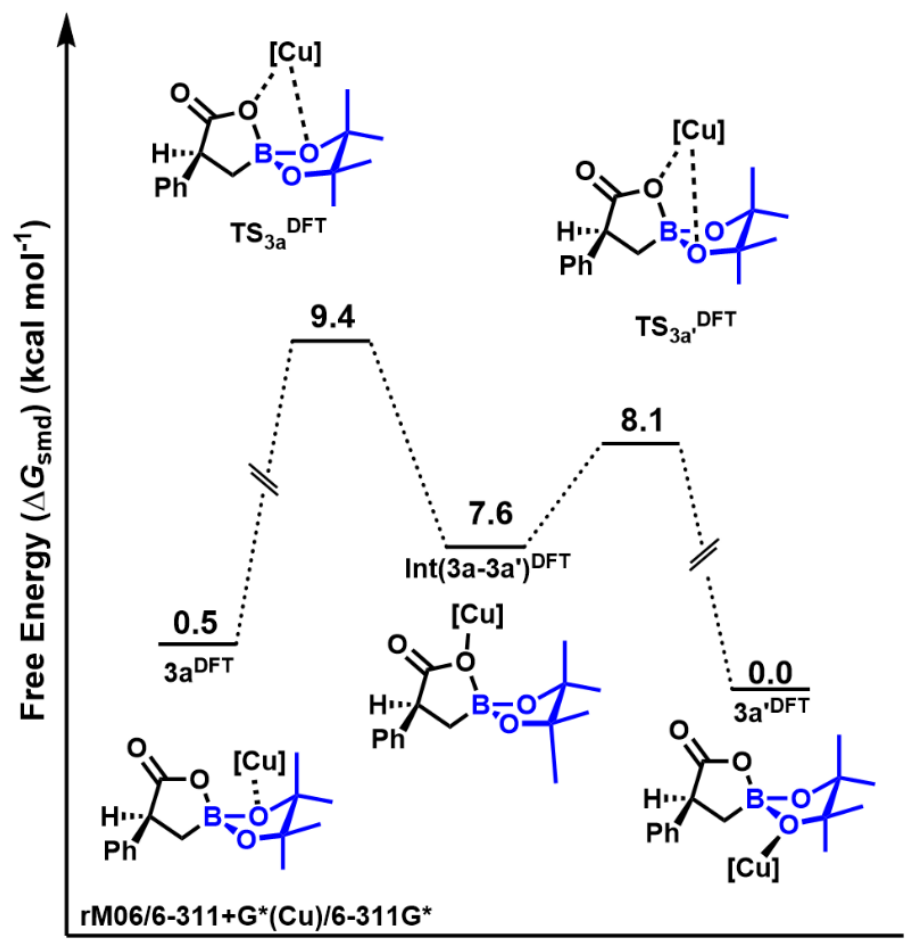

Figure 2.9. Interconversion of the binding of copper to each oxygen of the pinacol ring, including the carboxylate-bound intermediate, derived computationally (smd solvent model).

Comparison of experimentally and computationally predicted barriers (11.5 vs $9.4 \mathrm{kcal} / \mathrm{mol}$, respectively) are in good agreement. Attempts to identify an outer-sphere ion-pair interconversion mechanism that bypasses Int(3a-3a') ${ }^{\mathbf{D F T}}$ were unsuccessful, yielding only high energy ( $>40$ $\mathrm{kcal} / \mathrm{mol}$ ) ion-pair intermediates. Ground state and transition state energies varied by less than 2 $\mathrm{kcal} / \mathrm{mol}$ in both cases, which implies exchange occurs rapidly at room temperature and samples each isomeric geometry. Knowledge of such behavior could be consequential for future developments using spiroboronate salts for asymmetric catalysis as a chiral anion. ${ }^{94}$ 


\subsection{Characterization of the Salt-Metathesis Product}

Completion of the catalytic cycle is proposed to proceed through a salt metathesis reaction of spiroboralactonate copper salt with excess $\mathrm{NaO}^{\mathrm{t}} \mathrm{Bu}$ to produce a sodium spiroboralactonate salt and active $\mathrm{ICyCuO}^{t} \mathrm{Bu}$ catalyst (Scheme 2.1, Step IV). In previous stoichiometric studies of alkyne boracarboxylation, an aggregate of the salt metathesis product stabilized by both tetrahydrofuran and lithium ion coordination was isolated and characterized (Figure 2.10). ${ }^{68 b}$

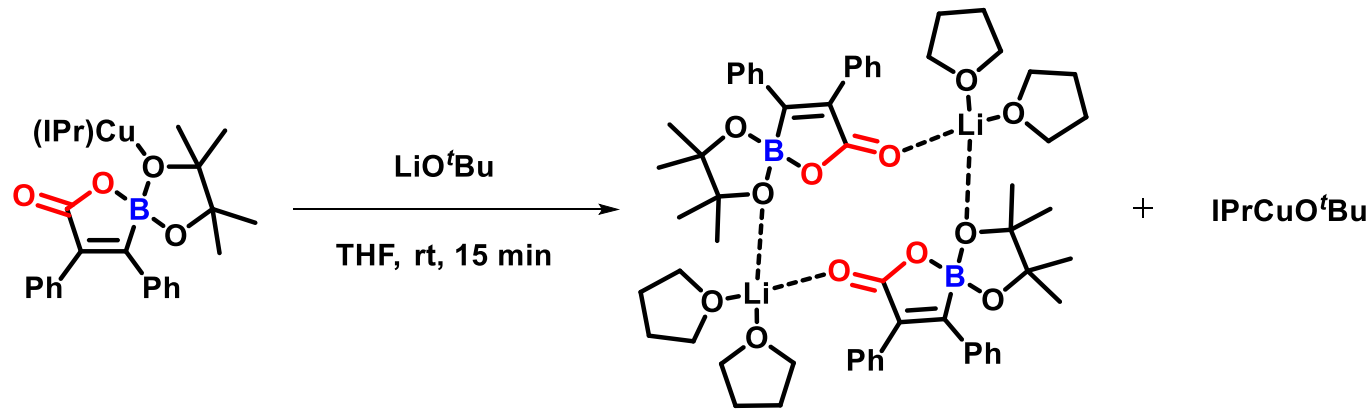

Figure 2.10. Formation of a salt metathesis product from the starting spiroboralactonate structure with the concomitant generation of $\mathrm{IPrCuO}^{\mathrm{t}} \mathrm{Bu} .{ }^{68 b}$

Similar treatment of $\mathbf{3 a}$ with $\mathrm{NaO}^{\mathrm{t}} \mathrm{Bu}$ (1 equiv.) in THF for 30 minutes revealed formation of $\mathrm{IPrCuO}^{t} \mathrm{Bu}$ as determined by ${ }^{1} \mathrm{H}$ NMR spectroscopy (Figure 2.11). Unfortunately, lack of solubility as well as poor crystallinity hampered isolation and further characterization. Attempts were also made using lithium tert-butoxide $\left(\mathrm{LiO}^{t} \mathrm{Bu}\right)$ in hopes that the countercation identity may aid in the crystallization. However, this too proved unsuccessful.

${ }^{1} \mathrm{H}$ NMR spectroscopy was instead employed to monitor the salt metathesis reaction in solution. Given the low solubility of the spiroboralactonate product, the complex was dissolved in a mixture of $40 \%$ protio-THF/benzene- $d_{6}$. Upon mixing $\mathbf{3 a}$ and $\mathrm{NaO}^{t} \mathrm{Bu}$, resonances associated with the ethenyl protons of the $\mathrm{NHC}$ heterocycle of $\mathrm{IPrCuO}^{t} \mathrm{Bu}$ increased over time with concomitant decrease of those associated with 3a (Figure 2.12). Accompanying this change in the ${ }^{1} \mathrm{H}$ NMR spectrum was the formation of a white solid, presumably the sodium spiroboralactonate product. Further, upon addition of $\mathrm{B}_{2}$ pinz (1 equiv.) to the NMR reaction mixture, the concentration of $\mathrm{IPrCuB}$ (pin) increased with concomitant decrease of $\mathrm{IPrCuO}^{t} \mathrm{Bu}$. Adding $\mathrm{B}_{2} \mathrm{pin}_{2}$ to a solution of $\mathbf{3 a}$ excluding $\mathrm{NaO}^{t} \mathrm{Bu}$ failed to generate $\operatorname{IPrCuB}($ pin), suggesting that salt metathesis is necessary for catalytic turnover. These results are consistent with conclusions from 
computational studies conducted by Lin demonstrating the importance of the alkoxide base in promoting the salt metathesis step in the boracarboxylation of styrene. ${ }^{86}$
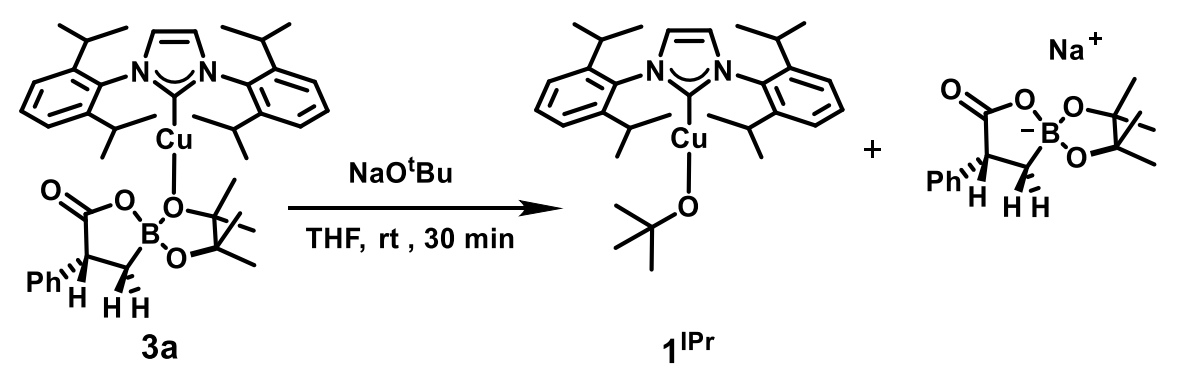

$\mathrm{IPrCu}(\mathrm{CO} 2(\mathrm{CHPhCH} 2 \mathrm{Bpin}))+\mathrm{NaOtBu}$

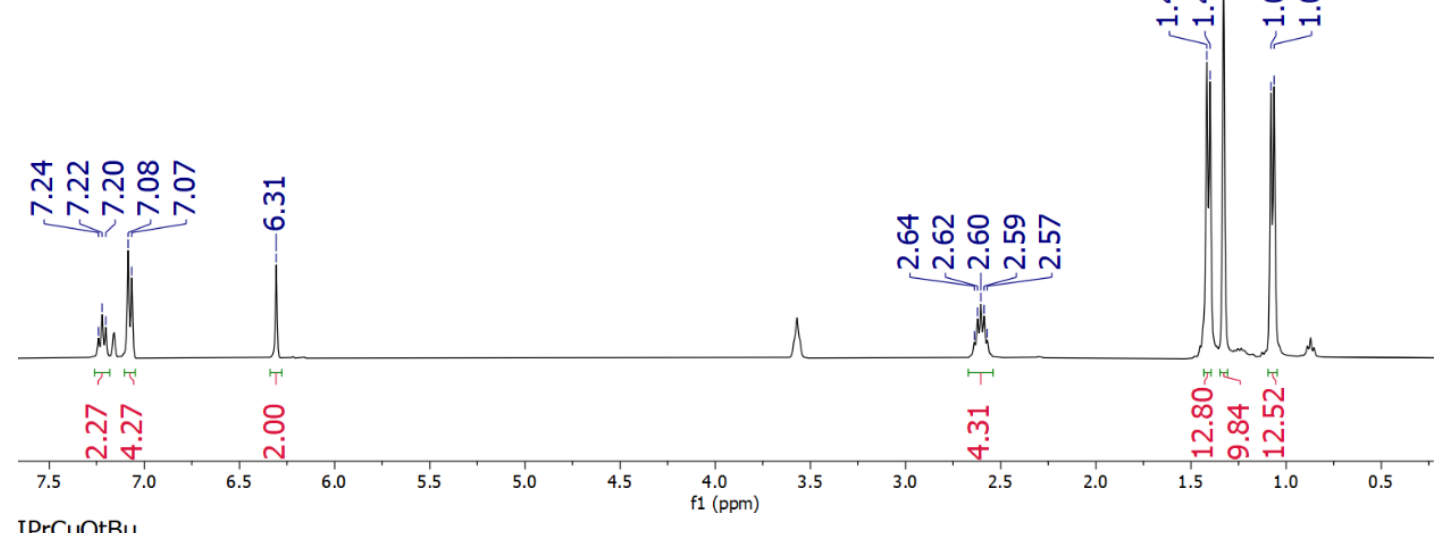

IPrCuOtBu

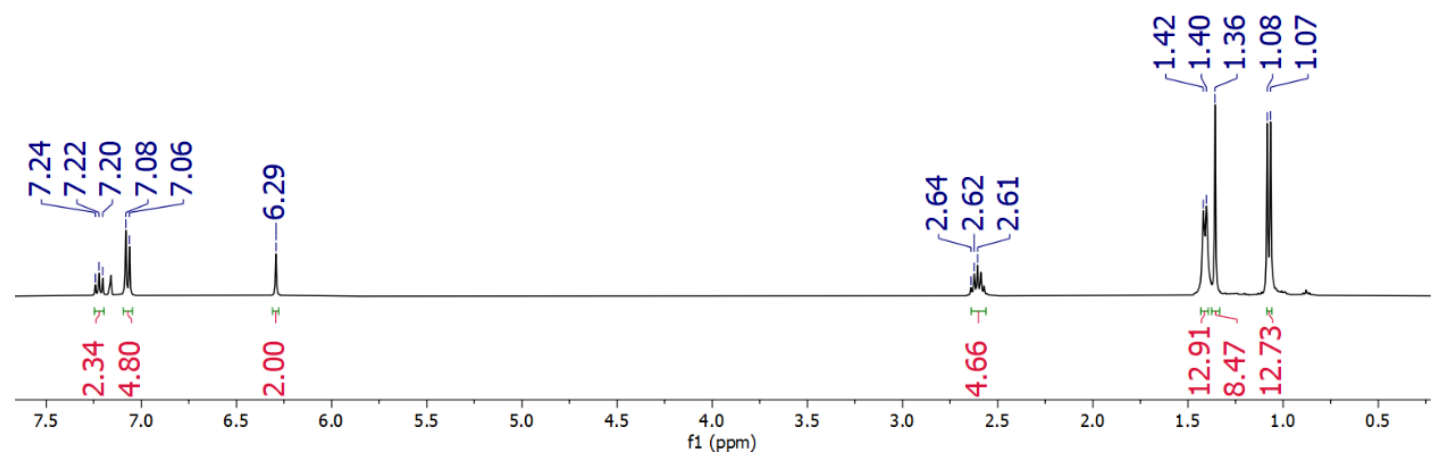

Figure 2.11. ${ }^{1} \mathrm{H}$ NMR spectra of $\mathrm{IPrCu}^{\mathrm{t}} \mathrm{OBu}$, as a product of salt metathesis reaction (top) and as the product of independent synthesis (bottom). Collected in benzene- $d_{6}$ at $25^{\circ} \mathrm{C}(400 \mathrm{MHz})$. 


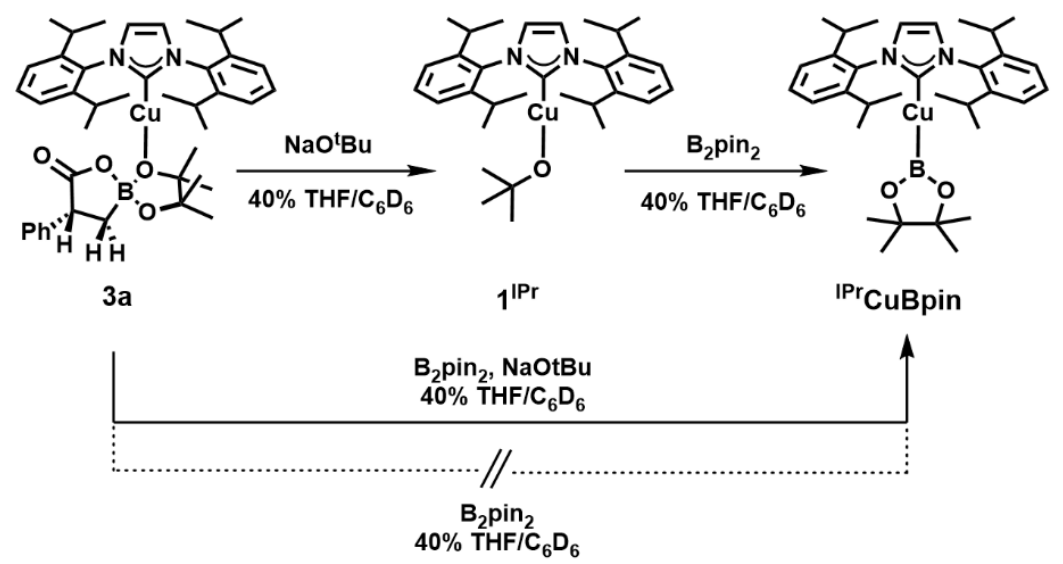

1H NMR (400 MHz, 40\% THF/benzene- $d_{6}$ )

$3 a$

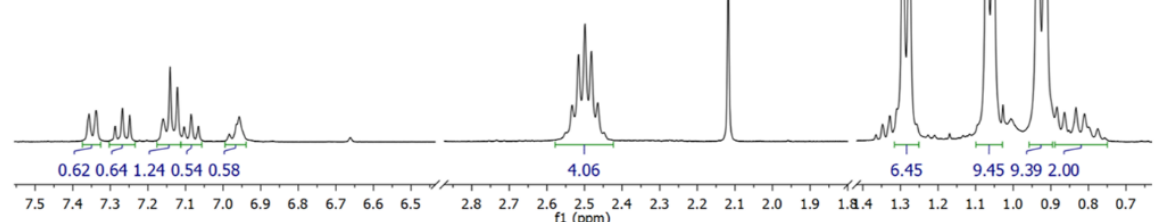
Addition of IPrCuOtBu: $1 \mathrm{IPr}$

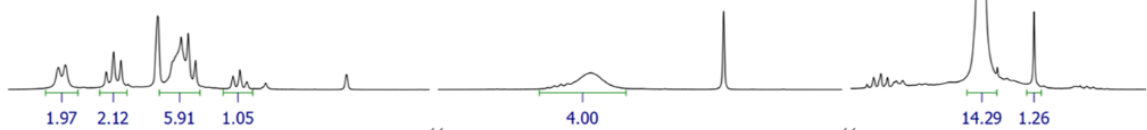

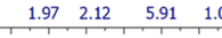
$14.29 \quad 1.26$

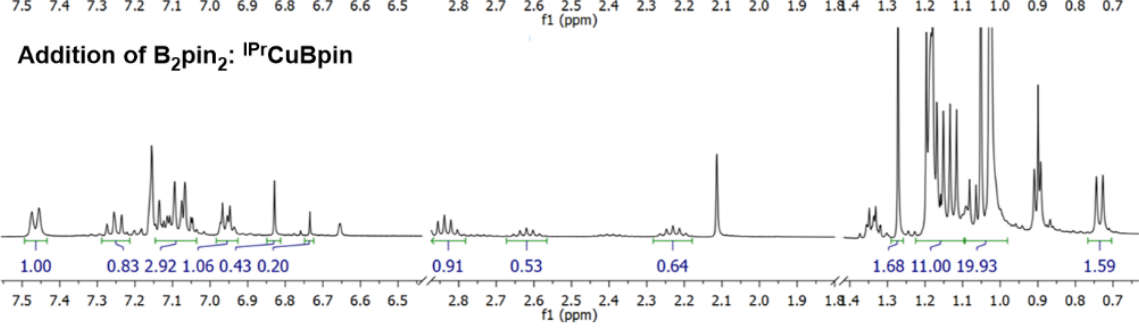

Figure 2.12. Top: ${ }^{1} \mathrm{H}$ NMR spectrum of 3a. Middle: spectrum demonstrating the production of $\mathbf{1}^{\mathbf{I P r}}$ upon the addition of $\mathrm{NaO}^{\mathrm{t}} \mathrm{Bu}$ to a $40 \% \mathrm{THF} /$ benzene- $d_{6}$ solution of 3a. Bottom: ${ }^{1} \mathrm{H}$ NMR in $40 \% \mathrm{THF} /$ benzene- $d_{6}$ solution of $\mathrm{B}_{2} \mathrm{pin}_{2}$ addition to reaction, generating IPrCuBpin. 


\subsection{Kinetic Analysis of Carboxylation using ${ }^{1} \mathrm{H}$ NMR}

Recent computational studies as well as experimental data indicate that carboxylation serves as the turnover-limiting step of the catalytic boracarboxylation reaction (Scheme 2.1, Step III). $86,87,88,95$ The electronic character of vinyl arene was determined to be important in terms of both yield and catalytic efficiency. ${ }^{74}$ Specifically, higher yields were observed under ambient conditions with more electron rich vinyl arenes whereas lower yields were observed for select electron deficient vinyl arenes with heating (e.g., $m$-fluorostyrene, $\sigma_{p}=+0.06$ ). This result is in contrast to observations made for stoichiometric vinyl arene insertion into the $\mathrm{Cu}-\mathrm{B}$ bond of $\mathrm{IPrCuB}(\mathrm{pin})$, in which electron deficient vinyl arenes reacted more quickly. ${ }^{83}$ Given the orthogonal reactivity of these two steps (Scheme 2.1, Step II and III), a better understanding and further analysis of the latter carboxylation step is necessary.

The ethenyl protons of the $\operatorname{IPr}$ heterocycle on the $\mathrm{Cu}^{\mathrm{I}}(\beta$-borylbenzyl) complexes at approximately $6.1 \mathrm{ppm}$ in the ${ }^{1} \mathrm{H}$ NMR spectrum made the carboxylation reaction amenable to monitoring by ${ }^{1} \mathrm{H}$ NMR spectroscopy. Benzene- $d_{6}$ solutions of 2a-2i were exposed to $\mathrm{CO}_{2}(1 \mathrm{~atm})$ in a J. Young NMR tube, and carboxylation was monitored to reaction completion (Figure 2.13). Over the timecourse of the reaction, the growth of a single resonance for IPr ethenyl protons was observed downfield from that of the starting complex, consistent with formation of the carboxylate species 3a-3i in comparison to independently prepared samples (vide supra). Reaction timecourses were determined to follow exponential behavior. Analysis of selected timecourses demonstrated that the decay of starting material and concomitant increase of product occurred at similar rates (Figure 2.14). Carboxylation of $\mathrm{Cu}^{\mathrm{I}}\left(\beta\right.$-borylbenzyl $\left.{ }^{\mathrm{p}-\mathrm{NMe}_{2}}\right)$ complex $\mathbf{2} \mathbf{b}$ occurred in less than 10

95. (a) Fiorito, D.; Liu, Y.; Besnard, C.; Mazet, C. Direct Access to Chiral Secondary Amides by Copper-Catalyzed Borylative Carboxamidation of Vinylarenes with Isocyanates. J. Am. Chem. Soc. 2020, 142, 623-632. (b) Su, Z.; Feng, Y.; Zou, R.; Qiu, X.; Wang, J.; Tao, C. Copper-Catalyzed Borylamidation of Vinyl Arenes with Isocyanates. Chem. Commun. 2020, 56, 7438-7468. (c) Wu, N. Y.; Xu, X. H.; Qing, F. L. Copper-Catalyzed Regioselective Borylfluoromethylation of Alkenes. ACS Catal. 2019, 9, 5726-5731. (d) Chen, B; Cao, P.; Liao, Y.; Wang, M; Laio, J. Enantioselective Copper-Catalyzed Methylboration of Alkenes. Org. Lett. 2018, 20, 1346-1349. (e) Logan, K. M.; Sardini, S. R.; White, S. D.; Brown, M. K. Nickel-Catalyzed Stereoselective Arylboration of Unactivated Alkenes. J. Am. Chem. Soc. 2018, 140, 159-162. (f) He, S. L.; Wang, B.; Lu, X.; Gong, T. J.; Yang, Y. N.; Wang, X. X.; Wang, Y.; Xiao, B.; Fu, Y. Copper-Catalyzed Reagent-Controlled Regioselective Cyanoborylation of Vinyl Arenes. Org. Lett. 2018, 20, 5208-5212. (g) Cheng, Y.; Mück-Lichtenfeld, C.; Studer, A. Transition Metal-Free 1,2-Carboboration of Unactivated Alkenes. J. Am. Chem. Soc. 2018, 140, 6221-6225. (h) Kim, N.; Han, J. T.; Ryu, D. H.; Yun, J. CopperCatalyzed Asymmetric Borylallylation of Vinyl Arenes. Org. Lett. 2017, 19, 6144-6147. (i) Huang, Y.; Smith, K. B.; Brown, M. K. Copper-Catalyzed Borylacylation of Activated Alkenes with Acid Chlorides. Angew. Chem. Int. Ed. 2017, 56, 13314-13318. 
minutes, whereas no appreciable carboxylation ( $<5 \%$ based on NMR integration) and some intractable decomposition was observed for $\mathrm{Cu}^{\mathrm{I}}\left(\beta\right.$-borylbenzyl $\left.{ }^{\mathrm{p}-\mathrm{CF}_{3}}\right)$ complex $\mathbf{2}$.

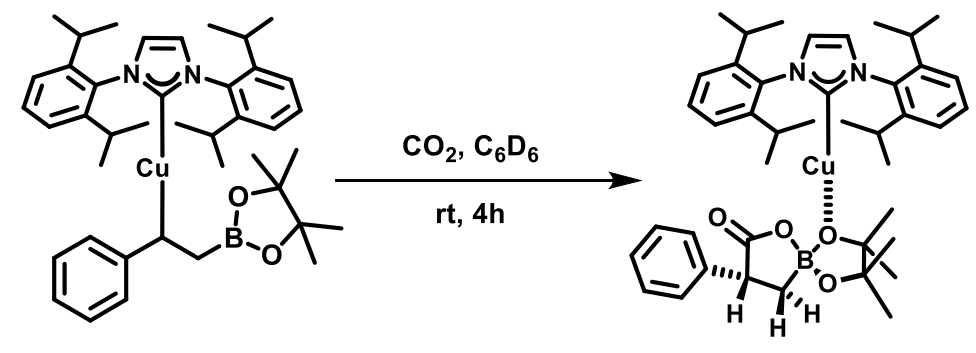

2a

$3 a$

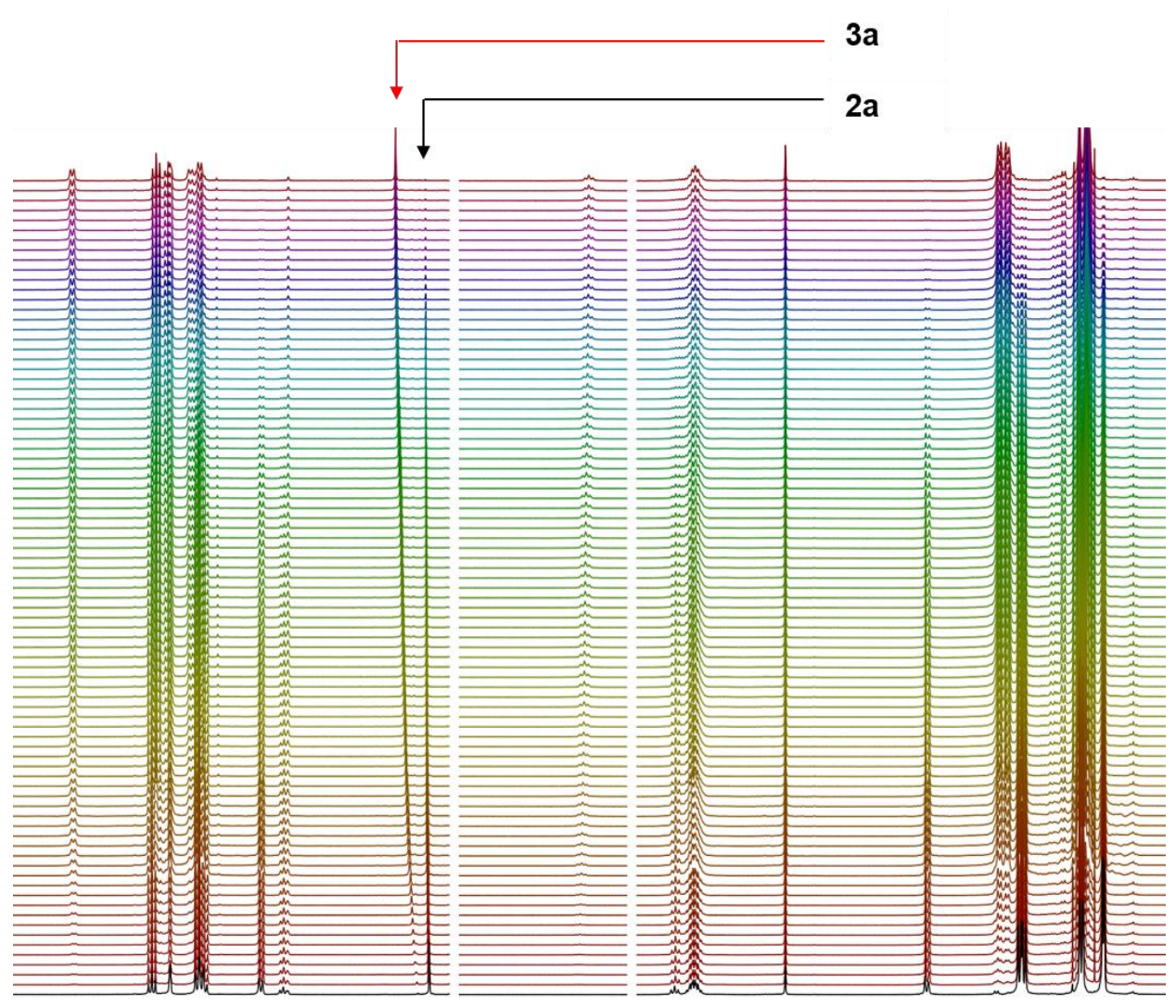

$\begin{array}{llllllllllllllllllllllll}7.6 & 7.4 & 7.2 & 7.0 & 6.8 & 6.6 & 6.4 & 6.2 & 4.0 & 3.8 & 3.6 & 2.6 & 2.4 & 2.2 & 2.0 & 1.8 & 1.6 & 1.4 & 1.2 & 1.0 & 0.8\end{array}$

Figure 2.13. ${ }^{1} \mathrm{H}$ NMR array depicting conversion of $\mathrm{IPrCu}\left(\mathrm{CHPhCH}_{2} \mathrm{Bpin}\right)$ (2a) to $\operatorname{IPrCu}\left(\left(\mathrm{CO}_{2}\right)\left(\mathrm{CHPhCH}_{2} \mathrm{Bpin}\right)\right)(3 \mathbf{a})$ at $25^{\circ} \mathrm{C}$ in benzene- $d_{6}$ under 1 atmosphere of $\mathrm{CO}_{2}$. 


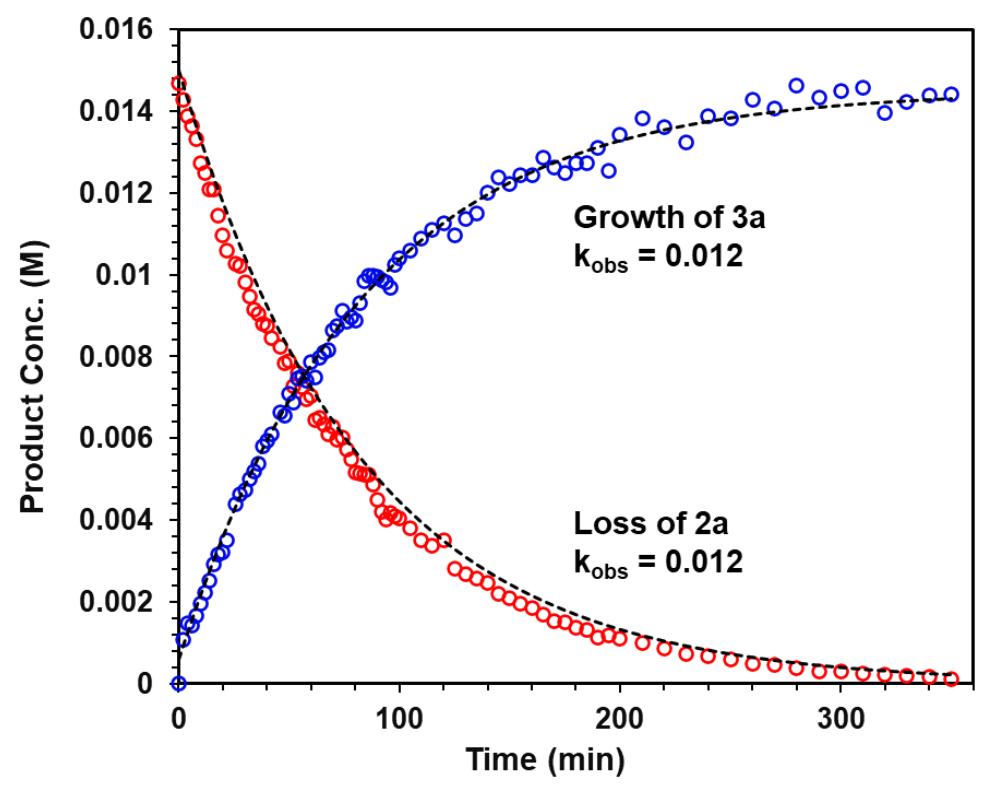

Figure 2.14. Kinetic traces for the growth of $\mathbf{3 a}$ and the concomitant loss of $\mathbf{2 a}$ with their respective observed rate constants $\left(k_{\text {obs }}\right)$ based on integration of ethenyl resonance. Data collected via ${ }^{1} \mathrm{H}$ NMR spectroscopy in benzene- $d_{6}$ at $25^{\circ} \mathrm{C}(600 \mathrm{MHz})$.

Several pathways were considered for carboxylation of the $\mathrm{Cu}^{\mathrm{I}}(\beta$-borylbenzyl) complexes (Scheme 2.5): the direct insertion pathway involving an interaction between copper and $\mathrm{CO}_{2}$ during the transition state; and electrophilic substitution proceeding with no copper mediation, both $\mathrm{S}_{\mathrm{E}} 1$ and $\mathrm{S}_{\mathrm{E}} 2$ processes. To elucidate the reaction mechanism, a Hammett analysis using pseudo-first order rate constants $\left(k_{2 n d}\right)$ and the Hammett $\sigma_{p}$ parameter for each aryl substitution was performed for complexes $\mathbf{2 a - 2 h}$ (Figure 2.15). It is speculated that a negative rho $(\rho)$ value would result from direct insertion or $\mathrm{S}_{E} 2$ carboxylation, assuming minimal pre-ionization of the $\mathrm{Cu}-\mathrm{C}_{\text {benzyl }}$ bond at the transition state. This could be due to reduction of negative charge at the benzylic carbon with electron-withdrawing para substituents. However, if initial ionization of the $\mathrm{Cu}-\mathrm{C}_{\text {benzyl }}$ bond is required prior to $\mathrm{CO}_{2}$ bond formation (i.e. an $\mathrm{S}_{E} 1$ mechanism), then a positive $\rho$ value (indicating negative charge buildup) would be expected resulting from the enhanced stability the anionic benzylic carbon by the electron-withdrawing aryl ring. 
Scheme 2.5. Potential pathways for the carboxylation of $\mathrm{Cu}^{\mathrm{I}}(\beta$-borylbenzyl) complexes.

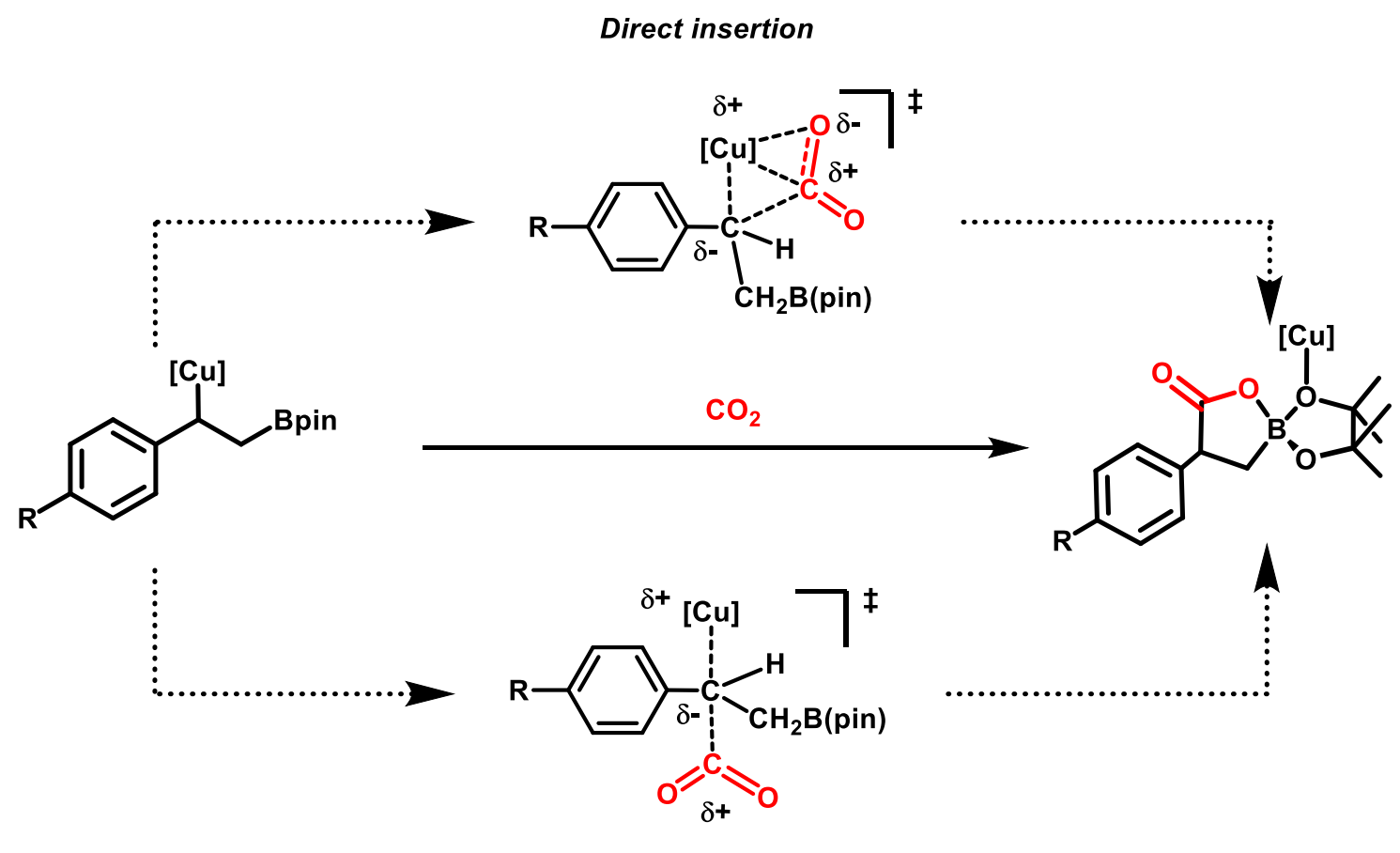

Electrophilic Substitution

The Hammett plot revealed a largely negative $\rho$ value (-1.61), which suggests positive charge buildup, or loss of negative charge, in the carboxylation transition state, which was inconsistent with an $\mathrm{S}_{\mathrm{E}} 1$ mechanism (Figure 2.15). The Hammett analysis, however, cannot distinguish between direct insertion and $\mathrm{S}_{\mathrm{E}} 2$ pathways. Further, details related to the intimate interactions along the pathways are not available from experiment alone. Computational modeling became necessary to answer questions such as whether direct insertion of $\mathrm{CO}_{2}$ proceeds through DewarChatt-Duncanson $\pi$-backbonding to $\mathrm{CO}_{2}$ and forms of a copper(III)-like intermediate/transition state. 

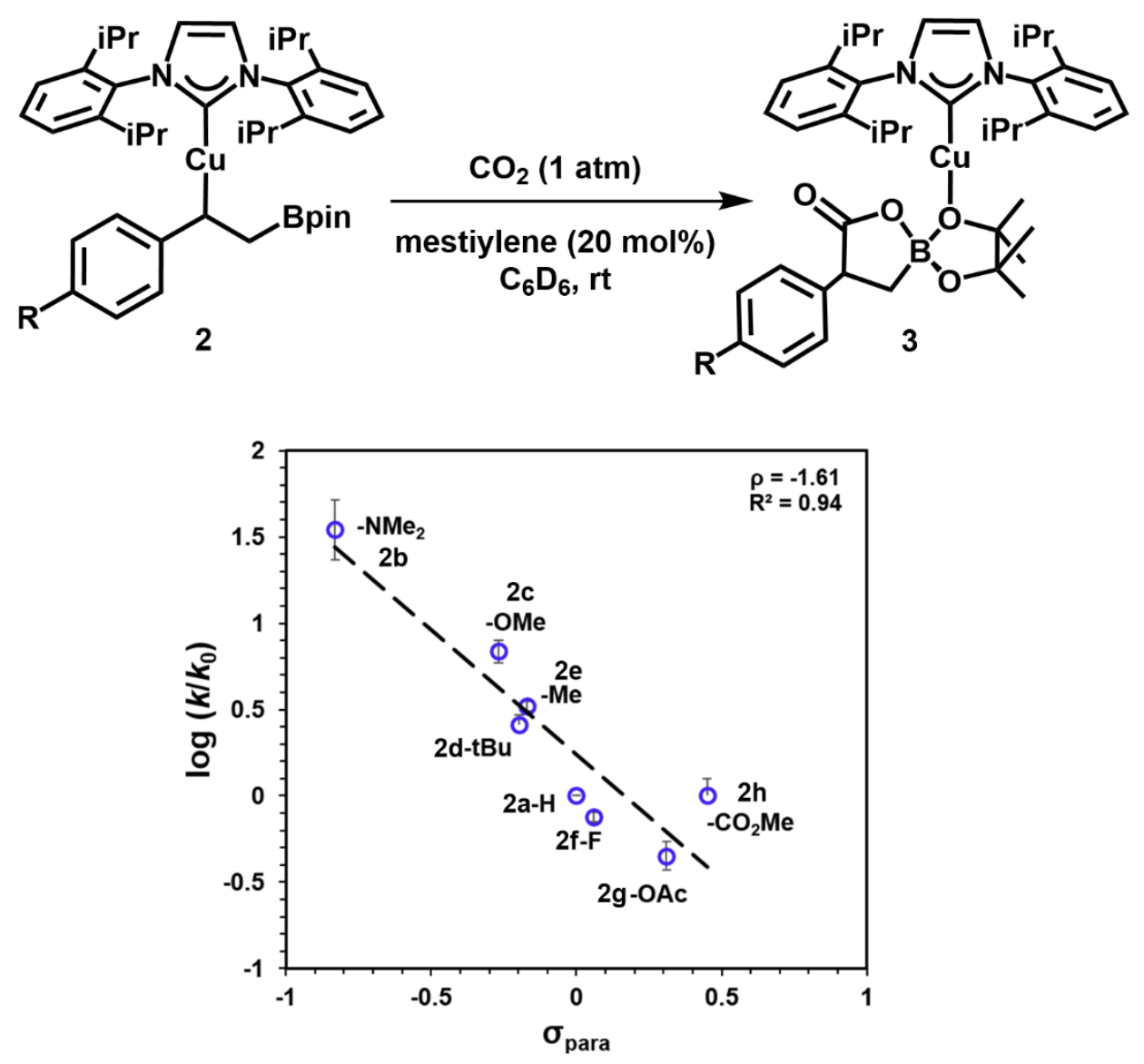

Figure 2.15. Hammett plot depicting relative rates of carboxylation of $\mathrm{Cu}^{\mathrm{I}}(\beta$-borylbenzyl) complexes 2a-2h. The labels in the plots reflect the substitution in the 4-position of the aryl ring.

\subsection{Computational Analysis of Carboxylation}

Density functional theory (DFT) was used to model the carboxylation of $\mathrm{Cu}^{\mathrm{I}}(\beta$-borylbenzyl) complexes. This study serves to complement the experimental data obtained here as well as bridge a gap in the existing computational literature on boracarboxylation of vinyl arenes. ${ }^{40}$ Computational expense was reduced by replacing IPr and B(pin) with truncated IMe ligand (IMe =1,3-bis(dimethyl)-4,5-dihydroimidazol-2-ylidene) and B(eg) (eg = ethyleneglycato), which is a strategy previously explored in other related $\mathrm{Cu}^{\mathrm{I}}$-catalyzed transformations. ${ }^{26,27,28,41}$ Para substituents of same or similar electronic character were used to mimic experimental complexes. Through independent computational studies (presented in Chapter 4), it was determined that the $\mathrm{S}_{E}$-like carboxylation pathways were disfavored relative to direct insertion (Scheme 2.5). ${ }^{28}$ Thus, each $\mathrm{Cu}^{\mathrm{I}}(\beta$-borylbenzyl) model complex (denoted 4a-i and corresponding to the experimental 
complex 2a-i), were optimized at M06 and B3LYP levels of theory, and subsequently direct $\mathrm{CO}_{2}$ insertion transition states for each complex were identified (Figure 2.16, Table 2.5.). ${ }^{42,43,44,45}$
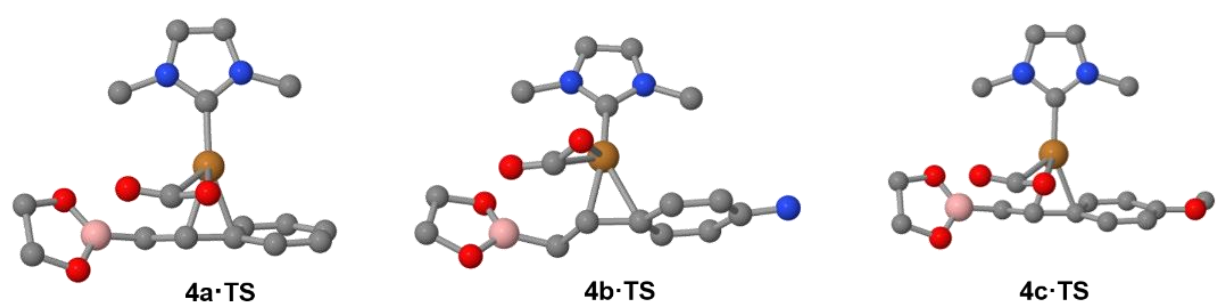

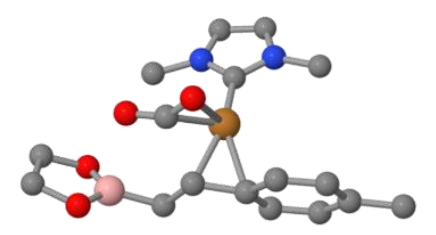

$4 \mathrm{e} \cdot \mathrm{TS}$

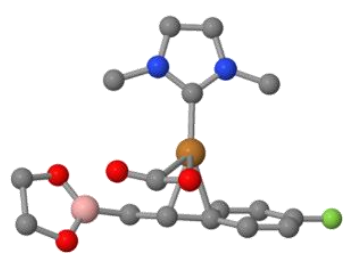

4f-TS

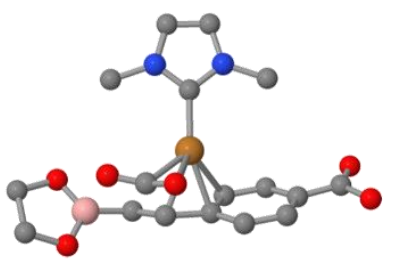

4h-TS

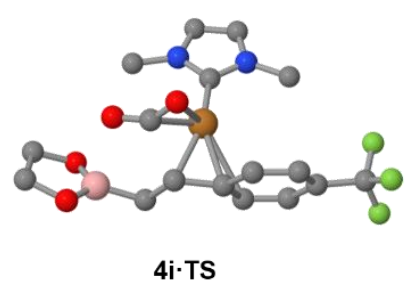

4i-TS

Figure 2.16. Direct insertion carboxylation transition state structures for $\mathbf{4 a - 4 i}$ optimized at M06 (4x-TS).

Previously reported computational studies on similar copper-based systems have largely utilized B3LYP as the functional of choice. ${ }^{96}$ Another common functional, M06, was also used in this study to serve as a comparison (data shown in Table 2.5.). Through comparison with the experimentally derived free energy barrier of carboxylation, it was observed that B3LYP led to systematic over-estimations in the computed $\Delta G^{\ddagger}$ values. Similar discrepancies have been reported in recent literature. ${ }^{97}$

96. (a) Fan, T.; Sheong, F. K.; Lin, Z. DFT Studies on Copper-Catalyzed Hydrocarboxylation of Alkynes Using $\mathrm{CO}_{2}$ and Hydrosilanes. Organometallics 2013, 32, 5224-5230. (b) Dang, L.; Lin, Z. DFT Studies on the Carboxylation of Arylboronate Esters with $\mathrm{CO}_{2}$ Catalyzed by Copper(I) Complexes. Organometallics 2010, 29, 917-927. (c) Zhao, H.; Dang, L.; Marder, T. B.; Lin, Z. DFT Studies on the Mechanism of the Diboration of Aldehydes Catalyzed by Copper(I) Boryl Complexes. J. Am. Chem. Soc. 2008, 130, 5586-5594. (d) Dang, L.; Zhao, H.; Lin, Z. DFT Studies of Alkene Insertions into Cu-B Bonds in Copper(I) Boryl Complexes. Organometallics 2007, 26, 2824-2832. (e) Zhao, H.; Lin, Z.; Marder, T. B. Density Functional Theory Studies on the Mechanism of the Reduction of $\mathrm{CO}_{2}$ to CO Catalyzed by Copper(I) Boryl Complexes. J. Am. Chem. Soc. 2006, 128, 15637-15643.

97. Collins, L. R.; Rajabi, N. A.; Macgregor, S. A.; Mahon, M. F.; Whittlesey, M. K. Experimental and Computational Studies of the Copper Borate Complexes $\left[(\mathrm{NHC}) \mathrm{Cu}\left(\mathrm{HBEt}_{3}\right)\right]$ and $\left[(\mathrm{NHC}) \mathrm{Cu}\left(\mathrm{HB}\left(\mathrm{C}_{6} \mathrm{~F}_{5}\right)_{3}\right)\right]$. Angew. Chem. Int. Ed. 2016, 128, 15768-15772. 
Table 2.5. Gibbs free energy of carboxylation using different functionals and dispersion corrections.

\begin{tabular}{|c|c|c|c|c|c|c|}
\hline $\begin{array}{c}\text { Para } \\
\text { substituent }\end{array}$ & $\sigma_{p}$ & $k_{2 n d^{a}}$ & $\begin{array}{r}\Delta G^{\ddagger} \\
(\exp )\end{array}$ & $\begin{array}{r}\Delta G^{\ddagger} \text { smd } \\
(M 06)\end{array}$ & $\begin{array}{r}\Delta G^{\ddagger} \text { smd } \\
\text { (B3LYP) }\end{array}$ & $\begin{array}{r}\Delta G^{\ddagger} \text { smc } \\
\text { (B97D3) }\end{array}$ \\
\hline $\mathrm{NMe}_{2}$ & -0.83 & 3.98 & 16.6 & -- & -- & -- \\
\hline $\mathrm{NH}_{2}$ & -0.66 & -- & -- & 20.3 & 28.0 & 17.9 \\
\hline OMe & -0.27 & 0.76 & 17.6 & 20.1 & 28.1 & 19.7 \\
\hline${ }^{t} \mathrm{Bu}$ & -0.20 & 0.28 & 18.2 & -- & -- & -- \\
\hline Me & -0.17 & 0.36 & 18.1 & 22.0 & 29.7 & 20.7 \\
\hline $\mathbf{H}$ & 0 & 0.11 & 18.8 & 23.6 & 29.7 & 21.2 \\
\hline $\mathbf{F}$ & +0.06 & 0.08 & 18.9 & 23.0 & 29.5 & 21.5 \\
\hline OCOMe & +0.31 & 0.05 & 19.2 & -- & -- & -- \\
\hline $\mathrm{CO}_{2} \mathrm{Me}$ & +0.45 & 0.05 & 19.2 & -- & -- & -- \\
\hline $\mathrm{CO}_{2} \mathrm{H}$ & +0.45 & -- & -- & 25.9 & 31.8 & 23.2 \\
\hline $\mathrm{CF}_{3}$ & +0.54 & -- & -- & 24.1 & 32.0 & 21.2 \\
\hline
\end{tabular}

${ }^{a}$ The reaction was treated as a pseudo-first order reaction due to a large excess of $\mathrm{CO}_{2}$; thus, $k$ was determined by the following equation: $k_{2 \text { nd }}=\mathrm{k}_{\mathrm{obs}} /\left[\mathrm{Cu}(\mathrm{I})\left(\beta\right.\right.$-borylbenzyl $\left.\left.{ }^{\mathrm{X}}\right)\right]$.

M06 led to reasonable values when compared to the experimental data. Attention was also given to the inclusion of dispersion corrections, which can be useful when describing non-covalent interactions. ${ }^{98}$ Using the B97D3 Grimme functional, the change in free energy for each carboxylation event yielded similar results to those of M06 (Table 2.5, Figure 2.17). Accordingly, M06 was chosen as a suitable functional for this study. Additionally, the SMD solvation-corrected relative Gibbs free energies of carboxylation $\left(\Delta \Delta G^{\ddagger}\right.$ smd $)$ were compared to $\sigma_{\text {para }}$ as well as to experimentally derived $\Delta \Delta G^{\ddagger}$ values (Figure 2.18).

98. Grimme, S.; Hansen, A.; Brandenburg, J. G.; Bannwarth, C. Dispersion-Corrected Mean-Field Electronic Structure Methods. Chem. Rev. 2016, 116, 5105-5154. 


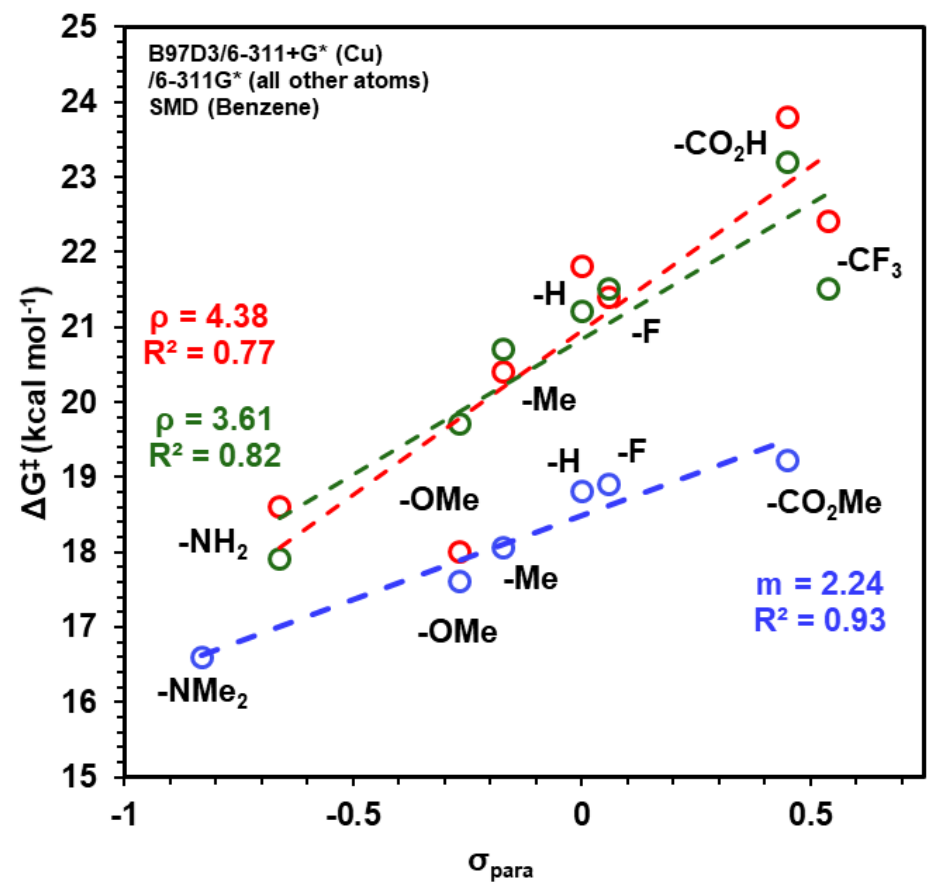

Figure 2.17. Blue: free energies derived from experimental data; Red: free energies of solvation obtained from single point calculations using the gas-phase minimum structure optimized without dispersion corrections (optimized using M06); Green: free energies of solvation obtained from single point calculations using the gas-phase minimum structure optimized with dispersion corrections. 

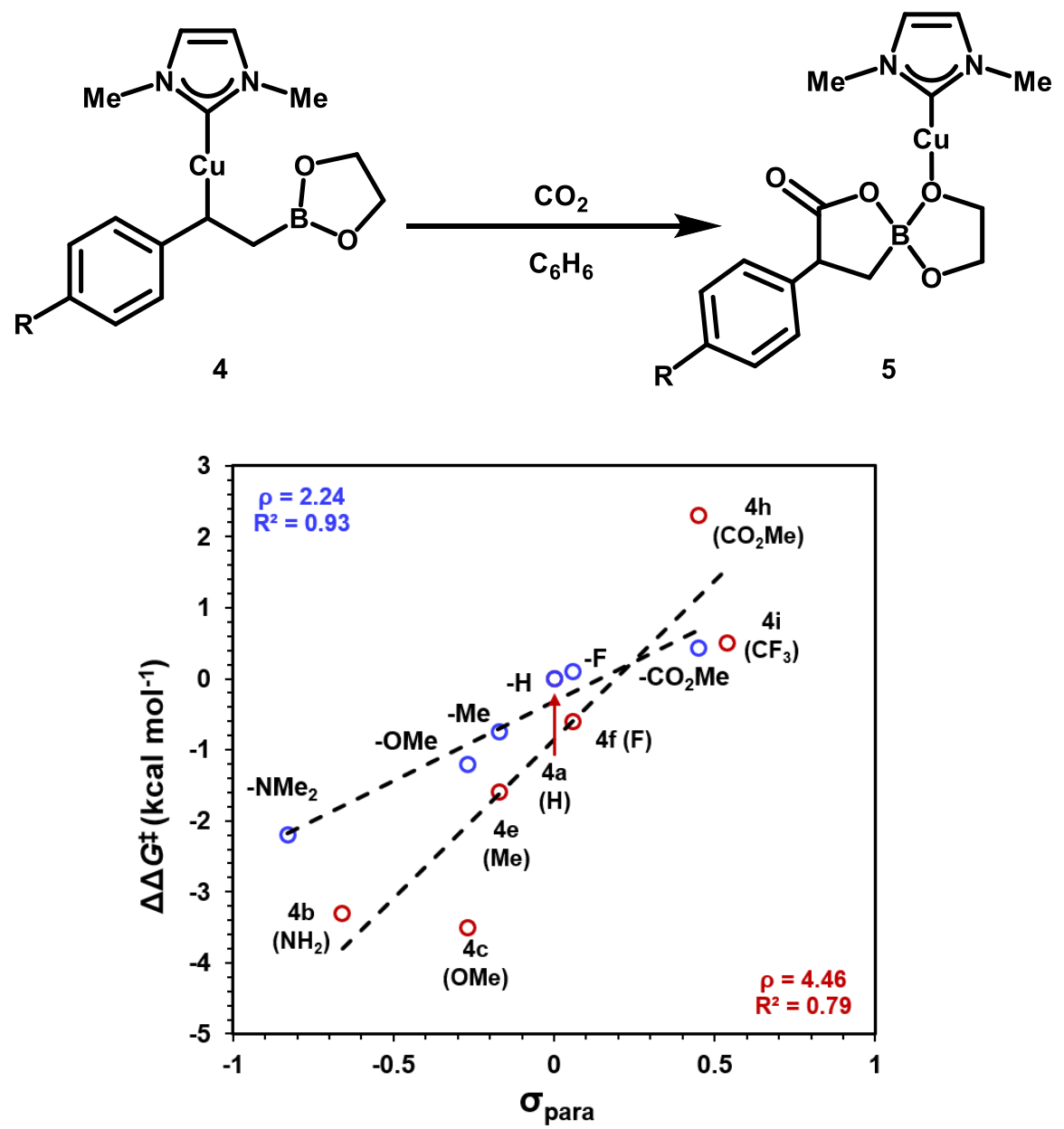

Figure 2.18. Comparison of experimental $\Delta \Delta G^{\ddagger}$ values for carboxylation of $\mathbf{2 a - 2 g}$ (blue) and computational $\Delta \Delta G^{\ddagger}$ values for carboxylation of $\mathbf{4 a}-\mathbf{4 i}$ (red). Theory: rm06/6-311+G*(Cu)/6$311 \mathrm{G} *$ (all other atoms).

Attempts were made to identify a metal-stable $\mathrm{CO}_{2}$ intermediate prior to the formation of 4a-TS using intrinsic reaction coordinate (IRC) calculations. However, it was determined that conversion from $\mathrm{Cu}^{\mathrm{I}}(\beta$-borylbenzyl) to the carboxylation transition state $\mathbf{4 a} \cdot \mathbf{T S}$ is a concerted process (Figure 2.19). 


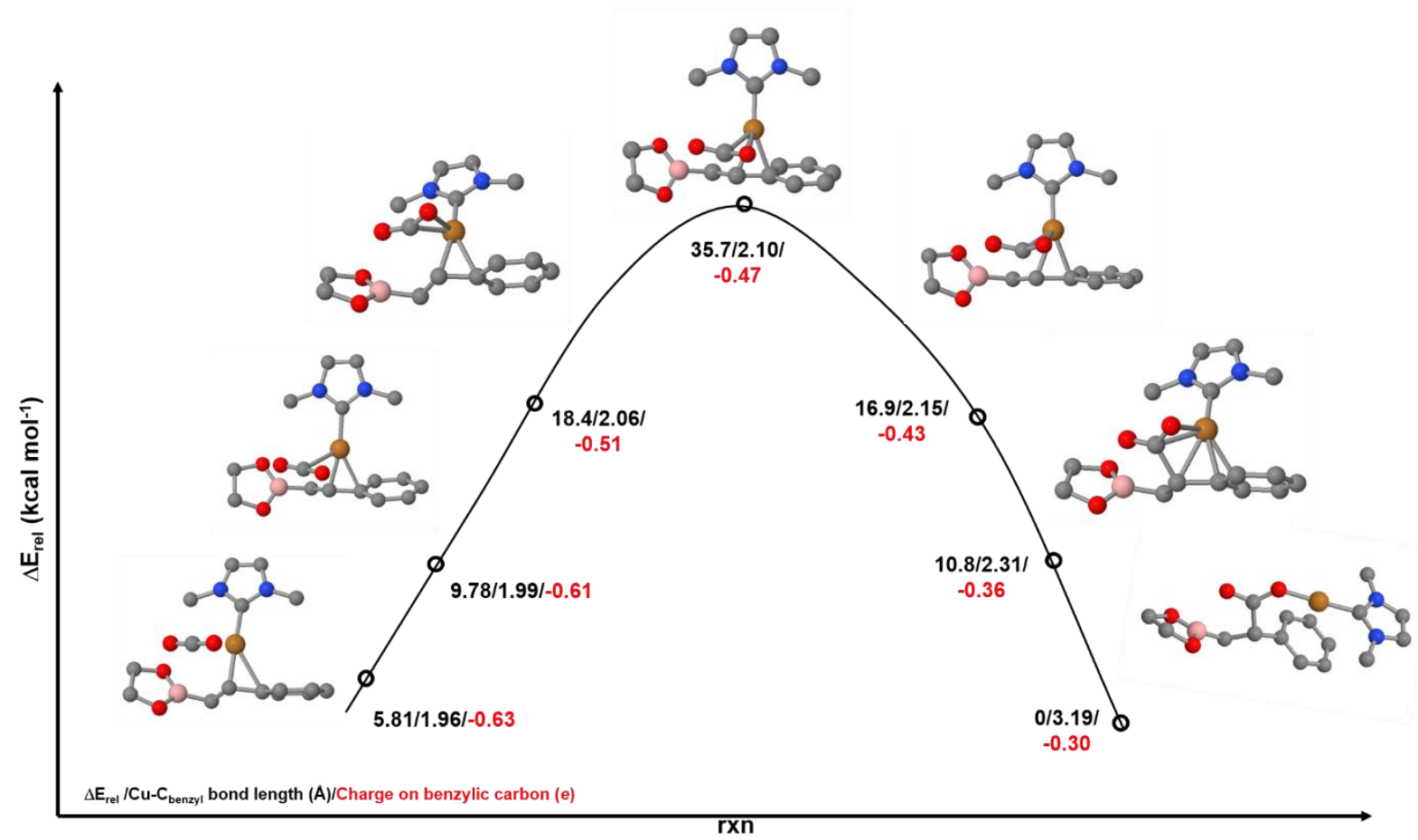

Figure 2.19. IRC calculation of 3a depicting the reverse and forward reactions.

DFT-calculated free energy changes were in reasonable agreement with experimental data (Figure 2.18.), with more electron-rich arenes (eg., $-\mathrm{NH}_{2}, 4 \mathbf{b}$, and -OMe, 4c) exhibiting systemically lower barriers than electron-deficient arenes (eg., $-\mathrm{CO}_{2} \mathrm{H}, \mathbf{4 h}$ and $-\mathrm{CF}_{3}, \mathbf{4 i}$ ). Substantial deviation in the fit for $\mathrm{CO}_{2} \mathrm{H}$ compared to $\mathrm{CF}_{3}$ could reflect the lack of steric bias in the smaller IMe-Cu model system and/or amplification of stereoelectronic contributions of the para-substituent not observed in the experimental study. An $\mathrm{S}_{E}$ pathway was also evaluated for $\mathbf{4 a}$, $\mathbf{4 b}$, and $\mathbf{4} \mathbf{i}$, and it was found that barrier changed by less than $1 \mathrm{kcal} / \mathrm{mol}$ across the Hammett series and was destabilized ( $>5 \mathrm{kcal} / \mathrm{mol}$ ) relative to direct insertion (Table 2.6.). 
Table 2.6. Computationally derived Gibbs free energy barriers associated with direct insertion $(\mathbf{4} \cdot \mathbf{T S})$ and electrophilic carboxylation $\left(\mathbf{4} \mathbf{x}^{\bullet} \mathbf{T} \mathbf{S}^{\mathbf{S}^{2}}\right)$.

\begin{tabular}{|c|c|c|c|}
\hline p-Aryl & $\mathrm{CF}_{3}$ & $\mathbf{H}$ & $\mathrm{NH}_{2}$ \\
\hline $\begin{array}{c}\Delta G^{\ddagger}(\mathrm{kcal} / \mathrm{mol}) \\
4 \mathrm{x} \cdot \mathrm{TS}\end{array}$ & $24.1^{b}$ & 23.6 & 20.3 \\
\hline $\begin{array}{c}\Delta G^{\ddagger}(\mathrm{kcal} / \mathrm{mol}) \\
4 x^{\circ} \mathrm{TS}^{S E 2 ~ a}\end{array}$ & 27.3 & 28.0 & 27.5 \\
\hline
\end{tabular}

Visualization of $\mathbf{4 a}$ (cf., Figure 2.20) showed slight deviation from the idealized linear geometry expected in the IMe-Cu- $\mathrm{C}_{\text {benzyl }}$ bond angle, allowing for a weak non-covalent interaction of the $\mathrm{Cu}$ center with neighboring $\mathrm{C}_{i p s o}$ of the Ar ring. At transition state $4 \mathbf{a}^{\bullet} \mathbf{T S}$, lengthening of $\mathrm{Cu}-\mathrm{C}_{\text {benzyl }}$ bond $(1.96 \rightarrow 2.10 \AA)$ with concomitant shortening of $\mathrm{Cu}-\mathrm{C}_{i p s o}$ bond $(2.57 \rightarrow 2.17 \AA)$ were noted. Similar metrical changes were observed for the other direct insertion carboxylation transition states (Table 2.7). Notably, electron-rich benzyl complexes (eg., $-\mathrm{NH}_{2}, \mathbf{4 b}$ ) featured the greatest asymmetry in the $\mathrm{Cu}-\mathrm{C}_{\text {benzylipso }}$ bonds. Alternatively, electron-poor benzyl complexes (eg., $\left.-\mathrm{CF}_{3}, 4 \mathbf{i}\right)$ featured similar $\mathrm{Cu}-\mathrm{C}_{\text {benzylipso }}$ bond lengths. These systematic geometric changes are ascribed to the increasing importance of benzyl anion stabilization in electron-deficient arenes, and consequently carboxylation barrier destabilization, through delocalization and multi-point copper coordination similar to that observed in $\pi$-benzyl complexes. ${ }^{46,47}$

Molecular orbital analysis of the HOMO of both $4 \mathbf{a}$ and $\mathbf{4 a} \cdot \mathbf{T S}$ lends further support to this conclusion. The HOMO of $\mathbf{4 a} \cdot \mathbf{T S}$ possesses significant benzyl and copper character. Coplanarity of the benzyl $\pi$-system allows for delocalization of the HOMO across the aryl unit, which leads to significant electronic impacts upon arene ring substitution as reflected in the Hammett study (Figure 2.20). 

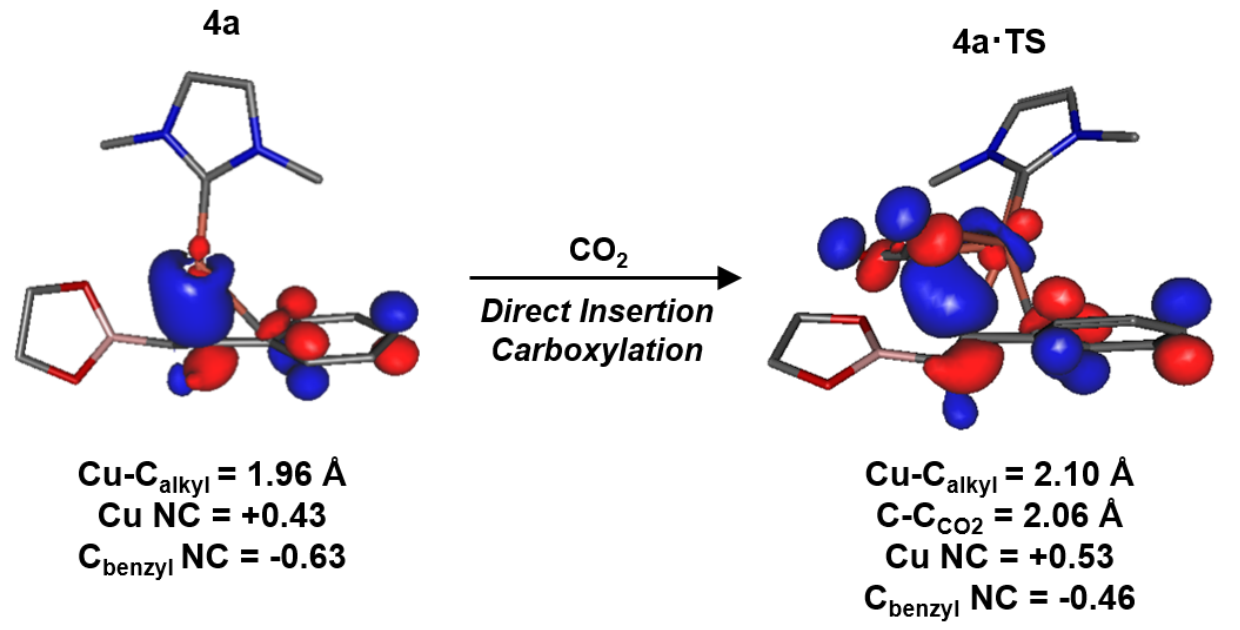

Figure 2.20. Visual representations of the highest occupied molecular orbital (HOMO) for the $\mathrm{IMeCu}(\beta$-borylbenzyl) structure 4a as well as the transition state for the cooperative carboxylation (4a-TS) obtained at the M06 DFT level. NC represents the natural charge obtained from the NBO analysis.

Natural bond orbital (NBO) analysis of the electronically perturbed transition states was also performed to gain deeper insight into the direct insertion carboxylation pathway. Natural charges (q) were compared (Figure 2.20 and Table 2.7) to address specific sites of charge buildup and localization inferred from the experimental Hammett analysis. The combined natural charge of the $\mathrm{C}_{\text {benzyl }}$ and $\mathrm{C}_{\text {ipso }}\left(q_{\mathrm{C}}\right)$ carbons and the extent of charge transfer to $\mathrm{CO}_{2}$ at the transition state systematically decreased with increased electron withdrawing character of the para substituent. The IMe- $\mathrm{Cu}$ fragment natural charge becomes more positive at the transition state $(\Delta q=+0.14)$, suggesting the possibility that the copper center is formally oxidized through $\pi$-backbonding to the incoming $\mathrm{CO}_{2}$ electrophile. However, further $\mathrm{MO}$ and $\mathrm{NBO}$ investigations showed no significant copper-based orbital overlap with $\mathrm{CO}_{2}$. Rather, increased charge buildup at the $\mathrm{C}_{i p s o}$ carbon $(\Delta q=$ $-0.10)$ suggests that the copper center backdonates electron density to the aryl ring upon formation of a $\pi$-benzyl-like structure at the transition state. 
Table 2.7. Metrical parameters and natural charges of 4•TS from natural bond orbital analysis.

\begin{tabular}{|c|c|c|c|c|c|c|c|c|}
\hline $\begin{array}{c}\text { Para } \\
\text { substituent }\end{array}$ & $\sigma_{p}$ & $\begin{array}{c}r_{\text {Cu-Çbenzyl }} \\
(\AA)\end{array}$ & $\begin{array}{c}r_{\text {Cu-Cipso }} \\
(\AA)\end{array}$ & $\begin{array}{c}r \text { Cu- } \\
\text { Cbenzyl·Ts } \\
(\AA)\end{array}$ & $\begin{array}{c}r \text { Cu- } \\
\text { Cipso:Ts } \\
(\AA)\end{array}$ & $\begin{array}{c}\text { Charge } \\
\mathrm{C}_{\text {benzyl/ipso }} \\
(q)^{a, b}\end{array}$ & $\begin{array}{c}\text { Charge } \\
\text { IMe-Cu } \\
(q)^{a}\end{array}$ & $\begin{array}{c}\text { Charge } \\
\mathrm{CO}_{2} \\
(q)^{a}\end{array}$ \\
\hline $\mathrm{NH}_{2}$ & -0.66 & 1.96 & 2.59 & 2.08 & 2.21 & -0.620 & +0.772 & -0.430 \\
\hline OMe & -0.27 & 1.96 & 2.62 & 2.08 & 2.19 & -0.615 & +0.776 & -0.413 \\
\hline Me & -0.17 & 1.96 & 2.58 & 2.09 & 2.18 & -0.594 & +0.781 & -0.407 \\
\hline H & 0 & 1.96 & 2.57 & 2.10 & 2.17 & -0.586 & +0.784 & -0.405 \\
\hline $\mathbf{F}$ & +0.06 & 1.96 & 2.62 & 2.09 & 2.20 & -0.603 & +0.784 & -0.412 \\
\hline $\mathrm{pCO}_{2} \mathrm{H}$ & +0.45 & 1.97 & 2.52 & 2.16 & 2.12 & -0.545 & +0.801 & -0.385 \\
\hline $\mathrm{pCF}_{3}$ & +0.54 & 1.97 & 2.48 & 2.15 & 2.14 & -0.561 & +0.800 & -0.402 \\
\hline
\end{tabular}

${ }^{a}$ Natural charge of the alkyl carbon and copper were calculated using rm06/6-311+G*(Cu)/6$311 \mathrm{G}^{*}$. SMD solvation model performed in benzene. ${ }^{b}$ Represents the sum of the $\mathrm{C}_{\text {benzyl }}$ and $\mathrm{C}_{i p s o}$ natural charges.

The emerging stereoelectronic picture suggests that the aryl para-substituents impact the nucleophilicity of the benzylic carbon, thus the early (better nucleophile, lower barrier) vs. late (poorer nucleophile, higher barrier) nature of the transition state. Given this description of the direct insertion carboxylation transition state, we speculated that the boron moiety, being positioned inside the B-O van der Waals radii, may help further stabilize the early transition state through cooperative polarization of the $\mathrm{C}=\mathrm{O}$ bond. ${ }^{28} \mathrm{All}$ metrical and NBO parameters (eg., natural charge, boron valency, B-O orbital overlap), however, showed no correlation to the observed kinetic trend. This finding suggests that while boron (Bpin) may help orient $\mathrm{CO}_{2}$ for insertion, the boronic ester utilized in this study is not sufficiently Lewis acidic to impart significant activation of $\mathrm{CO}_{2}$ in the direct insertion transition state. The influence of Lewis acidity will be discussed further in Chapter IV. 


\subsection{Conclusions}

In this chapter, a detailed experimental and computational mechanistic study of key steps proposed in the copper(I)-catalyzed boracarboxylation of vinyl arenes was presented. Preparation of a library of unique $\operatorname{IPrCu} \mathrm{I}^{\mathrm{I}}$-spiroboralactonate salts was achieved through stoichiometric reactions from both $\operatorname{IPrCuO}^{t} \mathrm{Bu}$ and $\operatorname{IPrCu}^{\mathrm{I}}\left(\beta\right.$-borylbenzyl $\left.{ }^{\mathrm{X}}\right)$ complexes. Multinuclear NMR techniques as well as X-ray crystallography were used to probe the solution behavior and solidstate structure of the carboxylated copper complexes.

Kinetic studies provided insight into the mechanisms by which carboxylation proceeds. A strong dependence was observed on the electronic character of the arene, which is due to the impact on the benzylic carbon engaged in nucleophilic attack. An experimental Hammett analysis corroborated prior computational evidence that direct insertion was the energetically preferred pathway by which $\mathrm{CO}_{2}$ is incorporated under standard boracarboxylation conditions. Further analysis of NBO-derived natural charges for the ground- and transition-state structures associated with carboxylation indicated that copper interacts with the ipso carbon of the arene ring in a manner similar to that observed in $\pi$-benzyl complexes. This interaction was critical in explaining the experimental Hammett data. The above studies have provided insights into the reactivity of various substrates in the boracarboxylation of vinyl arene substrates related specifically to carboxylation. With this knowledge, it may be possible to design catalytic systems wherein the challenges associated with scope limitations can be transcended, such as accessing non-aromatic alkenes as well as more electron-deficient substrates. 


\subsection{Experimental}

General Information: All air- and moisture-sensitive manipulations were performed under a dry atmosphere of argon using Schlenk line techniques and under a nitrogen atmosphere in an MBraun glovebox. Solvents used were purchased from Fisher and were further dried through a Glass Contour Solvent Purification System and stored over $4 \AA$ molecular sieves. Dichloromethane was further dried with $\mathrm{CaH}_{2}$, vacuum transferred, and stored over $4 \AA$ molecular sieves. Liquid reagents were degassed via freeze/pump/thaw method, and solids are dried under high vacuum prior to transfer to the glovebox. Dry $\mathrm{CO}_{2}$ was passed through drying column containing desiccant prior to use.

${ }^{1} \mathrm{H},{ }^{13} \mathrm{C},{ }^{19} \mathrm{~F}$, and ${ }^{11} \mathrm{~B}$ NMR spectra were recorded using Agilent $400 \mathrm{MHz}$, JEOL $400 \mathrm{MHz}$, and Varian INOVA $600 \mathrm{MHz}$ NMR spectrometers. Deuterated benzene $\left(\mathrm{C}_{6} \mathrm{D}_{6}\right)$ and dichloromethane $\left(\mathrm{CD}_{2} \mathrm{Cl}_{2}\right)$ were distilled from sodium metal and calcium hydride, respectively, and stored in the glovebox. IPrHCl, ${ }^{99} \mathrm{IPrCuCl},{ }^{100} \mathrm{IPrCuOtBu},{ }^{89}$ and $\mathrm{IPrCu}$-( $\beta$-borylbenzyl) complexes $\mathbf{2 a - 2 f}{ }^{83}$ were prepared following reported literature procedures.

Synthesis of Complexes 2g-2i: Compounds were prepared from the following procedure modified from literature: ${ }^{83}$ Under an atmosphere of $\mathrm{N}_{2}, 1$ equiv. of IPrCuO ${ }^{\mathrm{t}} \mathrm{Bu}(100 \mathrm{mg}, 0.19$ mmol) was combined with 1.1 equiv. of $\mathrm{B}_{2} \operatorname{pin}_{2}(54 \mathrm{mg}, 0.21 \mathrm{mmol})$ in $5 \mathrm{~mL}$ of $n$-pentane. After stirring at ambient temperature for 10 minutes, 1.1 equiv. of the appropriate styrene $(0.21 \mathrm{mmol})$ was added. The reaction was stirred for 1 hour, after which time the solid was collected on a fine porosity glass frit through vacuum filtration and was washed with $n$-pentane $(2 \mathrm{x})$. When THF was used as a solvent, following the reaction time, solvent is removed in vacuo. The solid was then triturated twice with $n$-pentane. The solid was collected on a medium porosity glass fritted funnel and washed with $n$-pentane.

2g - IPrCuI(CH(POCOMePh)CH2Bpin). Yield: $78 \mathrm{mg}(0.11 \mathrm{mmol}, 55 \%)$. ${ }^{1} \mathrm{H}$ NMR (400 MHz, benzene-d6) $\delta 7.92(\mathrm{~d}, \mathrm{~J}=8.2 \mathrm{~Hz}, 2 \mathrm{H}), 7.26(\mathrm{t}, \mathrm{J}=7.8 \mathrm{~Hz}, 2 \mathrm{H}), 7.03$ (ddd, J = 7.7, 6.4, $1.5 \mathrm{~Hz}$,

99. Dherbassy, Q.; Djukic, J. P.; Wencel-Delord, J.; Colobert, F. Two Stereoinduction Events in One C-H Activation Step: A Route towards Terphenyl Ligands with Two Atropisomeric Axes. Angew. Chem. Int. Ed. 2018, 57, 46684672 .

100. Jurkauskas, V.; Sadighi, J. P.; Buchwald, S. L. The Conjugate Reduction of $\alpha, \beta$-Unsaturated Carbonyl Compounds Catalyzed by a Copper Carbene Complex. Org. Lett. 2003, 5, 2417-2420. 
4H), $6.72-6.67(\mathrm{~d}, \mathrm{~J}=8.3 \mathrm{~Hz}, 2 \mathrm{H}), 6.17(\mathrm{~s}, 2 \mathrm{H}), 3.71(\mathrm{~s}, 3 \mathrm{H}), 2.77(\mathrm{t}, \mathrm{J}=7.3 \mathrm{~Hz}, 1 \mathrm{H}), 2.41(\mathrm{~h}, \mathrm{~J}$ $=7.0 \mathrm{~Hz}, 4 \mathrm{H}), 1.57(\mathrm{t}, \mathrm{J}=6.6 \mathrm{~Hz}, 2 \mathrm{H}), 1.23(\mathrm{dd}, \mathrm{J}=14.3,6.8 \mathrm{~Hz}, 12 \mathrm{H}), 1.03(\mathrm{dd}, \mathrm{J}=7.0,2.7 \mathrm{~Hz}$, 12H), $0.96(\mathrm{~s}, 12 \mathrm{H}) .{ }^{11} \mathrm{~B}$ NMR (128 MHz, benzene- $\left.d_{6}\right) \delta 35.27 \mathrm{ppm} .{ }^{13} \mathrm{C}$ NMR (101 MHz, benzene$\left.d_{6}\right) \delta 185.37$ ( $\left.\mathrm{C}_{\text {carbene }}\right), 169.38,156.95,145.61,143.22,135.31,130.42,124.59,124.23,122.00$, $120.45,81.82,29.70,28.97,25.15,24.94,23.73,23.67,20.99,16.01(b r)$.

2h - IPrCuI(CH( $\left.{ }^{\mathrm{P}-\mathrm{CO}_{2} \mathrm{Me}} \mathbf{P h}\right) \mathbf{C H}$ Bpin): Yield: $62 \mathrm{mg}(0.08 \mathrm{mmol}, 44 \%) .{ }^{1} \mathrm{H}$ NMR (400 MHz, benzene-d6) $\delta 7.29(\mathrm{t}, \mathrm{J}=7.8 \mathrm{~Hz}, 2 \mathrm{H}), 7.14(\mathrm{dd}, \mathrm{J}=7.7,3.1 \mathrm{~Hz}, 4 \mathrm{H}), 6.81(\mathrm{~d}, \mathrm{~J}=8.6 \mathrm{~Hz}, 2 \mathrm{H}), 6.72$ $(\mathrm{d}, \mathrm{J}=8.5 \mathrm{~Hz}, 2 \mathrm{H}), 6.20(\mathrm{~s}, 2 \mathrm{H}), 2.51(\mathrm{dp}, \mathrm{J}=13.7,7.2 \mathrm{~Hz}, 5 \mathrm{H}), 1.85$ (s, 3H), 1.61 (d, J = 5.4 Hz, 2H), $1.32(\mathrm{dd}, \mathrm{J}=9.9,6.9 \mathrm{~Hz}, 12 \mathrm{H}), 1.09$ (dd, J = 6.9, $1.8 \mathrm{~Hz}, 12 \mathrm{H}), 0.98(\mathrm{~s}, 12 \mathrm{H}) .{ }^{13} \mathrm{C} \mathrm{NMR}(151$ MHz, benzene- $\left.d_{6}\right) \delta 184.77,168.11,164.89,145.49,135.13,130.57,130.02,124.19,122.99$, 122.18, 117.96, 82.03, 28.93, 25.12, 25.09, 24.90, 24.86, 23.74, 23.70. ${ }^{11} \mathrm{~B}$ NMR (128 Hz, benzene- $\left.d_{6}\right) \delta 34.70 \mathrm{ppm}$.

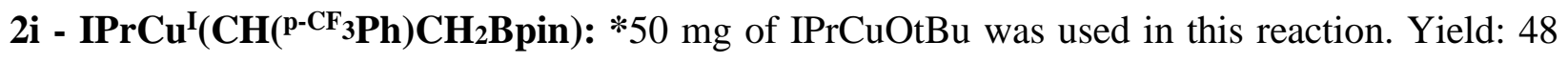
mg (0.06 mmol, 67\%). ${ }^{1} \mathrm{H}$ NMR (400 MHz, benzene- $\left.d_{6}\right) \delta 7.24(\mathrm{t}, \mathrm{J}=7.8 \mathrm{~Hz}, 2 \mathrm{H}), 7.19(\mathrm{~d}, \mathrm{~J}=8.2$ $\mathrm{Hz}, 2 \mathrm{H}), 7.06-7.00(\mathrm{~m}, 4 \mathrm{H}), 6.68-6.63(\mathrm{~m}, 2 \mathrm{H}), 6.17(\mathrm{~s}, 2 \mathrm{H}), 2.65(\mathrm{t}, \mathrm{J}=7.5 \mathrm{~Hz}, 1 \mathrm{H}), 2.42$ (dp, $\mathrm{J}=8.6,6.8 \mathrm{~Hz}, 4 \mathrm{H}), 1.57(\mathrm{~d}, \mathrm{~J}=2.0 \mathrm{~Hz}, 1 \mathrm{H}), 1.55(\mathrm{~s}, 1 \mathrm{H}), 1.25(\mathrm{~d}, \mathrm{~J}=6.9 \mathrm{~Hz}, 6 \mathrm{H}), 1.21(\mathrm{~d}, \mathrm{~J}=$ $6.9 \mathrm{~Hz}, 6 \mathrm{H}), 1.04(\mathrm{dd}, \mathrm{J}=6.9,1.6 \mathrm{~Hz}, 12 \mathrm{H}), 0.97(\mathrm{~s}, 12 \mathrm{H}) .{ }^{13} \mathrm{C}$ NMR: (101 MHz, benzene- $\left.d_{6}\right) \delta$ 184.8, 163.4, 145.5, 135.1, 130.5, 124.7, 124.2, 124.1, 123.3, 122.1, 82.0, 32.2, 28.9, 25.0, 24.9, 23.7, 23.6, 14.7. ${ }^{11} \mathrm{~B}$ NMR (128 Hz, benzene- $\left.d_{6}\right): 33.43$ ppm. ${ }^{19} \mathrm{~F}$ NMR (376 MHz, benzene- $\left.d_{6}\right): \delta$ $-59.85 \mathrm{ppm}$.

2j - IPrCu(I)(CHPhCH(CH3)Bpin). Yield: $88 \mathrm{mg}(0.12 \mathrm{mmol}, 67 \%) .{ }^{1} \mathrm{H}$ NMR (400 MHz, benzene- $\left.d_{6}\right) \delta 7.23(\mathrm{t}, J=7.7 \mathrm{~Hz}, 2 \mathrm{H}), 7.09-7.04(\mathrm{~m}, 4 \mathrm{H}), 7.00(\mathrm{t}, J=7.6 \mathrm{~Hz}, 2 \mathrm{H}), 6.84(\mathrm{~d}, J=$ $7.9 \mathrm{~Hz}, 2 \mathrm{H}), 6.75(\mathrm{t}, J=7.1 \mathrm{~Hz}, 1 \mathrm{H}), 6.22(\mathrm{~s}, 2 \mathrm{H}), 2.65-2.48(\mathrm{~m}, 6 \mathrm{H}), 2.05-1.92(\mathrm{~m}, 1 \mathrm{H}), 1.32$ $-1.27(\mathrm{~m}, 15 \mathrm{H}), 1.07(\mathrm{~d}, J=6.9 \mathrm{~Hz}, 12 \mathrm{H}), 0.99(\mathrm{~d}, J=5.6 \mathrm{~Hz}, 12 \mathrm{H}) .{ }^{13} \mathrm{C} \mathrm{NMR}(101 \mathrm{MHz}$, benzene- $\left.d_{6}\right) \delta 185.74,156.87,145.61,145.55,135.55,130.29,128.30,128.18,128.06,127.94$, 127.82, 127.73, 126.02, 124.21, 124.16, 122.06, 117.51, 81.74, 41.90, 28.95, 28.93, 25.57, 24.99, 24.85, 23.90, 19.77, 14.29. ${ }^{11} \mathrm{~B}$ NMR (128 MHz, benzene-d6) $\delta 34.93 \mathrm{ppm}$. 
2k - IPrCu(I)(CHPhCHPhBpin). Yield $108 \mathrm{mg}(0.14 \mathrm{mmol}, 75 \%){ }^{1} \mathrm{H}$ NMR ${ }^{1} \mathrm{H}$ NMR (400 MHz, benzene- $\left.d_{6}\right) \delta 7.49(\mathrm{~d}, J=8.3 \mathrm{~Hz}, 2 \mathrm{H}), 7.21(\mathrm{t}, J=7.8 \mathrm{~Hz}, 2 \mathrm{H}), 7.07-6.98(\mathrm{~m}, 6 \mathrm{H}), 6.87-6.75$ $(\mathrm{m}, 3 \mathrm{H}), 6.70(\mathrm{~d}, J=6.7 \mathrm{~Hz}, 2 \mathrm{H}), 6.58-6.50(\mathrm{~m}, 1 \mathrm{H}), 6.22(\mathrm{~s}, 2 \mathrm{H}), 3.52(\mathrm{~d}, J=11.4 \mathrm{~Hz}, 1 \mathrm{H})$, $3.10(\mathrm{~d}, J=11.4 \mathrm{~Hz}, 1 \mathrm{H}), 2.57(\mathrm{ddq}, J=10.0,6.8,3.4 \mathrm{~Hz}, 4 \mathrm{H}), 1.34(\mathrm{dd}, J=14.0,6.8 \mathrm{~Hz}, 12 \mathrm{H})$, $1.07(\mathrm{dd}, J=6.9,1.8 \mathrm{~Hz}, 12 \mathrm{H}), 0.91(\mathrm{~s}, 6 \mathrm{H}), 0.86(\mathrm{~s}, 6 \mathrm{H}) .{ }^{13} \mathrm{C}$ NMR (101 MHz, benzene- $\left.d_{6}\right) \delta$ $185.61,154.85,147.17,145.40,145.38,135.56,130.43$, 129.47, 128.30, 128.06, 127.94, 127.82, $127.70,127.60,126.15,124.28,124.23,123.78,122.30,117.42,82.00,37.06,29.00,28.95,25.24$, 24.91, 24.83, 24.64, 23.85, 23.83. ${ }^{11} \mathrm{~B}$ NMR (128 MHz, benzene- $\left.d_{6}\right) \delta 33.55 \mathrm{ppm}$.

Synthesis of 3a-3f: Under an atmosphere of $\mathrm{N}_{2}$, a Schlenk flask equipped with a magnetic stir bar was charged with 1 equiv. of $\mathrm{IPrCuO}^{t} \mathrm{Bu}(100 \mathrm{mg}, 0.190 \mathrm{mmol})$ and 1.1 equiv. $\mathrm{B}_{2}$ pin 2 (54 mg, 0.21 $\mathrm{mmol})$ in $10 \mathrm{~mL}$ of benzene. 1.1 equiv. of the appropriate styrene $(0.21 \mathrm{mmol})$ was added to the reaction vessel. Using Schlenk line techniques, the reaction underwent 3 freeze/pump/thaw cycles to remove the headspace as well as any dissolved nitrogen gas. After evacuation, 1 atmosphere of dry $\mathrm{CO}_{2}$ gas was added, and the reaction stirred at ambient temperature for 16 hours. The resulting suspensions underwent 2 additional freeze/pump/thaw cycles before returning to the glovebox. The solvent was removed in vacuo, and the resulting compounds were washed with $n$-pentane and collected on a fine porosity glass frit as white solids.

3a - IPrCu$\left.{ }^{\mathrm{I}}\left(\left(\mathbf{C O}_{2}\right) \mathbf{C H P h C H} 2 \mathbf{B p i n}\right)\right)$ : Yield: $99 \mathrm{mg}(0.14 \mathrm{mmol}, 72 \%) .{ }^{1} \mathrm{H} \mathrm{NMR}(400 \mathrm{MHz}$, dichloromethane- $\left.d_{2}\right) \delta(\mathrm{ppm}) 7.50(\mathrm{t}, \mathrm{J}=7.8 \mathrm{~Hz}, 2 \mathrm{H}), 7.35(\mathrm{~d}, \mathrm{~J}=6.4 \mathrm{~Hz}, 4 \mathrm{H}), 7.24(\mathrm{~d}, \mathrm{~J}=5.0 \mathrm{~Hz}$, 2H), $7.20(\mathrm{~d}, \mathrm{~J}=7.4 \mathrm{~Hz}, 1 \mathrm{H}), 7.12-7.06(\mathrm{~m}, 2 \mathrm{H}), 2.78(\mathrm{t}, \mathrm{J}=8.8 \mathrm{~Hz}, 1 \mathrm{H}), 2.56$ (p, J = 7.0 Hz, $4 \mathrm{H}), 1.27(\mathrm{dd}, \mathrm{J}=26.6,6.8 \mathrm{~Hz}, 21 \mathrm{H}), 0.85(\mathrm{~d}, \mathrm{~J}=7.0 \mathrm{~Hz}, 10 \mathrm{H}), 0.55-0.45(\mathrm{~m}, 2 \mathrm{H}) .{ }^{13} \mathrm{C} \mathrm{NMR}$ $\left(101 \mathrm{MHz}\right.$, dichloromethane- $\left.d_{2}\right) \delta 146.2,134.9,131.3,128.7,128.3,125.9,125.0,124.9,124.3$, 81. 3, 54.4, 54.2, 54.0, 53.8, 53.6, 49.7, 29.4, 25.4, 25.3, 25.0, 24.3, 24.3. ${ }^{11} \mathrm{~B}$ NMR (128 MHz, dichloromethane- $\left.d_{2}\right) \delta(\mathrm{ppm}) 13.9$. IR $v\left(\mathrm{KBr}\right.$ pellet): $1711 \mathrm{~cm}^{-1}$. Elemental analysis was attempted with three independent samples, and data consistent with the expected values were not obtained, likely due to extreme oxygen- and water sensitivity. Anal. Calcd.: C, 69.36; H, 7.76; N, 3.85. Found (avg of three samples): C, 65.8; H, 7.38; N, 3.56. Colorless single crystals suitable for X- 
ray analysis were obtained by slow diffusion of $n$-pentane into a concentration dichloromethane solution at $-35^{\circ} \mathrm{C}$.

3b - IPrCu${ }^{\mathrm{I}}\left(\left(\mathbf{C O}_{2}\right) \mathbf{C H}\left(\mathbf{P N M e}_{2} \mathbf{P h}\right) \mathbf{C H}_{2}\right.$ Bpin) $)$ : Yield: $99 \mathrm{mg}(0.13 \mathrm{mmol}, 68 \%) .{ }^{1} \mathrm{H}$ NMR (400 $\mathrm{MHz}$, dichloromethane- $\left.d_{2}\right) \delta 7.52(\mathrm{t}, \mathrm{J}=7.8 \mathrm{~Hz}, 2 \mathrm{H}), 7.36(\mathrm{~d}, \mathrm{~J}=7.7 \mathrm{~Hz}, 4 \mathrm{H}), 7.26(\mathrm{~s}, 2 \mathrm{H}), 6.95$ $(\mathrm{d}, \mathrm{J}=8.4 \mathrm{~Hz}, 2 \mathrm{H}), 6.68-6.61(\mathrm{~m}, 2 \mathrm{H}), 2.89(\mathrm{~s}, 6 \mathrm{H}), 2.68(\mathrm{t}, \mathrm{J}=8.8 \mathrm{~Hz}, 1 \mathrm{H}), 2.57$ (hept, $\mathrm{J}=7.0$ $\mathrm{Hz}, 4 \mathrm{H}), 1.31(\mathrm{~d}, \mathrm{~J}=6.9 \mathrm{~Hz}, 12 \mathrm{H}), 1.24(\mathrm{~d}, \mathrm{~J}=6.9 \mathrm{~Hz}, 12 \mathrm{H}), 0.85(\mathrm{~d}, \mathrm{~J}=6.0 \mathrm{~Hz}, 12 \mathrm{H}), 0.46$ (d, J $=8.8 \mathrm{~Hz}, 2 \mathrm{H}) .{ }^{13} \mathrm{C} \mathrm{NMR}\left(101 \mathrm{MHz}\right.$, dichloromethane- $\left.d_{2}\right) \delta 181.4,179.2,149.6,146.2,134.9$, $133.5,131.3,128.9,124.9,124.3,113.2,81.2,48.6,41.4,30.3,29.3,25.5,25.3,25.0,24.3 .{ }^{11} \mathrm{~B}$ NMR (128 MHz, dichloromethane- $\left.d_{2}\right): \delta(\mathrm{ppm})$ 13.73. IR $v\left(\mathrm{KBr}\right.$ pellet): $1699 \mathrm{~cm}^{-1}(\mathrm{C}=\mathrm{O})$.

3c - IPrCu$\left.{ }^{\mathrm{I}}\left(\left(\mathbf{C O}_{2}\right) \mathbf{C H}\left(\mathbf{p O C H}_{3} \mathbf{P h}\right) \mathbf{C H}_{2} \mathbf{B p i n}\right)\right)$ : Yield: $120 \mathrm{mg}(0.16 \mathrm{mmol}, 83 \%)$. ${ }^{1} \mathrm{H}$ NMR (400 MHz, dichloromethane- $\left.d_{2}\right) \delta 7.50(\mathrm{t}, \mathrm{J}=7.8 \mathrm{~Hz}, 2 \mathrm{H}), 7.35(\mathrm{~d}, \mathrm{~J}=7.7 \mathrm{~Hz}, 4 \mathrm{H}), 7.24(\mathrm{~s}, 2 \mathrm{H}), 7.02$ $(\mathrm{d}, \mathrm{J}=8.3 \mathrm{~Hz}, 2 \mathrm{H}), 6.76(\mathrm{~d}, \mathrm{~J}=8.5 \mathrm{~Hz}, 2 \mathrm{H}), 3.77$ (s, 3H), $2.72(\mathrm{t}, \mathrm{J}=8.8 \mathrm{~Hz}, 1 \mathrm{H}), 2.56$ (p, J = 6.9 $\mathrm{Hz}, 4 \mathrm{H}), 1.30(\mathrm{~d}, \mathrm{~J}=6.9 \mathrm{~Hz}, 12 \mathrm{H}), 1.24$ (d, J = 6.9 Hz, 12H), 0.85 (d, J = 6.9 Hz, 12H), 0.47 (d, J $=8.9 \mathrm{~Hz}, 2 \mathrm{H}) .{ }^{13} \mathrm{C}$ NMR (101 MHz, dichloromethane- $\left.d_{2}\right) \delta 181.0,179.2,158.1,146.2,137.1$, 134.9, 131.3, 129.4, 128.9, 124.9, 124.2, 113.6, 81.3, 55.7, 48.7, 30.3, 29.3, 25.4, 25.3, 25.0, 24.3. ${ }^{11} \mathrm{~B}$ NMR (400 MHz, dichloromethane- $\left.d_{2}\right) \delta(\mathrm{ppm})$ 14.32. IR $\vee\left(\mathrm{KBr}\right.$ pellet): $1709 \mathrm{~cm}^{-1}(\mathrm{C}=\mathrm{O})$.

3d -IPrCu${ }^{\mathrm{I}}\left(\left(\mathbf{C O}_{2}\right) \mathbf{C H}\left({ }^{\text {ptBu} P h}\right) \mathbf{C H}_{2}\right.$ Bpin $\left.)\right):$ Yield: $122 \mathrm{mg}(0.16 \mathrm{mmol}, 82 \%) .{ }^{1} \mathrm{H} \mathrm{NMR}(400 \mathrm{MHz}$, benzene- $d_{6} /$ dichloromethane- $\left.d_{2}\right) \delta 7.26(\mathrm{td}, J=7.8,1.4 \mathrm{~Hz}, 2 \mathrm{H}), 7.14(\mathrm{~s}, 4 \mathrm{H}), 7.12(\mathrm{~s}, 2 \mathrm{H}), 7.10$ $(\mathrm{t}, J=7.5 \mathrm{~Hz}, 2 \mathrm{H}), 6.50(\mathrm{~d}, J=1.6 \mathrm{~Hz}, 2 \mathrm{H}), 3.01(\mathrm{t}, J=8.6 \mathrm{~Hz}, 1 \mathrm{H}), 2.45-2.29(\mathrm{~m}, 4 \mathrm{H}), 1.27-$ $1.14(\mathrm{~m}, 21 \mathrm{H}), 1.08-0.96(\mathrm{~m}, 12 \mathrm{H}), 0.91-0.83(\mathrm{~m}, 12 \mathrm{H}), 0.78(\mathrm{dd}, J=14.4,7.8 \mathrm{~Hz}, 1 \mathrm{H}), 0.68$ - $0.60(\mathrm{~m}, 1 \mathrm{H}) .{ }^{13} \mathrm{C}$ NMR $\left(101 \mathrm{MHz}\right.$, benzene- $d_{6} /$ dichloromethane- $\left.d_{2}\right) \delta 180.0,147.6,145.3$, $141.8,134.2,130.6,127.8,127.7,124.5,80.7,48.8,33.9,31.1,28.5,24.9,24.8,24.4,23.5 .{ }^{11} \mathrm{~B}$ NMR (128 MHz, benzene-d $\mathrm{d}_{6} /$ dichloromethane- $\left.^{\mathrm{d} 2}\right) \delta 17.55$. IR $v(\mathrm{KBr}$ pellet $): 1707 \mathrm{~cm}^{-1}(\mathrm{C}=\mathrm{O})$.

3e - IPrCu${ }^{\mathrm{I}}\left(\left(\mathbf{C O}_{2}\right) \mathbf{C H}\left({ }^{\mathbf{p M e}} \mathbf{P h}\right) \mathbf{C H}_{2}\right.$ Bpin) $)$. Yield: $110 \mathrm{mg}(0.15 \mathrm{mmol}, 78 \%) .{ }^{1} \mathrm{H}$ NMR (400 MHz, dichloromethane- $\left.d_{2}\right) \delta 7.50(\mathrm{t}, J=7.8 \mathrm{~Hz}, 2 \mathrm{H}), 7.35(\mathrm{~d}, J=7.7 \mathrm{~Hz}, 4 \mathrm{H}), 7.24(\mathrm{~s}, 2 \mathrm{H}), 7.06-6.93$ (m, 4H), 2.73 (t, $J=8.8 \mathrm{~Hz}, 1 \mathrm{H}), 2.56$ (hept, $J=7.2 \mathrm{~Hz}, 4 \mathrm{H}), 2.29$ (s, 3H), 1.27 (dd, $J=25.9,6.9$ $\mathrm{Hz}, 24 \mathrm{H}), 0.85(\mathrm{~d}, J=7.1 \mathrm{~Hz}, 12 \mathrm{H}), 0.48(\mathrm{~d}, J=8.9 \mathrm{~Hz}, 2 \mathrm{H}) .{ }^{13} \mathrm{C} \mathrm{NMR}(101 \mathrm{MHz}$, dichloromethane- $\left.d_{2}\right) \delta 180.9,179.2,146.2,142.0,134.9,131.3,128.9,128.9,128.4,124.9,124.3$, 
81.3, 49.2, 29.3, 25.4, 25.3, 25.0, 24.3, 21.3. ${ }^{11}$ B NMR (128 MHz, dichloromethane- $\left.d_{2}\right) \delta 13.85$. IR $\vee\left(\mathrm{KBr}\right.$ pellet): $1717 \mathrm{~cm}^{-1}(\mathrm{C}=\mathrm{O})$.

3f - IPrCu $\left.{ }^{\mathrm{I}}\left(\left(\mathbf{C O}_{2}\right) \mathbf{C H}\left({ }^{\left({ }^{F}\right.} \mathbf{P h}\right) \mathbf{C H}_{2} \mathbf{B p i n}\right)\right)$. Yield: $59 \mathrm{mg}(0.08 \mathrm{mmol}, 42 \%) .{ }^{1} \mathrm{H}$ NMR $(400 \mathrm{MHz}$, dichloromethane- $\left.d_{2}\right) \delta 7.48(\mathrm{t}, J=7.8 \mathrm{~Hz}, 2 \mathrm{H}), 7.34(\mathrm{~s}, 4 \mathrm{H}), 7.24(\mathrm{~s}, 2 \mathrm{H}), 7.11(\mathrm{dd}, J=8.4,5.6$ $\mathrm{Hz}, 2 \mathrm{H}), 6.91(\mathrm{t}, J=8.8 \mathrm{~Hz}, 2 \mathrm{H}), 2.78(\mathrm{t}, J=9.0 \mathrm{~Hz}, 1 \mathrm{H}), 2.55(\mathrm{p}, J=7.0 \mathrm{~Hz}, 4 \mathrm{H}), 1.29$ (d, $J=$ $6.9 \mathrm{~Hz}, 12 \mathrm{H}), 1.23(\mathrm{~d}, J=6.8 \mathrm{~Hz}, 12 \mathrm{H}), 0.85$ (d, $J=7.0 \mathrm{~Hz}, 12 \mathrm{H}), 0.49$ (q, $J=7.1,5.8 \mathrm{~Hz}, 2 \mathrm{H})$. ${ }^{13} \mathrm{C}$ NMR (101 MHz, dichloromethane- $d_{2}$ ) $\delta 162.8,160.4,146.2,140.6,134.9,131.3,130.1,130.0$, $124.9,124.3,114.8,114.6,81.4,48.7,29.3,25.4,25.3,25.0,24.3$. The resonance associated with the methylene carbon is not detectable, most likely due to its proximity to quadrapolar boron. ${ }^{11} \mathrm{~B}$ NMR (128 MHz, dichloromethane- $\left.d_{2}\right) \delta 14.55 \mathrm{ppm} .{ }^{19} \mathrm{~F}$ NMR (376 MHz, dichloromethane- $\left.d_{2}\right) \delta$ $-119.44 \mathrm{ppm}$. IR $\vee\left(\mathrm{KBr}\right.$ pellet): $1709.3 \mathrm{~cm}^{-1}(\mathrm{C}=\mathrm{O})$.

Complexes $\mathbf{3 g}-\mathbf{3 i}$ were synthesized similarly to the general procedure. However, the addition of 1.0 equivalent $\mathrm{PPh}_{3}$ was necessary to achieve synthetically reasonable reaction times.

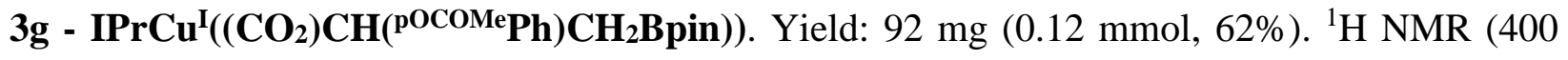
MHz, benzene- $d_{6} /$ dichloromethane- $\left.d_{2}\right) \delta 7.71(\mathrm{t}, J=7.7 \mathrm{~Hz}, 2 \mathrm{H}), 7.57(\mathrm{t}, J=7.2 \mathrm{~Hz}, 4 \mathrm{H}), 7.51(\mathrm{~d}$, $J=8.3 \mathrm{~Hz}, 2 \mathrm{H}), 7.24(\mathrm{~s}, 2 \mathrm{H}), 3.20(\mathrm{t}, J=8.7 \mathrm{~Hz}, 1 \mathrm{H}), 2.80(\mathrm{dt}, J=13.6,6.8 \mathrm{~Hz}, 4 \mathrm{H}), 2.42(\mathrm{~s}, 3 \mathrm{H})$, $1.59(\mathrm{~d}, J=6.8 \mathrm{~Hz}, 12 \mathrm{H}), 1.47(\mathrm{~d}, J=6.8 \mathrm{~Hz}, 12 \mathrm{H}), 1.17(\mathrm{~d}, J=6.0 \mathrm{~Hz}, 12 \mathrm{H}), 0.90(\mathrm{~d}, J=8.7 \mathrm{~Hz}$, $2 \mathrm{H}) .{ }^{13} \mathrm{C}$ NMR (101 MHz, benzene- $d_{6} /$ dichloromethane- $\left.d_{2}\right) \delta 180.11$ ( $\left.\mathrm{C}_{\mathrm{CO} 2}\right), 178.90$ ( $\left.\mathrm{C}_{\text {carbene }}\right)$, 169.74(Сосоме), 149.01, 145.85, 142.23, 134.60, 131.09, 129.31, 124.65, 123.79, 121.13, 81.09, 53.52, 48.74, 29.05, 25.20, 25.11, 24.86, 24.00, 21.09. ${ }^{11} \mathrm{~B}$ NMR (128 MHz, benzene$d_{6} /$ dichloromethane- $\left.d_{2}\right) \delta 11.23 \mathrm{ppm}$. IR $v(\mathrm{KBr}$ pellet $) 1710 \mathrm{~cm}^{-1}(\mathrm{C}=\mathrm{O}$, carboxylate $), 1762 \mathrm{~cm}^{-1}$ $(\mathrm{C}=\mathrm{O}$, ester).

3h - IPrCu$\left.\left(\left(\mathbf{C O}_{2}\right) \mathbf{C H}\left({ }^{\text {pCOOMePh}}\right) \mathbf{C H}_{2} \mathbf{B p i n}\right)\right)$. Yield: $111 \mathrm{mg}(0.14 \mathrm{mmol}, 74 \%) .{ }^{1} \mathrm{H}$ NMR (600 $\mathrm{MHz}$, dichloromethane- $\left.d_{2}\right) \delta 7.89(\mathrm{dd}, J=8.1,5.9 \mathrm{~Hz}, 2 \mathrm{H}), 7.47(\mathrm{t}, J=7.8 \mathrm{~Hz}, 2 \mathrm{H}), 7.34(\mathrm{t}, J=$ $9.0 \mathrm{~Hz}, 4 \mathrm{H}), 7.25$ (s, 2H), $7.22(\mathrm{~d}, J=8.0 \mathrm{~Hz}, 2 \mathrm{H}), 3.88$ (s, 3H), 2.84 (t, $J=9.0 \mathrm{~Hz}, 1 \mathrm{H}), 2.56$ (h, $J=6.8 \mathrm{~Hz}, 4 \mathrm{H}), 1.30(\mathrm{~d}, J=10.9 \mathrm{~Hz}, 12 \mathrm{H}), 1.24(\mathrm{~d}, J=6.8 \mathrm{~Hz}, 12 \mathrm{H}), 0.86(\mathrm{~d}, J=12.3 \mathrm{~Hz}, 12 \mathrm{H})$, $0.55(\mathrm{qd}, J=14.1,8.9 \mathrm{~Hz}, 2 \mathrm{H}) .{ }^{13} \mathrm{C}$ NMR $\left(151 \mathrm{MHz}\right.$, dichloromethane- $\left.d_{2}\right) \delta 179.73\left(\mathrm{C}_{\mathrm{CO} 2}\right)$, 
179.08( $\left.\mathrm{C}_{\text {carbene }}\right), 167.65$ ( $\left.\mathrm{C}_{\text {(O2Me }}\right), 150.36,146.22,134.92,131.31,129.53,128.66,127.97,124.84$, $124.31,81.47,52.26,49.58,29.35,25.40,25.30,25.05,24.33,24.29 .{ }^{11} \mathrm{~B}$ NMR (128 MHz, dichloromethane- $\left.d_{2}\right) \delta 12.20 \mathrm{ppm}$. IR $v$ (KBr pellet) $1719 \mathrm{~cm}^{-1}$ (overlapping).

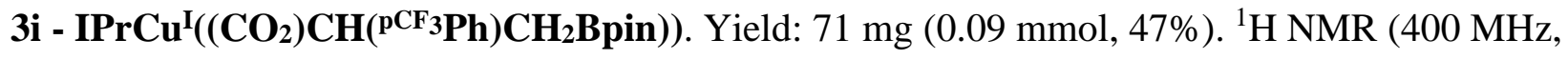
dichloromethane- $\left.d_{2}\right) \delta 7.51-7.39(\mathrm{~m}, 4 \mathrm{H}), 7.35-7.24(\mathrm{~m}, 6 \mathrm{H}), 7.23(\mathrm{~s}, 2 \mathrm{H}), 2.80(\mathrm{t}, \mathrm{J}=9.0 \mathrm{~Hz}$, 1H), 2.52 (hept, $\mathrm{J}=7.1 \mathrm{~Hz}, 4 \mathrm{H}), 1.26(\mathrm{~d}, \mathrm{~J}=6.9 \mathrm{~Hz}, 12 \mathrm{H}), 1.21(\mathrm{~d}, \mathrm{~J}=6.9 \mathrm{~Hz}, 12 \mathrm{H}), 0.82(\mathrm{~d}, \mathrm{~J}=$ $8.2 \mathrm{~Hz}, 12 \mathrm{H}), 0.56-0.45(\mathrm{~m}, 2 \mathrm{H}) .{ }^{13} \mathrm{C}$ NMR $\left(101 \mathrm{MHz}\right.$, dichloromethane- $\left.d_{2}\right) \delta 179.69,148.99$, 146.20, 134.85, 131.24, 128.93, 125.09, 124.93, 124.79, 124.28, 81.44, 54.27, 49.26, 29.29, 25.32, $25.22,25.05,24.22$. The methylene carbon is not visible in ${ }^{13} \mathrm{C}$ NMR as it is broad due to the quadrapolar nature of the adjacent boron. ${ }^{19} \mathrm{~F}$ NMR $\left(376 \mathrm{MHz}\right.$, dichloromethane- $\left.d_{2}\right) \delta-62.34 .{ }^{11} \mathrm{~B}$ NMR (128 MHz, dichloromethane- $\left.d_{2}\right) \delta 12.50$. IR $v(\mathrm{KBr}$ pellet $) 1708 \mathrm{~cm}^{-1}(\mathrm{C}=\mathrm{O})$.

3j - IPrCu((CO) $)$ CHPhCH(CH3)Bpin)). Yield: $95 \mathrm{mg}(0.13 \mathrm{mmol}, 67 \%) .{ }^{1} \mathrm{H}$ NMR (400 MHz, dichloromethane- $\left.d_{2}\right) \delta{ }^{1} \mathrm{H} \mathrm{NMR}\left(400 \mathrm{MHz}\right.$, methylene chloride- $\left.d_{2}\right) \delta 7.51(\mathrm{dt}, J=7.7,3.9 \mathrm{~Hz}, 2 \mathrm{H})$, 7.37 (q, $J=6.3,5.6 \mathrm{~Hz}, 5 \mathrm{H}), 7.27$ (d, $J=7.3 \mathrm{~Hz}, 3 \mathrm{H}), 7.26-7.19$ (m, 2H), $7.19-7.11(\mathrm{~m}, 1 \mathrm{H})$, $7.01(\mathrm{~d}, J=7.2 \mathrm{~Hz}, 1 \mathrm{H}), 6.93(\mathrm{~d}, J=8.9 \mathrm{~Hz}, 1 \mathrm{H}), 2.68-2.48(\mathrm{~m}, 5 \mathrm{H}), 1.37-1.28(\mathrm{~m}, 15 \mathrm{H}), 1.26$ $-1.20(\mathrm{~m}, 15 \mathrm{H}), 0.86(\mathrm{~d}, J=6.8 \mathrm{~Hz}, 6 \mathrm{H}), 0.80(\mathrm{~s}, 6 \mathrm{H}), 0.51(\mathrm{~s}, 2 \mathrm{H}), 0.03(\mathrm{~d}, J=7.5 \mathrm{~Hz}, 2 \mathrm{H}) \cdot{ }^{13} \mathrm{C}$ NMR (101 MHz, dichloromethane- $\left.d_{2}\right) \delta 179.47,179.25,145.62,142.51,140.34,134.44,130.69$, 129.71, 128.76, 127.53, 127.19, 125.37, 125.21, 124.41, 124.29, 123.84, 123.65, 80.48, 80.28, $30.49,29.48,28.75,25.20,25.10,24.91,24.77,24.39,24.22,23.84,14.92,13.27 .{ }^{11}$ B NMR (128 $\mathrm{MHz}$, dichloromethane- $\left.d_{2}\right) \delta 11.21$. IR $v\left(\mathrm{KBr}\right.$ pellet, THF film) $1701 \mathrm{~cm}^{-1}(\mathrm{C}=\mathrm{O})$.

3k - IPrCu((CO) $)$ CHPhCHPhBpin)). Yield: $103 \mathrm{mg}(0.13 \mathrm{mmol}, 67 \%) .{ }^{1} \mathrm{H}$ NMR (400 MHz, dichloromethane- $\left.d_{2}\right) \delta 7.53(\mathrm{t}, J=7.8 \mathrm{~Hz}, 3 \mathrm{H}), 7.45-7.37(\mathrm{~m}, 5 \mathrm{H}), 7.36(\mathrm{~s}, 3 \mathrm{H}), 7.30(\mathrm{~s}, 2 \mathrm{H})$, $7.26-7.10(\mathrm{~m}, 4 \mathrm{H}), 7.00(\mathrm{t}, J=7.5 \mathrm{~Hz}, 2 \mathrm{H}), 6.91(\mathrm{~d}, J=7.9 \mathrm{~Hz}, 3 \mathrm{H}), 6.78(\mathrm{~d}, J=7.7 \mathrm{~Hz}, 2 \mathrm{H})$, $3.69(\mathrm{~d}, J=12.9 \mathrm{~Hz}, 1 \mathrm{H}), 2.63(\mathrm{~h}, J=6.9 \mathrm{~Hz}, 5 \mathrm{H}), 1.92(\mathrm{~d}, J=13.0 \mathrm{~Hz}, 1 \mathrm{H}), 1.46-1.18(\mathrm{~m}, 34 \mathrm{H})$, $0.62(\mathrm{~s}, 7 \mathrm{H}), 0.51$ (s, 7H). ${ }^{11} \mathrm{~B}$ NMR (128 MHz, dichloromethane- $\left.d_{2}\right) \delta 8.94$. 
Carboxylation Kinetics: The following procedure was used in performing kinetic experiments for the carboxylation of $\mathrm{Cu}^{\mathrm{I}}\left(\beta\right.$-borylbenzyl) complexes. In a $\mathrm{N}_{2}$-filled glovebox, $5 \mathrm{mg}$ of each $\mathrm{Cu}^{\mathrm{I}}\left(\beta\right.$-borylbenzyl) complex (2a-2i) was dissolved in $\mathrm{C}_{6} \mathrm{D}_{6}$ and combined with $20 \mathrm{~mol} \%$ of mesitylene as an internal standard $\left(0.1 \mathrm{M}\right.$ in $\left.\mathrm{C}_{6} \mathrm{D}_{6}\right)$ to produce a $10 \mathrm{mM}$ sample. The sample was transferred to a J. Young NMR tube and was removed from the glovebox. The NMR tube was attached to a Schlenk line, and the sample was freeze/pump/thawed twice. The sample was then cooled to $-20^{\circ} \mathrm{C}(1: 3 \mathrm{NaCl} /$ ice bath), and the evacuated headspace was filled with $1 \mathrm{~atm}$ of dry $\mathrm{CO}_{2}$. The tube was sealed and kept frozen until loading into the NMR instrument. Spectra were then collected at consistent intervals for the duration of the reaction.

X-Ray Crystallography: Single crystals suitable for X-ray diffraction were coated with polybutene oil (Sigma-Aldrich), placed on a MiTeGen nylon loop, and then quickly mounted on the goniometer head of a Bruker AXS D8 Venture fix-chi X-ray diffractometer equipped with a Triumph monochromator, a Mo K $\alpha$ radiation source ( $\mathrm{I}=0.71073 \AA$ ), and a PHOTON $100 \mathrm{CMOS}$ detector. Samples were cooled to $100 \mathrm{~K}$ with an Oxford Cryostream 700 system and optically aligned. Three sets of 12 frames each were collected using the omega scan method with a 10 second exposure time. Integration of these frames followed by reflection indexing and least-squares refinement produced a crystal orientation matrix for the monoclinic crystal lattice that was used for the structural analysis. The APEX3 software program (version 2016.9-0) ${ }^{101}$ was used for diffractometer control, preliminary frame scans, indexing, orientation matrix calculations, leastsquares refinement of cell parameters, and the data collection. The frames were integrated with the Bruker SAINT software package using a narrow-frame algorithm. Data were corrected for absorption effects using the multi-scan method (SADABS). The structure was solved by direct methods and difference Fourier analysis using the programs provided by SHELXL-2014/7.2. ${ }^{102}$

101. APEX3: Crystallographic Software Package for Single Crystal Data Collection, Reduction and Preparation, version 2016.9-0; Bruker AXS: Madison, WI, 2016.

102. Sheldrick, G. M. SHELXL-2014: Crystallographic Software Package; Bruker AXS, Inc.: Madison, WI, 2014. 
Computational Methods: All calculations were performed using the Gaussian 16 package. ${ }^{103}$ Initial benchmarking experiments utilized B3LYP, ${ }^{104}$ M06, ${ }^{105}$ and B97D $3{ }^{106}$ functionals. For subsequent ground state and transition state geometry optimizations, the M06 and the Pople basis sets $6-311+\mathrm{G}^{*}$ for copper and $6-311 \mathrm{G}^{*}$ for all other atoms were used. ${ }^{107}$ Frequency calculations at the same level of theory in each case were performed to validate stationary points, with zero imaginary frequencies reflecting ground state minima and one imaginary frequency representing transition state minima. Transition states were further validated through intrinsic reaction coordinate (IRC) calculations, using the TS structure as starting point. ${ }^{108}$ Single-point selfconsistent reaction field calculations (SCRF) were also performed to identify solvent effects using the SMD model. ${ }^{109}$ Benzene was used in solvent calculations to reflect the experimental conditions in the kinetic studies. JMol was used to generate optimized molecular structures. ${ }^{110}$

103. Gaussian 16, Revision B.01, M. J. Frisch, G. W. Trucks, H. B. Schlegel, G. E. Scuseria, M. A. Robb, J. R. Cheeseman, G. Scalmani, V. Barone, G. A. Petersson, H. Nakatsuji, X. Li, M. Caricato, A. V. Marenich, J. Bloino, B. G. Janesko, R. Gomperts, B. Mennucci, H. P. Hratchian, J. V. Ortiz, A. F. Izmaylov, J. L. Sonnenberg, D. WilliamsYoung, F. Ding, F. Lipparini, F. Egidi, J. Goings, B. Peng, A. Petrone, T. Henderson, D. Ranasinghe, V. G. Zakrzewski, J. Gao, N. Rega, G. Zheng,W. Liang, M. Hada, M. Ehara, K. Toyota, R. Fukuda, J. Hasegawa, M. Ishida, T. Nakajima, Y. Honda, O. Kitao, H. Nakai, T. Vreven, K. Throssell, J. A. Montgomery, Jr., J. E. Peralta, F. Ogliaro, M. J. Bearpark, J. J. Heyd, E. N. Brothers, K. N. Kudin, V. N. Staroverov, T. A. Keith, R. Kobayashi, J. Normand, K. Raghavachari, A. P. Rendell, J. C. Burant, S. S. Iyengar, J. Tomasi, M. Cossi, J. M. Millam, M. Klene, C. Adamo, R. Cammi, J. W. Ochterski, R. L. Martin, K. Morokuma, O. Farkas, J. B. Foresman, and D. J. Fox, Gaussian, Inc., Wallingford CT, 2016.

104. (a) Becke, A. D. Density Functional Calculations of Molecular Bond Energies. J. Chem. Phys. 1986, 84, 45244529. (b) Becke, A. D. Density-Functional Thermochemistry. III. The Role of Exact Exchange. J. Chem. Phys. 1993, 98, 5648-5652.

105. (a) McLean, A. D.; Chandler, G. S. Contracted Gaussian-basis sets for molecular calculations. 1. 2nd row atoms, Z=11-18. J. Chem. Phys. 1980, 72, 5639-5648. (b) Raghavachari, K.; Binkley, J. S.; Seeger, R.; Pople, J. A. SelfConsistent Molecular Orbital Methods. 20. Basis set for correlated wave-functions," J. Chem. Phys. 1980, 72, 6506554.

106. Chai, D.; Head-Gordon; M. Long-range Corrected Hybrid Density Functionals with Damped Atom-Atom Dispersion Corrections. Phys. Chem. Chem. Phys. 2008, 10, 6615-20.

107. (a) Wachters, A. J. H. Gaussian Basis Set for Molecular Wavefunctions Containing Third-row Atoms. J. Chem. Phys., 1970, 52, 1033. (b) Hay, P. J. Gaussian Basis sets for Molecular Calculations - Representation of 3D Orbitals in Transition-metal Atoms. J. Chem. Phys., 1977, 66, 4377-4384. (c) Raghavachari, K.; Trucks, G. W. Highly correlated systems: Excitation Energies of First Row Transition Metals Sc-Cu. J. Chem. Phys., 1989, 91, $1062-65$. 108. (a) Fukui, K. Formulation of the Reaction Coordinate. J. Phys. Chem. 1970, 74, 4161-4163. (b) Fukui, K. The Path of Chemical Reactions - the IRC Approach. Acc. Chem. Res. 1981, 14, 363-368.

109. Marenich, A. V.; Cramer, C. J.; Truhlar, D. G. Universal solvation model based on solute electron density and a continuum model of the solvent defined by the bulk dielectric constant and atomic surface tensions. J. Phys. Chem. B. 2009, 113, 6378-96.

110. Jmol: an open-source Java viewer for chemical structures in 3D. http://www.jmol.org/ 


\section{CHAPTER 3}

\section{Experimental and Computational Analysis of Additive Effects in Copper- Facilitated Boracarboxylation of Vinyl Arenes}

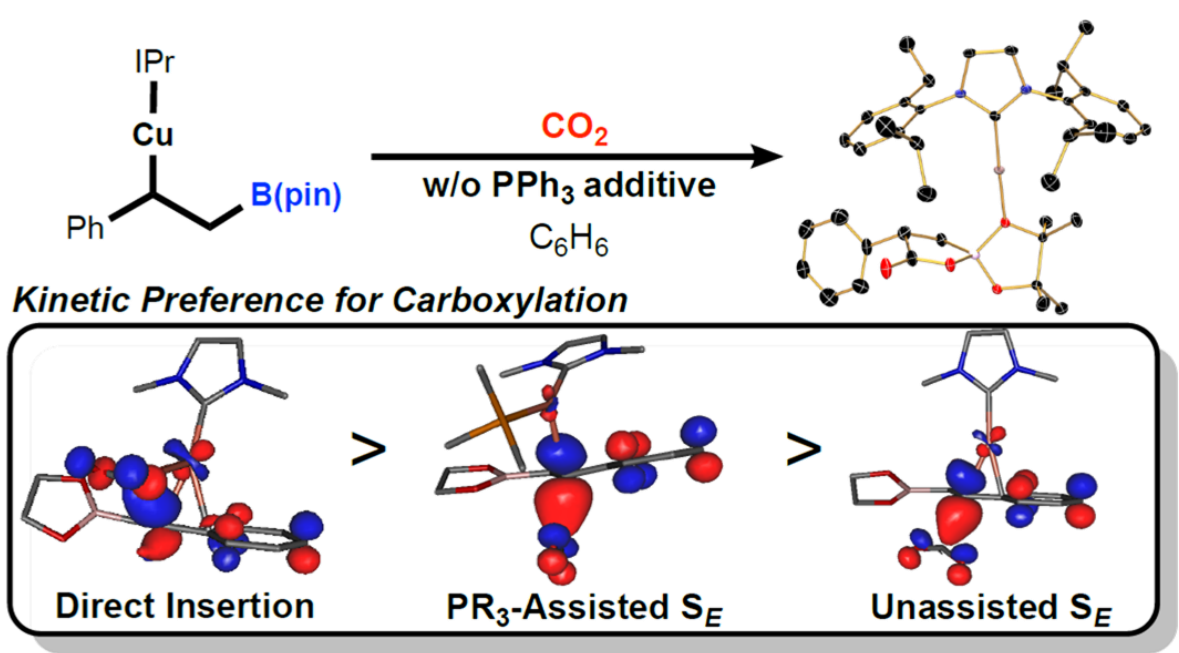

\subsection{Abstract}

Kinetically sluggish stoichiometric carboxylation of electron-poor $\operatorname{IPrCu}\left(\mathrm{CH}\left(\mathrm{P}^{\mathrm{p}-}\right.\right.$ $\left.{ }^{\mathrm{CF}_{3}} \mathrm{Ph}\right) \mathrm{CH}_{2} \mathrm{Bpin}$ ) was accelerated upon addition of exogenous $\mathrm{PPh}_{3}$, analogous to results demonstrated in the catalytic reaction. Conversely, $\mathrm{PPh}_{3}$ was found to inhibit reactions of electron rich $\mathrm{IPrCu}\left(\mathrm{CH}\left({ }^{\mathrm{p}-\mathrm{BBu}} \mathrm{Ph}\right) \mathrm{CH}_{2}\right.$ Bpin). These kinetic observations implied that a second carboxylation pathway was likely operative. DFT analysis demonstrated that binding of the electron-rich additive at ( $\beta$-borylbenzyl)copper(I) yields a meta-stable intermediate that precedes carboxylation via an $\mathrm{S}_{E}$-type pathway. This alternative mechanism is kinetically favorable for electron deficient benzylcopper species and circumvents the direct insertion mechanism. The mechanistic picture that emerges from this complementary experimental/computational study highlights the kinetic complexities associated with the multiple pathways available to copper-based carboxylation chemistry. 


\subsection{Additives in Catalysis}

The introduction of Lewis basic additives to catalytic reactions is a common strategy to enhance reactivity, increase enantioselectivity, and expand methodology scope. ${ }^{111}$ Several types of effective additives have been identified, monophosphines $\left(\mathrm{PR}_{3}\right)$ being one class. Some of the first examples leveraging monophosphines were reported by Hoveyda and coworkers using triphenylphosphine $\left(\mathrm{PPh}_{3}\right)$ as an additive. Following a report on nonasymmetric selective addition of Grignard reagents to allylic ethers using $\left(\mathrm{PPh}_{3}\right)_{2} \mathrm{NiCl}_{2}$, wherein it was determined the presence of the monophosphine was crucial to catalysis, ${ }^{112}$ nickel-catalyzed asymmetric addition of Grignards to unsaturated cyclic acetals was also realized. ${ }^{113}$ A mixture of $(S, S)$-chiraphos $(2 S, 3 S$ (-)-bis(diphenylphosphino)butane) and $\mathrm{PPh}_{3}$ was required to achieve good enantioselectivity in the similar addition of Grignard reagents to cyclic acetals (Figure 3.1).
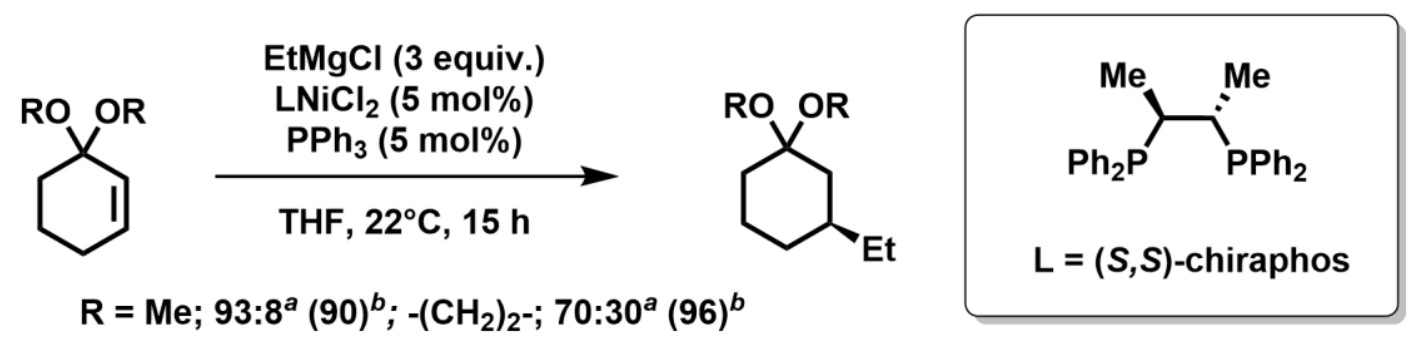

Figure 3.1. Asymmetric addition of EtMgCl to cyclic acetals. ${ }^{a} \%$ ee. ${ }^{b} \%$ yield. ${ }^{113}$

111. For selected works on utilization of Lewis basic additives in catalysis, see: (a) Hong, L.; Sun, W.; Yang, D.; Li, G.; Wang, R. Additive Effects on Asymmetric Catalysis. Chem. Rev. 2016, 116, 4006-4123, and references therein. (b) Balaji, P. V.; Brewitz, L.; Kumagai, N.; Shibasaki, M. Achiral Trisubstituted Thioureas as Secondary Ligands to $\mathrm{Cu}^{\mathrm{I} C a t a l y s t s: ~ D i r e c t ~ C a t a l y t i c ~ A s y m m e t r i c ~ A d d i t i o n ~ o f ~} \alpha$-Fluoronitriles to Imines. Angew. Chem. Int. Ed. 2019, 131, 2670-2674. (c) Xu-Xu, Q. F.; Zhang, X.; You, S. L. Enantioselective Synthesis of 4-Aminotetrahydroquinolines via 1,2-Reductive Dearomatization of Quinolines a Copper(I) Hydride-Catalyzed Asymmetric Hydroamination. Org. Lett. 2019, 21, 5357-5362. (d) Lu, D. F.; Zhu, C. L.; Xu, H. Copper(I)-catalyzed Diastereoselective Hydroxytrifluoromethylation of Dienes Accelerated by Phosphine Ligands. Chem. Sci. 2013, 4, 2478-2482. (e) Zhao, D.; Mao, L.; Yang, D.; Wang, R. Catalytic Asymmetric Construction of Tetrasubstituted Carbon Stereocenters by Conjugate Addition of Dialkyl Phosphine Oxides to $\beta, \beta$-Disubstituted $\alpha, \beta$-Unsaturated Carbonyl Compounds. Chem. Comm. 2012, 48, 889-891. (f) Jin, W.; Li, X.; Wan, B. Highly Diastereo- and Enantioselective Copper(I)-Catalyzed Henry Reaction Using a Bis(sulfonamide)-Diamine Ligand. J. Org. Chem. 2011, 76, 484-491. (h) Zhao, D.; Mao, L.; Wang, Y.; Yang, D.; Zhang, Q.; Wang, R. Catalytic Asymmetric Hydrophosphinylation of $\alpha, \beta$-Unsaturated NAcylpyrroles: Application of Dialkyl Phosphine Oxides in Enantioselective Synthesis of Chiral Phosphine Oxides or Phosphines. Org. Lett. 2010, 12, 1880-1882.

112. Didiuk, M. T.; Morken, J. P.; Hoveyda, A. H. Directed Regio- and Stereoselective Nickel-Catalyzed Addition of Alkyl Grignard Reagents to Allylic Ethers. J. Am. Chem. Soc. 1995, 117, 7273-7274.

113. Gomez-Bengoa, E.; Heron, N. M.; Didiuk, M. T.; Luchaco, C. A.; Hoveyda, A. H. Ni-Catalyzed Asymmetric Addition of Grignard Reagents to Unsaturated Cyclic Acetals. The Influence of Added Phosphine on Enantioselectivity. J. Am. Chem. Soc. 1998, 120, 7649-7650. 
The mixed phosphine ligand strategy has since been used to great success in other transition metal catalyzed transformations. For instance, Fergina et al. demonstrated Rh-catalyzed hydrogenation of $\alpha, \beta$-disubstituted unsaturated carboxylic acids using $\mathrm{PPh}_{3}{ }^{114} \mathrm{~A}$ more contemporary example by Ding and coworkers describes a similar Rh-catalyzed asymmetric hydrogenation of $\alpha$ - or $\beta-\mathrm{CF}_{3}$-substituted acrylic acids wherein $\mathrm{PPh}_{3}$ led to significantly higher $\%$ ee than in its absence. ${ }^{115}$

Examples of phosphine-enhanced copper(I) catalysis have also been reported. ${ }^{116}$ In 2013, Xu and coworkers observed that in hydroxytrifluoromethylation of 1,4-cyclohexadiene, introduction of tri-tert-butylphosphine $\left(\mathrm{P}^{\mathrm{t}} \mathrm{Bu}_{3}\right)$ to $\mathrm{Cu}^{\mathrm{I}} \mathrm{CN}$ led to increased yields from trace (no phosphine) to $77 \%$ (Scheme 3.1). On the basis of mechanistic studies, it was proposed that the bulky phosphine ligand pushes the equilibrium from a $\pi$-coordinated copper(II)-olefin complex (A) to a transient copper(III)-allyl complex (B) that induces transfer of the carboxylate ligand.

114. Hoen, R.; Boogers, J. A. F.; Bernsmann, H.; Minnaard, A. J.; Meetsma, A.; Tiemersma-Wagman, T. D.; de Vries, A. H. M.; Feringa, B. L. Achiral Ligands Dramatically Enhance Rate and Enantioselectivity in the $\mathrm{Rh} /$ Phosphoramidite-Catalyzed Hydrogenation of $\alpha, \beta$-Disubstituted Unsaturated Acids. Angew. Chem. Int. Ed. 2005, 44, 4209-4212.

115. Dong, K.; Li, Y.; Wang, Z.; Ding, K. Catalytic Asymmetric Hydrogenation of $\alpha-\mathrm{CF}_{3}$ or $\beta-\mathrm{CF}_{3}-\mathrm{Substituted} \mathrm{Acrylic}$ Acids using Rhodium(I) Complexes with a Combination of Chiral and Achiral Ligands. Angew. Chem. Int. Ed. 2013, 52, 14191-14195.

116. (a) Bandar, J. S.; Ascic, E.; Buchwald, S. L. Enantioselective CuH-Catalyzed Reductive Coupling of Aryl Alkenes and Activated Carboxylic Acids. J. Am. Chem. Soc. 2016, 138, 5821-5824. (b) Ascic, E.; Buchwald, S. L. Highly Diastereo- and Enantioselective CuH-Catalyzed Synthesis of 2,3-Disubstituted Indolines. J. Am. Chem. Soc. 2015, 137, 4666-4669. (c) Lipshutz, B. H.; Servesko, J. M.; Taft, B. R. Asymmetric 1,4-Hydrosilylations of a $\alpha, \beta$ Unsaturated Esters. J. Am. Chem. Soc. 2004, 126, 8352-8353. (d) Lipshutz, B. H.; Noson, K.; Chrisman, W.; Lower, A. Asymmetric Hydrosilylation of Aryl Ketones Catalyzed by Copper Hydride Complexed by Nonracemic Biphenyl Bis-phosphine Ligands. 2003, 125, 8779-8789. 
Scheme 3.1. Ligand-accelerated diastereoselective hydroxytrifluoromethylation of dienes by $\mathrm{Xu}$ and coworkers. ${ }^{111 \mathrm{~d}}$
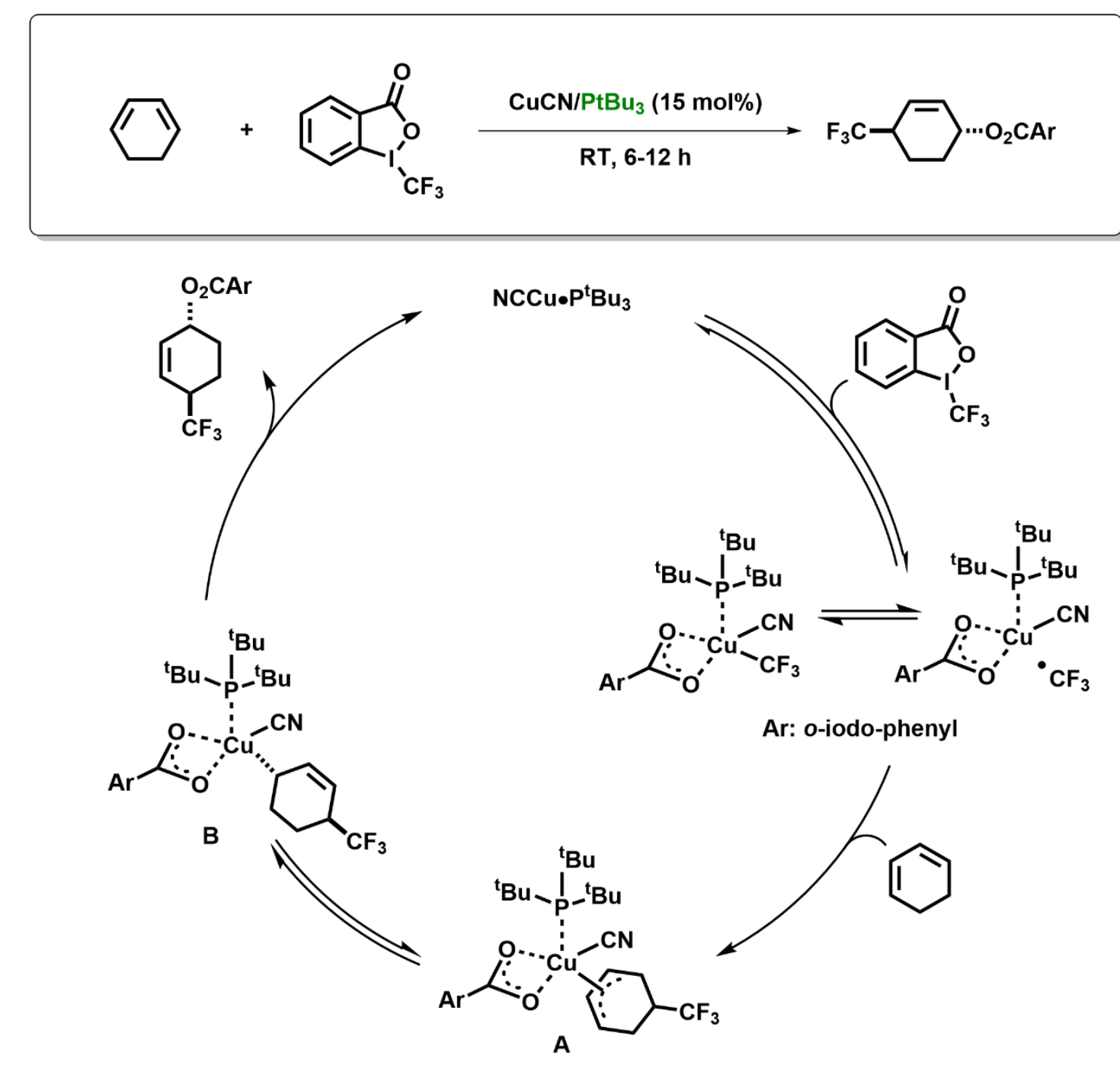

1,4-cyclohexadiene without $\mathrm{P}^{\mathrm{t}} \mathrm{Bu}_{3}$ : trace

1,4-cyclohexadiene with $\mathrm{P}^{\mathrm{t}} \mathrm{Bu}_{3}: 77 \%$ yield

The addition of $\mathrm{PPh}_{3}$ has also been employed to reduce decomposition of active copper(I) species. Using monophosphines to prevent catalyst death was first established by Lipshutz in the CuH-catalyzed asymmetric hydrosilylation of ketones. ${ }^{117}$ When $\mathrm{PPh}_{3}$ is added to the active catalyst

117. Lipshutz, B. H.; Noson, K.; Chrisman, W.; Lower, A. Asymmetric Hydrosilylation of Aryl Ketones Catalyzed by Copper Hydride Complexed by Nonracemic Biphenyl Bis-Phosphine Ligands. J. Am. Chem. Soc. 2003, 125, 87798789. 
mixture, thermal decomposition does not occur when warmed to $0^{\circ} \mathrm{C}$, as it does in the absence of additive. This suggests that triphenylphosphine does not make a catalytically active complex with $\mathrm{CuH}$ and instead sequesters the reactive species until it can ligate to the chiral bisphosphine ligand. Further, in both the $\left((S, S)\right.$-Ph-BPE)copper(I)-catalyzed synthesis of indolines ${ }^{116 \mathrm{~b}}$ and the reductive coupling of alkenes and carboxylic acids, ${ }^{16 a}$ inclusion of $\mathrm{PPh}_{3}$ increased yields without erosion of enantioselectivity (Figure 3.2).

Buchwald, 2015

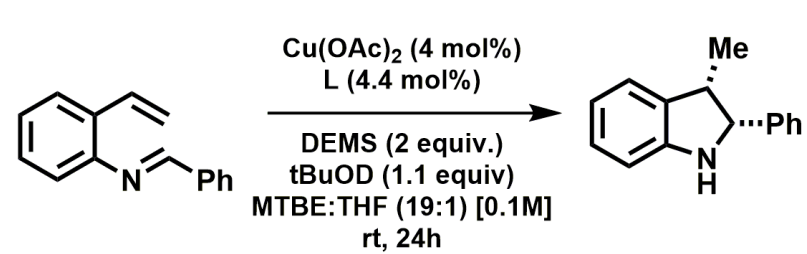

$\mathrm{L}=(S, S)-\mathrm{Ph}-\mathrm{BPE}$

$L=(S, S)-P h-B P E+\mathrm{PPh}_{3}(5 \%)$ yield: $\mathbf{9 6 \%}$ ee: $\mathbf{9 0 \%}$

yield: $99 \%$ ee: $90 \%$
Buchwald, 2016

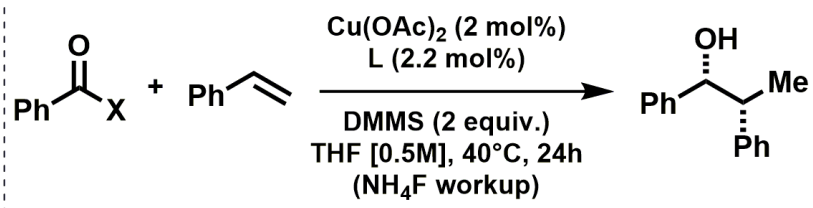

$L=(S, S)-P h-B P E$

$L=(S, S)-P h-B P E+P P h_{3}$

yield: $\mathbf{7 7 \%}$ ee: $\mathbf{9 4 \%}$ yield: $91 \%$ ee: $94 \%$

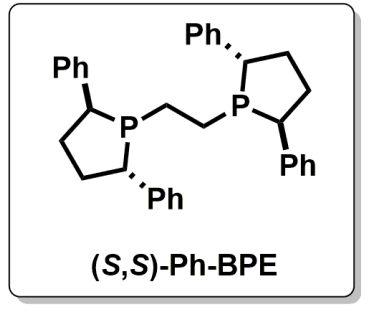

Figure 3.2. Select catalytic examples wherein exogenous $\mathrm{PPh}_{3}$ plays a role in enhancing reactivity. ${ }^{116 a, 116 \mathrm{~b}}$

Inspired by the reports of Lipshutz and Buchwald, Popp and colleagues introduced $\mathrm{PPh}_{3}$ as a secondary ligand to the catalytic boracarboxylation conditions (cf. Chapter 1.5 and 2.2). This led to enhanced reactivity of previously inaccessible 4-trifluoromethylstyrene, ${ }^{118}$ allowing for synthesis of the respective $\alpha$-aryl carboxylic acid in a 36\% yield by ${ }^{1} \mathrm{H}$ NMR spectroscopy (Table 3.1.). ${ }^{119}$ Acetoxy- and cyano-substituted vinyl arenes were carboxylated as well, and low yielding substrates from the original report experienced increased yields with the $\mathrm{PPh}_{3}$ additive. It was

118. Butcher, T. W.; McClain, E. J.; Hamilton, T. G.; Perrone, T. M.; Kroner, K. M.; Donohoe, G. C.; Akhmedov, N. G.; Petersen, J. L.; Popp, B. V. Regioselective Copper-Catalyzed Boracarboxylation of Vinyl Arenes. Org. Lett. 2016, $18,6428-6431$.

119. Perrone, T. M.; Gregory, A. S.; Knowlden, S. W.; Ziemer, N. R.; Alsulami, R. N.; Petersen, J. L.; Popp, B. V. Beneficial Effect of a Secondary Ligand on the Catalytic Difunctionalization of Vinyl Arenes with $\mathrm{Boron}$ and $\mathrm{CO}_{2}$. ChemCatChem 2019, 11, 5814-5820. 
initially thought the $\mathrm{PPh}_{3}$ was acting to prevent copper catalyst decomposition, as reported by Lipshutz and Buchwald. ${ }^{116}$ However, following an initial mechanistic investigation wherein a loss of regioselectivity was observed upon inclusion of $\mathrm{PPh}_{3}$, a change in mechanism altogether seemed more likely than sequestrating reactive species that may undergo decomposition. Thus, kinetic analysis of carboxylation in the presence of $\mathrm{PPh}_{3}$ was conducted stoichiometrically to identify the role of the additive.

Table 3.1. Representative examples of accessible substrates for boracarboxylation upon addition of $\mathrm{PPh}_{3}{ }^{119}$

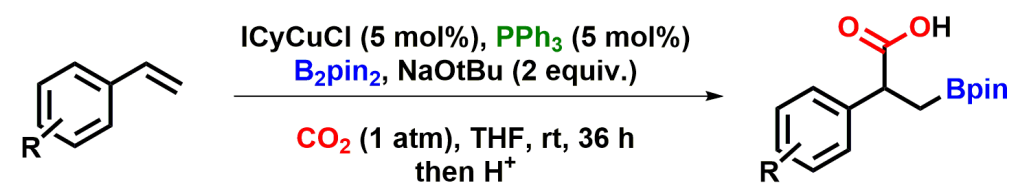

\section{Previously low yielding or inaccessible substrates}<smiles>CC(=O)N(C)c1ccc(C(CBr)C(=O)O)cc1</smiles><smiles>CC(=O)Oc1ccc(C(CBr)C(=O)O)cc1</smiles><smiles>O=C(O)C(CBr)c1ccc(C(F)(F)F)cc1</smiles><smiles>N#Cc1ccc(C(CBr)C(=O)O)cc1</smiles><smiles>O=C(O)C(CBr)c1ccc(Cl)cc1</smiles><smiles>O=C(O)C(CBr)c1ccc(C(F)(F)F)cc1</smiles>

${ }^{a}$ Isolated yields and NMR yields in parentheses. ${ }^{b}$ Isolated yields from the original catalytic conditions $\left(\mathrm{ICyCuCl}(12 \mathrm{~mol} \%) /\right.$ absence of $\left.\mathrm{PPh}_{3}\right)$ reported in ref. 118.

\subsection{Stoichiometric Carboxylation of $\mathrm{CF}_{3}$ and ${ }^{\mathrm{t}} \mathrm{Bu}$ Complexes with $\mathrm{PPh}_{3}$}

Given that electron deficient $p-\mathrm{CF}_{3}$ complex $\mathbf{2 i}$ was not amenable to stoichiometric boracarboxylation (see Chapter 2), $\mathrm{PPh}_{3}$ was added to determine whether its role was to facilitate carboxylation. Thus, the rate of carboxylation was determined by introducing $\mathrm{PPh}_{3}$ (1 equiv.) to a benzene- $d_{6}$ solution of $\mathbf{2 i}$, which was subsequently monitored by ${ }^{1} \mathrm{H}$ NMR spectroscopy (Figure 3.3). Growth of product $\mathbf{3 i}$, identified by comparison to independently synthesized material 
(Chapter 2), was observed. A yield of $5.9 \%$ was observed after the first 3 hours of the reaction, whereas no discernible quantity of $\mathbf{3 i}$ was produced over several days when no $\mathrm{PPh}_{3}$ was added (Figure 3.3). Interestingly, prior to the introduction of $\mathrm{CO}_{2}$, no reactivity was observed between the $\mathrm{Cu}^{\mathrm{I}}\left(\beta\right.$-borylbenzyl $\left.{ }^{\mathrm{CF}_{3}}\right)$ complex and the phosphine.

The impacts of $\mathrm{PPh}_{3}$ concentration over a range of 0.5-5.0 equivalents were then examined by comparing initial rates of reaction (Figure 3.4). A positive correlation was observed wherein the initial rate of carboxylation increases with a mild saturation dependence on $\mathrm{PPh}_{3}$ up to 3 equivalents. This suggests an alternative carboxylation pathway is operative, outcompeting unfavorable direct insertion of $\mathrm{CO}_{2}$ into the electron deficient $\mathrm{Cu}(\beta$-borylbenzyl) complex $2 \mathbf{i}$. Higher concentrations of $\mathrm{PPh}_{3}$ at (5 equiv.) led to diminished initial reaction rate with no appreciable side-products detected.

The same study was conducted with electron rich $p$-tBu complex $2 \mathbf{d}$ using initial rates (Figure 3.3.). No rate acceleration was observed, but rather, the phosphine significantly inhibited the reaction. Higher concentrations of $\mathrm{PPh}_{3}$ (up to 5.6 equiv.) resulted in an overall 15 -fold decrease in the initial rates of carboxylation compared to the reaction containing no additive. Interestingly, the inhibition of $\mathbf{2} \mathbf{d}$ carboxylation proceeds at a rate that is 2 -fold faster than the enhancement of $2 \mathbf{i}$ carboxylation. This disparity in the observed rate profiles implies that $\mathrm{PPh}_{3}$ acts directly on the $\mathrm{Cu}^{\mathrm{I}}(\beta$-borylbenzyl) complex and either accelerates or inhibits carboxylation depending on the electronic characteristics of the benzyl ligand. This additive effect contrasts previous mechanistic proposals that suggest $\mathrm{PPh}_{3}$ sequesters reactive copper species (e.g., $\mathrm{Cu}-\mathrm{H}$ ) in alkene hydrofunctionalization. ${ }^{116,117,119}$ 


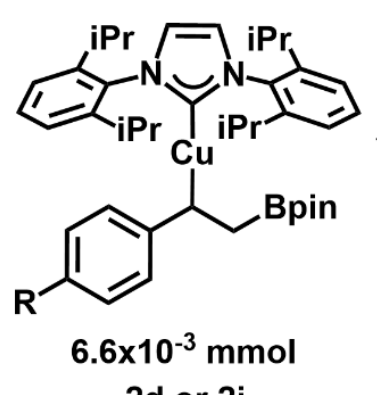

$2 d$ or $2 i$

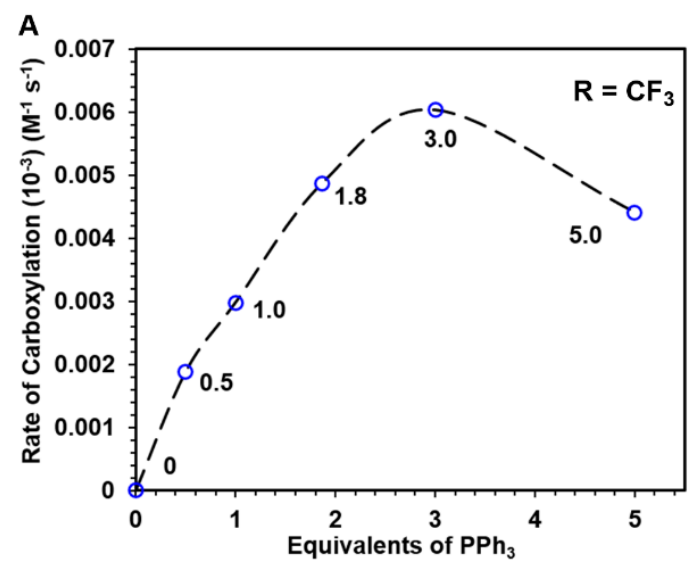

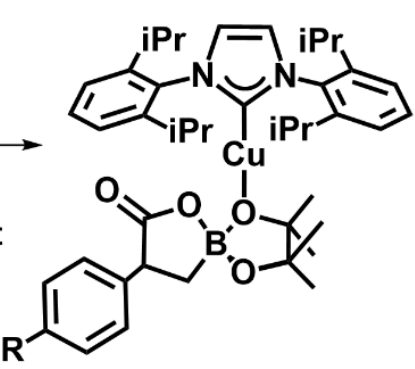

$3 d$ or $3 \mathbf{i}$<smiles>c1ccc(P(c2ccccc2)c2ccccc2)cc1</smiles>

triphenylphosphine $\left(\mathrm{PPh}_{3}\right)$

Figure 3.3. Rates of carboxylation for A) $\mathrm{p}-\mathrm{CF}_{3}$ complex $2 \mathbf{i}$ with varying amounts of $\mathrm{PPh}_{3}$ and $\mathrm{B}$ )

tBu complex $2 \mathbf{d}$ with varying amounts of $\mathrm{PPh}_{3}$. Note: charges have been omitted from the copper(I)spiroboralactonate complex for clarity. 

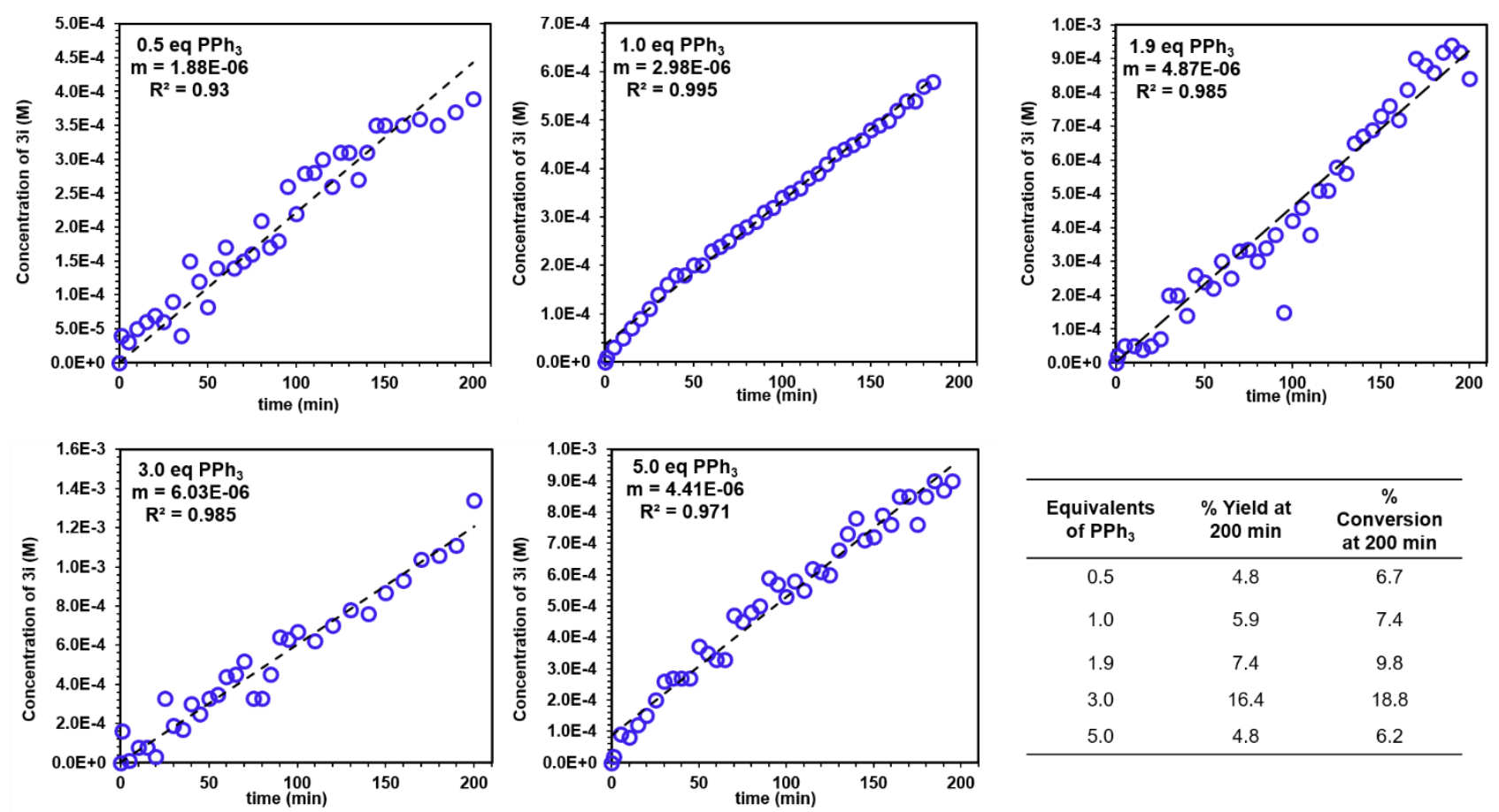

Figure 3.4. Plots depicting the initial rates of carboxylation of $2 \mathbf{i}$ at $25^{\circ} \mathrm{C}$ with various amounts of $\mathrm{PPh}_{3}$. Table contains the \% yields and \% conversion after 200 minutes.

The impact of the phosphine electronic character was then considered to determine if the reaction favors more electron deficient or electron rich phosphine additives. Under the same conditions, 1 equivalent of electron rich tris(4-methoxyphenyl)phosphine $\left(((4-\mathrm{OMe}) \mathrm{Ph})_{3} \mathrm{P}\right)$ was used in place of $\mathrm{PPh}_{3}$. Initial rate data, when compared to the analogous $\mathrm{PPh}_{3}$ run, demonstrated faster carboxylation by almost 1.5 times when using the more electron rich additive (Figure 3.5). On the contrary, using electron deficient tris(4-trifluoromethylphenyl)phosphine $\left(\left(\left(4-\mathrm{CF}_{3}\right) \mathrm{Ph}\right)_{3} \mathrm{P}\right)$ led to a decrease in rate, although not as substantial of a change. This trend is consistent with those seen in nickel-catalyzed addition of Grignards to cyclic acetals, with higher yields (but lower enantioselectivity) associated with more electron rich phosphines. ${ }^{113}$ 


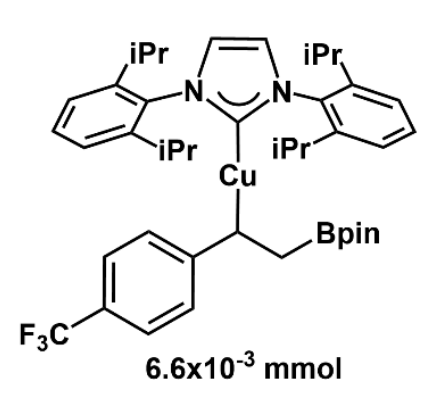

$2 \mathbf{i}$

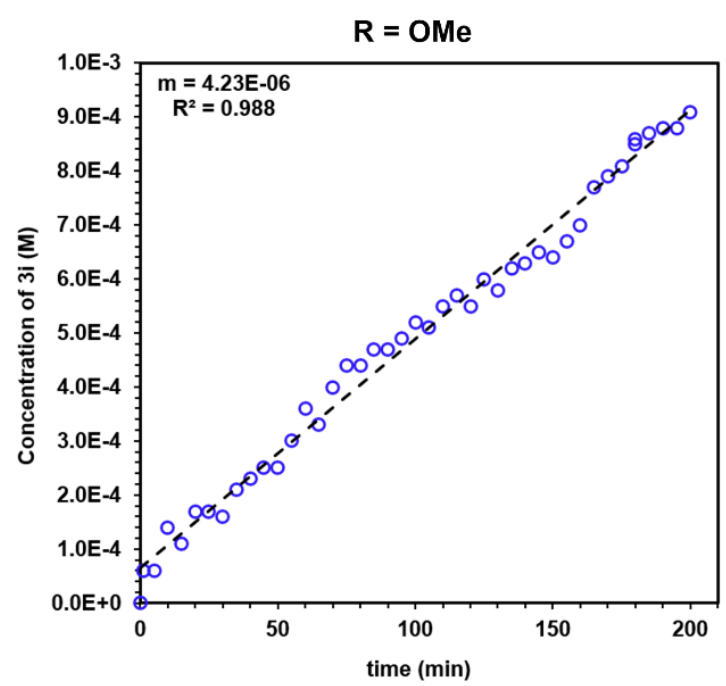

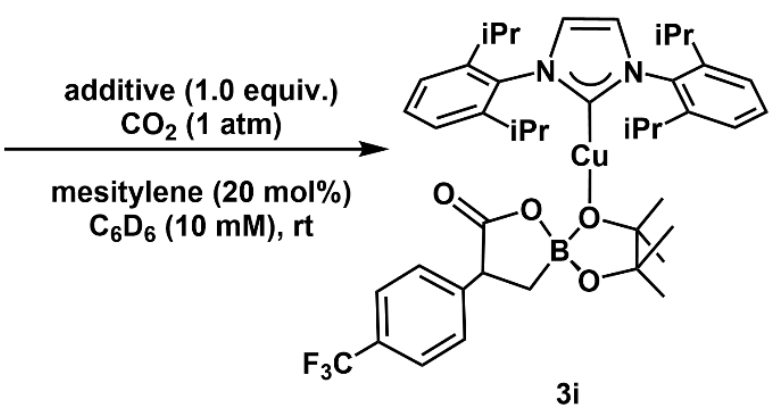
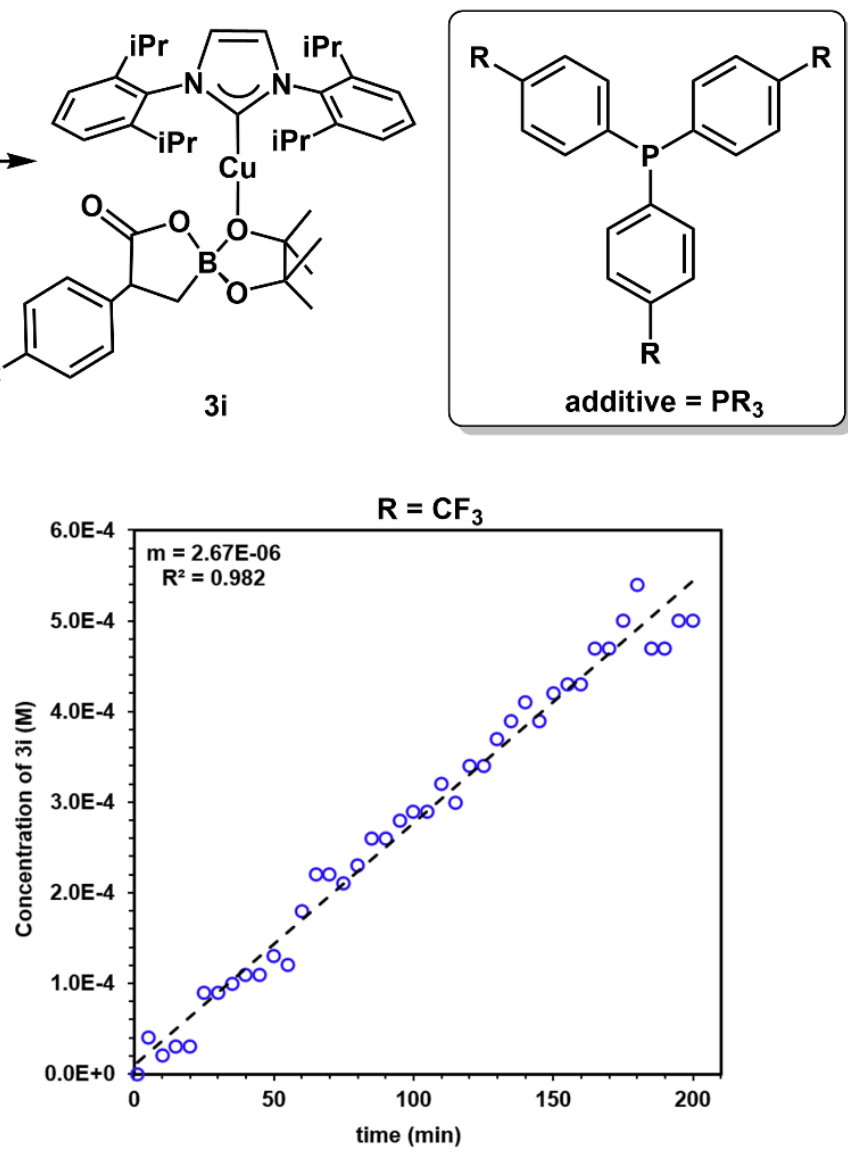

Figure 3.5. Initial rates of carboxylation of $\mathbf{2 i}$ using electronically differing phosphine additives.

Carboxylation mechanisms that are most reasonable to result from both the absence and inclusion of $\mathrm{PPh}_{3}$ were explored further (Scheme 3.2). ${ }^{120}$ Given the significant loss of reactivity when added to $\mathbf{2 d}$, the phosphine appears to inhibit the favored direct insertion route of carboxylation, resulting from a sterically congested coordination sphere at the copper center. Additionally, the enhancement of reactivity in the case of $\mathbf{2 i}$, which was not accessible without additive, suggests that the direct insertion pathway is being outcompeted by a reaction that involves phosphine playing an active role. The inclusion of $\mathrm{PPh}_{3}$ in the catalytic boracarboxylation of trans$\beta$-methylstyrene resulted in erosion of regioselectivity $(d r 2: 1)$ as compared to the original conditions $(d r 7: 1) .{ }^{119}$ The direct $\mathrm{CO}_{2}$ insertion pathway should maintain regioselectivity, given that there is no ionization event of the $\mathrm{Cu}-\mathrm{C}_{\text {benzyl }}$ bond to generate an anionic carbon. However, an

120. García-López, D.; Pavlovic, L.; Hopmann, K. H. To Bind or Not to Bind: Mechanistic Insights into C- $\mathrm{CO}_{2}$ Bond Formation with Late Transition Metals. Organometallics 2020, 8, 1339-1347. 
$\mathrm{S}_{\mathrm{E}}$-type pathway may be competitive if the coordination sphere of copper is saturated by a large phosphine ligand, which would explain the loss of selectivity. A computational study was conducted to assess the viability of a competing pathway resulting from $\mathrm{PPh}_{3}$ in carboxylation.

Scheme 3.2. Proposed competitive pathways for carboxylation with $\mathrm{PPh}_{3}$ additive.

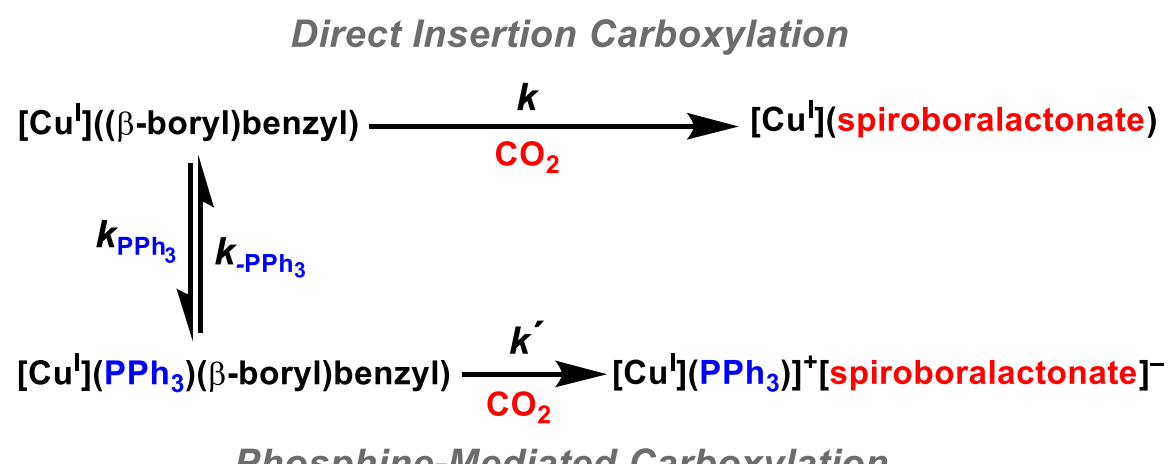

Phosphine-Mediated Carboxylation

\subsection{Computational Exploration of Carboxylation with Phosphine Additives}

In the $\mathrm{PPh}_{3}$-mediated pathway, the additive is anticipated to form a 1:1 adduct with $\operatorname{IPrCu}(\beta-$ borylbenzyl), resulting in three-coordinate $(\operatorname{IPr})\left(\mathrm{PPh}_{3}\right) \mathrm{Cu}^{\mathrm{I}}(\beta$-borylbenzyl). Thus, DFT was used to assess the viability of the proposed role of $\mathrm{PPh}_{3}$ in carboxylation. As with the initial DFT study (Chapter 2), IMe NHC as well as trimethylphosphine $\left(\mathrm{PMe}_{3}\right)$ were used to reduce computational cost. Initial interaction of $\mathrm{PMe}_{3}$ with $\mathrm{IMeCu}^{\mathrm{I}}$-benzyl (4a) led to a three-coordinate $\mathrm{Cu}^{\mathrm{I}}$ species (Figure 3.6). A meta-stable ground state intermediate (4a·PMe 3 ) was identified, destabilized on the free energy surface relative to $4 \mathrm{a}$ by $6.1 \mathrm{kcal} / \mathrm{mol}$. 


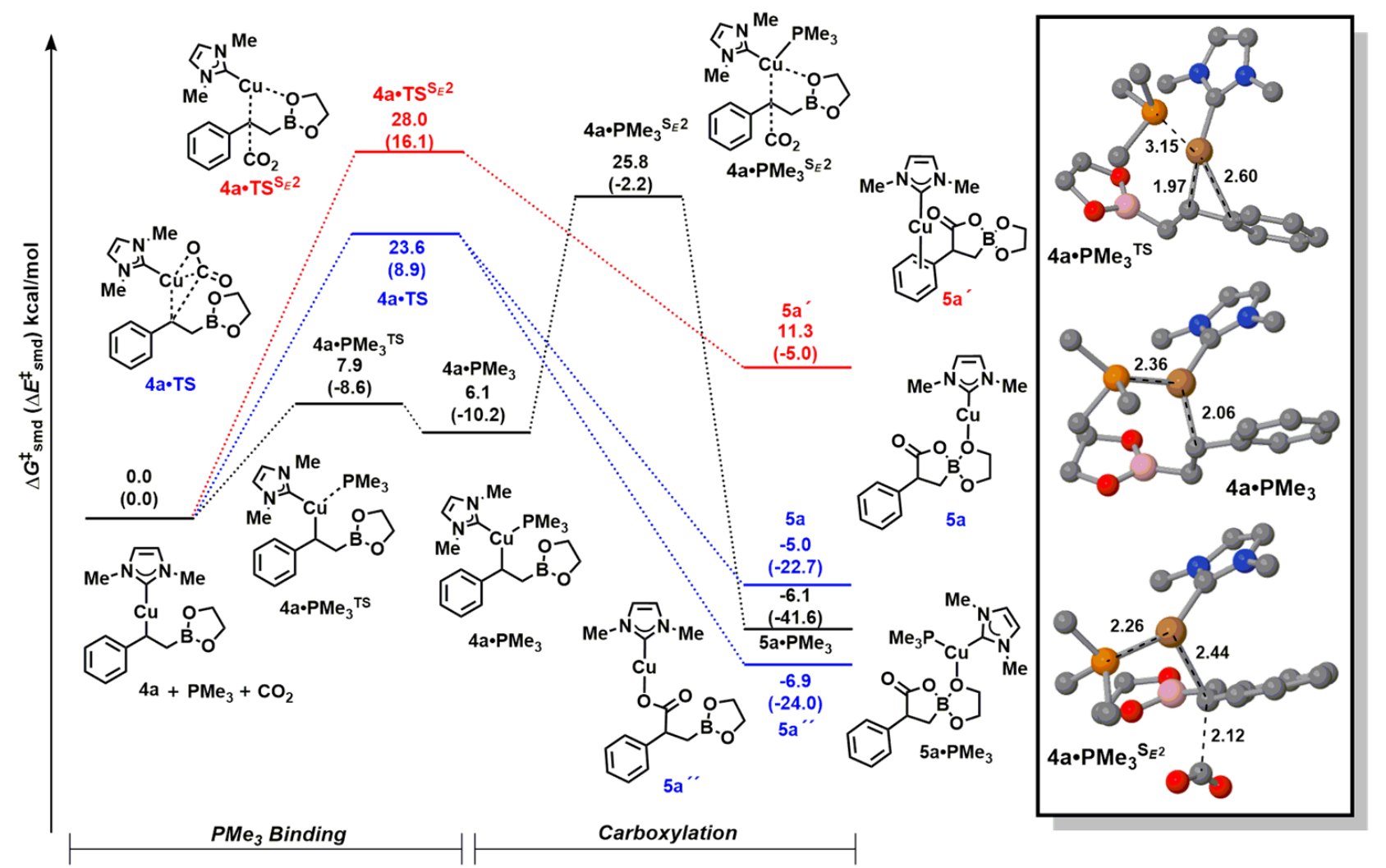

Figure 3.6. Reaction coordinates for $\mathrm{Cu}^{\mathrm{I}}$-catalyzed boracarboxylation via 1) cooperative insertion (blue), 2) unassisted $\mathrm{S}_{\mathrm{E}} 2$, and 3) $\mathrm{PMe}_{3}$-assisted pathways calculated at the M06 level of theory.

Each spiroboralactonate structure is depicted as neutral; however, the formal charges are believed to reside on the copper (+1) and the tetracoordinate boron $(-1)$.

The structure shows significant bending out of plane of the NHC ligand to accommodate the phosphine ligand, a phenomenon not observed in the case of the standard 4a. Intermediate 4a $\cdot \mathbf{P M e}_{3}$ possesses a $\mathrm{Cu}-\mathrm{P}$ distance of $2.35 \AA$, which although slightly longer than those reported for tri-coordinate copper(I)phosphine complexes (2.26 $\AA$ on average) ${ }^{121}$ falls within the Van der Waals radii range for these two atoms $(\mathrm{Cu}=2.0 \AA ; \mathrm{P}=1.95 \AA) .{ }^{122}$

121. Lotito, K. J.; Peters, J. C. Efficient Luminescence from Easily Prepared Three-Coordinate Copper(I) Arylamidophosphines. Chem. Commun. 2010, 46, 3690-3692.

122. Batsanov, S. S. Van der Waals Radii of Elements. Inorg. Mater. 2001, 37, 1031-1046. 
The transition state $\mathbf{4 a} \cdot \mathbf{P M e}_{3}{ }^{\mathrm{TS}}$ was located on a shallow potential energy surface using RPES (relaxed potential energy surface scan) with a free energy barrier of $7.9 \mathrm{kcal} / \mathrm{mol}$ (Figure 3.7). Indeed, the low free energy barrier between the intermediate $\mathbf{4 a} \cdot \mathbf{P M e} 3$ and the preceding transition state is consistent with the inability to observe such a complex experimentally via NMR spectroscopy.

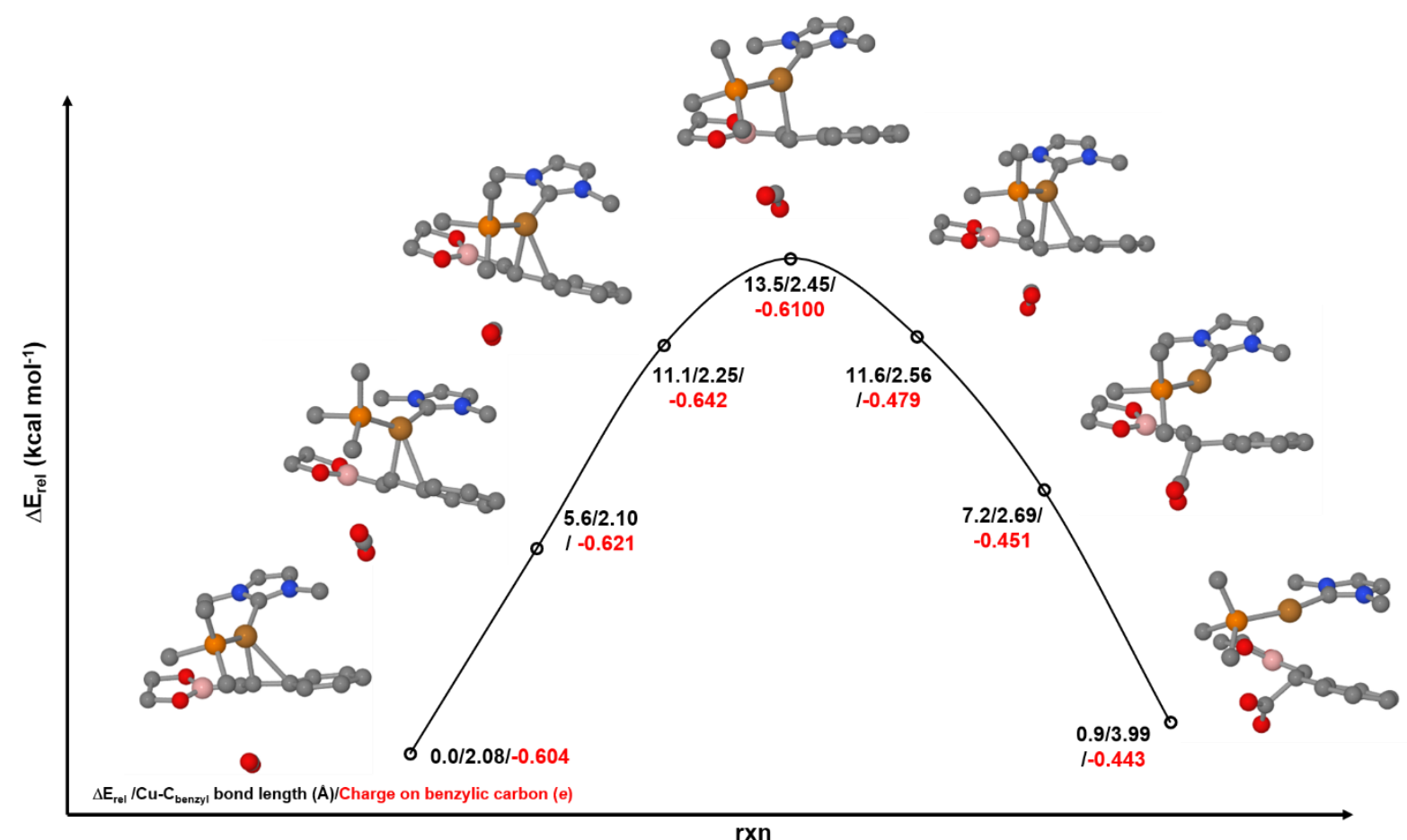

Figure 3.7. IRC calculation starting from the TS. $\mathrm{PMe}_{3}{ }^{\mathrm{SE} 2}$ using rm06 level of theory.

Previous computational studies indicate that the carboxylation under standard conditions (i.e. no additive) proceeds by a cooperative direct insertion mechanism. ${ }^{120,123,124,125}$ Thus, direct insertion of $\mathrm{CO}_{2}$ into the trigonal $\mathbf{4 a} \cdot \mathbf{P M e} 3$ was considered. All attempts to locate a transition state wherein $\mathrm{CO}_{2}$ inserts into the sterically congested copper center of $\mathbf{4 a} \cdot \mathbf{P M e} 3$ were unsuccessful.

123. Baughman, N. N.; Popp, B. V. Evidence of Boron Assistance for $\mathrm{CO}_{2}$ Activation during Copper-Catalyzed Boracarboxylation of Vinyl Arenes: A Synthetic Model for Cooperative Fixation of $\mathrm{CO}_{2}$. Comment. Inorg. Chem. 2020, $40,159-175$.

124. Lin, S.; Lin, Z. DFT Studies on the Mechanism of Copper-Catalyzed Boracarboxylation of Alkene with $\mathrm{CO}_{2}$ and Diboron. Organometallics 2019, 38, 240-247.

125. Lv, X.; Wu, Y. B.; Lu, G. Computational Exploration of Ligand Effects in Copper-Catalyzed Boracarboxylation of Styrene with $\mathrm{CO}_{2}$. Catal. Sci. Technol. 2017, 7,5049-5054. 
The $\mathrm{S}_{\mathrm{E}} 1$ addition pathway through full ionization of the $\mathrm{Cu}$-benzyl bond prior to carboxylation was then considered. However, the free energy barrier exceeding $40 \mathrm{kcal} / \mathrm{mol}$ for the resulting linear $\mathrm{IMeCu}-\mathrm{PMe}_{3}$ cation accompanied by a close-contact benzyl anion suggests this is an unlikely scenario.

$\mathrm{S}_{\mathrm{E}} 2$ addition was also considered as a viable pathway. Multiple transition states were identified depending on the orientation of the Beg moiety (eg = ethyleneglycato). The most stabilized transition state $\left(\mathbf{4} \mathbf{a} \cdot \mathbf{P M} \mathbf{S}_{3} \mathbf{S}_{E^{2}}\right)$ resulted from Beg positioned close to the $\mathrm{Cu}$ center, providing an anchor as depicted in Figure 3.6. A transition state with similar geometry was previously identified for unassisted electrophilic substitution $\left(\mathbf{4} \mathbf{a} \cdot \mathbf{T S} \mathbf{S}_{E^{2}}\right)$. The free energy of activation for the $\mathrm{PMe}_{3}$-assisted pathway $\left(\mathbf{4 a} \cdot \mathbf{P M e}{ }^{\mathbf{S}_{E}}{ }^{2}\right)$ was over $2 \mathrm{kcal} / \mathrm{mol}$ more favorable than the unassisted pathway (i.e., $4 \mathbf{4} \cdot \mathbf{P M e} \mathbf{S}^{\mathbf{S}_{E^{2}}}$ and $\mathbf{4 a} \cdot \mathbf{T S}^{\mathrm{S}_{E^{2}}}$, respectively); however, the direct addition barrier was still more stable by over $2 \mathrm{kcal} / \mathrm{mol}$. These results are consistent with the diverging reactivity observed in $\mathrm{PPh}_{3}$ concentration dependence studies in which inhibition by $\mathrm{PPh}_{3}$ is expected due to the favorability of direct insertion carboxylation.

Comparison of the metrics and natural charge $(q)$ derived from natural bond orbital analysis of the electrophilic substitution ground state and transition state structures revealed substantial differences (Figure 3.8). Consistent with expectation, $\mathrm{PMe}_{3}$ binding, forming $\mathbf{4 a} \cdot \mathbf{P M e}$, resulted in a longer $\mathrm{Cu}-\mathrm{C}_{\text {benzyl }}$ bond relative to the analogous bond in $\mathbf{4 a}(\Delta r=0.1 \AA)$. This effect was more apparent when comparing the electrophilic substitution transition states in which the $\mathrm{Cu}-\mathrm{C}_{b e n z y l}$ bond increases by $0.26 \AA$, leading to the more accessible, energetically stabilized transition state

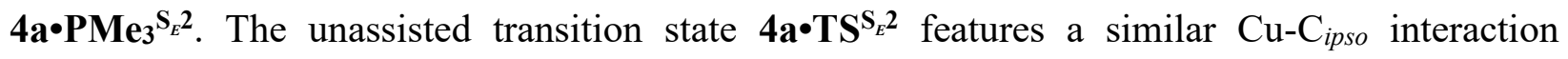
observed in the direct insertion transition state $\mathbf{4 a} \cdot \mathbf{T S}$; in fact, $\mathbf{4 a} \cdot \mathbf{T S} \mathbf{S}_{{ }^{2}}{ }^{2}$ has a short $\mathrm{Cu}-\mathrm{C}_{i p s o}$ bond length of $2.05 \AA$. This ipso-interaction is not structurally feasible in the $\mathrm{PMe}_{3}$-assisted pathway and likely is the major reason why the additive leads to a stabilized carboxylation barrier. Visualization of the respective $\mathrm{HOMO}$ of unassisted and $\mathrm{PMe}_{3}$-assisted transition states shows reduced copper character and significant benzyl anion character, as would be anticipated for an $\mathrm{S}_{E} 1$ transition state in the latter case (Figure 3.8). $\mathrm{PMe}_{3}$ plays a key role in stabilizing the cationic copper center at this transition state as indicated by the significantly reduced natural charge ( $q=$ +0.56 ) at the IMe-Cu fragment (cf., $q=+0.82$ at $\mathbf{4 a} \cdot \mathbf{T S} \mathbf{S}_{E^{2}}$ ), as well as leading to greater charge transfer from the benzyl anion to the $\mathrm{CO}_{2}$ moiety. 
A Unassisted Electrophilic Substitution

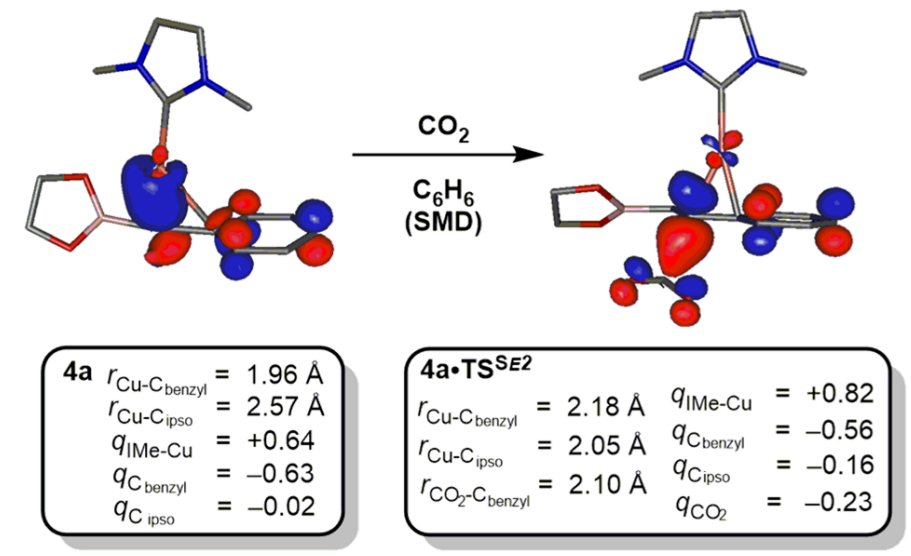

B $\mathrm{PMe}_{3}$-Assisted Electrophilic Substitution

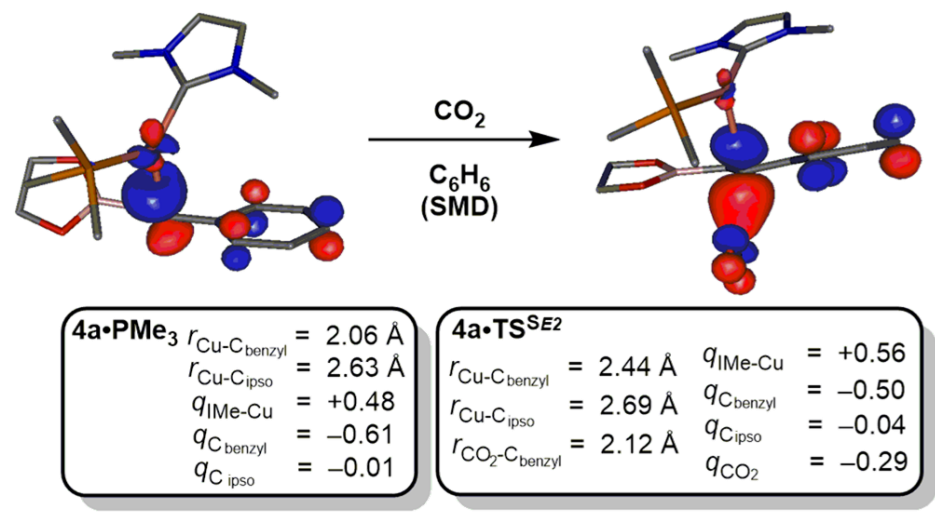

Figure 3.8. Visual representations of the highest occupied molecular orbital (HOMO) for the $\mathrm{IMeCu}(\beta$-borylbenzyl) structures as well as the transition states for the unassisted electrophilic substitution $\left(\mathbf{4} \mathbf{a} \cdot \mathbf{T S}{ }^{\mathbf{S E 2}}\right)$ and the $\mathrm{PMe}_{3}$-mediated (TS $\cdot \mathbf{P M e}{ }^{\mathbf{S E 2}}$ ) obtained at M06 level of theory. $q$ represents the natural charge obtained from NBO analysis.

Evaluation of electrophilic carboxylation of electronically perturbed $\mathrm{IMeCu}^{\mathrm{I}}\left(\beta\right.$-borylbenzyl $\left.{ }^{\mathrm{X}}\right)$ (4x) complexes $\left(\mathbf{X}=\mathrm{NH}_{2}, \mathbf{4 b}\right.$ and $\left.\mathrm{CF}_{3}, 4 \mathbf{i}\right)$ by DFT shed further light on the role of $\mathrm{PMe}_{3}(\mathrm{Table}$ 3.2). In the unassisted pathway, minimal electronic effects were observed with free energy barriers separated by less than $1 \mathrm{kcal} / \mathrm{mol}$. This reflects differing electronic contributions at the transition state arising from increasing $\pi$-benzyl-like character due to the $\mathrm{Cu}-\mathrm{C}_{i p s o}$ interaction. In the $\mathrm{PMe}_{3}-$ assisted pathway, electronic effects were more important, with the electron-deficient $4 \mathbf{i}$ being lowest in energy and the electron rich complex $\mathbf{4 b}$ being highest in energy $\left(\Delta G^{\ddagger}=23.9\right.$ vs. 26.9 $\mathrm{kcal} / \mathrm{mol}$, respectively). The former transition state also features the longest $\mathrm{Cu}-\mathrm{C}_{\text {benzyl }}$ bond and least negative charge on $\mathrm{C}_{\text {benzyl }}$ atom. These results are consistent with observations made above that support an $\mathrm{S}_{E} 2$ description of the phosphine-assisted pathway. 
Table 3.2. Computationally derived free energies associated with carboxylation of substituted $\mathrm{Cu}^{\mathrm{I}}$ benzyl complexes.

\begin{tabular}{|c|c|c|c|c|}
\hline $\begin{array}{l}\text { p-Aryl } \\
\text { Subs. }\end{array}$ & $\begin{array}{c}\Delta G^{\ddagger} \\
(\mathrm{kcal} / \mathrm{mol}) \\
4 x \cdot \mathrm{TS}^{\mathrm{S}_{\mathrm{E}^{2}}{ }^{a}}\end{array}$ & $\begin{array}{c}\Delta G^{\ddagger} \\
(\mathrm{kcal} / \mathrm{mol}) \\
4 \mathrm{x} \cdot \mathrm{PMe}_{3} \mathrm{~S}^{\mathrm{S}^{2}}{ }^{a}\end{array}$ & $\begin{array}{r}\mathrm{Cu}-\mathrm{C}_{\text {benzyl }}(\AA) \\
4 \mathrm{x} \cdot \mathrm{PMe}_{3} \mathrm{~S}^{2}{ }^{2}\end{array}$ & $\begin{array}{c}\mathrm{C}_{\text {benzyl }} 9 \\
4 \mathrm{x} \cdot \mathrm{PMe}_{3}{ }^{\mathrm{S}_{\mathrm{E}^{2}}}\end{array}$ \\
\hline $\mathrm{CF}_{3}$ & 27.3 & 23.9 & 2.46 & -0.48 \\
\hline $\mathbf{H}$ & 28.0 & 25.8 & 2.44 & -0.50 \\
\hline $\mathrm{NH}_{2}$ & 27.5 & 26.9 & 2.33 & -0.53 \\
\hline
\end{tabular}

\subsection{Stoichiometric Carboxylation of $2 \mathrm{i}$ with 4-tert-butylstyrene}

Electron rich phosphines were not the only additives that have demonstrated enhancement in copper(I) catalysis. Inclusion of 4-tert-butylstyrene was found to facilitate the catalytic boracarboxylation of 4-trifluoromethylstyrene (Figure 3.9). ${ }^{119}$ In fact, although the carboxylation of 4-tert-butylstyrene is favorable in the standard reaction, the presence of both 4-tert-butylstyrene and 4-trifluoromethylstyrene leads to exclusive carboxylation of the electron deficient substrate. Thus, a stoichiometric study similar to that of the phosphine additives was conducted to elucidate the role of the alkene additive in the boracarboxylation reaction.

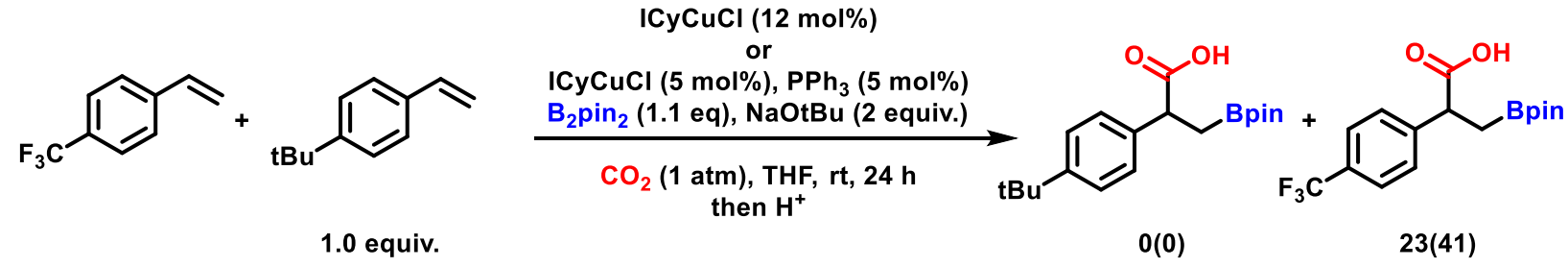

Figure 3.9. Alkene competition experiments for copper(I)-catalyzed boracarboxylation.

${ }^{a}$ Yields in parentheses reflect ICyCuCl only conditions. ${ }^{119}$

To focus on whether the exogeneous alkene affects carboxylation, $\mathrm{IPrCu}\left(\mathrm{CH}\left({ }^{\mathrm{PCF}_{3}} \mathrm{Ph}\right) \mathrm{CH}_{2}\right.$ Bpin) $\mathbf{2} \mathbf{i}$ was synthesized and isolated. Following the same protocol as with the phosphine study, a $10 \mathrm{mM}$ sample of $\mathbf{2} \mathbf{i}$ in benzene- $d_{6}$ was treated with 1 equivalent of 4-tertbutylstyrene. Importantly, a control experiment without $\mathrm{CO}_{2}$ addition revealed no reactivity between the $\mathrm{Cu}^{\mathrm{I}}\left(\beta\right.$-borylbenzyl $\left.{ }^{\mathrm{CF} 3}\right)$ complex, $2 \mathbf{i}$, and 4-tert-butylstyrene (1 equiv.) by ${ }^{1} \mathrm{H} \mathrm{NMR}$. 
Upon introduction of $\mathrm{CO}_{2}$, resonances indicative of spiroboralactonate $3 \mathbf{i}$ were observed, albeit slowly, with 50\% conversion after 21 hours. Increased initial rates were observed upon adding 2 equivalents of 4-tert-butylstyrene, after which a saturation dependence was observed up to 5 equivalents (Figure 3.10.). Importantly, no scrambling of the aryl substituents was observed, suggesting that deinsertion of the $p-\mathrm{CF}_{3}$ benzyl moiety and subsequent insertion of the 4-tertbutylstyrene into the $\mathrm{Cu}-\mathrm{Bpin}$ bond is not operative (Figure 3.11).

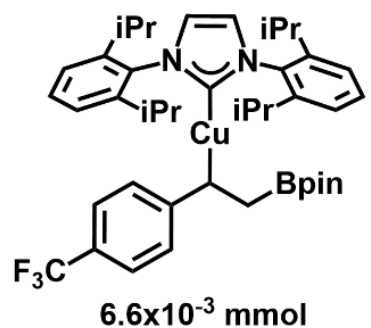

2i

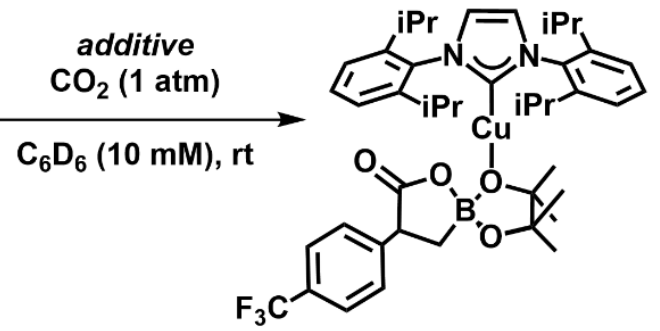

$3 \mathbf{i}$

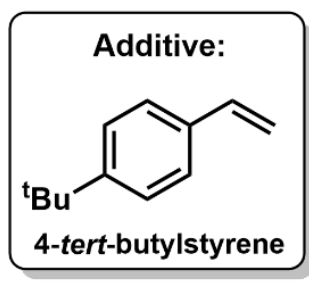

4-tert-butylstyrene

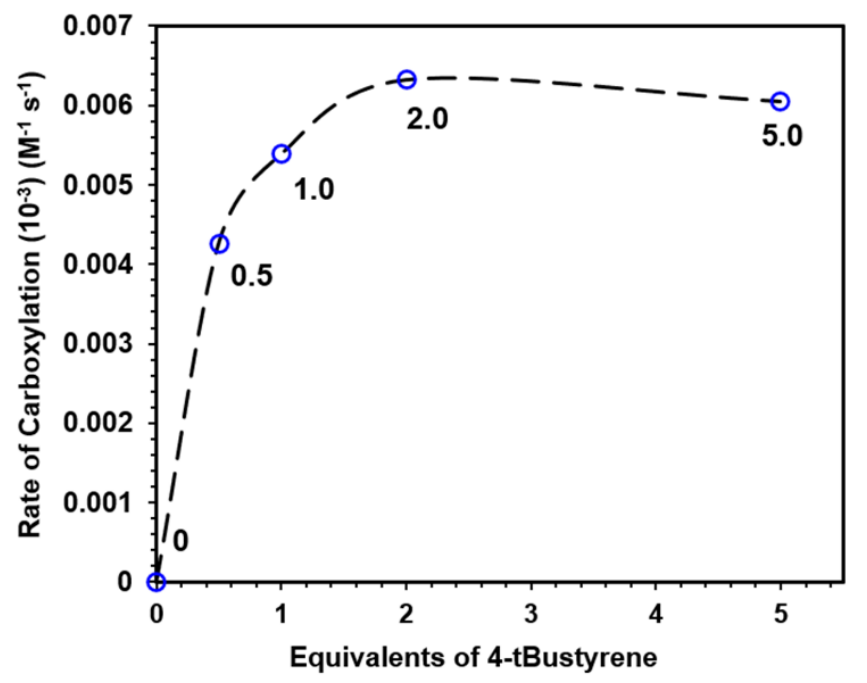

Figure 3.10. Rates of carboxylation for $p-\mathrm{CF}_{3}$ complex $2 \mathbf{i}$ with varying amounts of 4-tert-butylstyrene. 


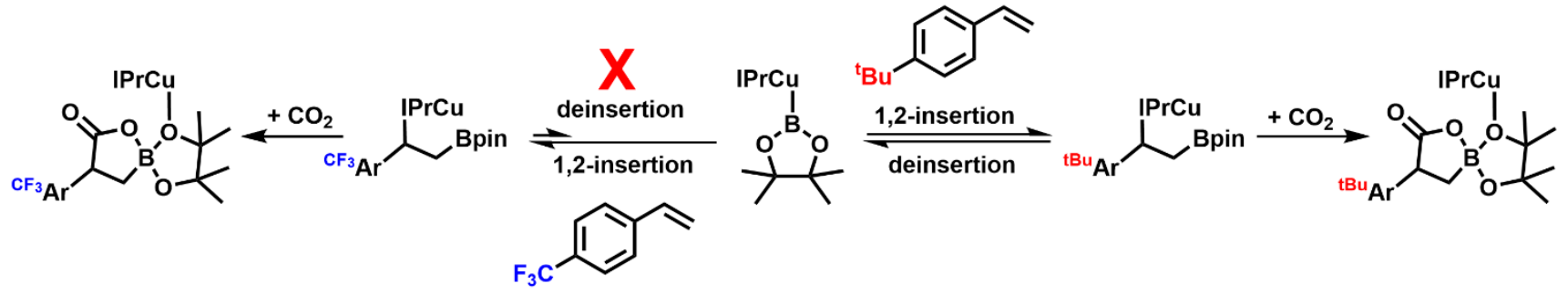

Figure 3.11. Visual representation of deinsertion of 4-trifluoromethylstyrene and subsequent insertion of 4-tert-butylstyrene into $\mathrm{Cu}$-Bpin bond.

The rate enhancement for carboxylation of $2 \mathbf{i}$ using electron rich $\mathrm{PPh}_{3}$ and 4-tert-butylstyrene, in addition to a rate reduction with electron-deficient phosphine additives (see above), suggests that a more electron deficient alkene additive would not serve as a potent accelerant. This was considered using a series of para-substituted styrene derivatives with varying electronic properties (Figure 3.12). As expected, the rate of carboxylation dramatically decreased with the increasingly electron deficient styrene derivatives.
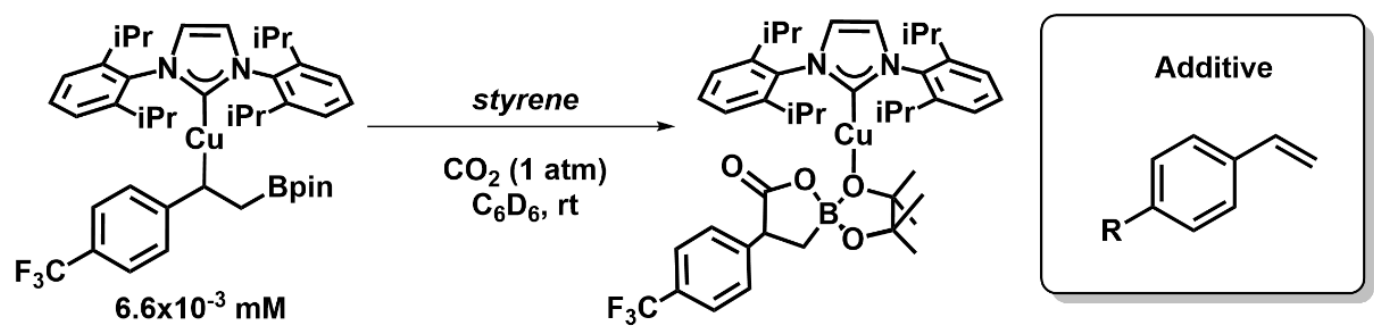

$2 \mathbf{i}$

$3 \mathbf{i}$

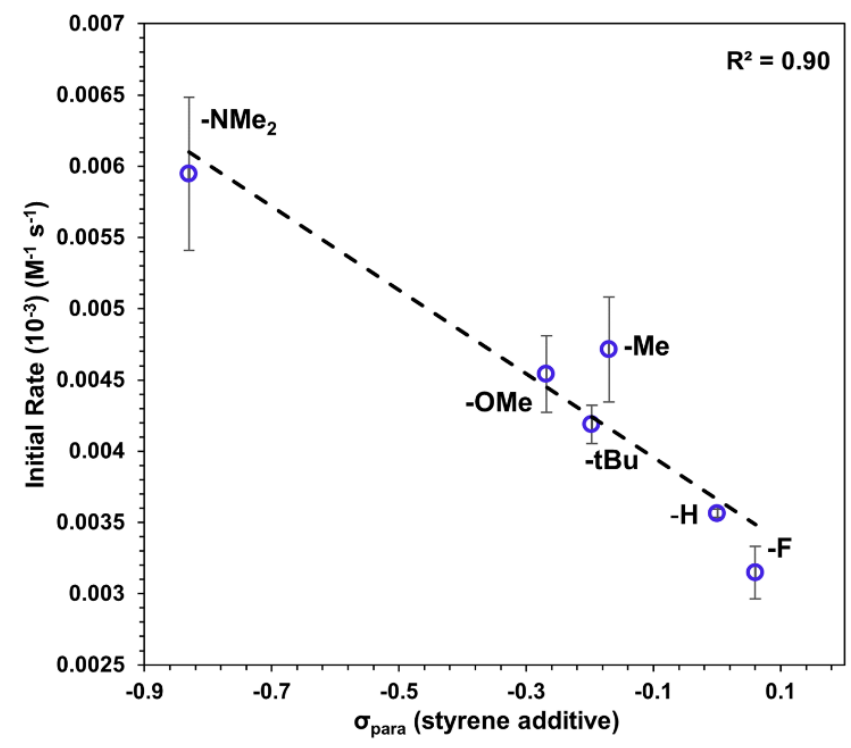

Figure 3.12. Initial rates of carboxylation of $\mathbf{2 i}$ with varying $p$-substituted styrene derivatives. 


\subsection{Computational Exploration of Carboxylation with Alkene Additives}

It is apparent that an electronic dependence on the styrene additive is operative, and with a desire to understand the mechanism, DFT was used to elucidate relevant intermediates and transition states of an alkene-aided carboxylation pathway. Along with IMe and B(eg), ethylene was used as an alkene model to reduce computational expense. Addition of ethylene in silico to $4 \mathbf{a}$ yielded a side-on $\mathrm{Cu}$-ethylene complex, wherein the ethylene retains a significant amount of its double bond character (calculated $\mathrm{C}=\mathrm{C}$ bond length of $1.38 \AA$ vs. $1.33 \AA$ of free ethylene) (Figure 3.13). As in the analogous $\mathrm{PMe}_{3}$ structure, the IMe ligand bends out of plane to accommodate the presence of ethylene binding in $4 \mathbf{a} \cdot\left(\mathbf{C}_{2} \mathbf{H}_{4}\right)$. Ethylene remains bound in the carboxylation transition state structure, although small changes in its bond lengths suggest that binding to copper is slightly compromised upon introduction of a $\mathrm{CO}_{2}$ molecule. $4 \mathbf{a} \cdot\left(\mathbf{C}_{2} \mathbf{H}_{4}\right)^{\mathrm{TS}}$ proved to be the most accessible transition state structure of carboxylation starting from $4 \mathbf{a} \cdot\left(\mathbf{C}_{2} \mathbf{H}_{4}\right)$ identified, and attempts to elucidate a transition state reflecting copper-assisted cooperative carboxylation on the potential energy surface were unsuccessful (Figure 3.13). 


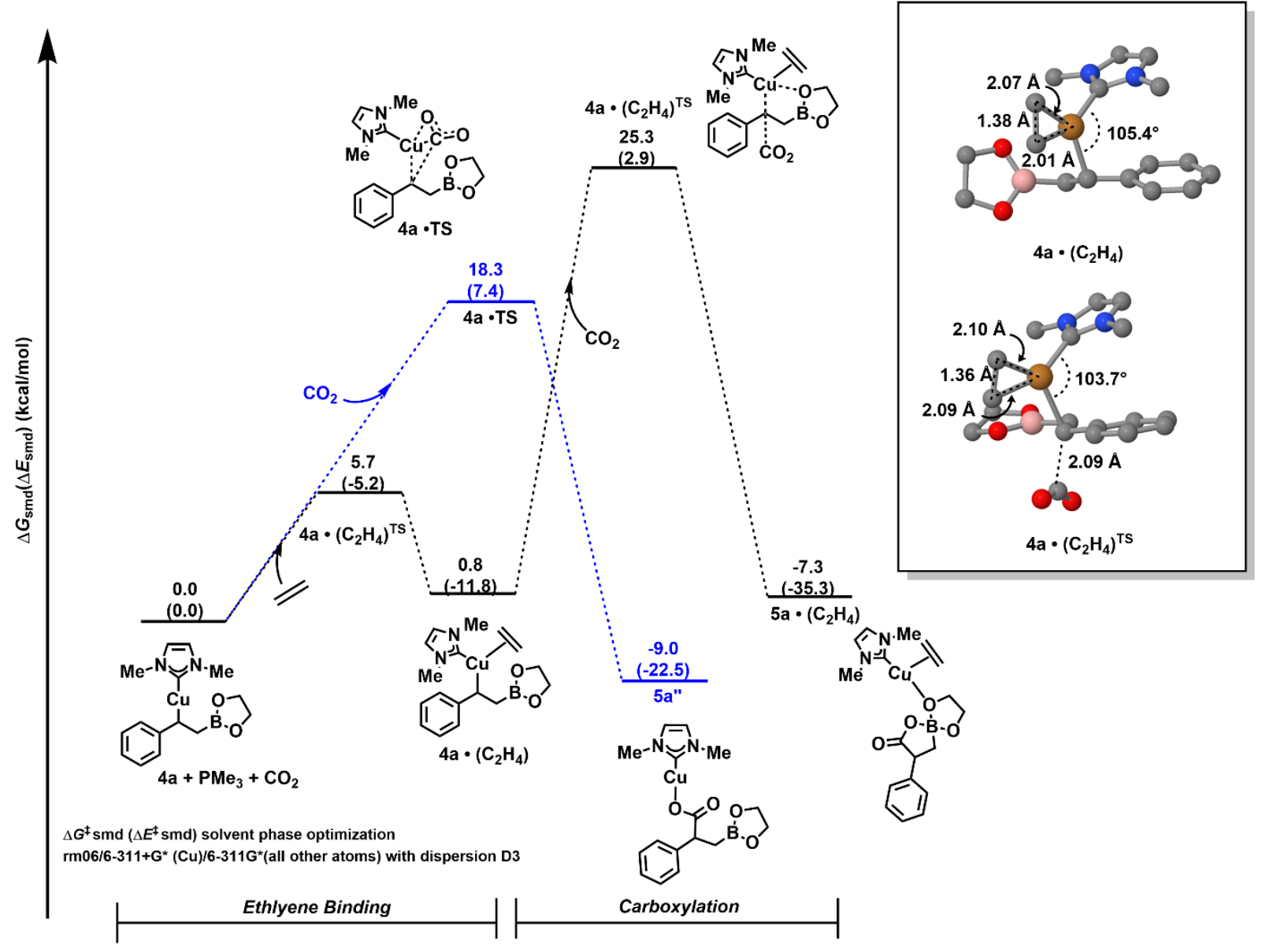

Figure 3.13. Reaction pathways for carboxylation of styrene a) under a cooperative regime without additive (blue trace); b) under an $\mathrm{S}_{\mathrm{E}} 2$ mechanism with 4-tertbutylstyrene as an additive (black).

Natural charge and other metrical data were also analyzed to better understand the effect of ethylene binding structurally (Figure 3.14). The ground state structure $4 \mathbf{a} \cdot\left(\mathbf{C}_{2} \mathbf{H}_{4}\right)$ resulted in an elongation of the $\mathrm{Cu}-\mathrm{C}_{\text {benzyl }}$ bond $(\Delta r=0.1 \AA)$ relative to $\mathbf{4 a}$. Further distortion of the structure was noted when comparing the transition state structures. The $\mathrm{Cu}-\mathrm{C}_{\text {benzyl }}$ bond was significantly elongated from $2.09 \AA$ in the case of $\mathbf{4 a} \cdot \mathbf{T S}^{\mathbf{S}_{\mathbf{E}}{ }^{2}}$ to $2.29 \AA$ for $\mathbf{4 a} \cdot\left(\mathbf{C}_{2} \mathbf{H}_{4}\right)^{\mathbf{S}_{\mathbf{E}}}$. This data is consistent with that from the case of $\mathrm{PMe}_{3}$ binding discussed above, supporting a similar role in carboxylation. 
A Unassisted Electrophilic Substitution
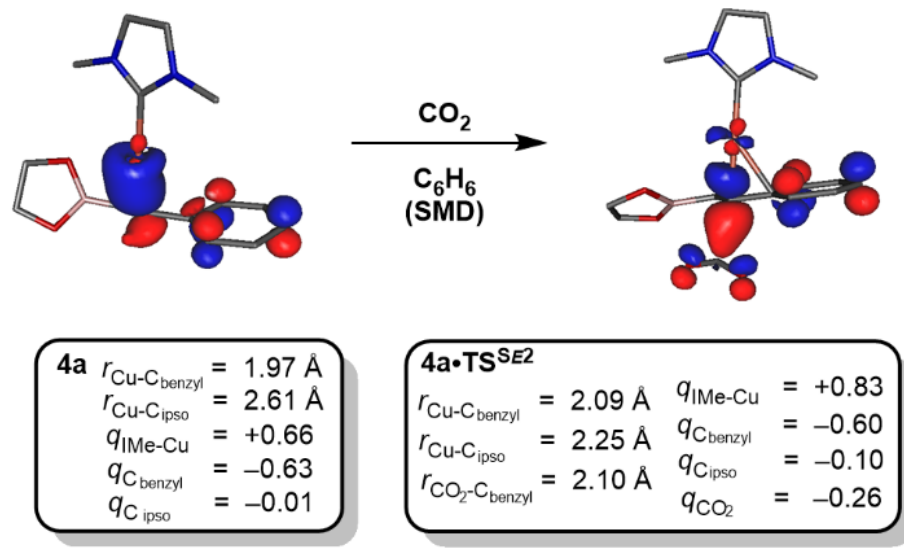

B Ethylene-Assisted Electrophilic Substitution
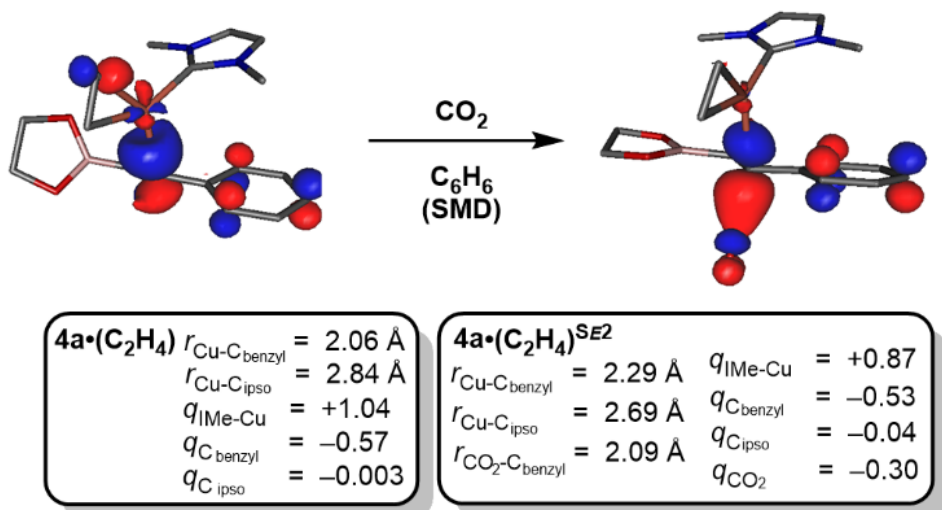

Figure 3.14. Renderings of the HOMOs for electrophilic substitution pathways as well as structural parameters and natural charges $(q)$ for relevant fragments obtained from NBO analysis.

\subsection{Conclusions}

This chapter presented stoichiometric reactivity studies of additive effects in carboxylation of $\mathrm{Cu}^{\mathrm{I}}(\beta$-borylbenzyl) complexes as well as computational elucidation of potential pathways that are relevant in the presence of these additives. It was demonstrated that the rate of carboxylation of electron-deficient $2 \mathbf{i}$ benefited from the presence of $\mathrm{PPh}_{3}$, enabling reactivity where it was otherwise absent. Alternatively, the carboxylation of electron-rich $\mathbf{2 d}$ suffered with increasing quantities of $\mathrm{PPh}_{3}$, suggesting that coordinative saturation of the copper center is deleterious and that alternative $\mathrm{S}_{\mathrm{E}}-$ like pathways are not favorable. The electronic impact of the phosphine additive was also considered, wherein it was shown that more electron rich phosphines lead to higher rates than when electron deficient phosphines of similar size are employed. 
The trends observed with phosphine additive extended to exogeneous styrene additives. Inclusion of 4-tert-butylstyrene increased the rate of carboxylation for $\mathbf{2} \mathbf{i}$, and that rate was directly dependent on the electronic character of the para-substituted vinyl arene additives. One notable difference, however, is that minimal inhibition of the carboxylation rate of $\mathbf{2} \mathbf{i}$ was noted with large excess of 4-tert-butylstyrene. Computational analysis of both systems suggested an additivemediated pathway would likely involve initial interaction of $\mathrm{PPh}_{3}$ or vinyl arene with the copper center to block the binding site for $\mathrm{CO}_{2}$. Further, the increased steric bulk imposed by the additive initiates a $\mathrm{Cu}-\mathrm{C}_{b e n z y l}$ bond elongation or scission, providing a largely anionic benzylic carbon for attack on the electrophilic carbon of $\mathrm{CO}_{2}$.

Understanding the mechanism by which additives affect the copper-catalyzed boracarboxylation of vinyl arenes could allow for expansion of the substrate scope, not only to styrene derivatives but perhaps to include aliphatic alkenes. Additionally, this methodology could be applied in other areas of carboxylation chemistry to potentially facilitate more challenging transformations. 


\subsection{Experimental}

General Information: All air- and moisture-sensitive manipulations were performed under a dry atmosphere of argon using Schlenk line techniques and under a nitrogen atmosphere in an MBraun glovebox. Solvents used were purchased from Fisher and were further dried through a Glass Contour Solvent Purification System and stored over $4 \AA$ molecular sieves. Liquid reagents were degassed via freeze/pump/thaw method, and solids are dried under vacuum prior to transfer to the glovebox. Dry carbon dioxide was passed through drying column containing desiccant prior to use. ${ }^{1} \mathrm{H}$ NMR spectra were recorded using Agilent $400 \mathrm{MHz}$ and Varian INOVA $600 \mathrm{MHz}$ NMR spectrometers. Deuterated benzene $\left(\mathrm{C}_{6} \mathrm{D}_{6}\right)$ was distilled from sodium metal and stored in the glovebox.

Synthesis of Complexes 2i: Under an atmosphere of $\mathrm{N}_{2}, 1$ equiv. of $\mathrm{IPrCuO}^{\mathrm{t}} \mathrm{Bu}(100 \mathrm{mg}, 0.19$ mmol) was combined with 1.1 equiv. of $\mathrm{B}_{2} \operatorname{pin}_{2}(54 \mathrm{mg}, 0.21 \mathrm{mmol})$ in $5 \mathrm{~mL}$ of THF. After stirring at ambient temperature for 10 minutes, 1.1 equiv. of the 4-tert-butylstyrene $(0.21 \mathrm{mmol})$ was added. The reaction was stirred for 1 hour, after which time the solvent was removed. The resulting residue was triturated with $n$-pentane twice and was subsequently collected on a medium porosity ground glass fritted funnel. See Chapter 2 for characterization details.

Carboxylation Kinetics: The following procedure was used in performing kinetic experiments for the carboxylation of $\mathrm{Cu}^{\mathrm{I}}\left(\beta\right.$-borylbenzyl) complexes. Under a $\mathrm{N}_{2}$ glovebox atmosphere, $5 \mathrm{mg}$ of $\mathrm{Cu}^{\mathrm{I}}\left(\beta\right.$-borylbenzyl $\left.{ }^{\mathrm{ptBu}}\right)(\mathbf{2 d})$ and $\mathrm{Cu}^{\mathrm{I}}\left(\beta\right.$-borylbenzyl $\left.{ }^{\mathrm{pCF}_{3}}\right)$ complex (2i) were dissolved in $\mathrm{C}_{6} \mathrm{D}_{6}$ and combined with mesitylene as an internal standard $\left(0.1 \mathrm{M}\right.$ in $\left.\mathrm{C}_{6} \mathrm{D}_{6}\right)$ to produce a $10 \mathrm{mM}$ sample. The appropriate additive (in stock solutions in $\mathrm{C}_{6} \mathrm{D}_{6}$ ) was added, and the sample was transferred to a J. Young NMR tube. Using Schlenk techniques, the sample was freeze/pump/thawed 2 times. The sample was then cooled to $-20^{\circ} \mathrm{C}(1: 3 \mathrm{NaCl} /$ ice bath $)$, and the evacuated headspace was filled with $1 \mathrm{~atm}$ of dry $\mathrm{CO}_{2}$. The tube was resealed and kept frozen until loading into the NMR instrument. Spectra were then collected at consistent intervals for the duration of the reaction. 
Computational Methods: All calculations were performed using the Gaussian 16 package. ${ }^{126}$ For ground state and transition state geometry optimizations, the M06 ${ }^{127}$ and the Pople basis sets $6-311+\mathrm{G}^{*}$ for copper and $6-311 \mathrm{G}^{*}$ for all other atoms were used. ${ }^{128}$ For alkene calculations, dispersion corrections were employed using the keyword 'empiricaldispersion $=\mathrm{GD} 3$ '. Frequency calculations at the same level of theory in each case were performed to validate stationary points, with zero imaginary frequencies reflecting ground state minima and one imaginary frequency representing transition state minima. Transition states were further validated through intrinsic reaction coordinate (IRC) calculations, using the TS structure as starting point. ${ }^{129}$ Single-point selfconsistent reaction field calculations (SCRF) were also performed to identify solvent effects using the SMD model. ${ }^{130}$ Benzene was used in solvent calculations to reflect the experimental conditions in the kinetic studies. JMol was used to generate optimized molecular structures. ${ }^{131}$

126. Gaussian 16, Revision B.01, M. J. Frisch, G. W. Trucks, H. B. Schlegel, G. E. Scuseria, M. A. Robb, J. R. Cheeseman, G. Scalmani, V. Barone, G. A. Petersson, H. Nakatsuji, X. Li, M. Caricato, A. V. Marenich, J. Bloino, B. G. Janesko, R. Gomperts, B. Mennucci, H. P. Hratchian, J. V. Ortiz, A. F. Izmaylov, J. L. Sonnenberg, D. WilliamsYoung, F. Ding, F. Lipparini, F. Egidi, J. Goings, B. Peng, A. Petrone, T. Henderson, D. Ranasinghe, V. G. Zakrzewski, J. Gao, N. Rega, G. Zheng,W. Liang, M. Hada, M. Ehara, K. Toyota, R. Fukuda, J. Hasegawa, M. Ishida, T. Nakajima, Y. Honda, O. Kitao, H. Nakai, T. Vreven, K. Throssell, J. A. Montgomery, Jr., J. E. Peralta, F. Ogliaro, M. J. Bearpark, J. J. Heyd, E. N. Brothers, K. N. Kudin, V. N. Staroverov, T. A. Keith, R. Kobayashi, J. Normand, K. Raghavachari, A. P. Rendell, J. C. Burant, S. S. Iyengar, J. Tomasi, M. Cossi, J. M. Millam, M. Klene, C. Adamo, R. Cammi, J. W. Ochterski, R. L. Martin, K. Morokuma, O. Farkas, J. B. Foresman, and D. J. Fox, Gaussian, Inc., Wallingford CT, 2016.

127. (a) McLean, A. D.; Chandler, G. S. Contracted Gaussian-basis sets for molecular calculations. 1. 2nd row atoms, $\mathrm{Z}=11$-18. J. Chem. Phys. 1980, 72, 5639-5648. (b) Raghavachari, K.; Binkley, J. S.; Seeger, R.; Pople, J. A. SelfConsistent Molecular Orbital Methods. 20. Basis set for correlated wave-functions," J. Chem. Phys. 1980, 72, 6506554.

128. (a) Wachters, A. J. H. Gaussian basis set for molecular wavefunctions containing third-row atoms. J. Chem. Phys., 1970, 52, 1033. (b) Hay, P. J. Gaussian basis sets for molecular calculations - representation of 3D orbitals in transition-metal atoms. J. Chem. Phys., 1977, 66, 4377-4384. (c) Raghavachari, K.; Trucks, G. W. Highly correlated systems: Excitation energies of first row transition metals Sc-Cu. J. Chem. Phys. 1989, 91, 1062-65.

129. (a) Fukui, K. Formulation of the reaction coordinate. J. Phys. Chem. 1970, 74, 4161-4163. (b) Fukui, K. The path of chemical reactions - the IRC approach. Acc. Chem. Res. 1981, 14, 363-368.

130. Marenich, A. V.; Cramer, C. J.; Truhlar, D. G. Universal solvation model based on solute electron density and a continuum model of the solvent defined by the bulk dielectric constant and atomic surface tensions. J. Phys. Chem. B. 2009, 113, 6378-96.

131. Jmol: an open-source Java viewer for chemical structures in 3D. http://www.jmol.org/ 


\section{CHAPTER 4}

\section{Evidence of Boron Assistance for $\mathrm{CO}_{2}$ Activation during Copper-Catalyzed Boracarboxylation of Vinyl Arenes}

Reproduced with permission from Comments on Inorganic Chemistry, 2020, 1-16.

Copyright Taylor \& Francis 2020

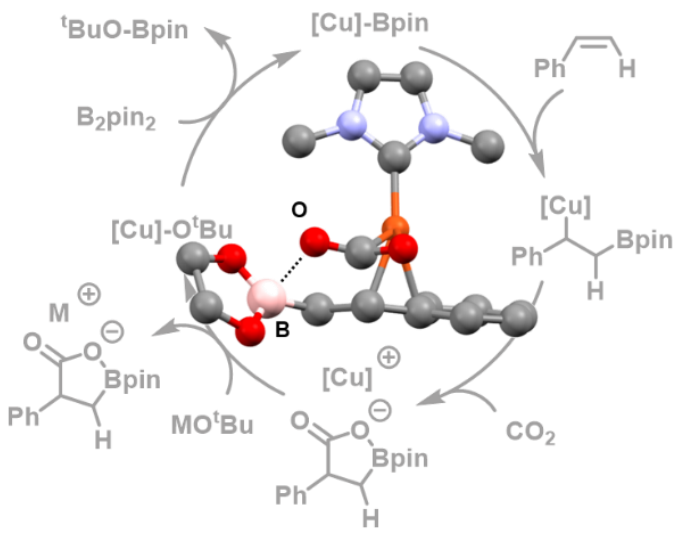

Lewis Acid Assisted Carboxylation

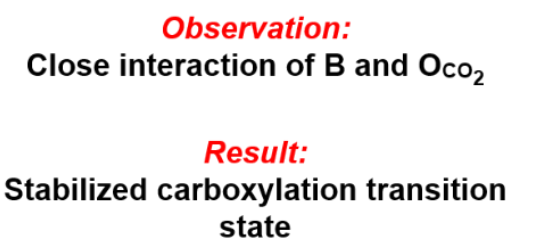

\subsection{Abstract}

Density functional theory was utilized to explore the mechanism by which $\mathrm{Cu}(\mathrm{I})$-catalyzed boracarboxylation of vinyl arene occurs, with specific focus on $\mathrm{CO}_{2}$ insertion into the $\mathrm{Cu}$-benzyl bond. These calculations indicate a potential non-covalent interaction between boron and $\mathrm{CO}_{2}$ in the carboxylation transition state, implicating cooperative $\mathrm{CO}_{2}$ activation. Study of the boron Lewis acidity, thought to be the driving force for this interaction, was conducted through substitution of the $\mathrm{sp}^{2}$ mono-boron substituent located adjacent to the point of copper attachment. An inverse correlation between boron valence deficiency (BVD) and the enthalpic barrier of $\mathrm{CO}_{2}$ insertion into $\mathrm{Cu}(\mathrm{I})(\beta$-borylbenzyl) structure was revealed, supporting Lewis acid/base cooperativity between boron and the proximal oxygen of $\mathrm{CO}_{2}$ at the transition state. 


\subsection{Cooperative Activation in Nature}

Examples of cooperative catalysis in enzymatic processes occur through both first- and second-sphere interactions in the form of H-bonding, charge stabilization, and substrate positioning induced by the surrounding residues that comprise the binding pocket. ${ }^{132}$ Such interactions lead to efficient catalysis under the biological conditions of the organism. Specifically, it has been demonstrated that ligands located in the secondary coordination sphere are paramount for successful transformations (Figure 4.1).

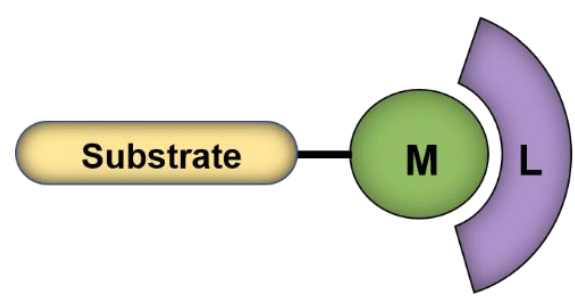

Classical Catalysis

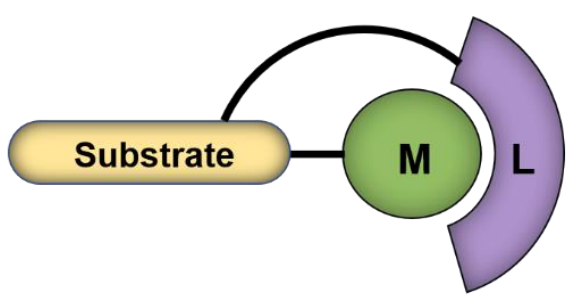

Cooperative Catalysis

Figure 4.1. Depiction of classical catalysis and cooperative catalysis, wherein transformation is aided by the ligand. Figure reproduced from Ref. 133.

Hydrogenase enzymes, for example, rely on the presence of secondary sphere ligands (azadithiolate in the case of $[\mathrm{Fe}, \mathrm{Fe}]$ and an arginine residue in $[\mathrm{Ni}, \mathrm{Fe}]$ ) as proximal bases to facilitate $\mathrm{H}_{2}$ activation (Figure 4.2). ${ }^{133}$ Cooperative activation is operative in other enzymes, such as alcohol dehydrogenase, which reversibly oxidizes alcohols to aldehydes or ketones, ${ }^{133}$ as well as in a number of heme enzymes, to name a few. ${ }^{132}$

132. De Visser, S. P. Second-Coordination Sphere Effects on Selectivity and Specificity of Heme and Nonheme Iron Enzymes. Chem. Eur. J. 2020, 26, 5208-5327.

133. Wodrich, M. D.; Xu, X. Natural Inspirations for Metal-Ligand Cooperative Catalysis. Nat. Chem. Rev. 2018, 2, $1-7$. 
[Fe,Fe]-Hydrogenase
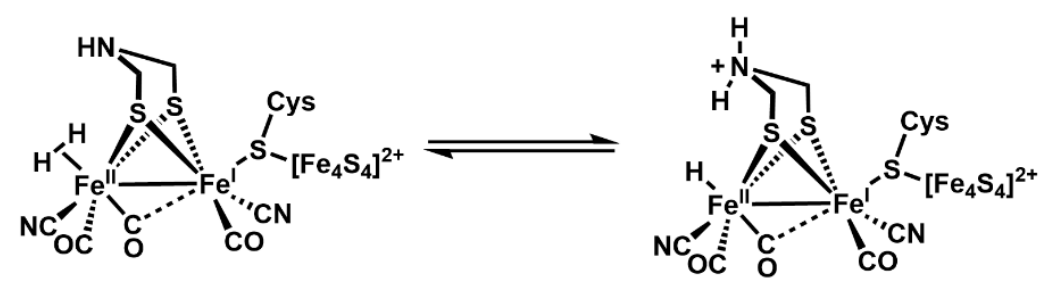

[Ni,Fe]-Hydrogenase
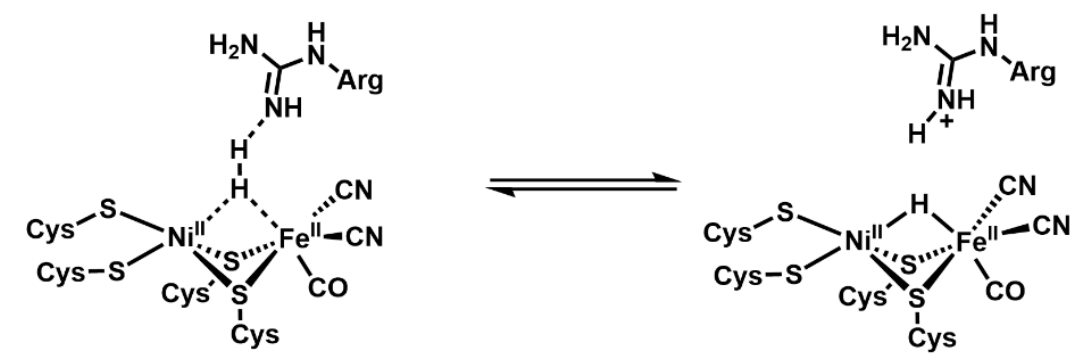

Figure 4.2. Second-sphere cooperative $\mathrm{H}_{2}$ scission in the active sites of [Fe,Fe]and $[\mathrm{Ni}, \mathrm{Fe}]$-hydrogenases.

In Chapter 1, carbon monoxide dehydrogenase enzymes were briefly discussed. In both the case of the Mo, $\mathrm{Cu}$ (aerobic) and $\mathrm{Ni}, \mathrm{Fe}$ (anaerobic) enzymes, the active sites are surrounded by an amino acid pocket that provides stability to the substrate entering the cavity as well as sets selectivity of the transformation. Crystallographic analysis of the isolated aerobic carbon monoxide dehydrogenase (CODH) enzyme supports the presence of glutamic acid 763 (Glu763) that stabilizes the active site pocket, and a water molecule that occupies the active site until a molecule of $\mathrm{CO}$ or $\mathrm{CO}_{2}$ is bound. ${ }^{134}$ In the case of anaerobic $\mathrm{CODH}$, the $\mathrm{CO}_{2}$ molecule is stabilized and subsequently activated by $\mathrm{Ni}^{\mathrm{II}}$ and $\mathrm{Fe}^{\mathrm{II}}$ centers of the $[\mathrm{Ni}-4 \mathrm{Fe}-5 \mathrm{~S}]$ cluster as well as through interaction with proximal histidine $\left(\mathrm{H}_{93}\right)$ and lysine $\left(\mathrm{K}_{563}\right)$ residues (Figure 4.3). ${ }^{135,136}$ Further,

134. Gourlay, C.; Nielsen, D. J.; Evans, D. J.; White, J. M.; Young, C. G. Models for Aerobic Carbon Monoxide Dehydrogenase: Synthesis, Characterization, and Reactivity of Paramagnetic $\mathrm{Mo}^{\mathrm{V}} \mathrm{O}(\mu-\mathrm{S}) \mathrm{Cu}^{\mathrm{I}}$ Complexes. Chem. Sci. 2018, 9, 876-888.

135. Dobbek, H.; Svetlitchnyi, V.; Gremer, L.; Huber, R.; Meyer, O. Crystal Structure of a Carbon Monoxide Dehydrogenase Reveals a [Ni-4Fe-5S] Cluster. Science 2001, 17, 1281-1285.

136. Jeoung, J. H.; Dobbek, H. Carbon Dioxide Activation at the Ni,Fe-Cluster of Anaerobic Carbon Monoxide Dehydrogenase. Science 2007, 318, 1461-1464. 
there is evidence to suggest that the $\mathrm{K}_{563}$ residue is responsible for shuttling protons to and from the active site. ${ }^{137,138}$

A.

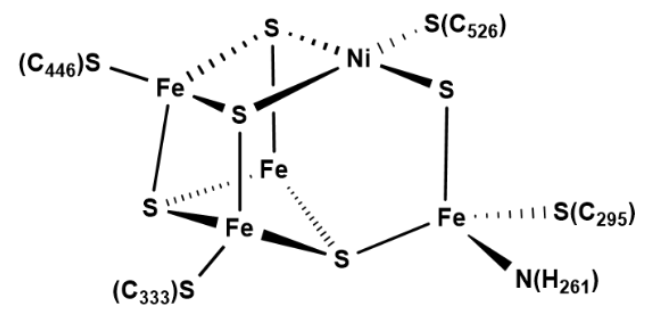

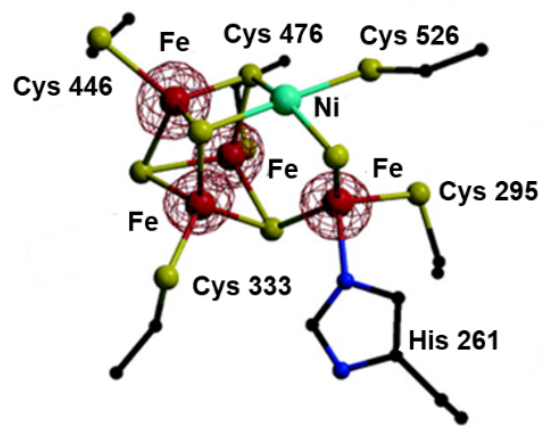

B.

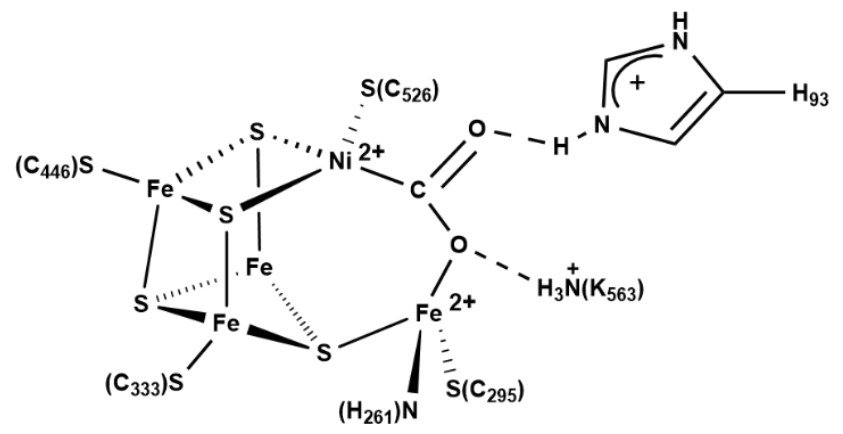

Figure 4.3. A) Molecular structure of the inactivated Ni,Fe-carbon monoxide dehydrogenase (CODH II) cofactor from the anaerobic bacterium Carboxydothermus hydrogenoformans. ${ }^{135} \mathrm{~B}$ ) Visual representation of the Ni-Fe CODH cofactor binding carbon dioxide, which was characterized crystallographically. ${ }^{136}$

\subsection{Cooperative Activation of $\mathrm{CO}_{2}$ at Transition Metal Complexes}

Enzymes have been the inspiration for several models synthesized with the purpose of exploring secondary sphere effects on the activation of organic compounds. ${ }^{139}$ A contemporary

137. Kim, E. J.; Bramlett, M. R.; Lindahl, P. A. Evidence for a Proton Transfer Network and a Required PersulfideBond-Forming Cysteine Residue in Ni-Containing Carbon Monoxide Dehydrogenases. Biochemistry 2004, 43, 57285734.

138. Fesseler, J.; Jeoung, J. H.; Dobbek, H. How the $\left[\mathrm{NiFe}_{4} \mathrm{~S}_{4}\right]$ Cluster of $\mathrm{CO}$ Dehydrogenase Activates $\mathrm{CO}_{2}$ and $\mathrm{NCO}^{-}$. Angew. Chem. Int. Ed. 2015, 54, 8560-8564.

139. For selected works on the synthetic manipulation of second coordination sphere interactions, see: (a) Schmeier, T. J.; Dobereiner, G. E.; Crabtree, R. H.; Hazari, N. Secondary Coordination Sphere Interactions Facilitate the Insertion Step in an Iridium(III) $\mathrm{CO}_{2}$ Reduction Catalyst. J. Am. Chem. Soc. 2011, 133, 9274-9277. (b) Feller, M.; Gellrich, U.; Anaby, A.; Diskin-Posner, Y.; Milstein, D. Reductive Cleavage of $\mathrm{CO}_{2}$ by Metal-Ligand-Cooperation Mediated by an Iridium Pincer Complex. J. Am. Chem. Soc. 2016, 138, 6445-6454. (c) Oren, D.; Diskin-Posner, Y.; Avram, L.; Feller, M.; Milstein, D. Metal-Ligand Cooperation as Key in Formation of Dearomatized Ni ${ }^{\mathrm{II}}$-H Pincer Complexes and in Their Reactivity toward $\mathrm{CO}$ and $\mathrm{CO}_{2}$. Organometallics 2018, 37, 2217-2221. (d) Jiang, Y.; Blacque, O.; Fox, T.; Berke, H. Catalytic $\mathrm{CO}_{2}$ Activation Assisted by Rhenium Hydride/B $\left(\mathrm{C}_{6} \mathrm{~F}_{5}\right)_{3}$ Frustrated Lewis 
example from Mankad and coworkers is a tungsten/copper analog of the aerobic CODH that leverages frustrated Lewis pair (FLP) chemistry integrated into the ligand (Figure 4.4.A). ${ }^{140}$ This mimic was modeled to oxidize $\mathrm{CO}$ to $\mathrm{CO}_{2}$ in a similar fashion to the $\mathrm{CODH}$ enzymatic active site (Figure 4.4.B).

A.

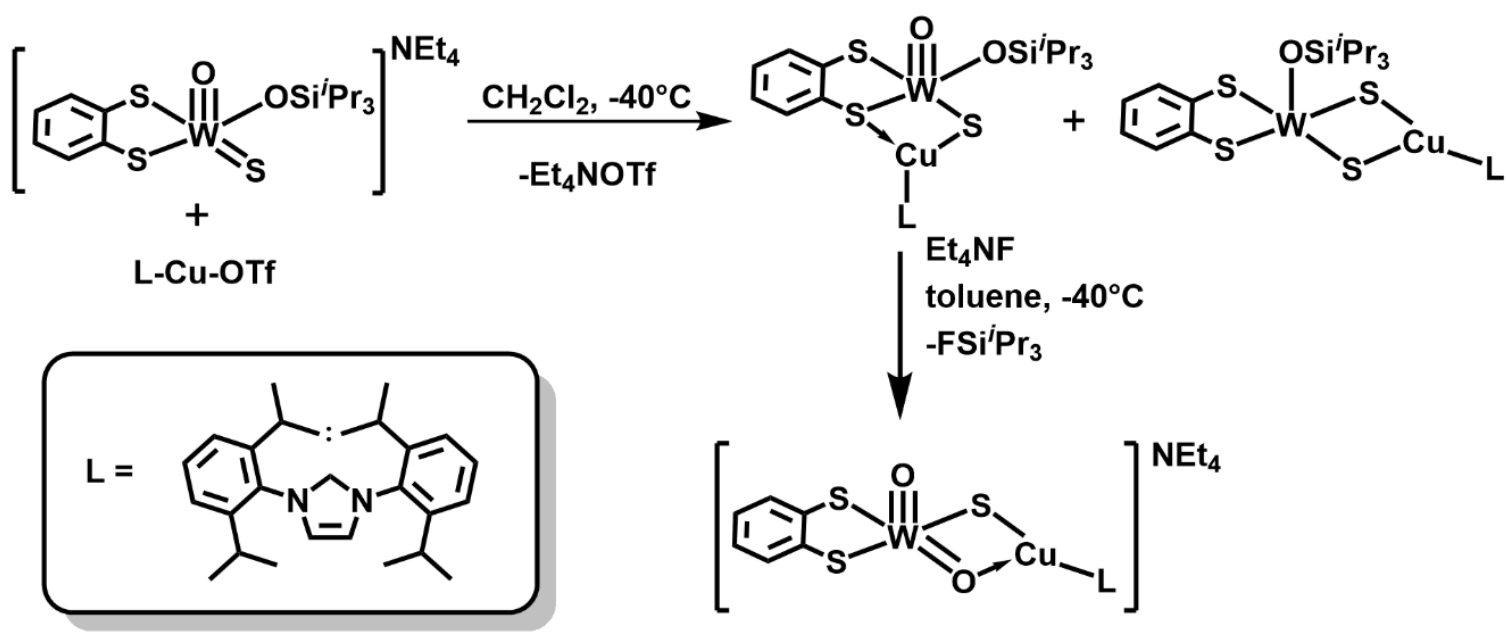

B.

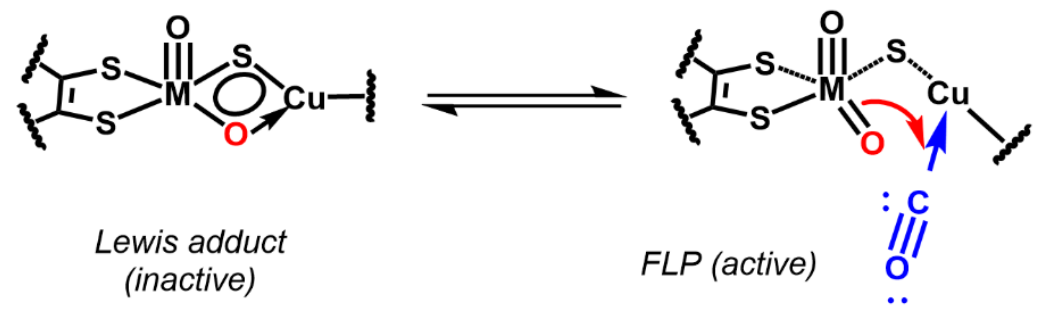

Figure 4.4. A) Tungsten-oxo complexes bearing frustrated-Lewis pair ligands. B) A theoretical representation of the conversion of $\mathrm{CO}$ to $\mathrm{CO}_{2} .{ }^{140}$

Pairs-Metal Hydrides Functioning as FLP Bases. J. Am. Chem. Soc. 2013, 135, 7751-7760. (e) Courtemanche, M.; Légaré, M.; Maron, L.; Fontaine, F. A Highly Active Phosphine-Borane Organocatalyst for the Reduction of $\mathrm{CO}_{2}$ to Methanol Using Hydroboranes. J. Am. Chem. Soc. 2013, 135, 9326-9329. (f) Courtemanche, M.; Légaré, M.; Maron, L.; Fontaine, F. Reducing $\mathrm{CO}_{2}$ to Methanol Using Frustrated Lewis Pairs: On the Mechanism of Phosphine-BoraneMediated Hydroboration of $\mathrm{CO}_{2}$. J. Am. Chem. Soc. 2014, 136, 10708-10717. (g) Parks, D. J.; Piers, W. E. Tris (Pentafluorophenyl)Boron-Catalyzed Hydrosilation of Aromatic Aldehydes, Ketones, and Esters. J. Am. Chem. Soc. 1996, 118, 9440-9441. (h) Chen, D.; Gau, M. R.; Dobereiner, G. E. Palladium and Platinum Acyl Complexes and their Lewis Acid Adducts: Experimental and Computational Study of Thermodynamics and Bonding. Organometallics 2015, 34, 4069-4075. (i) Becica, J.; Dobereiner, G. E. The Roles of Lewis Acidic Additives in Organotransition Metal Catalysis. Org. Biomol. Chem. 2019, 17, 2055-2069.

140. Dibbendu, G.; Sinhababu, S.; Santarsiero, B. D.; Mankad, N. P. A W/Cu Synthetic Model for the Mo/Cu Cofactor of Aerobic CODH Indicates that Biochemical CO Oxidation Requires a Frustrated Lewis Acid/Base Pair. J. Am. Chem. Soc. 2020. 142, 12635-12642. 
Other discrete organic and organometallic molecules have demonstrated cooperative secondary sphere activation capabilities. In 2011, Crabtree and Hazari reported an iridium(III)PNP-hydride complex $\left(\mathrm{PNP}=\mathrm{HN}\left({ }^{\mathrm{i}} \mathrm{Pr}_{2} \mathrm{PC}_{2} \mathrm{H}_{4}\right)_{2}\right)$ suitable for the hydrogenation of $\mathrm{CO}_{2}$ gas (Figure 4.5, Top). Interaction of carbon dioxide with the $\mathrm{N}-\mathrm{H}$ bond in the ligand backbone provided stabilization during its insertion into the metal-hydride to generate a formate-appended iridium complex. ${ }^{139 a}$ Exclusion of exogeneous Lewis acid has also led to $\mathrm{CO}_{2}$ activation through secondary sphere interactions. Such was the case with the rhenium(I) hydride complex developed by Berke. ${ }^{139 \mathrm{~d}}$ It was found that only in the presence of $\mathrm{B}\left(\mathrm{C}_{6} \mathrm{~F}_{5}\right)_{3}$ would the complex activate $\mathrm{CO}_{2}$, which they attributed to weak hydridic and nucleophilic character of the Re-H bond (Figure 4.5, Middle).

Hazari, 2011

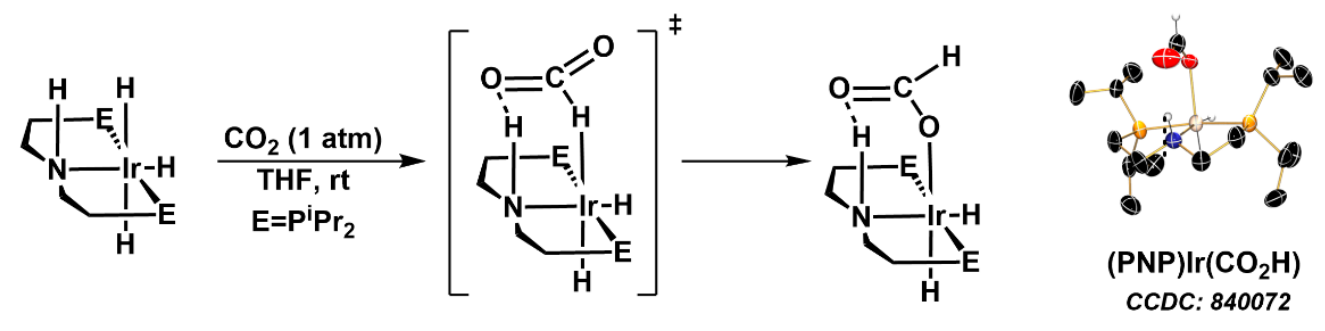

Berke, 2013
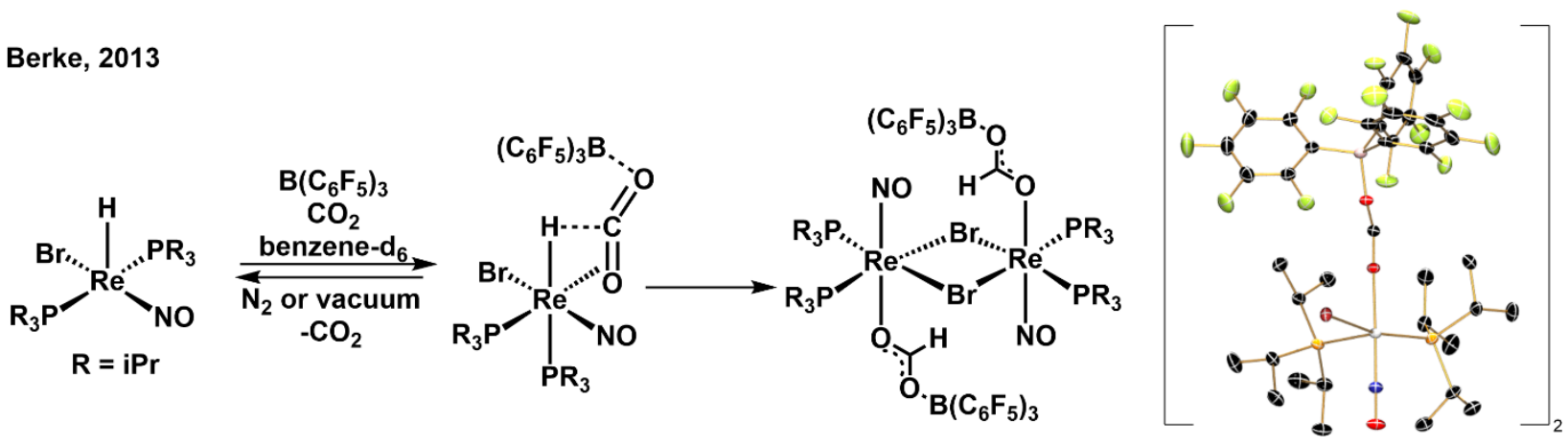

Fontaine, 2014

$\left[\left\{\operatorname{Re}(\mu-\mathrm{Br})(\mathrm{NO})\left(\eta^{1}-\mathrm{OCH}=\mathrm{O}-\mathrm{B}\left(\mathrm{C}_{6} \mathrm{~F}_{5}\right)_{3}\right)-\left(\mathrm{PiPr}_{3}\right)_{2}\right\}_{2}\right]$

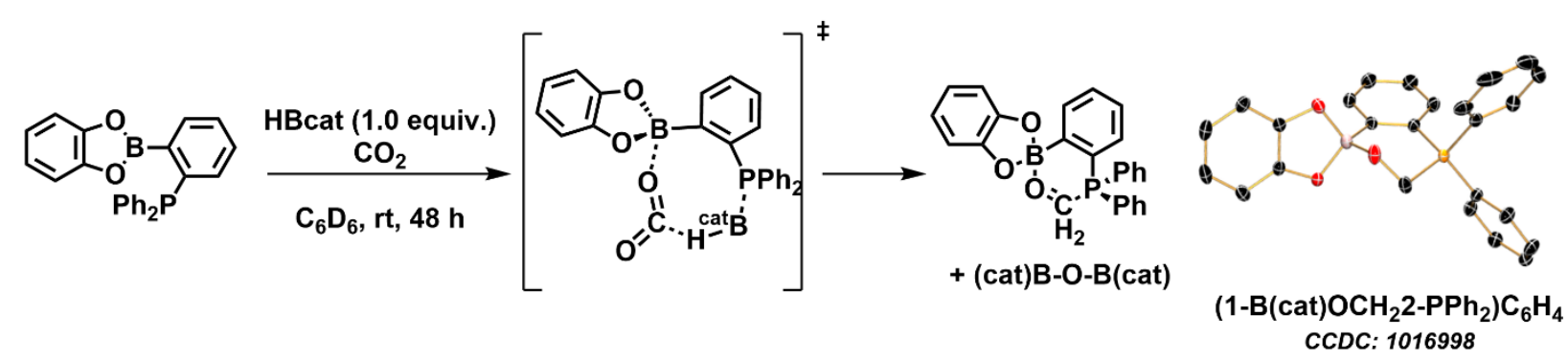

Figure 4.5. Examples of $\mathrm{CO}_{2}$ activation and functionalization using secondary sphere effects. 
There have also been metal-free examples where the concept of secondary sphere cooperative activation is operative. In 2014, Fontaine provided experimental and computational evidence that suggested a phosphine-borane FLP was responsible for the activation and ultimate reduction of $\mathrm{CO}_{2}$ to methanol with a proton transfer from excess catecholborane (HBcat) in solution (Figure 4.5 , Bottom). ${ }^{139}$

\subsection{Boron as a Second-Sphere Activator}

Installation of boron moieties into ligand frameworks provides access to multifunctional complexes as effective catalysts. For example, Szymczak has demonstrated the utility of Lewis acid-appended ligands in the hydrogenation of internal alkynes (100\% selective for the Z-isomer product) and terminal alkynes (selective for semi-hydrogenation to alkene) (Table 4.1). ${ }^{141}$ The presence of the borane is thought to not only promote the heterolysis of $\mathrm{H}_{2}$, but also stabilizes the reactive $\mathrm{Ru}-\mathrm{H}$ intermediate and provides additional steric bulk. This also modulates selectivity for semi-hydrogenation to alkene products.

Table 4.1. The Ru-catalyzed hydrogenation of alkynes assisted by secondary sphere interactions with a pendent boron on an NNN ligand. ${ }^{141}$

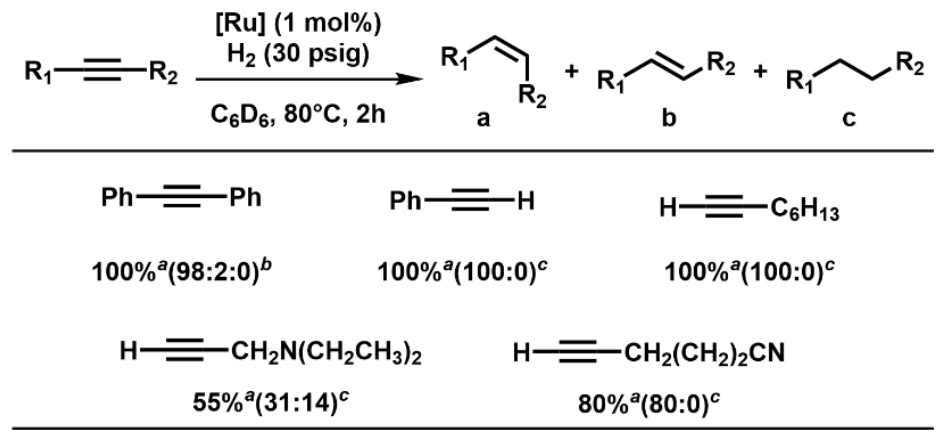

${ }^{a}$ Percent conversion. ${ }^{b}(\mathrm{a}: \mathrm{b}: \mathrm{c}) .{ }^{c}(\mathrm{~b}: \mathrm{c})$.

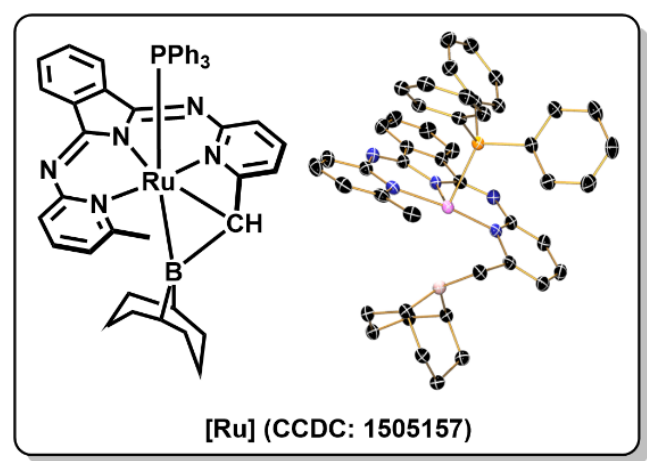

In a more recent report, hydrazine was activated using $\left({ }^{\mathrm{BBN}} \mathrm{NN}^{\mathrm{tBu}}\right) \mathrm{FeBr}_{2}$, an iron complex ligated with a nitrogen-based bidentate ligand featuring a pendent $\mathrm{BBN}$ group $(\mathrm{BBN}=9$ -

141. Tseng, K. N. T.; Kampf, J. W.; Szymczak, N. K. Modular Attachment of Appended Boron Lewis Acids to a Ruthenium Pincer Catalyst: Metal-Ligand Cooperativity Enables Selective Alkyne Hydrogenation. J. Am. Chem. Soc. 2016, 138, 10378-10381. 
borabicyclo[3.3.1]nonyl) (Figure 4.6). ${ }^{142}$ Adding $\mathrm{KC}_{8}$ resulted in the scission of the appended hydrazine, and ammonium chloride was released following acidic workup.

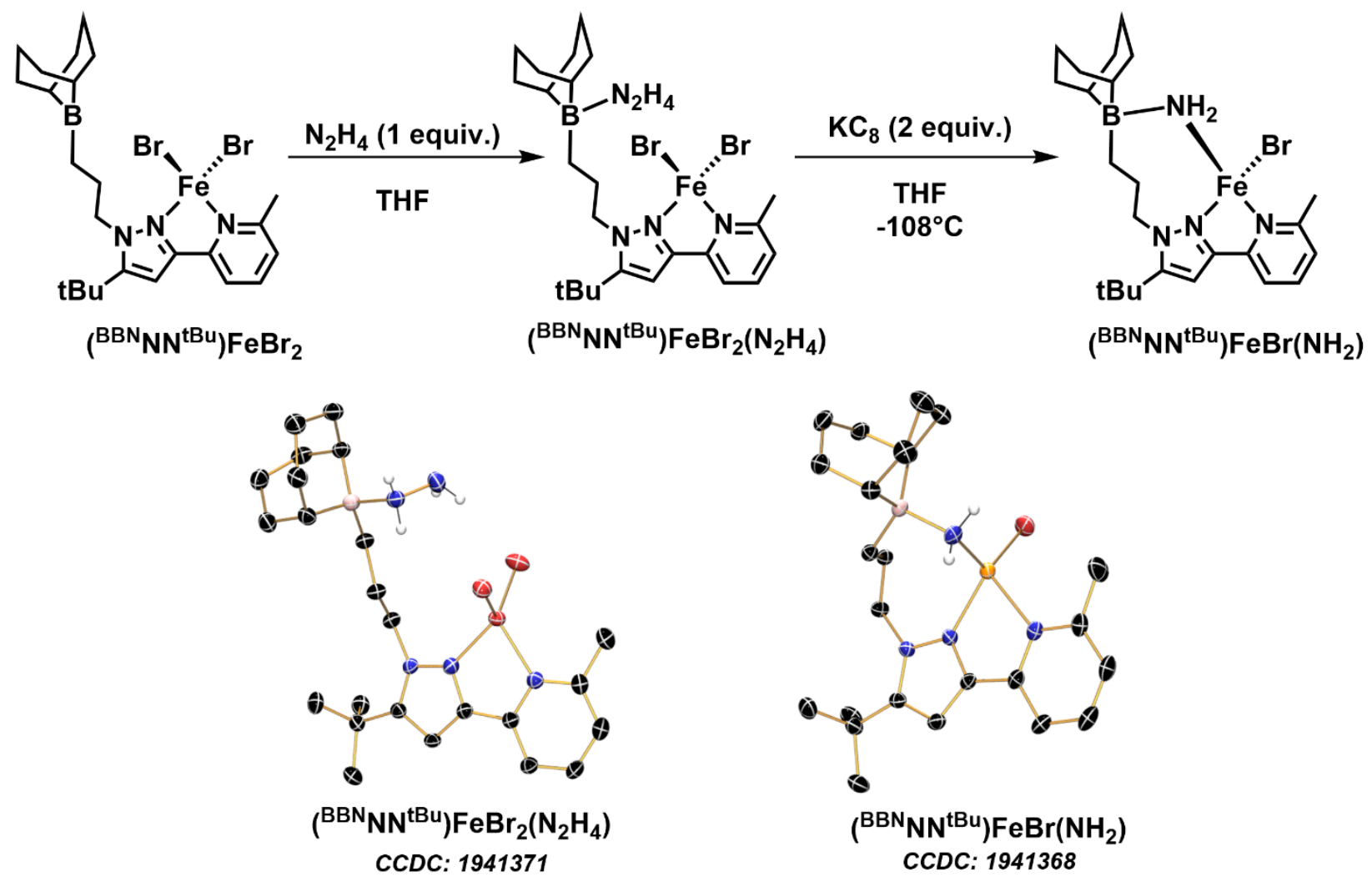

Figure 4.6. Activation of hydrazine by $\left({ }^{\mathrm{BBN}} \mathrm{NN}^{\mathrm{tBu}}\right) \mathrm{FeBr}_{2} .{ }^{142}$

The disproportionation of hydroxylamine was also demonstrated in the same report using $\left({ }^{\mathrm{BBN}} \mathrm{NN}^{\mathrm{tBu}}\right) \mathrm{MBr}_{2} \cdot{ }^{142}$ Interestingly, the choice of the metal center leads to differing reactivity. Hydroxylamine is reduced to $\mathrm{NH}_{3}$ in the case of iron, whereas it forms only the Lewis acid/base pair when using zinc, demonstrating the importance of not only the pendent Lewis acid but also the redox-active character of the metal center (Figure 4.7). These examples are of particular interest

142. Kiernicki, J. J.; Norwine, E. E.; Zeller, M.; Szymczak, N. K. Tetrahedral Iron Featuring an Appended Lewis Acid: Distinct Pathways for the Reduction of Hydroxylamine and Hydrazine. Chem. Commun. 2019, 55, 1189611899. 
as they demonstrate key proposed intermediates in ammonia formation via nitrogenase enzymes. $^{143}$
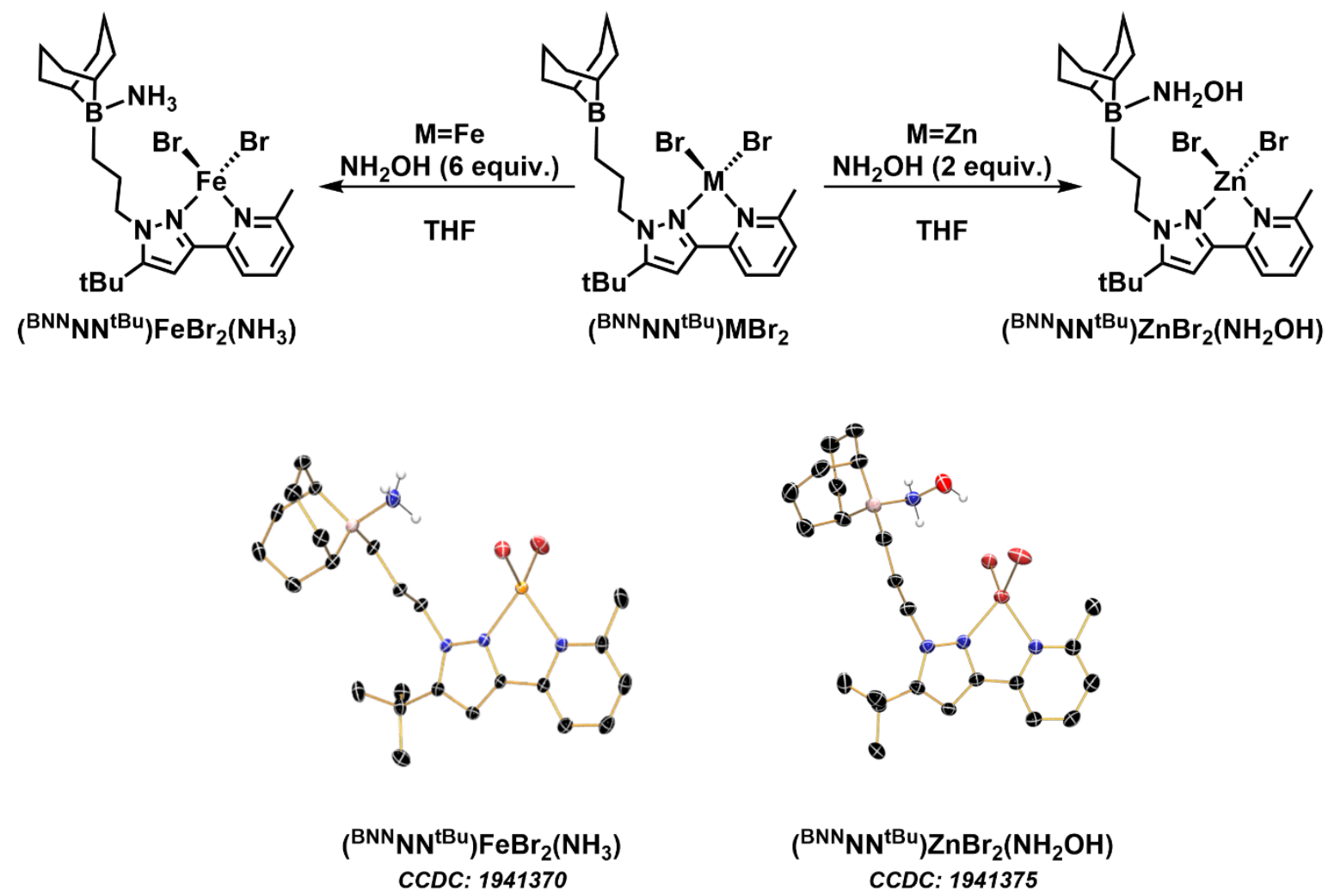

Figure 4.7. The activation of hydroxylamine by iron and zinc complexes bearing a bidentate Nbased ligand with an appended Lewis acid. ${ }^{142}$

Boronic esters has also be used to promote organic transformations through Lewis acid-base interactions. An example of this was reported by Hall and coworkers wherein introduction of a boron group adjacent to a Lewis-basic substituent facilitated cross coupling of diborylated esters with a series of aryl halides (Figure 4.8). ${ }^{144}$ Intramolecular chelation is thought to result in activation of the boron moiety by the adjacent carbonyl oxygen, leading to products selectively retaining the Bdan group (dan = aminonaphthyl).

143. Hoffman, B. M.; Lukoyanov, D.; Yang, Z. Y.; Dean, D. R.; Seefeldt, L. C. Mechanism of Nitrogen Fixation by Nitrogenase: The Next Stage. Chem. Rev. 2014, 114, 4041-4062.

144. Lee, J. C. H.; McDonald, R.; Hall D. G. Enantioselective Preparation and Chemoselective Cross-Coupling of 1,1-Diboron Compounds. Nat. Chem. 2011, 3, 894-900. 


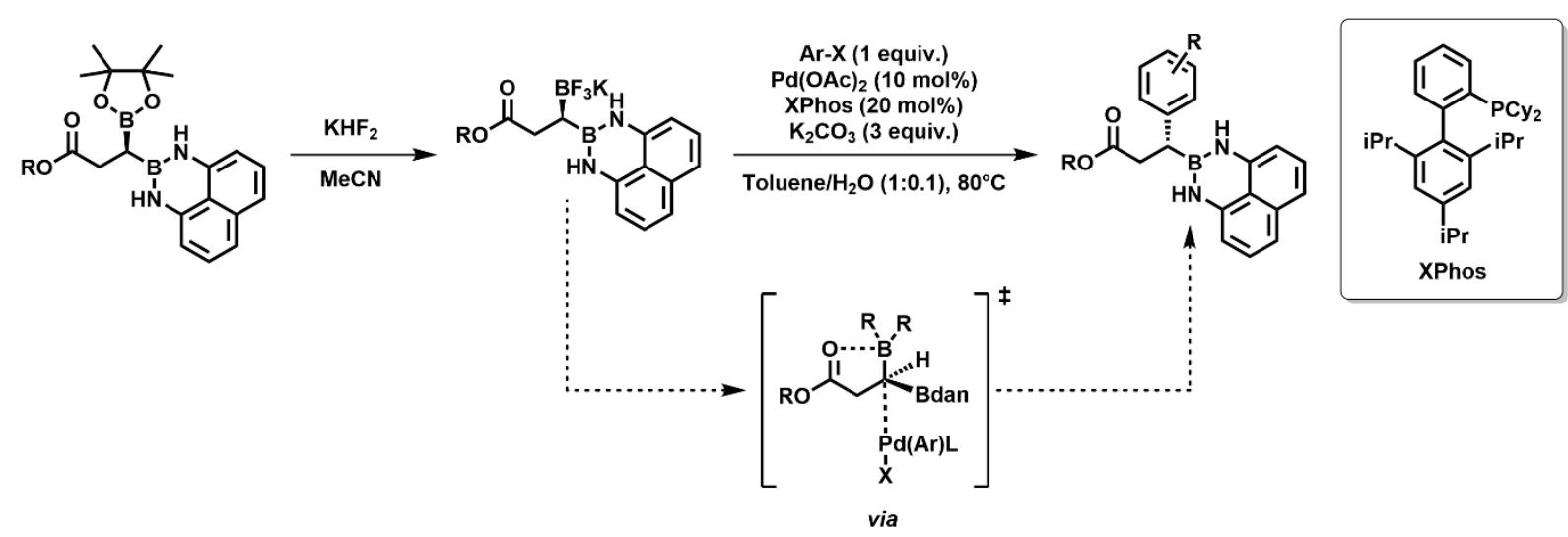

Figure 4.8. Cross coupling achieved selectively through neighboring group stabilization of the transmetalation transition state. ${ }^{144}$

There are few methods that manipulate secondary sphere effects that do not require preinstallation of the boron functionality as well as prior isolation. From an efficiency standpoint, the ability to perform this step in tandem with subsequent transformation in a one-pot reaction would be ideal. Only one example exists of a system that couples, in a single reaction vessel, the introduction of a Lewis acid functional group with subsequent Lewis-acid-promoted proximal functionalization. Morken and coworkers proposed that a pinacolboryl substituent, introduced during alkene diboration, activates the second pinacolboryl substituent for transmetalation in a subsequent Pd-catalyzed arylation reaction through an effect similar to that proposed by Hall above (Figure 4.9.). ${ }^{145}$

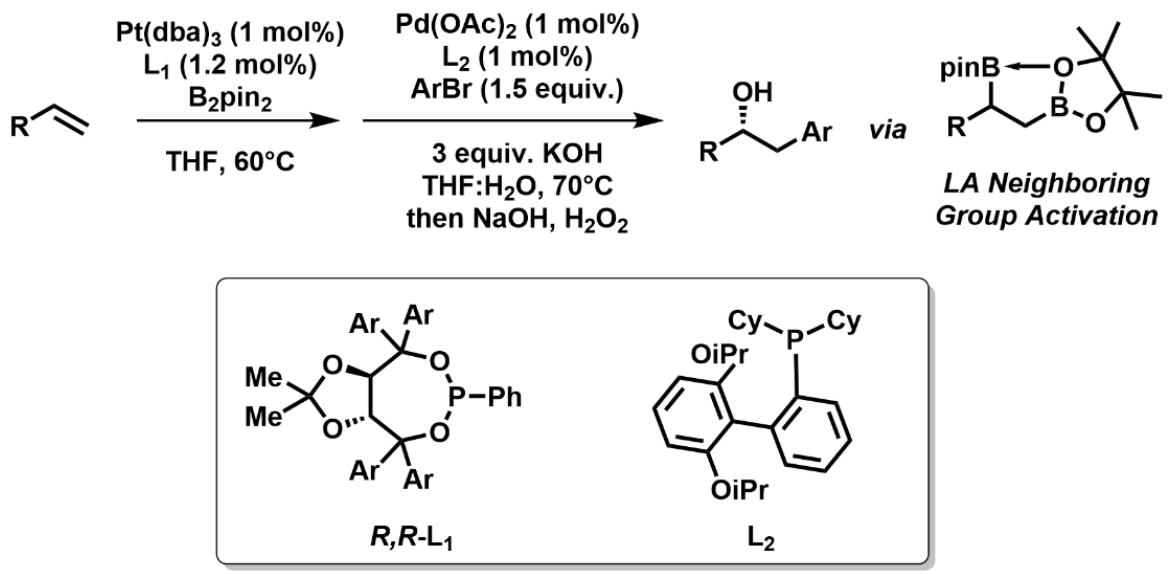

Figure 4.9. One-pot diboration/cross-coupling through neighboring group activation. ${ }^{145}$

145. Mlynarski, S. N.; Schuster, C. H.; Morken, J. P. Asymmetric Synthesis from Terminal Alkenes by Cascades of Diboration and Cross Coupling. Nature 2014, 505, 386-390. 
The copper-catalyzed boracarboxylation of vinyl arenes, as discussed in the preceding chapters, is a reaction where a boron group and $\mathrm{CO}_{2}$ are installed across a double bond to yield $\alpha, \beta$-functionalized boracarboxylic acids (Figure 4.10.A). Inspired by the examples above, there was interest in determining whether the initial installation of the Bpin group in the catalytic reaction provides a Lewis acid in the second sphere that may participate in the activation of $\mathrm{CO}_{2}$. Indeed, while investigating the copper-catalyzed boracarboxylation mechanism computationally, ${ }^{146}$ it was observed that in the $\mathrm{CO}_{2}$ insertion transition state featured a closecontact interaction between the boron and the proximal oxygen of the copper-appended $\mathrm{CO}_{2}$ (Figure 4.10.B).

A.
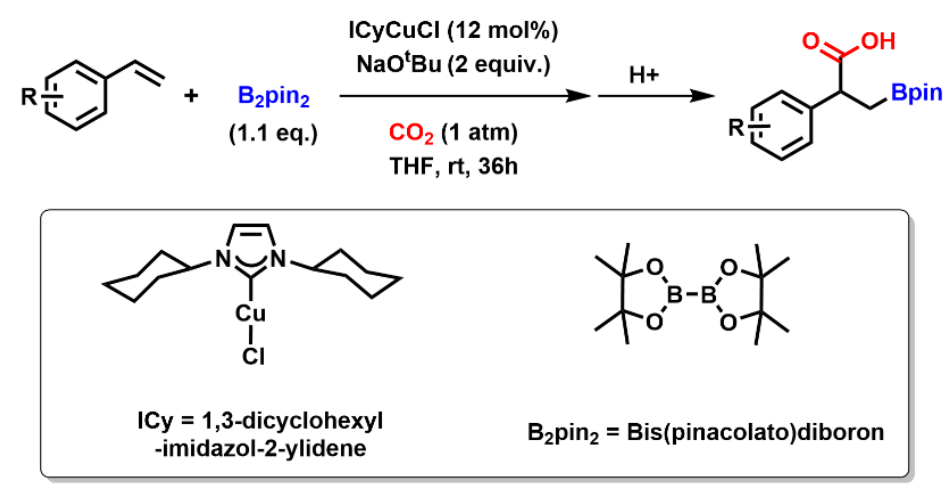

B.

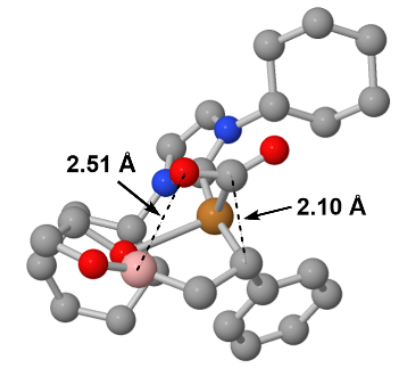

Figure 4.10. A) the $\mathrm{Cu}^{\mathrm{I}}$-catalyzed boracarboxylation of vinyl arenes. B) Close-contact interaction in the $\mathrm{CO}_{2}$ insertion transition state.

If boron-facilitated activation of $\mathrm{CO}_{2}$ in copper-catalyzed boracarboxylation is operative, the reaction would demonstrate only the second example of a tandem reaction of this kind and may allow for further expansion of the reaction to other boron-based reductants. Thus, based on the observed close-contact interaction in the transition state, as well as the implications of the potential novelty of this reaction, boracarboxylation with respect to the boron fragment and its Lewis acidic character was studied computationally.

Prior computational studies regarding the copper-catalyzed boracarboxylation of vinyl arenes have been reported, focusing on a variety of aspects from the reaction. In 2017, Lu and coworkers

146. Butcher, T. W.; McClain, E. J.; Hamilton, T. G.; Perrone, T. M.; Kroner, K. M.; Donohoe, G. C.; Akhmedov, N. G.; Petersen, J. L.; Popp, B. V. Regioselective Copper-Catalyzed Boracarboxylation of Vinyl Arenes. Org. Lett. 2016, 18, 6428-6431. 
determined that the ancillary ligands employed in the initial screening of the catalytic conditions were subject to both steric and electronic effects. ${ }^{147}$ Tolman's electronic parameter analysis of the monophosphines revealed that carboxylation in their presence is controlled by electron donating capability, with those more strongly donating leading to a decrease in the free energy barrier of carboxylation. On the contrary, the dominate contributor for the NHC ligands was steric profile. Comparing percent buried volume values, defined as the percent of the total volume of a sphere of defined radius that is occupied by a ligand, ${ }^{148}$ to the respective free energy barrier of $\mathrm{CO}_{2}$ insertion demonstrated that the larger ligands were responsible for higher energy barriers. Further, Hbonding imposed by the proximity of the ancillary ligand to the oxygen atoms of the carbon dioxide inhibits the insertion of $\mathrm{CO}_{2}$ into the $\mathrm{M}-\mathrm{C}$ bond, which also contributes to the barrier height (Figure 4.11).
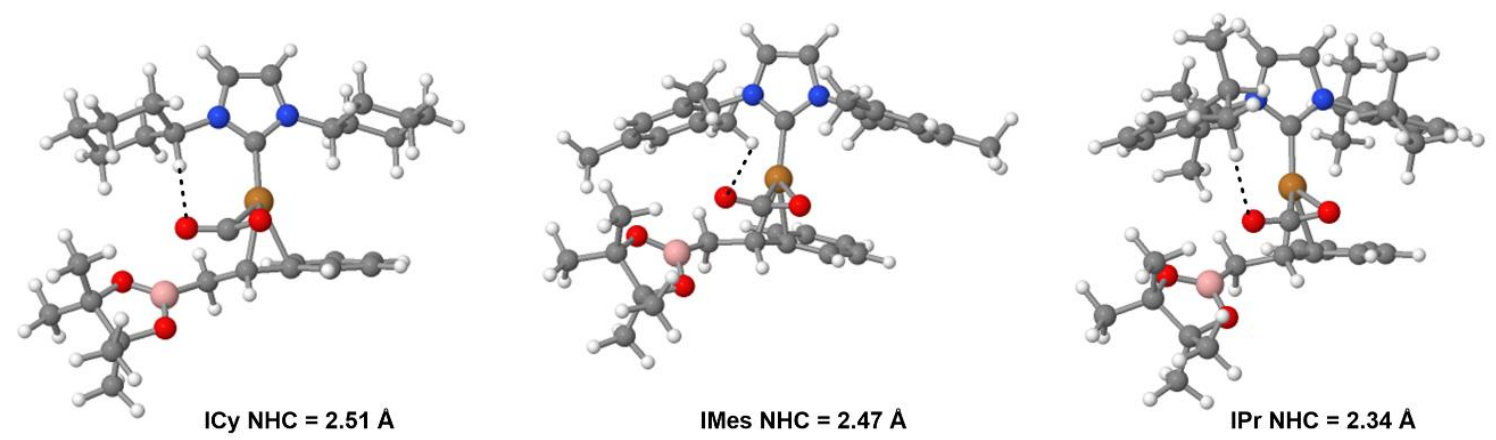

Figure 4.11. O-H bonding interactions between ancillary NHC ligand and $\mathrm{CO}_{2}$ computed by Lu et. al. ${ }^{147}$

More recent studies have explored the side reactions of the boracarboxylation catalysis, and it was ultimately determined that the excess amount of $\mathrm{NaO}^{t} \mathrm{Bu}$ base employed in the reaction is necessary to suppress these other non-productive pathways. ${ }^{149}$ Despite the importance of these findings, investigation of the boron reductant used had not been explored. The identity of the boron fragment has significant implications on the utility of the boracarboxylated product in synthetic

147. Lv, X.; Wu, Y. B.; Lu, G. Computational Exploration of Ligand Effects in Copper-Catalyzed Boracarboxylation of Styrene with $\mathrm{CO}_{2}$. Catal. Sci. Technol. 2017, 7, 5049-5054.

148. Clavier, H.; Nolan, S. P. Percent Buried Volume for Phosphine and N-heterocyclic Carbene Ligands: Steric Properties in Organometallic Chemistry. Chem. Commun. 2010, 46, 841-861.

149 . Lin, S.; Lin, Z. DFT Studies on the Mechanism of Copper-Catalyzed Boracarboxylation of Alkene with $\mathrm{CO}_{2}$ and Diboron. Organometallics 2019, 38, 240-247. 
derivatization, and as a result, a theoretical study was undertaken to determine what role, if any, they played.

\subsection{Computational Analysis of $\mathrm{ICyCu}^{\mathrm{I}}$ Facilitated Carboxylation}

The study began using the catalytically relevant ICy NHC ligand (ICy = 1,3-dicyclohexyl

-imidazol-2-ylidene) in each copper(I) structure to calculate the reaction pathway (Figure 4.12). ${ }^{146}$ Two energetically feasible transition states for the direct insertion of $\mathrm{CO}_{2}$ were found, differing in the orientation of the boron group. One structure features boron directed away (exo) from the copper center ( $\mathrm{TS}^{\text {indirect }}$ ), and the other directed toward (endo) the copper center and the appended $\mathrm{CO}_{2}$ (TS $\left.{ }^{\text {direct }}\right)$. Based on the free energy data, the structures are close to being isoenergetic, suggesting that the endo-placement of the boron does not pose significant steric hinderance. Indeed, this orientation would be necessary for a Lewis acid/base interaction to be operative during carboxylation.

Transition state $\mathbf{T S}^{\text {direct }}$ possesses an NHC-Cu-C $\mathrm{C}_{\text {benzyl }}$ angle of $136^{\circ}$, resulting from the NHC ligand bending slightly to accommodate that incorporation of the $\mathrm{CO}_{2}$ molecule, and a $\mathrm{Cu}-\mathrm{C}_{\mathrm{CO} 2}$ bond length of $2.26 \AA$. As stated above, a B-O distance is calculated to be $2.51 \AA$, which falls within the Van der Waals radii for these atoms $(\mathrm{O}=1.5 \AA$; $\mathrm{B}=1.8 \AA$ ) (Figure $4.10, \mathrm{~B}) .{ }^{150}$ The close contact suggests the potential for a non-covalent cooperative interaction that promotes insertion of $\mathrm{CO}_{2}$ into the $\mathrm{Cu}-\mathrm{C}_{\text {benzyl }}$ bond.

150. Batsanov, S. S. van der Waals Radii of Elements. Inorg. Mater. 2001, 37, 871-885. 
A.

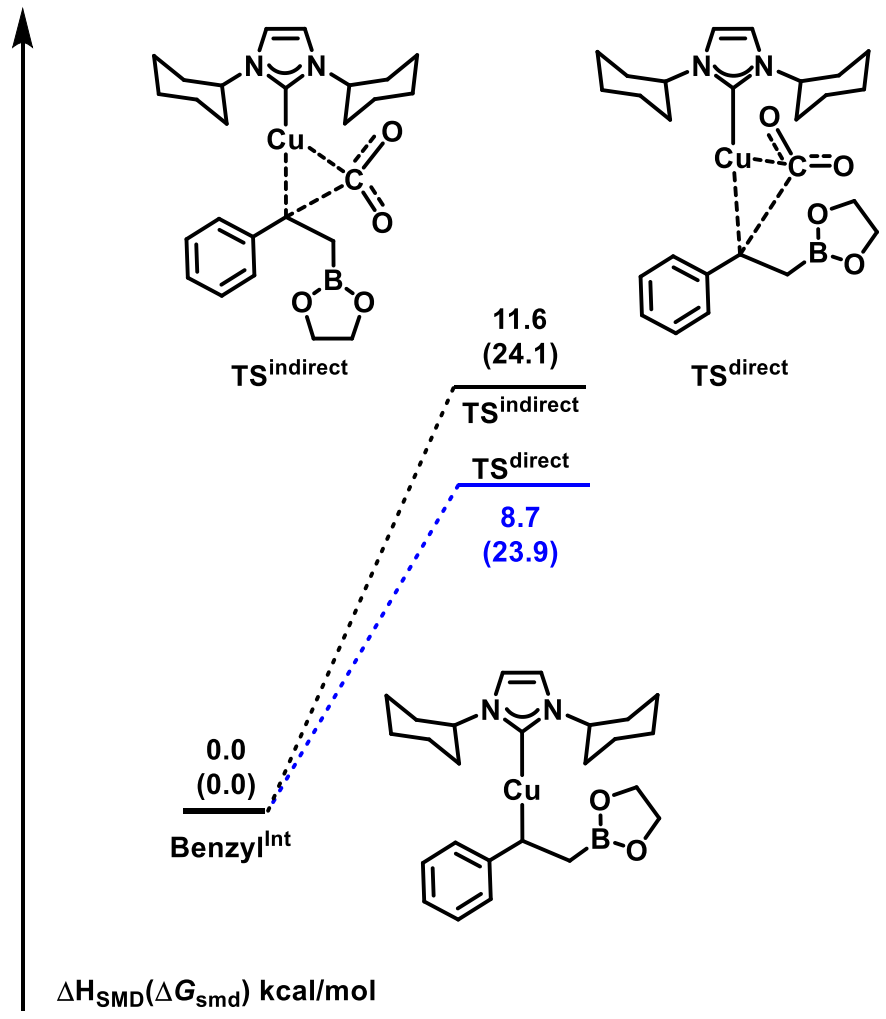

B.

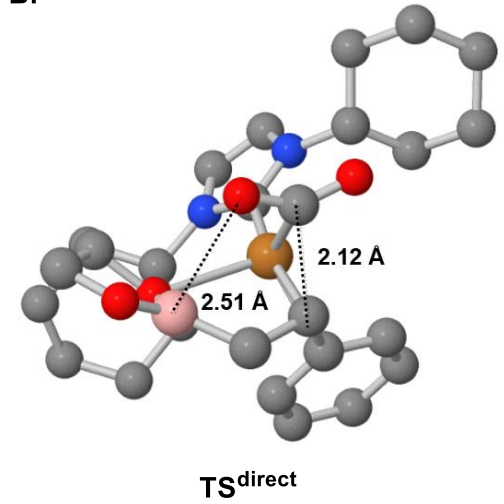

C.

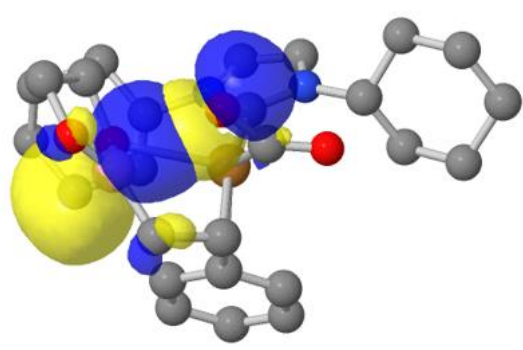

Figure 4.12. A) Depiction of optimized ground state- and transition state structures containing the ICy ligand. B) Computed molecular structure of $\mathrm{ICyCu}(\mathrm{I})$-benzyl carboxylation (TS ${ }^{\text {direct }}$ ), illustrating an interaction between the boron atom of the ethyleneglycato (eg) boron ester and the proximal oxygen of $\mathrm{CO}_{2}$. C) Relevant natural bond orbitals illustrating a noncovalent Lewis acid/base interaction. Hydrogen atoms are omitted for clarity.

Natural bond orbital analysis (NBO) was used to further understand the nature of the apparent B-O interaction in $\mathrm{TS}^{\text {direct }}$. NBO analysis is a powerful tool that provides information about the electron density distribution in atoms and bonds of a molecular structure, and it is commonly used to describe covalent bonds formed between atoms within a molecule. ${ }^{151}$ However, it can also be useful in evaluating non-covalent interactions in a structure or between molecules. In the case of $\mathrm{TS}^{\text {direct }}$, it was revealed that the vacant acceptor $\mathrm{p}$ orbital on the boronic ester moiety overlaps with the appropriately oriented donor oxygen lone pair orbital (Figure 4.12.C). Consistent with this qualitative picture, a stabilization energy of $8.7 \mathrm{kcal} / \mathrm{mol}$, obtained from the $\mathrm{NBO} 2^{\text {nd }}$ order

151. Weinhold, F.; Landis, C. R. Valency and Bonding: A Natural Bond Orbital Donor-Acceptor Perspective; Cambridge University Press: Cambridge, United Kingdom, 2005. 
perturbation analysis, was calculated for the same orbitals. Stabilization energy results from interactions between Lewis (donor) and non-Lewis (acceptor) NBOs where delocalization of electron density takes place. This is a feature that is not traditionally well represented in other computational analyses, such as MO theory, due to imposing degeneracy in the orbitals of the molecule. ${ }^{152} \mathrm{~A}$ value of $8.7 \mathrm{kcal} / \mathrm{mol}$ suggests that the delocalization of electron density from the lone pair of oxygen to the vacant p-orbital of the boron center and further provides evidence that boron may play a role in facilitating carboxylation. These findings led to exploration of the electronic variability at boron through modification of the boronic ester functional group to assess the resulting energetic effect on donor/acceptor orbitals identified in the $\mathrm{TS}^{\text {direct }}$ structure.

\subsection{Computational Analysis of IMeCu${ }^{\mathrm{I}}$ Facilitated Carboxylation - Exploration of $\mathrm{BX}_{2}$ Moieties}

Boracarboxylation qualitatively differs from copper-facilitated hydrocarboxylation of alkenes only in the identity of the reductant used. However, although stoichiometric hydrocarboxylation of styrene has been demonstrated using a $\mathrm{Cu}(\mathrm{I})(\mathrm{NHC})$ complex, ${ }^{153}$ no reports of the analogous catalytic hydrocarboxylation of vinyl arenes have been reported. Optimization of both reaction coordinates beginning from the respective $\mathrm{Cu}-\mathrm{E}(\mathrm{E}=\mathrm{H}, \mathrm{B}(\mathrm{eg})$ ) is shown in Figure 4.13 to identify large differences, if any, between the systems.

Given that the reported thermodynamic data are relative to the respective $\mathrm{IMeCu}-\mathrm{X}$ starting structures $(\mathrm{X}=\mathrm{H}$ or $\mathrm{B}(\mathrm{eg})$; eg = ethyleneglycato), the absolute values cannot be compared. However, information can be gleaned from analysis of individual barrier heights. Although the insertion of styrene into the $\mathrm{Cu}-\mathrm{H}$ bond has a higher free energy barrier than insertion into $\mathrm{Cu}$ $\mathrm{B}(\mathrm{eg})$, the remainder of the reaction coordinate is strikingly similar, especially regarding the carboxylation step. This begs the question: does the close contact interaction noted above make catalytic boracarboxylation reaction alkenes possible?

152. Weinhold, F.; Landis, C. R.; Glendening, E. D. What is NBO Analysis and How Is It Useful? Int. Rev. Phys. Chem. 2016, 35, 399-440.

153. Sirokman, G. N-Heterocyclic-Carbene Copper(I)-Catalyzed Carbon-Carbon Bond Formation Using Carbon Dioxide. Ph. D. Dissertation, Massachusetts Institute of Technology, Cambridge. May 2007. 


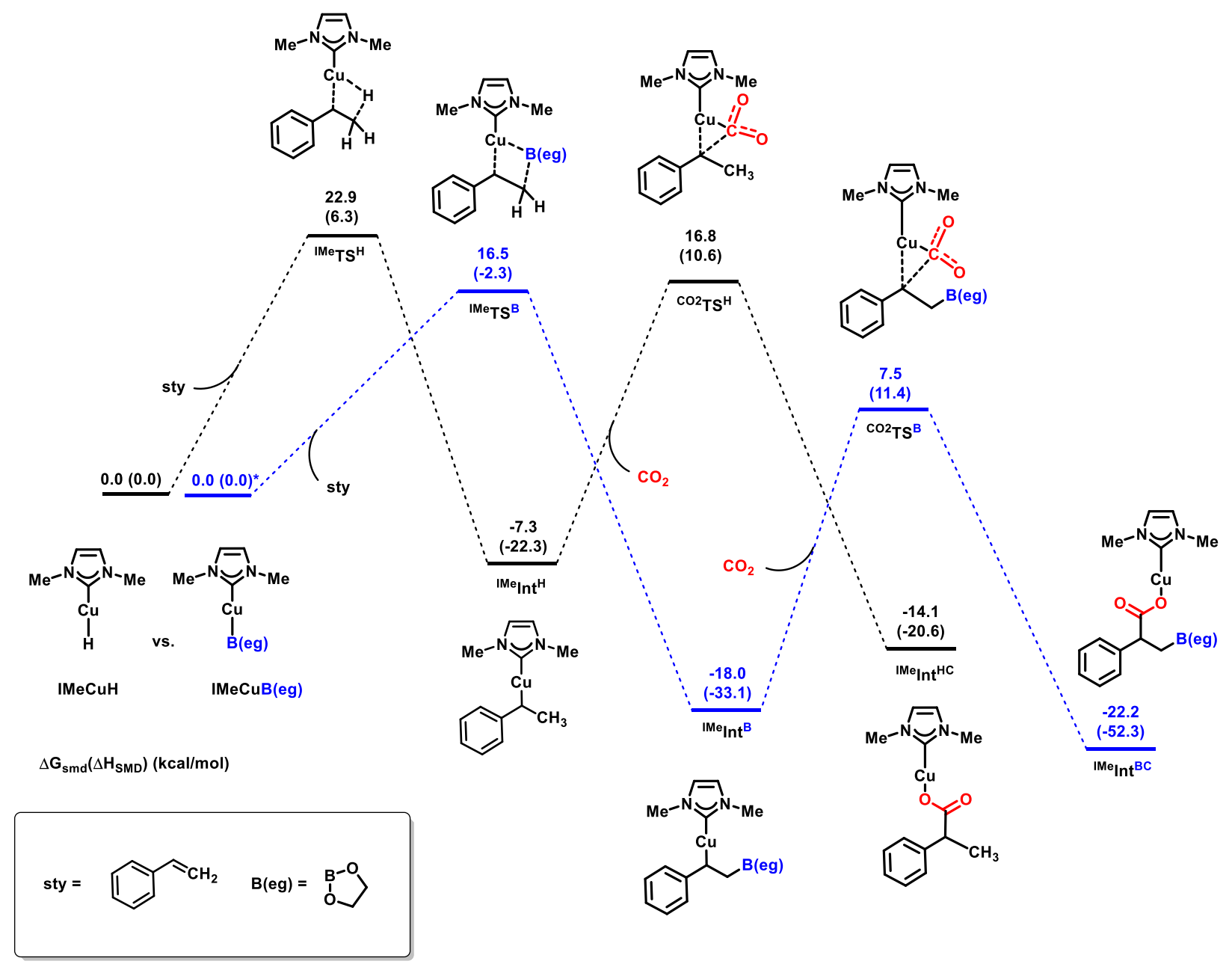

Figure 4.13. Reaction coordinates of hydrocarboxylation of styrene using $\mathrm{Cu}-\mathrm{H}$ (black trace) and boracarboxylation of styrene using $\mathrm{Cu}-\mathrm{B}(\mathrm{eg})$ obtained at rm06 level of theory. Note: The thermodynamic data of each reaction coordinate are based relative to its initial starting structure.

To focus strictly on the boron center and its effects on carboxylation, steric contributions were minimized by replacing the ICy ligand with an IMe (IMe = dimethyl-2H-imidazolylidene) model ligand system, as it has been demonstrated to have minimal effects on the overall energetics of the copper(I)NHC system in previous computational studies. ${ }^{154}$ Analogous structures to those bearing ICy were calculated using the IMe ligand (Figure 4.14). Gratifyingly, the enthalpic barriers of $\mathrm{CO}_{2}$ insertion for the ICy and IMe model systems were comparable, differing by less than $1 \mathrm{kcal} / \mathrm{mol}$. Based on these results, the IMe ligand was employed for the remainder of the study.

154. Lin, S.; Lin, Z. DFT Studies on the Mechanism of Copper-Catalyzed Boracarboxylation of Alkene with $\mathrm{CO}_{2}$ and diboron. Organometallics 2019, 38(2), 240-247. 
Three energetically feasible transition states for the carboxylation of $\mathrm{IMeCu}(\beta$-borylbenzyl) $\left({ }^{\text {IMe }}\right.$ Int $\left.^{\text {Benzyl }}\right)$ complex were identified: 1) a cooperative pathway in which boron interacts with proximal oxygen of the carbon dioxide molecule (structure A); 2) a noncooperative pathway wherein the boron moiety is directed away from the copper center (structure B); and 3) an SEnlike pathway in which copper does not participate directly in C-C bond formation (structure $\mathbf{C}$ ). The pathway resulting in structure $\mathrm{C}$ was considered based on a report of styrene derivative carboxylation through the formation of a "masked" carbanion from boronic ester-substituted substrates (Figure 4.15) ) $^{155}$ as well as our own research using a stereochemical probe substrate ( $\beta$ methylstyrene) that revealed the major and minor diastereomers $(\mathrm{dr}>7: 1)$ resulted from direct insertion and presumably electrophilic substitution, respectively. ${ }^{146}$

Attempts to identify ground-state and/or transition-state structures that feature competing boron-THF Lewis pairing were unsuccessful. ${ }^{156}$ The $\mathrm{S}_{\mathrm{E}} \mathrm{N}$ pathway was found to be less favorable than direct insertion, which is consistent with our previous experimental data as well as other computational studies. ${ }^{157}$

155. Grigg, R. D.; Rigoli, J. W.; Van Hoveln, R.; Neale, S.; Schomaker, J. M. Beyond Benzyl Grignards: Facile Generation of Benzyl Carbanions from Styrenes. Chem. Eur. J. 2012, 18, 9391-9396.

156. Sadighi and coworkers previously prepared and characterized similar $\beta$-borylbenzyl-Cu ${ }^{\mathrm{I}} \mathrm{NHC}$ complexes; however, their work was performed in pentane solvent and no studies were reported addressing the Lewis acidic character of the boron moiety. See: Laitar, D. S.; Tsui, E. Y.; Sadighi, J. P. Copper(I) $\beta$-Boroalkyls from Alkene Insertion: Isolation and Rearrangement. Organometallics 2006, 25, 2405-2408.

157. García-López, D.; Pavlovic, L.; Hopmann, K. To Bind or Not to Bind: Mechanistic Insights into C-CO $\mathrm{CO}_{2}$ Bond Formation with Late Transition Metals. Organometallics 2020, 39, 1339-1347. 


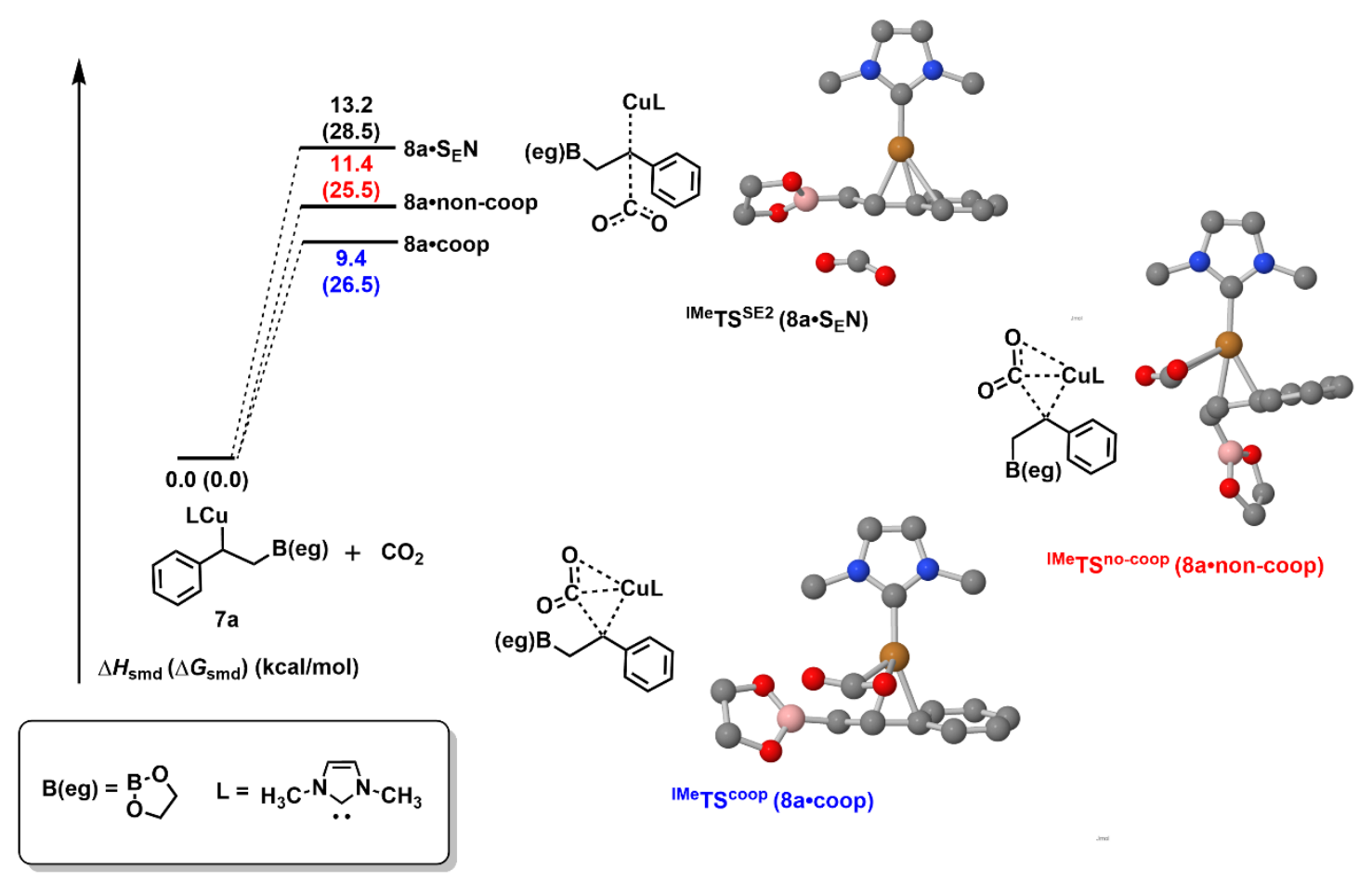

Figure 4.14. Geometry optimization of structures relevant to carboxylation using IMe model ligand.
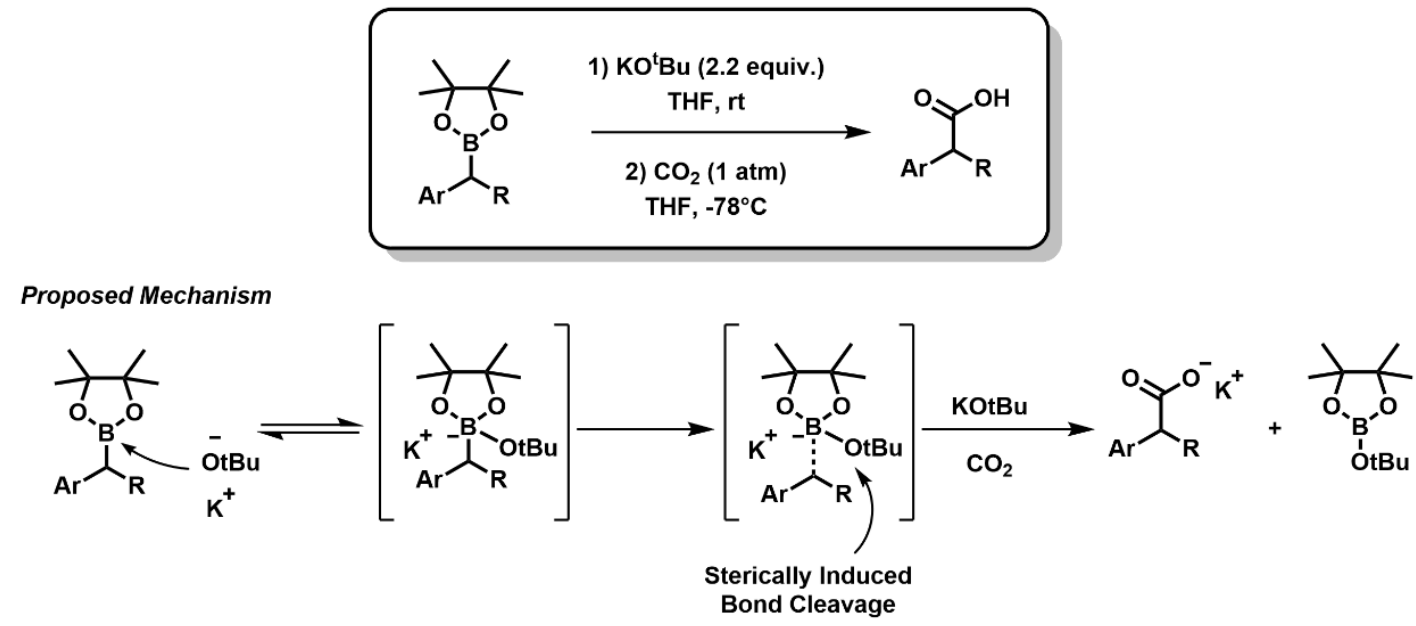

Figure 4.15. Based-promoted carboxylation of benzylic boronic esters. ${ }^{155}$

The presence of a potential Lewis-acid interaction was probed using structure 7a given the orientation of the boron fragment toward the copper center. A series of boron moieties of varying electronic properties were selected to assess their energetic impact on the Lewis acidity of the boron center (Figure 4.16). Steric contributions were avoided by choosing mostly halides as well 
as simple alkoxy and amino groups. The absolute minima of the $\mathrm{Cu}^{\mathrm{I}}$ complexes bearing the substituents in Figure 4.16 were optimized, and following this, transition state searches were initiated through addition of $\mathrm{CO}_{2}$ to the optimized ground state structures.
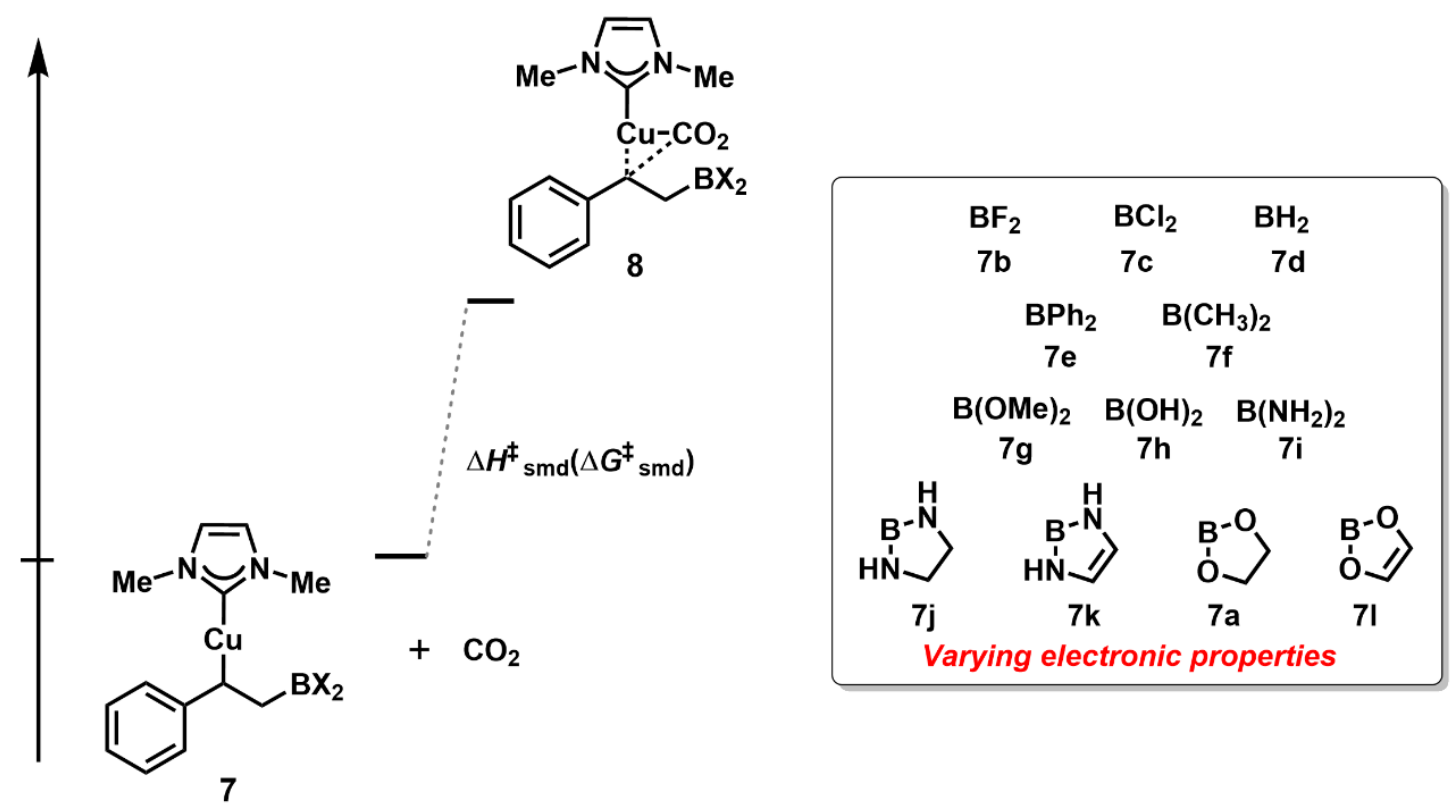

Figure 4.16. Carboxylation of $\mathrm{Cu}^{\mathrm{I}}(\beta$-borylbenzyl) species and the various boron substituents employed.

The Lewis acidity of each boron fragment was evaluated initially using the electronegativities of the boron substituents, which was determined by averaging the formal electronegativities of the atoms directly connected to boron using the Pauling electronegativity scale. ${ }^{158}$ However, it was observed that the average electronegativities of the substituents do not correlate well with the enthalpic barrier associated with carboxylation $\left(R^{2}=0.375\right)$ (Figure 4.17, Left). This is likely because summing electronegativities of the atoms present in a multiatomic substituent may not account for polarization of bonds, thereby not providing an accurate representation of electron delocalization. This would be an issue especially for those substituents bearing unsaturated ethene backbones. Additionally, the length of the alkyl chain attached to copper comprising the remainder of the compound would not be considered.

158. Pauling, L. Nature of the Chemical Bond. IV. The Energy of Single Bonds and the Relative Electronegativity of Atoms. J. Am. Chem. Soc. 1932, 54, 3570-3582. 
Thus, an alternative method of evaluating Lewis acidity of the boron in each complex was identified using natural bond orbital analysis (NBO). An extension of this concept, called boron valence deficiency (BVD), was developed by Plumley and Evanseck in a study of the binding enthalpies of a large series of trivalent borane- $\mathrm{NH}_{3}$ adducts. ${ }^{159}$ Boron valence deficiency is defined as the ability of boron to accept electrons, analogous to the concept of Lewis acid/base theory, ${ }^{160}$ and it is determined by subtracting the NBO computed natural valency of boron from its formal valence of three. NBO analysis was performed for each ground state and transition state molecular structure, and the BVD was evaluated using the computed valency values at boron. The average electronegativities of the boron substituents were compared to these BVD values, and a moderate correlation was observed $\left(\mathrm{R}^{2}=0.653\right)$ (Figure 4.17, Right). This suggested that although parameters are related, BVD might provide a more accurate description of Lewis acidity of the boron in these systems.
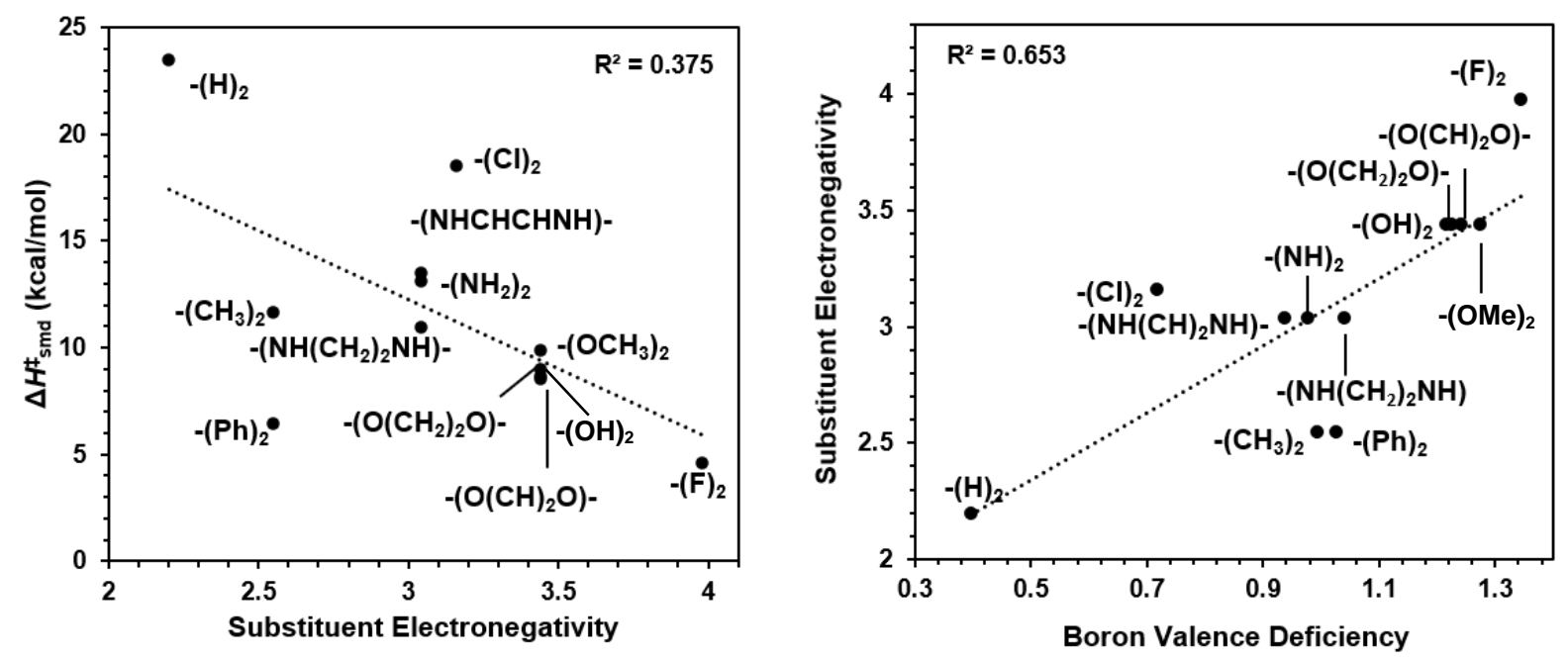

Figure 4.17. Left: Comparison of the enthalpic barrier for carboxylation of $\mathrm{Cu}^{\mathrm{I}}(\beta$-borylbenzyl) complexes to the average electronegativity of the varying boron substituents. Right: Comparison of the average substituent electronegativity to the boron valence deficiency calculated for each boron substituent.

159. Plumley, J. A.; Evanseck, J. D. Periodic Trends and Index of Boron Lewis Acidity. J. Phys. Chem. A. 2009, $113,5985-5992$.

160. Lewis, G. N. Acids and Bases. J. Franklin. Inst. 1938, 226, 293-313. 
Thermodynamic barriers associated with carboxylation for each $\mathrm{Cu}^{\mathrm{I}}(\beta$-borylbenzyl) complex were compared to the respective boron valence deficiency values computed for the transition states (Table 4.2.) The natural charge on boron and distance between the boron and the proximal oxygen at the transition state are also included $\left(r_{\mathrm{b}-\mathrm{o}}\right)$. Unsurprisingly, boron valence deficiency and the natural charge at boron correlate strongly $\left(\mathrm{R}^{2}=0.99\right)$, suggesting either are equally reliable in describing the electronic nature at boron in this model system.

Table 4.2. Boron valence deficiency (BVD), natural charge on boron, thermodynamic parameters for $\mathrm{CO}_{2}$ insertion, and the distance between the boron and oxygen of the $\mathrm{CO}_{2}$ molecule in the carboxylation transition state.

\begin{tabular}{|c|c|c|c|c|c|}
\hline $\begin{array}{l}\text { Boron } \\
\text { Fragment } \\
\left(-\mathrm{BX}_{2}\right)\end{array}$ & BVD $^{a}$ & $\begin{array}{c}\text { Boron } \\
\text { Charge }(q)\end{array}$ & $\underset{(\mathrm{kcal} / \mathrm{mol})}{\Delta G_{\text {smd }}^{\ddagger}}$ & $\begin{array}{c}\Delta H_{\text {smd }}^{\ddagger} \\
(\mathrm{kcal} / \mathrm{mol})\end{array}$ & $r_{\mathrm{B}-\mathrm{O}}$ \\
\hline $8 b-(F)_{2}$ & 1.33 & 1.30 & 18.4 & 4.60 & 1.93 \\
\hline $8 \mathbf{g}-(\mathrm{OMe})_{2}$ & 1.27 & 1.24 & 24.5 & 9.87 & 2.45 \\
\hline $8 \mathrm{a}-\mathrm{OCH}_{2} \mathrm{CH}_{2} \mathrm{O}-$ & 1.24 & 1.20 & 26.5 & 8.70 & 2.49 \\
\hline $8 \mathrm{I}-\mathrm{O}(\mathrm{CH})_{2} \mathrm{O}-$ & 1.23 & 1.19 & 23.3 & 8.54 & 2.45 \\
\hline $\mathbf{8 h}-(\mathrm{OH})_{2}$ & 1.22 & 1.18 & 24.2 & 8.96 & 2.48 \\
\hline $8 \mathbf{j}-\mathrm{NH}\left(\mathrm{CH}_{2}\right)_{2} \mathrm{NH}-$ & 1.04 & 1.02 & 25.5 & 10.93 & 2.75 \\
\hline $\mathbf{8 e}-(\mathrm{Ph})_{2}$ & 1.03 & 1.00 & 23.6 & 6.42 & 2.03 \\
\hline $8 f-\left(\mathrm{CH}_{3}\right)_{2}$ & 0.99 & 0.96 & 24.6 & 11.66 & 2.09 \\
\hline $\mathbf{8 i}-\left(\mathrm{NH}_{2}\right)_{2}$ & 0.98 & 0.95 & 27.3 & 13.10 & 2.92 \\
\hline 8k-NH(CH) ${ }_{2} \mathrm{NH}-$ & 0.94 & 0.92 & 27.3 & 13.50 & 2.90 \\
\hline $8 c-(C l)_{2}$ & 0.72 & 0.64 & 30.0 & 18.52 & 2.06 \\
\hline $8 d-(H)_{2}$ & 0.40 & 0.39 & 37.0 & 23.46 & 1.90 \\
\hline
\end{tabular}

The enthalpic barrier as well as the free energy barrier of carboxylation demonstrate moderate correlation to the BVD values in most cases (Figure 4.18). The enthalpic barrier decreased 20 $\mathrm{kcal} / \mathrm{mol}$ moving from $\mathrm{BH}_{2}$ to $\mathrm{BF}_{2}\left(\mathrm{EN}: \mathrm{H}=2.1 ; \mathrm{F}=4.1\right.$ ) (Figure 4.18, Left). ${ }^{158}$ Similarly, an overall change in free energy of $19 \mathrm{kcal} / \mathrm{mol}$ was observed (Figure 4.18, Right). The trends suggest that more electron-withdrawing substituents subsequently lead to a more electron deficient boron, 
which is poised to accept electrons from the $\mathrm{CO}_{2}$ molecule in the transition state through delocalization.
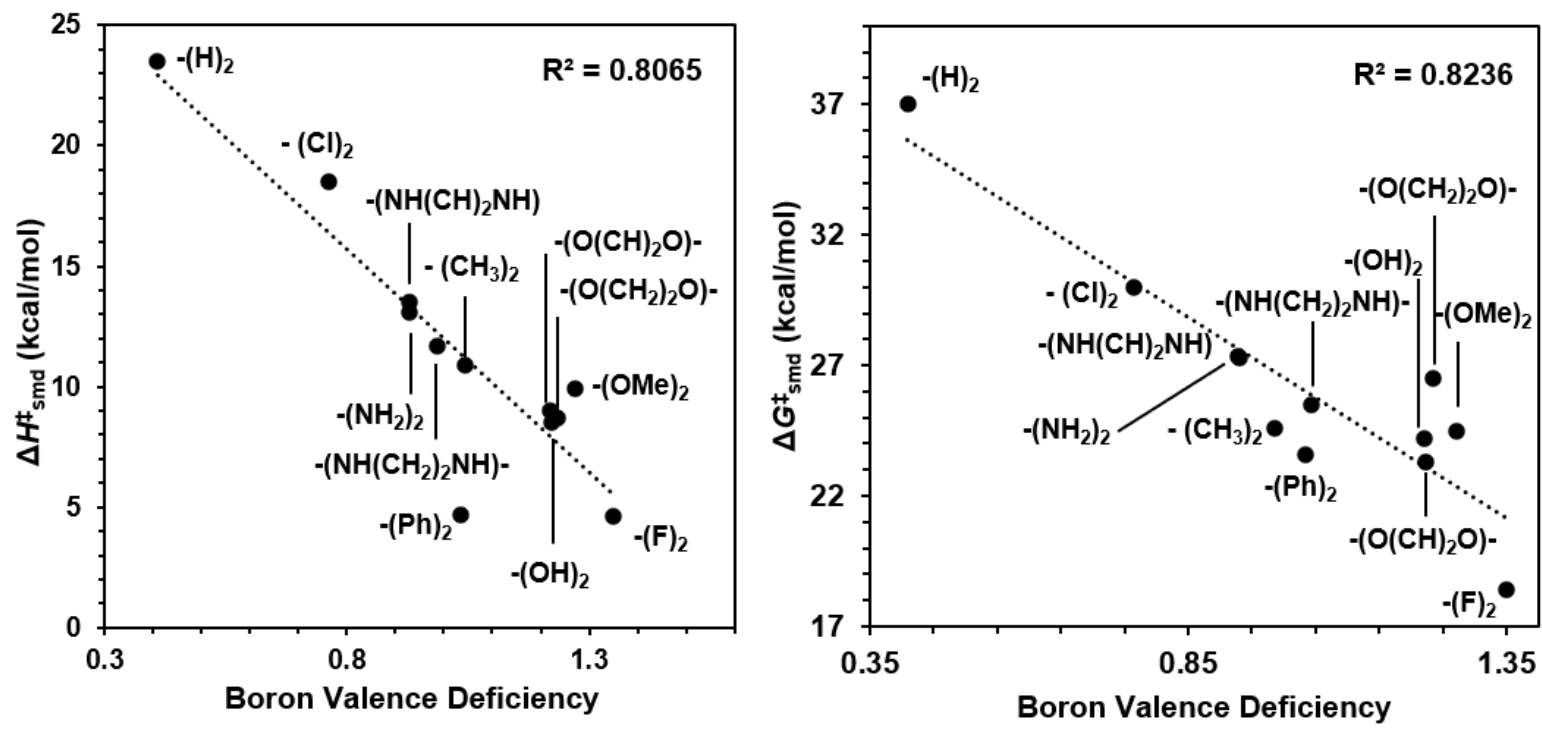

Figure 4.18. Effect boron valence deficiency has on the enthalpic (left) and free energy (right) barriers of the $\mathrm{CO}_{2}$ insertion.

Theory benchmarking in the assessment of copper(I) complexes was necessary to ensure that the observed phenomenon was not functional dependent. The functionals used were chosen from a collections of publications in which aspects of boracarboxylation was assessed. ${ }^{147,149}$ The most common choice of functional is B3LYP, thus 7a and 8a were reoptimized using this functional. Additionally, the effective core potential (ECP) SDD basis set was used for copper to emulate recently reported methods. ${ }^{149}$ The energetic and thermodynamic barriers for carboxylation were assessed using each method, the data of each shown in Table 4.3.

A slight increase in the energetic and enthalpic barriers of carboxylation was noted when switching from M06 to B3LYP. However, the difference in free energy is negligible. Significant changes arise when ECPs are included (SDD), leading to a $3 \mathrm{kcal} / \mathrm{mol}$ decrease in the free energy barrier, suggesting careful consideration of the copper center is necessary for a more accurate representation. 
Table 4.3. Comparison of thermodynamic information of $\mathrm{CO}_{2}$ insertion into 7a using different levels of theory. ${ }^{1-4,7,8}$

\begin{tabular}{|c|c|c|c|c|c|}
\hline$\left(\mathrm{kcal} \mathrm{mol}^{-1}\right)$ & $M 06^{a}$ & B3LYPb & $\begin{array}{c}\text { B3LYP } \\
\text { with SDD }\end{array}$ & M06 $^{d}$ & $\begin{array}{c}\text { B3LYP } \\
\text { with SDD }\end{array}$ \\
\hline$\Delta E_{\text {smd }}^{\ddagger}$ & 9.00 & 11.92 & 9.70 & 5.53 & 9.69 \\
\hline$\Delta H_{\text {smd }}^{\Phi_{\text {sm }}}$ & 9.44 & 11.88 & 9.71 & 5.64 & 9.70 \\
\hline$\Delta G^{\ddagger}$ smd & 26.49 & 26.36 & 23.77 & 20.19 & 23.76 \\
\hline
\end{tabular}

Structures 7a and 8a were also analyzed with respect to the relevant bond lengths (Figure 4.19). A full analysis is included in Table 4.4. Differences in some of the bond lengths and distances were noted, mostly within the transition state structure. Arguably the most important discrepancy is that of the $\mathrm{B}-\mathrm{O}_{\mathrm{CO}_{2}}$ distance, which increases from 2.49 to $2.54 \AA$ when moving from B3LYP/SDD are used. The effect is slightly more with B3LYP only (Table 4.4). A recent publication evaluated a series of copper borate complexes computationally, where it was reported that during benchmarking calculations, B3LYP demonstrated systematic over-estimation of bond lengths within the structures. ${ }^{161}$ This could account for differences in the values. Despite this, the values obtained in all instances for the B-O distance fall within the Van der Waal radii of the atoms, thus the presence of a Lewis acid/base interaction is not invalidated by these benchmarking experiments.

161. Collins, L. R.; Rajabi, N. A.; Macgregor, S. A.; Mahon, M. F.; Whittlesey, M. K. Experimental and Computational Studies of the Copper Borate Complexes [( $\left.\mathrm{NHC}) \mathrm{Cu}\left(\mathrm{HBEt}_{3}\right)\right]$ and $\left[(\mathrm{NHC}) \mathrm{Cu}\left(\mathrm{HB}\left(\mathrm{C}_{6} \mathrm{~F}_{5}\right)_{3}\right)\right]$. Angew. Chem. Int. Ed. 2016, 55, 15539-15543. 

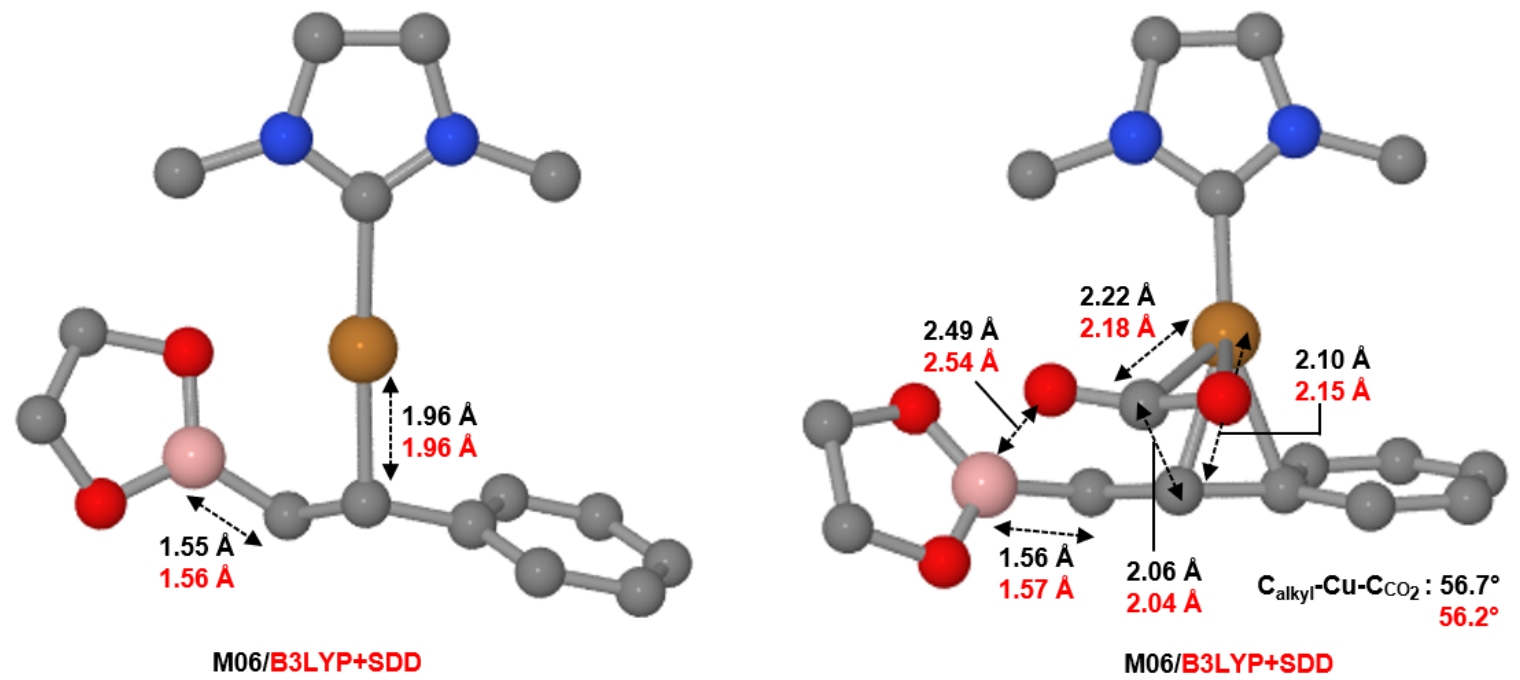

Figure 4.19. Computed ground state 7a (left) and transition state 8a (right) structures annotated with relevant physical information. Numbers depicted in black correspond to data from calculations performed at rm06/6-311+ $\mathrm{G}^{*}(\mathrm{Cu}) / 6-311 \mathrm{G}^{*}(\mathrm{C}, \mathrm{N}, \mathrm{O}, \mathrm{H}, \mathrm{B})$ level of theory, and numbers in red correspond to data from calculations performed at $\mathrm{B} 3 \mathrm{LYP} / \mathrm{SDD}(\mathrm{Cu}) / 6-31 \mathrm{G}^{*}(\mathrm{C}$, $\mathrm{N}, \mathrm{O}, \mathrm{H}, \mathrm{B})$ level of theory.

Table 4.4. Structural information from optimized $\mathbf{7 a}$ and $\mathbf{8 a}$ at different levels of theory. ${ }^{1-4,7,8}$

\begin{tabular}{|c|c|c|c|c|c|c|c|c|c|c|c|}
\hline GS & M06a & B3LYPb & $\begin{array}{c}\text { B3LYP } \\
\text { with } \\
\text { SDD }^{c}\end{array}$ & M06 ${ }^{d}$ & $\begin{array}{c}\text { B3LYP } \\
\text { with } \\
\text { SDDe }\end{array}$ & TS & M06 ${ }^{a}$ & B3LYP $^{b}$ & $\begin{array}{c}\text { B3LYP } \\
\text { with } \\
\text { SDD }^{c}\end{array}$ & M06 ${ }^{d}$ & $\begin{array}{c}\text { B3LYP } \\
\text { with } \\
\text { SDDe }\end{array}$ \\
\hline $\begin{array}{c}r\left(\mathrm{Cu}-\mathrm{C}_{\text {alkyl }}\right) \\
(\AA)\end{array}$ & 1.96 & 1.95 & 1.96 & 1.96 & 1.96 & $\begin{array}{c}\mathrm{r}\left(\mathrm{Cu}-\mathrm{C}_{\text {alkyl }}\right) \\
(\AA)\end{array}$ & 2.10 & 2.15 & 2.15 & 2.10 & 2.15 \\
\hline $\begin{array}{c}\mathrm{r}\left(\mathrm{B}-\mathrm{O}_{\mathrm{CO}_{2}}\right) \\
(\AA)\end{array}$ & --- & --- & --- & --- & --- & $\begin{array}{c}\mathrm{r}\left(\mathrm{B}-\mathrm{O}_{\mathrm{CO}_{2}}\right) \\
(\AA)\end{array}$ & 2.49 & 2.56 & 2.54 & 2.48 & 2.54 \\
\hline$r(B-C)(\AA)$ & 1.55 & 1.56 & 1.56 & 1.55 & 1.56 & $r(B-C)(\AA)$ & 1.56 & 1.57 & 1.57 & 1.57 & 1.58 \\
\hline$r(C-C)(\AA)$ & --- & --- & --- & --- & --- & $r(C-C)(\AA)$ & 2.06 & 2.04 & 2.04 & 2.06 & 2.04 \\
\hline $\begin{array}{c}\mathrm{r}\left(\mathrm{Cu}-\mathrm{C}_{\mathrm{CO}_{2}}\right) \\
(\AA)\end{array}$ & --- & --- & --- & --- & --- & $\begin{array}{c}\mathrm{r}\left(\mathrm{Cu}-\mathrm{C}_{\mathrm{CO}_{2}}\right) \\
(\AA)\end{array}$ & 2.22 & 2.20 & 2.18 & 2.23 & 2.18 \\
\hline C-Cu-C $\left({ }^{\circ}\right)$ & --- & --- & --- & --- & --- & $\mathrm{C}-\mathrm{Cu}-\mathrm{C}\left({ }^{\circ}\right)$ & 56.7 & 55.5 & 56.2 & 56.7 & 56.2 \\
\hline
\end{tabular}

${ }^{a} \mathrm{rm06} / 6-311+\mathrm{G}^{*}(\mathrm{Cu})$ and 6-311G* $(\mathrm{C}, \mathrm{O}, \mathrm{N}, \mathrm{H}, \mathrm{B}) .{ }^{b} \mathrm{~B} 3 \mathrm{LYP} / 6-31 \mathrm{G}^{*}(\mathrm{Cu})$ and 6-311G** $(\mathrm{C}, \mathrm{O}, \mathrm{N}, \mathrm{H}, \mathrm{B})$. ${ }^{c} \mathrm{~B} 3 \mathrm{LYP} / \mathrm{SDD}(\mathrm{Cu})$ and 6-31G* $(\mathrm{C}, \mathrm{O}, \mathrm{N}, \mathrm{H}, \mathrm{B}) .{ }^{d} \mathrm{rm06} / 6-311+\mathrm{G}^{*}(\mathrm{Cu})$ and 6-311G* $(\mathrm{C}, \mathrm{O}, \mathrm{N}, \mathrm{H}, \mathrm{B})$ with Ultra Fine Integral Grid. ${ }^{e} \mathrm{~B} 3 \mathrm{LYP} / \mathrm{SDD}(\mathrm{Cu})$ and 6-31G* $(\mathrm{C}, \mathrm{O}, \mathrm{N}, \mathrm{H}, \mathrm{B})$ with Ultra Fine Integral Grid. 


\subsection{Second Order Perturbation Analysis of Lewis Acid/Base Interaction}

Second order perturbation theory was used to further examine the correlation between the $\mathrm{BVD}$ and $\mathrm{CO}_{2}$ insertion by evaluating stabilization energies, denoted $\Delta \mathrm{E}(2) \mathrm{i} \rightarrow \mathrm{j}^{*}$ or $\mathrm{E}(2)$. Donor/acceptor behavior was quantified through stabilization of the donor orbital upon overlap with an unoccupied orbital $\left(i=\right.$ appropriately oriented lone pair of the $\mathrm{CO}_{2}$ oxygen; $\mathrm{j}=$ vacant $p$ orbital of boron).

Stabilization energies of boron ester and amide derivatives were found to correlate well with BVD (Figure 4.20, black trace). For example, a stronger stabilizing interaction (of $5 \mathrm{kcal} / \mathrm{mol}$ ) between the donor/acceptor pair of $\mathrm{B}(\mathrm{eg})$ exists relative to analogous $\mathrm{B}(\mathrm{en})(\mathrm{en}=$ ethylenediamino) $(\mathrm{BVD}=1.24$ and 1.02, respectively). A rendering of the natural bonding orbitals responsible for this interaction in the case of the boron ester derivative illustrates significant orbital overlap (Figure 4.20). Further, the interaction distance between the boron and the participating oxygen atom of the $\mathrm{CO}_{2}$ moiety was examined (Figure 4.20, red trace). An inverse correlation was observed with the alkoxy- and amino- substituted compounds, wherein decreasing BVD led to an increased distance $\left(\mathrm{r}_{\mathrm{B}-\mathrm{O}}\right)$ between the Lewis pair.

This lengthening in the $\mathrm{B}-\mathrm{O}$ interaction as the polarization of the $\mathrm{B}-\mathrm{X}$ bond ( $\mathrm{X}=$ substituent) is reduced reflects the importance of the increased Lewis acidic character of boron in promoting delocalization of electron density away from carbon dioxide, and this aligns well with the corresponding decrease in stabilization energy. All these elements aid in providing a more electrophilic carbon to initiate insertion into the copper-benzyl bond. However, there were instances in which the bond length analysis did not provide the anticipated results. Examination of the Lewis pair interaction distance for hydrocarbyl and halo substituents showed no correlation either to BVD or $\mathrm{E}(2)$. This can be attributed to the fact that the Lewis pair distance is significantly shorter in these transition states, thus reflecting significant structural changes at the boron fragment at the transition state. 

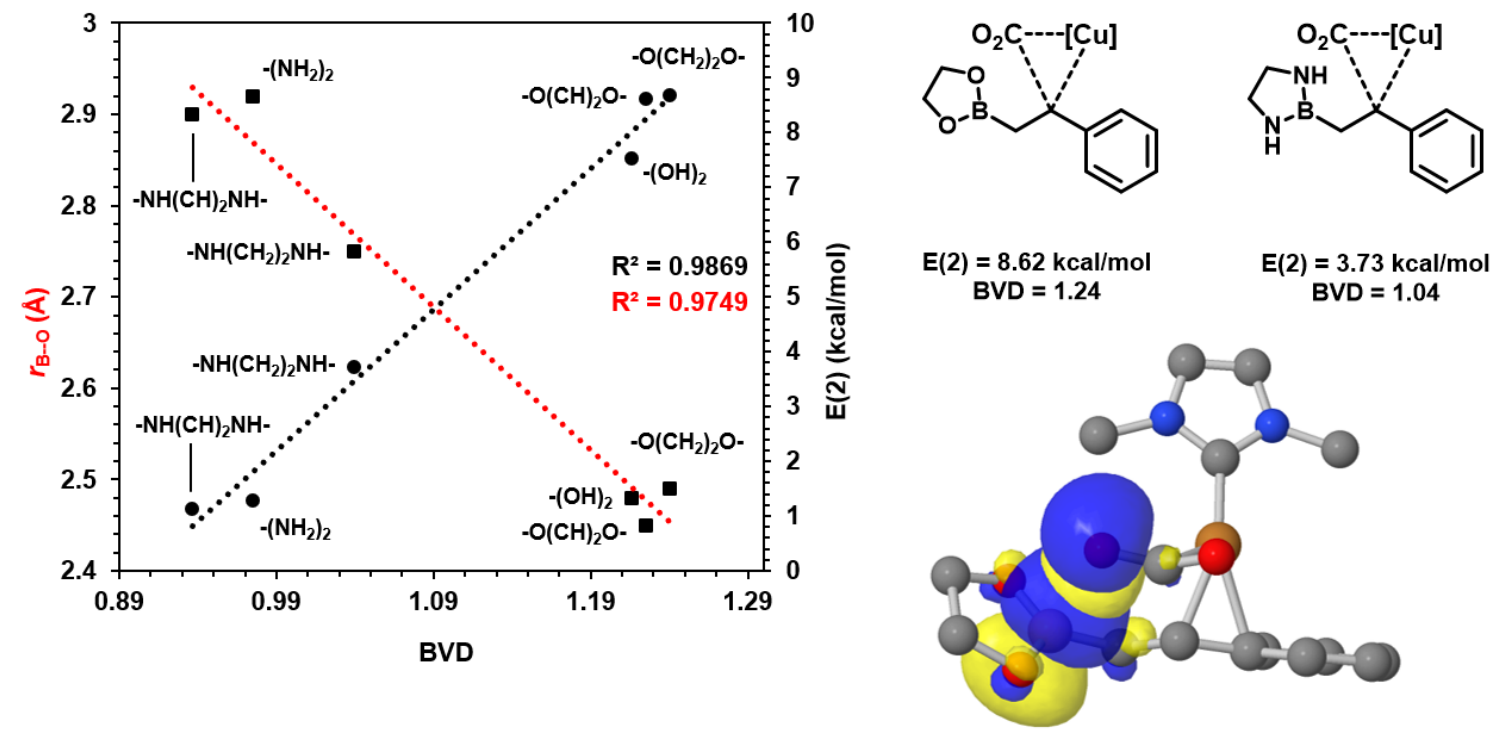

Figure 4.20. Stabilization energies from NBO analysis of analogous oxygen- and nitrogencontaining boron fragments (black trace) and the relationship to the corresponding B-O interaction distances (red trace). Molecular structures featuring computed NBO interaction $\mathrm{O}(\mathrm{lp})$

$\rightarrow \mathrm{B}(\mathrm{lp} *)$ in $\mathrm{IMeCu}\left(\mathrm{CH}(\mathrm{Ph}) \mathrm{CH}_{2} \mathrm{~B}(\mathrm{eg})\right)$ is shown on right. Hydrogen atoms are omitted for clarity.

\subsection{Exceptions to the Model}

When extending the series of boron fragments to those containing sulfur, there were deviations from the abovementioned trends. The sulfur substituents employed, $\mathrm{B}\left(\mathrm{SH}_{2}\right)_{2}, \mathrm{~B}\left(\mathrm{~S}\left(\mathrm{CH}_{2}\right)_{2} \mathrm{~S}\right)$, and $\mathrm{B}\left(\mathrm{S}(\mathrm{CH})_{2} \mathrm{~S}\right)$, demonstrated poor correlation between the electronegativities of the atoms and the corresponding boron valence deficiency $\left(\mathrm{R}^{2}=0.55\right)$ (Figure 4.21. A). This reflects the limitations of describing Lewis acidity in a strictly electronic manner. When extending past the second-row elements, atomic radius is no longer negligible in the model. ${ }^{162}$ Thus, multiple regression analysis was employed, including atomic radius and electronegativity in the correlation to BVD.

162. Clementi, E.; Rainmondi, D. L.; Reinhardt. Atomic Screening Constants from SCF Functions II. Atoms with 37 to 86 Electrons. J. Chem. Phys. 1967, 47, 1300-1309. 

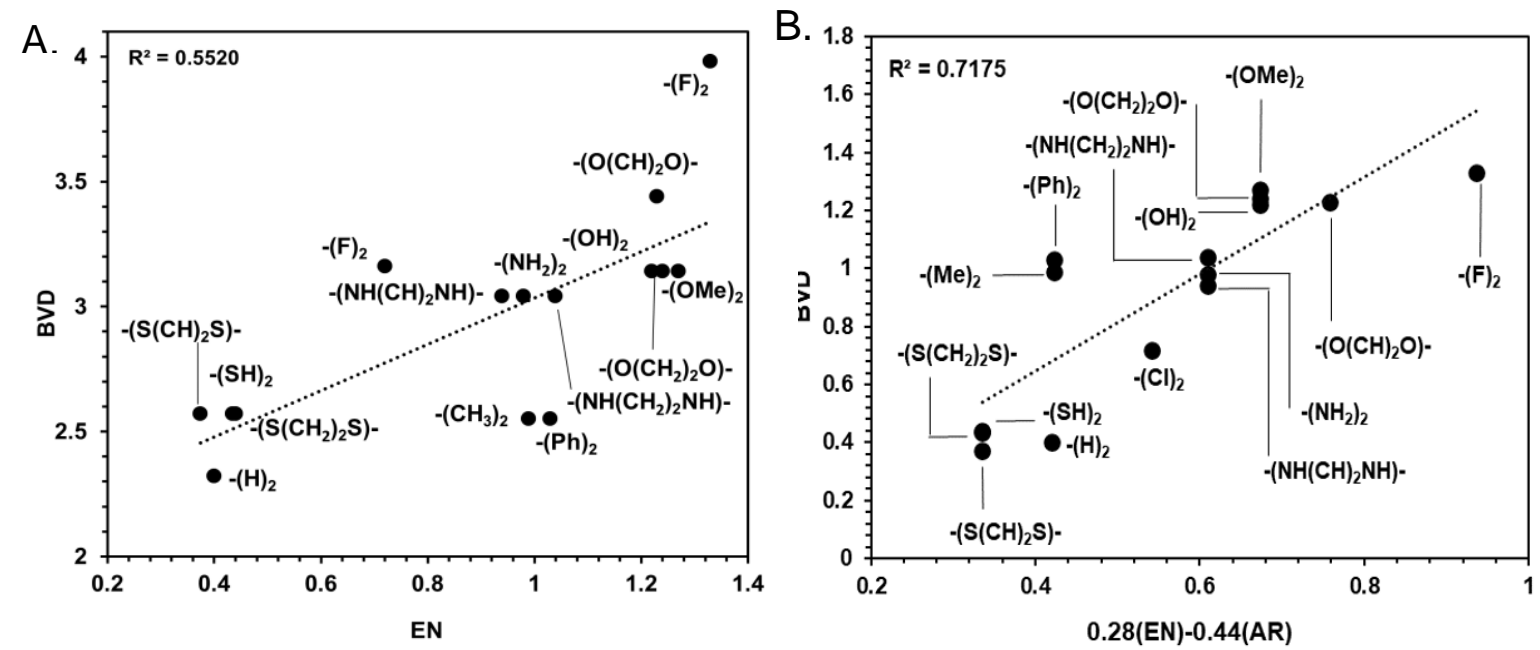

Figure 4.21. Right: Comparison of BVD and the average electronegativity of $\mathrm{BX}_{2}$ fragments, including sulfur variants. Left: Comparison between BVD and a linear combination of both electronegativity and atomic radius for $\mathrm{BX}_{2}$ fragments, including several sulfur variants.

The combination of $28 \%$ electronegative and $44 \%$ atomic radius provided the best fit when evaluated with ANOVA $\left(\mathrm{R}^{2}=0.72\right)$, suggesting a more accurate reflection of the Lewis acidity of the sulfur-ligated boron center through including the atomic radius of sulfur (Figure 4.21.B). ${ }^{159}$ These results underscore the need to consider Lewis acidity from multiple approaches rather than strictly from an electronic aspect.

\subsection{Conclusions}

This computational study has evaluated the potential for an intramolecular Lewis donor/acceptor interaction to facilitate carboxylation of $\beta$-borylbenzyl- $\mathrm{Cu}(\mathrm{I})$ species relevant to catalytic boracarboxylation. Data shows that the enthalpic barrier of $\mathrm{CO}_{2}$ insertion decreases with increasing electron deficiency at the boron center as quantified using NBO-determined boron valence deficiency. The apparent kinetic benefit of an electron deficient boron suggests a more active role in which boron participates as a Lewis acid that promotes $\mathrm{CO}_{2}$ insertion through the removal of electron density from the proximal oxygen, thereby yielding a more electrophilic carbon poised for metalation by copper.

The study provides a conceptual framework for understanding how pinacolboryl- and other boron moieties could play a cooperative role in catalytic boracarboxylation. Given the prevalence 
of Lewis-acid-assisted activation of $\mathrm{C}=\mathrm{O}$ bonds in organometallic transformations, ${ }^{163}$ most notably migratory insertion, this concept of boron-assisted copper-catalyzed carboxylation might be extended to similar transition-metal-catalyzed carboxylation systems through strategic catalyst/reaction design. ${ }^{164}$ If the model can be demonstrated to be effective catalytically, it could create significant new opportunities for the improved installation of $\mathrm{CO}_{2}$ in organic molecules via transition metal-catalyzed processes.

163. (a) Miller, A. J. M.; Labinger, J. A.; Bercaw, J. E. Homogeneous CO Hydrogenation: Ligand Effects on the Lewis Acid-Assisted Reductive Coupling of Carbon Monoxide. Organometallics 2010, 29, 4499-4516. (b) Wang, C.; Xi, Z. Cooperative Effect of Lewis Acids with Transition Metals for Organic Synthesis. Chem. Soc. Rev. 2007, 36, 13951406 and references therein.

164. For selected works on the activation of carbon dioxide at transition metal complexes, see: (a) Aresta, M.; Nobile, C. F. New Nickel-Carbon Dioxide Complex: Synthesis, Properties, and Crystallographic Characterization of (Carbon Dioxide)-bis(tricyclohexylphosphine)nickel. J. Chem. Soc. Chem. Commun. 1975, 15, 636-637. (b) Alvarez, R.; Carmona, E.; Gutierrez-Puebla, E.; Marín, J. M.; Monge, A.; Poveda, M. L. Synthesis and X-Ray Crystal Structure of $\left[\mathrm{Mo}\left(\mathrm{CO}_{2}\right)_{2}\left(\mathrm{PMe}_{3}\right)_{3}(\mathrm{CNiPr})\right]$ : the First Structurally Characterized Bis(Carbon Dioxide) Adduct of a Transition Metal. J. Chem. Soc. Chem. Commun. 1984, 1326-1327. (c) Aresta, M.; Gobetto, R.; Quaranta, E.; Tommasi, I. A BondingReactivity Relationship for $\mathrm{Ni}\left(\mathrm{PCy}_{3}\right)_{2}\left(\mathrm{CO}_{2}\right)$ : A Comparative Solid-State-Solution Nuclear Magnetic Resonance Study $\left({ }^{31} \mathrm{P},{ }^{13} \mathrm{C}\right)$ as a Diagnostic Tool to Determine the Mode of Bonding of $\mathrm{CO}_{2}$ to a Metal Center. Inorg. Chem. 1992, 31, 4286-4290. (d) Komiya, S.; Akita, M.; Kasuga, N.; Hirano, M.; Fukuoka, A. Synthesis, Structure and Reactions of a Carbon Dioxide Complex of Iron(0) Containing 1,2-bis(diethylphosphino)ethane Ligands. J. Chem. Soc. Chem. Commun. 1994, 1115-1116. (e) Hirano, M.; Akita, M.; Tani, K.; Kumagai, K.; Kasuga, N. C.; Fukuoka, A.; Komiya, S. Activation of Coordinated Carbon Dioxide in $\mathrm{Fe}\left(\mathrm{CO}_{2}\right)(\mathrm{depe})_{2}$ by Group 14 Electrophiles. Organometallics 1997, 16, 4206-4213. (f) Yin, X.; Moss, J. R. Recent Developments in the Activation of Carbon Dioxide by Metal Complexes. Coord. Chem. Rev. 1999, 181, 27-59. (g) Yeung, C. S.; Dong, V. M. Beyond Aresta's Complex: Ni- and Pd-Catalyzed Organozinc Coupling with $\mathrm{CO}_{2}$. J. Am. Chem. Soc. 2008, 130, 7826-7827. (h) Grice, K. A. Carbon Dioxide Reduction with Homogeneous Early Transition Metal Complexes: Opportunities and Challenges for Developing $\mathrm{CO}_{2}$ Catalysis. Coord. Chem. Rev. 2017, 336, 78-95. (i) Mascetti, J. Metal Coordination of $\mathrm{CO}_{2}$. Encyclopedia of Inorganic and Bioinorganic Chemistry 2014, 1-17. 


\subsection{Computational Methods}

Calculations were performed using the Gaussian 09 package. ${ }^{165}$ For ground state and transition state geometry optimizations, the M06 functional ${ }^{166,167}$ and the Pople basis sets 6$311+\mathrm{G}^{*}$ for copper and $6-311 \mathrm{G}^{*}$ for all other atoms were used, ${ }^{168}$ applying a fine integral grid $(75,302)$ to all calculations. Normal-mode analyses were performed at the same level of theory, confirming that each optimized minimum or transition state has zero or one imaginary frequency, respectively. Single-point self-consistent reaction field calculations (SCRF) were also performed with tetrahydrofuran solvation, the catalytic reaction solvent, ${ }^{146}$ specified using the SMD model. ${ }^{169}$ Natural bond orbital (NBO) analysis was performed using the Gaussian NBO version $3.1^{170}$ with the same level of theory. Natural bonding orbitals were visualized using NBOPro $6.0,{ }^{170}$ and Jmol visualization software was used for the generation of $3 \mathrm{D}$ NBO plots. ${ }^{171}$

165. Frisch, M. J.; Trucks, G. W.; Schlegel, H. B.; Scuseria, G. E.; Robb, M. A.; Cheeseman, J. R.; Scalmani, G.; Barone, V.; Petersson, G. A.; Nakatsuji, H.; et al. Gaussian 09; Gaussian, Inc.: Wallingford CT, 2009. revision D.01. 166. The M06 functional was chosen for geometry optimizations after consideration of benchmarking results for a comparatively similar NHC-copper(I) system; see Collins, L. R.; Rajabi, N. A.; Macgregor, S. A.; Mahon, M. F.; Whittlesey, M. K. Experimental and Computational Studies of the Copper Borate Complexes $\left[(\mathrm{NHC}) \mathrm{Cu}\left(\mathrm{HBEt}_{3}\right)\right]$ and $\left[(\mathrm{NHC}) \mathrm{Cu}\left(\mathrm{HB}\left(\mathrm{C}_{6} \mathrm{~F}_{5}\right)_{3}\right)\right]$. Angew. Chem. Int. Ed. 2016, 55, 15539-15543.

167. Zhao, Y.; Truhlar, D. G. The M06 Suite of Density Functionals for Main Group Thermochemistry, Thermochemical Kinetics, Noncovalent Interactions, Excited States, and Transition Elements: Two New Functionals and Systematic Testing of Four M06-class Functionals and 12 Other Functionals. Theor. Chem. Acc. 2008, 120, 215241.

168. (a) Krishman, R.; Binkley, J. S.; Seeger, R.; Pople, J. A. Self-consistent Molecular Orbital Methods. XX. A Basis Set for Correlated Wave Functions. J. Chem. Phys. 1980, 72, 650. (b) Clark, T.; Chandrasekhar, J.; Schleyer, P. V. R. Efficient Diffuse Function-Augmented Basis Sets for Anion Calculations. III. The 3-21 G Basis Set for First-Row Elements, Lithium to Fluorine. J. Comp. Chem. 1983, 4, 294.

169. Marenich, A. V.; Cramer, C. J.; Truhlar, D. G. Universal Solvation Model Based on Solute Electron Density and on a Continuum Model of the Solvent Defined by the Bulk Dielectric Constant and Atomic Surface Tensions. J. Phys. Chem. B. 2009, 113, 6378-6396.

170. (a) Glendening, E. D.; Reed, A. E.; Carpenter, J. E.; Weinhold, F. NBO 3.1; Theoretical Chemistry Institute, University of Wisconsin: Madison, 1998. (b) Glendening, E. D.; Badenhoop, J. K.; Reed, A. E., Carpenter, J. E.; Bohmann, J. A.; Morales, C. M.; Landis, C. R.; Weinhold, F. NBO 6.0. 2013, Theoretical Chemistry Institute, University of Wisconsin, Madison. (c) E. D. Glendening, C. R. Landis, and F. Weinhold, NBO 6.0: Natural Bond Orbital Analysis Program. J. Comp. Chem. 2013, 34, 1429-1437.

171. Jmol: an open-source Java viewer for chemical structures in 3D. http://www.jmol.org/ 
APPENDIX I: SPECTRAL AND CRYSTALLOGRAPHIC DATA 


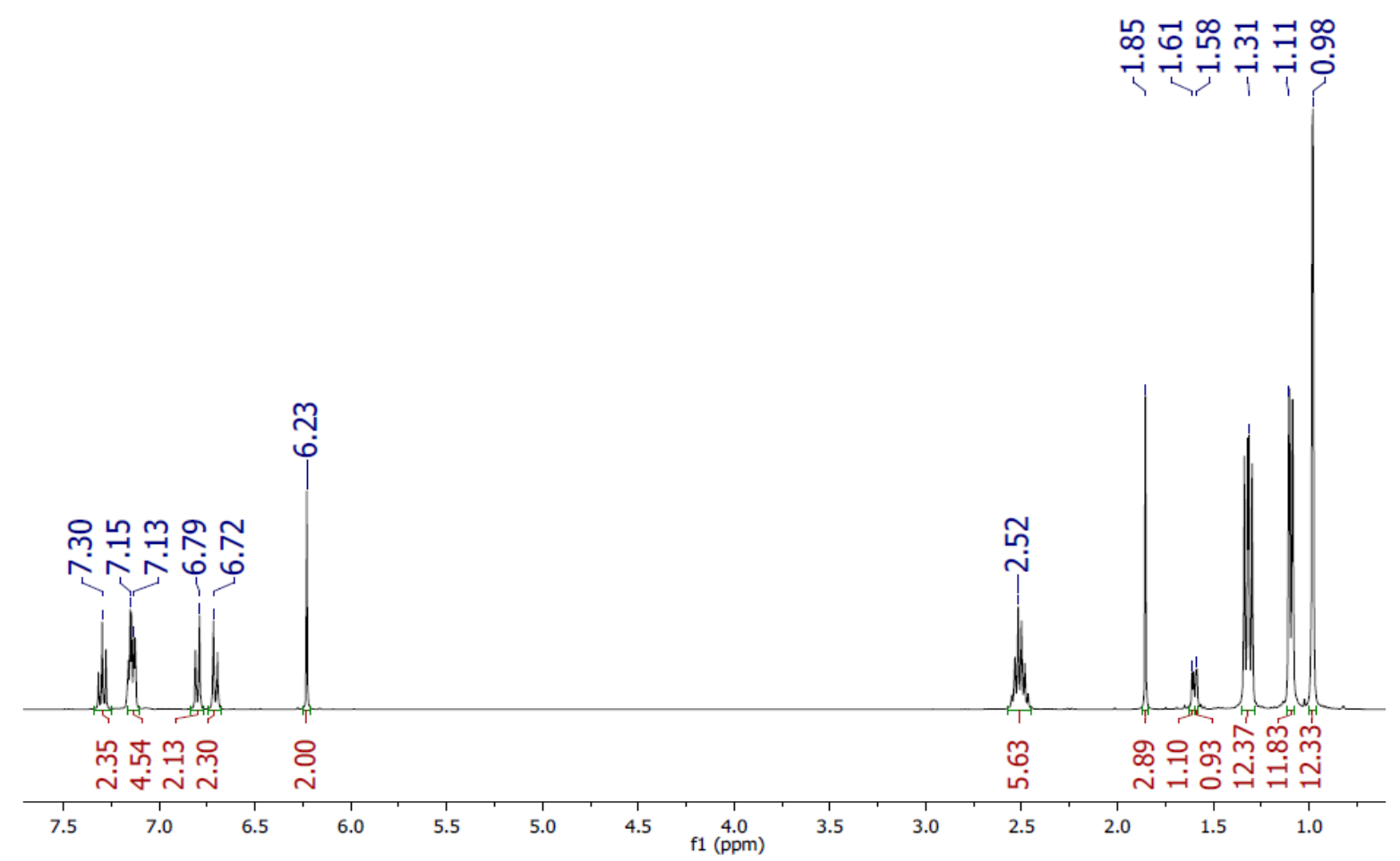

Figure A1.1. ${ }^{1} \mathrm{H}-\mathrm{NMR}$ spectrum of $\mathbf{2 g}$ in benzene- $\mathrm{d}_{6}$.

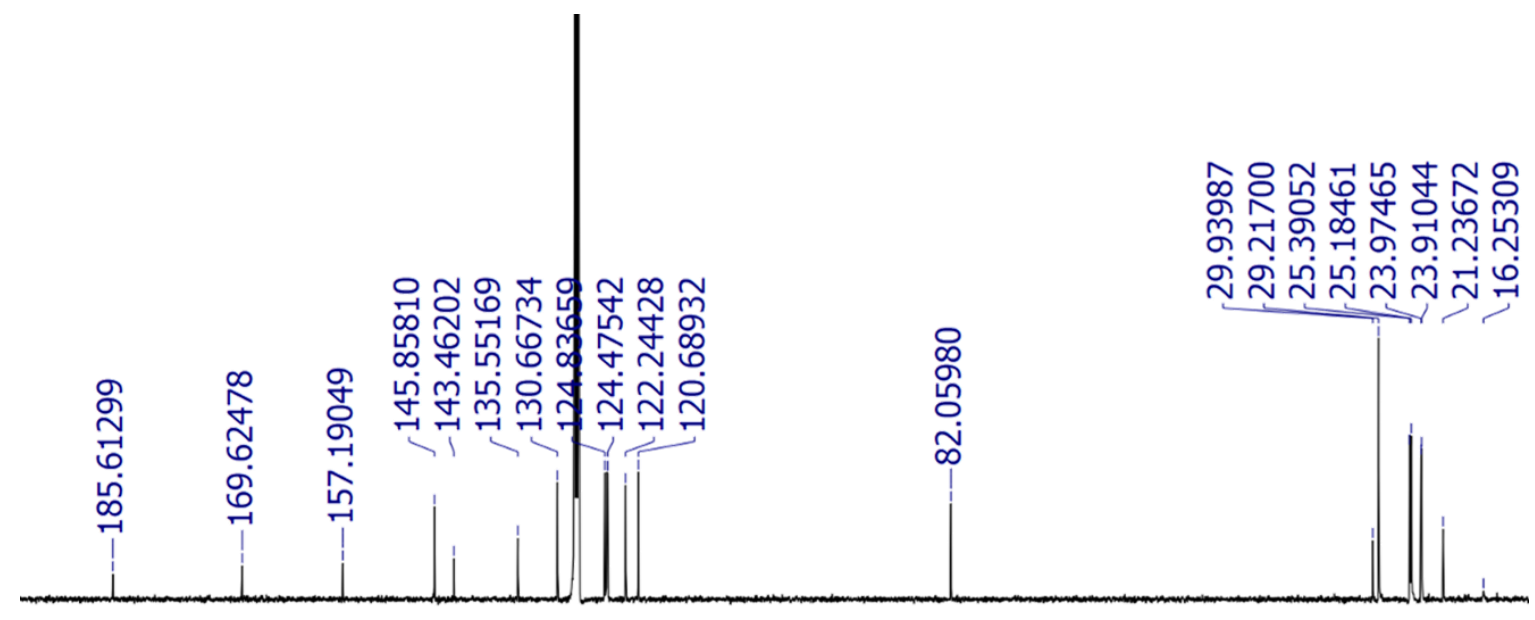

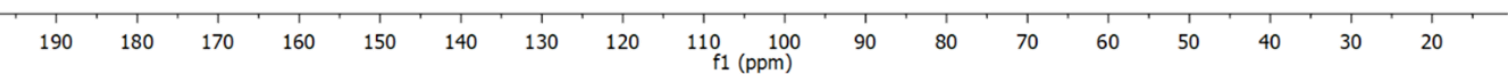

Figure A1.2. ${ }^{13} \mathrm{C}-\mathrm{NMR}$ spectrum of $\mathbf{2 g}$ in benzene- $\mathrm{d}_{6}$. 


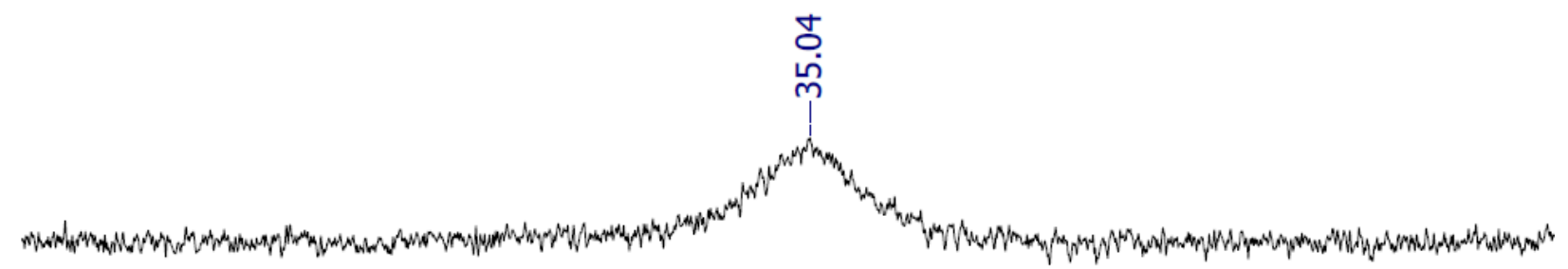

\begin{tabular}{|c|c|c|c|c|c|c|c|c|c|c|c|c|c|c|c|c|c|c|c|}
\hline 1 & 1 & 1 & 1 & 1 & 1 & 1 & 1 & 1 & 1 & 1 & $T$ & $T$ & $T$ & $T$ & $T$ & 1 & 1 & $T$ & $T$ \\
\hline 85 & 80 & 75 & 70 & 65 & 60 & 55 & 50 & 45 & ${ }^{40} \mathrm{f}$ & $\begin{array}{c}35 \\
\mathrm{ppm})\end{array}$ & 30 & 25 & 20 & 15 & 10 & 5 & 0 & -5 & -10 \\
\hline
\end{tabular}

Figure A1.3. ${ }^{11}$ B-NMR spectrum of $\mathbf{2 g}$ in benzene- $\mathrm{d}_{6}$.

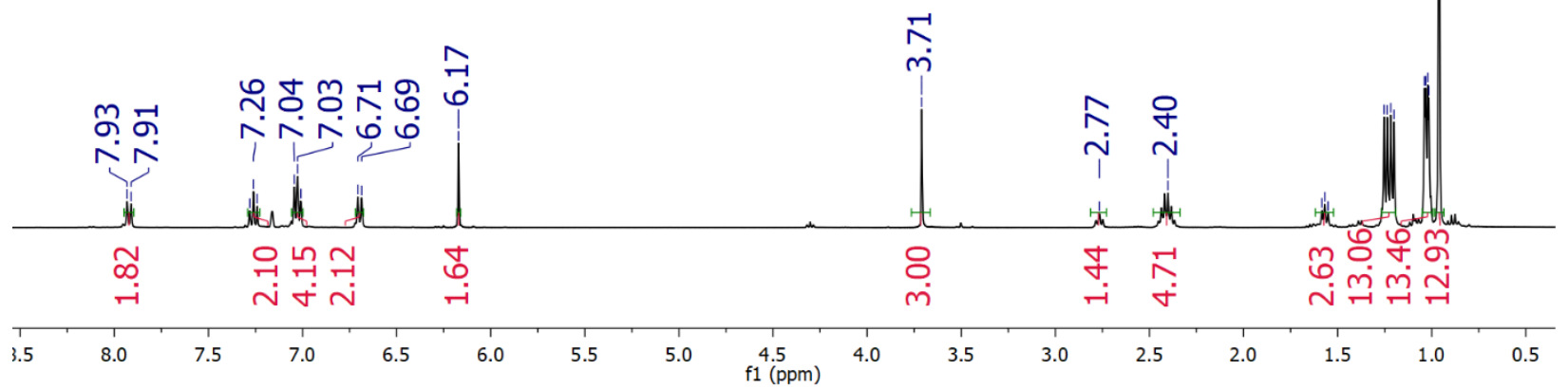

Figure A1.4. ${ }^{1} \mathrm{H}-\mathrm{NMR}$ spectrum of $\mathbf{2 h}$ in benzene- $\mathrm{d}_{6}$. 


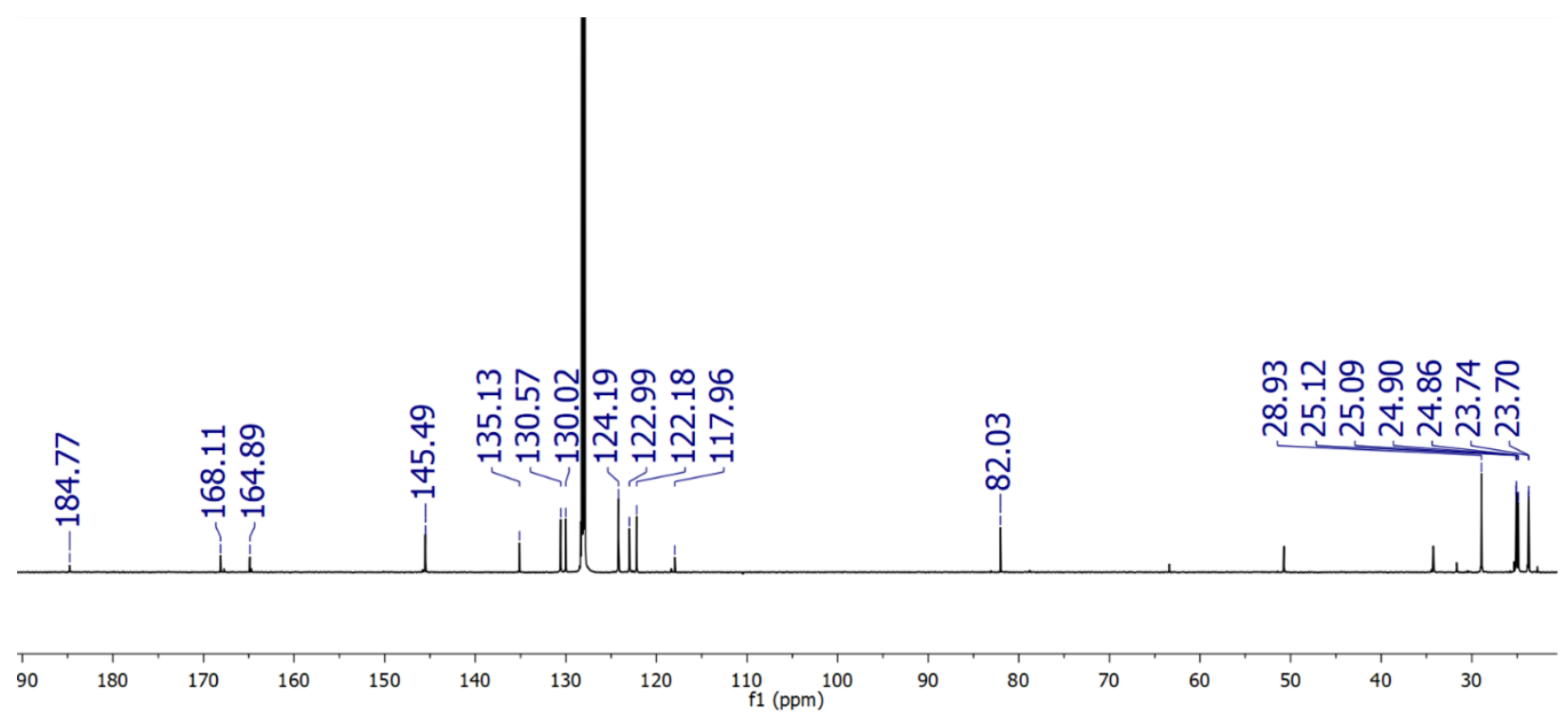

Figure A1.5. ${ }^{13} \mathrm{C}-\mathrm{NMR}$ spectrum of $\mathbf{2 h}$ in benzene- $\mathrm{d}_{6}$.

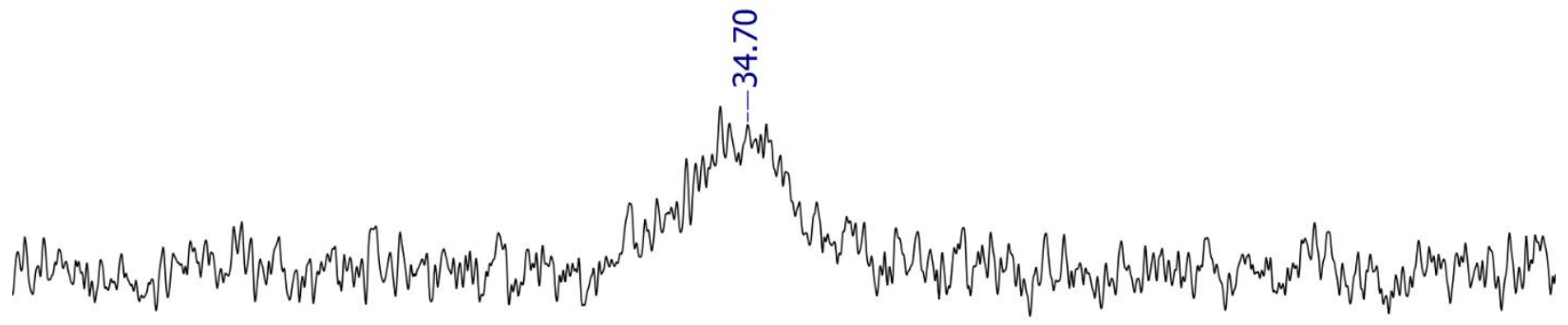

\begin{tabular}{|c|c|c|c|c|c|c|c|c|c|c|c|c|c|c|c|c|c|c|}
\hline 1 & 1 & 1 & 1 & $T$ & 1 & 1 & 1 & $T$ & 1 & 1 & 1 & 1 & 1 & $T$ & 1 & 1 & 1 & 1 \\
\hline 80 & 75 & 70 & 65 & 60 & 55 & 50 & 45 & 40 & $\begin{array}{c}35 \quad 30 \\
\text { f1 (ppm) }\end{array}$ & 25 & 20 & 15 & 10 & 5 & 0 & -5 & -10 & -15 \\
\hline
\end{tabular}

Figure A1.6. ${ }^{11}$ B-NMR spectrum of $\mathbf{2 h}$ in benzene- $\mathrm{d}_{6}$. 


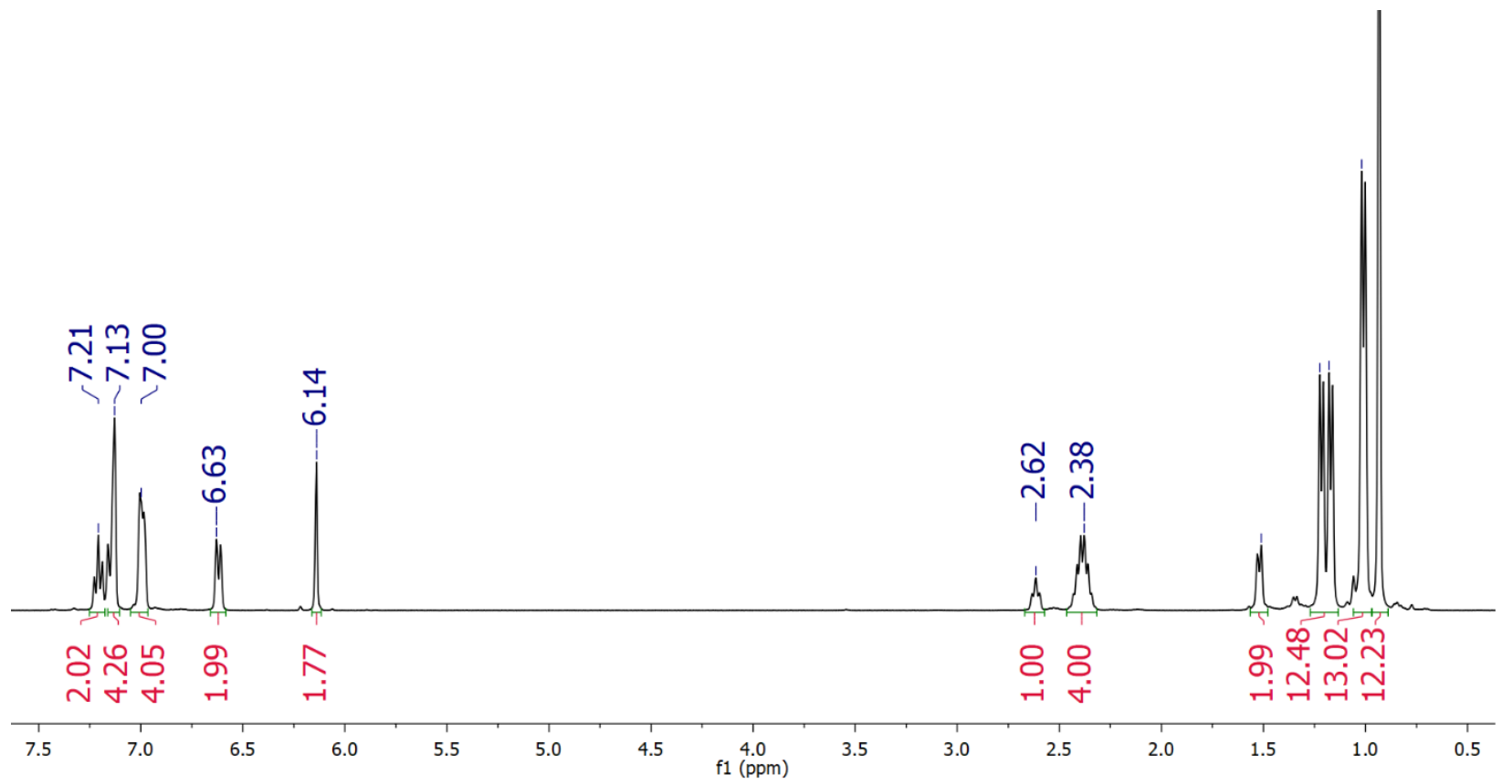

Figure A1.7. ${ }^{1} \mathrm{H}-\mathrm{NMR}$ spectrum of $\mathbf{2 i}$ in benzene- $\mathrm{d}_{6}$.
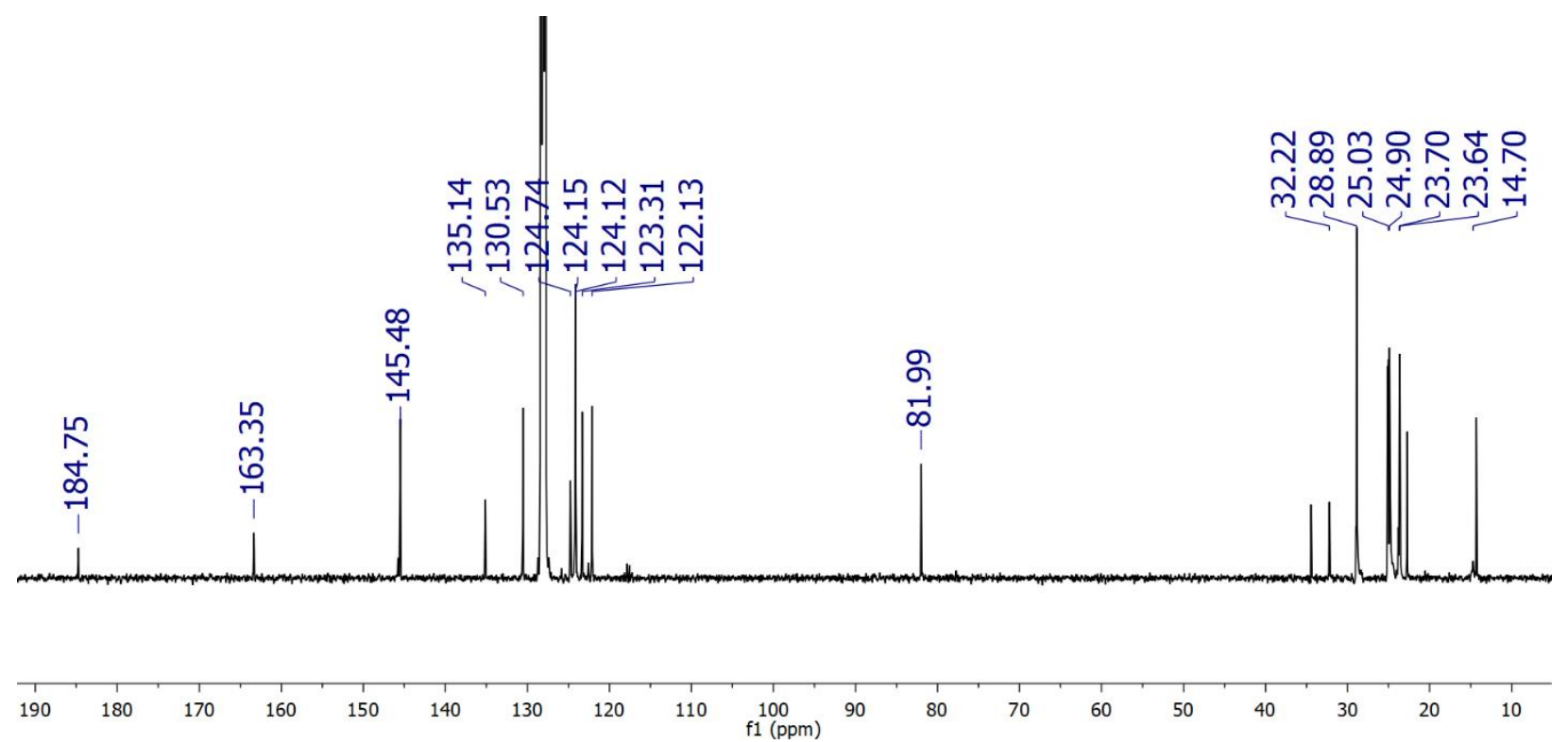

Figure A1.8. ${ }^{13} \mathrm{C}-\mathrm{NMR}$ spectrum of $\mathbf{2 i}$ in benzene- $\mathrm{d}_{6}$. 


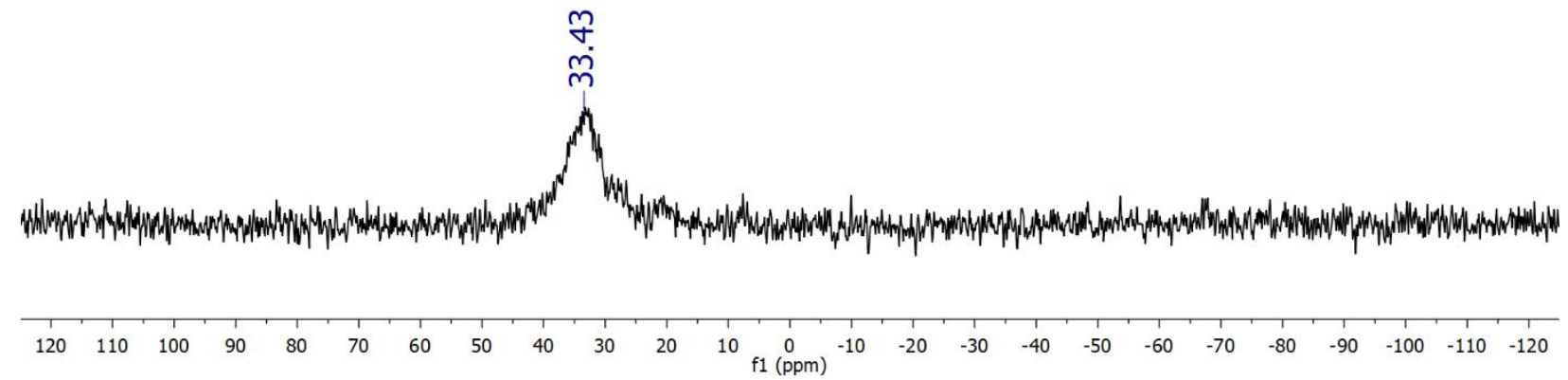

Figure A1.9. ${ }^{11}$ B-NMR spectrum of $2 \mathbf{i}$ in benzene- $d_{6}$.

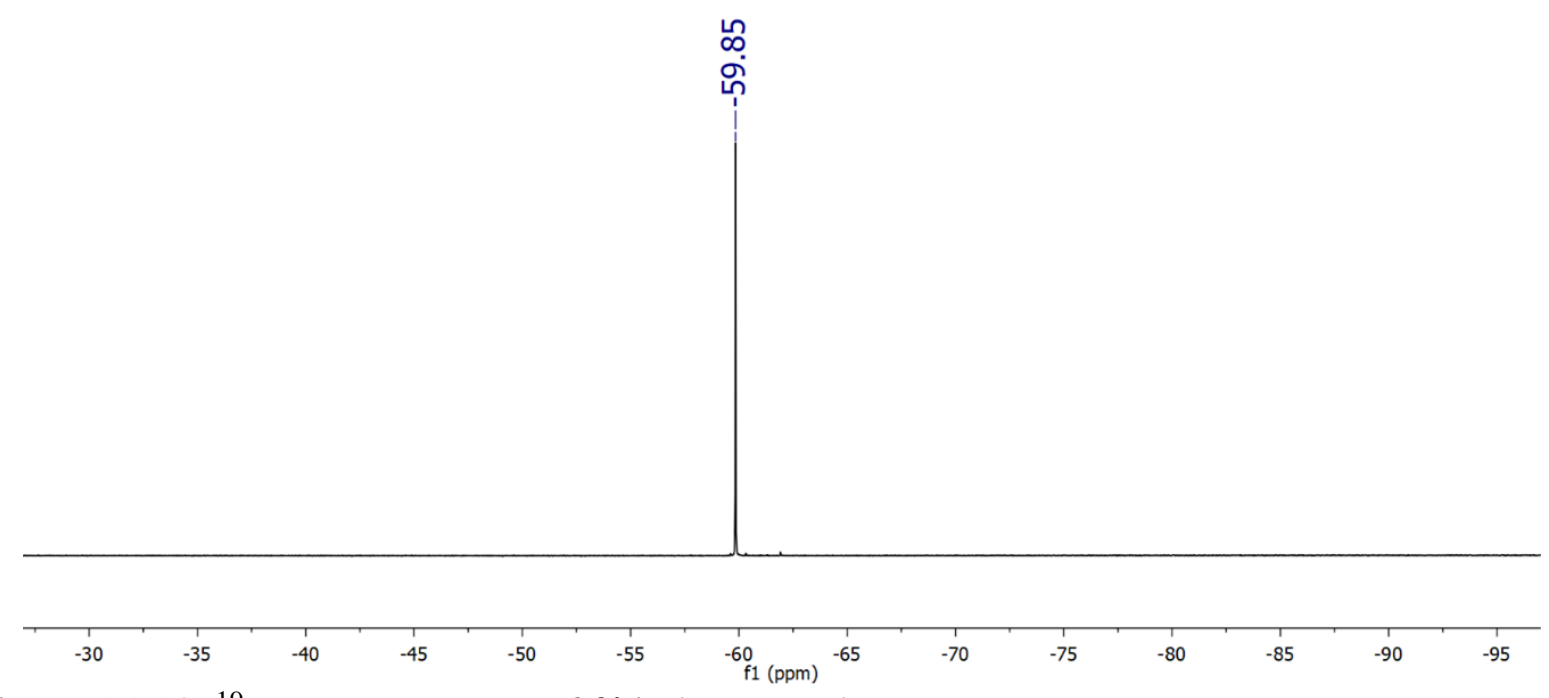

Figure A1.10. ${ }^{19} \mathrm{~F}$ NMR spectrum of $2 \mathbf{i}$ in benzene- $\mathrm{d}_{6}$. 


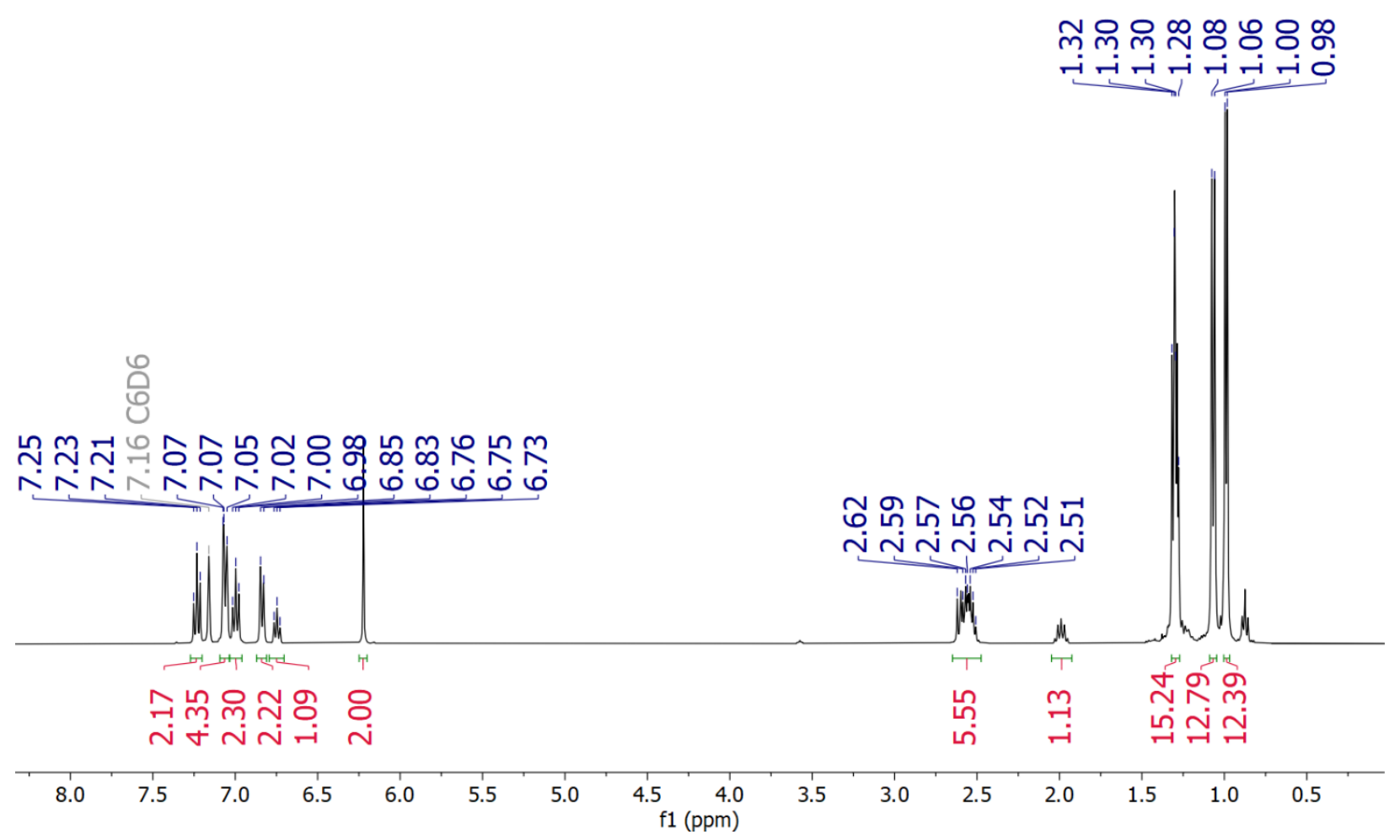

Figure A1.11. ${ }^{1} \mathrm{H}$ NMR spectrum of $\mathbf{2} \mathbf{j}$ in benzene- $\mathrm{d}_{6}$. 


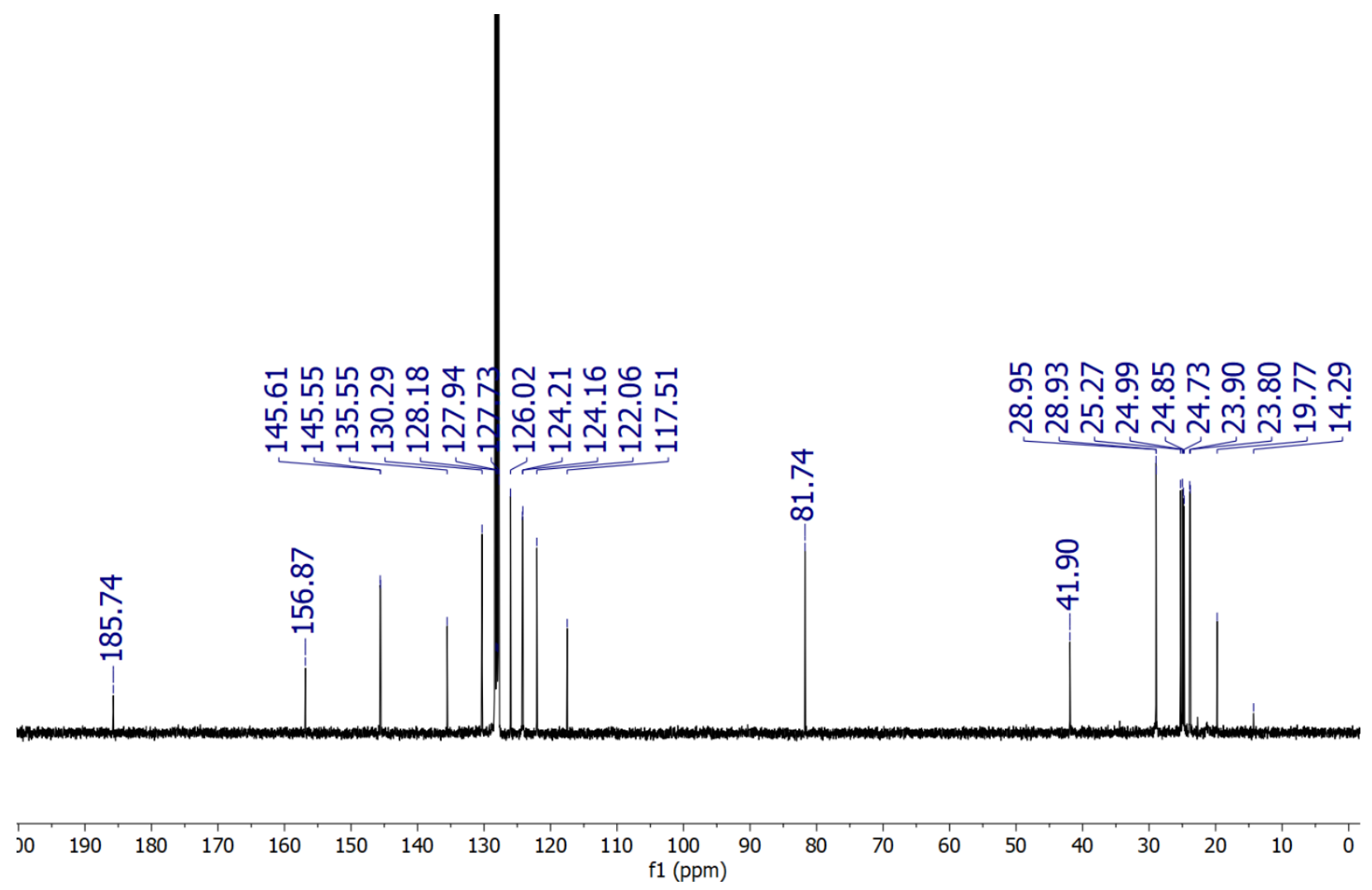

Figure A1.12. ${ }^{13} \mathrm{C}$ NMR spectrum of $\mathbf{2} \mathbf{j}$ in benzene- $\mathrm{d}_{6}$.

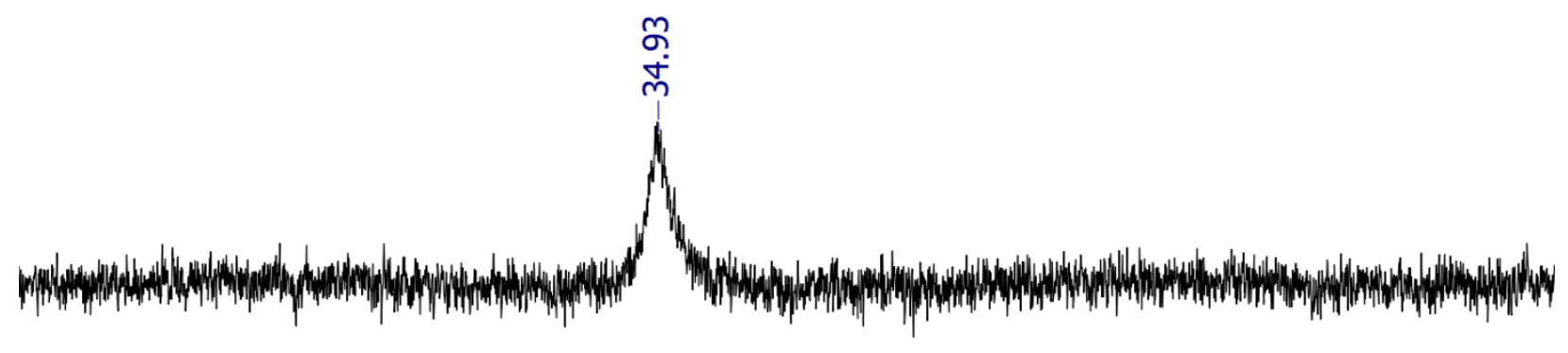

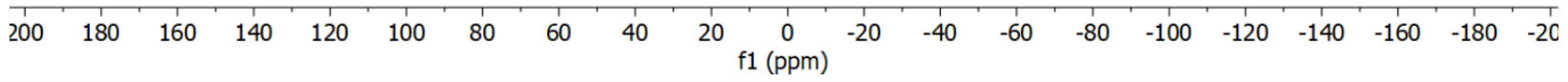

Figure A1.13. ${ }^{11}$ B NMR spectrum of $\mathbf{2} \mathbf{j}$ in benzene- $\mathrm{d}_{6}$. 


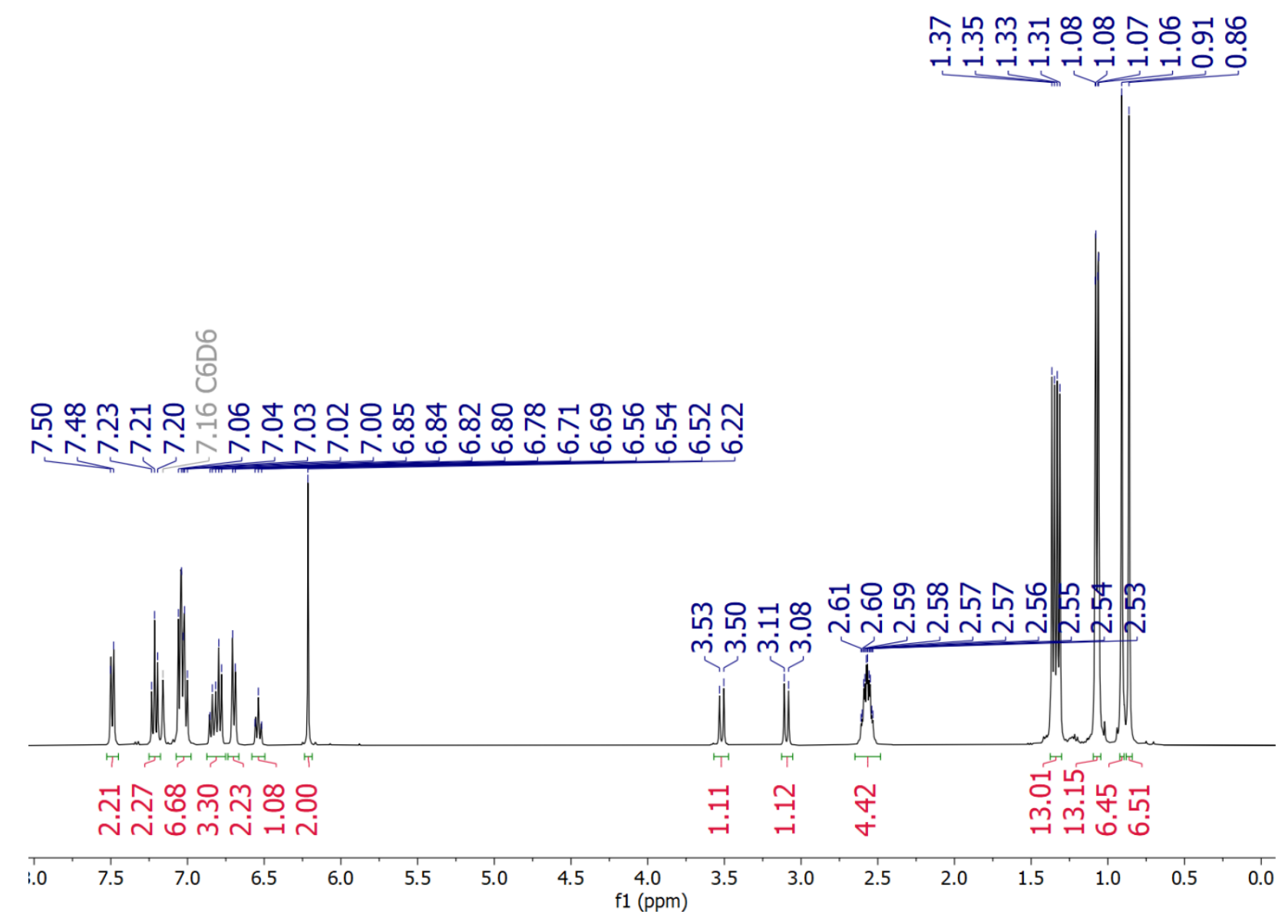

Figure A1.14. ${ }^{1} \mathrm{H}$ NMR spectrum of $\mathbf{2} \mathbf{k}$ in benzene-d 6 . 

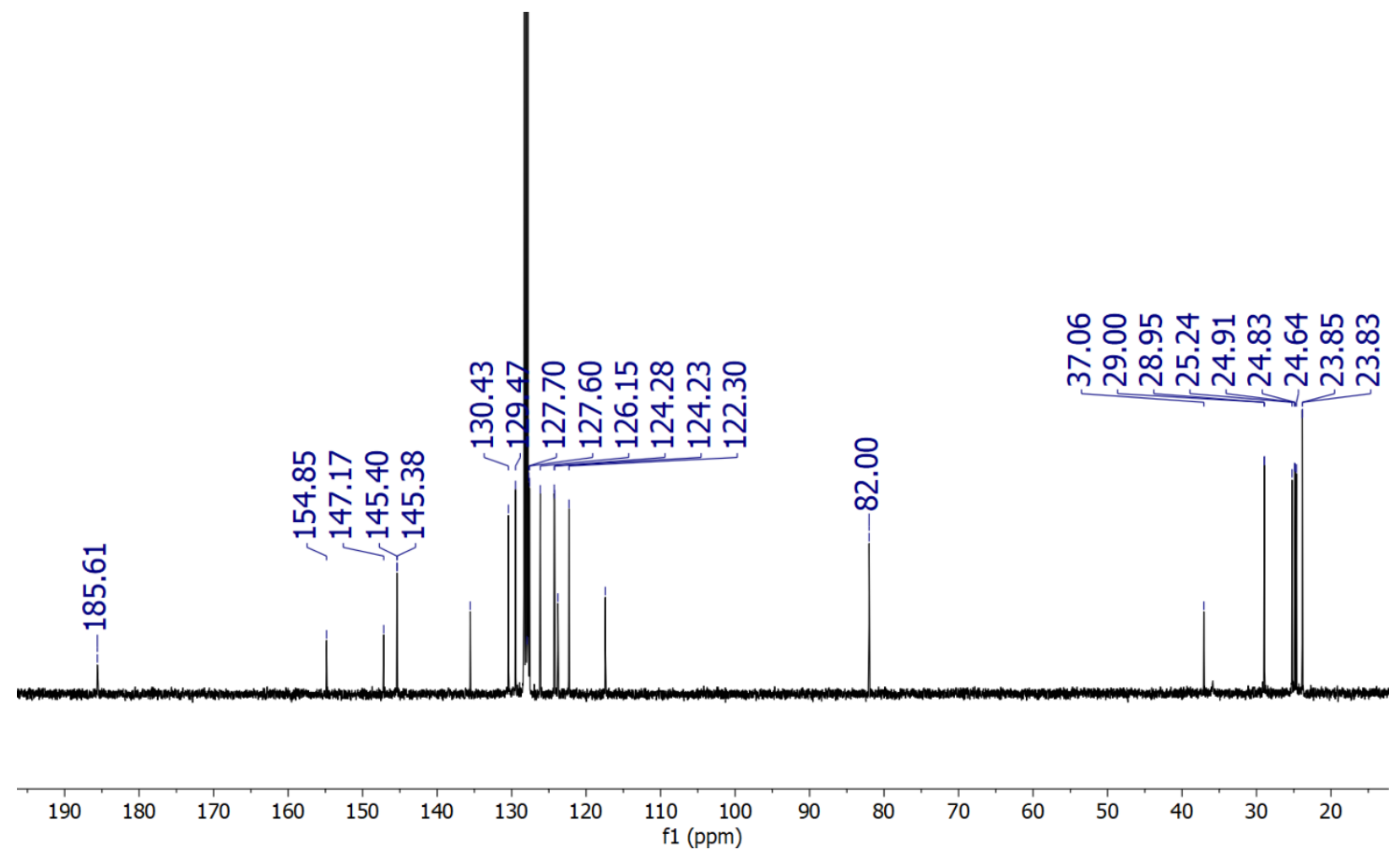

Figure A1.15. ${ }^{13} \mathrm{C}$ NMR spectrum of $\mathbf{2 k}$ in benzene- $\mathrm{d}_{6}$.

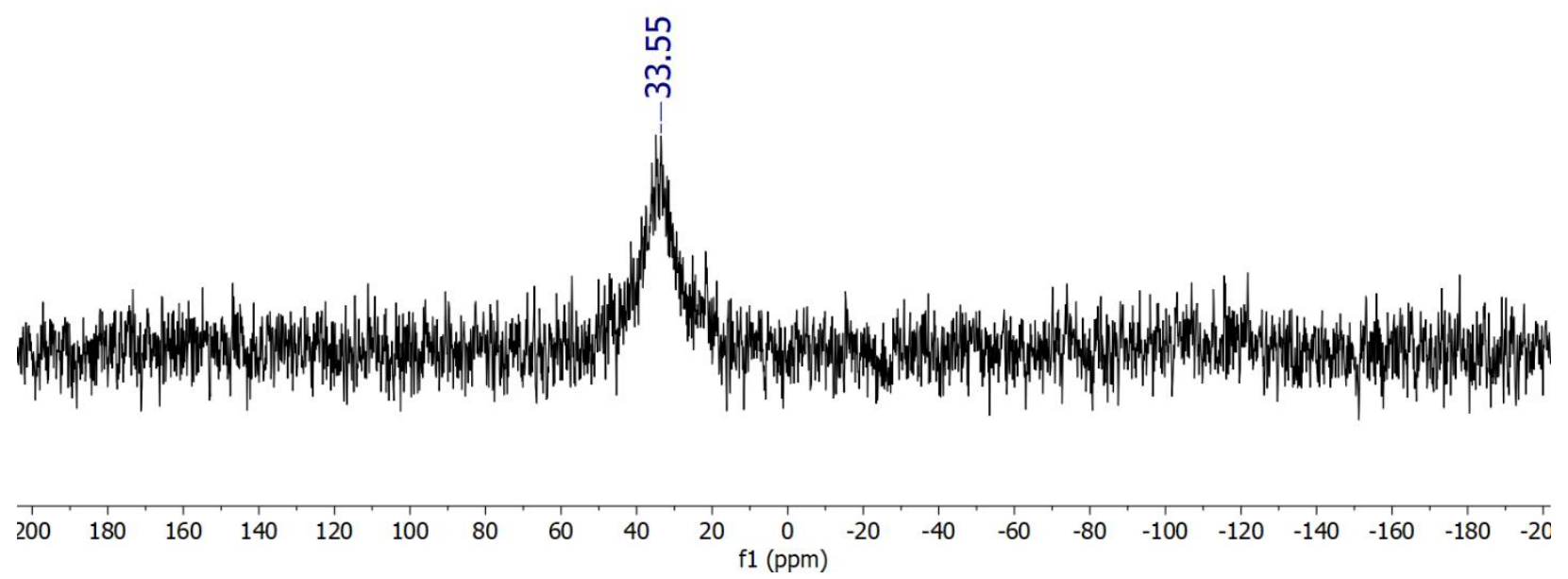

Figure A1.16. ${ }^{11}$ B NMR spectrum of $\mathbf{2} \mathbf{k}$ in benzene- $\mathrm{d}_{6}$. 


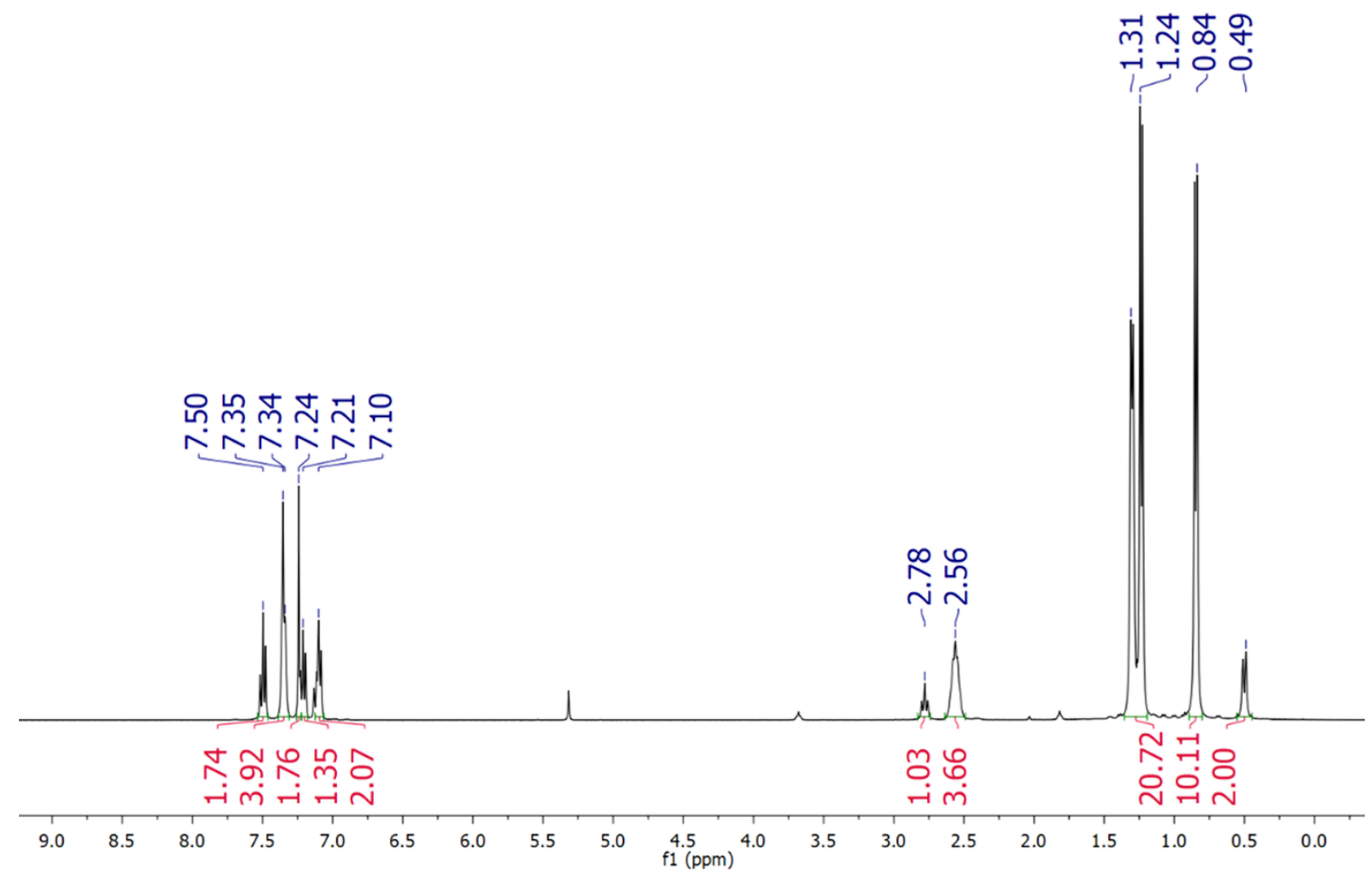

Figure A1.17. ${ }^{1} \mathrm{H}-\mathrm{NMR}$ spectrum of $\mathbf{3 a}$ in dichloromethane- $\mathrm{d}_{2}$.

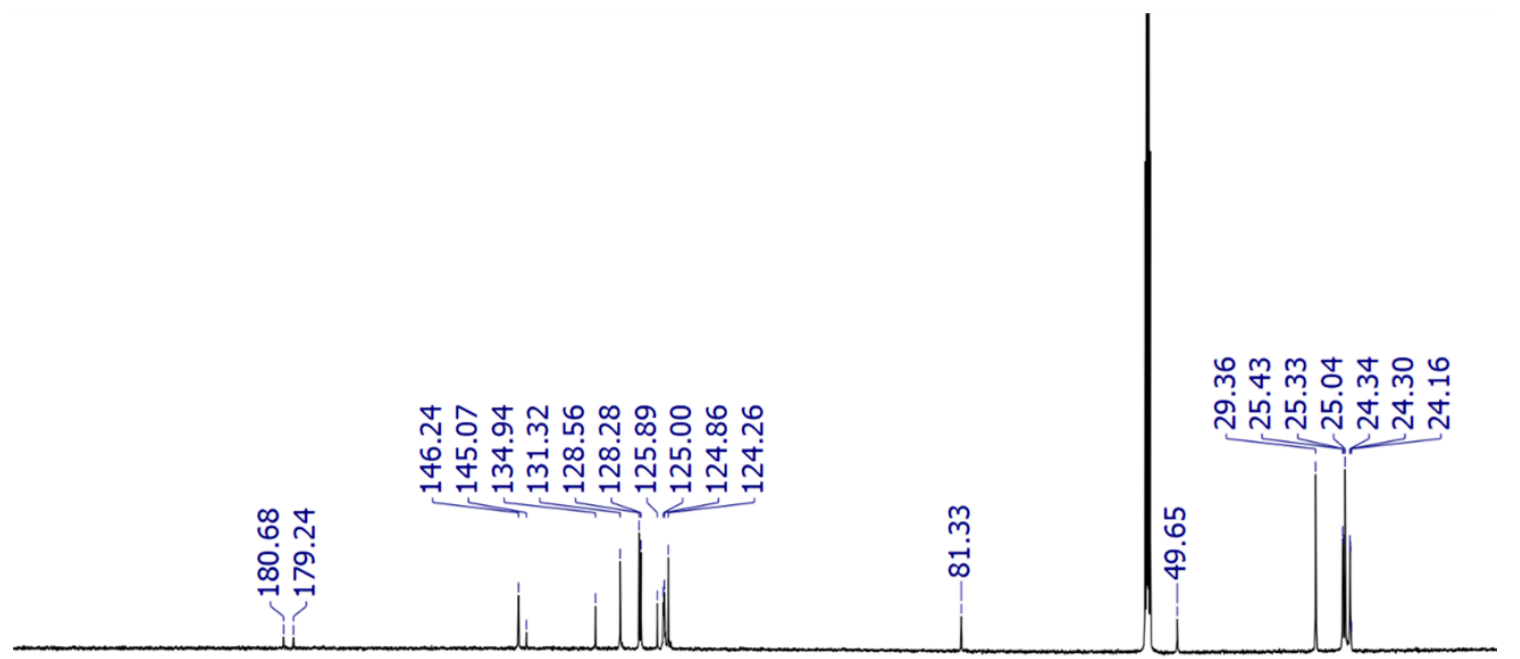

$\begin{array}{llllllllllllllllllllllll}20 & 210 & 200 & 190 & 180 & 170 & 160 & 150 & 140 & 130 & 120 & 110 & 100 & 90 & 80 & 70 & 60 & 50 & 40 & 30 & 20 & 10\end{array}$

Figure A1.18. ${ }^{13} \mathrm{C}-\mathrm{NMR}$ spectrum of $\mathbf{3 a}$ in dichloromethane- $\mathrm{d}_{2}$. 


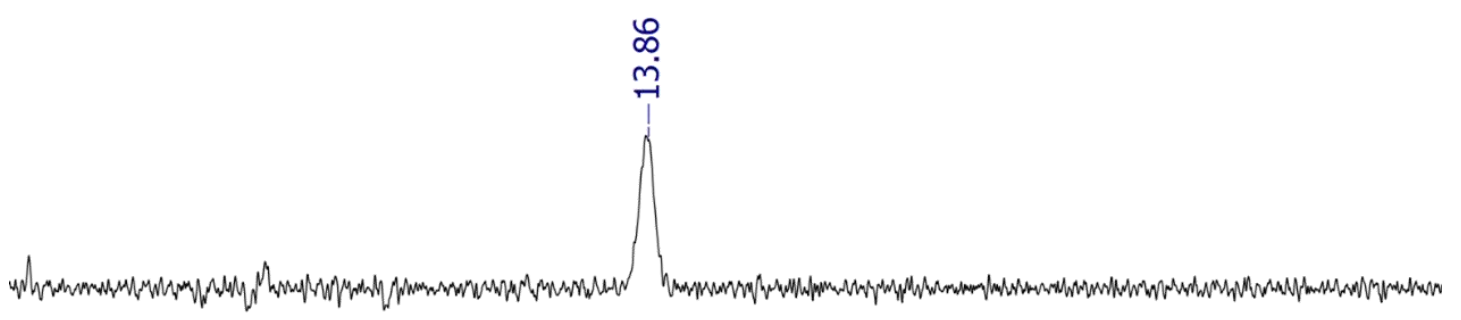

\begin{tabular}{|c|c|c|c|c|c|c|c|c|c|c|c|c|c|c|c|c|c|}
\hline 1 & $T$ & $T$ & $T$ & $T$ & $T$ & $T$ & $T$ & $T$ & 7 & 1 & $T$ & $T$ & T & $T$ & 1 & $T$ & \\
\hline 90 & 80 & 70 & 60 & 50 & 40 & 30 & 20 & 10 & $\begin{array}{c}0 \\
\mathrm{f} 1 \stackrel{(\mathrm{ppm})}{ }\end{array}$ & -10 & -20 & -30 & -40 & -50 & -60 & -70 & -80 \\
\hline
\end{tabular}

Figure A1.18. ${ }^{11} \mathrm{~B}-\mathrm{NMR}$ spectrum of $\mathbf{3 a}$ in dichloromethane- $\mathrm{d}_{2}$.

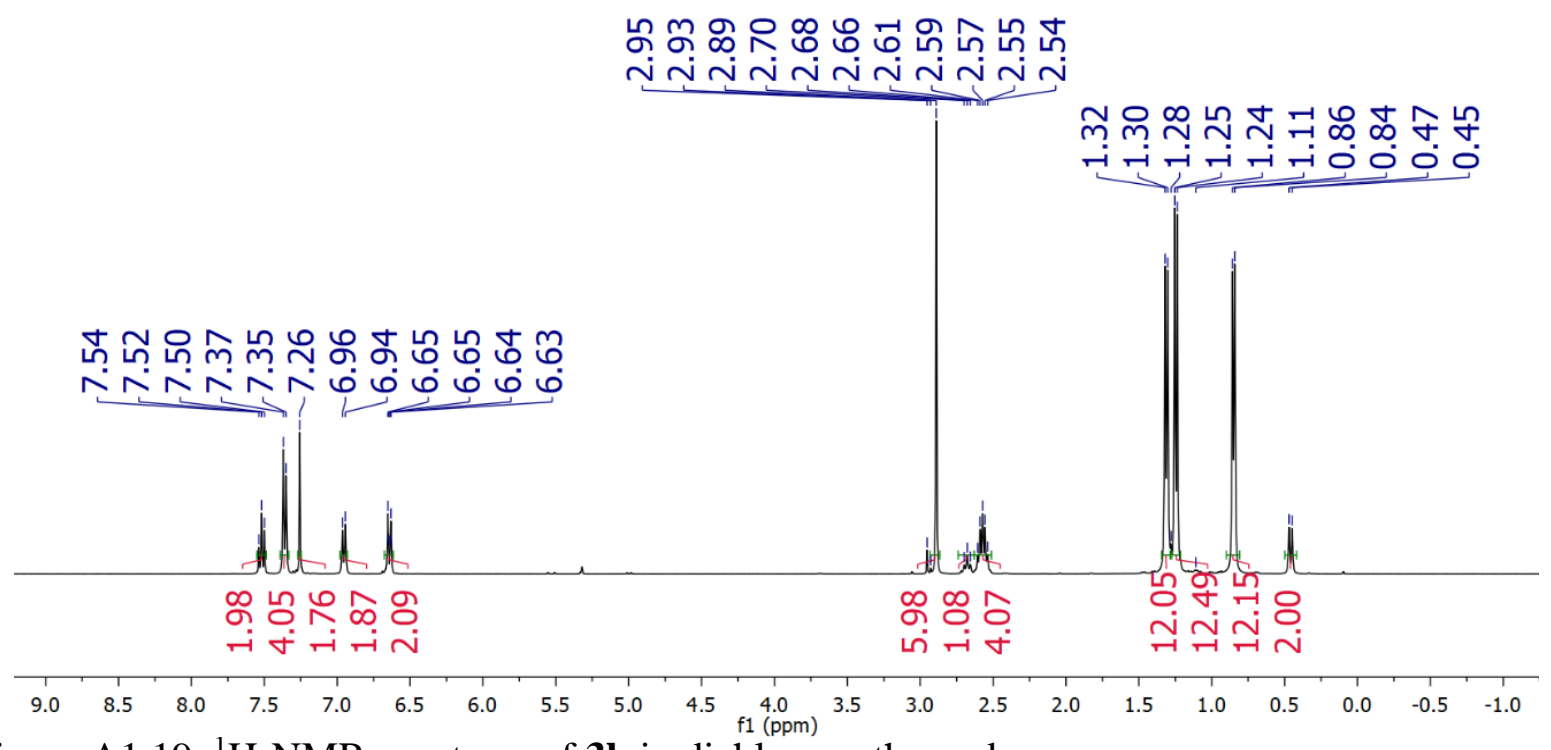

Figure A1.19. ${ }^{1} \mathrm{H}-\mathrm{NMR}$ spectrum of $\mathbf{3 b}$ in dichloromethane- $\mathrm{d}_{2}$. 


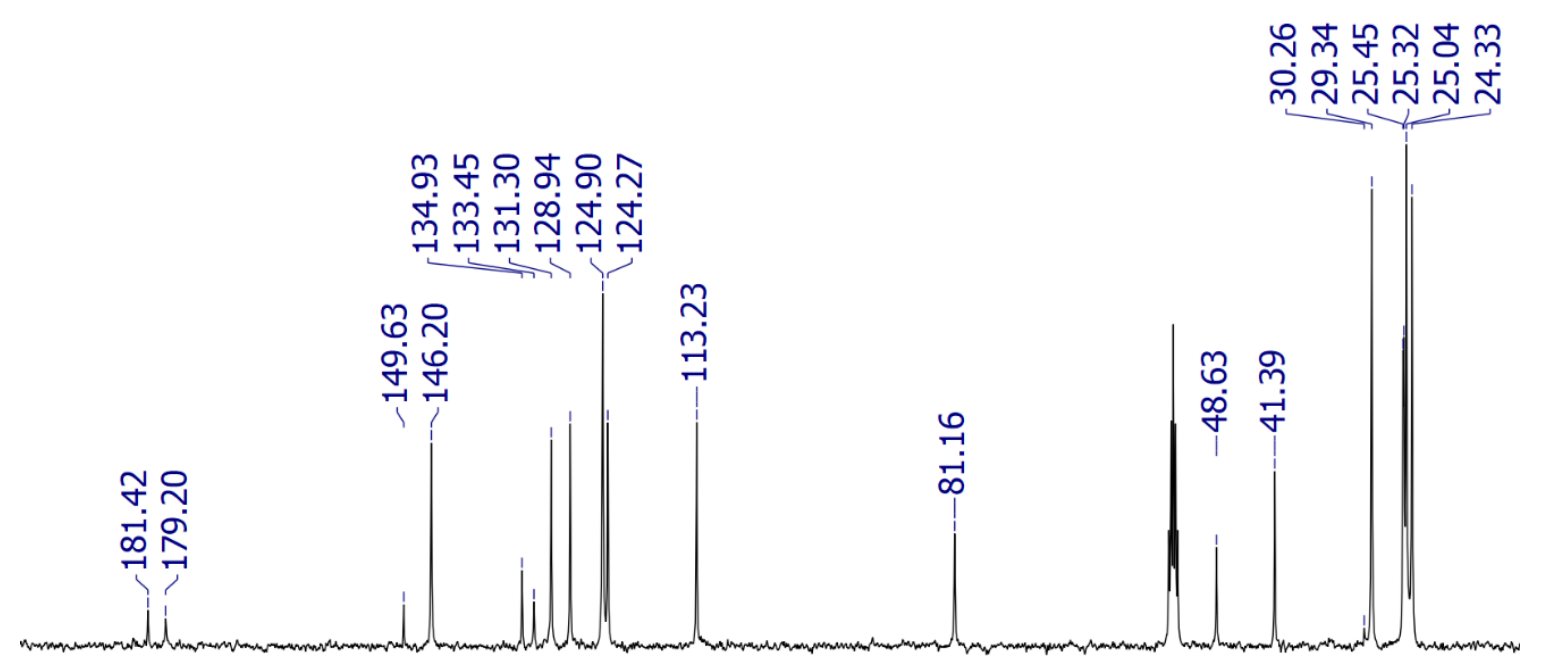

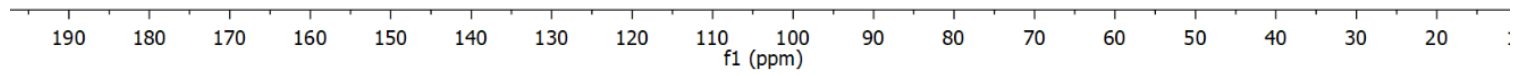

Figure A1.20. ${ }^{13} \mathrm{C}-\mathrm{NMR}$ spectrum of $\mathbf{3 b}$ in dichloromethane- $\mathrm{d}_{2}$.

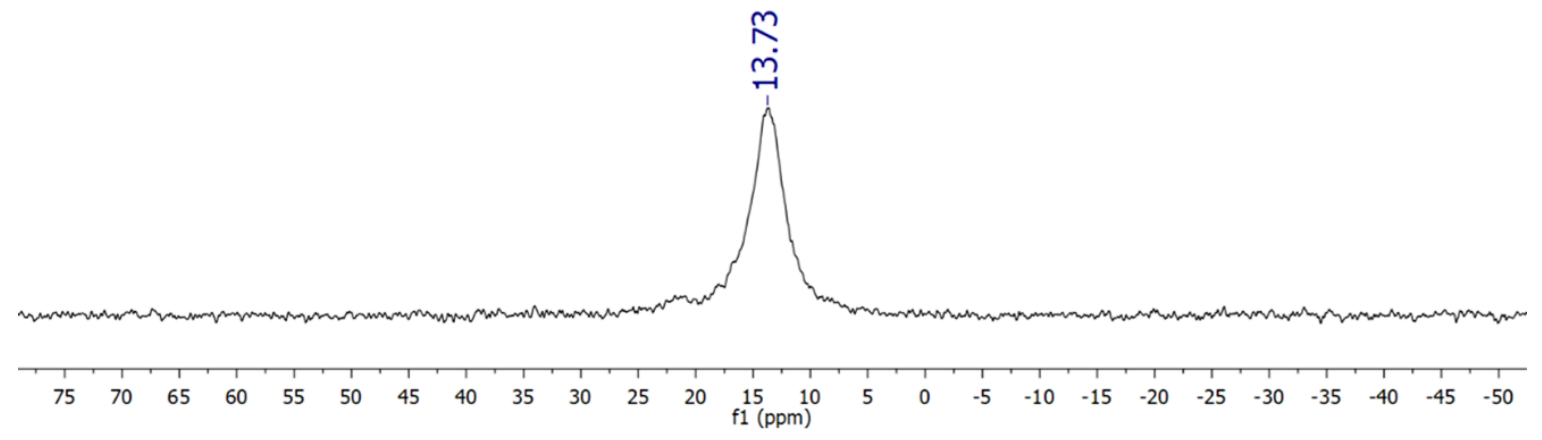

Figure A1.21. ${ }^{11} \mathrm{~B}-\mathrm{NMR}$ spectrum of $\mathbf{3 b}$ in dichloromethane- $\mathrm{d}_{2}$. 


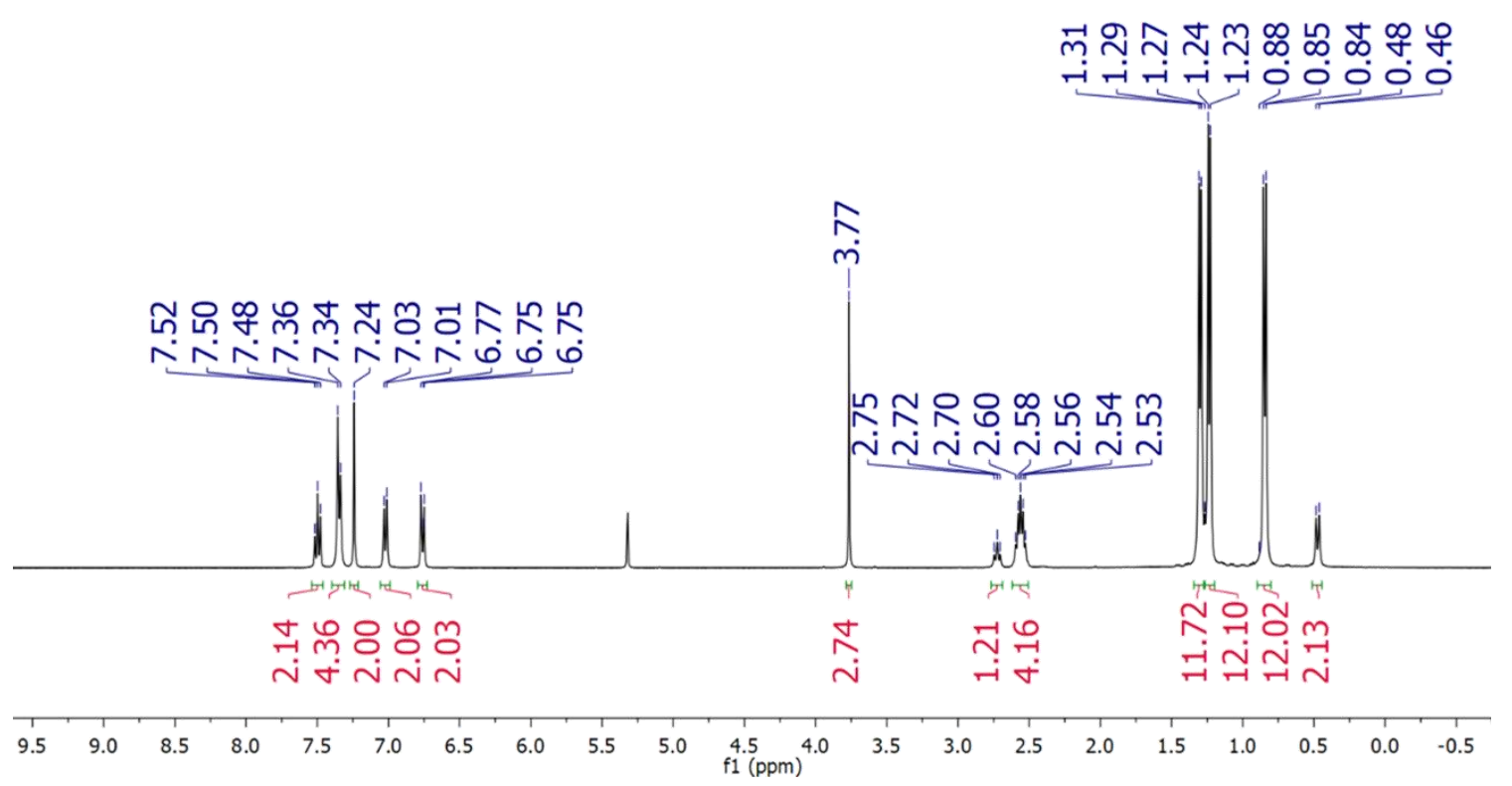

Figure A1.22. ${ }^{1} \mathrm{H}-\mathrm{NMR}$ spectrum of $\mathbf{3 c}$ in dichloromethane- $\mathrm{d}_{2}$.
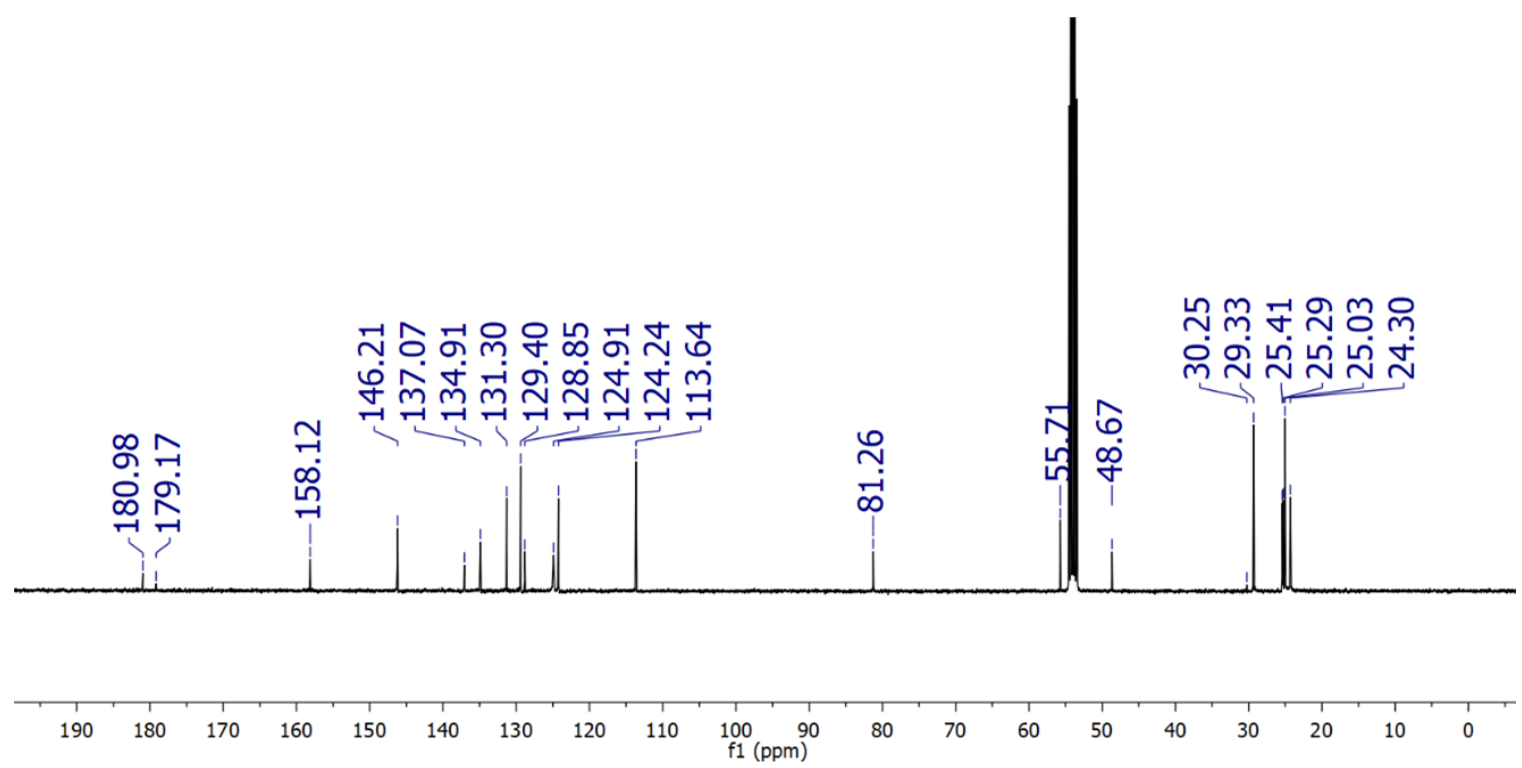

Figure A1.23. ${ }^{13} \mathrm{C}-\mathrm{NMR}$ spectrum of $\mathbf{3 c}$ in dichloromethane- $\mathrm{d}_{2}$. 


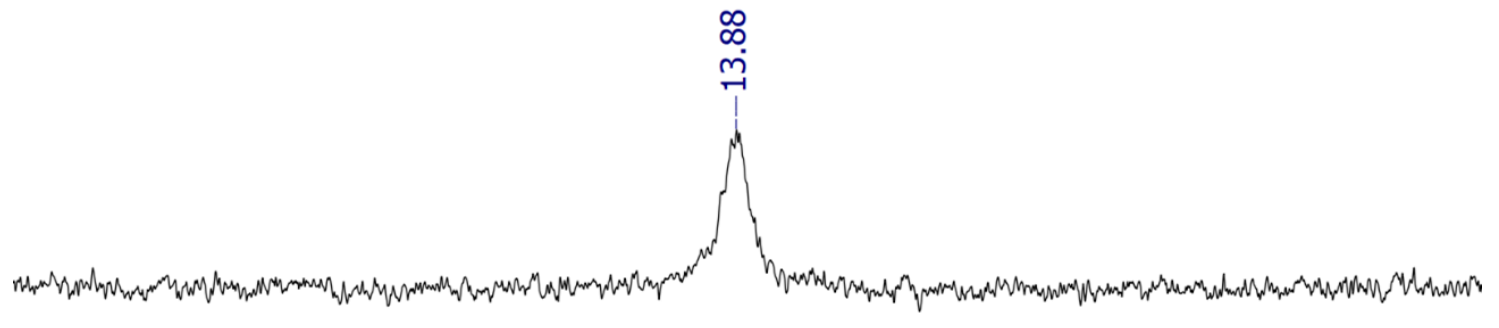

\begin{tabular}{|c|c|c|c|c|c|c|c|c|c|c|c|c|}
\hline 70 & 60 & $\begin{array}{l}1 \\
50\end{array}$ & 40 & 30 & 20 & $\begin{array}{c}10 \\
\mathrm{f} 1(\mathrm{ppm})\end{array}$ & 1 & $\frac{1}{-10}$ & ${ }^{1}-20$ & $\begin{array}{l}1 \\
-30\end{array}$ & $\begin{array}{l}1 \\
-40\end{array}$ & $\begin{array}{l}1 \\
-50\end{array}$ \\
\hline
\end{tabular}

Figure A1.24. ${ }^{11}$ B-NMR spectrum of $3 \mathbf{c}$ in dichloromethane- $\mathrm{d}_{2}$.

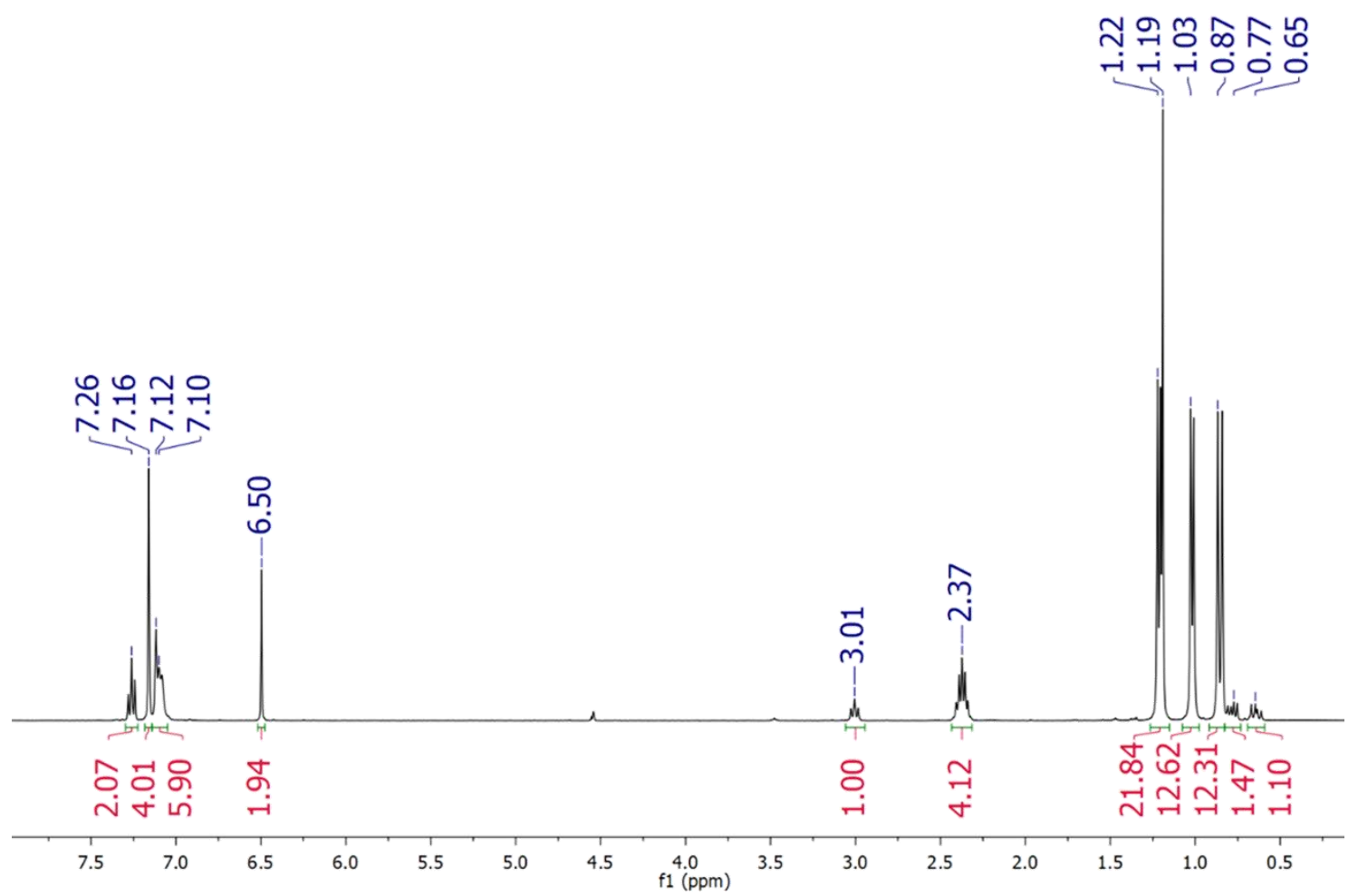

Figure A1.25. ${ }^{1} \mathrm{H}-\mathrm{NMR}$ spectrum of $\mathbf{3 d}$ in dichloromethane- $\mathrm{d}_{2}{ }^{\prime}$ benzene- $\mathrm{d}_{6}(1: 1)$. 


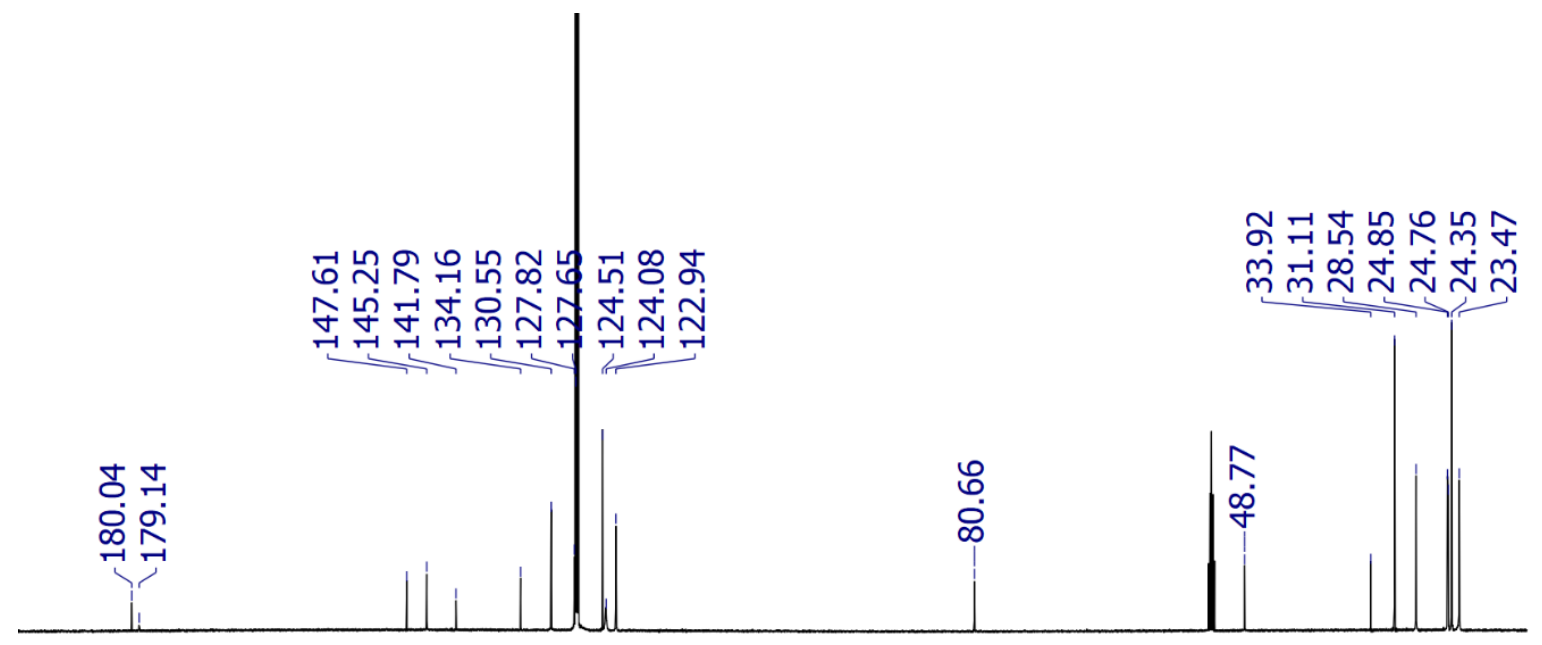

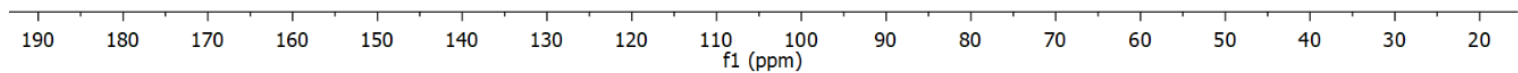

Figure A1.26. ${ }^{13} \mathrm{C}-\mathrm{NMR}$ spectrum of $\mathbf{3 d}$ in dichloromethane- $\mathrm{d}_{2}{ }^{\prime}$ benzene- $\mathrm{d}_{6}(1: 1)$.

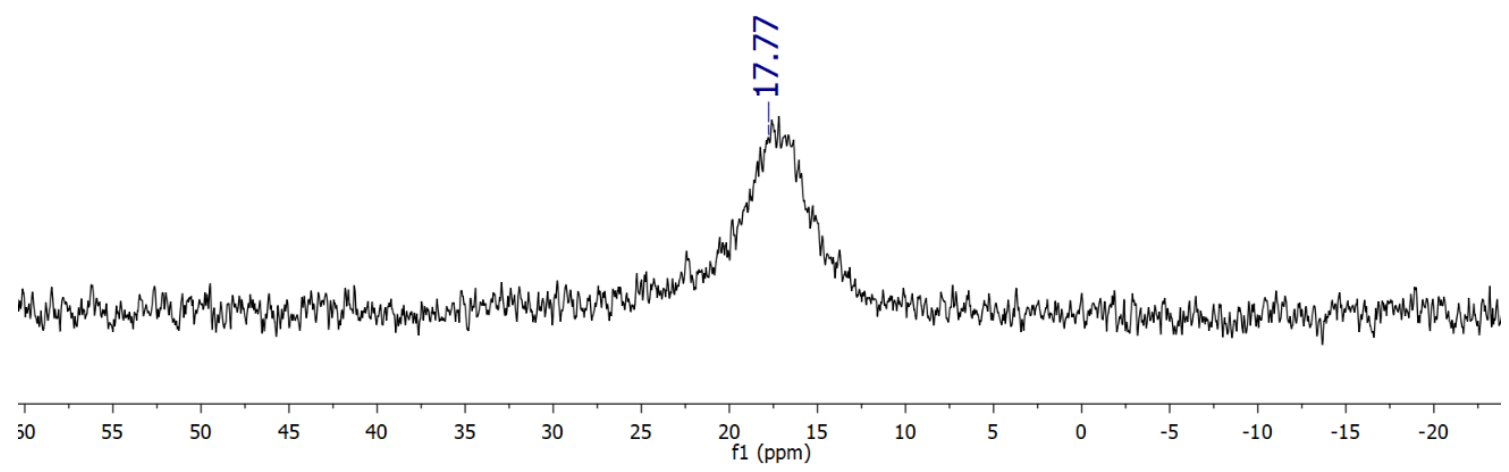

Figure A1.27. ${ }^{11} \mathrm{~B}-\mathrm{NMR}$ spectrum of $\mathbf{3 d}$ in dichloromethane- $\mathrm{d}_{2}{ }^{\prime}$ benzene- $\mathrm{d}_{6}(1: 1)$. 


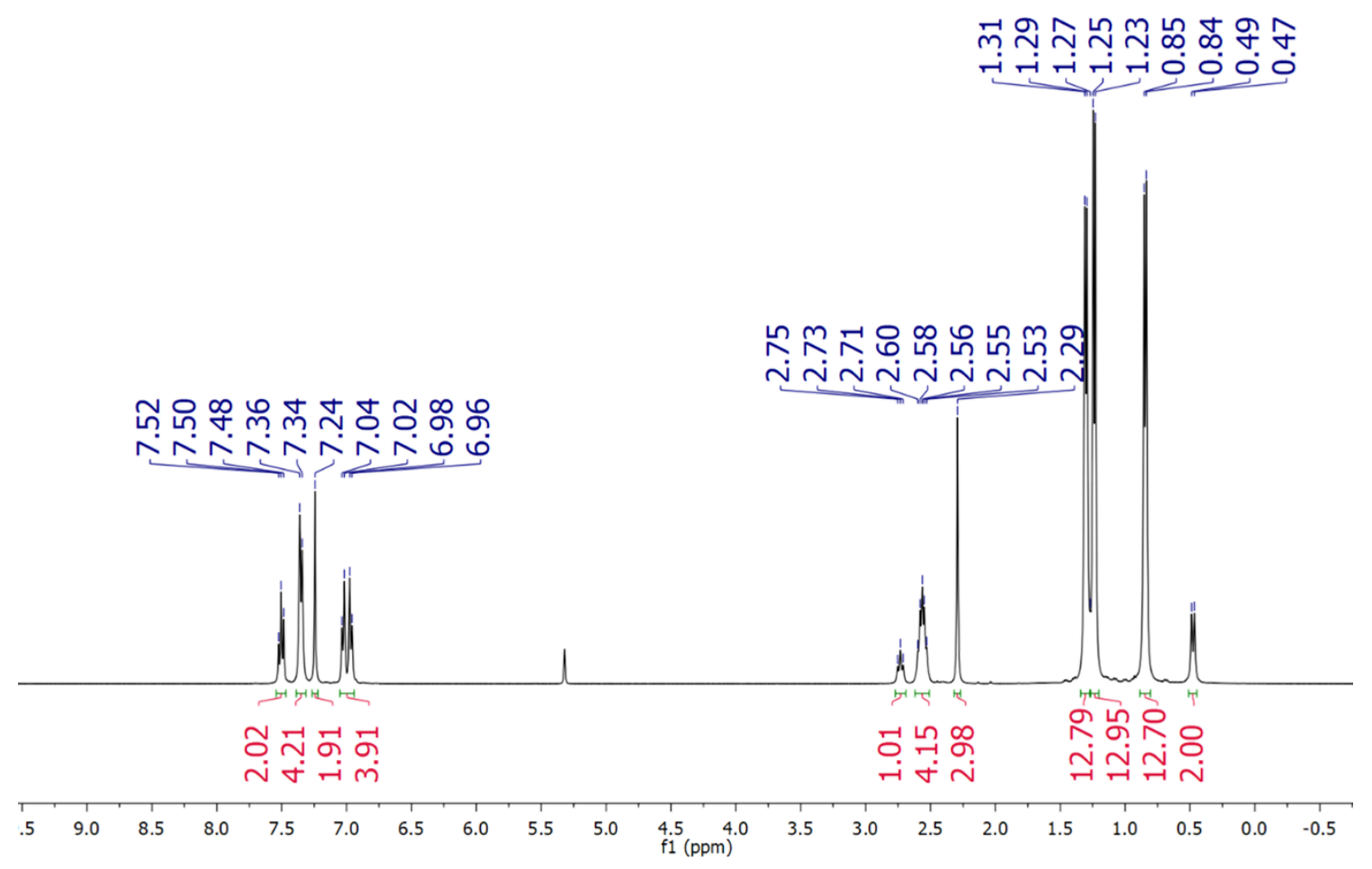

Figure A2.28. ${ }^{1} \mathrm{H}-\mathrm{NMR}$ spectrum of $\mathbf{3 e}$ in dichloromethane- $\mathrm{d}_{2}$.

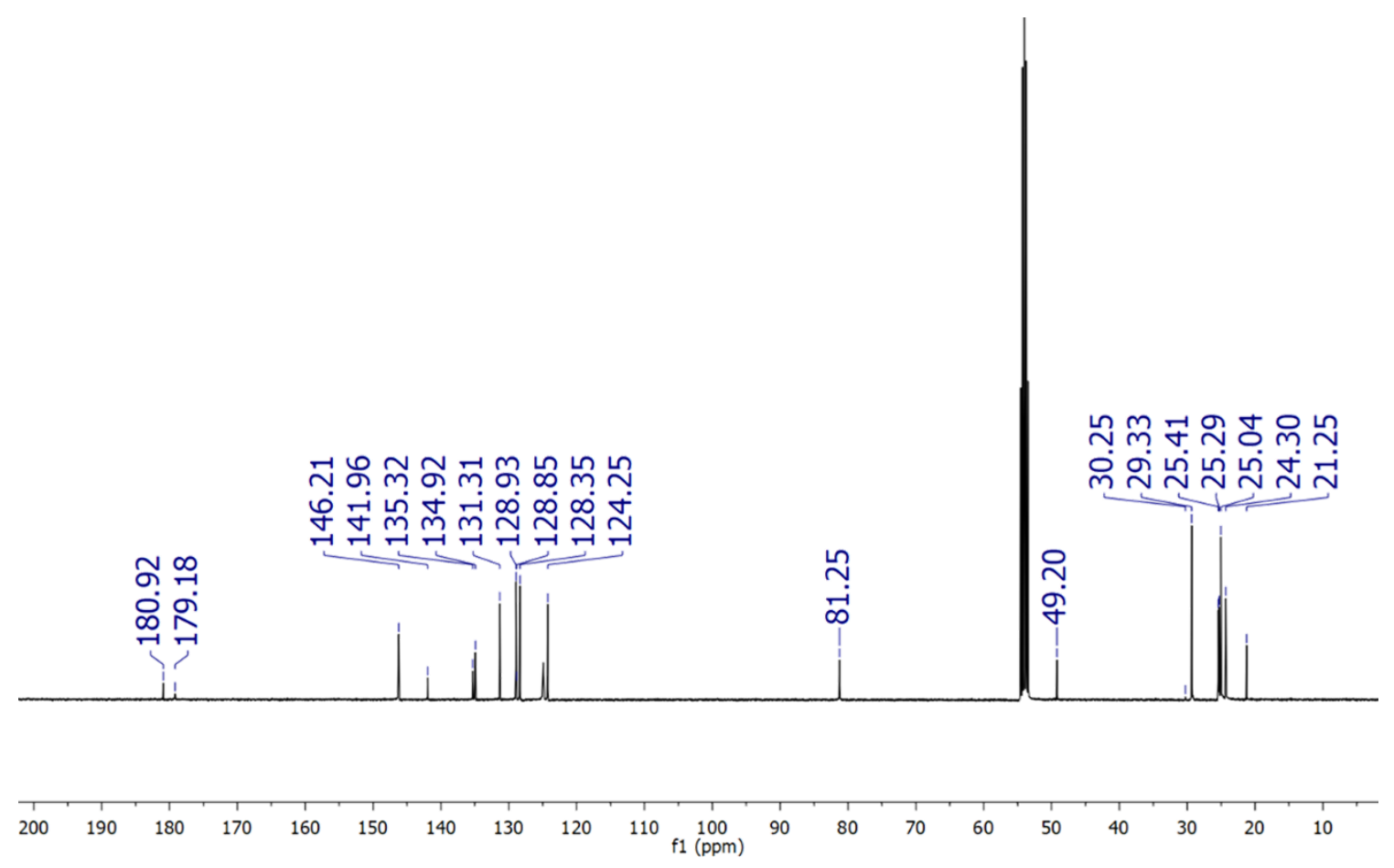

Figure A1.29. ${ }^{13} \mathrm{C}-\mathrm{NMR}$ spectrum of $\mathbf{3 e}$ in dichloromethane- $\mathrm{d}_{2}$. 


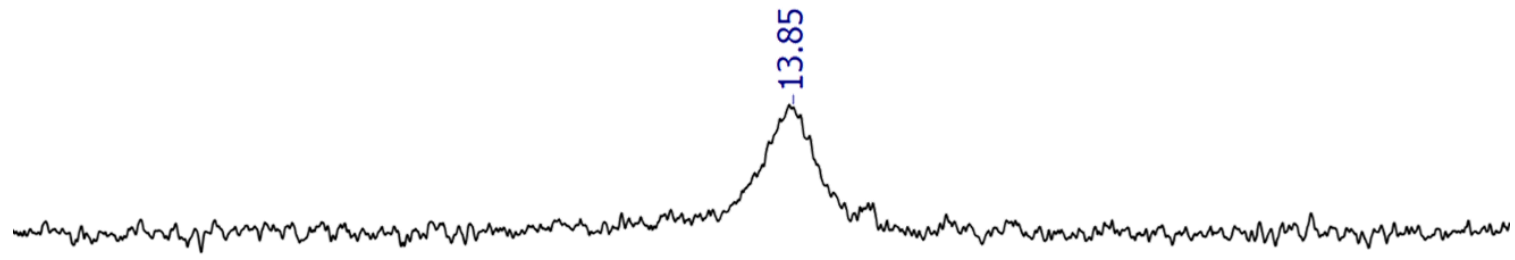

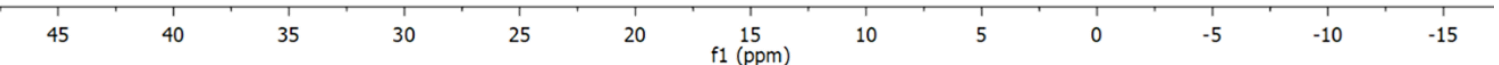

Figure A1.30. ${ }^{11}$ B-NMR spectrum of $3 \mathbf{e}$ in dichloromethane- $\mathrm{d}_{2}$.

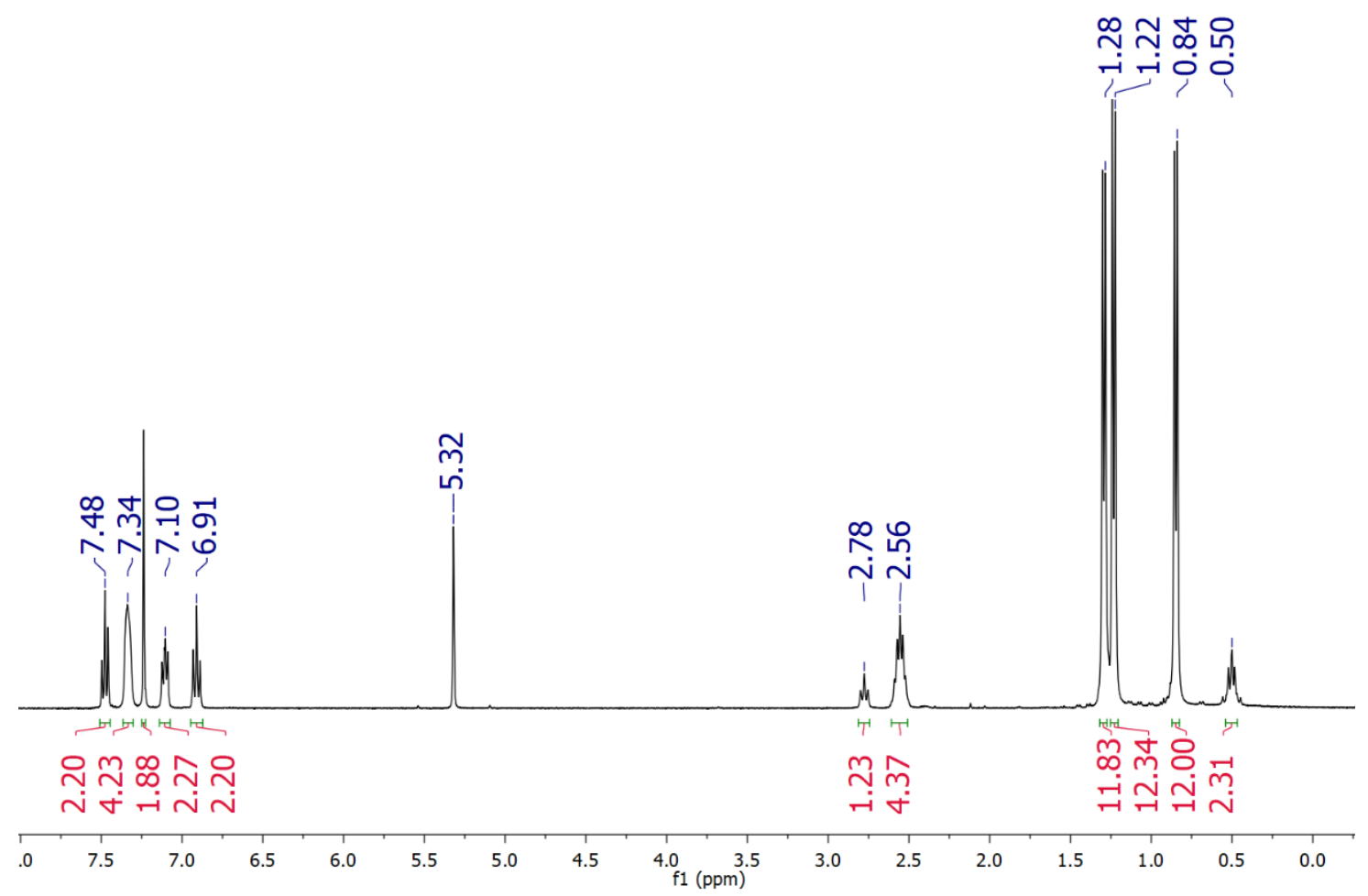

Figure A1.31. ${ }^{1} \mathrm{H}-\mathrm{NMR}$ spectrum of $\mathbf{3 f}$ in dichloromethane- $\mathrm{d}_{2}$. 

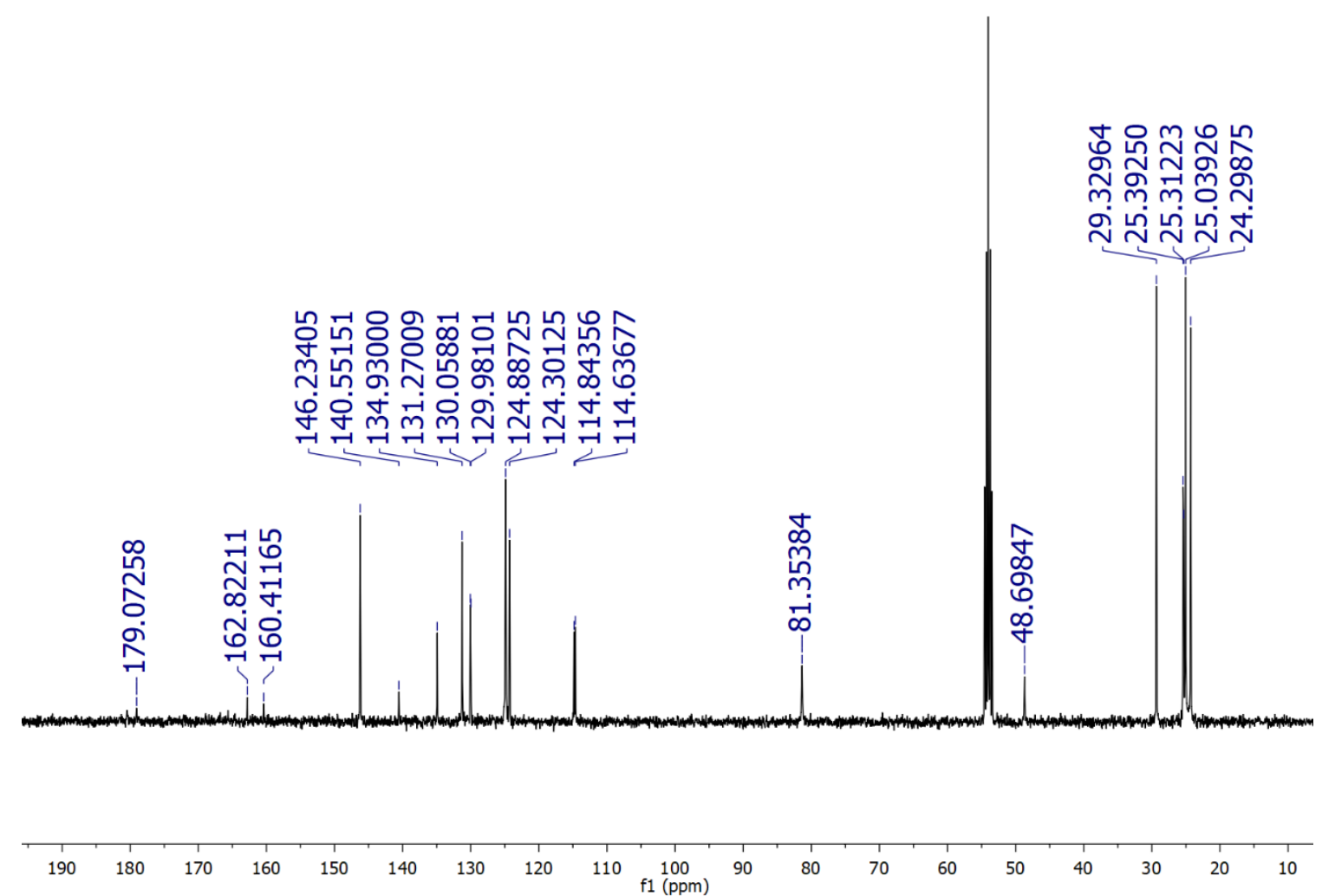

Figure A1.32. ${ }^{13} \mathrm{C}-\mathrm{NMR}$ spectrum of $\mathbf{3 f}$ in dichloromethane- $\mathrm{d}_{2}$.

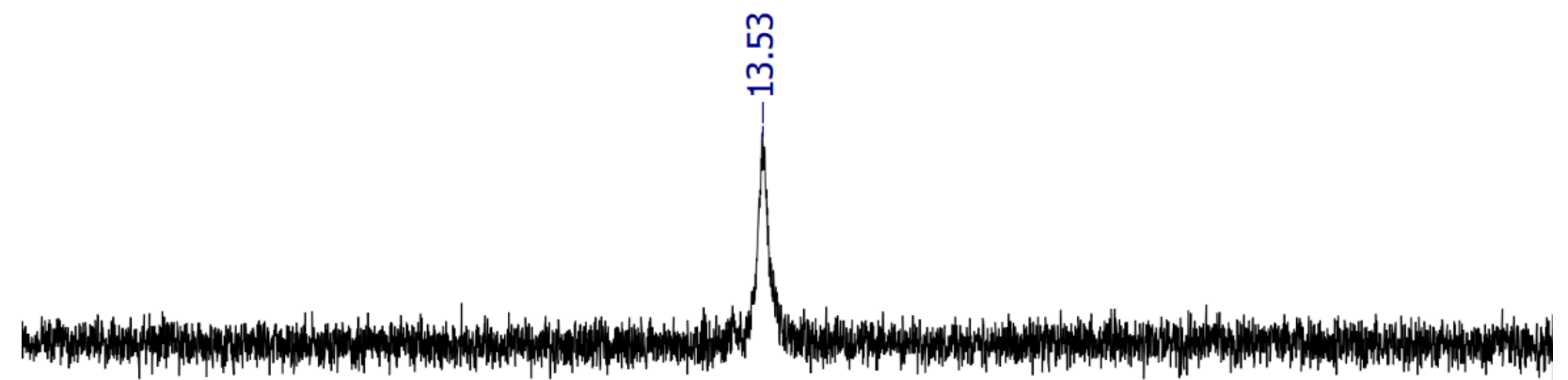

$\begin{array}{llllllllllllllllllllllllllllll} & 200 & 180 & 160 & 140 & 120 & 100 & 80 & 60 & 40 & 20 & 0 & -20 & -40 & -60 & -80 & -100 & -120 & -140 & -160 & -180\end{array}$

Figure A1.33. ${ }^{11} \mathrm{~B}-\mathrm{NMR}$ spectrum of $\mathbf{3 f}$ in dichloromethane- $\mathrm{d}_{2}$. 

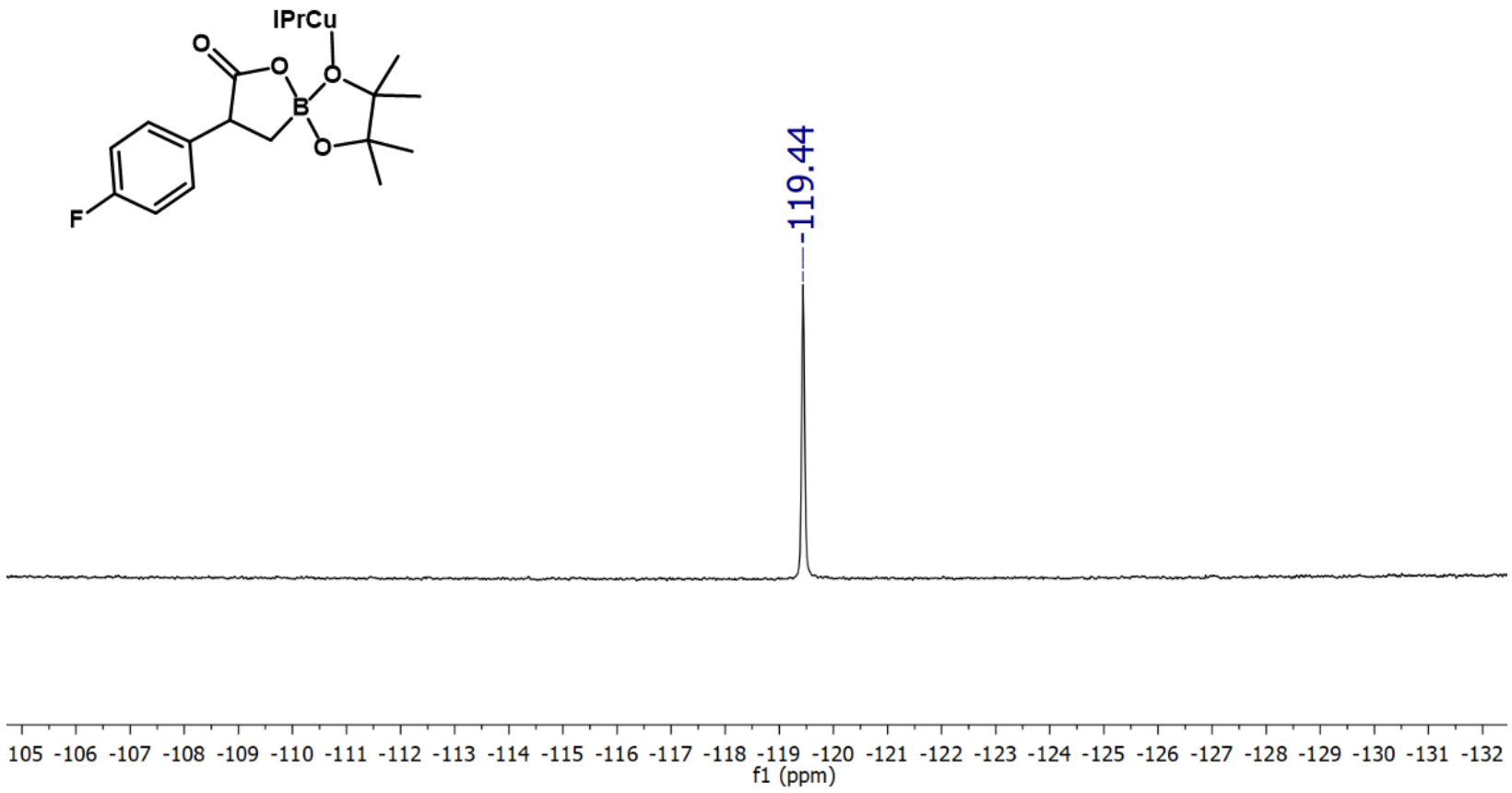

Figure A1.34. ${ }^{19}$ F-NMR spectrum of $\mathbf{3 f}$ in dichloromethane- $\mathrm{d}_{2}$.

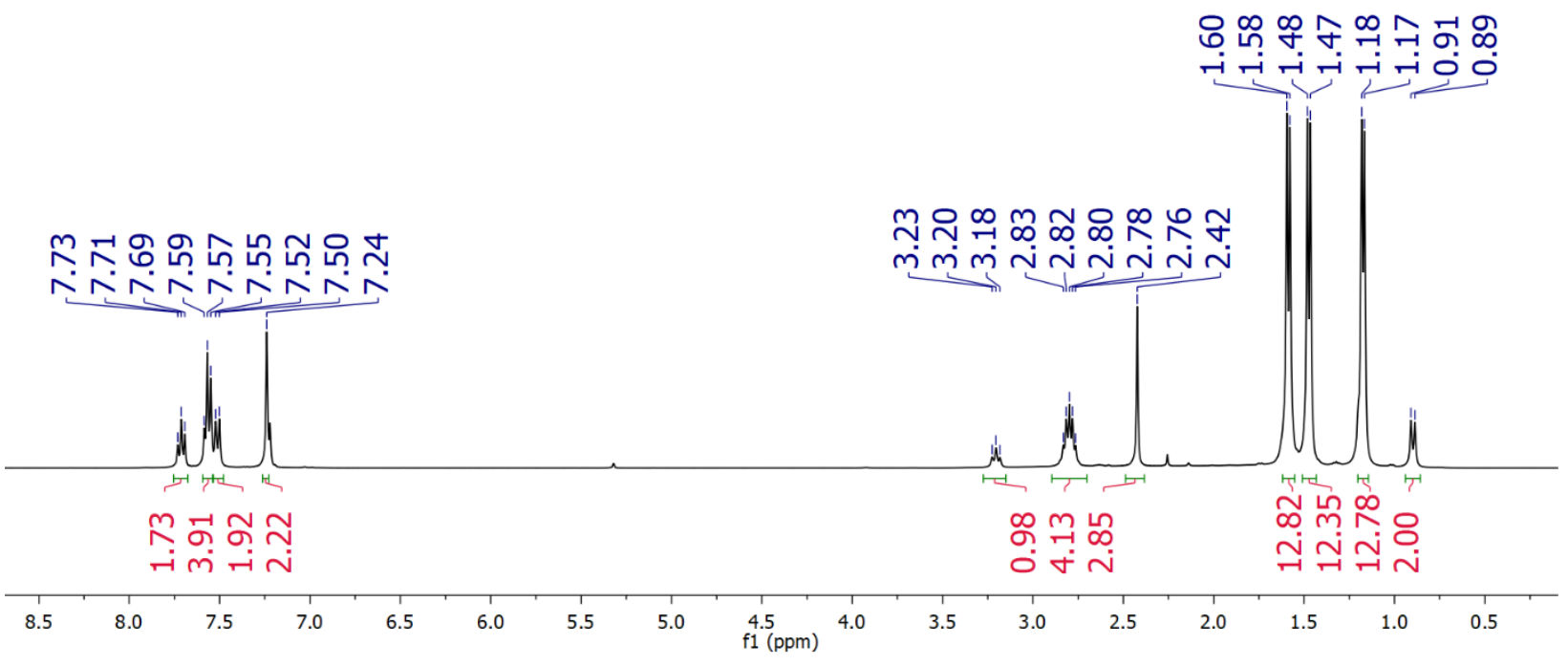

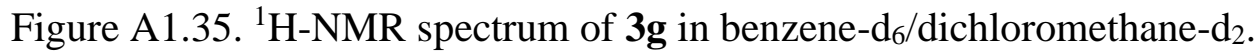



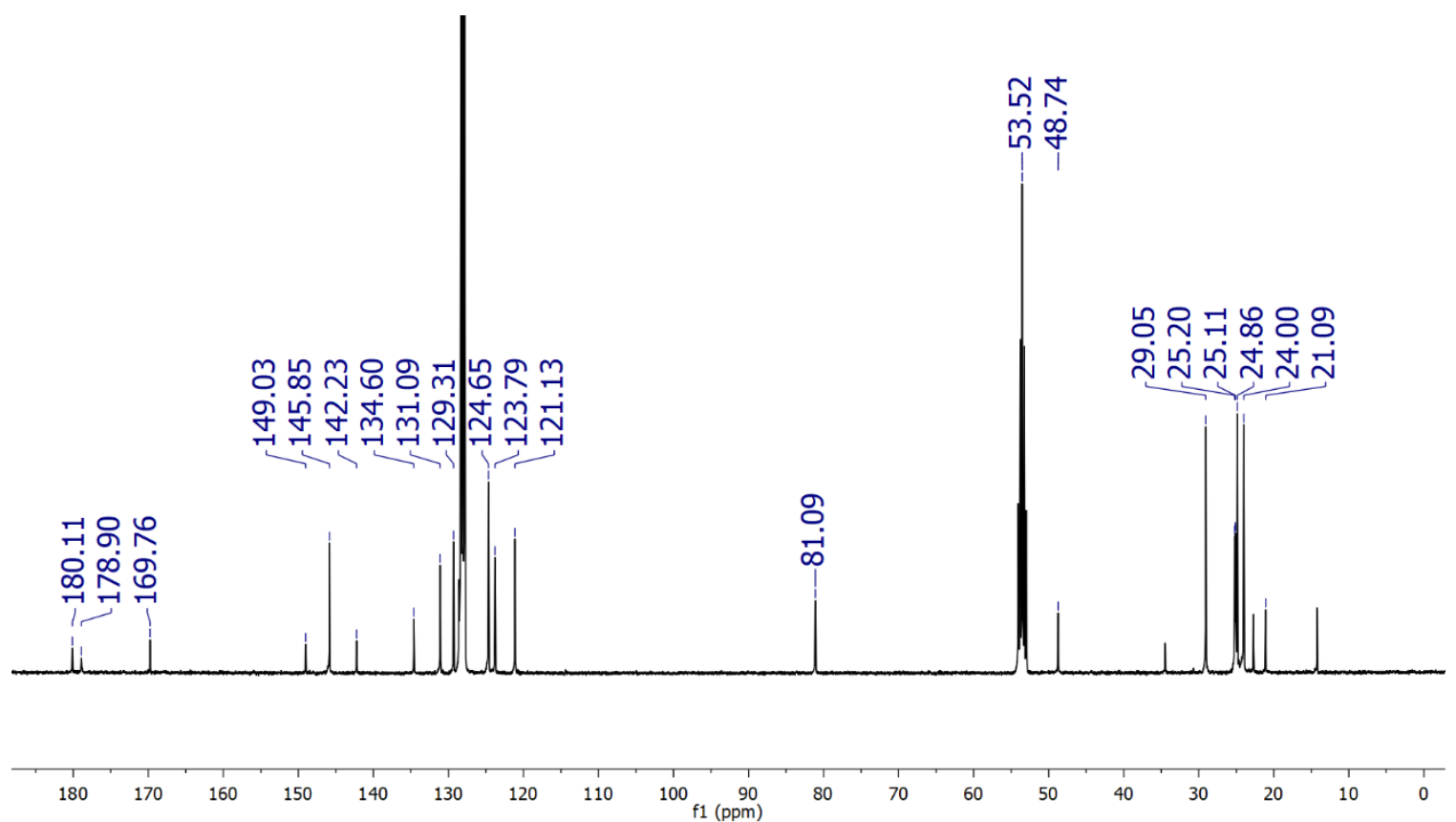

Figure A1.36. ${ }^{13} \mathrm{C}-\mathrm{NMR}$ spectrum of $\mathbf{3 g}$ in benzene- $\mathrm{d}_{6} /$ dichloromethane- $\mathrm{d}_{2}$. Unlabeled signals correspond to $n$-pentane from the glovebox atmosphere dissolved into $\mathrm{C}_{6} \mathrm{D}_{6}$.

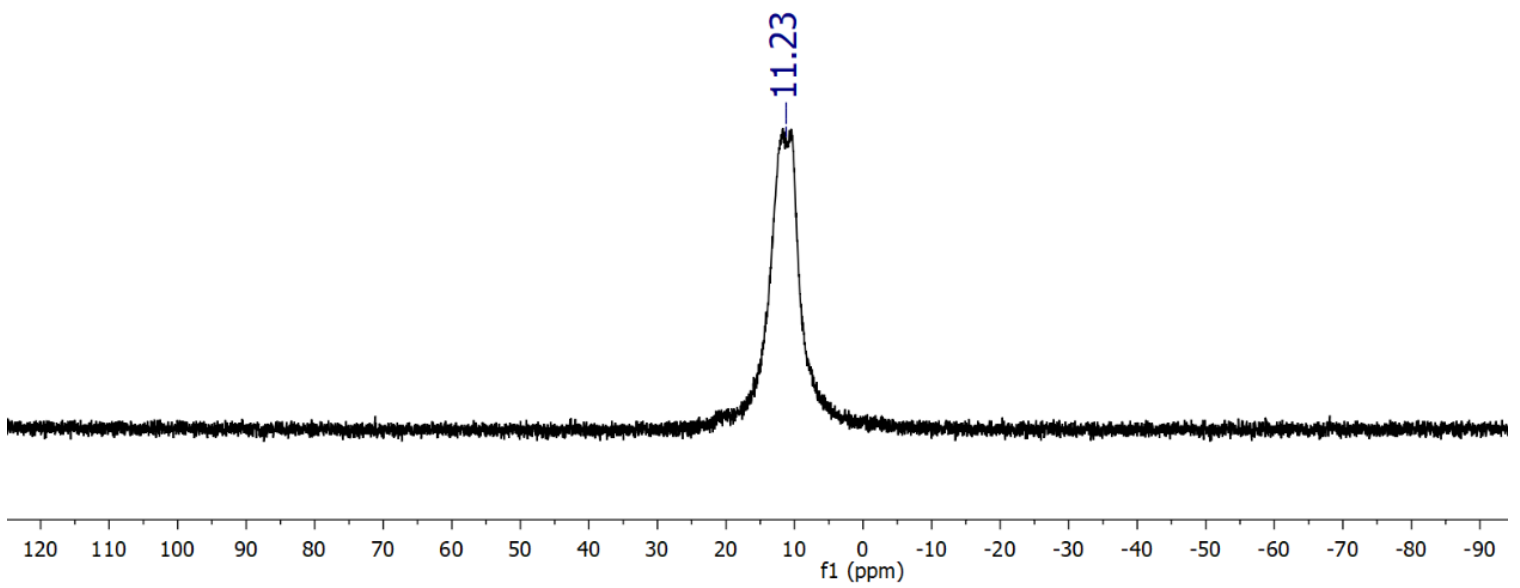

Figure A1.37. ${ }^{11} \mathrm{~B}-\mathrm{NMR}$ spectrum of $\mathbf{3 g}$ in dichloromethane- $\mathrm{d}_{2}$. 


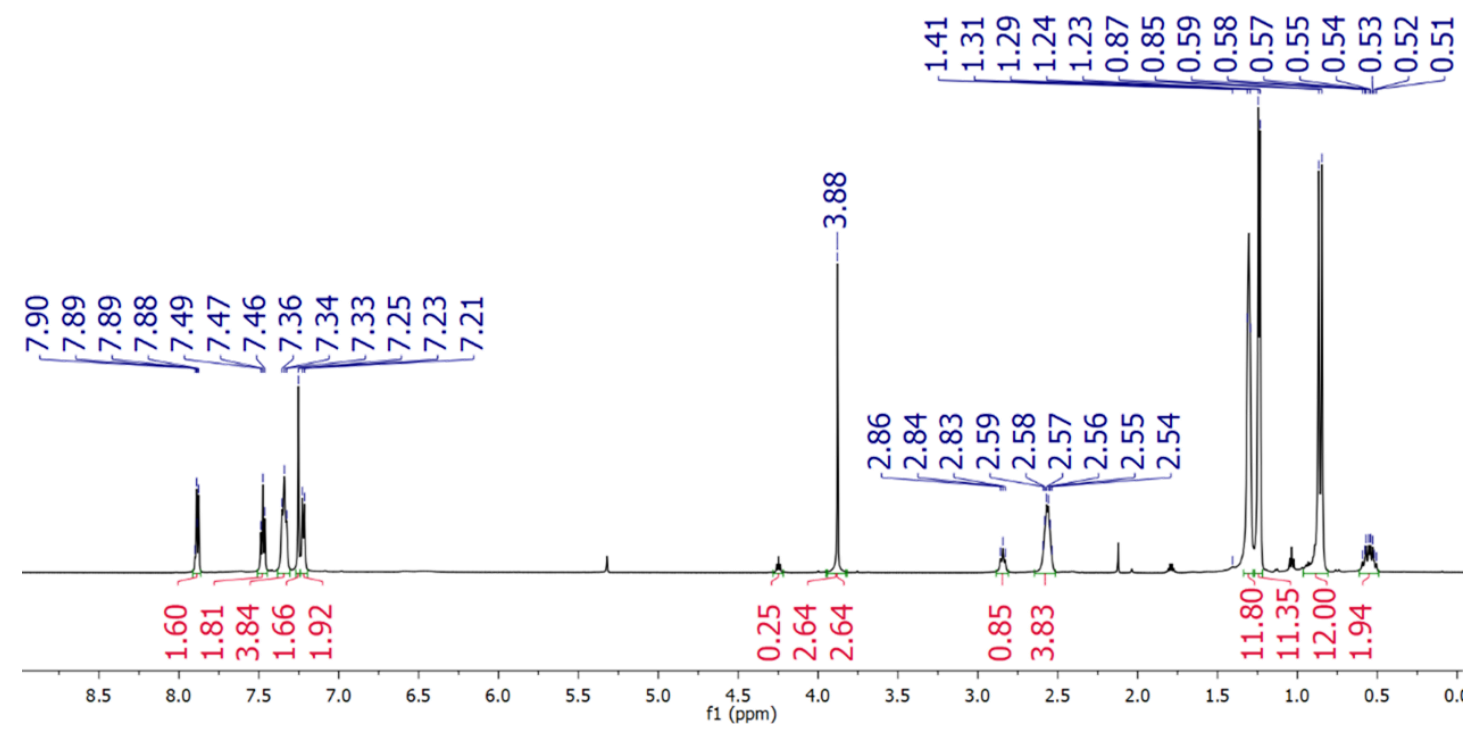

Figure A1.38. ${ }^{1} \mathrm{H}-\mathrm{NMR}$ spectrum of $\mathbf{3 h}$ in dichloromethane- $\mathrm{d}_{2}$. Unlabeled resonances correspond to $n$-pentane in glovebox atmosphere. Additionally, a small impurity exists which eluded extraction via purification of the complex.

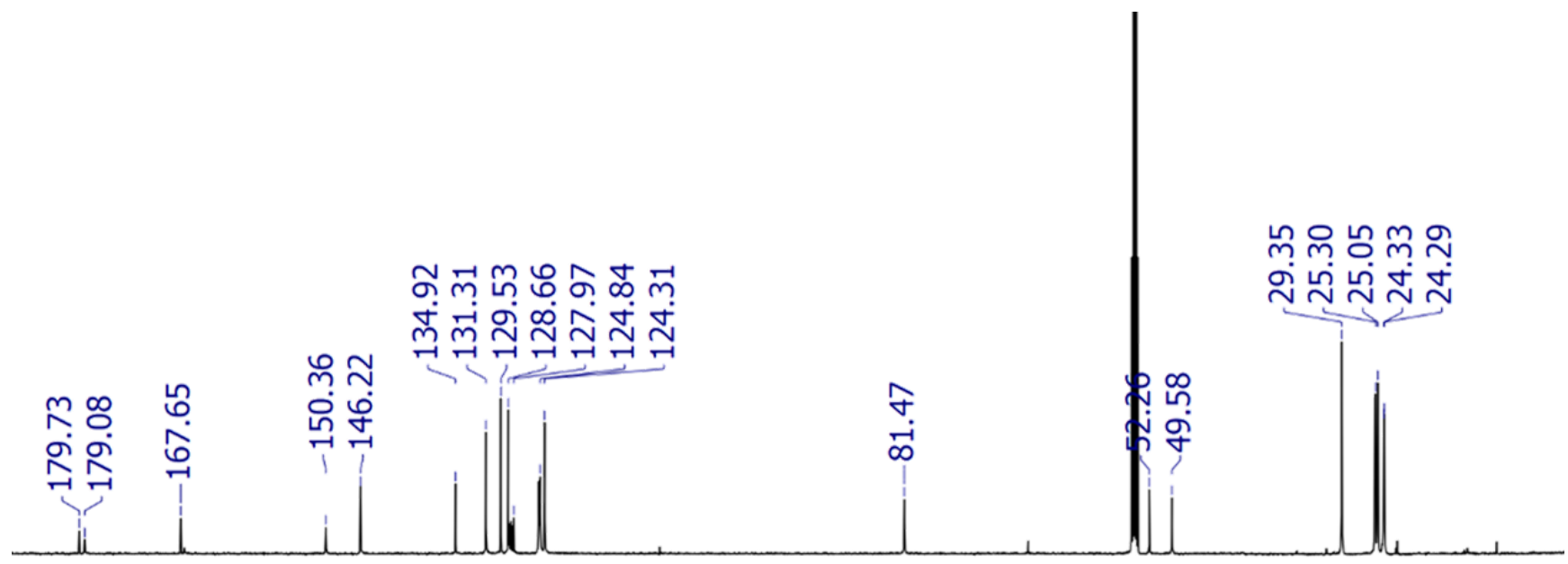

\begin{tabular}{|c|c|c|c|c|c|c|c|c|c|c|c|c|c|c|c|c|}
\hline$T_{1}$ & 1 & 1 & $T_{1}$ & $\square_{1}$ & $T$ & $T_{1}$ & $T_{1}$ & $T$ & $T_{1}$ & 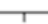 & $T_{1}$ & $T_{1}$ & 1 & 1 & $T$ & 1 \\
\hline 180 & 170 & 160 & 150 & 140 & 130 & 120 & 110 & 100 f1 (ppm) & 80 & 70 & 60 & 50 & 40 & 30 & 20 & 10 \\
\hline
\end{tabular}

Figure A1.39. ${ }^{13} \mathrm{C}-\mathrm{NMR}$ spectrum of $\mathbf{3 h}$ in dichloromethane- $\mathrm{d}_{2}$. Unlabeled resonances correspond to $n$-pentane in glovebox atmosphere. Additionally, a small impurity exists which eluded extraction via purification of the complex. 

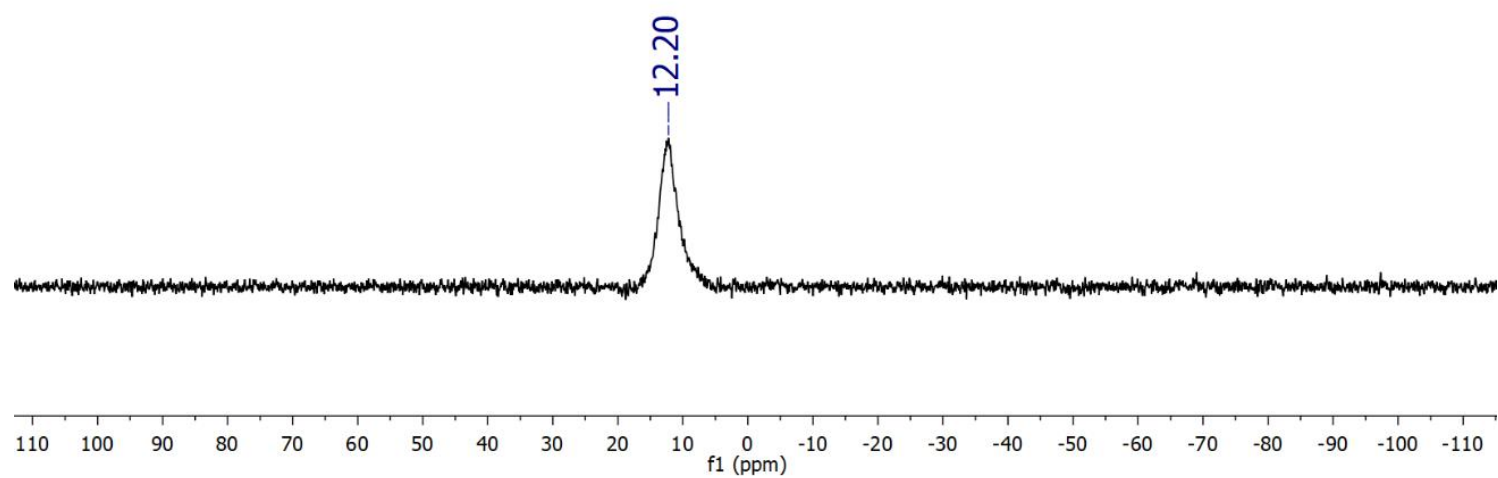

Figure A1.40. ${ }^{11} \mathrm{~B}-\mathrm{NMR}$ spectrum of $\mathbf{3 h}$ in dichloromethane-d 2 .

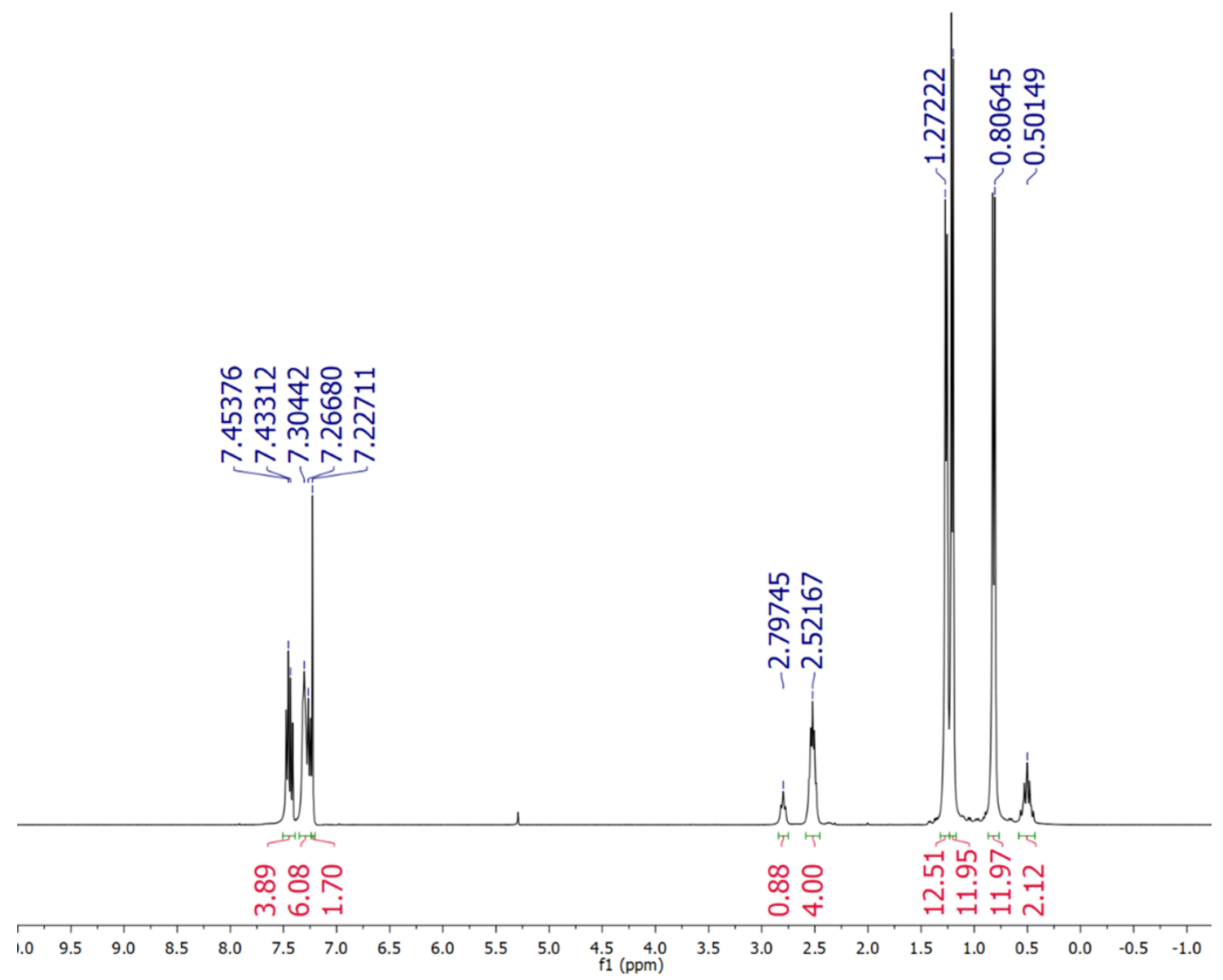

Figure A1.41. ${ }^{1} \mathrm{H}-\mathrm{NMR}$ spectrum of $\mathbf{3 i}$ in dichloromethane- $\mathrm{d}_{2}$. 


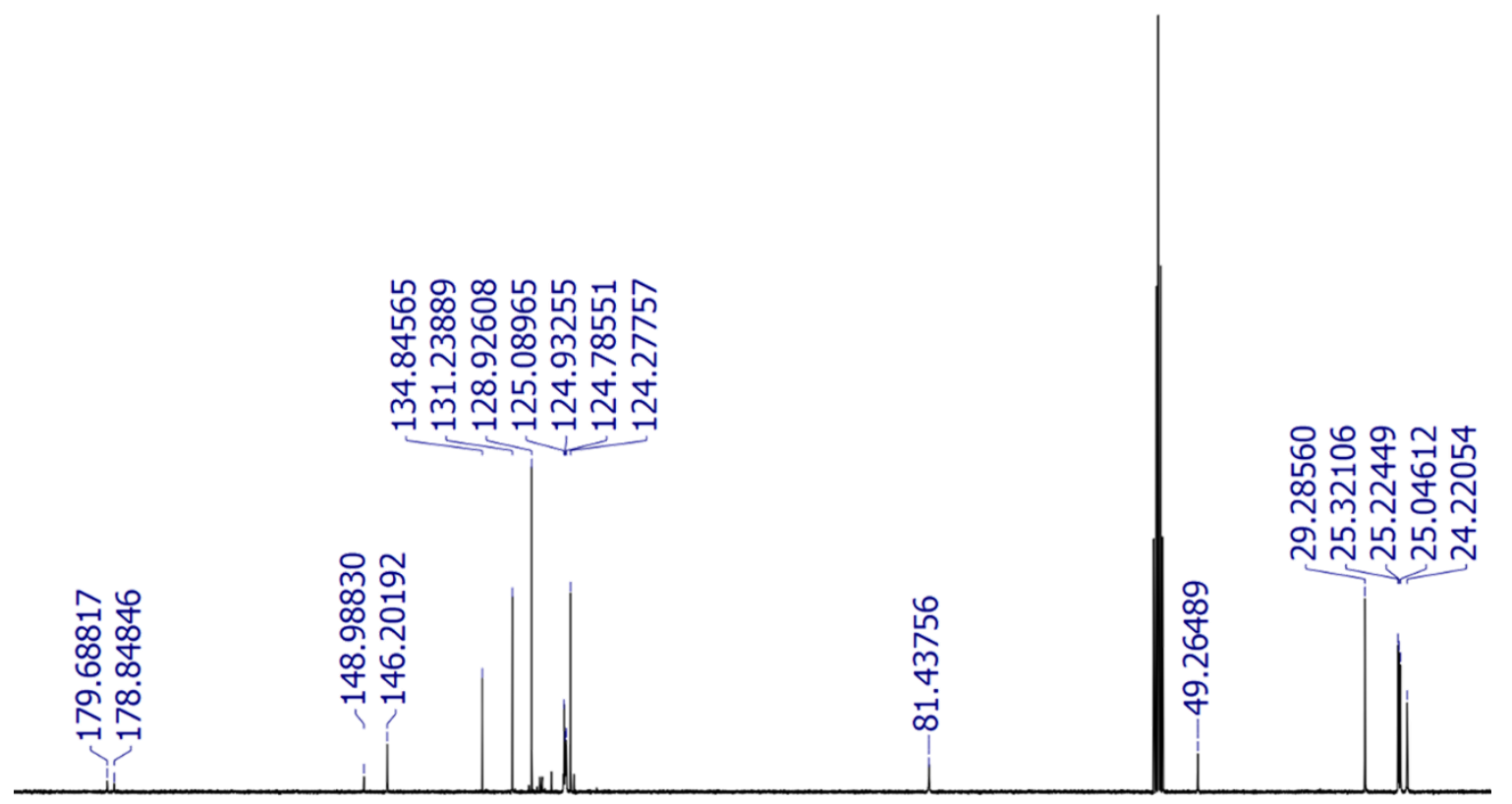

90

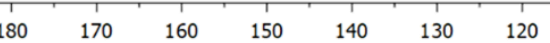

$110 \quad 100$

Figure A1.42. ${ }^{13} \mathrm{C}-\mathrm{NMR}$ spectrum of $\mathbf{3 i}$ in dichloromethane- $\mathrm{d}_{2}$.

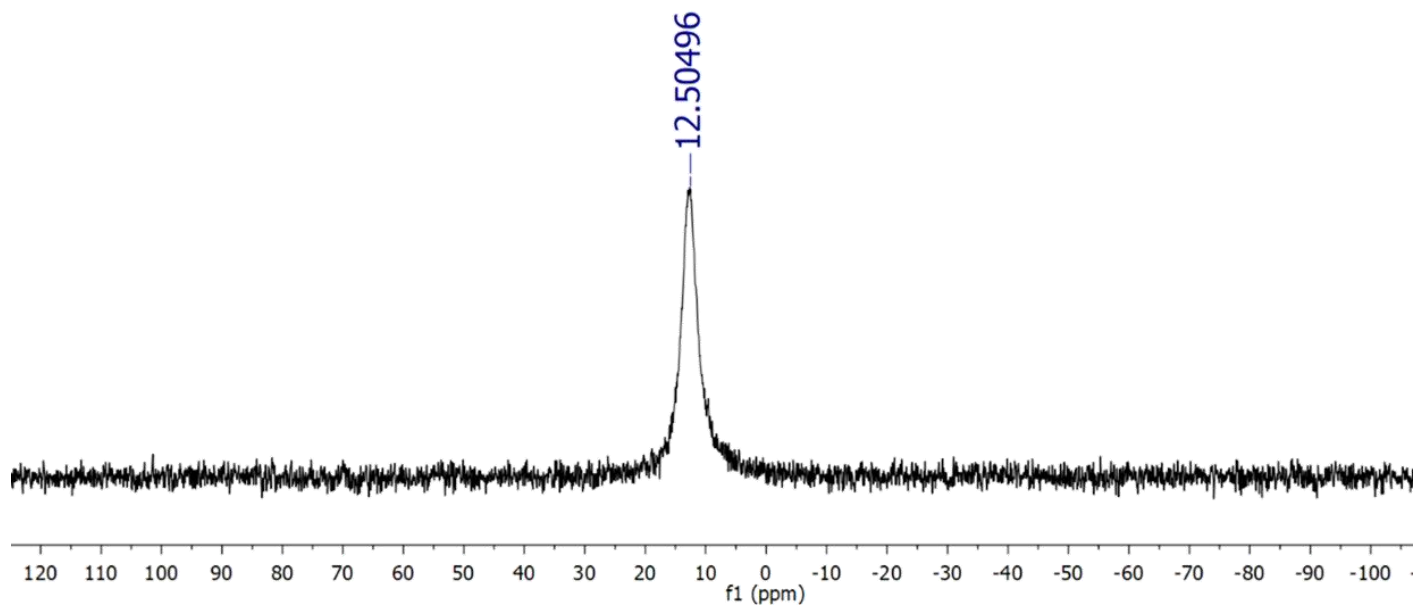

Figure A1.43. ${ }^{11} \mathrm{~B}-\mathrm{NMR}$ spectrum of $\mathbf{3 i}$ in dichloromethane-d 2 . 


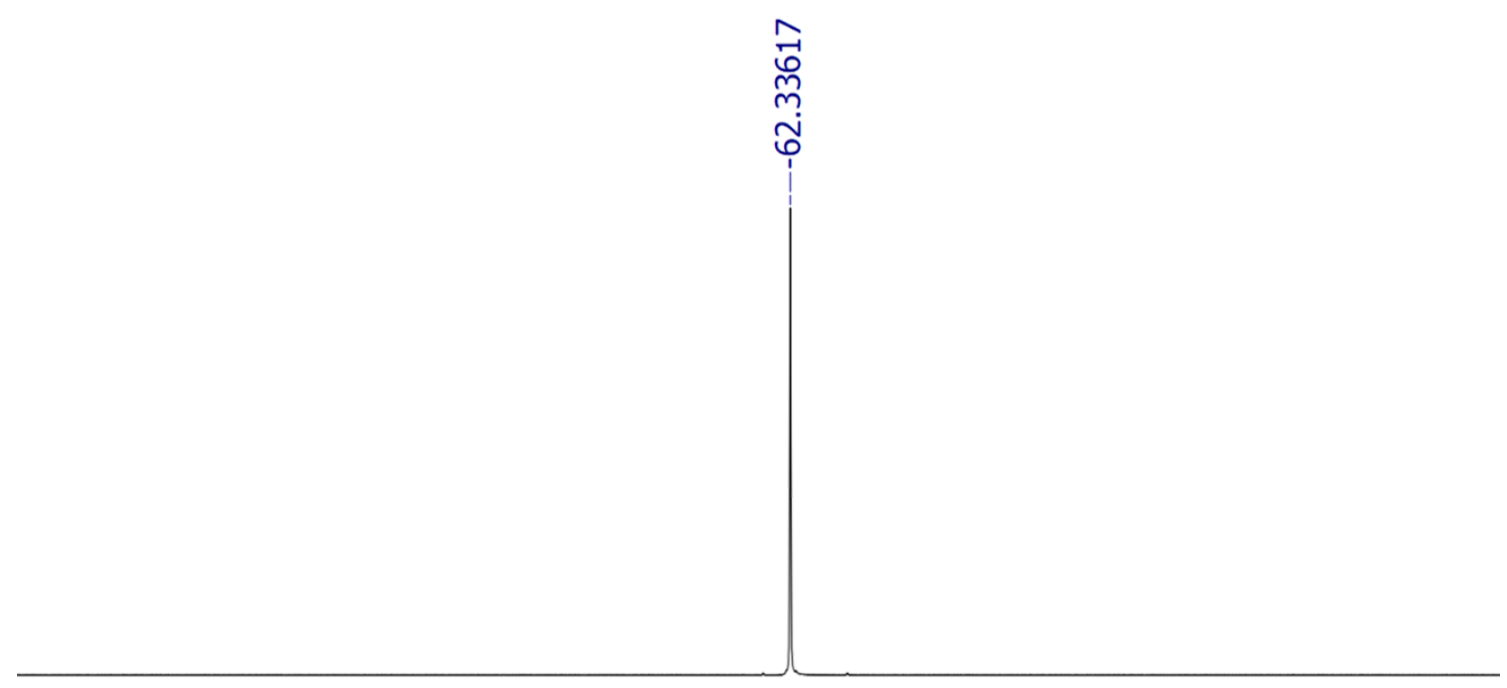

$\begin{array}{llllllllllllllllllllllllllllllll} & -56.0 & -56.5 & -57.0 & -57.5 & -58.0 & -58.5 & -59.0 & -59.5 & -60.0 & -60.5 & -61.0 & -61.5 & -62.0 & -62.5 & -63.0 & -63.5 & -64.0 & -64.5 & -65.0 & -65.5 & -66.0 & -66.5 & -67.0 & -67.5 & -68.0 & -6\end{array}$

Figure A1.44. ${ }^{19}$ F-NMR spectrum of $3 \mathbf{i}$ in dichloromethane-d 2 . 


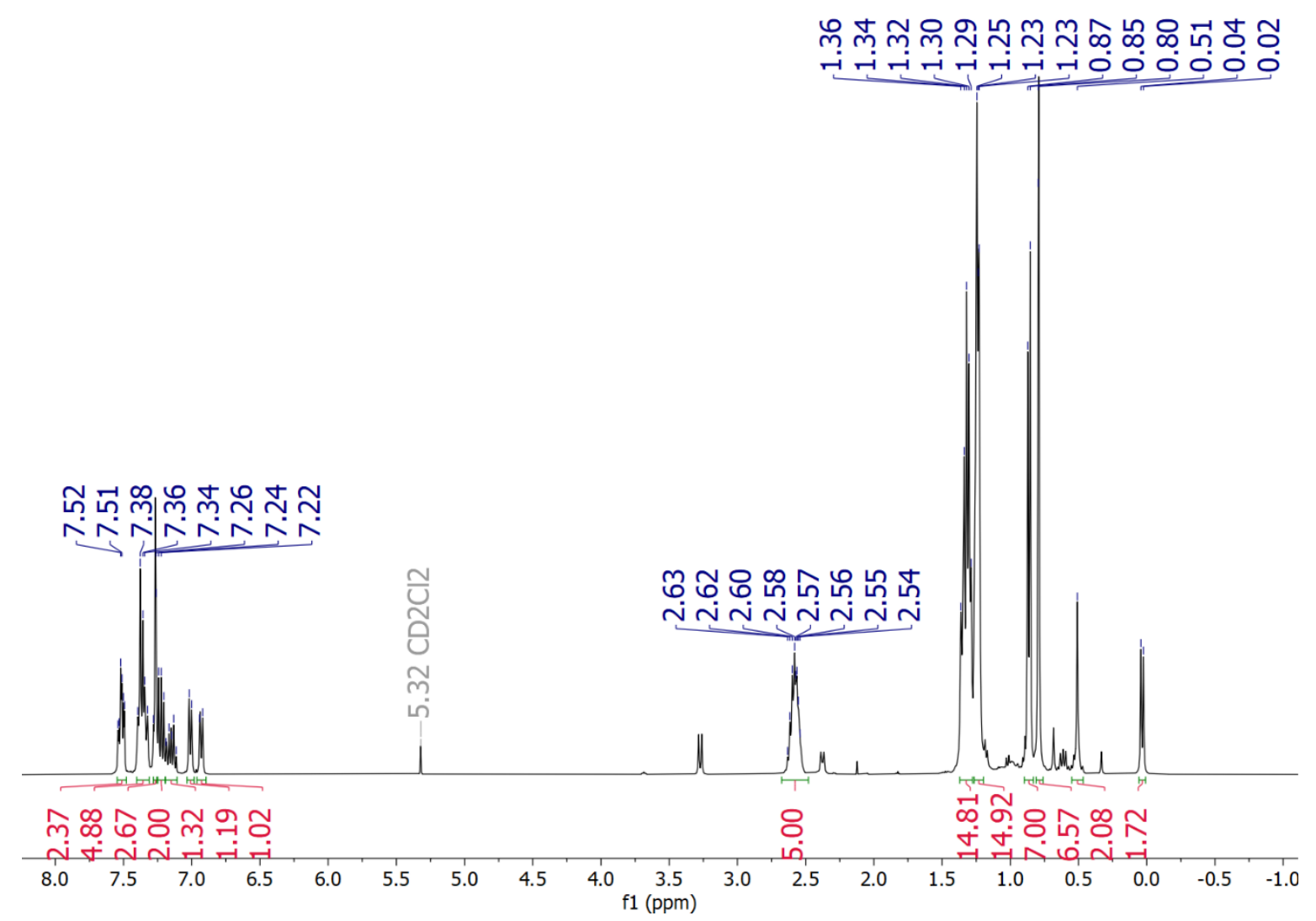

Figure A1.45. ${ }^{1} \mathrm{H}-\mathrm{NMR}$ spectrum of $\mathbf{3 j}$ in dichloromethane-d $\mathrm{d}_{2}$. 

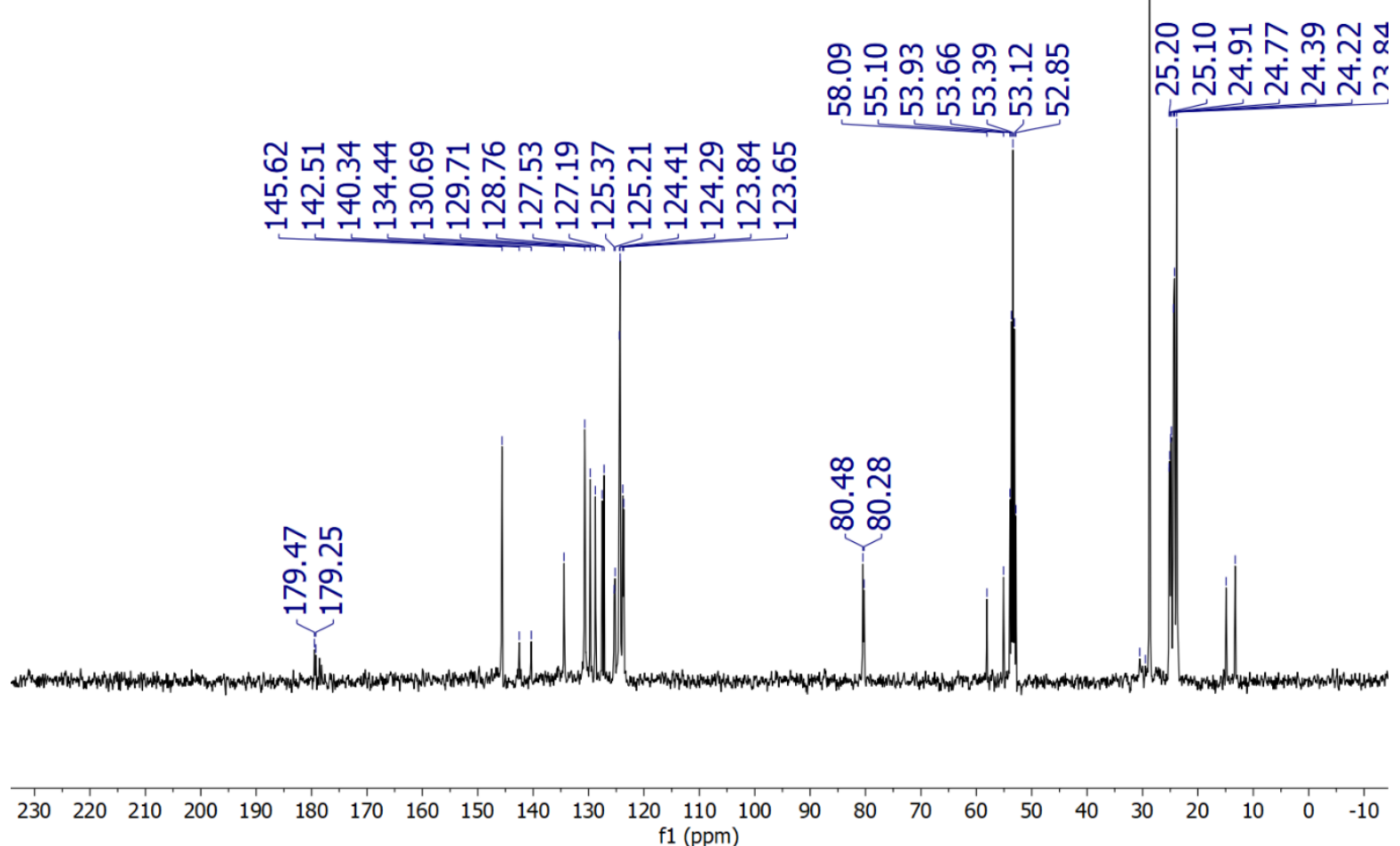

Figure A1.46. ${ }^{13} \mathrm{C}-\mathrm{NMR}$ spectrum of $\mathbf{3 j}$ in dichloromethane- $\mathrm{d}_{2}$.

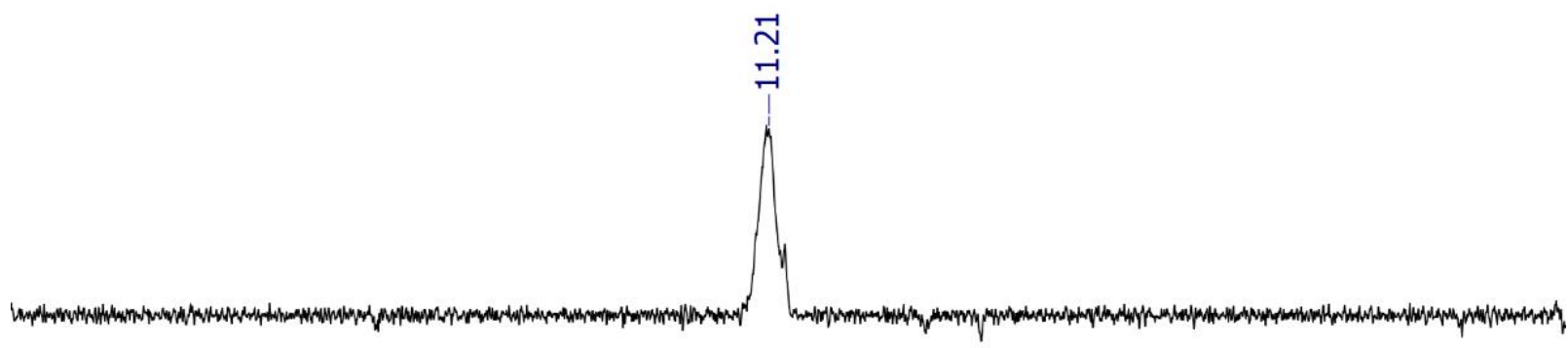

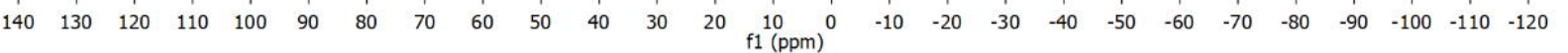

Figure A1.47. ${ }^{11}$ B-NMR spectrum of $\mathbf{3 j}$ in dichloromethane- $\mathrm{d}_{2}$. 
นกำ ํำ ำㅇำ

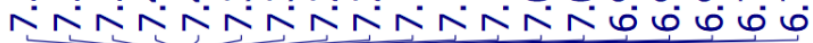

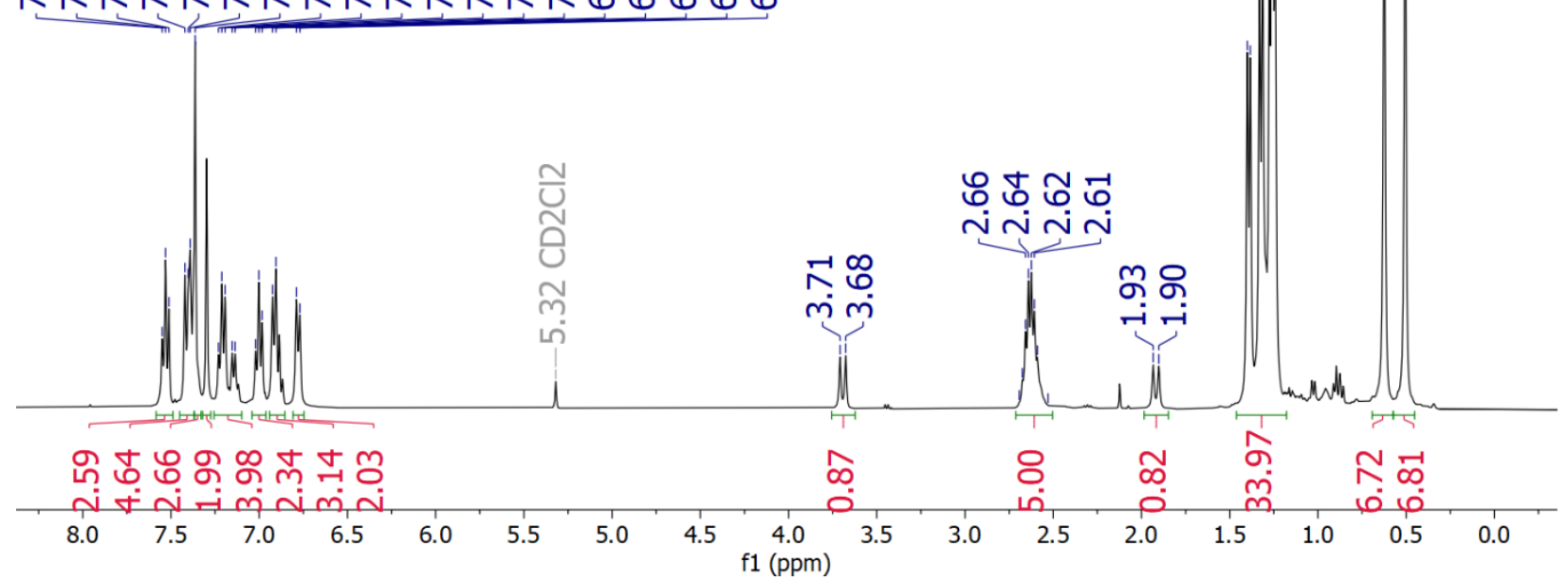

Figure A1.48. ${ }^{1} \mathrm{H}-\mathrm{NMR}$ spectrum of $\mathbf{3 k}$ in dichloromethane- $\mathrm{d}_{2}$. A small impurity of IPrCuOBpin is present, as its removal was challenging. 


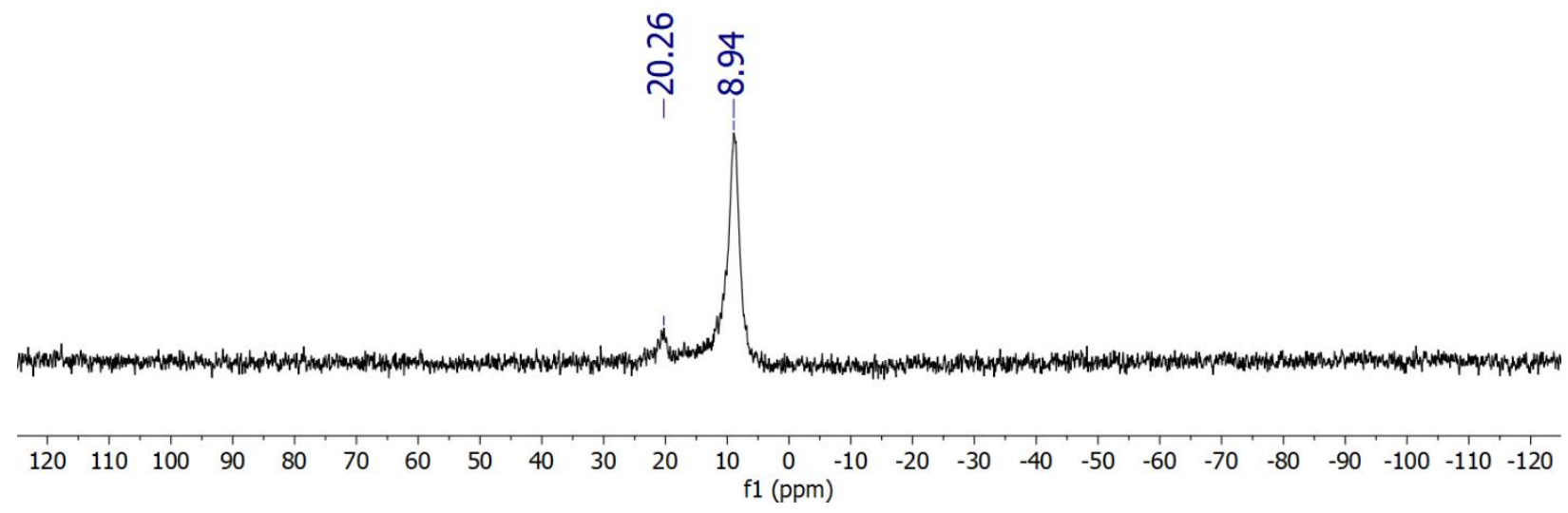

Figure A1.49. ${ }^{11} \mathrm{~B}-\mathrm{NMR}$ spectrum of $\mathbf{3 k}$ in dichloromethane- $\mathrm{d}_{2}$. An impurity at $-20.26 \mathrm{ppm}$ represents IPrCuOBpin that proved difficult to remove.

Infrared Spectroscopy

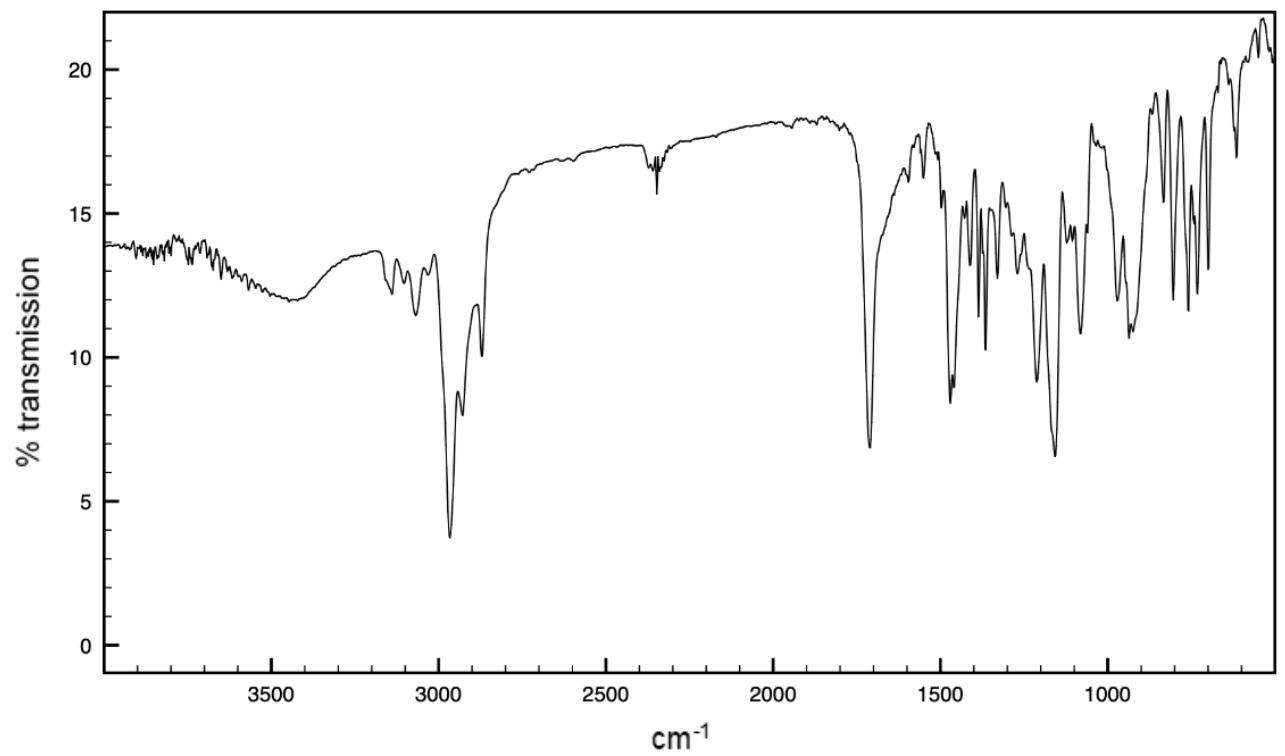

Figure A1.50. FT-IR spectrum of $\mathbf{3 a}$; $\mathrm{KBr}$ pellet. 


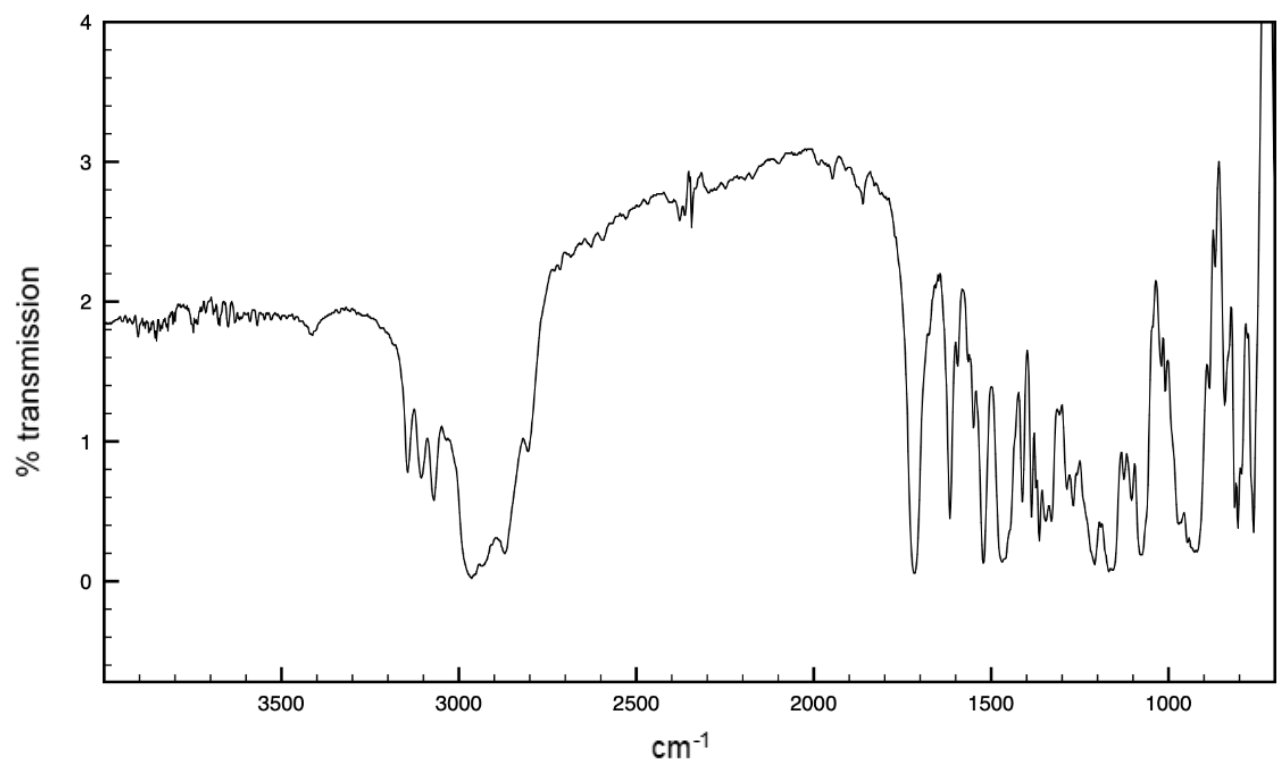

Figure A1.51. FT-IR spectrum of $\mathbf{3 b} ; \mathrm{KBr}$ pellet.

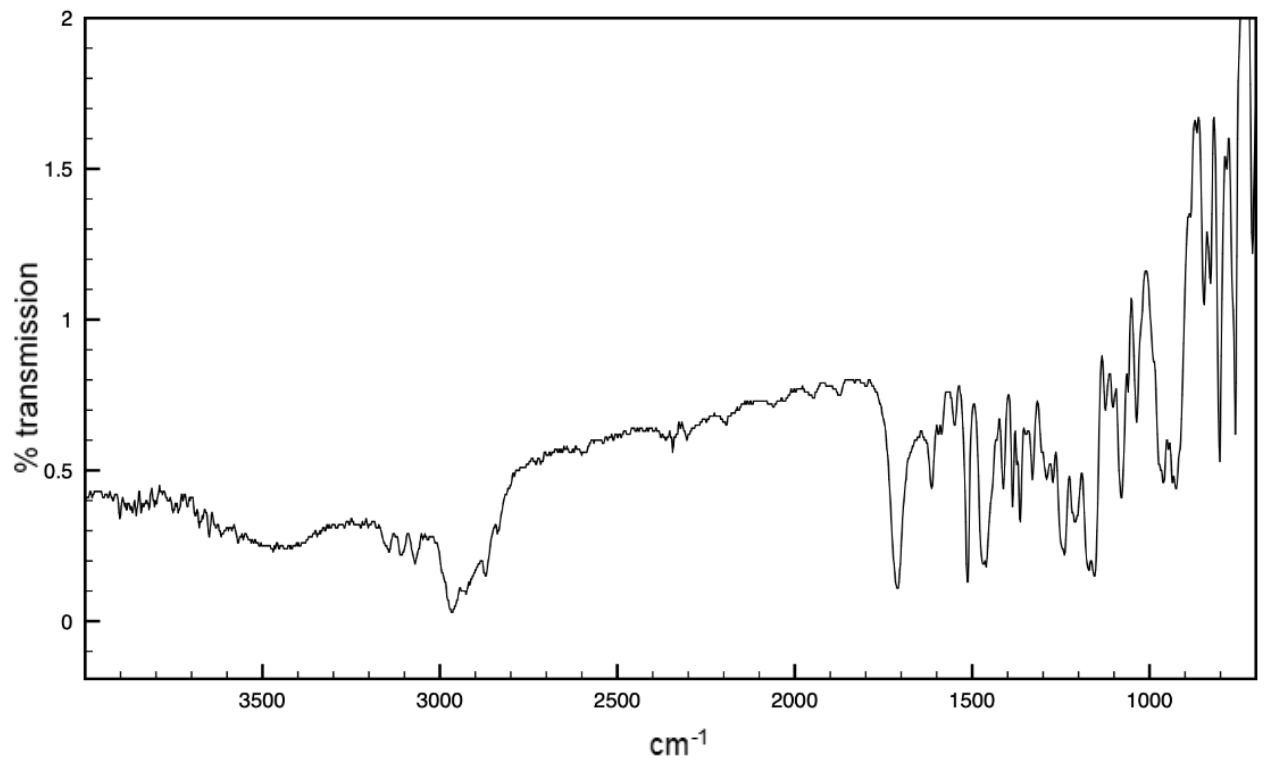

Figure A1.52. FT-IR spectrum of $\mathbf{3 c} ; \mathrm{KBr}$ pellet. 


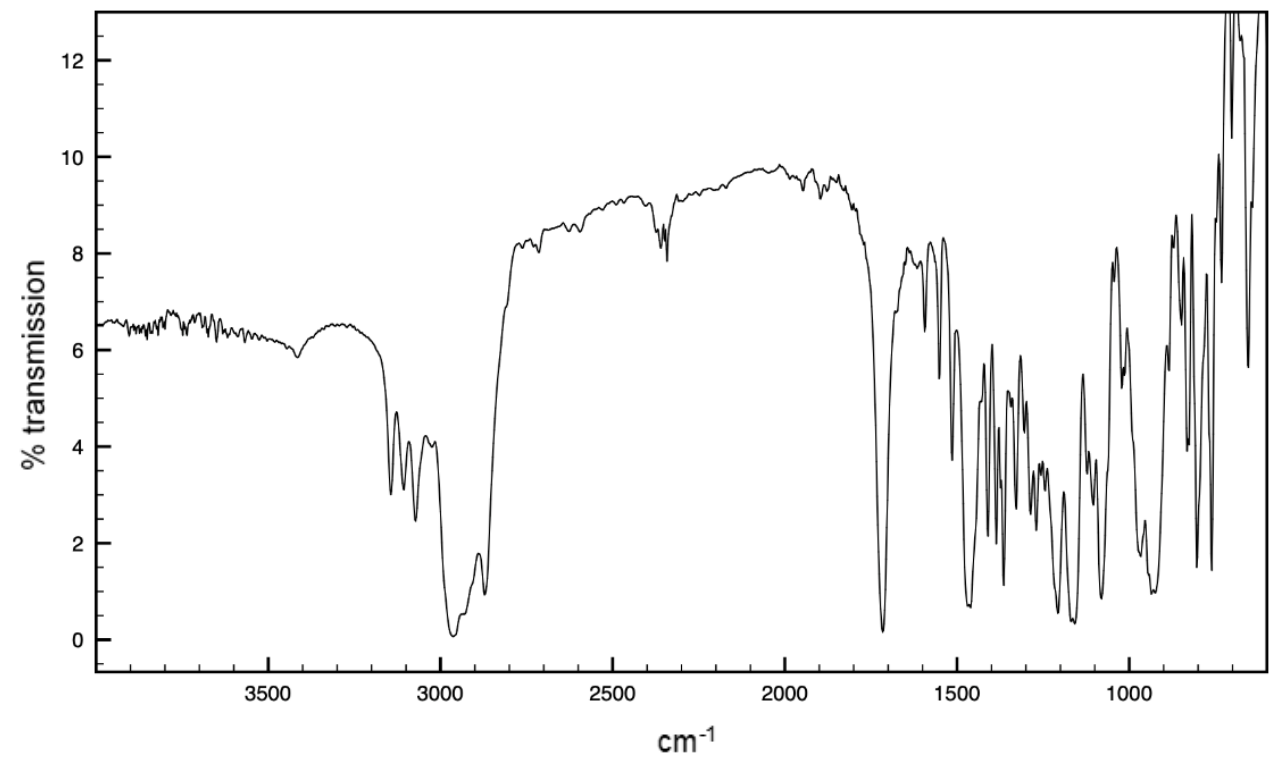

Figure A1.53. FT-IR spectrum of 3d; KBr pellet.

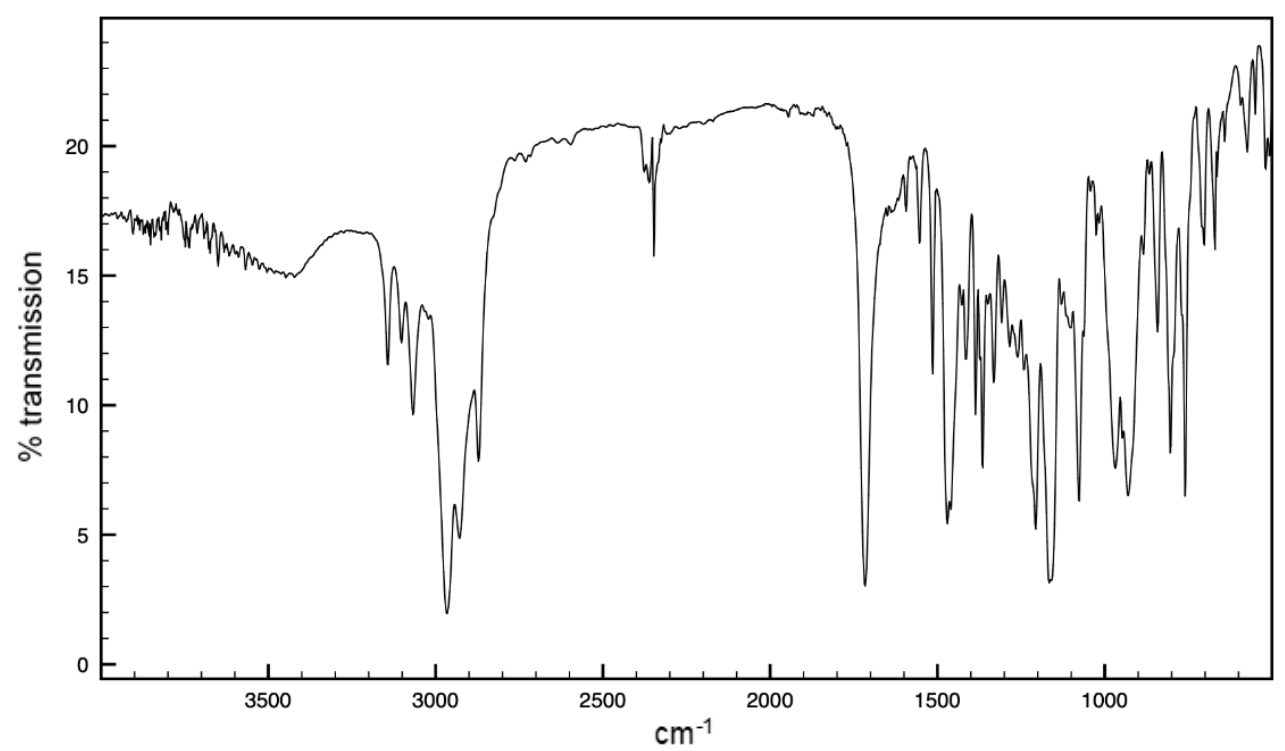

Figure A1.54. FT-IR spectrum of $\mathbf{3 e}$; $\mathrm{KBr}$ pellet. 


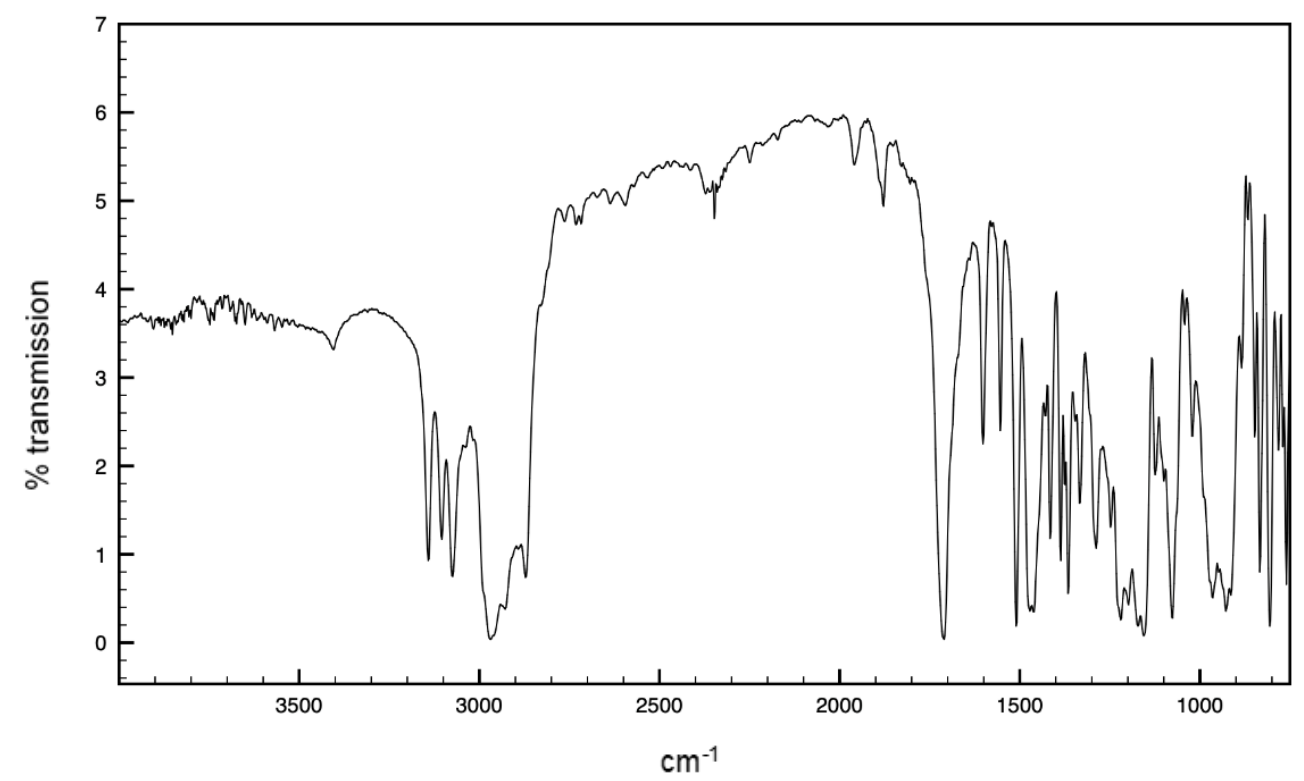

Figure A1.55. FT-IR spectrum of 3f; KBr pellet.

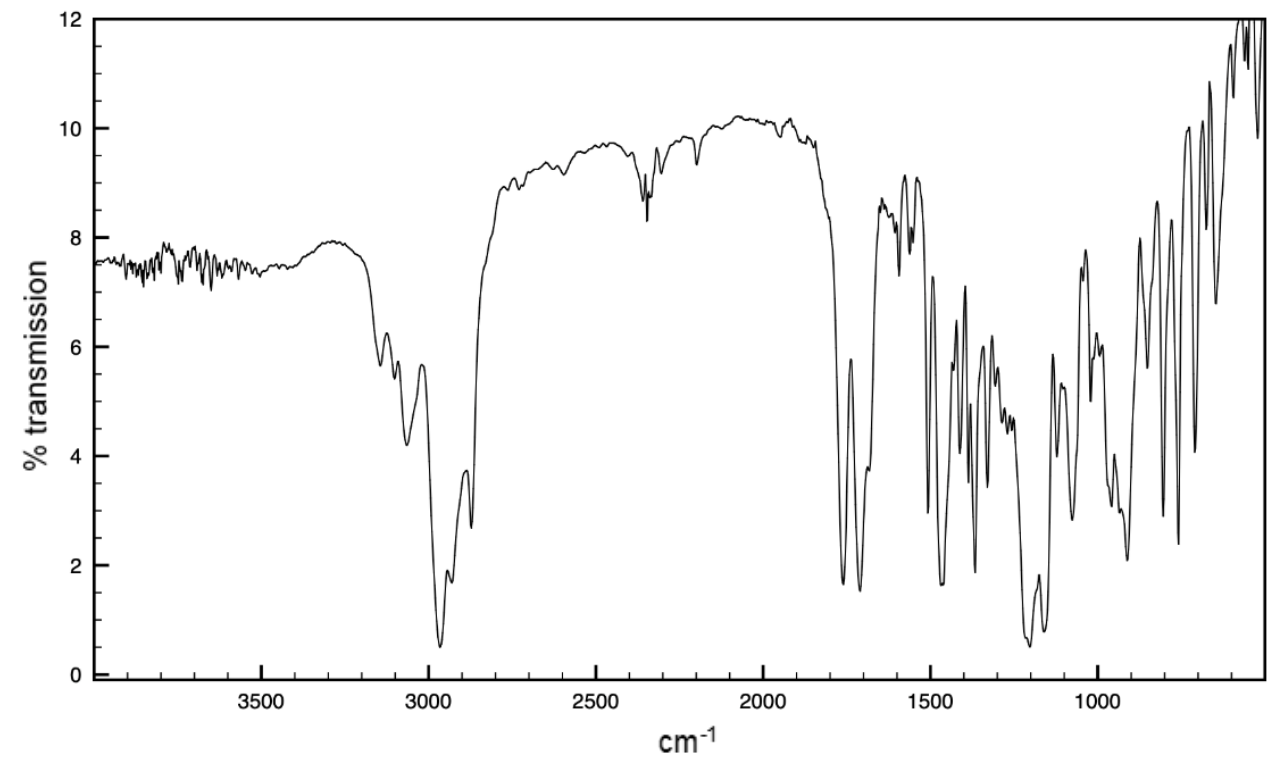

Figure A1.56. FT-IR spectrum of $\mathbf{3 g}$; $\mathrm{KBr}$ pellet. 


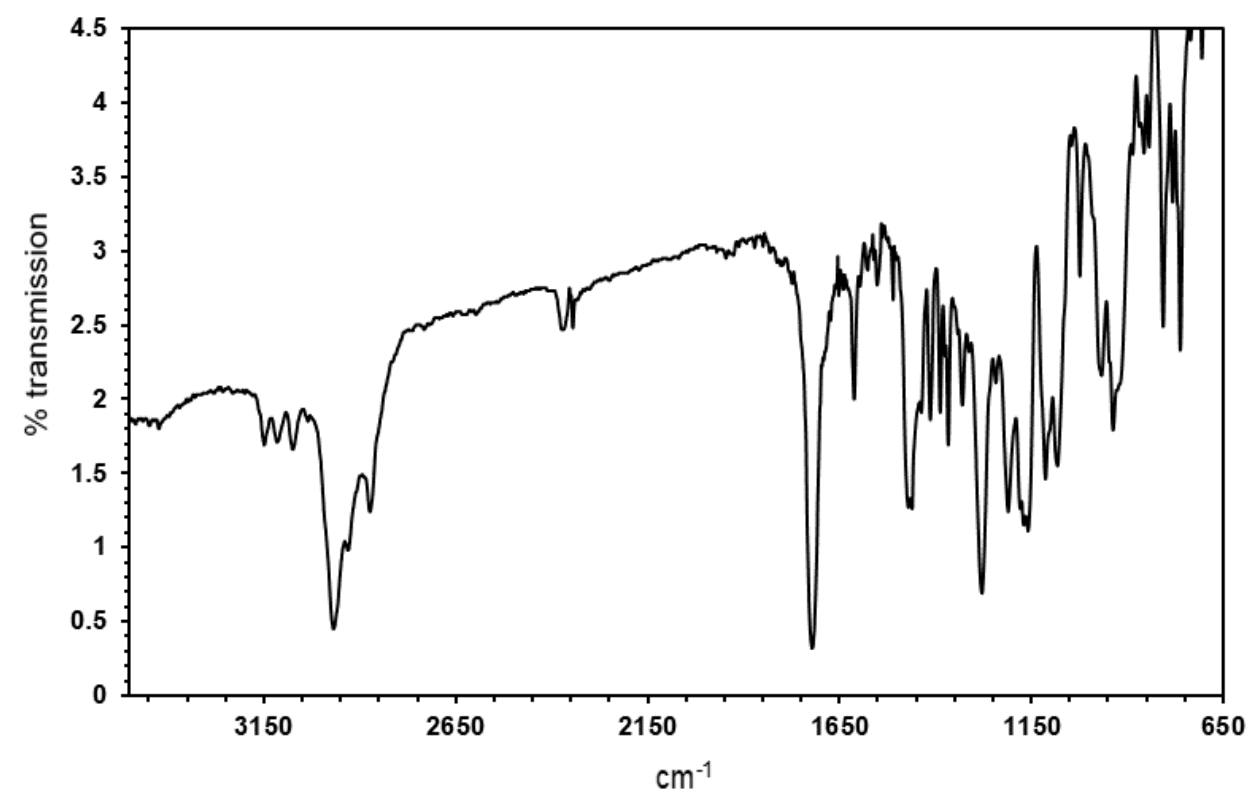

Figure A1.57. FT-IR spectrum of $\mathbf{3 h} ; \mathrm{KBr}$ pellet.

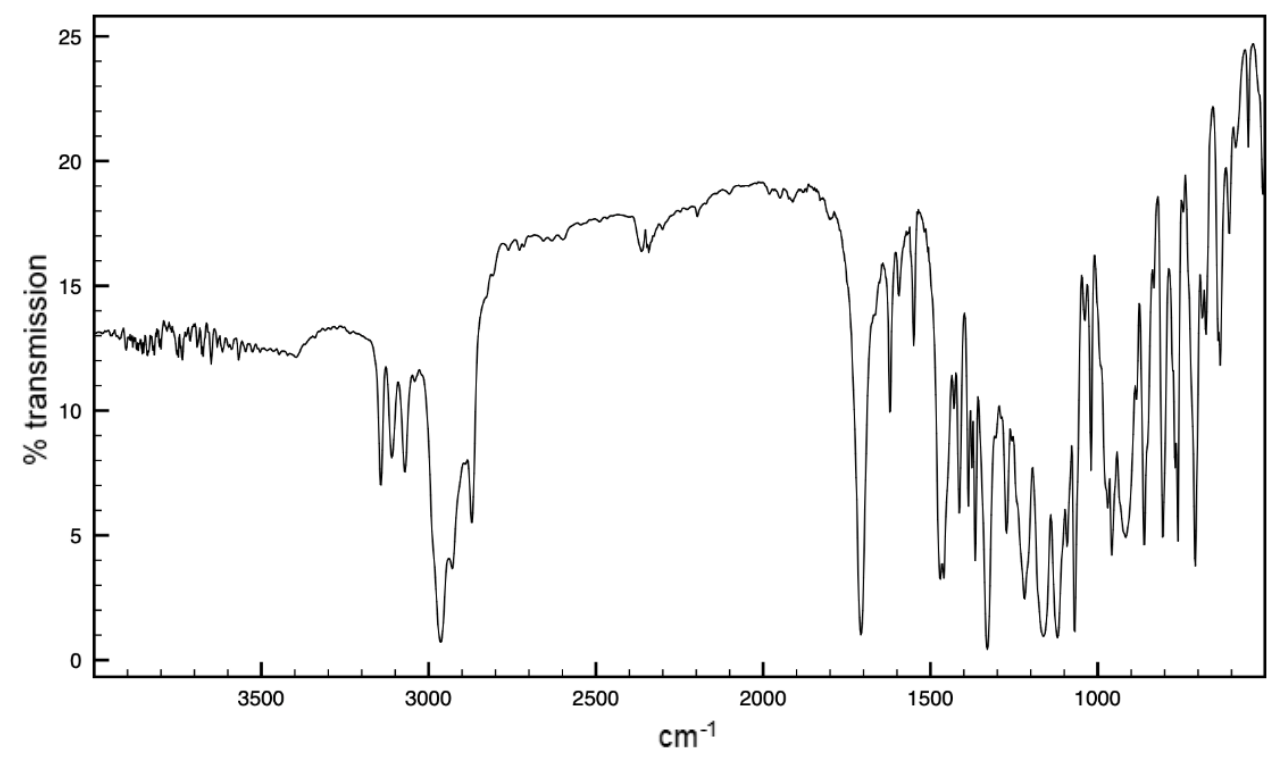

Figure A1.58. FT-IR spectrum of 3i; KBr pellet. 


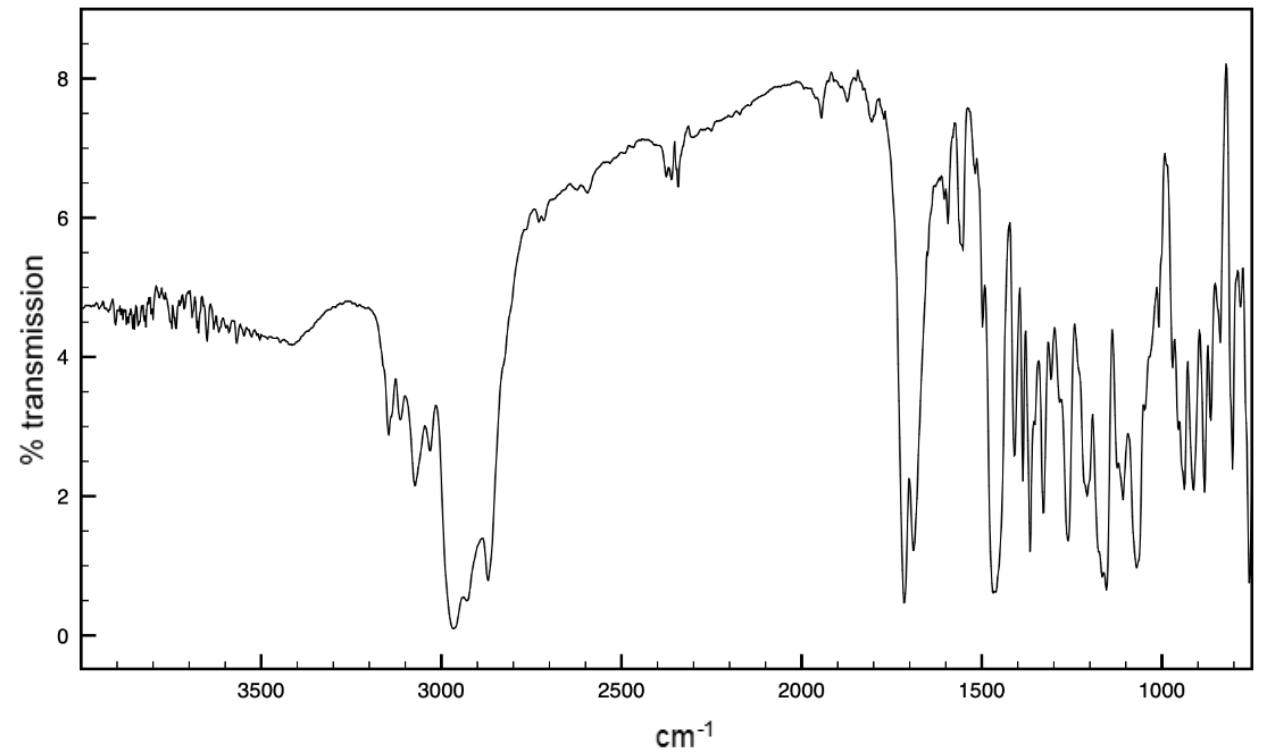

Figure A1.59. FT-IR spectrum of $\mathbf{3 j}$; KBr pellet. 


\begin{tabular}{lrlll}
\hline $\mathrm{T} /{ }^{\circ} \mathrm{C}$ & $\mathrm{T} / \mathrm{K}$ & \multicolumn{1}{c}{$1 / \mathrm{T}$} & $\mathrm{k}, \mathrm{s}^{-1}$ & $\mathrm{ln}(\mathrm{k} / \mathrm{T})$ \\
\hline 0 & 273.15 & 0.00366 & 4120 & 2.71359 \\
-10 & 263.15 & 0.0038 & 1800 & 1.92282 \\
-20 & 253.15 & 0.00395 & 805 & 1.15686 \\
-30 & 243.15 & 0.00411 & 312 & 0.24932 \\
-40 & 233.15 & 0.00429 & 112 & -0.73318 \\
-50 & 223.15 & 0.00448 & 38 & -1.77026 \\
-60 & 213.15 & 0.00469 & 11.01 & -2.96319 \\
-70 & 203.15 & 0.00492 & 3.2 & -4.15079
\end{tabular}

B: Slope is $\frac{-\Delta \mathrm{H}^{\ddagger}}{\mathrm{R}}$

A: Intercept is $\frac{\Delta s^{\ddagger}}{R}+23.76$

$\frac{-\Delta H^{\ddagger}}{R}=-5461.3999$

$\mathrm{R}=1.987 \mathrm{cal} \mathrm{K}^{-1} \mathrm{~mol}^{-1}$

$\Delta \mathrm{H}^{\ddagger}=10.9 \mathrm{kcal} \mathrm{mol}^{-1}$

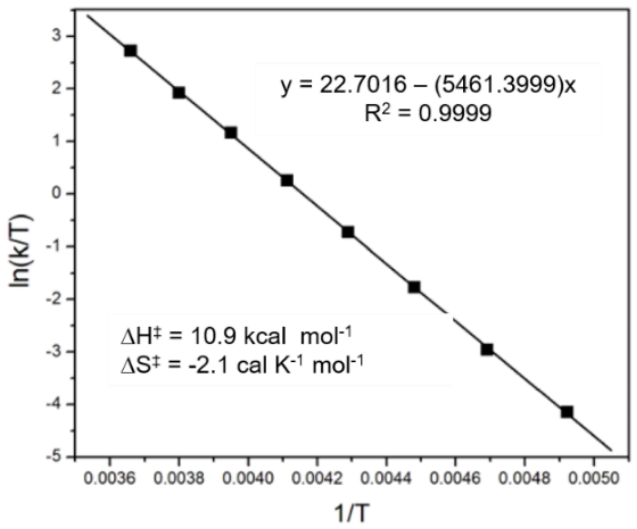

$\frac{\Delta s^{\ddagger}}{R}+23.7622 .7016$

$\Delta \mathrm{S}^{\ddagger}=-\mathbf{2 . 1} \mathrm{cal} \mathrm{K}^{-1} \mathrm{~mol}^{-1}$

$\Delta G^{\ddagger}=\Delta H^{\ddagger}-T \Delta S^{\ddagger}(T=273.15 K)$

$\Delta G^{\ddagger}=10.9-273.15\left(-2.1 \times 10^{-3}\right)=11$

$\Delta G \ddagger=11.5 \mathrm{kcal} \mathrm{mol}^{-1}$

Figure A1.60. Eyring plot of $\ln (\mathrm{k} / \mathrm{T})$ vs. $1 / \mathrm{T}$ for rate constants obtained by simulation of ${ }^{1} \mathrm{H}$ NMR spectra at temperatures between $203 \mathrm{~K}$ and $273 \mathrm{~K}$ of $\mathbf{3 a}$ in dichloromethane- $\mathrm{d}_{2}$.

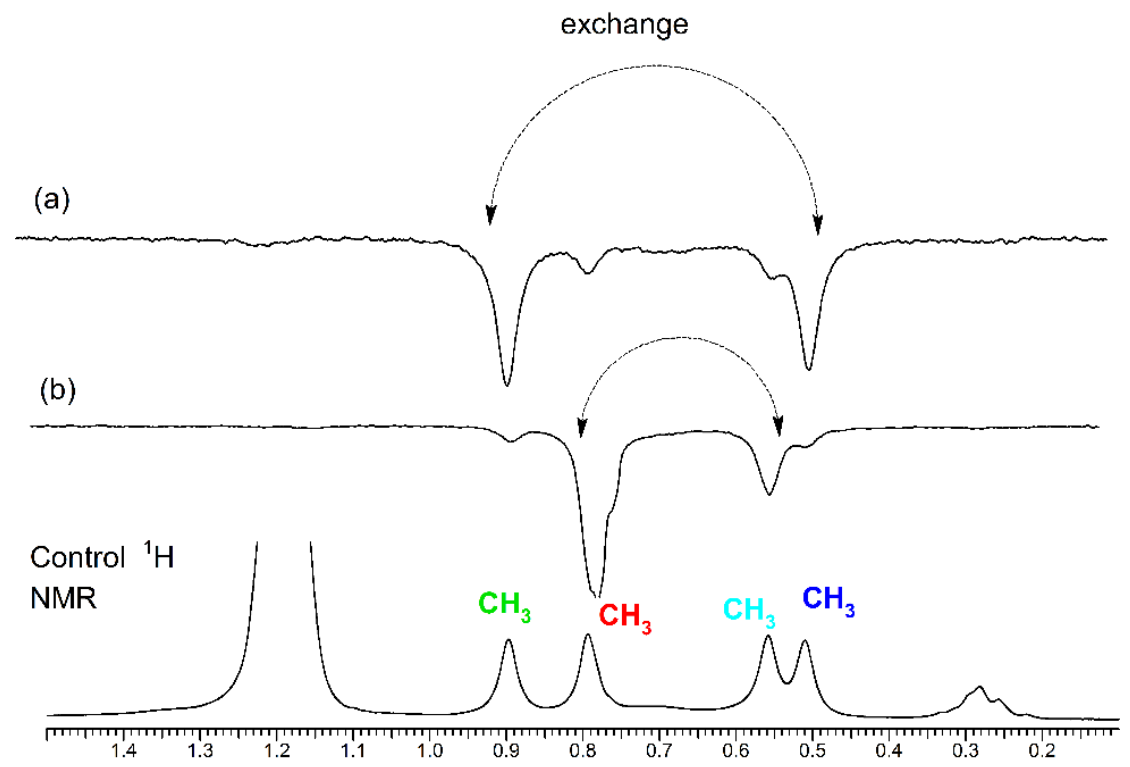

Figure A1.61. DPFGSENOE subspectrum of 3a at $-90^{\circ} \mathrm{C}$ demonstrating exchange between the protons of Bpin methyl substituents in dichloromethane- $\mathrm{d}_{2}$. 


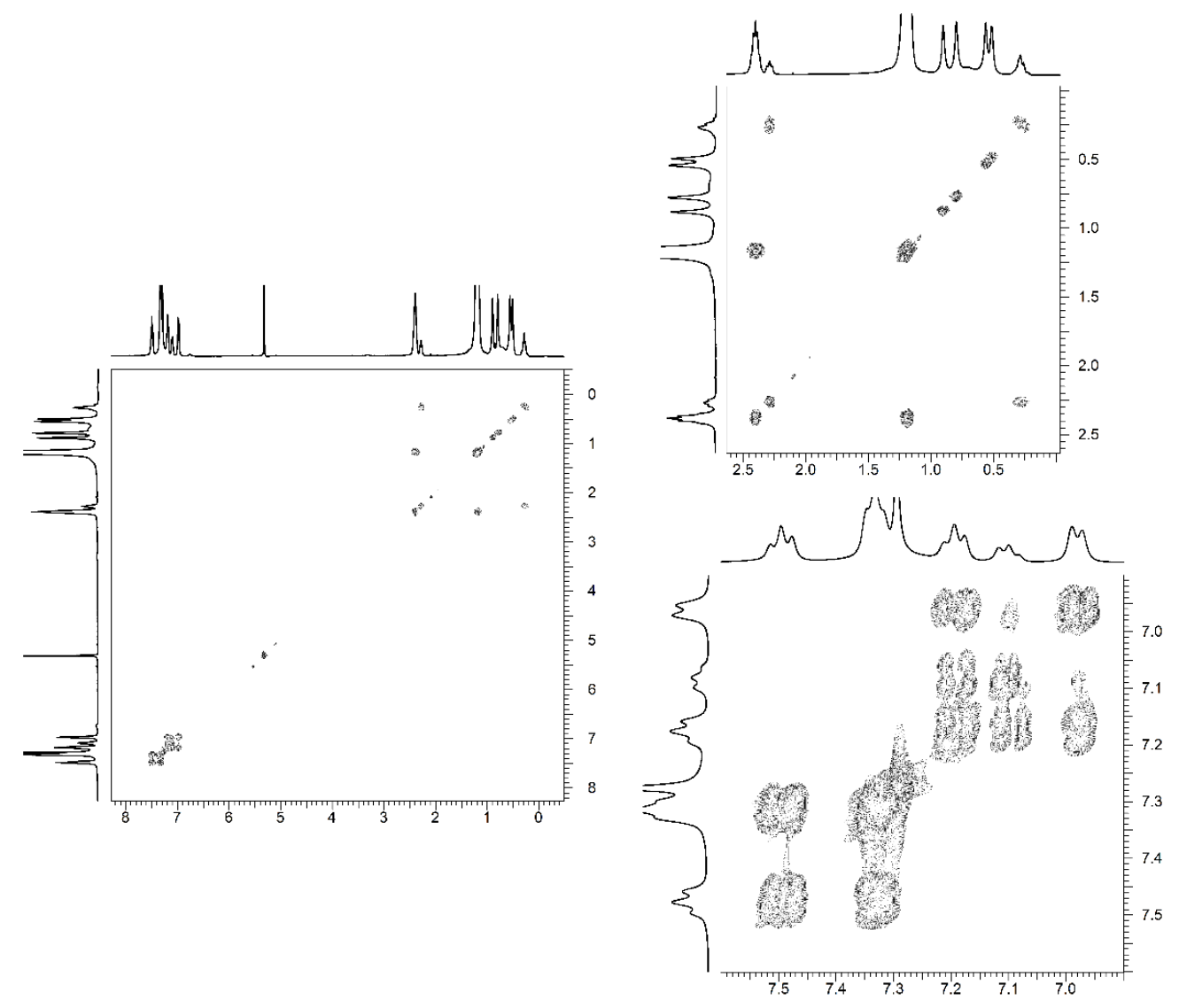

Figure A1.62. gCOSY spectrum of 3a in dichloromethane- $\mathrm{d}_{2}$ at $-90^{\circ} \mathrm{C}$.

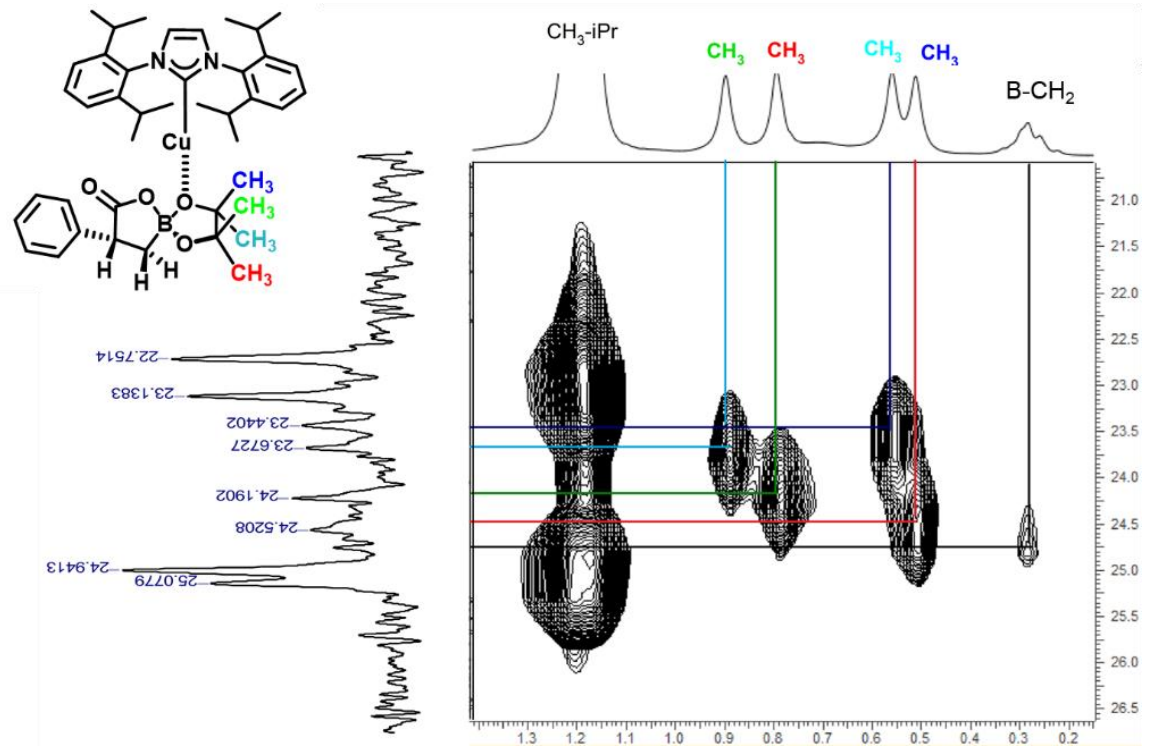

Figure A1.63. gHSQCAD spectrum of 3a in dichloromethane- $\mathrm{d}_{2}$ at $-90^{\circ} \mathrm{C}$. 


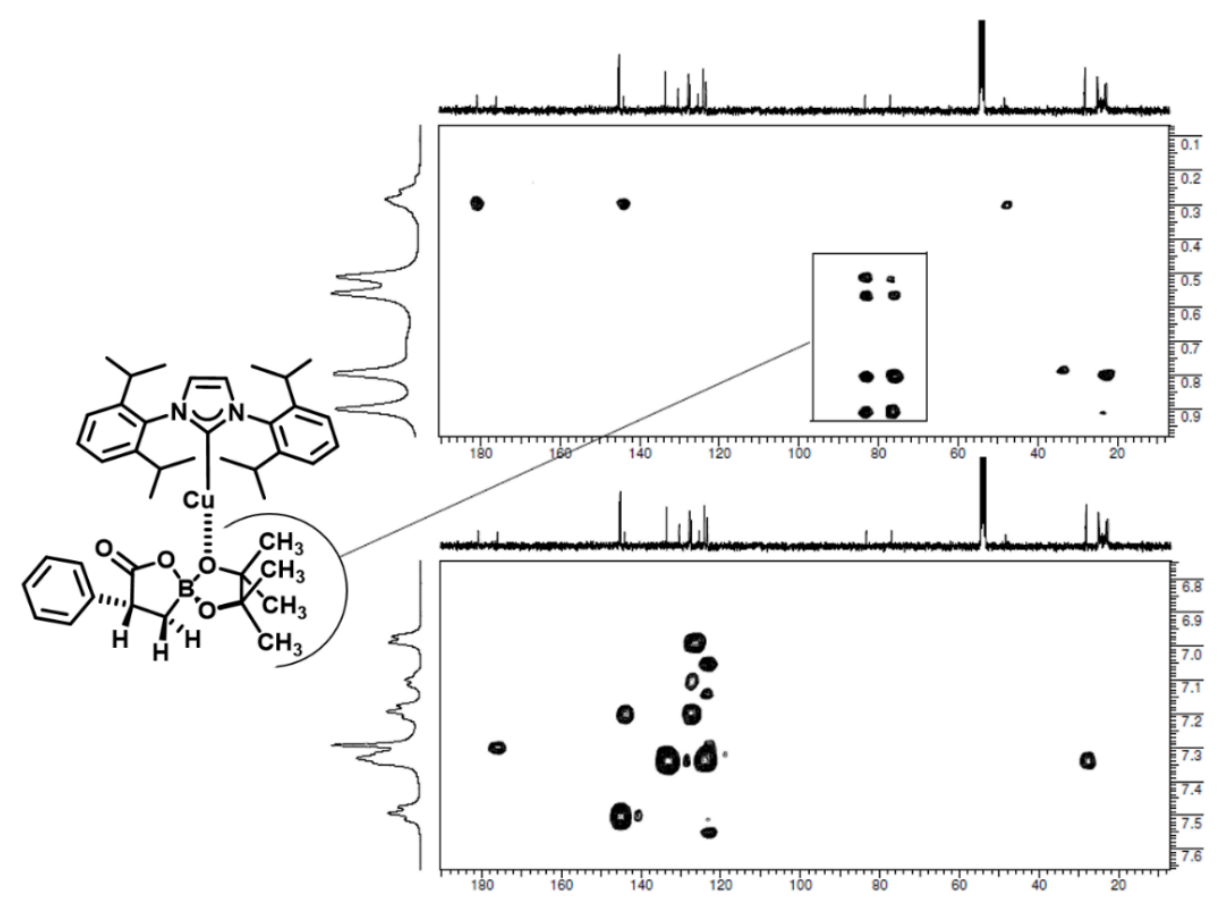

Figure A1.64. gHMBCAD spectrum 3a in dichloromethane- $\mathrm{d}_{2}$ at $-90^{\circ} \mathrm{C}$. 


\section{$\underline{\text { X-ray Crystallographic Data }}$}

Table A1.1. Crystallographic data collection and refinement details for $\operatorname{IPrCu}\left(\mathrm{CO}_{2}\left(\mathrm{CHPhCH}_{2}-\right.\right.$ Bpin) $\cdot 2 \mathrm{CH}_{2} \mathrm{Cl}_{2}$.

\begin{tabular}{|c|c|}
\hline & $\mathrm{IPrCu}\left(\mathrm{CO}_{2}\left(\mathrm{CHPhCH}_{2} \mathrm{Bpin}\right)\right) \cdot 2 \mathrm{CH}_{2} \mathrm{Cl}_{2}$ \\
\hline Chem. Formula & $\mathrm{C}_{44} \mathrm{H}_{60} \mathrm{BCl}_{4} \mathrm{CuN}_{2} \mathrm{O}_{4}$ \\
\hline Crystal size $\left(\mathrm{mm}^{3}\right)$ & $0.106 \times 0.263 \times 0.408 \mathrm{~mm}$ \\
\hline Formal weight $\left(\mathrm{g} \mathrm{mol}^{-1}\right)$ & 897.09 \\
\hline Space group & $\mathrm{P} 2_{1} / \mathrm{n}$ (non-standard setting for $\mathrm{P} 2_{1} / \mathrm{c}$, No. 14 ) \\
\hline $\mathrm{a}(\AA)$ & $12.0784(5)$ \\
\hline $\mathrm{b}(\AA)$ & $20.6951(8)$ \\
\hline c $(\AA)$ & $18.4798(7)$ \\
\hline$\alpha(\operatorname{deg})$ & 90 \\
\hline$\beta(\operatorname{deg})$ & $94.1305(12)$ \\
\hline$\gamma(\operatorname{deg})$ & 90 \\
\hline $\mathrm{V}\left(\AA^{3}\right)$ & $4607.3(3)$ \\
\hline Z & 4 \\
\hline $\mathrm{T}(\mathrm{K})$ & $100(2)$ \\
\hline$\rho$ calculated $\left(\mathrm{g} \mathrm{cm}^{-3}\right)$ & 1.293 \\
\hline Reflections collected $/ 2 \Theta_{\max }$ & $43722 / 27.50^{\circ}$ \\
\hline Unique reflections/ $\mathrm{I}>2 \sigma(I)$ & $10554 / 8617$ \\
\hline No. of params/restraints & $517 / 0$ \\
\hline$\lambda(\AA)$ & 0.71073 \\
\hline $\mathrm{R} 1^{a} /$ goodness of fit ${ }^{b}$ & $0.0406 / 1.034$ \\
\hline $\mathrm{wR}^{\mathrm{c}}(\mathrm{I}>2 \sigma(I))$ & 0.0951 \\
\hline Residual density $\left(\mathrm{e}^{-} / \AA^{-3}\right)$ & $1.533 /-0.430$ \\
\hline
\end{tabular}

a Observation criterion: $I>2 \sigma(I), \mathrm{R}_{1}=\Sigma(\|F o|-| F c\|) / \Sigma|F o| .{ }^{\mathrm{b}} \mathrm{GoF}=\left[\Sigma\left[\mathrm{w}\left(\mathrm{F}_{\mathrm{o}}{ }^{2}-\mathrm{F}_{\mathrm{c}}{ }^{2}\right)^{2}\right] /(\mathrm{n}-\mathrm{p})\right]^{1 / 2}$. $\left.{ }^{c} \mathrm{wR}_{2}=\left[\mathrm{w}\left(\mathrm{F}_{\mathrm{o}}^{2}-\mathrm{F}_{\mathrm{c}}^{2}\right)^{2}\right] / \Sigma\left[\mathrm{w}\left(\mathrm{F}_{\mathrm{o}}^{2}\right)^{2}\right]\right]^{1 / 2}$. 
APPENDIX III: XYZ COORDINATES OF OPTIMIZED STRUCTURES 


\section{Chapter 2 XYZ Coordinates}

\section{GS IMeCu(CH(4-NH2 $\left.\mathrm{Nh}_{2} \mathrm{CH}_{2} \mathrm{~B}(\mathrm{eg})\right)$ (4b):}

Total Energy (kcal/mol): -1608837.915

Enthalpy Correction (AU): 0.373814

Free Energy Correction (AU): 0.294872

Three lowest frequencies $\left(\mathrm{cm}^{-1}\right): 21.7,32.7,40.5$

$\begin{array}{rrrr}\mathrm{N} & -3.283019 & -1.797312 & 1.541966 \\ \mathrm{C} & -4.160869 & -1.576680 & 0.536258 \\ \mathrm{~N} & -3.467180 & -1.875787 & -0.586842 \\ \mathrm{C} & -2.182793 & -2.282228 & -0.286977 \\ \mathrm{C} & -2.066558 & -2.235463 & 1.057487 \\ \mathrm{Cu} & -5.951661 & -0.882306 & 0.602905 \\ \mathrm{C} & -7.614554 & 0.118387 & 0.348792 \\ \mathrm{C} & -7.711477 & 1.279405 & 1.350786 \\ \mathrm{~B} & -7.792796 & 0.594698 & 2.738493 \\ \mathrm{O} & -8.945463 & 0.071655 & 3.267064 \\ \mathrm{C} & -8.637456 & -0.501167 & 4.524830 \\ \mathrm{C} & -7.109951 & -0.574334 & 4.543838 \\ \mathrm{O} & -6.696821 & 0.342500 & 3.545366 \\ \mathrm{C} & -3.989594 & -1.726905 & -1.933485 \\ \mathrm{C} & -3.596019 & -1.591860 & 2.942365 \\ \mathrm{C} & -7.365040 & 0.463618 & -1.075003 \\ \mathrm{C} & -7.752337 & -0.418215 & -2.098464 \\ \mathrm{C} & -7.433597 & -0.202293 & -3.426951 \\ \mathrm{C} & -6.708375 & 0.925615 & -3.816535 \\ \mathrm{C} & -6.332363 & 1.822529 & -2.820758 \\ \mathrm{C} & -6.657768 & 1.600235 & -1.489666 \\ \mathrm{~N} & -6.319774 & 1.109735 & -5.154608 \\ \mathrm{H} & -1.472037 & -2.557825 & -1.052835 \\ \mathrm{H} & -1.235301 & -2.466804 & 1.707999 \\ \mathrm{H} & -8.508727 & -0.514788 & 0.424561 \\ \mathrm{H} & -6.340526 & 2.332772 & -0.748896 \\ \mathrm{H} & -8.313144 & -1.313455 & -1.824345 \\ \mathrm{H} & -7.755128 & -0.919014 & -4.184718 \\ \mathrm{H} & -5.774197 & 2.719497 & -3.095063 \\ \mathrm{H} & -6.807298 & 1.903598 & 1.315285 \\ \mathrm{H} & -9.032835 & 0.143727 & 5.321881 \\ \mathrm{H} & -9.114659 & -1.483036 & 4.612069 \\ \mathrm{H} & -6.752563 & -1.581096 & 4.275261 \\ \mathrm{H} & -6.672089 & -0.298627 & 5.509657 \\ \mathrm{H} & -8.570201 & 1.940461 & 1.139306 \\ \mathrm{H} & -3.949091 & -2.682044 & -2.464771 \\ \mathrm{H} & -5.028211 & -1.389982 & -1.876548 \\ \mathrm{H} & -3.413690 & -0.979027 & -2.485739 \\ & & & \end{array}$




$\begin{array}{rrrr}\mathrm{H} & -2.756864 & -1.098298 & 3.440203 \\ \mathrm{H} & -4.478373 & -0.949762 & 3.012495 \\ \mathrm{H} & -3.798845 & -2.545617 & 3.439826 \\ \mathrm{H} & -6.970990 & 0.701980 & -5.814314 \\ \mathrm{H} & -6.161781 & 2.082178 & -5.388902\end{array}$

TS IMeCu(( $\left.\mathrm{CO}_{2}\right)\left(\mathrm{CH}\left(4-\mathrm{NH}_{2} \mathrm{Ph}\right) \mathrm{CH}_{2} \mathrm{~B}(\mathrm{eg})\right)(4 \mathrm{~b} \cdot \mathrm{TS})$ :

Total Energy (kcal/mol): - 1727150.164 Enthalpy Correction (AU): 0.389328 Free Energy Correction (AU): 0.304718 Three lowest frequencies $\left(\mathrm{cm}^{-1}\right)$ : -173.7, 23.7, 28.6

$\begin{array}{crrr}\mathrm{C} & 2.889124 & -0.946080 & -1.346934 \\ \mathrm{C} & 3.697128 & -0.992547 & -0.213141 \\ \mathrm{C} & 3.094263 & -1.320901 & 1.005636 \\ \mathrm{C} & 1.741847 & -1.583413 & 1.085421 \\ \mathrm{C} & 0.904368 & -1.525609 & -0.048650 \\ \mathrm{C} & 1.528450 & -1.206010 & -1.266381 \\ \mathrm{Cu} & -0.265104 & 0.323032 & 0.282063 \\ \mathrm{O} & -0.813499 & -0.618282 & 2.570953 \\ \mathrm{C} & -1.562251 & -0.817145 & 1.643118 \\ \mathrm{O} & -2.735783 & -0.862547 & 1.366191 \\ \mathrm{C} & -0.574097 & -1.724866 & 0.102751 \\ \mathrm{C} & -1.410387 & -1.843107 & -1.164442 \\ \mathrm{~B} & -2.949042 & -1.683129 & -0.915724 \\ \mathrm{O} & -3.629267 & -0.536890 & -1.268302 \\ \mathrm{C} & -4.960520 & -0.682958 & -0.806315 \\ \mathrm{C} & -5.065827 & -2.144607 & -0.328461 \\ \mathrm{O} & -3.776495 & -2.695474 & -0.522583 \\ \mathrm{C} & -0.290760 & 2.213838 & 0.035620 \\ \mathrm{~N} & 0.749512 & 3.071869 & -0.049835 \\ \mathrm{C} & 0.308393 & 4.375886 & -0.141627 \\ \mathrm{C} & -1.041959 & 4.327330 & -0.121561 \\ \mathrm{~N} & -1.389430 & 2.997377 & -0.017840 \\ \mathrm{C} & 2.140208 & 2.661618 & 0.013871 \\ \mathrm{C} & -2.749498 & 2.489100 & 0.088212 \\ \mathrm{H} & 0.988986 & 5.210764 & -0.223361 \\ \mathrm{H} & -1.781151 & 5.112707 & -0.182426 \\ \mathrm{H} & 2.502316 & 2.678257 & 1.045856 \\ \mathrm{H} & -3.433435 & 3.206486 & -0.371720 \\ \mathrm{H} & 0.939838 & -1.178072 & -2.180553 \\ \mathrm{H} & 1.294936 & -1.818161 & 2.048519 \\ \mathrm{H} & 3.705552 & -1.368057 & 1.907267 \\ \mathrm{H} & 3.334774 & -0.706805 & -2.313118 \\ \mathrm{~N} & 5.048437 & -0.654967 & -0.275779\end{array}$




$\begin{array}{lrrr}\mathrm{H} & -1.126436 & -1.070075 & -1.893803 \\ \mathrm{H} & -0.748861 & -2.588748 & 0.753655 \\ \mathrm{H} & 2.234224 & 1.644382 & -0.375602 \\ \mathrm{H} & 2.749292 & 3.334598 & -0.594495 \\ \mathrm{H} & -3.020972 & 2.344608 & 1.137766 \\ \mathrm{H} & -2.831333 & 1.528187 & -0.428539 \\ \mathrm{H} & -1.214947 & -2.812290 & -1.653868 \\ \mathrm{H} & -5.324529 & -2.208046 & 0.734825 \\ \mathrm{H} & -5.798146 & -2.728020 & -0.900390 \\ \mathrm{H} & -5.131869 & 0.025029 & 0.016178 \\ \mathrm{H} & -5.656225 & -0.444893 & -1.620472 \\ \mathrm{H} & 5.611522 & -1.053795 & 0.463734 \\ \mathrm{H} & 5.475381 & -0.809470 & -1.179653\end{array}$

GS IMeCu(CH(4-OMePh) $\left.\mathrm{CH}_{2} \mathrm{~B}(\mathrm{eg})\right)(\mathbf{4 c})$ :

Total Energy (kcal/mol): -1645956.795

Enthalpy Correction (AU): 0.391287

Free Energy Correction (AU): 0.310942

Three lowest frequencies $\left(\mathrm{cm}^{-1}\right): 22.5,24.9,40.3$
C $\quad-3.445882-2.021172$
1.584852
$\begin{array}{llll}\text { C } & -4.350889 & -1.747083\end{array}$
0.570729
$\begin{array}{llll}\text { C } & -3.894506 & -1.729488 & -0.748901\end{array}$
$\begin{array}{llll}\text { C } & -2.568186 & -1.971465 & -1.031072\end{array}$
$\begin{array}{llll}\text { C } & -1.619420 & -2.242049 & -0.025303\end{array}$
$\begin{array}{llll}\text { C } & -2.107103 & -2.269561 & 1.282407\end{array}$
$\begin{array}{llll}\mathrm{Cu} & 0.346504 & -0.534871 & -0.486768\end{array}$
$\begin{array}{llll}\text { C } & -0.188622 & -2.413425 & -0.383158\end{array}$
$\begin{array}{llll}\text { C } & 0.695202 & -3.160546 & 0.628159\end{array}$
$\begin{array}{llll}\text { B } & 2.127792 & -3.093474 & 0.041660\end{array}$
$\begin{array}{llll}\text { O } & 3.062324 & -2.131315 & 0.387964\end{array}$
$\begin{array}{llll}\text { C } & 4.098614 & -2.183310 & -0.578383\end{array}$
$\begin{array}{llll}\text { C } & 3.922269 & -3.543460 & -1.254500\end{array}$
$\begin{array}{llll}\mathrm{O} & 2.587800 & -3.911897 & -0.957067\end{array}$
$\begin{array}{llll}\text { O } & -5.680629 & -1.495169 & 0.750587\end{array}$
$\begin{array}{llll}\text { C } & -6.177726 & -1.562487 & 2.054735\end{array}$
$\begin{array}{llll}\text { C } & 0.652349 & 1.355195 & -0.319430\end{array}$
$\begin{array}{llll}\mathrm{N} & -0.291828 & 2.320435 & -0.412949\end{array}$
$\begin{array}{llll}\text { C } & 0.236134 & 3.565017 & -0.137442\end{array}$
$\begin{array}{llll}\text { C } & 1.546594 & 3.377002 & 0.129284\end{array}$
$\begin{array}{llll}\mathrm{N} & 1.779681 & 2.020409 & 0.018313\end{array}$
$\begin{array}{llll}\text { C } & -1.692544 & 2.036835 & -0.674036\end{array}$
$\begin{array}{llll}\text { C } & 3.066714 & 1.382763 & 0.219338\end{array}$
$\begin{array}{llll}\mathrm{H} & -0.362564 & 4.464359 & -0.153632\end{array}$
$\begin{array}{llll}\mathrm{H} & 2.328195 & 4.078131 & 0.384060\end{array}$ 


$\begin{array}{crrr}\mathrm{H} & -0.115034 & -2.897250 & -1.367238 \\ \mathrm{H} & -1.427904 & -2.492641 & 2.103475 \\ \mathrm{H} & -2.230769 & -1.951172 & -2.068940 \\ \mathrm{H} & -4.616391 & -1.532358 & -1.539505 \\ \mathrm{H} & -3.763924 & -2.059100 & 2.623712 \\ \mathrm{H} & 0.687117 & -2.651688 & 1.602849 \\ \mathrm{H} & 4.605176 & -4.301103 & -0.845719 \\ \mathrm{H} & 4.063452 & -3.505527 & -2.339643 \\ \mathrm{H} & 3.960156 & -1.355834 & -1.292333 \\ \mathrm{H} & 5.072271 & -2.061413 & -0.091110 \\ \mathrm{H} & 0.344617 & -4.193643 & 0.800169 \\ \mathrm{H} & -7.249605 & -1.364186 & 1.992526 \\ \mathrm{H} & -6.024737 & -2.556101 & 2.501347 \\ \mathrm{H} & -5.715364 & -0.810051 & 2.711844 \\ \mathrm{H} & -2.200479 & 2.959383 & -0.963924 \\ \mathrm{H} & -1.774873 & 1.310583 & -1.484926 \\ \mathrm{H} & -2.175146 & 1.616829 & 0.213713 \\ \mathrm{H} & 3.557514 & 1.810438 & 1.097880 \\ \mathrm{H} & 2.911673 & 0.312412 & 0.383982 \\ \mathrm{H} & 3.709346 & 1.527096 & -0.655243\end{array}$

TS IMeCu((CO) $)\left(\mathrm{CH}(4-\mathrm{OMePh}) \mathrm{CH}_{2} \mathrm{~B}(\mathrm{eg})\right)(4 \mathrm{c} \cdot \mathrm{TS})$ :

Total Energy (kcal/mol): -1764268.177

Enthalpy Correction (AU): 0.406219

Free Energy Correction (AU): 0.318504

Three lowest frequencies $\left(\mathrm{cm}^{-1}\right)$ : -174.99, 18.7, 25.0

$\begin{array}{cccc}\mathrm{Cu} & 0.678975 & -3.276655 & 2.425856 \\ \mathrm{C} & 0.670890 & -4.775205 & 1.242862 \\ \mathrm{~N} & 1.423164 & -5.013752 & 0.146040 \\ \mathrm{C} & 1.107083 & -6.234241 & -0.415354 \\ \mathrm{C} & 0.136967 & -6.771757 & 0.356066 \\ \mathrm{~N} & -0.119821 & -5.864531 & 1.361860 \\ \mathrm{H} & 1.591111 & -6.600450 & -1.309060 \\ \mathrm{H} & -0.393250 & -7.709799 & 0.278425 \\ \mathrm{C} & 2.415835 & -4.095821 & -0.374866 \\ \mathrm{H} & 2.505220 & -3.252735 & 0.314560 \\ \mathrm{C} & -1.064763 & -6.065649 & 2.451448 \\ \mathrm{H} & -1.888342 & -6.691487 & 2.099520 \\ \mathrm{C} & 0.513764 & -2.166966 & 4.176248 \\ \mathrm{C} & 1.833385 & -1.813894 & 3.572530 \\ \mathrm{C} & 4.268013 & -1.154326 & 2.283457 \\ \mathrm{C} & 2.991968 & -2.587163 & 3.739143 \\ \mathrm{C} & 1.942102 & -0.688254 & 2.720778 \\ \mathrm{C} & 3.125181 & -0.370098 & 2.095294\end{array}$




$\begin{array}{rrrr}\mathrm{C} & 4.193927 & -2.266807 & 3.109033 \\ \mathrm{H} & 2.970191 & -3.448183 & 4.403585 \\ \mathrm{H} & 1.058184 & -0.077213 & 2.553731 \\ \mathrm{H} & 3.202924 & 0.500895 & 1.448325 \\ \mathrm{H} & 5.062955 & -2.893393 & 3.289527 \\ \mathrm{O} & 5.381852 & -0.746301 & 1.623904 \\ \mathrm{C} & 0.484768 & -3.238803 & 5.255684 \\ \mathrm{~B} & -0.969670 & -3.578725 & 5.723004 \\ \mathrm{H} & 0.959612 & -4.172018 & 4.915125 \\ \mathrm{C} & -1.178732 & -2.207084 & 2.981482 \\ \mathrm{O} & -1.979447 & -2.911068 & 3.548266 \\ \mathrm{O} & -1.075208 & -1.386755 & 2.106258 \\ \mathrm{H} & 0.019773 & -1.253444 & 4.524185 \\ \mathrm{H} & 3.386045 & -4.593987 & -0.456967 \\ \mathrm{H} & 2.115862 & -3.722212 & -1.357955 \\ \mathrm{H} & -1.458255 & -5.100351 & 2.780995 \\ \mathrm{H} & -0.577505 & -6.548116 & 3.303321 \\ \mathrm{H} & 1.072761 & -2.903716 & 6.128717 \\ \mathrm{O} & -1.764232 & -2.692006 & 6.393050 \\ \mathrm{C} & -3.026900 & -3.304186 & 6.584427 \\ \mathrm{C} & -2.876910 & -4.728146 & 6.015398 \\ \mathrm{O} & -1.517459 & -4.834452 & 5.627969 \\ \mathrm{H} & -3.789838 & -2.726427 & 6.050075 \\ \mathrm{H} & -3.272908 & -3.297207 & 7.653853 \\ \mathrm{H} & -3.508973 & -4.880820 & 5.130771 \\ \mathrm{H} & -3.109963 & -5.510648 & 6.747794 \\ \mathrm{C} & 6.560980 & -1.476379 & 1.820332 \\ \mathrm{H} & 7.334061 & -0.983798 & 1.228678 \\ \mathrm{H} & 6.866653 & -1.480474 & 2.876126 \\ \mathrm{H} & 6.459050 & -2.517010 & 1.478530\end{array}$

GS IMeCu(CH(4-MePh) $\left.\mathrm{CH}_{2} \mathrm{~B}(\mathrm{eg})\right)$ (4e):

Total Energy (kcal/mol): -1598771.637

Enthalpy Correction (AU): 0.38452

Free Energy Correction (AU): 0.303688

Three lowest frequencies $\left(\mathrm{cm}^{-1}\right): 17.5,24.5,41.5$

$\begin{array}{cccc}\mathrm{N} & 2.824836 & -4.564693 & -0.157995 \\ \mathrm{C} & 1.495085 & -4.355591 & -0.024589 \\ \mathrm{~N} & 0.946592 & -5.586596 & -0.149708 \\ \mathrm{C} & 1.917516 & -6.547360 & -0.350159 \\ \mathrm{C} & 3.103688 & -5.902461 & -0.353296 \\ \mathrm{Cu} & 0.543516 & -2.699847 & 0.175062 \\ \mathrm{C} & -0.617265 & -1.128133 & 0.032530 \\ \mathrm{C} & 0.054831 & -0.043058 & -0.823425 \\ \mathrm{~B} & 1.329359 & 0.352217 & -0.035573\end{array}$




$\begin{array}{lrrr}\mathrm{O} & 1.342586 & 1.225082 & 1.021272 \\ \mathrm{C} & 2.668862 & 1.309593 & 1.511452 \\ \mathrm{C} & 3.386192 & 0.124254 & 0.865427 \\ \mathrm{O} & 2.573555 & -0.220457 & -0.243792 \\ \mathrm{C} & -0.480780 & -5.849508 & -0.134181 \\ \mathrm{C} & 3.818688 & -3.509965 & -0.102276 \\ \mathrm{C} & -1.774453 & -1.845424 & -0.548053 \\ \mathrm{C} & -1.958251 & -2.038436 & -1.925011 \\ \mathrm{C} & -2.992722 & -2.820677 & -2.419512 \\ \mathrm{C} & -3.909896 & -3.441461 & -1.579084 \\ \mathrm{C} & -3.748493 & -3.240264 & -0.206754 \\ \mathrm{C} & -2.717310 & -2.467979 & 0.292957 \\ \mathrm{C} & -5.050837 & -4.249806 & -2.116592 \\ \mathrm{H} & 1.676232 & -7.592640 & -0.479854 \\ \mathrm{H} & 4.112131 & -6.269058 & -0.481223 \\ \mathrm{H} & -0.882881 & -0.722579 & 1.017857 \\ \mathrm{H} & -1.266591 & -1.576528 & -2.627738 \\ \mathrm{H} & -2.611047 & -2.339894 & 1.371601 \\ \mathrm{H} & -4.458032 & -3.698470 & 0.484832 \\ \mathrm{H} & -3.093616 & -2.947060 & -3.498911 \\ \mathrm{H} & 0.355413 & -0.447384 & -1.800199 \\ \mathrm{H} & 3.104066 & 2.272497 & 1.210410 \\ \mathrm{H} & 2.663479 & 1.263741 & 2.605426 \\ \mathrm{H} & 3.437749 & -0.737583 & 1.550060 \\ \mathrm{H} & 4.401584 & 0.359149 & 0.527369 \\ \mathrm{H} & -0.619903 & 0.808016 & -1.019167 \\ \mathrm{H} & -0.794694 & -6.288981 & -1.085163 \\ \mathrm{H} & -0.733983 & -6.532078 & 0.682121 \\ \mathrm{H} & -1.014656 & -4.905442 & 0.006243 \\ \mathrm{H} & 4.564376 & -3.664249 & -0.887019 \\ \mathrm{H} & 3.323859 & -2.548184 & -0.267169 \\ \mathrm{H} & 4.319736 & -3.500219 & 0.871076 \\ \mathrm{H} & -4.852505 & -4.601966 & -3.135281 \\ \mathrm{H} & -5.256185 & -5.131255 & -1.496704 \\ \mathrm{H} & -5.982024 & -3.668172 & -2.155280\end{array}$

TS IMeCu((CO) $)\left(\mathrm{CH}(4-\mathrm{MePh}) \mathrm{CH}_{2} \mathrm{~B}(\mathrm{eg})\right)(4 \mathrm{e} \cdot \mathrm{TS})$ :

Total Energy (kcal/mol): -1717082.404 Enthalpy Correction (AU): 0.399981

Free Energy Correction (AU): 0.311989

Three lowest frequencies $\left(\mathrm{cm}^{-1}\right)$ : $-177.7965,13.96,21.38$
$\begin{array}{llll}\text { C } & 2.970734 & -1.640669 & -1.520574\end{array}$
$\begin{array}{llll}\text { C } & 3.758616 & -2.069413 & -0.462036\end{array}$
$\begin{array}{llll}\text { C } & 3.113442 & -2.372937 & 0.741719\end{array}$
$\begin{array}{llll}\text { C } & 1.746014 & -2.258974 & 0.880628\end{array}$ 


$\begin{array}{crrr}\text { C } & 0.932935 & -1.827068 & -0.192308 \\ \mathrm{C} & 1.590377 & -1.518000 & -1.397515 \\ \mathrm{Cu} & 0.389377 & 0.230093 & 0.278449 \\ \mathrm{O} & -0.406289 & -0.702737 & 2.568002 \\ \mathrm{C} & -1.173672 & -0.550306 & 1.653421 \\ \mathrm{O} & -2.282557 & -0.156202 & 1.384096 \\ \mathrm{C} & -0.529015 & -1.630953 & 0.014858 \\ \mathrm{C} & -1.408535 & -1.402201 & -1.205181 \\ \mathrm{~B} & -2.898619 & -1.114700 & -0.822166 \\ \mathrm{O} & -3.561523 & 0.034536 & -1.176832 \\ \mathrm{C} & -4.828690 & -0.001312 & -0.542193 \\ \mathrm{C} & -4.952805 & -1.423921 & 0.035974 \\ \mathrm{O} & -3.706472 & -2.042559 & -0.227674 \\ \mathrm{C} & 0.712430 & 2.102217 & 0.074044 \\ \mathrm{~N} & 1.879631 & 2.782503 & 0.105826 \\ \mathrm{C} & 1.674347 & 4.129038 & -0.115896 \\ \mathrm{C} & 0.345208 & 4.289966 & -0.295681 \\ \mathrm{~N} & -0.227106 & 3.041835 & -0.172111 \\ \mathrm{C} & 3.171134 & 2.172871 & 0.349804 \\ \mathrm{C} & -1.642526 & 2.750764 & -0.351272 \\ \mathrm{H} & 2.484886 & 4.843278 & -0.116734 \\ \mathrm{H} & -0.242124 & 5.174512 & -0.494996 \\ \mathrm{H} & 3.853638 & 2.386790 & -0.477580 \\ \mathrm{H} & -2.230157 & 3.605719 & -0.008194 \\ \mathrm{H} & 1.007619 & -1.207898 & -2.262306 \\ \mathrm{H} & 1.270711 & -2.484634 & 1.832401 \\ \mathrm{H} & 3.707992 & -2.714672 & 1.589782 \\ \mathrm{H} & 3.440294 & -1.406675 & -2.476425 \\ \mathrm{C} & 5.241096 & -2.232156 & -0.594899 \\ \mathrm{H} & -1.045445 & -0.563362 & -1.818703 \\ \mathrm{H} & -0.921056 & -2.448203 & 0.629835 \\ \mathrm{H} & 3.602525 & 2.547595 & 1.282330 \\ \mathrm{H} & 3.035538 & 1.091445 & 0.427863 \\ \mathrm{H} & -1.914694 & 1.867636 & 0.232676 \\ \mathrm{H} & -1.866974 & 2.551902 & -1.402910 \\ \mathrm{H} & -1.372977 & -2.290464 & -1.860546 \\ \mathrm{H} & -5.126972 & -1.414167 & 1.118082 \\ \mathrm{H} & -5.752400 & -2.007281 & -0.437990 \\ \mathrm{H} & -4.849302 & 0.761264 & 0.247463 \\ \mathrm{H} & -5.610491 & 0.235419 & -1.273984 \\ \mathrm{H} & 5.779968 & -1.740511 & 0.224325 \\ \mathrm{H} & 5.533342 & -3.289812 & -0.571967 \\ \mathrm{H} & 5.612613 & -1.813298 & -1.535967\end{array}$


GS IMeCu(CHPhCH $2 \mathrm{~B}(\mathrm{eg}))$ (4a):

Total Energy (kcal/mol): -1574115.98

Enthalpy Correction (AU): 0.355418

Free Energy Correction (AU): 0.275905

Three lowest frequencies $\left(\mathrm{cm}^{-1}\right): 2.3,23.8,335.7$

$\begin{array}{crrr}\mathrm{Cu} & 0.027414 & 0.207400 & -0.313230 \\ \mathrm{C} & -0.338326 & 2.081714 & -0.114430 \\ \mathrm{~N} & -1.547451 & 2.679195 & -0.227532 \\ \mathrm{C} & -1.461761 & 4.031913 & 0.033318 \\ \mathrm{C} & -0.167620 & 4.288483 & 0.320617 \\ \mathrm{~N} & 0.501760 & 3.084344 & 0.230316 \\ \mathrm{H} & -2.324817 & 4.681231 & 0.000425 \\ \mathrm{H} & 0.333240 & 5.208720 & 0.585380 \\ \mathrm{C} & -2.779670 & 1.977559 & -0.538849 \\ \mathrm{H} & -2.565805 & 0.909944 & -0.640314 \\ \mathrm{C} & 1.920764 & 2.904392 & 0.469011 \\ \mathrm{H} & 2.116713 & 1.844897 & 0.658550 \\ \mathrm{~B} & 2.481599 & -1.697506 & 0.390469 \\ \mathrm{O} & 3.282895 & -2.330302 & -0.523516 \\ \mathrm{C} & 4.457584 & -1.558044 & -0.696022 \\ \mathrm{C} & 4.126438 & -0.213455 & -0.046053 \\ \mathrm{O} & 3.020134 & -0.488691 & 0.796647 \\ \mathrm{C} & 0.118935 & -1.748303 & -0.268741 \\ \mathrm{H} & 0.421046 & -2.158356 & -1.241765 \\ \mathrm{C} & -1.325374 & -1.976865 & -0.050384 \\ \mathrm{C} & -4.131674 & -2.210226 & 0.296859 \\ \mathrm{C} & -1.905206 & -2.082909 & 1.223724 \\ \mathrm{C} & -2.210447 & -2.016526 & -1.146091 \\ \mathrm{C} & -3.578292 & -2.130761 & -0.978411 \\ \mathrm{C} & -3.278719 & -2.190329 & 1.391017 \\ \mathrm{H} & -1.263827 & -2.076396 & 2.103283 \\ \mathrm{H} & -1.790697 & -1.946812 & -2.151172 \\ \mathrm{H} & -4.224832 & -2.165115 & -1.854762 \\ \mathrm{H} & -3.688314 & -2.269056 & 2.397544 \\ \mathrm{H} & -5.207265 & -2.302020 & 0.430993 \\ \mathrm{C} & 1.087795 & -2.214373 & 0.828833 \\ \mathrm{H} & 0.829564 & -1.760030 & 1.795783 \\ \mathrm{H} & -3.204248 & 2.349498 & -1.475780 \\ \mathrm{H} & -3.506292 & 2.112161 & 0.267238 \\ \mathrm{H} & 2.223269 & 3.483234 & 1.345980 \\ \mathrm{H} & 2.504560 & 3.233106 & -0.396691 \\ \mathrm{H} & 5.297428 & -2.063379 & -0.199427 \\ \mathrm{H} & 4.691948 & -1.473410 & -1.762297 \\ \mathrm{H} & 3.824898 & 0.535518 & -0.795332 \\ \mathrm{H} & 4.951877 & 0.200568 & 0.543462\end{array}$




\section{H $\quad 1.057820 \quad-3.308951 \quad 0.968299$}

TS IMeCu((CO) $)\left(\mathrm{CHPhCH}_{2} \mathrm{~B}(\mathrm{eg})\right)(\mathbf{4 a} \cdot \mathrm{TS})$ :

Total Energy (kcal/mol): -1692426.342

Enthalpy Correction (AU): 0.370995

Free Energy Correction (AU): 0.289363

Three lowest frequencies $\left(\mathrm{cm}^{-1}\right):-178.7,23.2,35.8$

$\begin{array}{cccc}\mathrm{Cu} & 0.635795 & 0.001028 & 0.248560 \\ \mathrm{C} & 1.345719 & 1.764979 & 0.055997 \\ \mathrm{~N} & 2.632035 & 2.178659 & 0.060825 \\ \mathrm{C} & 2.714904 & 3.540733 & -0.144999 \\ \mathrm{C} & 1.447122 & 3.985276 & -0.286333 \\ \mathrm{~N} & 0.623681 & 2.887304 & -0.156500 \\ \mathrm{H} & 3.659558 & 4.064562 & -0.162857 \\ \mathrm{H} & 1.058397 & 4.977863 & -0.461715 \\ \mathrm{C} & 3.769346 & 1.303106 & 0.259795 \\ \mathrm{H} & 3.406098 & 0.277615 & 0.361004 \\ \mathrm{C} & -0.825532 & 2.908555 & -0.297231 \\ \mathrm{H} & -1.205168 & 3.870759 & 0.054734 \\ \mathrm{C} & -0.679524 & -1.613800 & -0.015869 \\ \mathrm{C} & 0.701400 & -2.112472 & -0.261128 \\ \mathrm{C} & 3.386064 & -2.931649 & -0.600925 \\ \mathrm{C} & 1.380977 & -1.922013 & -1.481515 \\ \mathrm{C} & 1.422284 & -2.729901 & 0.786179 \\ \mathrm{C} & 2.734063 & -3.127823 & 0.614953 \\ \mathrm{C} & 2.700565 & -2.329394 & -1.643141 \\ \mathrm{H} & 0.853895 & -1.480057 & -2.324172 \\ \mathrm{H} & 0.925041 & -2.872611 & 1.742543 \\ \mathrm{H} & 3.257838 & -3.606569 & 1.440163 \\ \mathrm{H} & 3.188614 & -2.182864 & -2.605089 \\ \mathrm{H} & 4.415231 & -3.257753 & -0.732688 \\ \mathrm{C} & -1.516741 & -1.176222 & -1.208043 \\ \mathrm{~B} & -2.903547 & -0.589405 & -0.780892 \\ \mathrm{H} & -0.997882 & -0.419298 & -1.815942 \\ \mathrm{C} & -1.037279 & -0.451707 & 1.645522 \\ \mathrm{O} & -2.041533 & 0.175297 & 1.409440 \\ \mathrm{O} & -0.296854 & -0.774938 & 2.537739 \\ \mathrm{H} & -1.223659 & -2.340416 & 0.597228 \\ \mathrm{H} & 4.444939 & 1.357158 & -0.598566 \\ \mathrm{H} & 4.312560 & 1.581124 & 1.167344 \\ \mathrm{H} & -1.266117 & 2.105962 & 0.299798 \\ \mathrm{H} & -1.115809 & 2.761362 & -1.341221 \\ \mathrm{H} & -1.685114 & -2.036573 & -1.879662 \\ \mathrm{O} & -3.873184 & -1.337878 & -0.175256 \\ \mathrm{C} & -4.953582 & -0.475569 & 0.132791\end{array}$




$\begin{array}{lrrr}\mathrm{C} & -4.550140 & 0.897953 & -0.436664 \\ \mathrm{O} & -3.319519 & 0.678359 & -1.105363 \\ \mathrm{H} & -5.089813 & -0.445722 & 1.220017 \\ \mathrm{H} & -5.871356 & -0.871164 & -0.320388 \\ \mathrm{H} & -4.391589 & 1.636904 & 0.359693 \\ \mathrm{H} & -5.283490 & 1.302381 & -1.144755\end{array}$

GS IMeCu(CH(4-FPh) $\left.\mathrm{CH}_{2} \mathrm{~B}(\mathrm{eg})\right)(\mathbf{4 f} \cdot \mathrm{TS})$ :

Total Energy (kcal/mol): -1636389.71

Enthalpy Correction (AU): 0.348462

Free Energy Correction (AU): 0.270572

Three lowest frequencies $\left(\mathrm{cm}^{-1}\right): 23.4,26.5,39.5$

$\begin{array}{cccc}\mathrm{C} & -1.974180 & -2.038178 & -1.939260 \\ \mathrm{C} & -1.796604 & -1.853310 & -0.559588 \\ \mathrm{C} & -2.750965 & -2.458715 & 0.279600 \\ \mathrm{C} & -3.794570 & -3.220678 & -0.216293 \\ \mathrm{C} & -3.909855 & -3.393800 & -1.584115 \\ \mathrm{C} & -3.012794 & -2.804809 & -2.450403 \\ \mathrm{C} & -0.630197 & -1.150138 & 0.024573 \\ \mathrm{C} & 0.042668 & -0.063752 & -0.829463 \\ \mathrm{~B} & 1.316336 & 0.336902 & -0.042021 \\ \mathrm{O} & 2.560599 & -0.234479 & -0.250667 \\ \mathrm{C} & 3.375036 & 0.116241 & 0.855918 \\ \mathrm{C} & 2.656916 & 1.303364 & 1.497547 \\ \mathrm{O} & 1.328965 & 1.212300 & 1.011966 \\ \mathrm{~F} & -4.917704 & -4.140014 & -2.074212 \\ \mathrm{Cu} & 0.536472 & -2.717014 & 0.174502 \\ \mathrm{C} & 1.499013 & -4.368963 & -0.013142 \\ \mathrm{~N} & 0.958051 & -5.604488 & -0.125576 \\ \mathrm{C} & 1.934183 & -6.560679 & -0.322938 \\ \mathrm{C} & 3.115943 & -5.907944 & -0.336892 \\ \mathrm{~N} & 2.829317 & -4.570543 & -0.150816 \\ \mathrm{C} & -0.467279 & -5.876411 & -0.100097 \\ \mathrm{C} & 3.817390 & -3.509752 & -0.108470 \\ \mathrm{H} & 1.699345 & -7.608505 & -0.443348 \\ \mathrm{H} & 4.126201 & -6.268713 & -0.466852 \\ \mathrm{H} & -0.896552 & -0.742122 & 1.008790 \\ \mathrm{H} & -1.274695 & -1.579843 & -2.635459 \\ \mathrm{H} & -2.650495 & -2.326845 & 1.357545 \\ \mathrm{H} & -4.529276 & -3.677602 & 0.443239 \\ \mathrm{H} & -3.139171 & -2.943956 & -3.521879 \\ \mathrm{H} & 0.347588 & -0.467119 & -1.805400 \\ \mathrm{H} & 3.088289 & 2.265483 & 1.188959 \\ \mathrm{H} & 2.655013 & 1.264201 & 2.591675 \\ \mathrm{H} & 3.428470 & -0.742654 & 1.544011\end{array}$




$\begin{array}{cccc}\mathrm{H} & 4.389439 & 0.350781 & 0.515046 \\ \mathrm{H} & -0.633162 & 0.785962 & -1.027306 \\ \mathrm{H} & -0.785357 & -6.322097 & -1.046746 \\ \mathrm{H} & -0.711979 & -6.556190 & 0.721018 \\ \mathrm{H} & -1.003941 & -4.934110 & 0.040199 \\ \mathrm{H} & 4.554901 & -3.660610 & -0.901558 \\ \mathrm{H} & 3.315217 & -2.551141 & -0.269118 \\ \mathrm{H} & 4.329718 & -3.495703 & 0.858904\end{array}$

TS IMeCu$\left(\left(\mathrm{CO}_{2}\right)\left(\mathrm{CH}(4-\mathrm{FPh}) \mathrm{CH}_{2} \mathrm{~B}(\mathrm{eg})\right)(4 \mathrm{f} \cdot \mathrm{TS})\right.$ :

Total Energy (kcal/mol): -1754699.801

Enthalpy Correction (AU): 0.36386

Free Energy Correction (AU): 0.279165

Three lowest frequencies $\left(\mathrm{cm}^{-1}\right)$ : $-177.3356,17.13,27.06$

$\begin{array}{crrr}\text { C } & 4.166720 & -2.178985 & 3.035471 \\ \mathrm{C} & 4.187576 & -1.062804 & 2.227300 \\ \mathrm{C} & 3.059565 & -0.277260 & 2.052646 \\ \mathrm{C} & 1.888877 & -0.620724 & 2.700923 \\ \mathrm{C} & 1.814261 & -1.756255 & 3.538323 \\ \mathrm{C} & 2.986760 & -2.522142 & 3.68511 \\ \mathrm{Cu} & 0.682103 & -3.246299 & 2.390928 \\ \mathrm{O} & -1.080189 & -1.376153 & 2.104111 \\ \mathrm{C} & -1.170770 & -2.191506 & 2.986539 \\ \mathrm{O} & -1.961603 & -2.905950 & 3.554052 \\ \mathrm{C} & 0.510913 & -2.137185 & 4.157216 \\ \mathrm{C} & 0.510549 & -3.220364 & 5.225772 \\ \mathrm{~B} & -0.934373 & -3.576198 & 5.712797 \\ \mathrm{O} & -1.472839 & -4.835595 & 5.620246 \\ \mathrm{C} & -2.827887 & -4.740740 & 6.027377 \\ \mathrm{C} & -2.975955 & -3.325384 & 6.617512 \\ \mathrm{O} & -1.724400 & -2.698642 & 6.399344 \\ \mathrm{C} & 0.705203 & -4.768973 & 1.238024 \\ \mathrm{~N} & 1.477924 & -5.022896 & 0.159167 \\ \mathrm{C} & 1.188963 & -6.261638 & -0.375807 \\ \mathrm{C} & 0.214407 & -6.794131 & 0.393361 \\ \mathrm{~N} & -0.071468 & -5.866464 & 1.372305 \\ \mathrm{C} & 2.471668 & -4.107913 & -0.365316 \\ \mathrm{C} & -1.028123 & -6.061211 & 2.452619 \\ \mathrm{H} & 1.693137 & -6.642803 & -1.251943 \\ \mathrm{H} & -0.301447 & -7.741257 & 0.330700 \\ \mathrm{H} & 3.455903 & -4.584271 & -0.381721 \\ \mathrm{H} & -1.867339 & -6.657026 & 2.085638 \\ \mathrm{H} & 2.983428 & -3.387193 & 4.343877 \\ \mathrm{H} & 0.993254 & -0.021876 & 2.557108 \\ \mathrm{H} & 3.115818 & 0.600034 & 1.413045\end{array}$




$\begin{array}{lccc}\mathrm{H} & 5.074154 & -2.763840 & 3.163788 \\ \mathrm{~F} & 5.322842 & -0.725392 & 1.599703 \\ \mathrm{H} & 0.988208 & -4.146194 & 4.869615 \\ \mathrm{H} & 0.010881 & -1.234315 & 4.524538 \\ \mathrm{H} & 2.205133 & -3.790611 & -1.377282 \\ \mathrm{H} & 2.512437 & -3.230477 & 0.284494 \\ \mathrm{H} & -1.397476 & -5.091943 & 2.797812 \\ \mathrm{H} & -0.558857 & -6.572603 & 3.297650 \\ \mathrm{H} & 1.107491 & -2.887667 & 6.093264 \\ \mathrm{H} & -3.758985 & -2.748705 & 6.112045 \\ \mathrm{H} & -3.191983 & -3.333675 & 7.693316 \\ \mathrm{H} & -3.470572 & -4.884034 & 5.148881 \\ \mathrm{H} & -3.047714 & -5.534146 & 6.751757\end{array}$

GS IMeCu(CH(4-CO $\left.\left.{ }_{2} \mathrm{HPh}\right) \mathrm{CH}_{2} \mathrm{~B}(\mathrm{eg})\right)(4 \mathrm{~h})$ :

Total Energy (kcal/mol): -1692432.329

Enthalpy Correction (AU): 0.374466

Free Energy Correction (AU): 0.292675

Three lowest frequencies $\left(\mathrm{cm}^{-1}\right): 23.2,29.5,40.3$

$\begin{array}{crrr}\mathrm{N} & 2.751345 & -4.564443 & -0.173579 \\ \mathrm{C} & 1.423257 & -4.343279 & -0.046945 \\ \mathrm{~N} & 0.862668 & -5.567953 & -0.175747 \\ \mathrm{C} & 1.824977 & -6.537222 & -0.374267 \\ \mathrm{C} & 3.017586 & -5.904295 & -0.370170 \\ \mathrm{Cu} & 0.491588 & -2.676462 & 0.148237 \\ \mathrm{C} & -0.636826 & -1.067363 & 0.027733 \\ \mathrm{C} & 0.061398 & 0.000926 & -0.822536 \\ \mathrm{~B} & 1.342031 & 0.377886 & -0.032679 \\ \mathrm{O} & 1.369294 & 1.260329 & 1.013729 \\ \mathrm{C} & 2.696227 & 1.319906 & 1.509242 \\ \mathrm{C} & 3.389480 & 0.111929 & 0.878414 \\ \mathrm{O} & 2.569536 & -0.230054 & -0.227800 \\ \mathrm{C} & -0.567469 & -5.819002 & -0.176065 \\ \mathrm{C} & 3.757561 & -3.522137 & -0.105692 \\ \mathrm{C} & -1.764343 & -1.807802 & -0.537648 \\ \mathrm{C} & -1.947430 & -2.007857 & -1.922660 \\ \mathrm{C} & -2.948560 & -2.822741 & -2.406220 \\ \mathrm{C} & -3.834271 & -3.471580 & -1.543004 \\ \mathrm{C} & -3.696380 & -3.254899 & -0.165498 \\ \mathrm{C} & -2.693332 & -2.447717 & 0.318230 \\ \mathrm{C} & -4.869502 & -4.329147 & -2.115121 \\ \mathrm{H} & 1.573442 & -7.579572 & -0.507434 \\ \mathrm{H} & 4.023141 & -6.280631 & -0.491798 \\ \mathrm{H} & -0.876866 & -0.687412 & 1.028840 \\ \mathrm{H} & -1.278398 & -1.516610 & -2.626138\end{array}$




$\begin{array}{cccc}\mathrm{H} & -2.590924 & -2.294993 & 1.393317 \\ \mathrm{H} & -4.395150 & -3.729083 & 0.519672 \\ \mathrm{H} & -3.071306 & -2.974132 & -3.476929 \\ \mathrm{H} & 0.356003 & -0.407491 & -1.799023 \\ \mathrm{H} & 3.153140 & 2.269563 & 1.199774 \\ \mathrm{H} & 2.684355 & 1.285948 & 2.603329 \\ \mathrm{H} & 3.423699 & -0.743450 & 1.571766 \\ \mathrm{H} & 4.408940 & 0.322093 & 0.537220 \\ \mathrm{H} & -0.595705 & 0.864852 & -1.017581 \\ \mathrm{H} & -0.896975 & -6.155307 & -1.163170 \\ \mathrm{H} & -0.817225 & -6.579025 & 0.569370 \\ \mathrm{H} & -1.091768 & -4.891178 & 0.067225 \\ \mathrm{H} & 4.503908 & -3.678795 & -0.889181 \\ \mathrm{H} & 3.275772 & -2.552833 & -0.264185 \\ \mathrm{H} & 4.255316 & -3.527291 & 0.869322 \\ \mathrm{O} & -5.667601 & -4.895062 & -1.177822 \\ \mathrm{O} & -5.038260 & -4.551855 & -3.289885 \\ \mathrm{H} & -6.309849 & -5.424873 & -1.669634\end{array}$

TS IMeCu$\left(\left(\mathrm{CO}_{2}\right)\left(\mathrm{CH}\left(4-\mathrm{CO}_{2} \mathrm{HPh}\right) \mathrm{CH}_{2} \mathrm{~B}(\mathrm{eg})\right)(4 \mathrm{~h} \cdot \mathrm{TS})\right.$ :

Total Energy (kcal/mol): -1810740.347

Enthalpy Correction (AU): 0.38947

Free Energy Correction (AU): 0.301553

Three lowest frequencies $\left(\mathrm{cm}^{-1}\right)$ : -194.6, 24.8, 32.1

$\begin{array}{cccc}\mathrm{C} & -1.625744 & 3.085672 & 2.498955 \\ \mathrm{Cu} & -1.764809 & 2.392974 & 4.638803 \\ \mathrm{C} & -3.219512 & 1.959031 & 3.097153 \\ \mathrm{C} & -3.867785 & 2.346396 & 4.363475 \\ \mathrm{C} & -4.289905 & 3.684418 & 4.571251 \\ \mathrm{H} & -4.226276 & 4.382215 & 3.740534 \\ \mathrm{C} & -4.730938 & 4.113765 & 5.802842 \\ \mathrm{H} & -5.036832 & 5.147598 & 5.938553 \\ \mathrm{C} & -4.773825 & 3.236106 & 6.894152 \\ \mathrm{C} & -5.157758 & 3.661705 & 8.246408 \\ \mathrm{O} & -5.075198 & 2.982413 & 9.239987 \\ \mathrm{O} & -5.610395 & 4.930208 & 8.290770 \\ \mathrm{H} & -5.826000 & 5.110004 & 9.216603 \\ \mathrm{H} & -4.464214 & 1.225486 & 7.548736 \\ \mathrm{C} & -4.404091 & 1.908528 & 6.704149 \\ \mathrm{C} & -3.967300 & 1.463851 & 5.468555 \\ \mathrm{H} & -3.699668 & 2.464195 & 2.251629 \\ \mathrm{H} & -3.714779 & 0.414360 & 5.339297 \\ \mathrm{C} & -2.970290 & 0.490202 & 2.808199 \\ \mathrm{H} & -2.420324 & -0.000085 & 3.625551 \\ \mathrm{H} & -3.933046 & -0.045069 & 2.732960\end{array}$




$\begin{array}{cccc}\mathrm{O} & -2.634376 & 0.649943 & 0.256801 \\ \mathrm{~B} & -2.169691 & 0.260004 & 1.482622 \\ \mathrm{O} & -1.020368 & -0.486244 & 1.415943 \\ \mathrm{C} & -1.596634 & 0.410720 & -0.678087 \\ \mathrm{H} & -2.014091 & -0.054669 & -1.578070 \\ \mathrm{H} & -1.146090 & 1.370947 & -0.958464 \\ \mathrm{H} & -0.605851 & -1.528407 & -0.310477 \\ \mathrm{C} & -0.597538 & -0.495224 & 0.061369 \\ \mathrm{H} & 0.429616 & -0.116932 & -0.000196 \\ \mathrm{H} & 0.834384 & -0.317720 & 4.101981 \\ \mathrm{C} & 1.085860 & 0.746524 & 4.080255 \\ \mathrm{H} & 0.452096 & 1.238435 & 3.337845 \\ \mathrm{H} & 2.133093 & 0.867061 & 3.792065 \\ \mathrm{C} & 1.726258 & 1.223657 & 6.461154 \\ \mathrm{O} & -0.953151 & 2.368799 & 1.800331 \\ \mathrm{H} & 1.482112 & 2.028026 & 8.512656 \\ \mathrm{C} & 1.149745 & 1.871956 & 7.496670 \\ \mathrm{H} & -1.716978 & 3.603904 & 7.164885 \\ \mathrm{C} & -1.011737 & 3.102451 & 7.831721 \\ \mathrm{H} & -1.570877 & 2.422560 & 8.482173 \\ \mathrm{H} & -0.501307 & 3.852441 & 8.441155 \\ \mathrm{C} & -0.227784 & 2.058050 & 5.727449 \\ \mathrm{O} & -1.782840 & 4.229709 & 2.836562 \\ \mathrm{H} & 2.665892 & 0.695589 & 6.388121 \\ \mathrm{~N} & 0.870533 & 1.350036 & 5.386853 \\ \mathrm{~N} & -0.045704 & 2.376722 & 7.028145\end{array}$

GS IMeCu(CH(4-CF3 Ph) $\left.\mathrm{CH}_{2} \mathrm{~B}(\mathrm{eg})\right)(4 \mathrm{i})$ :

Total Energy (kcal/mol): -1785609.373

Enthalpy Correction (AU): 0.365184

Free Energy Correction (AU): 0.283324

Three lowest frequencies $\left(\mathrm{cm}^{-1}\right): 23.1,39.1,47.5$
$\begin{array}{llll}\mathrm{N} & 2.041650 & 2.896513 & 0.196967\end{array}$
$\begin{array}{llll}\mathrm{C} & 1.031318 & 2.061427 & -0.136593\end{array}$
$\begin{array}{llll}\mathrm{N} & -0.059004 & 2.860085 & -0.206848\end{array}$
$\begin{array}{llll}\text { C } & 0.267367 & 4.171237 & 0.073871\end{array}$
C $\quad 1.594008 \quad 4.195663 \quad 0.324987$
$\begin{array}{llll}\mathrm{Cu} & 1.070858 & 0.153418 & -0.351337\end{array}$
$\begin{array}{llll}\text { C } & 0.766381 & -1.796119 & -0.300982\end{array}$
$\begin{array}{llll}\text { C } & 1.555403 & -2.429540 & 0.848791\end{array}$
B $\quad 3.047131 \quad-2.259249 \quad 0.456250$
O $\quad 3.708660 \quad-3.095664 \quad-0.402560$
C $\quad 5.033056-2.615650 \quad-0.557841$
$\begin{array}{llll}\text { C } & 5.001245 & -1.208235 & 0.042898\end{array}$
$\begin{array}{llll}\text { O } & 3.827585 & -1.185714 & 0.839659\end{array}$ 


$\begin{array}{rrrr}\text { C } & -1.413205 & 2.389005 & -0.445987 \\ \text { C } & 3.414042 & 2.468792 & 0.386654 \\ \text { C } & -0.674274 & -1.584772 & -0.155115 \\ \text { C } & -1.322028 & -1.451075 & 1.089815 \\ \text { C } & -2.635697 & -1.028813 & 1.181254 \\ \text { C } & -3.377788 & -0.759950 & 0.036612 \\ \text { C } & -2.786631 & -0.966382 & -1.212077 \\ \text { C } & -1.477543 & -1.379787 & -1.302116 \\ \text { C } & -4.717922 & -0.135674 & 0.125766 \\ \text { H } & -0.471666 & 4.959459 & 0.076853 \\ \text { H } & 2.254586 & 5.010997 & 0.582557 \\ \text { H } & 1.004097 & -2.267353 & -1.262634 \\ \text { H } & -0.768084 & -1.650842 & 2.004527 \\ \text { H } & -1.020987 & -1.517428 & -2.282632 \\ \text { H } & -3.365258 & -0.794592 & -2.117851 \\ \text { H } & -3.095179 & -0.903899 & 2.159832 \\ \text { H } & 1.371798 & -1.894368 & 1.791072 \\ \text { H } & 5.722154 & -3.281744 & -0.021364 \\ \text { H } & 5.306883 & -2.623378 & -1.617888 \\ \text { H } & 4.917272 & -0.435779 & -0.737392 \\ \text { H } & 5.876100 & -0.979807 & 0.661152 \\ \text { H } & 1.273570 & -3.483360 & 1.013493 \\ \text { H } & -1.996752 & 2.400403 & 0.478673 \\ \text { H } & -1.905643 & 3.021743 & -1.189085 \\ \text { H } & -1.378599 & 1.361671 & -0.818132 \\ \text { H } & 3.846574 & 2.991579 & 1.243789 \\ \text { H } & 3.423287 & 1.393428 & 0.585252 \\ \text { H } & 4.014592 & 2.680186 & -0.503653 \\ \text { F } & -5.337487 & -0.389901 & 1.283116 \\ \text { F } & -4.642693 & 1.215929 & 0.032002 \\ \text { F } & -5.538203 & -0.520679 & -0.859538\end{array}$

TS IMeCu$\left(\left(\mathrm{CO}_{2}\right)\left(\mathrm{CH}\left(4-\mathrm{CF}_{3} \mathrm{Ph}\right) \mathrm{CH}_{2} \mathrm{~B}(\mathrm{eg})\right)(4 \mathrm{i} \cdot \mathrm{TS})\right.$ :

Total Energy (kcal/mol): -1903917.535

Enthalpy Correction (AU): 0.380095

Free Energy Correction (AU): 0.289848

Three lowest frequencies $\left(\mathrm{cm}^{-1}\right):-190.9,20.1,25.7$
$\begin{array}{llll}\text { C } & 2.663060 & -1.251470 & -1.295628\end{array}$
$\begin{array}{llll}\text { C } & 1.283832 & -1.216596 & -1.171048\end{array}$
$\begin{array}{llll}\mathrm{Cu} & 0.236935 & 0.485188 & 0.529482\end{array}$
$\begin{array}{llll}\text { C } & 0.617647 & 2.351710 & 0.378885\end{array}$
$\begin{array}{llll}\mathrm{N} & 1.822797 & 2.957925 & 0.305774\end{array}$
$\begin{array}{llll}\text { C } & 1.681198 & 4.327010 & 0.213413\end{array}$
$\begin{array}{llll}\text { C } & 0.353911 & 4.578709 & 0.233556\end{array}$ 


$\begin{array}{rrrr}\mathrm{N} & -0.280863 & 3.358449 & 0.329260 \\ \mathrm{H} & 2.530638 & 4.990230 & 0.139160 \\ \mathrm{H} & -0.192706 & 5.509516 & 0.192291 \\ \mathrm{C} & -1.720975 & 3.174688 & 0.443487 \\ \mathrm{H} & -2.224730 & 4.011352 & -0.045846 \\ \mathrm{H} & -2.018565 & 3.128722 & 1.494414 \\ \mathrm{H} & -2.024710 & 2.242223 & -0.039198 \\ \mathrm{H} & 3.478512 & 2.203450 & -0.754838 \\ \mathrm{H} & 2.938960 & 1.232504 & 0.630619 \\ \mathrm{C} & 3.089543 & 2.251203 & 0.266513 \\ \mathrm{H} & 3.817967 & 2.752839 & 0.908223 \\ \mathrm{~F} & 5.376229 & -1.932773 & -1.539626 \\ \mathrm{C} & 4.937285 & -1.537728 & -0.340144 \\ \mathrm{~F} & 5.574225 & -2.262442 & 0.580501 \\ \mathrm{~F} & 5.363176 & -0.264326 & -0.188626 \\ \mathrm{C} & 3.456291 & -1.627283 & -0.220547 \\ \mathrm{C} & 2.852394 & -1.996657 & 0.980272 \\ \mathrm{H} & 3.467408 & -2.307626 & 1.820821 \\ \mathrm{H} & 1.017113 & -2.244668 & 2.054670 \\ \mathrm{C} & 1.478669 & -1.973558 & 1.109386 \\ \mathrm{H} & -1.199260 & -2.202757 & 0.868199 \\ \mathrm{C} & -0.809391 & -1.376942 & 0.261915 \\ \mathrm{C} & -1.697702 & -1.108981 & -0.941140 \\ \mathrm{H} & -1.297767 & -0.294119 & -1.562596 \\ \mathrm{H} & -1.725823 & -2.000426 & -1.590857 \\ \mathrm{O} & -4.052276 & -1.595653 & 0.007797 \\ \mathrm{~B} & -3.162439 & -0.719994 & -0.544904 \\ \mathrm{O} & -3.722255 & 0.491423 & -0.873101 \\ \mathrm{H} & -5.439397 & -0.901410 & 1.357093 \\ \mathrm{C} & -4.987611 & 0.548122 & -0.235933 \\ \mathrm{H} & -4.934744 & 1.272339 & 0.587942 \\ \mathrm{H} & -5.742827 & 0.890925 & -0.952971 \\ \mathrm{H} & -6.082800 & -1.372328 & -0.232908 \\ \mathrm{H} & 0.682472 & -0.942692 & -2.033776 \\ \mathrm{H} & 3.126616 & -0.988133 & -2.244199 \\ \mathrm{C} & -1.374759 & -0.298747 & 1.872087 \\ \mathrm{O} & -2.482346 & 0.115397 & 1.637852 \\ \mathrm{O} & -0.570518 & -0.426228 & 2.762335 \\ \mathrm{C} & 0.645318 & -1.558606 & 0.043242 \\ \mathrm{C} & -5.245540 & -0.881043 & 0.278617\end{array}$


$\underline{\text { XYZ files for Calculated Structures in Chapter } 3}$

GS IMeCu(PhCHCH $2 B(e g))(4 a)$ :

Total Energy (kcal/mol): -1574116.235

Enthalpy Correction (AU): 0.355158

Free Energy Correction (AU): 0.277553

Three lowest frequencies $\left(\mathrm{cm}^{-1}\right): 17.5,20.3,39.0$

$\begin{array}{lrrr}\mathrm{H} & 0.17306 & 5.20222 & 0.57782 \\ \mathrm{C} & -0.29080 & 4.26268 & 0.31398 \\ \mathrm{H} & -2.46447 & 4.56652 & 0.00846 \\ \mathrm{H} & -3.32367 & 2.26580 & -1.39388 \\ \mathrm{~N} & -1.60549 & 2.60033 & -0.23601 \\ \mathrm{C} & -1.57496 & 3.95360 & 0.03324 \\ \mathrm{C} & -2.81232 & 1.84581 & -0.52315 \\ \mathrm{H} & -2.54224 & 0.80656 & -0.72996 \\ \mathrm{H} & -3.48649 & 1.86318 & 0.33792 \\ \mathrm{C} & -0.37221 & 2.05296 & -0.13125 \\ \mathrm{~N} & 0.42736 & 3.08787 & 0.21374 \\ \mathrm{H} & 2.14356 & 3.56918 & 1.30425 \\ \mathrm{C} & 1.85437 & 2.96420 & 0.44067 \\ \mathrm{H} & 2.08984 & 1.91584 & 0.64588 \\ \mathrm{H} & 2.41767 & 3.29888 & -0.43633 \\ \mathrm{Cu} & 0.05308 & 0.19030 & -0.32005 \\ \mathrm{C} & 0.16921 & -1.76588 & -0.24089 \\ \mathrm{H} & 0.48355 & -2.19591 & -1.20113 \\ \mathrm{C} & 1.13655 & -2.19028 & 0.87453 \\ \mathrm{H} & 1.13267 & -3.28194 & 1.03562 \\ \mathrm{H} & 0.86271 & -1.72112 & 1.82987 \\ \mathrm{C} & -2.14062 & -2.08580 & -1.14227 \\ \mathrm{H} & -4.14093 & -2.26605 & -1.88243 \\ \mathrm{C} & -1.88008 & -2.04735 & 1.23340 \\ \mathrm{C} & -3.51137 & -2.19240 & -0.99624 \\ \mathrm{C} & -3.25677 & -2.14829 & 1.37855 \\ \mathrm{C} & -4.08944 & -2.21552 & 0.27037 \\ \mathrm{H} & -3.68470 & -2.18334 & 2.37990 \\ \mathrm{H} & -5.16727 & -2.30229 & 0.38836 \\ \mathrm{~B} & 2.51425 & -1.64247 & 0.42258 \\ \mathrm{O} & 3.00625 & -0.39853 & 0.78076 \\ \mathrm{O} & 3.33824 & -2.27777 & -0.46969 \\ \mathrm{H} & 5.33921 & -1.91175 & -0.15705 \\ \mathrm{C} & 4.47987 & -1.46517 & -0.67616 \\ \mathrm{H} & 4.71260 & -1.41779 & -1.74512 \\ \mathrm{H} & 4.89925 & 0.37277 & 0.47236 \\ \mathrm{H} & 3.74366 & 0.58566 & -0.86842 \\ \mathrm{C} & 4.08987 & -0.10955 & -0.08685\end{array}$




$\begin{array}{llll}\mathrm{H} & -1.25599 & -1.99946 & 2.12434 \\ \mathrm{C} & -1.27611 & -1.99580 & -0.03344 \\ \mathrm{H} & -1.70270 & -2.05960 & -2.14148\end{array}$

TS IMeCu$\left(\mathrm{PhCHCH}_{2} \mathrm{~B}(\mathrm{eg})\right)+\mathrm{PMe}_{3}\left(4 \mathrm{a} \cdot \mathrm{PMe}_{3}{ }^{\mathrm{TS}}\right)$ :

Total Energy (kcal/mol): -2969.53388689

Enthalpy Correction (AU): 0.475796

Free Energy Correction (AU): 0.383594

Three lowest frequencies $\left(\mathrm{cm}^{-1}\right)$ : -18.9, 24.7, 29.8

$\begin{array}{lccc}\mathrm{C} & 4.62297 & -0.95461 & -0.88707 \\ \mathrm{C} & 5.10248 & -0.40301 & 0.29260 \\ \mathrm{C} & 4.24553 & -0.32487 & 1.38702 \\ \mathrm{C} & 2.94179 & -0.77521 & 1.29221 \\ \mathrm{C} & 2.42823 & -1.32441 & 0.10089 \\ \mathrm{C} & 3.31595 & -1.41138 & -0.98217 \\ \mathrm{Cu} & 0.30580 & 0.08910 & -0.40969 \\ \mathrm{C} & 1.00065 & -1.69709 & 0.02298 \\ \mathrm{C} & 0.56860 & -2.73109 & -1.02529 \\ \mathrm{~B} & -0.98091 & -2.71441 & -0.96728 \\ \mathrm{O} & -1.79015 & -2.06375 & -1.87873 \\ \mathrm{C} & -3.13916 & -2.21165 & -1.47134 \\ \mathrm{C} & -3.06888 & -2.89364 & -0.09685 \\ \mathrm{O} & -1.71231 & -3.26595 & 0.05774 \\ \mathrm{C} & -0.14183 & 1.86942 & -0.98377 \\ \mathrm{~N} & 0.45019 & 2.99821 & -0.53078 \\ \mathrm{C} & -0.15918 & 4.12400 & -1.04516 \\ \mathrm{C} & -1.15235 & 3.69081 & -1.85182 \\ \mathrm{~N} & -1.12204 & 2.30999 & -1.80477 \\ \mathrm{C} & 1.55737 & 2.98400 & 0.40992 \\ \mathrm{C} & -2.02515 & 1.44162 & -2.53270 \\ \mathrm{H} & 0.17309 & 5.12314 & -0.80281 \\ \mathrm{H} & -1.86183 & 4.23229 & -2.46080 \\ \mathrm{H} & 2.29285 & 2.23587 & 0.10137 \\ \mathrm{H} & -1.71308 & 0.40357 & -2.38433 \\ \mathrm{H} & 0.65329 & -2.00813 & 1.01750 \\ \mathrm{H} & 2.97078 & -1.83970 & -1.92185 \\ \mathrm{H} & 2.27549 & -0.69873 & 2.15420 \\ \mathrm{H} & 4.60407 & 0.08783 & 2.32959 \\ \mathrm{H} & 5.28065 & -1.03853 & -1.75155 \\ \mathrm{H} & 6.12948 & -0.05181 & 0.36489 \\ \mathrm{H} & 0.88724 & -2.42914 & -2.03223 \\ \mathrm{H} & 1.20075 & 2.72581 & 1.41196 \\ \mathrm{H} & 2.02919 & 3.96902 & 0.42647 \\ \mathrm{H} & -1.99364 & 1.67382 & -3.60116\end{array}$




$\begin{array}{lrrr}\mathrm{H} & -3.05128 & 1.56666 & -2.16996 \\ \mathrm{H} & -3.70491 & -3.78308 & -0.02730 \\ \mathrm{H} & -3.34852 & -2.21254 & 0.72026 \\ \mathrm{H} & -3.61969 & -1.22434 & -1.42667 \\ \mathrm{H} & -3.67675 & -2.81347 & -2.21528 \\ \mathrm{H} & 1.00364 & -3.72813 & -0.83402 \\ \mathrm{P} & -1.21386 & 0.64983 & 2.28828 \\ \mathrm{C} & -1.43729 & -1.08301 & 2.88687 \\ \mathrm{C} & -1.96251 & 1.53143 & 3.74038 \\ \mathrm{C} & -2.68056 & 0.73908 & 1.15913 \\ \mathrm{H} & -2.07743 & 2.59760 & 3.51774 \\ \mathrm{H} & -2.94560 & 1.12534 & 4.01242 \\ \mathrm{H} & -1.30218 & 1.44518 & 4.60950 \\ \mathrm{H} & -2.43932 & -1.23983 & 3.30849 \\ \mathrm{H} & -1.28247 & -1.79349 & 2.06768 \\ \mathrm{H} & -0.69695 & -1.31009 & 3.66135 \\ \mathrm{H} & -3.60306 & 0.39842 & 1.64870 \\ \mathrm{H} & -2.82559 & 1.76979 & 0.81363 \\ \mathrm{H} & -2.49115 & 0.11527 & 0.27692\end{array}$

GS IMeCu(PhCHCH2B(eg))-PMe3 (4a·PMe3):

Total Energy (kcal/mol): -1863413.207

Enthalpy Correction (AU): 0.476428

Free Energy Correction (AU): 0.383159

Three lowest frequencies $\left(\mathrm{cm}^{-1}\right): 21.4,28.4,37.1$

$\begin{array}{lccc}\mathrm{Cu} & 0.04410 & -0.02683 & 0.50597 \\ \mathrm{P} & -1.20588 & -1.20459 & 2.01997 \\ \mathrm{C} & 1.39583 & -1.37782 & -1.30339 \\ \mathrm{C} & -0.03280 & -1.06491 & -1.27119 \\ \mathrm{C} & 2.33018 & -0.67763 & -2.09376 \\ \mathrm{H} & 1.97939 & 0.10052 & -2.76896 \\ \mathrm{C} & 4.18373 & -1.95506 & -1.20949 \\ \mathrm{C} & 3.68578 & -0.96324 & -2.04590 \\ \mathrm{C} & 3.28118 & -2.67289 & -0.42902 \\ \mathrm{H} & 1.23729 & -2.98180 & 0.13086 \\ \mathrm{C} & 1.92775 & -2.39337 & -0.47614 \\ \mathrm{H} & 3.63980 & -3.47268 & 0.21847 \\ \mathrm{~N} & 2.33714 & 1.89399 & 0.83391 \\ \mathrm{C} & 2.63819 & 3.24241 & 0.79310 \\ \mathrm{H} & 3.65060 & 3.60929 & 0.88204 \\ \mathrm{C} & 1.46887 & 3.89341 & 0.62447 \\ \mathrm{H} & 1.24789 & 4.94765 & 0.53899 \\ \mathrm{~N} & 0.48636 & 2.92400 & 0.56236 \\ \mathrm{C} & 1.00685 & 1.67753 & 0.69174\end{array}$




$\begin{array}{lrrr}\mathrm{H} & -4.51646 & 2.00265 & -1.94551 \\ \mathrm{H} & -3.91120 & 1.46977 & -0.36068 \\ \mathrm{H} & -4.91554 & -0.25725 & -2.65729 \\ \mathrm{H} & -4.84269 & -0.66289 & -0.92936 \\ \mathrm{C} & -4.29789 & -0.18473 & -1.75220 \\ \mathrm{O} & -3.07221 & -0.86136 & -1.97190 \\ \mathrm{~B} & -2.07786 & 0.07908 & -2.11962 \\ \mathrm{O} & -2.55599 & 1.35646 & -1.90376 \\ \mathrm{H} & -0.06239 & 0.72086 & -2.51138 \\ \mathrm{H} & -0.46973 & -0.74718 & -3.40416 \\ \mathrm{C} & -0.59356 & -0.23972 & -2.42717 \\ \mathrm{H} & 4.36845 & -0.40403 & -2.68610 \\ \mathrm{C} & -3.89140 & 1.25773 & -1.44150 \\ \mathrm{C} & 3.32347 & 0.84506 & 0.99282 \\ \mathrm{H} & 3.95524 & 0.76271 & 0.10372 \\ \mathrm{H} & 2.80470 & -0.10790 & 1.12022 \\ \mathrm{H} & 3.94412 & 1.04329 & 1.87241 \\ \mathrm{C} & -0.93166 & 3.16933 & 0.39856 \\ \mathrm{H} & -1.31560 & 2.62047 & -0.46707 \\ \mathrm{H} & -1.09830 & 4.23881 & 0.24843 \\ \mathrm{H} & -1.47607 & 2.84900 & 1.29441 \\ \mathrm{H} & -0.62520 & -1.98019 & -1.12729 \\ \mathrm{C} & -0.97095 & -3.02674 & 2.03151 \\ \mathrm{C} & -1.45650 & -0.89479 & 3.82039 \\ \mathrm{C} & -2.94222 & -1.11394 & 1.42351 \\ \mathrm{H} & 5.24743 & -2.18078 & -1.18195 \\ \mathrm{H} & -1.76150 & -3.52785 & 2.60372 \\ \mathrm{H} & -0.98848 & -3.40230 & 1.00359 \\ \mathrm{H} & -0.00133 & -3.28295 & 2.46962 \\ \mathrm{H} & -2.22292 & -1.55353 & 4.24883 \\ \mathrm{H} & -0.51751 & -1.05058 & 4.36040 \\ \mathrm{H} & -1.75946 & 0.14571 & 3.97587 \\ \mathrm{H} & -3.61610 & -1.73499 & 2.02712 \\ \mathrm{H} & -3.29240 & -0.07537 & 1.45962 \\ \mathrm{H} & -2.97147 & -1.44761 & 0.38043\end{array}$

\section{TS IMeCu(PhCHCH $2 B(e g))-P_{2 M e}+\mathrm{CO}_{2}\left(\mathrm{TS} \cdot \mathrm{PMe}^{\mathrm{SE} 2}\right)$ :}

Total Energy (kcal/mol): - 1981723.055

Enthalpy Correction (AU): 0.492295

Free Energy Correction (AU): 0.390243

Three lowest frequencies $\left(\mathrm{cm}^{-1}\right)$ : -422.1, 8.1, 20.5

$\begin{array}{llll}\mathrm{C} & 1.23743 & 1.78698 & 0.77854 \\ \mathrm{~N} & 2.52925 & 2.12557 & 0.56783 \\ \mathrm{C} & 2.66021 & 3.47472 & 0.30604\end{array}$




\begin{tabular}{|c|c|c|c|}
\hline $\mathrm{C}$ & 1.41957 & 4.00101 & 0.35875 \\
\hline $\mathrm{N}$ & 0.56399 & 2.95723 & 0.65406 \\
\hline $\mathrm{C}$ & 3.64118 & 1.19620 & 0.60555 \\
\hline $\mathrm{C}$ & -0.87187 & 3.09948 & 0.77420 \\
\hline $\mathrm{Cu}$ & 0.46044 & -0.00296 & 0.96180 \\
\hline $\mathrm{C}$ & -0.27296 & -0.66107 & -1.17958 \\
\hline $\mathrm{C}$ & -0.84636 & 0.55432 & -1.84842 \\
\hline B & -2.29219 & 0.88610 & -1.40278 \\
\hline $\mathrm{O}$ & -2.91360 & 2.08962 & -1.64858 \\
\hline $\mathrm{C}$ & -4.15794 & 2.09246 & -0.96920 \\
\hline $\mathrm{C}$ & -4.37105 & 0.63701 & -0.54224 \\
\hline $\mathrm{O}$ & -3.09173 & 0.03860 & -0.67390 \\
\hline$P$ & -0.58018 & -1.43433 & 2.37749 \\
\hline $\mathrm{C}$ & -2.37372 & -1.05269 & 2.40227 \\
\hline $\mathrm{C}$ & -0.61293 & -3.21868 & 1.97333 \\
\hline $\mathrm{C}$ & -0.17845 & -1.45817 & 4.16668 \\
\hline $\mathrm{C}$ & 1.13533 & -0.96059 & -1.28585 \\
\hline $\mathrm{C}$ & 1.97231 & -0.25458 & -2.18527 \\
\hline $\mathrm{C}$ & 3.30825 & -0.57494 & -2.33751 \\
\hline $\mathrm{C}$ & 3.89870 & -1.59121 & -1.59075 \\
\hline $\mathrm{C}$ & 3.10124 & -2.30063 & -0.70133 \\
\hline $\mathrm{C}$ & 1.75623 & -2.00184 & -0.54904 \\
\hline $\mathrm{C}$ & -1.09825 & -2.31721 & -2.23730 \\
\hline $\mathrm{O}$ & -1.04100 & -3.22399 & -1.46953 \\
\hline $\mathrm{O}$ & -1.40067 & -1.87590 & -3.29323 \\
\hline $\mathrm{H}$ & 1.54370 & 0.53498 & -2.79855 \\
\hline $\mathrm{H}$ & 1.14001 & -2.63677 & 0.08191 \\
\hline $\mathrm{H}$ & 3.52715 & -3.12374 & -0.12855 \\
\hline $\mathrm{H}$ & 3.61919 & 3.93086 & 0.10690 \\
\hline $\mathrm{H}$ & 1.06647 & 5.01148 & 0.21168 \\
\hline $\mathrm{H}$ & -4.94314 & 2.46732 & -1.63363 \\
\hline $\mathrm{H}$ & -4.09115 & 2.77200 & -0.10568 \\
\hline $\mathrm{H}$ & -5.08033 & 0.10964 & -1.19241 \\
\hline $\mathrm{H}$ & -4.71733 & 0.53672 & 0.49343 \\
\hline $\mathrm{H}$ & -0.22324 & 1.46091 & -1.73463 \\
\hline $\mathrm{H}$ & -0.88544 & 0.38382 & -2.94155 \\
\hline $\mathrm{H}$ & 3.90506 & -0.02163 & -3.06285 \\
\hline $\mathrm{H}$ & 4.12951 & 1.14465 & -0.37060 \\
\hline $\mathrm{H}$ & 3.25826 & 0.20047 & 0.83985 \\
\hline $\mathrm{H}$ & 4.36194 & 1.50236 & 1.37011 \\
\hline $\mathrm{H}$ & -1.33106 & 3.30366 & -0.19855 \\
\hline $\mathrm{H}$ & -1.11227 & 3.90648 & 1.47304 \\
\hline $\mathrm{H}$ & -1.27907 & 2.16063 & 1.16103 \\
\hline $\mathrm{H}$ & 4.94933 & -1.84074 & -1.71964 \\
\hline $\mathrm{H}$ & -1.30201 & -3.75012 & 2.64073 \\
\hline $\mathrm{H}$ & -0.93213 & -3.36453 & 0.93444 \\
\hline
\end{tabular}




$\begin{array}{lrrr}\mathrm{H} & 0.38602 & -3.65120 & 2.08681 \\ \mathrm{H} & -0.85024 & -2.12825 & 4.71685 \\ \mathrm{H} & 0.85209 & -1.79457 & 4.31391 \\ \mathrm{H} & -0.26501 & -0.44963 & 4.58206 \\ \mathrm{H} & -2.91627 & -1.73638 & 3.06646 \\ \mathrm{H} & -2.53635 & -0.02421 & 2.74338 \\ \mathrm{H} & -2.77003 & -1.13976 & 1.38495 \\ \mathrm{H} & -0.85096 & -1.10368 & -0.36590\end{array}$

GS IMeCu(PhCHCH $2 \mathrm{~B}(\mathrm{eg}))-\mathrm{PMe}_{3}-\mathrm{CO}_{2}\left(\mathrm{Fa}^{\mathrm{a}} \cdot \mathrm{PMe}_{3}\right)$ :

Total Energy (kcal/mol): -1981762.44

Enthalpy Correction (AU): 0.495237

Free Energy Correction (AU): 0.402241

Three lowest frequencies $\left(\mathrm{cm}^{-1}\right): 38.2,38.8,44.5$

$\begin{array}{lrrr}\mathrm{C} & -0.05243 & 1.65282 & -1.54642 \\ \mathrm{~N} & -1.33552 & 1.50077 & -1.95418 \\ \mathrm{C} & -2.04860 & 2.67428 & -1.82126 \\ \mathrm{C} & -1.18833 & 3.59263 & -1.33366 \\ \mathrm{~N} & 0.02506 & 2.95351 & -1.18030 \\ \mathrm{C} & -1.92085 & 0.26003 & -2.42360 \\ \mathrm{C} & 1.19310 & 3.56938 & -0.57947 \\ \mathrm{Cu} & 1.22739 & 0.23144 & -1.06476 \\ \mathrm{C} & -1.06952 & -0.40387 & 1.10262 \\ \mathrm{C} & -0.67270 & 0.90143 & 1.77703 \\ \mathrm{~B} & 0.88151 & 0.64217 & 2.08025 \\ \mathrm{O} & 1.53339 & 1.29854 & 3.17153 \\ \mathrm{C} & 2.79201 & 1.75169 & 2.77713 \\ \mathrm{C} & 3.05336 & 1.09056 & 1.42713 \\ \mathrm{O} & 1.76070 & 0.93375 & 0.89494 \\ \mathrm{P} & 2.09158 & -1.83673 & -1.23822 \\ \mathrm{C} & 3.03308 & -2.44191 & 0.20446 \\ \mathrm{C} & 0.80665 & -3.12753 & -1.41888 \\ \mathrm{C} & 3.21583 & -2.21174 & -2.63583 \\ \mathrm{C} & -2.52739 & -0.72646 & 0.91430 \\ \mathrm{C} & -3.48741 & 0.27514 & 1.05201 \\ \mathrm{C} & -4.82298 & 0.03596 & 0.75298 \\ \mathrm{C} & -5.22558 & -1.21475 & 0.31014 \\ \mathrm{C} & -4.28084 & -2.22465 & 0.17840 \\ \mathrm{C} & -2.94721 & -1.98425 & 0.47200 \\ \mathrm{C} & -0.15396 & -1.46029 & 1.73963 \\ \mathrm{O} & -0.30290 & -2.66080 & 1.65954 \\ \mathrm{O} & 0.89458 & -0.88711 & 2.27178 \\ \mathrm{H} & -3.18359 & 1.26164 & 1.39551 \\ \mathrm{H} & -2.21395 & -2.78101 & 0.38760\end{array}$




$\begin{array}{lrrr}\mathrm{H} & -4.58667 & -3.21429 & -0.15599 \\ \mathrm{H} & -3.09440 & 2.74310 & -2.08398 \\ \mathrm{H} & -1.32549 & 4.63481 & -1.08415 \\ \mathrm{H} & 3.55980 & 1.49098 & 3.51972 \\ \mathrm{H} & 2.79353 & 2.85356 & 2.67479 \\ \mathrm{H} & 3.54024 & 0.10827 & 1.55798 \\ \mathrm{H} & 3.67420 & 1.69617 & 0.75004 \\ \mathrm{H} & -0.88500 & 1.78641 & 1.16165 \\ \mathrm{H} & -1.22177 & 1.01758 & 2.72239 \\ \mathrm{H} & -5.55380 & 0.83366 & 0.87373 \\ \mathrm{H} & -2.68975 & -0.08912 & -1.72601 \\ \mathrm{H} & -1.13011 & -0.49068 & -2.48784 \\ \mathrm{H} & -2.36110 & 0.40238 & -3.41479 \\ \mathrm{H} & 1.16192 & 3.46850 & 0.50925 \\ \mathrm{H} & 1.22931 & 4.62507 & -0.86061 \\ \mathrm{H} & 2.08926 & 3.06839 & -0.94817 \\ \mathrm{H} & -6.27100 & -1.40566 & 0.07675 \\ \mathrm{H} & 1.26655 & -4.11538 & -1.54491 \\ \mathrm{H} & 0.18839 & -3.14598 & -0.51378 \\ \mathrm{H} & 0.17240 & -2.92032 & -2.28669 \\ \mathrm{H} & 3.53784 & -3.25959 & -2.60662 \\ \mathrm{H} & 2.70862 & -2.02424 & -3.58689 \\ \mathrm{H} & 4.10163 & -1.57124 & -2.59287 \\ \mathrm{H} & 3.29183 & -3.50028 & 0.08063 \\ \mathrm{H} & 3.95435 & -1.86177 & 0.31771 \\ \mathrm{H} & 2.43128 & -2.31743 & 1.11173 \\ \mathrm{H} & -0.65049 & -0.37089 & 0.07066\end{array}$

TS IMeCu(PhCHCH 2 B(eg) $)+\mathrm{CO}_{2}(4 \mathbf{a} \cdot \mathrm{TS}):$

Total Energy (kcal/mol): -1692426.342

Enthalpy Correction (AU): 0.370995

Free Energy Correction (AU): 0.289363

Three lowest frequencies $\left(\mathrm{cm}^{-1}\right):-178.7,23.2,35.8$

$\begin{array}{llll}\mathrm{Cu} & 0.63509 & -0.00656 & 0.24633 \\ \mathrm{C} & 1.36440 & 1.74974 & 0.05629 \\ \mathrm{~N} & 2.65515 & 2.14934 & 0.06261 \\ \mathrm{C} & 2.75306 & 3.51065 & -0.14164 \\ \mathrm{C} & 1.49033 & 3.96917 & -0.28352 \\ \mathrm{~N} & 0.65484 & 2.88012 & -0.15556 \\ \mathrm{H} & 3.70340 & 4.02415 & -0.15816 \\ \mathrm{H} & 1.11261 & 4.96614 & -0.45812 \\ \mathrm{C} & 3.78267 & 1.26120 & 0.26153 \\ \mathrm{H} & 3.40816 & 0.23963 & 0.36132 \\ \mathrm{C} & -0.79394 & 2.91735 & -0.29744\end{array}$




$\begin{array}{lrrr}\mathrm{H} & -1.16333 & 3.88326 & 0.05528 \\ \mathrm{C} & -0.69757 & -1.60663 & -0.02095 \\ \mathrm{C} & 0.67803 & -2.12009 & -0.26564 \\ \mathrm{C} & 3.35386 & -2.96817 & -0.60416 \\ \mathrm{C} & 1.36065 & -1.93573 & -1.48526 \\ \mathrm{C} & 1.39127 & -2.74650 & 0.78157 \\ \mathrm{C} & 2.69876 & -3.15854 & 0.61097 \\ \mathrm{C} & 2.67584 & -2.35733 & -1.64627 \\ \mathrm{H} & 0.83912 & -1.48712 & -2.32786 \\ \mathrm{H} & 0.89171 & -2.88482 & 1.73737 \\ \mathrm{H} & 3.21660 & -3.64388 & 1.43607 \\ \mathrm{H} & 3.16625 & -2.21508 & -2.60766 \\ \mathrm{H} & 4.37952 & -3.30536 & -0.73545 \\ \mathrm{C} & -1.52898 & -1.15863 & -1.21331 \\ \mathrm{~B} & -2.90964 & -0.55717 & -0.78664 \\ \mathrm{H} & -1.00138 & -0.40676 & -1.81996 \\ \mathrm{C} & -1.04397 & -0.44252 & 1.64144 \\ \mathrm{O} & -2.04112 & 0.19567 & 1.40523 \\ \mathrm{O} & -0.30785 & -0.77480 & 2.53389 \\ \mathrm{H} & -1.25011 & -2.32793 & 0.59091 \\ \mathrm{H} & 4.45952 & 1.30881 & -0.59622 \\ \mathrm{H} & 4.32814 & 1.53227 & 1.16983 \\ \mathrm{H} & -1.24375 & 2.11897 & 0.29835 \\ \mathrm{H} & -1.08495 & 2.77448 & -1.34183 \\ \mathrm{H} & -1.70618 & -2.01636 & -1.88602 \\ \mathrm{O} & -3.88789 & -1.29567 & -0.18261 \\ \mathrm{C} & -4.95906 & -0.42195 & 0.12551 \\ \mathrm{C} & -4.54017 & 0.94771 & -0.44210 \\ \mathrm{O} & -3.31147 & 0.71542 & -1.11005 \\ \mathrm{H} & -5.09585 & -0.39180 & 1.21266 \\ \mathrm{H} & -5.88073 & -0.80700 & -0.32885 \\ \mathrm{H} & -4.37421 & 1.68401 & 0.35520 \\ \mathrm{H} & -5.26848 & 1.36090 & -1.15034\end{array}$

TS IMeCu$\left(\mathrm{PhCHCH}_{2} \mathrm{~B}(\mathrm{eg})\right)+\mathrm{CO}_{2}\left(\mathrm{TS}^{\mathrm{SE} 2}\right)$ :

Total Energy (kcal/mol): -1692417.523

Enthalpy Correction (AU): 0.370221

Free Energy Correction (AU): 0.285005

Three lowest frequencies $\left(\mathrm{cm}^{-1}\right):-399.2,18.6,25.2$

$\begin{array}{llrl}\mathrm{Cu} & 0.96946 & 0.05707 & -0.04268 \\ \mathrm{C} & 2.20137 & -1.38994 & -0.10171 \\ \mathrm{~N} & 3.55230 & -1.33625 & -0.07765 \\ \mathrm{C} & 4.09939 & -2.60171 & -0.12829 \\ \mathrm{C} & 3.06428 & -3.46740 & -0.18325 \\ \mathrm{~N} & 1.91222 & -2.70901 & -0.16840\end{array}$




$\begin{array}{lrrr}\mathrm{H} & 5.16678 & -2.76866 & -0.12432 \\ \mathrm{H} & 3.04205 & -4.54645 & -0.23255 \\ \mathrm{C} & 4.32129 & -0.10825 & -0.01245 \\ \mathrm{H} & 4.96571 & -0.11187 & 0.87091 \\ \mathrm{C} & 0.56724 & -3.25684 & -0.18504 \\ \mathrm{H} & 0.47043 & -3.97896 & -1.00007 \\ \mathrm{C} & -1.04371 & 0.88425 & -0.05277 \\ \mathrm{C} & 0.01733 & 1.86542 & 0.12384 \\ \mathrm{C} & 2.09758 & 3.78226 & 0.42355 \\ \mathrm{C} & 0.49991 & 2.25488 & 1.40188 \\ \mathrm{C} & 0.65579 & 2.46390 & -0.99908 \\ \mathrm{C} & 1.66277 & 3.39801 & -0.84305 \\ \mathrm{C} & 1.50735 & 3.19963 & 1.53650 \\ \mathrm{H} & 0.04554 & 1.82398 & 2.29177 \\ \mathrm{H} & 0.30007 & 2.20405 & -1.99395 \\ \mathrm{H} & 2.10933 & 3.84680 & -1.72888 \\ \mathrm{H} & 1.83503 & 3.48327 & 2.53551 \\ \mathrm{H} & 2.88385 & 4.52449 & 0.53736 \\ \mathrm{C} & -1.67342 & 0.17219 & 1.12841 \\ \mathrm{~B} & -2.79581 & -0.79678 & 0.64726 \\ \mathrm{H} & 3.62905 & 0.73487 & 0.05404 \\ \mathrm{H} & 4.93655 & 0.00444 & -0.90943 \\ \mathrm{H} & -0.15334 & -2.44906 & -0.34116 \\ \mathrm{H} & 0.34672 & -3.75286 & 0.76465 \\ \mathrm{H} & -0.95226 & -0.39916 & 1.74650 \\ \mathrm{C} & -2.68451 & 1.90407 & -0.87932 \\ \mathrm{O} & -2.25886 & 2.82870 & -1.48034 \\ \mathrm{O} & -3.60884 & 1.23506 & -0.53065 \\ \mathrm{H} & -1.06411 & 0.35353 & -1.01608 \\ \mathrm{H} & -2.12370 & 0.89946 & 1.82063 \\ \mathrm{O} & -3.96152 & -1.05276 & 1.31491 \\ \mathrm{C} & -4.77141 & -1.82658 & 0.44837 \\ \mathrm{C} & -3.79248 & -2.41574 & -0.57226 \\ \mathrm{O} & -2.63077 & -1.60906 & -0.45784 \\ \mathrm{H} & -5.50566 & -1.16470 & -0.03020 \\ \mathrm{H} & -5.30987 & -2.58858 & 1.02247 \\ \mathrm{H} & -4.17115 & -2.37388 & -1.59921 \\ & -3.53058 & -3.45953 & -0.34472\end{array}$

GS IMeCu(PhCHCH $2 \mathrm{~B}(\mathrm{eg}))-\mathrm{CO}_{2}\left(\mathrm{Int}^{\mathrm{SE} 2}\right)$ :

Total Energy (kcal/mol): -1692433.785

Enthalpy Correction (AU): 0.37249

Free Energy Correction (AU): 0.292048

Three lowest frequencies $\left(\mathrm{cm}^{-1}\right): 8.6,35.7,42.2$

$\begin{array}{llll}\mathrm{Cu} & 1.38108 & 0.18815 & 0.57248\end{array}$ 


$\begin{array}{lrrr}\mathrm{C} & 1.93512 & -1.58322 & 0.09533 \\ \mathrm{~N} & 3.13288 & -1.94614 & -0.41675 \\ \mathrm{C} & 3.14258 & -3.28416 & -0.74731 \\ \mathrm{C} & 1.91962 & -3.76363 & -0.43176 \\ \mathrm{~N} & 1.19372 & -2.71206 & 0.08094 \\ \mathrm{H} & 4.00963 & -3.76632 & -1.17439 \\ \mathrm{H} & 1.50005 & -4.75406 & -0.52908 \\ \mathrm{C} & 4.25360 & -1.04984 & -0.61577 \\ \mathrm{H} & 5.11487 & -1.37721 & -0.02688 \\ \mathrm{C} & -0.19133 & -2.81357 & 0.53772 \\ \mathrm{H} & -0.50311 & -3.85645 & 0.45450 \\ \mathrm{C} & -0.99498 & 1.11578 & -0.17788 \\ \mathrm{C} & 0.24944 & 1.92684 & 0.02175 \\ \mathrm{C} & 2.67807 & 3.32579 & 0.34755 \\ \mathrm{C} & 0.82869 & 2.09570 & 1.29966 \\ \mathrm{C} & 0.92605 & 2.47815 & -1.08578 \\ \mathrm{C} & 2.10722 & 3.17423 & -0.91849 \\ \mathrm{C} & 2.04382 & 2.78978 & 1.45019 \\ \mathrm{H} & 0.27268 & 1.77533 & 2.18078 \\ \mathrm{H} & 0.47018 & 2.37534 & -2.06656 \\ \mathrm{H} & 2.59836 & 3.61024 & -1.78571 \\ \mathrm{H} & 2.46308 & 2.91918 & 2.44528 \\ \mathrm{H} & 3.61122 & 3.87138 & 0.46438 \\ \mathrm{C} & -1.69041 & 0.48812 & 1.01475 \\ \mathrm{~B} & -3.01814 & -0.03543 & 0.25979 \\ \mathrm{H} & 3.96213 & -0.04664 & -0.29498 \\ \mathrm{H} & 4.52990 & -1.01656 & -1.67310 \\ \mathrm{H} & -0.87588 & -2.19315 & -0.05677 \\ \mathrm{H} & -0.25584 & -2.51515 & 1.58677 \\ \mathrm{H} & -1.11163 & -0.30474 & 1.51253 \\ \mathrm{C} & -2.14753 & 1.80770 & -0.95445 \\ \mathrm{O} & -1.98476 & 2.76261 & -1.67509 \\ \mathrm{O} & -3.24516 & 1.16133 & -0.72607 \\ \mathrm{H} & -0.73245 & 0.29911 & -0.88128 \\ \mathrm{H} & -1.93814 & 1.25091 & 1.76698 \\ \mathrm{O} & -4.19262 & -0.30254 & 1.02072 \\ \mathrm{C} & -4.91315 & -1.24785 & 0.28168 \\ \mathrm{H} & -3.83380 & -2.11397 & -0.36084 \\ \mathrm{H} & -2.75605 & -1.23989 & -0.55103 \\ \mathrm{H} & -5.591599 & -0.75551 & -0.49971 \\ \mathrm{H} & -1.81111 & 0.93660 \\ \mathrm{H} & & -2.56089 & -1.31363 \\ \mathrm{H} & & 0.31773\end{array}$


GS IMeCu(PhCHCH $2 B(e g))-\mathrm{CO}_{2}$ : $5 \mathrm{a}$

Total Energy (kcal/mol): -1692456.946

Enthalpy Correction (AU): 0.37367

Free Energy Correction (AU): 0.293184

Three lowest frequencies $\left(\mathrm{cm}^{-1}\right): 18.3,36.7,44.7$

\begin{tabular}{|c|c|c|c|}
\hline $\mathrm{Cu}$ & -1.05111 & -1.04669 & -0.62682 \\
\hline $\mathrm{C}$ & -2.88251 & -0.83009 & -0.19268 \\
\hline $\mathrm{N}$ & -3.49578 & -1.14209 & 0.97274 \\
\hline $\mathrm{C}$ & -4.79443 & -0.67590 & 0.99530 \\
\hline $\mathrm{C}$ & -5.00537 & -0.06764 & -0.19047 \\
\hline $\mathrm{N}$ & -3.82996 & -0.17824 & -0.90494 \\
\hline $\mathrm{H}$ & -5.44592 & -0.82730 & 1.84378 \\
\hline $\mathrm{H}$ & -5.87976 & 0.42245 & -0.59360 \\
\hline $\mathrm{C}$ & -2.85629 & -1.82050 & 2.08004 \\
\hline $\mathrm{H}$ & -1.86288 & -2.14275 & 1.76182 \\
\hline $\mathrm{C}$ & -3.62970 & 0.37929 & -2.22626 \\
\hline $\mathrm{H}$ & -4.36993 & -0.02182 & -2.92430 \\
\hline $\mathrm{C}$ & 1.59873 & 0.37198 & 0.44019 \\
\hline $\mathrm{C}$ & 0.29883 & 1.12474 & 0.46647 \\
\hline $\mathrm{C}$ & -2.10301 & 2.57860 & 0.52188 \\
\hline $\mathrm{C}$ & -0.10739 & 1.88502 & -0.63444 \\
\hline $\mathrm{C}$ & -0.51773 & 1.12289 & 1.59601 \\
\hline $\mathrm{C}$ & -1.70878 & 1.83888 & 1.62631 \\
\hline $\mathrm{C}$ & -1.29176 & 2.60384 & -0.60777 \\
\hline $\mathrm{H}$ & 0.52014 & 1.90177 & -1.52569 \\
\hline $\mathrm{H}$ & -0.20589 & 0.54755 & 2.46843 \\
\hline $\mathrm{H}$ & -2.32908 & 1.82455 & 2.52167 \\
\hline $\mathrm{H}$ & -1.58259 & 3.19599 & -1.47413 \\
\hline $\mathrm{H}$ & -3.03213 & 3.14546 & 0.54412 \\
\hline $\mathrm{C}$ & 2.81826 & 1.29407 & 0.45886 \\
\hline B & 4.12052 & 0.43833 & 0.29044 \\
\hline $\mathrm{H}$ & 2.75081 & 2.02196 & -0.36131 \\
\hline $\mathrm{C}$ & 1.74807 & -0.62373 & -0.73443 \\
\hline $\mathrm{O}$ & 2.86953 & -0.77682 & -1.19610 \\
\hline $\mathrm{O}$ & 0.71092 & -1.27064 & -1.12488 \\
\hline $\mathrm{H}$ & 1.64140 & -0.26539 & 1.34018 \\
\hline $\mathrm{H}$ & -2.75347 & -1.14525 & 2.93510 \\
\hline $\mathrm{H}$ & -3.43920 & -2.69653 & 2.37763 \\
\hline $\mathrm{H}$ & -2.62885 & 0.11065 & -2.56921 \\
\hline $\mathrm{H}$ & -3.71030 & 1.47002 & -2.19371 \\
\hline $\mathrm{H}$ & 2.83232 & 1.87347 & 1.39275 \\
\hline $\mathrm{O}$ & 4.40796 & -0.61688 & 1.13343 \\
\hline $\mathrm{C}$ & 5.56339 & -1.23574 & 0.59951 \\
\hline $\mathrm{C}$ & 6.22164 & -0.14461 & -0.25208 \\
\hline $\mathrm{O}$ & 5.19051 & 0.79530 & -0.49217 \\
\hline
\end{tabular}




$\begin{array}{llll}\mathrm{H} & 5.25566 & -2.09322 & -0.01556 \\ \mathrm{H} & 6.20304 & -1.59782 & 1.41268 \\ \mathrm{H} & 6.60424 & -0.52675 & -1.20536 \\ \mathrm{H} & 7.04903 & 0.35320 & 0.27489\end{array}$

The remainder of the xyz files for Chapter 3 reflect structures optimized with Grimme D3 dispersion corrections in benzene as solvent. SMD model used.

GS IMeCu(PhCHCH $2 B(e g)):$

Total Energy (kcal/mol): -1574137.807

Enthalpy Correction (AU): 0.35326

Free Energy Correction (AU): 0.281099

Three lowest frequencies $\left(\mathrm{cm}^{-1}\right)$ : $-22.3,6.1,20.2$

$\begin{array}{lccc}\mathrm{N} & -1.24702 & 2.88420 & -0.24236 \\ \mathrm{C} & -0.12579 & 2.14219 & -0.09656 \\ \mathrm{~N} & 0.82823 & 3.03937 & 0.23894 \\ \mathrm{C} & 0.31582 & 4.31935 & 0.29366 \\ \mathrm{C} & -0.99751 & 4.22020 & -0.00508 \\ \mathrm{Cu} & 0.00976 & 0.22884 & -0.27211 \\ \mathrm{C} & -0.06580 & -1.73840 & -0.25089 \\ \mathrm{C} & 0.86885 & -2.29410 & 0.83337 \\ \mathrm{~B} & 2.30424 & -1.91672 & 0.37985 \\ \mathrm{O} & 3.00443 & -2.60550 & -0.57748 \\ \mathrm{C} & 4.26651 & -1.97121 & -0.73804 \\ \mathrm{C} & 4.09436 & -0.61696 & -0.05854 \\ \mathrm{O} & 2.98549 & -0.79638 & 0.81364 \\ \mathrm{C} & 2.21410 & 2.69971 & 0.49387 \\ \mathrm{C} & -2.55365 & 2.34422 & -0.56484 \\ \mathrm{C} & -1.52012 & -1.87775 & -0.04034 \\ \mathrm{C} & -2.39643 & -1.89913 & -1.14391 \\ \mathrm{C} & -3.77044 & -1.92353 & -0.98920 \\ \mathrm{C} & -4.34091 & -1.93137 & 0.28128 \\ \mathrm{C} & -3.49810 & -1.93341 & 1.38473 \\ \mathrm{C} & -2.11879 & -1.91539 & 1.23077 \\ \mathrm{H} & 0.20728 & -2.15346 & -1.23127 \\ \mathrm{H} & -1.96602 & -1.88424 & -2.14685 \\ \mathrm{H} & 0.66943 & -1.82269 & 1.80620 \\ \mathrm{H} & -4.40918 & -1.94160 & -1.87179 \\ \mathrm{H} & -5.42148 & -1.95018 & 0.40591 \\ \mathrm{H} & -3.92077 & -1.95566 & 2.38882 \\ \mathrm{H} & -1.48756 & -1.91728 & 2.11841 \\ \mathrm{H} & 0.73964 & -3.38306 & 0.97303 \\ \mathrm{H} & 5.03974 & -2.58420 & -0.25492 \\ \mathrm{H} & 4.50793 & -1.89083 & -1.80293 \\ \mathrm{H} & 3.84912 & 0.17115 & -0.78729\end{array}$




$\begin{array}{rrrr}\mathrm{H} & 4.97254 & -0.29903 & 0.51322 \\ \mathrm{H} & 2.28686 & 1.62372 & 0.67444 \\ \mathrm{H} & 2.56933 & 3.23142 & 1.38051 \\ \mathrm{H} & 2.84216 & 2.96828 & -0.36168 \\ \mathrm{H} & 0.92711 & 5.17445 & 0.54506 \\ \mathrm{H} & -1.77362 & 4.96992 & -0.06542 \\ \mathrm{H} & -2.46999 & 1.26037 & -0.67728 \\ \mathrm{H} & -3.26341 & 2.55990 & 0.23880 \\ \mathrm{H} & -2.92378 & 2.77380 & -1.50007\end{array}$

TS IMeCu(PhCHCH $2 \mathrm{~B}(\mathrm{eg}))+\mathrm{C}_{2} \mathrm{H}_{4}$

Total Energy (kcal/mol): -1623422.358

Enthalpy Correction (AU): 0.4102

Free Energy Correction (AU): 0.326651

Three lowest frequencies $\left(\mathrm{cm}^{-1}\right):-91.4,23.9,31.9$

$\begin{array}{lccc}\mathrm{N} & 1.67887 & 2.51619 & 0.10579 \\ \mathrm{C} & 0.43811 & 1.98423 & 0.00764 \\ \mathrm{~N} & -0.29732 & 2.96489 & -0.56722 \\ \mathrm{C} & 0.46625 & 4.08873 & -0.81510 \\ \mathrm{C} & 1.71583 & 3.80404 & -0.39162 \\ \mathrm{Cu} & -0.08724 & 0.15717 & 0.44442 \\ \mathrm{C} & 0.05896 & -1.78824 & -0.02182 \\ \mathrm{C} & -0.79196 & -2.05470 & -1.27100 \\ \mathrm{~B} & -2.24144 & -1.64394 & -0.89959 \\ \mathrm{O} & -3.05357 & -2.35605 & -0.04969 \\ \mathrm{C} & -4.30299 & -1.68394 & 0.03742 \\ \mathrm{C} & -4.04014 & -0.30874 & -0.57367 \\ \mathrm{O} & -2.83996 & -0.47127 & -1.31668 \\ \mathrm{C} & -1.70914 & 2.84370 & -0.86455 \\ \mathrm{C} & 2.83563 & 1.80740 & 0.61447 \\ \mathrm{C} & -1.74417 & 0.97674 & 2.50562 \\ \mathrm{C} & -1.52024 & -0.33644 & 2.47321 \\ \mathrm{C} & 1.51797 & -1.92483 & -0.14897 \\ \mathrm{C} & 2.30749 & -2.17468 & 0.99274 \\ \mathrm{C} & 3.68823 & -2.22726 & 0.93553 \\ \mathrm{C} & 4.35647 & -2.03705 & -0.27188 \\ \mathrm{C} & 3.60077 & -1.80824 & -1.41462 \\ \mathrm{C} & 2.21518 & -1.75788 & -1.35878 \\ \mathrm{H} & -0.29972 & -2.40792 & 0.81234 \\ \mathrm{H} & 1.80170 & -2.32566 & 1.94897 \\ \mathrm{H} & -0.46434 & -1.42299 & -2.10878 \\ \mathrm{H} & -1.08683 & 1.66078 & 3.03806 \\ \mathrm{H} & -2.60044 & 1.42667 & 2.00430 \\ \mathrm{H} & 4.25500 & -2.42639 & 1.84474 \\ \mathrm{H} & 5.44236 & -2.08183 & -0.32061\end{array}$




$\begin{array}{lrrr}\mathrm{H} & 4.09895 & -1.67224 & -2.37437 \\ \mathrm{H} & 1.65713 & -1.57446 & -2.27567 \\ \mathrm{H} & -0.71397 & -3.10342 & -1.61429 \\ \mathrm{H} & -5.05535 & -2.25275 & -0.52495 \\ \mathrm{H} & -4.62566 & -1.63468 & 1.08348 \\ \mathrm{H} & -3.88160 & 0.46087 & 0.19807 \\ \mathrm{H} & -4.84377 & 0.03313 & -1.23435 \\ \mathrm{H} & -1.95431 & 1.78678 & -1.00436 \\ \mathrm{H} & -1.93800 & 3.37946 & -1.78946 \\ \mathrm{H} & -2.31756 & 3.26004 & -0.05421 \\ \mathrm{H} & 0.05403 & 4.97610 & -1.27408 \\ \mathrm{H} & 2.62474 & 4.38858 & -0.40711 \\ \mathrm{H} & 2.52828 & 0.80253 & 0.91535 \\ \mathrm{H} & 3.60002 & 1.71587 & -0.16265 \\ \mathrm{H} & 3.25679 & 2.33046 & 1.47824 \\ \mathrm{H} & -2.18998 & -1.03564 & 1.97572 \\ \mathrm{H} & -0.68639 & -0.78765 & 3.00870\end{array}$

\section{GS IMeCu(PhCHCH $2 \mathrm{~B}(\mathrm{eg})) \cdot \mathrm{C}_{2} \mathrm{H}_{4}$}

Total Energy (kcal/mol): -1623428.877

Enthalpy Correction (AU): 0.411082

Free Energy Correction (AU): 0.329322

Three lowest frequencies $\left(\mathrm{cm}^{-1}\right): 28.0,30.5,49.5$

$\begin{array}{lccc}\mathrm{N} & 2.17952 & 1.60092 & 0.51251 \\ \mathrm{C} & 0.84465 & 1.56937 & 0.29290 \\ \mathrm{~N} & 0.65798 & 2.45132 & -0.71785 \\ \mathrm{C} & 1.85290 & 3.01556 & -1.12331 \\ \mathrm{C} & 2.81462 & 2.47485 & -0.34761 \\ \mathrm{Cu} & -0.40861 & 0.20267 & 1.00547 \\ \mathrm{C} & -0.28901 & -1.38641 & -0.30175 \\ \mathrm{C} & -1.05017 & -0.99385 & -1.57424 \\ \mathrm{~B} & -2.52024 & -0.72872 & -1.14905 \\ \mathrm{O} & -3.42007 & -1.71572 & -0.84330 \\ \mathrm{C} & -4.64980 & -1.10277 & -0.47811 \\ \mathrm{C} & -4.31092 & 0.37959 & -0.31174 \\ \mathrm{O} & -3.04481 & 0.53058 & -0.94244 \\ \mathrm{C} & -0.62755 & 2.79671 & -1.28606 \\ \mathrm{C} & 2.87636 & 0.78086 & 1.47992 \\ \mathrm{C} & -1.39727 & 0.80990 & 2.71929 \\ \mathrm{C} & -1.70781 & -0.49011 & 2.37221 \\ \mathrm{C} & 1.13877 & -1.68367 & -0.44018 \\ \mathrm{C} & 1.77679 & -2.54046 & 0.47915 \\ \mathrm{C} & 3.13461 & -2.79483 & 0.42631 \\ \mathrm{C} & 3.93011 & -2.19826 & -0.55020\end{array}$




$\begin{array}{lccc}\mathrm{C} & 3.32300 & -1.35895 & -1.47648 \\ \mathrm{C} & 1.95851 & -1.11105 & -1.42857 \\ \mathrm{H} & -0.79546 & -2.23389 & 0.18155 \\ \mathrm{H} & 1.16802 & -3.01210 & 1.25355 \\ \mathrm{H} & -0.63421 & -0.07844 & -2.02046 \\ \mathrm{H} & -0.65278 & 1.02974 & 3.48244 \\ \mathrm{H} & -2.04571 & 1.64104 & 2.44410 \\ \mathrm{H} & 3.58319 & -3.47052 & 1.15395 \\ \mathrm{H} & 4.99830 & -2.39962 & -0.59703 \\ \mathrm{H} & 3.92151 & -0.89118 & -2.25823 \\ \mathrm{H} & 1.51679 & -0.44916 & -2.17286 \\ \mathrm{H} & -0.97845 & -1.77784 & -2.35105 \\ \mathrm{H} & -5.38590 & -1.27608 & -1.27402 \\ \mathrm{H} & -5.02984 & -1.56049 & 0.44186 \\ \mathrm{H} & -4.21856 & 0.66993 & 0.74502 \\ \mathrm{H} & -5.03994 & 1.04616 & -0.78404 \\ \mathrm{H} & -1.39632 & 2.14124 & -0.87199 \\ \mathrm{H} & -0.60904 & 2.66542 & -2.37253 \\ \mathrm{H} & -0.87916 & 3.83773 & -1.05847 \\ \mathrm{H} & 1.90224 & 3.74566 & -1.91878 \\ \mathrm{H} & 3.88517 & 2.62225 & -0.32818 \\ \mathrm{H} & 2.14149 & 0.29350 & 2.12428 \\ \mathrm{H} & 3.47010 & 0.01040 & 0.97564 \\ \mathrm{H} & 3.53136 & 1.40336 & 2.09691 \\ \mathrm{H} & -2.63130 & -0.73948 & 1.84938 \\ \mathrm{H} & -1.22103 & -1.33488 & 2.85952\end{array}$

TS IMeCu(PhCHCH 2 B(eg)) $\cdot \mathbf{C}_{2} \mathrm{H}_{4}+\mathrm{CO}_{2}$ :

Total Energy (kcal/mol): -1741734.238

Enthalpy Correction (AU): 0.426967

Free Energy Correction (AU): 0.33635

Three lowest frequencies $\left(\mathrm{cm}^{-1}\right):-495.3,26.3,34.7$

$\begin{array}{lrrr}\text { C } & 1.82678 & -0.94561 & -1.72208 \\ \text { C } & 1.24042 & -1.31444 & -0.49343 \\ \text { C } & 2.11008 & -1.87128 & 0.47250 \\ \text { C } & 3.46026 & -2.04077 & 0.22431 \\ \text { C } & 4.01648 & -1.66727 & -0.99615 \\ \text { C } & 3.17979 & -1.12651 & -1.96458 \\ \text { C } & -0.19014 & -1.17797 & -0.27383 \\ \text { C } & -1.04947 & -0.47445 & -1.28449 \\ \text { B } & -2.51907 & -0.26170 & -0.83358 \\ \text { O } & -3.03240 & -0.70032 & 0.36106 \\ \text { C } & -4.43466 & -0.45154 & 0.34524 \\ \text { C } & -4.62573 & 0.55013 & -0.79030\end{array}$




$\begin{array}{lrrr}\mathrm{O} & -3.44982 & 0.42043 & -1.58053 \\ \mathrm{Cu} & 0.25061 & 0.40399 & 1.32138 \\ \mathrm{C} & -0.23435 & -0.62139 & 3.08202 \\ \mathrm{C} & 0.37192 & 0.55494 & 3.40970 \\ \mathrm{C} & 0.70620 & 2.01502 & 0.27115 \\ \mathrm{~N} & 1.91380 & 2.35745 & -0.22780 \\ \mathrm{C} & 1.80373 & 3.36926 & -1.15991 \\ \mathrm{C} & 0.49305 & 3.68015 & -1.23885 \\ \mathrm{~N} & -0.16052 & 2.84733 & -0.35202 \\ \mathrm{C} & 3.17314 & 1.75477 & 0.16117 \\ \mathrm{C} & -1.59280 & 2.86720 & -0.13972 \\ \mathrm{C} & -0.73095 & -3.19026 & -0.45776 \\ \mathrm{O} & -0.44943 & -3.70588 & 0.57837 \\ \mathrm{O} & -1.18495 & -3.30019 & -1.55116 \\ \mathrm{H} & -0.60759 & -1.36080 & 0.72225 \\ \mathrm{H} & 1.69475 & -2.21895 & 1.41619 \\ \mathrm{H} & -0.63464 & 0.49157 & -1.62509 \\ \mathrm{H} & 1.43751 & 0.60079 & 3.63083 \\ \mathrm{H} & -0.20176 & 1.44697 & 3.65311 \\ \mathrm{H} & 4.08903 & -2.48635 & 0.99421 \\ \mathrm{H} & 5.07677 & -1.81076 & -1.19189 \\ \mathrm{H} & 3.58656 & -0.84171 & -2.93463 \\ \mathrm{H} & 1.20058 & -0.52722 & -2.50727 \\ \mathrm{H} & -1.09949 & -1.08374 & -2.20540 \\ \mathrm{H} & -4.69431 & 1.58515 & -0.42236 \\ \mathrm{H} & -5.50979 & 0.34786 & -1.40294 \\ \mathrm{H} & -4.95821 & -1.39774 & 0.15803 \\ \mathrm{H} & -4.75340 & -0.06909 & 1.32019 \\ \mathrm{H} & -1.83379 & 2.21447 & 0.70377 \\ \mathrm{H} & -2.12351 & 2.51213 & -1.02898 \\ \mathrm{H} & -1.92247 & 3.88249 & 0.09853 \\ \mathrm{H} & -0.03355 & 4.41174 & -1.83485 \\ \mathrm{H} & 2.66524 & 3.77292 & -1.67228 \\ \mathrm{H} & 3.60182 & 1.18798 & -0.66989 \\ \mathrm{H} & 3.87451 & 2.53131 & 0.47959 \\ \mathrm{H} & 2.99688 & 1.06895 & 0.99198 \\ \mathrm{H} & -1.31943 & -0.70974 & 3.04698 \\ \mathrm{H} & 0.31328 & -1.56089 & 3.05468\end{array}$




\section{GS IMeCu(PhCHCH $\left.2 \mathrm{~B}(\mathrm{eg}) \mathrm{CO}_{2}\right) \cdot \mathrm{C}_{2} \mathrm{H}_{4}$}

Total Energy (kcal/mol): -1741772.445

Enthalpy Correction (AU): 0.429638

Free Energy Correction (AU): 0.345323

Three lowest frequencies $\left(\mathrm{cm}^{-1}\right): 28.8,37.7,48.1$

$\begin{array}{lccc}\mathrm{C} & 3.01620 & -0.30568 & -1.45988 \\ \mathrm{C} & 2.41312 & -0.97686 & -0.39664 \\ \mathrm{C} & 3.22625 & -1.41296 & 0.65309 \\ \mathrm{C} & 4.59460 & -1.18736 & 0.63212 \\ \mathrm{C} & 5.18157 & -0.51024 & -0.42970 \\ \mathrm{C} & 4.38549 & -0.07209 & -1.47740 \\ \mathrm{C} & 0.91294 & -1.08350 & -0.33162 \\ \mathrm{C} & 0.09782 & -0.83652 & -1.59386 \\ \mathrm{~B} & -1.32848 & -1.44598 & -1.18801 \\ \mathrm{O} & -2.20566 & -0.44259 & -0.46601 \\ \mathrm{C} & -3.51800 & -0.95268 & -0.58657 \\ \mathrm{C} & -3.50754 & -1.55021 & -1.98398 \\ \mathrm{O} & -2.20088 & -1.99973 & -2.18281 \\ \mathrm{Cu} & -1.44018 & 0.54656 & 1.17479 \\ \mathrm{C} & -2.18355 & -0.78067 & 2.57312 \\ \mathrm{C} & -1.28438 & 0.02579 & 3.20114 \\ \mathrm{C} & -0.45108 & 2.05879 & 0.34343 \\ \mathrm{~N} & 0.83703 & 2.43743 & 0.51367 \\ \mathrm{C} & 1.23387 & 3.32685 & -0.46315 \\ \mathrm{C} & 0.16334 & 3.52197 & -1.26183 \\ \mathrm{~N} & -0.85238 & 2.73887 & -0.75598 \\ \mathrm{C} & 1.73233 & 1.95078 & 1.54457 \\ \mathrm{C} & -2.18224 & 2.64847 & -1.33220 \\ \mathrm{C} & 0.28441 & -2.33364 & 0.29983 \\ \mathrm{O} & 0.77598 & -3.01009 & 1.17374 \\ \mathrm{O} & -0.93135 & -2.50892 & -0.16365 \\ \mathrm{H} & 0.60795 & -0.30880 & 0.40300 \\ \mathrm{H} & 2.76805 & -1.94632 & 1.48095 \\ \mathrm{H} & 0.07818 & 0.21956 & -1.89626 \\ \mathrm{H} & -0.25181 & -0.29721 & 3.33821 \\ \mathrm{H} & -1.59048 & 0.90746 & 3.76079 \\ \mathrm{H} & 5.20981 & -1.54283 & 1.45679 \\ \mathrm{H} & 6.25460 & -0.32993 & -0.44145 \\ \mathrm{H} & 4.83147 & 0.45432 & -2.31942 \\ \mathrm{H} & 2.40300 & 0.05002 & -2.28515 \\ & 0.52157 & -1.40927 & -2.43172 \\ \mathrm{H} & -3.77208 & -0.77892 & -2.73188 \\ \mathrm{H} & -3.23068 & -2.37186 & -2.08725 \\ \mathrm{H} & & -1.72831 & 0.17523 \\ \mathrm{H} & -0.14640 & -0.45023\end{array}$




$\begin{array}{lrrr}\mathrm{H} & -2.89492 & 3.24559 & -0.75541 \\ \mathrm{H} & -2.49275 & 1.60063 & -1.34215 \\ \mathrm{H} & -2.15545 & 3.02192 & -2.35775 \\ \mathrm{H} & 0.03130 & 4.13654 & -2.14054 \\ \mathrm{H} & 2.23842 & 3.72325 & -0.50142 \\ \mathrm{H} & 2.53651 & 1.35214 & 1.10275 \\ \mathrm{H} & 2.16664 & 2.79231 & 2.09108 \\ \mathrm{H} & 1.16751 & 1.33080 & 2.24235 \\ \mathrm{H} & -3.25141 & -0.56223 & 2.60073 \\ \mathrm{H} & -1.90025 & -1.75778 & 2.18320\end{array}$

TS IMeCu(PhCHCH2B(eg) $\left.\mathrm{CO}_{2}\right)-\mathrm{SE}_{\mathrm{E}} 2$

Total Energy (kcal/mol): -1692442.538

Enthalpy Correction (AU): 0.370166

Free Energy Correction (AU): 0.286191

Three lowest frequencies $\left(\mathrm{cm}^{-1}\right)$ : $-479.0,13.1,31.4$

$\begin{array}{lrrr}\mathrm{Cu} & 0.67730 & -0.29865 & -0.14596 \\ \mathrm{C} & 2.24705 & -1.39180 & -0.12104 \\ \mathrm{~N} & 3.51109 & -0.93670 & 0.02684 \\ \mathrm{C} & 4.41496 & -1.97671 & 0.03359 \\ \mathrm{C} & 3.69985 & -3.11134 & -0.12665 \\ \mathrm{~N} & 2.37656 & -2.73289 & -0.21565 \\ \mathrm{H} & 5.47710 & -1.81521 & 0.14641 \\ \mathrm{H} & 4.00743 & -4.14539 & -0.19004 \\ \mathrm{C} & 3.85378 & 0.45795 & 0.24017 \\ \mathrm{H} & 3.77019 & 0.72404 & 1.29837 \\ \mathrm{C} & 1.28111 & -3.65642 & -0.43289 \\ \mathrm{H} & 1.31904 & -4.06549 & -1.44652 \\ \mathrm{C} & -1.05611 & 0.86049 & -0.07861 \\ \mathrm{C} & 0.01912 & 1.83509 & 0.10189 \\ \mathrm{C} & 2.08574 & 3.75124 & 0.42799 \\ \mathrm{C} & 0.44097 & 2.26102 & 1.38024 \\ \mathrm{C} & 0.67376 & 2.41900 & -1.00780 \\ \mathrm{C} & 1.68171 & 3.35077 & -0.84384 \\ \mathrm{C} & 1.45012 & 3.19977 & 1.53285 \\ \mathrm{H} & -0.04107 & 1.84739 & 2.26419 \\ \mathrm{H} & 0.35820 & 2.13149 & -2.00961 \\ \mathrm{H} & 2.15594 & 3.78134 & -1.72464 \\ \mathrm{H} & 1.74316 & 3.50498 & 2.53649 \\ \mathrm{H} & 2.87501 & 4.48918 & 0.55211 \\ \mathrm{C} & -1.75614 & 0.22013 & 1.10789 \\ \mathrm{~B} & -2.86650 & -0.77892 & 0.66052 \\ \mathrm{H} & 3.17426 & 1.09181 & -0.33482 \\ \mathrm{H} & 4.87631 & 0.63475 & -0.09946 \\ \mathrm{H} & 0.34013 & -3.11932 & -0.30304\end{array}$




$\begin{array}{lrrr}\mathrm{H} & 1.33137 & -4.47453 & 0.29021 \\ \mathrm{H} & -1.07337 & -0.30770 & 1.80102 \\ \mathrm{C} & -2.66577 & 1.90513 & -0.92461 \\ \mathrm{O} & -2.24381 & 2.89114 & -1.42633 \\ \mathrm{O} & -3.60591 & 1.20847 & -0.68625 \\ \mathrm{H} & -1.11335 & 0.33885 & -1.05261 \\ \mathrm{H} & -2.23459 & 0.99111 & 1.73295 \\ \mathrm{O} & -4.01155 & -1.01825 & 1.37281 \\ \mathrm{C} & -4.71849 & -2.06302 & 0.72102 \\ \mathrm{C} & -3.98131 & -2.26447 & -0.60473 \\ \mathrm{O} & -2.72877 & -1.62022 & -0.42029 \\ \mathrm{H} & -5.76441 & -1.76804 & 0.58328 \\ \mathrm{H} & -4.69758 & -2.96192 & 1.35319 \\ \mathrm{H} & -4.50574 & -1.78561 & -1.44291 \\ \mathrm{H} & -3.82243 & -3.31936 & -0.85494\end{array}$

TS IMeCu(PhCHCH $\left.2 \mathrm{~B}(\mathrm{eg}) \mathrm{CO}_{2}\right)$ - direct insertion

Total Energy (kcal/mol): - 1692450.418

Enthalpy Correction (AU): 0.370965

Free Energy Correction (AU): 0.289863

Three lowest frequencies $\left(\mathrm{cm}^{-1}\right)$ : -197.1, 22.4, 33.5

$\begin{array}{lccc}\mathrm{Cu} & 0.57724 & 0.05616 & 0.32423 \\ \mathrm{C} & 1.44166 & 1.75320 & 0.10577 \\ \mathrm{~N} & 2.75365 & 2.06802 & 0.11382 \\ \mathrm{C} & 2.94349 & 3.40571 & -0.16397 \\ \mathrm{C} & 1.71549 & 3.93848 & -0.34866 \\ \mathrm{~N} & 0.81012 & 2.91317 & -0.17671 \\ \mathrm{H} & 3.92683 & 3.85262 & -0.19341 \\ \mathrm{H} & 1.40406 & 4.94808 & -0.57527 \\ \mathrm{C} & 3.82040 & 1.11380 & 0.33930 \\ \mathrm{H} & 3.38922 & 0.19522 & 0.74292 \\ \mathrm{C} & -0.62829 & 3.04415 & -0.33598 \\ \mathrm{H} & -0.96265 & 3.98390 & 0.11021 \\ \mathrm{C} & -0.70525 & -1.53612 & -0.02932 \\ \mathrm{C} & 0.63925 & -2.12096 & -0.29849 \\ \mathrm{C} & 3.24254 & -3.14439 & -0.68651 \\ \mathrm{C} & 1.32462 & -1.93925 & -1.51399 \\ \mathrm{C} & 1.30316 & -2.84283 & 0.71474 \\ \mathrm{C} & 2.57791 & -3.34120 & 0.52184 \\ \mathrm{C} & 2.60587 & -2.44467 & -1.69974 \\ \mathrm{H} & 0.83743 & -1.41186 & -2.33155 \\ \mathrm{H} & 0.79462 & -2.99276 & 1.66468 \\ \mathrm{H} & 3.06109 & -3.89745 & 1.32302 \\ \mathrm{H} & 3.10428 & -2.29492 & -2.65593\end{array}$




$\begin{array}{lrrr}\mathrm{H} & 4.24306 & -3.54409 & -0.83584 \\ \mathrm{C} & -1.51577 & -1.01719 & -1.20833 \\ \mathrm{~B} & -2.91286 & -0.45307 & -0.78642 \\ \mathrm{H} & -0.97663 & -0.23894 & -1.77013 \\ \mathrm{C} & -1.06872 & -0.43828 & 1.68657 \\ \mathrm{O} & -2.05396 & 0.22237 & 1.45652 \\ \mathrm{O} & -0.38971 & -0.84191 & 2.59722 \\ \mathrm{H} & -1.29306 & -2.25569 & 0.55168 \\ \mathrm{H} & 4.33403 & 0.88164 & -0.59849 \\ \mathrm{H} & 4.53876 & 1.51612 & 1.05812 \\ \mathrm{H} & -1.12738 & 2.21264 & 0.16833 \\ \mathrm{H} & -0.90167 & 3.02757 & -1.39530 \\ \mathrm{H} & -1.68300 & -1.83871 & -1.92861 \\ \mathrm{O} & -3.88470 & -1.23256 & -0.21824 \\ \mathrm{C} & -4.95658 & -0.37448 & 0.14009 \\ \mathrm{C} & -4.65777 & 0.95508 & -0.56893 \\ \mathrm{O} & -3.34553 & 0.81148 & -1.09498 \\ \mathrm{H} & -4.97230 & -0.26324 & 1.23141 \\ \mathrm{H} & -5.90573 & -0.82359 & -0.17457 \\ \mathrm{H} & -4.67994 & 1.80774 & 0.12018 \\ \mathrm{H} & -5.35383 & 1.16260 & -1.39234\end{array}$

\section{$\underline{\text { XYZ files for Calculated Structures in Chapter } 4}$}

$\mathrm{BF}_{2}$ :

Total Energy (kcal/mol): -1555745.575

Enthalpy Correction (AU): 0.293279

Free Energy Correction (AU): 0.21997

Three lowest frequencies $\left(\mathrm{cm}^{-1}\right): 17.4,29.2,34.7$
C $\quad 2.644100000 \quad 0.503040000$
1.104124000
C $\quad 3.259154000 \quad-1.732892000 \quad 1.291586000$
$\begin{array}{llll}\text { C } & 3.490396000 & -2.586137000 & 0.221782000\end{array}$
C $\quad 3.099569000 \quad-2.178411000 \quad-1.050179000$
C $\quad 2.482405000 \quad-0.954559000 \quad-1.237250000$
C $\quad 1.474585000 \quad 1.176471000 \quad-0.402950000$
C $\quad 2.225331000 \quad-0.078285000 \quad-0.165839000$
C $\quad 1.703424000 \quad 2.337335000 \quad 0.580422000$
B $\quad 0.577466000 \quad 3.323933000 \quad 0.204785000$
F $\quad-0.557890000 \quad 3.414270000 \quad 0.896300000$
F $\quad 0.636486000 \quad 4.096738000 \quad-0.869920000$
$\mathrm{Cu}-0.310957000 \quad 0.370174000 \quad-0.299723000$
C $\quad-1.898898000 \quad-0.693961000 \quad-0.080636000$ 


$\begin{array}{lrrr}\mathrm{C} & -0.750310000 & -2.892703000 & 0.024020000 \\ \mathrm{~N} & -1.927340000 & -2.042482000 & 0.038207000 \\ \mathrm{C} & -3.216971000 & -2.500063000 & 0.216202000 \\ \mathrm{C} & -4.017570000 & -1.413036000 & 0.206626000 \\ \mathrm{~N} & -3.194210000 & -0.319889000 & 0.027271000 \\ \mathrm{C} & -3.656038000 & 1.051912000 & -0.050928000 \\ \mathrm{H} & 2.479794000 & 0.142848000 & 1.964972000 \\ \mathrm{H} & 3.570335000 & -2.024869000 & 2.293857000 \\ \mathrm{H} & 3.979664000 & -3.545943000 & 0.371844000 \\ \mathrm{H} & 3.286953000 & -2.821389000 & -1.909231000 \\ \mathrm{H} & 2.177082000 & -0.649462000 & -2.239458000 \\ \mathrm{H} & 1.653432000 & 1.522535000 & -1.430176000 \\ \mathrm{H} & 2.721016000 & 2.753858000 & 0.498328000 \\ \mathrm{H} & 1.561305000 & 2.006924000 & 1.616819000 \\ \mathrm{H} & 0.122937000 & -2.291541000 & -0.243248000 \\ \mathrm{H} & -0.872671000 & -3.690110000 & -0.714101000 \\ \mathrm{H} & -0.584345000 & -3.333988000 & 1.010918000 \\ \mathrm{H} & -3.444537000 & -3.549707000 & 0.335195000 \\ \mathrm{H} & -5.088868001 & -1.316901000 & 0.309407000 \\ \mathrm{H} & -4.296645001 & 1.282450000 & 0.804579000 \\ \mathrm{H} & -4.214601001 & 1.219309000 & -0.976433000 \\ \mathrm{H} & -2.787818000 & 1.713112000 & -0.031647000\end{array}$

$\mathrm{BF}_{2}-\mathrm{CO}_{2}$ :

Total Energy (kcal/mol): -1674058.939

Enthalpy Correction (AU): 0.308619

Free Energy Correction (AU): 0.230032

Three lowest frequencies $\left(\mathrm{cm}^{-1}\right)$ : $-230.7,1.80,27.3$

$\begin{array}{lrrr}\mathrm{N} & 0.448991000 & 2.864143000 & -0.351370000 \\ \mathrm{C} & 0.935756000 & 1.663103000 & 0.032165000 \\ \mathrm{~N} & 2.278645000 & 1.813919000 & -0.006533000 \\ \mathrm{C} & 2.625469000 & 3.088284000 & -0.405706000 \\ \mathrm{C} & 1.469149000 & 3.751359000 & -0.620053000 \\ \mathrm{Cu} & -0.087229000 & 0.077275000 & 0.477471000 \\ \mathrm{C} & 0.324243000 & -2.146848000 & 0.213085000 \\ \mathrm{C} & 1.327339000 & -2.516667000 & 1.133092000 \\ \mathrm{C} & 2.586339000 & -2.905305000 & 0.712459000 \\ \mathrm{C} & 2.901877000 & -2.929832000 & -0.642647000 \\ \mathrm{C} & 1.935918000 & -2.553933000 & -1.566900000 \\ \mathrm{C} & 0.671217000 & -2.164930000 & -1.152772000 \\ \mathrm{C} & -0.999852000 & -1.697996000 & 0.692068000 \\ \mathrm{C} & -2.216946000 & -1.933491000 & -0.187976000 \\ \mathrm{~B} & -2.747595000 & -0.649033000 & -0.931276000 \\ \mathrm{~F} & -4.009326000 & -0.577905000 & -1.358812000 \\ \mathrm{C} & 3.236388000 & 0.764229000 & 0.280979000\end{array}$




$\begin{array}{lrrr}\mathrm{C} & -0.968549000 & 3.179561000 & -0.428543000 \\ \mathrm{C} & -1.993544000 & 0.421188000 & 1.472001000 \\ \mathrm{O} & -2.868286000 & 0.480623000 & 0.630334000 \\ \mathrm{O} & -1.695431000 & 0.708063000 & 2.582484000 \\ \mathrm{~F} & -1.869397000 & 0.094882000 & -1.664823000 \\ \mathrm{H} & 2.167179000 & -2.567101000 & -2.630327000 \\ \mathrm{H} & 3.329118000 & -3.205568000 & 1.449507000 \\ \mathrm{H} & 3.888395000 & -3.246244000 & -0.973372000 \\ \mathrm{H} & 1.085150000 & -2.508954000 & 2.195716000 \\ \mathrm{H} & -0.068978000 & -1.864229000 & -1.891712000 \\ \mathrm{H} & -1.371668000 & 3.377378000 & 0.568521000 \\ \mathrm{H} & -1.506435000 & 2.342225000 & -0.875444000 \\ \mathrm{H} & -1.102126000 & 4.065445000 & -1.052685000 \\ \mathrm{H} & 1.280244000 & 4.766100001 & -0.938905000 \\ \mathrm{H} & 3.654996000 & 3.400306000 & -0.504720000 \\ \mathrm{H} & 3.911054000 & 1.077985000 & 1.082412000 \\ \mathrm{H} & 2.700294000 & -0.134569000 & 0.594903000 \\ \mathrm{H} & 3.819702000 & 0.526622000 & -0.613137000 \\ \mathrm{H} & -2.013769000 & -2.723737000 & -0.928918000 \\ \mathrm{H} & -3.043794000 & -2.316793000 & 0.424638000 \\ \mathrm{H} & -1.145788000 & -2.005736000 & 1.731212000\end{array}$

$\mathrm{B}(\mathrm{OMe})_{2}$ :

Total Energy (kcal/mol): -1574866.559

Enthalpy Correction (AU): 0.377714

Free Energy Correction (AU): 0.297412

Three lowest frequencies $\left(\mathrm{cm}^{-1}\right): 10.9,28.1,39.8$

$\begin{array}{llll}\mathrm{C} & 0.757322000 & 0.375352000 & 1.241326000 \\ \mathrm{~N} & 0.862498000 & -0.969761000 & 0.713099000 \\ \mathrm{C} & 0.243094000 & -2.076408000 & 1.259782000 \\ \mathrm{C} & 0.604504000 & -3.132736000 & 0.500484000 \\ \mathrm{~N} & 1.436646000 & -2.644533000 & -0.485771000 \\ \mathrm{C} & 2.032016000 & -3.449569000 & -1.538370000 \\ \mathrm{C} & 1.601083000 & -1.306003000 & -0.369489000 \\ \mathrm{Cu} & 2.672572000 & -0.210805000 & -1.534802000 \\ \mathrm{C} & 5.519835001 & -1.305135000 & -3.025467000 \\ \mathrm{C} & 5.870268001 & -2.546851000 & -3.535918000 \\ \mathrm{C} & 5.078380001 & -3.178262000 & -4.485237001 \\ \mathrm{C} & 3.927248000 & -2.530910000 & -4.925306001 \\ \mathrm{C} & 3.575694000 & -1.294872000 & -4.414276001 \\ \mathrm{C} & 4.352643001 & -0.641059000 & -3.437251000\end{array}$




$\begin{array}{lrrr}\mathrm{C} & 3.876566000 & 0.624611000 & -2.836156000 \\ \mathrm{C} & 4.914127001 & 1.596632000 & -2.256322000 \\ \mathrm{~B} & 4.084951000 & 2.617567000 & -1.409518000 \\ \mathrm{O} & 3.894021000 & 2.543259000 & -0.049344000 \\ \mathrm{O} & 3.430700000 & 3.621413000 & -2.058090000 \\ \mathrm{C} & 2.529344000 & 4.448634001 & -1.370886000 \\ \mathrm{C} & 4.510279001 & 1.558371000 & 0.731566000 \\ \mathrm{H} & -0.284521000 & 0.708282000 & 1.236847000 \\ \mathrm{H} & 1.143645000 & 0.414612000 & 2.264330000 \\ \mathrm{H} & 1.349383000 & 1.043525000 & 0.611773000 \\ \mathrm{H} & -0.387267000 & -2.011809000 & 2.135102000 \\ \mathrm{H} & 0.349043000 & -4.180116000 & 0.573224000 \\ \mathrm{H} & 2.409985000 & -4.385402001 & -1.118826000 \\ \mathrm{H} & 2.862204000 & -2.898654000 & -1.987734000 \\ \mathrm{H} & 1.297403000 & -3.671760000 & -2.318003000 \\ \mathrm{H} & 6.164110001 & -0.840102000 & -2.281109000 \\ \mathrm{H} & 6.784285001 & -3.027015000 & -3.188069000 \\ \mathrm{H} & 5.359094001 & -4.148968000 & -4.887885001 \\ \mathrm{H} & 3.299493000 & -2.995299000 & -5.685120001 \\ \mathrm{H} & 2.667793000 & -0.801285000 & -4.765134001 \\ \mathrm{H} & 3.238472000 & 1.160051000 & -3.553193000 \\ \mathrm{H} & 5.497551001 & 2.083656000 & -3.055503000 \\ \mathrm{H} & 5.637068001 & 1.060492000 & -1.627171000 \\ \mathrm{H} & 1.664000000 & 3.877710000 & -1.006572000 \\ \mathrm{H} & 2.998654000 & 4.936657001 & -0.508252000 \\ \mathrm{H} & 2.174861000 & 5.215208001 & -2.065352000 \\ \mathrm{H} & 4.221582001 & 1.719519000 & 1.775351000 \\ \mathrm{H} & 4.188699001 & 0.546964000 & 0.430967000 \\ \mathrm{H} & 5.604714001 & 1.604523000 & 0.666994000\end{array}$

$\mathrm{B}(\mathrm{OMe})_{2}-\mathrm{CO}_{2}$ :

Total Energy (kcal/mol): -1693175.676

Enthalpy Correction (AU): 0.393558

Free Energy Correction (AU): 0.30925

Three lowest frequencies $\left(\mathrm{cm}^{-1}\right):-175.5,15.9,37.3$

$\begin{array}{lrrr}\mathrm{Cu} & 0.517901000 & -3.396486000 & 2.665306000 \\ \mathrm{C} & 0.315369000 & -5.330547001 & 1.618657000 \\ \mathrm{O} & 1.368246000 & -5.172602001 & 1.051084000 \\ \mathrm{O} & -0.341865000 & -6.157986001 & 2.200857000 \\ \mathrm{C} & -0.973438000 & -3.776927000 & 1.228639000 \\ \mathrm{C} & -0.535683000 & -2.360230000 & 1.067059000 \\ \mathrm{C} & -0.692702000 & 0.012395000 & 1.601454000 \\ \mathrm{C} & 0.566032000 & -2.048318000 & 0.238869000 \\ \mathrm{C} & -1.145851000 & -1.291346000 & 1.752218000\end{array}$




$\begin{array}{lrrr}\mathrm{C} & 1.017925000 & -0.747313000 & 0.106298000 \\ \mathrm{C} & 0.390855000 & 0.295416000 & 0.782230000 \\ \mathrm{C} & 1.708833000 & -3.190024000 & 4.153312000 \\ \mathrm{~N} & 2.256948000 & -2.054148000 & 4.641065001 \\ \mathrm{C} & 3.164931000 & -2.330702000 & 5.642236001 \\ \mathrm{C} & 3.180975000 & -3.673227000 & 5.786754001 \\ \mathrm{~N} & 2.282098000 & -4.180761000 & 4.872726001 \\ \mathrm{C} & 2.050579000 & -5.597533001 & 4.644737001 \\ \mathrm{C} & 1.980445000 & -0.726681000 & 4.127388000 \\ \mathrm{~B} & -2.700187000 & -5.569609001 & 1.885979000 \\ \mathrm{C} & -2.286141000 & -4.044265000 & 1.938273000 \\ \mathrm{O} & -3.118531000 & -6.314219001 & 2.951907000 \\ \mathrm{O} & -2.814395000 & -6.114414001 & 0.642630000 \\ \mathrm{C} & -3.029815000 & -7.496354001 & 0.504779000 \\ \mathrm{C} & -2.877175000 & -5.907795001 & 4.266700001 \\ \mathrm{H} & -1.203627000 & 0.818688000 & 2.125513000 \\ \mathrm{H} & 1.864278000 & -0.540498000 & -0.546041000 \\ \mathrm{H} & 0.737864000 & 1.318882000 & 0.659639000 \\ \mathrm{H} & 1.059113000 & -2.858944000 & -0.294547000 \\ \mathrm{H} & -2.007200000 & -1.489475000 & 2.386316000 \\ \mathrm{H} & 1.049909000 & -5.743707001 & 4.233271001 \\ \mathrm{H} & 2.136881000 & -6.136154001 & 5.591326001 \\ \mathrm{H} & 2.775177000 & -5.992290001 & 3.927446000 \\ \mathrm{H} & 3.740430000 & -4.309480001 & 6.457160001 \\ \mathrm{H} & 3.704213000 & -1.551711000 & 6.161229001 \\ \mathrm{H} & 1.061569000 & -0.756235000 & 3.536543000 \\ \mathrm{H} & 1.853414000 & -0.025795000 & 4.956747001 \\ \mathrm{H} & 2.797240000 & -0.384483000 & 3.484927000 \\ \mathrm{H} & -2.262306000 & -3.665455000 & 2.970635000 \\ \mathrm{H} & -3.092841000 & -3.480176000 & 1.435049000 \\ \mathrm{H} & -0.961290000 & -4.255395001 & 0.242997000 \\ \mathrm{H} & -3.030552000 & -7.733920001 & -0.562657000 \\ \mathrm{H} & -2.231913000 & -8.065981001 & 0.997140000 \\ \mathrm{H} & -3.989427000 & -7.802875001 & 0.938638000 \\ \mathrm{H} & -3.148118000 & -6.730697001 & 4.935089001 \\ \mathrm{H} & -1.816226000 & -5.667826001 & 4.424284001 \\ \mathrm{H} & -3.478798000 & -5.030732001 & 4.545344001\end{array}$

$\mathrm{B}\left(-\mathrm{O}\left(\mathrm{CH}_{2}\right)_{2} \mathrm{O}-\right)$ :

Total Energy (kcal/mol): -1574115.98

Enthalpy Correction (AU): 0.355418

Free Energy Correction (AU): 0.276863

Three lowest frequencies $\left(\mathrm{cm}^{-1}\right): 6.2,24.0,35.7$

$\begin{array}{llll}\mathrm{Cu} & 1.843902000 & -0.422500000 & 2.075991000\end{array}$ 


$\begin{array}{lrrr}\mathrm{C} & 2.439938000 & -0.792102000 & 0.288665000 \\ \mathrm{~N} & 3.709771000 & -0.694587000 & -0.169364000 \\ \mathrm{C} & 3.795919000 & -1.090487000 & -1.488853000 \\ \mathrm{C} & 2.550044000 & -1.448632000 & -1.866588000 \\ \mathrm{~N} & 1.736918000 & -1.264422000 & -0.766109000 \\ \mathrm{C} & 4.839438001 & -0.270961000 & 0.638052000 \\ \mathrm{C} & 0.312781000 & -1.535824000 & -0.732596000 \\ \mathrm{~B} & -0.806254000 & -1.022472000 & 3.737851000 \\ \mathrm{O} & -1.700064000 & -0.079610000 & 4.173768000 \\ \mathrm{C} & -2.775582000 & -0.026548000 & 3.253757000 \\ \mathrm{C} & -2.267806000 & -0.794247000 & 2.031908000 \\ \mathrm{O} & -1.183799000 & -1.565440000 & 2.521757000 \\ \mathrm{C} & 1.516193000 & -0.276826000 & 4.001235000 \\ \mathrm{C} & 2.926764000 & -0.419608000 & 4.420613001 \\ \mathrm{C} & 5.691316001 & -0.641159000 & 5.019367001 \\ \mathrm{C} & 3.519527000 & -1.655404000 & 4.724249001 \\ \mathrm{C} & 3.774116000 & 0.705766000 & 4.452892001 \\ \mathrm{C} & 5.121523001 & 0.599386000 & 4.745046001 \\ \mathrm{C} & 4.873375001 & -1.761871000 & 5.010314001 \\ \mathrm{C} & 0.524197000 & -1.357131000 & 4.458863001 \\ \mathrm{H} & 4.730611001 & -1.090409000 & -2.030992000 \\ \mathrm{H} & 2.171633000 & -1.820921000 & -2.807865000 \\ \mathrm{H} & 4.494715001 & -0.072455000 & 1.656676000 \\ \mathrm{H} & -0.006340000 & -1.626440000 & 0.309914000 \\ \mathrm{H} & 1.143428000 & 0.720442000 & 4.270853001 \\ \mathrm{H} & 2.904825000 & -2.553801000 & 4.731611001 \\ \mathrm{H} & 3.342159000 & 1.683364000 & 4.231642001 \\ \mathrm{H} & 5.738044001 & 1.497515000 & 4.766194001 \\ \mathrm{H} & 5.294173001 & -2.740385000 & 5.239437001 \\ \mathrm{H} & 6.750645001 & -0.726881000 & 5.251283001 \\ \mathrm{H} & 0.858817000 & -2.354349000 & 4.139914000 \\ \mathrm{H} & 5.283398001 & 0.639498000 & 0.225236000 \\ \mathrm{H} & 5.596304001 & -1.059462000 & 0.673936000 \\ \mathrm{H} & 0.104578000 & -2.476337000 & -1.250028000 \\ \mathrm{H} & -0.247395000 & -0.728909000 & -1.215715000 \\ \mathrm{H} & -3.658850000 & -0.500350000 & 3.703933000 \\ \mathrm{H} & -3.022907000 & 1.017032000 & 3.032864000 \\ & -1.894924000 & -0.112543000 & 1.251173000 \\ & 0.423877000 & -1.386578000 & 5.557730001\end{array}$

$\mathrm{B}\left(\mathrm{O}\left(\mathrm{CH}_{2}\right)_{2} \mathrm{O}\right)-\mathrm{CO}_{2}$ :

Total Energy (kcal/mol): -1692426.204

Enthalpy Correction (AU): 0.371776

Free Energy Correction (AU): 0.293165 
Three lowest frequencies $\left(\mathrm{cm}^{-1}\right):-176.7,33.2,44.8$

$\begin{array}{lrrr}\mathrm{Cu} & 0.711891000 & -3.251303000 & 2.402102000 \\ \mathrm{C} & 0.710052000 & -4.776919001 & 1.249190000 \\ \mathrm{~N} & 1.481889000 & -5.040869001 & 0.171990000 \\ \mathrm{C} & 1.174186000 & -6.273239001 & -0.367872000 \\ \mathrm{C} & 0.190076000 & -6.792504001 & 0.398106000 \\ \mathrm{~N} & -0.084013000 & -5.862877001 & 1.378264000 \\ \mathrm{C} & 2.476864000 & -4.130756000 & -0.358762000 \\ \mathrm{C} & -1.044154000 & -6.045095001 & 2.458019000 \\ \mathrm{C} & 0.519045000 & -2.139443000 & 4.172394000 \\ \mathrm{C} & 1.814516000 & -1.753235000 & 3.549323000 \\ \mathrm{C} & 4.199990001 & -1.045122000 & 2.208173000 \\ \mathrm{C} & 2.986502000 & -2.527174000 & 3.673247000 \\ \mathrm{C} & 1.884146000 & -0.608989000 & 2.722758000 \\ \mathrm{C} & 3.051924000 & -0.267682000 & 2.068988000 \\ \mathrm{C} & 4.157347000 & -2.171555000 & 3.013272000 \\ \mathrm{C} & 0.520526000 & -3.220181000 & 5.243209001 \\ \mathrm{~B} & -0.925711000 & -3.576374000 & 5.723540001 \\ \mathrm{C} & -1.158761000 & -2.205691000 & 2.987182000 \\ \mathrm{O} & -1.951055000 & -2.921080000 & 3.551632000 \\ \mathrm{O} & -1.063885000 & -1.394835000 & 2.102017000 \\ \mathrm{O} & -1.726808000 & -2.692055000 & 6.388784001 \\ \mathrm{C} & -2.996689000 & -3.300223000 & 6.542916001 \\ \mathrm{C} & -2.808829000 & -4.754675001 & 6.067813001 \\ \mathrm{O} & -1.460106000 & -4.837653001 & 5.639319001 \\ \mathrm{H} & 1.674707000 & -6.659974001 & -1.243745000 \\ \mathrm{H} & -0.338745000 & -7.732413001 & 0.333876000 \\ \mathrm{H} & 2.633539000 & -3.324845000 & 0.362520000 \\ \mathrm{H} & -1.844601000 & -6.705101001 & 2.115398000 \\ \mathrm{H} & 2.987732000 & -3.398412000 & 4.324574001 \\ \mathrm{H} & 0.988027000 & -0.006055000 & 2.596686000 \\ \mathrm{H} & 3.072899000 & 0.624149000 & 1.445518000 \\ \mathrm{H} & -2.049384001 & -2.781240000 & 3.146821000 \\ \mathrm{H} & 5.120029001 & -0.764021000 & 1.700607000 \\ \mathrm{H} & 1.005659000 & -4.143678000 & 4.892758001 \\ \mathrm{H} & 0.007500000 & -1.240126000 & 4.532607001 \\ \mathrm{H} & 3.422414000 & -4.657278001 & -0.514461000 \\ \mathrm{H} & 2.141075000 & -3.701215000 & -1.307002000 \\ \mathrm{H} & -1.468540000 & -5.078984001 & 2.742049000 \\ \mathrm{H} & -0.560912000 & -6.482005001 & 3.336177000 \\ \mathrm{H} & -3.723887000 & -2.880937000 & 6.111694001 \\ \mathrm{H} & -2.761179000 & 5.924754001 \\ \mathrm{H} & -3.46513000 & -3.229760000 & 7.592009001 \\ \mathrm{H} & -4.995100001 & 5.221621001 \\ \mathrm{H} & -5.4900 & -51895001 & 6.861516001\end{array}$


$\mathrm{B}\left(\mathrm{O}(\mathrm{CH})_{2} \mathrm{O}\right)$ :

Total Energy (kcal/mol): -1573350.541

Enthalpy Correction (AU): 0.331113

Free Energy Correction (AU): 0.255596

Three lowest frequencies $\left(\mathrm{cm}^{-1}\right): 20.7,24.3,36.2$

$\begin{array}{lrrr}\mathrm{C} & -1.188680000 & -2.307867000 & 3.003557000 \\ \mathrm{Cu} & 0.707329000 & -3.313047000 & 2.418218000 \\ \mathrm{C} & 0.532049000 & -2.157445000 & 4.151572000 \\ \mathrm{C} & 1.824052000 & -1.804179000 & 3.506794000 \\ \mathrm{C} & 1.894060000 & -0.707083000 & 2.617026000 \\ \mathrm{C} & 3.060603000 & -0.407945000 & 1.940137000 \\ \mathrm{C} & 4.206397001 & -1.181550000 & 2.116308000 \\ \mathrm{C} & 4.162319000 & -2.262347000 & 2.982134000 \\ \mathrm{C} & 2.993582000 & -2.575161000 & 3.666720000 \\ \mathrm{C} & 0.525590000 & -3.190863000 & 5.262982001 \\ \mathrm{O} & -1.555519000 & -2.376947000 & 6.404699001 \\ \mathrm{~B} & -0.914319000 & -3.448178000 & 5.845702001 \\ \mathrm{O} & -1.357505000 & -4.742612001 & 5.939165001 \\ \mathrm{O} & -1.925829000 & -3.043986000 & 3.612982000 \\ \mathrm{O} & -1.154381000 & -1.504609000 & 2.108971000 \\ \mathrm{C} & -0.932149000 & -6.179369001 & 2.492944000 \\ \mathrm{~N} & -0.050287000 & -5.924494001 & 1.364214000 \\ \mathrm{C} & 0.182665000 & -6.804545001 & 0.328308000 \\ \mathrm{C} & 1.093685000 & -6.221097001 & -0.480493000 \\ \mathrm{~N} & 1.399893000 & -5.001630001 & 0.088442000 \\ \mathrm{C} & 2.329840000 & -4.039697000 & -0.468694000 \\ \mathrm{C} & 0.697831000 & -4.807483001 & 1.226441000 \\ \mathrm{H} & 0.015641000 & -1.243083000 & 4.461732001 \\ \mathrm{H} & 0.998671000 & -0.108648000 & 2.463332000 \\ \mathrm{H} & 3.082391000 & 0.448516000 & 1.268667000 \\ \mathrm{H} & 5.125139001 & -0.932546000 & 1.590067000 \\ \mathrm{H} & 5.051589001 & -2.869735000 & 3.142030000 \\ \mathrm{H} & 2.988631000 & -3.412160000 & 4.361614001 \\ \mathrm{H} & 0.954242000 & -4.151881000 & 4.938942001 \\ \mathrm{H} & 1.166550000 & -2.844889000 & 6.094524001 \\ \mathrm{H} & -2.233053000 & -4.835597001 & 6.321656001 \\ \mathrm{H} & -2.473713000 & -2.520175000 & 6.641933001 \\ \mathrm{H} & -0.408965000 & -6.740251001 & 3.272713000 \\ \mathrm{H} & -1.275053000 & -5.229851001 & 2.912400000 \\ \mathrm{H} & -1.797576000 & -6.752566001 & 2.151492000 \\ \mathrm{H} & -0.319545000 & -7.758685001 & 0.260379000 \\ \mathrm{H} & 1.542946000 & -6.554777001 & -1.404612000 \\ \mathrm{H} & 3.288497000 & -4.522135001 & -0.678080000 \\ \mathrm{H} & 1.930974000 & -3.608395000 & -1.391198000\end{array}$




\section{H $\quad 2.485395000 \quad-3.241101000 \quad 0.260675000$}

\section{$\mathrm{B}\left(\mathrm{O}(\mathrm{CH})_{2} \mathrm{O}\right)-\mathrm{CO}_{2}$ :}

Total Energy (kcal/mol): -1691659.189

Enthalpy Correction (AU): 0.346083

Free Energy Correction (AU): 0.267679

Three lowest frequencies $\left(\mathrm{cm}^{-1}\right):-180.2,-28.4,{ }^{172} 5.54$

$\begin{array}{lrrr}\mathrm{C} & 0.71409 & -3.16004 & 2.45947 \\ \mathrm{C} & 0.65094 & -4.25901 & 1.61763 \\ \mathrm{C} & 1.51224 & -4.32571 & 0.52491 \\ \mathrm{C} & 2.41891 & -3.31250 & 0.27722 \\ \mathrm{C} & 2.50340 & -2.18334 & 1.12243 \\ \mathrm{C} & 1.62306 & -2.13574 & 2.22134 \\ \mathrm{Cu} & 1.56926 & -0.57140 & -0.01885 \\ \mathrm{O} & 3.19750 & -1.20750 & -1.89762 \\ \mathrm{C} & 3.47269 & -0.33851 & -1.10729 \\ \mathrm{O} & 3.93919 & 0.77195 & -1.02987 \\ \mathrm{C} & 3.43948 & -1.07266 & 0.78257 \\ \mathrm{C} & 3.65686 & 0.02634 & 1.80885 \\ \mathrm{~B} & 4.54530 & 1.20844 & 1.30453 \\ \mathrm{O} & 4.14550 & 2.53717 & 1.29470 \\ \mathrm{C} & 5.25911 & 3.23566 & 0.89995 \\ \mathrm{C} & 6.28553 & 2.40215 & 0.74437 \\ \mathrm{O} & 5.89797 & 1.12022 & 1.03302 \\ \mathrm{C} & -0.02712 & 0.37881 & -0.44340 \\ \mathrm{~N} & -1.27782 & -0.09013 & -0.63910 \\ \mathrm{C} & -2.14043 & 0.93087 & -0.98103 \\ \mathrm{C} & -1.40902 & 2.06712 & -0.98441 \\ \mathrm{~N} & -0.11822 & 1.70871 & -0.65862 \\ \mathrm{C} & -1.62809 & -1.49640 & -0.57483 \\ \mathrm{C} & 1.00610 & 2.62104 & -0.50268 \\ \mathrm{H} & -3.18669 & 0.75758 & -1.18676 \\ \mathrm{H} & -1.68975 & 3.09050 & -1.18645 \\ \mathrm{H} & -1.52358 & -1.96808 & -1.55610 \\ \mathrm{H} & 0.77181 & 3.56310 & -1.00282 \\ \mathrm{H} & 1.66788 & -1.29607 & 2.91119 \\ \mathrm{H} & 3.07299 & -3.35804 & -0.59026 \\ \mathrm{H} & 1.47867 & -5.18560 & -0.14133 \\ \mathrm{H} & 0.05792 & -3.09868 & 3.32602 \\ & & & \end{array}$

${ }^{172}$ Several attempts to further optimize the geometry to a saddle point characterized by a single negative frequency were unsuccessful. The surrounding potential energy surface was characterized as relatively flat, which suggests that the calculated electronic energy and resulting enthalpic barrier will not be impacted significantly. 


$\begin{array}{lrrc}\mathrm{H} & -0.05270 & -5.06482 & 1.81403 \\ \mathrm{H} & 2.70166 & 0.45865 & 2.14551 \\ \mathrm{H} & 4.39541 & -1.49505 & 0.45366 \\ \mathrm{H} & -0.95891 & -1.99616 & 0.13098 \\ \mathrm{H} & -2.65896 & -1.60212 & -0.22813 \\ \mathrm{H} & 1.89772 & 2.18381 & -0.95626 \\ \mathrm{H} & 1.21265 & 2.80909 & 0.55484 \\ \mathrm{H} & 4.12373 & -0.39522 & 2.71708 \\ \mathrm{H} & 7.31276 & 2.57208 & 0.45534 \\ \mathrm{H} & 5.17427 & 4.30574 & 0.77733\end{array}$

$\mathrm{B}(\mathrm{OH})_{2}$ :

Total Energy (kcal/mol): -1525570.838

Enthalpy Correction (AU): 0.318338

Free Energy Correction (AU): 0.243938

Three lowest frequencies $\left(\mathrm{cm}^{-1}\right): 20.8,26.6,33.7$

$\begin{array}{lrrr}\mathrm{Cu} & 0.501623000 & -3.681544000 & 2.592756000 \\ \mathrm{C} & 0.402642000 & -5.046409001 & 1.237756000 \\ \mathrm{~N} & 0.897421000 & -4.999437001 & -0.021412000 \\ \mathrm{C} & 0.650122000 & -6.175083001 & -0.701577000 \\ \mathrm{C} & -0.012771000 & -6.982275001 & 0.153432000 \\ \mathrm{~N} & -0.153979000 & -6.276431001 & 1.331610000 \\ \mathrm{C} & 1.597042000 & -3.858803000 & -0.579583000 \\ \mathrm{C} & -0.787104000 & -6.793121001 & 2.529141000 \\ \mathrm{C} & 0.777536000 & -2.320667000 & 3.968845000 \\ \mathrm{C} & 2.121182000 & -1.806542000 & 3.616140000 \\ \mathrm{C} & 4.669533001 & -0.854018000 & 2.820747000 \\ \mathrm{C} & 3.292195000 & -2.194046000 & 4.281892001 \\ \mathrm{C} & 2.277078000 & -0.909658000 & 2.542138000 \\ \mathrm{C} & 3.518842000 & -0.444045000 & 2.152591000 \\ \mathrm{C} & 4.540062001 & -1.729608000 & 3.887848000 \\ \mathrm{C} & 0.622545000 & -2.918947000 & 5.374351001 \\ \mathrm{~B} & -0.866091000 & -3.341791000 & 5.554058001 \\ \mathrm{O} & -1.777232000 & -2.389193000 & 5.916789001 \\ \mathrm{O} & -1.238824000 & -4.645670001 & 5.301710001 \\ \mathrm{H} & 0.970163000 & -6.329164001 & -1.722160000 \\ \mathrm{H} & -0.389473000 & -7.988212001 & 0.034980000 \\ \mathrm{H} & 1.774172000 & -3.132726000 & 0.217564000 \\ \mathrm{H} & -1.833471000 & -7.042677001 & 2.327449000 \\ \mathrm{H} & 3.222299000 & -2.872426000 & 5.130465001 \\ \mathrm{H} & 1.381580000 & -0.579457000 & 2.011114000 \\ \mathrm{H} & 3.593904000 & 0.256700000 & 1.321389000 \\ \mathrm{H} & 5.426179001 & -2.053548000 & 4.432873001 \\ \mathrm{H} & 5.647906001 & -0.487450000 & 2.517418000 \\ \mathrm{H} & 1.265634000 & -3.802551000 & 5.495560001\end{array}$




$\begin{array}{rrrr}\mathrm{H} & 0.038766000 & -1.518366000 & 3.822356000 \\ \mathrm{H} & 2.560070000 & -4.172423000 & -0.991783000 \\ \mathrm{H} & 1.001604000 & -3.389553000 & -1.368362000 \\ \mathrm{H} & -0.739718000 & -6.030435001 & 3.311901000 \\ \mathrm{H} & -0.265953000 & -7.690450001 & 2.875311000 \\ \mathrm{H} & 0.924907000 & -2.194672000 & 6.152844001 \\ \mathrm{H} & -2.178204000 & -4.817777001 & 5.407475001 \\ \mathrm{H} & -2.694947000 & -2.669092000 & 5.947627001\end{array}$

$\mathrm{B}(\mathrm{OH})_{2}-\mathrm{CO}_{2}$ :

Total Energy (kcal/mol): -1643881.916

Enthalpy Correction (AU): 0.333685

Free Energy Correction (AU): 0.256308

Three lowest frequencies $\left(\mathrm{cm}^{-1}\right)$ : $-176.3,23.3,36.0$

$\begin{array}{lccc}\mathrm{C} & -1.188680000 & -2.307867000 & 3.003557000 \\ \mathrm{Cu} & 0.707329000 & -3.313047000 & 2.418218000 \\ \mathrm{C} & 0.532049000 & -2.157445000 & 4.151572000 \\ \mathrm{C} & 1.824052000 & -1.804179000 & 3.506794000 \\ \mathrm{C} & 1.894060000 & -0.707083000 & 2.617026000 \\ \mathrm{C} & 3.060603000 & -0.407945000 & 1.940137000 \\ \mathrm{C} & 4.206397001 & -1.181550000 & 2.116308000 \\ \mathrm{C} & 4.162319000 & -2.262347000 & 2.982134000 \\ \mathrm{C} & 2.993582000 & -2.575161000 & 3.666720000 \\ \mathrm{C} & 0.525590000 & -3.190863000 & 5.262982001 \\ \mathrm{O} & -1.555519000 & -2.376947000 & 6.404699001 \\ \mathrm{~B} & -0.914319000 & -3.448178000 & 5.845702001 \\ \mathrm{O} & -1.357505000 & -4.742612001 & 5.939165001 \\ \mathrm{O} & -1.925829000 & -3.043986000 & 3.612982000 \\ \mathrm{O} & -1.154381000 & -1.504609000 & 2.108971000 \\ \mathrm{C} & -0.932149000 & -6.179369001 & 2.492944000 \\ \mathrm{~N} & -0.050287000 & -5.924494001 & 1.364214000 \\ \mathrm{C} & 0.182665000 & -6.804545001 & 0.328308000 \\ \mathrm{C} & 1.093685000 & -6.221097001 & -0.480493000 \\ \mathrm{~N} & 1.399893000 & -5.001630001 & 0.088442000 \\ \mathrm{C} & 2.329840000 & -4.039697000 & -0.468694000 \\ \mathrm{C} & 0.697831000 & -4.807483001 & 1.226441000 \\ \mathrm{H} & 0.015641000 & -1.243083000 & 4.461732001 \\ \mathrm{H} & 0.998671000 & -0.108648000 & 2.463332000 \\ \mathrm{H} & 3.082391000 & 0.448516000 & 1.268667000 \\ \mathrm{H} & 5.125139001 & -0.932546000 & 1.590067000 \\ \mathrm{H} & 5.051589001 & -2.869735000 & 3.142030000 \\ \mathrm{H} & 2.988631000 & -3.412160000 & 4.361614001 \\ \mathrm{H} & 0.954242000 & -4.151881000 & 4.938942001 \\ \mathrm{H} & 1.166550000 & -2.844889000 & 6.094524001\end{array}$




$\begin{array}{lrrr}\mathrm{H} & -2.233053000 & -4.835597001 & 6.321656001 \\ \mathrm{H} & -2.473713000 & -2.520175000 & 6.641933001 \\ \mathrm{H} & -0.408965000 & -6.740251001 & 3.272713000 \\ \mathrm{H} & -1.275053000 & -5.229851001 & 2.912400000 \\ \mathrm{H} & -1.797576000 & -6.752566001 & 2.151492000 \\ \mathrm{H} & -0.319545000 & -7.758685001 & 0.260379000 \\ \mathrm{H} & 1.542946000 & -6.554777001 & -1.404612000 \\ \mathrm{H} & 3.288497000 & -4.522135001 & -0.678080000 \\ \mathrm{H} & 1.930974000 & -3.608395000 & -1.391198000 \\ \mathrm{H} & 2.485395000 & -3.241101000 & 0.260675000\end{array}$

$\mathrm{B}\left(\mathrm{CH}_{3}\right)_{2}$ :

Total Energy (kcal/mol): -1480429.717

Enthalpy Correction (AU): 0.362323

Free Energy Correction (AU): 0.28913

Three lowest frequencies $\left(\mathrm{cm}^{-1}\right): 27.4,47.2,58.4$

$\begin{array}{lrrr}\mathrm{C} & 1.876759000 & -0.974168000 & 0.558153000 \\ \mathrm{C} & 2.841701000 & -1.196709000 & -0.358667000 \\ \mathrm{C} & -0.603745000 & -0.680264000 & 0.485564000 \\ \mathrm{~N} & 0.682671000 & -0.928290000 & -0.132303000 \\ \mathrm{C} & 0.874359000 & -1.114613000 & -1.459368000 \\ \mathrm{~N} & 2.212095000 & -1.284141000 & -1.582635000 \\ \mathrm{C} & 2.902354000 & -1.460078000 & -2.848062000 \\ \mathrm{Cu} & -0.407127000 & -1.007472000 & -2.891974000 \\ \mathrm{C} & -1.373901000 & -1.126373000 & -4.681629001 \\ \mathrm{C} & -0.056660000 & -1.246974000 & -5.355447001 \\ \mathrm{C} & 0.669314000 & -0.142346000 & -5.826880001 \\ \mathrm{C} & 1.913547000 & -0.296490000 & -6.419276001 \\ \mathrm{C} & 2.479095000 & -1.555908000 & -6.573900001 \\ \mathrm{C} & 1.770604000 & -2.665189000 & -6.127485001 \\ \mathrm{C} & 0.532190000 & -2.511411000 & -5.525377001 \\ \mathrm{C} & -2.367421000 & -0.058770000 & -5.154461001 \\ \mathrm{~B} & -2.206245000 & 0.223960000 & -3.637290000 \\ \mathrm{C} & -3.329958000 & -0.354652000 & -2.652686000 \\ \mathrm{C} & -1.377618000 & 1.516610000 & -3.151211000 \\ \mathrm{H} & 1.926762000 & -0.853524000 & 1.630617000 \\ \mathrm{H} & 3.911339000 & -1.306789000 & -0.252696000 \\ \mathrm{H} & -0.768408000 & -1.380368000 & 1.309260000 \\ \mathrm{H} & -0.657141000 & 0.344650000 & 0.864321000 \\ \mathrm{H} & -1.383780000 & -0.820279000 & -0.265140000 \\ \mathrm{H} & 3.745366000 & -2.142399000 & -2.712574000 \\ \mathrm{H} & 3.266709000 & -0.501496000 & -3.228612000 \\ \mathrm{H} & 2.213958000 & -1.884873000 & -3.582441000 \\ \mathrm{H} & -1.930572000 & 0.637347000 & -5.874186001\end{array}$




$\begin{array}{rrrr}\mathrm{H} & -1.856562000 & -2.105514000 & -4.588354001 \\ \mathrm{H} & 0.246548000 & 0.855090000 & -5.725632001 \\ \mathrm{H} & 2.446132000 & 0.584141000 & -6.775165001 \\ \mathrm{H} & 3.449257000 & -1.673039000 & -7.051500001 \\ \mathrm{H} & 2.185578000 & -3.664063000 & -6.253950001 \\ \mathrm{H} & -0.011719000 & -3.390190000 & -5.177230001 \\ \mathrm{H} & -3.295942000 & -0.485404000 & -5.540201001 \\ \mathrm{H} & -3.031288000 & -0.465208000 & -1.598661000 \\ \mathrm{H} & -4.185009000 & 0.340426000 & -2.643531000 \\ \mathrm{H} & -3.730372000 & -1.325152000 & -2.976924000 \\ \mathrm{H} & -1.035238000 & 1.495743000 & -2.104121000 \\ \mathrm{H} & -0.505930000 & 1.778119000 & -3.766783000 \\ \mathrm{H} & -2.059110000 & 2.380650000 & -3.215531000\end{array}$

$\mathrm{B}\left(\mathrm{CH}_{3}\right)_{2}-\mathrm{CO}_{2}$ :

Total Energy (kcal/mol): -1598736.405

Enthalpy Correction (AU): 0.378132

Free Energy Correction (AU): 0.298357

Three lowest frequencies $\left(\mathrm{cm}^{-1}\right)$ : -183.1, 25.0, 34.0

$\begin{array}{lccc}\mathrm{C} & 0.001391000 & 0.149629000 & 0.071774000 \\ \mathrm{C} & 0.037307000 & 0.040078000 & 1.454260000 \\ \mathrm{C} & 1.270678000 & -0.078859000 & 2.091325000 \\ \mathrm{C} & 2.441568000 & -0.091972000 & 1.357345000 \\ \mathrm{C} & 2.428091000 & 0.012805000 & -0.050012000 \\ \mathrm{C} & 1.173417000 & 0.134028000 & -0.672721000 \\ \mathrm{Cu} & 3.176922000 & -2.031182000 & -0.746078000 \\ \mathrm{C} & 5.324053001 & -1.608415000 & -0.559522000 \\ \mathrm{O} & 5.471852001 & -1.948760000 & 0.572480000 \\ \mathrm{C} & 3.704651000 & -0.077591000 & -0.802120000 \\ \mathrm{C} & 3.751180000 & 0.253501000 & -2.276801000 \\ \mathrm{~B} & 5.176977001 & -0.018388000 & -2.953688000 \\ \mathrm{C} & 5.215529001 & -0.870473000 & -4.283747001 \\ \mathrm{C} & 2.435754000 & -3.785096000 & -0.993236000 \\ \mathrm{~N} & 1.330387000 & -4.310692001 & -0.419636000 \\ \mathrm{C} & 1.104100000 & -5.596309001 & -0.865953000 \\ \mathrm{C} & 2.094732000 & -5.882219001 & -1.737630000 \\ \mathrm{~N} & 2.898774000 & -4.763367001 & -1.802880000 \\ \mathrm{C} & 0.472211000 & -3.597299000 & 0.507695000 \\ \mathrm{C} & 4.083360000 & -4.655018001 & -2.635720000 \\ \mathrm{C} & 6.337331001 & 1.015031000 & -2.670721000 \\ \mathrm{O} & 5.846287001 & -1.508632000 & -1.645306000 \\ \mathrm{H} & 0.268147000 & -6.186948001 & -0.520341000 \\ \mathrm{H} & 2.305020000 & -6.775350001 & -2.308016000 \\ \mathrm{H} & 1.002732000 & -2.719065000 & 0.883514000\end{array}$




$\begin{array}{rrrr}\mathrm{H} & 4.792177001 & -5.449227001 & -2.387260000 \\ \mathrm{H} & 1.125251000 & 0.241591000 & -1.754254000 \\ \mathrm{H} & 3.403728000 & -0.192681000 & 1.859148000 \\ \mathrm{H} & 1.317429000 & -0.153764000 & 3.176330000 \\ \mathrm{H} & -0.953435000 & 0.261869000 & -0.439460000 \\ \mathrm{H} & -0.882281000 & 0.063118000 & 2.034534000 \\ \mathrm{H} & 2.962097000 & -0.290590000 & -2.822769000 \\ \mathrm{H} & 4.488804001 & 0.438871000 & -0.237069000 \\ \mathrm{H} & -0.442722000 & -3.263485000 & 0.009682000 \\ \mathrm{H} & 0.214393000 & -4.245999001 & 1.348751000 \\ \mathrm{H} & 4.557491001 & -3.687097000 & -2.457276000 \\ \mathrm{H} & 3.811314000 & -4.727378001 & -3.692567000 \\ \mathrm{H} & 3.523098000 & 1.327838000 & -2.423919000 \\ \mathrm{H} & 6.220990001 & -1.211577000 & -4.559776001 \\ \mathrm{H} & 4.553804001 & -1.748392000 & -4.244532001 \\ \mathrm{H} & 4.852092001 & -0.252687000 & -5.119769001 \\ \mathrm{H} & 7.335329001 & 0.596322000 & -2.847419000 \\ \mathrm{H} & 6.228315001 & 1.862967000 & -3.365218000 \\ \mathrm{H} & 6.326176001 & 1.443232000 & -1.659200000\end{array}$


$\mathrm{B}\left(-\mathrm{NH}\left(\mathrm{CH}_{2}\right)_{2} \mathrm{HN}-\right)$ :

Total Energy (kcal/mol): - 1549153.605

Enthalpy Correction (AU): 0.379719

Free Energy Correction (AU): 0.301932

Three lowest frequencies $\left(\mathrm{cm}^{-1}\right): 21.7,29.6,35.4$

$\begin{array}{lccc}\mathrm{N} & 3.577807000 & -3.082715000 & -1.207771000 \\ \mathrm{C} & 4.259471001 & -3.256805000 & -0.051757000 \\ \mathrm{~N} & 3.394422000 & -2.855043000 & 0.909681000 \\ \mathrm{C} & 2.200013000 & -2.433084000 & 0.362499000 \\ \mathrm{C} & 2.313261000 & -2.579043000 & -0.974749000 \\ \mathrm{Cu} & 6.059465001 & -3.850670000 & 0.296826000 \\ \mathrm{C} & 7.814655001 & -4.316268001 & 1.035518000 \\ \mathrm{C} & 8.981144001 & -3.558308000 & 0.395912000 \\ \mathrm{~B} & 9.059136001 & -3.976024000 & -1.109696000 \\ \mathrm{~N} & 9.577848001 & -5.191796001 & -1.643081000 \\ \mathrm{C} & 9.532186001 & -5.153805001 & -3.093906000 \\ \mathrm{C} & 3.710402000 & -2.818846000 & 2.328078000 \\ \mathrm{C} & 4.109293000 & -3.390774000 & -2.518488000 \\ \mathrm{C} & 7.490664001 & -4.022847000 & 2.447298000 \\ \mathrm{C} & 6.795283001 & -4.968038001 & 3.228459000 \\ \mathrm{C} & 6.387688001 & -4.694579001 & 4.521558001 \\ \mathrm{C} & 6.655361001 & -3.457778000 & 5.102494001 \\ \mathrm{C} & 7.355298001 & -2.516486000 & 4.360020001 \\ \mathrm{C} & 7.770337001 & -2.792045000 & 3.065026000 \\ \mathrm{~N} & 8.512806001 & -3.247517000 & -2.217421000 \\ \mathrm{C} & 8.430020001 & -4.129484000 & -3.367951000 \\ \mathrm{H} & 9.301788001 & -6.129298001 & -3.541943000 \\ \mathrm{H} & 8.581264001 & -3.610156000 & -4.323658001 \\ \mathrm{H} & 7.452018001 & -4.645968001 & -3.417748000 \\ \mathrm{H} & 10.487399001 & -4.807122001 & -3.526080000 \\ \mathrm{H} & 1.382247000 & -2.073950000 & 0.970731000 \\ \mathrm{H} & 1.614598000 & -2.380780000 & -1.774866000 \\ \mathrm{H} & 4.547424001 & -3.492745000 & 2.531085000 \\ \mathrm{H} & 5.124527001 & -3.773589000 & -2.393466000 \\ \mathrm{H} & 7.948241001 & -5.400046001 & 0.904524000 \\ \mathrm{H} & 8.322352001 & -2.033404000 & 2.513051000 \\ \mathrm{H} & 6.572005001 & -5.939751001 & 2.784162000 \\ \mathrm{H} & 5.858522001 & -5.459085001 & 5.089739001 \\ \mathrm{H} & 7.593715001 & -1.548911000 & 4.800796001 \\ \mathrm{H} & 6.339084001 & -3.241388000 & 6.120559001 \\ \mathrm{H} & 8.817731001 & -2.470984000 & 0.449847000 \\ \mathrm{H} & 2.841707000 & -3.144242000 & 2.906173000 \\ \mathrm{H} & 3.995321000 & -1.808845000 & 2.636525000 \\ \mathrm{H} & 4.136514000 & -2.492393000 & -3.142399000 \\ \mathrm{H} & 3.499236000 & -4.152758000 & -3.012131000\end{array}$




$\begin{array}{cccc}\mathrm{H} & 9.925860001 & -3.745376000 & 0.941056000 \\ \mathrm{H} & 10.254542001 & -5.788795001 & -1.194678000 \\ \mathrm{H} & 7.806324001 & -2.533453000 & -2.112216000\end{array}$

$\mathrm{B}\left(-\mathrm{NH}\left(\mathrm{CH}_{2}\right)_{2} \mathrm{HN}-\right)-\mathrm{CO}_{2}$ :

Total Energy (kcal/mol): -1667461.02

Enthalpy Correction (AU): 0.395634

Free Energy Correction (AU): 0.313769

Three lowest frequencies $\left(\mathrm{cm}^{-1}\right)$ : -180.4, 24.3, 27.2

$\begin{array}{lrrr}\mathrm{C} & 4.018224000 & -1.968346000 & 3.167750000 \\ \mathrm{C} & 4.070580000 & -0.941421000 & 2.241255000 \\ \mathrm{C} & 2.899685000 & -0.252995000 & 1.925628000 \\ \mathrm{C} & 1.700952000 & -0.582662000 & 2.526407000 \\ \mathrm{C} & 1.619101000 & -1.624425000 & 3.482049000 \\ \mathrm{C} & 2.816053000 & -2.313178000 & 3.778887000 \\ \mathrm{Cu} & 0.838042000 & -3.277047000 & 2.398115000 \\ \mathrm{O} & -1.118146000 & -1.653894000 & 1.785466000 \\ \mathrm{C} & -1.217204000 & -2.413390000 & 2.716459000 \\ \mathrm{O} & -1.965368000 & -3.197563000 & 3.241271000 \\ \mathrm{C} & 0.301515000 & -2.024567000 & 4.043290000 \\ \mathrm{C} & 0.286485000 & -2.961993000 & 5.237068001 \\ \mathrm{~B} & -1.130504000 & -3.281596000 & 5.844997001 \\ \mathrm{~N} & -1.553613000 & -4.565956001 & 6.300659001 \\ \mathrm{C} & -2.801956000 & -4.426022001 & 7.033270001 \\ \mathrm{C} & -3.368018000 & -3.125659000 & 6.470025001 \\ \mathrm{~N} & -2.172321000 & -2.353782000 & 6.157591001 \\ \mathrm{C} & 0.956066000 & -4.883422001 & 1.365491000 \\ \mathrm{~N} & 1.755167000 & -5.147202001 & 0.307314000 \\ \mathrm{C} & 1.531498000 & -6.419525001 & -0.178259000 \\ \mathrm{C} & 0.574449000 & -6.965293001 & 0.602461000 \\ \mathrm{~N} & 0.232393000 & -6.011776001 & 1.538329000 \\ \mathrm{C} & 2.692016000 & -4.200188001 & -0.263149000 \\ \mathrm{C} & -0.734219000 & -6.214029001 & 2.607030000 \\ \mathrm{H} & 2.064700000 & -6.812422001 & -1.031862000 \\ \mathrm{H} & 0.106516000 & -7.938808001 & 0.577058000 \\ \mathrm{H} & 3.666571000 & -4.675968001 & -0.402978000 \\ \mathrm{H} & -1.113368000 & -5.248007001 & 2.952285000 \\ \mathrm{H} & 2.808177000 & -3.098766000 & 4.531195001 \\ \mathrm{H} & 0.789206000 & -0.052572000 & 2.262026000 \\ \mathrm{H} & 2.926963000 & 0.560136000 & 1.202620000 \\ \mathrm{H} & 4.924646001 & -2.508503000 & 3.435812000 \\ \mathrm{H} & 5.013189001 & -0.667597000 & 1.772739000 \\ \mathrm{H} & 0.777826000 & -3.919247000 & 4.991614001 \\ \mathrm{H} & -0.290681000 & -1.120626000 & 4.224921001\end{array}$




$\begin{array}{rrrr}\mathrm{H} & 2.328338000 & -3.829016000 & -1.225610000 \\ \mathrm{H} & 2.802284000 & -3.358226000 & 0.424683000 \\ \mathrm{H} & -0.269958000 & -6.742806001 & 3.445221000 \\ \mathrm{H} & -1.571750000 & -6.804861001 & 2.228341000 \\ \mathrm{H} & 0.903191000 & -2.531719000 & 6.048763001 \\ \mathrm{H} & -4.027607000 & -2.619796000 & 7.187087001 \\ \mathrm{H} & -3.486000000 & -5.270739001 & 6.878143001 \\ \mathrm{H} & -2.326002000 & -1.521126000 & 5.606947001 \\ \mathrm{H} & -0.939826000 & -5.328719001 & 6.542384001 \\ \mathrm{H} & -3.949631000 & -3.336791000 & 5.556435001 \\ \mathrm{H} & -2.630387000 & -4.329605001 & 8.119858001\end{array}$

$\mathrm{B}\left(\mathrm{NH}_{2}\right)_{2}$ :

Total Energy (kcal/mol): -1500612.068

Enthalpy Correction (AU): 0.342457

Free Energy Correction (AU): 0.267864

Three lowest frequencies $\left(\mathrm{cm}^{-1}\right): 23.7,34.2,39.5$

$\begin{array}{lccc}\mathrm{N} & 0.40836 & 2.90757 & -0.22785 \\ \mathrm{C} & 0.92126 & 1.67963 & 0.00976 \\ \mathrm{~N} & 2.26039 & 1.85915 & -0.03199 \\ \mathrm{C} & 2.57806 & 3.17662 & -0.29290 \\ \mathrm{C} & 1.40779 & 3.83980 & -0.40961 \\ \mathrm{Cu} & -0.06845 & 0.06671 & 0.38489 \\ \mathrm{C} & 0.33626 & -2.19689 & 0.20710 \\ \mathrm{C} & 1.33636 & -2.47656 & 1.16545 \\ \mathrm{C} & 2.60120 & -2.89518 & 0.79711 \\ \mathrm{C} & 2.93543 & -3.04547 & -0.54653 \\ \mathrm{C} & 1.97222 & -2.77254 & -1.50882 \\ \mathrm{C} & 0.70059 & -2.35446 & -1.14640 \\ \mathrm{C} & -0.98086 & -1.68994 & 0.63433 \\ \mathrm{C} & -2.19002 & -1.91702 & -0.26821 \\ \mathrm{~B} & -2.61296 & -0.67139 & -1.13859 \\ \mathrm{H} & -3.71412 & -0.57622 & -1.59312 \\ \mathrm{C} & 3.23661 & 0.79238 & 0.08679 \\ \mathrm{C} & -1.01659 & 3.19116 & -0.22963 \\ \mathrm{C} & -2.16405 & 0.60340 & 1.33570 \\ \mathrm{O} & -2.87270 & 0.62209 & 0.37366 \\ \mathrm{O} & -1.89710 & 0.86835 & 2.44510 \\ \mathrm{H} & -1.73859 & -0.05442 & -1.69795 \\ \mathrm{H} & 2.21173 & -2.89046 & -2.56442 \\ \mathrm{H} & 3.33666 & -3.11933 & 1.56844 \\ \mathrm{H} & 3.92750 & -3.38388 & -0.83607 \\ \mathrm{H} & 1.08543 & -2.36702 & 2.22097 \\ \mathrm{H} & -0.03164 & -2.14049 & -1.92260\end{array}$




$\begin{array}{lrrr}\mathrm{H} & -1.36959 & 3.38526 & 0.78911 \\ \mathrm{H} & -1.55719 & 2.33041 & -0.62609 \\ \mathrm{H} & -1.21462 & 4.05744 & -0.86373 \\ \mathrm{H} & 1.19707 & 4.88136 & -0.60451 \\ \mathrm{H} & 3.60015 & 3.51798 & -0.36879 \\ \mathrm{H} & 3.67488 & 0.56807 & -0.88960 \\ \mathrm{H} & 4.02905 & 1.08871 & 0.77932 \\ \mathrm{H} & 2.74346 & -0.10687 & 0.46656 \\ \mathrm{H} & -2.00014 & -2.75200 & -0.96825 \\ \mathrm{H} & -3.04311 & -2.25913 & 0.33584 \\ \mathrm{H} & -1.15996 & -1.95297 & 1.68193\end{array}$

$\mathrm{B}\left(\mathrm{NH}_{2}\right)_{2}-\mathrm{CO}_{2}$ :

Total Energy (kcal/mol): -1618918.292

Enthalpy Correction (AU): 0.358857

Free Energy Correction (AU): 0.279609

Three lowest frequencies $\left(\mathrm{cm}^{-1}\right):-180.2,27.1,30.7$

$\begin{array}{lccc}\mathrm{Cu} & 0.63040 & -3.32699 & 2.77865 \\ \mathrm{C} & 0.38773 & -5.40376 & 2.00548 \\ \mathrm{O} & 1.42063 & -5.33099 & 1.38198 \\ \mathrm{O} & -0.22473 & -6.10863 & 2.76347 \\ \mathrm{C} & -0.88882 & -3.94090 & 1.36260 \\ \mathrm{C} & -0.45842 & -2.53342 & 1.14348 \\ \mathrm{H} & -1.10404 & 0.68140 & 2.11380 \\ \mathrm{C} & -0.60587 & -0.14078 & 1.60200 \\ \mathrm{C} & 0.63233 & -2.24576 & 0.28778 \\ \mathrm{C} & -1.05162 & -1.43896 & 1.81013 \\ \mathrm{C} & 1.07621 & -0.94933 & 0.09995 \\ \mathrm{C} & 0.45754 & 0.11682 & 0.74917 \\ \mathrm{H} & 1.91074 & -0.76400 & -0.57390 \\ \mathrm{H} & 0.79800 & 1.13621 & 0.58209 \\ \mathrm{H} & 1.11829 & -3.07479 & -0.22418 \\ \mathrm{H} & -1.89264 & -1.61910 & 2.47629 \\ \mathrm{C} & 1.81996 & -3.03535 & 4.26087 \\ \mathrm{~N} & 2.34094 & -1.85813 & 4.67861 \\ \mathrm{C} & 3.20682 & -2.04337 & 5.73575 \\ \mathrm{C} & 3.23579 & -3.37095 & 5.97957 \\ \mathrm{~N} & 2.37947 & -3.95952 & 5.07379 \\ \mathrm{C} & 2.18506 & -5.39490 & 4.94619 \\ \mathrm{H} & 1.19249 & -5.59887 & 4.54049 \\ \mathrm{H} & 2.27988 & -5.85801 & 5.93123 \\ \mathrm{H} & 2.92742 & -5.82068 & 4.26590 \\ \mathrm{H} & 3.78912 & -3.94882 & 6.70549 \\ \mathrm{H} & 3.71808 & -1.22049 & 6.21371\end{array}$




$\begin{array}{lrrr}\mathrm{C} & 1.99654 & -0.57058 & 4.10663 \\ \mathrm{H} & 2.83196 & 0.12029 & 4.24257 \\ \mathrm{H} & 1.79852 & -0.68609 & 3.03835 \\ \mathrm{H} & 1.10323 & -0.15724 & 4.58486 \\ \mathrm{~B} & -2.88631 & -5.59736 & 1.68067 \\ \mathrm{C} & -2.24381 & -4.18172 & 2.00200 \\ \mathrm{H} & -2.19626 & -4.03550 & 3.09271 \\ \mathrm{H} & -2.96249 & -3.42386 & 1.63852 \\ \mathrm{~N} & -3.41247 & -6.39878 & 2.72744 \\ \mathrm{~N} & -3.01379 & -5.98938 & 0.32354 \\ \mathrm{H} & -0.77576 & -4.47606 & 0.41314 \\ \mathrm{H} & -3.72333 & -7.34405 & 2.55712 \\ \mathrm{H} & -3.40721 & -6.86820 & 0.02632 \\ \mathrm{H} & -2.77924 & -5.37762 & -0.44140 \\ \mathrm{H} & -3.01451 & -6.29331 & 3.64832\end{array}$

$\mathrm{B}\left(\mathrm{NH}(\mathrm{CH})_{2} \mathrm{HN}\right)$ :

Total Energy (kcal/mol): -1548398.601 Enthalpy Correction (AU): 0.35598

Free Energy Correction (AU): 0.280644

Three lowest frequencies $\left(\mathrm{cm}^{-1}\right): 25.9,30.2,39.7$

$\begin{array}{lrrr}\mathrm{Cu} & 2.158525000 & -0.417846000 & 2.055358000 \\ \mathrm{C} & 2.386584000 & -0.651445000 & 0.156742000 \\ \mathrm{~N} & 3.527527000 & -0.649830000 & -0.571206000 \\ \mathrm{C} & 3.273763000 & -0.918045000 & -1.901778000 \\ \mathrm{C} & 1.939521000 & -1.092422000 & -2.010401000 \\ \mathrm{~N} & 1.414539000 & -0.922877000 & -0.745415000 \\ \mathrm{C} & 4.844129001 & -0.399589000 & -0.019716000 \\ \mathrm{C} & 0.009459000 & -1.069920000 & -0.408534000 \\ \mathrm{~B} & -0.531114000 & -1.186225000 & 3.496963000 \\ \mathrm{~N} & -1.087097000 & 0.023939000 & 2.952532000 \\ \mathrm{C} & -2.260331000 & -0.261524000 & 2.261275000 \\ \mathrm{C} & -2.483357000 & -1.590679000 & 2.316095000 \\ \mathrm{~N} & -1.458498000 & -2.187132000 & 3.044836000 \\ \mathrm{C} & 1.841017000 & -0.317690000 & 3.982836000 \\ \mathrm{C} & 3.145507000 & -0.418162000 & 4.676049001 \\ \mathrm{C} & 5.697791001 & -0.545901000 & 5.901942001 \\ \mathrm{C} & 3.607486000 & -1.588970000 & 5.291413001 \\ \mathrm{C} & 4.009557000 & 0.691202000 & 4.711639001 \\ \mathrm{C} & 5.253799001 & 0.633509000 & 5.309749001 \\ \mathrm{C} & 4.861881001 & -1.650942000 & 5.885558001 \\ \mathrm{C} & 0.782419000 & -1.367473000 & 4.331273001 \\ \mathrm{H} & 4.058935000 & -0.954119000 & -2.643302000 \\ \mathrm{H} & 1.319456000 & -1.317227000 & -2.866408000\end{array}$




$\begin{array}{rrrr}\mathrm{H} & 4.744829001 & -0.236487000 & 1.056071000 \\ \mathrm{H} & -0.164052000 & -0.666580000 & 0.592364000 \\ \mathrm{H} & 1.433878000 & 0.691258000 & 4.166846000 \\ \mathrm{H} & 2.971693000 & -2.472333000 & 5.308923001 \\ \mathrm{H} & 3.676019000 & 1.620475000 & 4.245021001 \\ \mathrm{H} & 5.887636001 & 1.519657000 & 5.320538001 \\ \mathrm{H} & 5.184578001 & -2.581020000 & 6.352761001 \\ \mathrm{H} & 6.677107001 & -0.596025000 & 6.373254001 \\ \mathrm{H} & 1.165602000 & -2.380588000 & 4.127296000 \\ \mathrm{H} & 5.288630001 & 0.488779000 & -0.477660000 \\ \mathrm{H} & 5.498554001 & -1.259334000 & -0.189653000 \\ \mathrm{H} & -0.281830000 & -2.124557000 & -0.413159000 \\ \mathrm{H} & -0.606303000 & -0.522368000 & -1.127392000 \\ \mathrm{H} & -2.856366000 & 0.504215000 & 1.782311000 \\ \mathrm{H} & -3.305735000 & -2.155142000 & 1.896442000 \\ \mathrm{H} & 0.558347000 & -1.372058000 & 5.417695001 \\ \mathrm{H} & -1.450481000 & -3.177678000 & 3.224639000 \\ \mathrm{H} & -0.729198000 & 0.962541000 & 3.029200000\end{array}$

$\mathrm{B}\left(-\mathrm{NH}(\mathrm{CH})_{2} \mathrm{HN}-\right)-\mathrm{CO}_{2}$ :

Total Energy (kcal/mol): -1666703.479

Enthalpy Correction (AU): 0.371867

Free Energy Correction (AU): 0.291356

Three lowest frequencies $\left(\mathrm{cm}^{-1}\right)$ : -186.0, 26.3, 28.7

$\begin{array}{lrrr}\mathrm{Cu} & 0.712877000 & -3.639888000 & 2.332766000 \\ \mathrm{C} & 0.988128000 & -4.943466001 & 0.947528000 \\ \mathrm{~N} & 2.060658000 & -5.052801001 & 0.128831000 \\ \mathrm{C} & 1.865579000 & -6.035271001 & -0.819033000 \\ \mathrm{C} & 0.642710000 & -6.557167001 & -0.584203000 \\ \mathrm{~N} & 0.123603000 & -5.881546001 & 0.499324000 \\ \mathrm{C} & 3.225270000 & -4.192214001 & 0.191867000 \\ \mathrm{C} & -1.211284000 & -6.095682001 & 1.035087000 \\ \mathrm{C} & 0.173502000 & -2.507925000 & 4.113593000 \\ \mathrm{C} & 1.419909000 & -2.010605000 & 3.470798000 \\ \mathrm{C} & 3.751943000 & -1.049831000 & 2.183212000 \\ \mathrm{C} & 2.700337000 & -2.514628000 & 3.788089000 \\ \mathrm{C} & 1.354149000 & -1.028593000 & 2.452690000 \\ \mathrm{C} & 2.496872000 & -0.562953000 & 1.827081000 \\ \mathrm{C} & 3.841058000 & -2.028878000 & 3.162430000 \\ \mathrm{C} & 0.310498000 & -3.273373000 & 5.416718001 \\ \mathrm{~B} & -0.976531000 & -3.253945000 & 6.317719001 \\ \mathrm{C} & -1.378517000 & -3.329286000 & 3.071496000 \\ \mathrm{O} & -1.796685000 & -4.250950001 & 3.718024000 \\ \mathrm{O} & -1.621241000 & -2.633216000 & 2.113122000\end{array}$




$\begin{array}{rrrr}\mathrm{N} & -1.825843000 & -2.135293000 & 6.601660001 \\ \mathrm{C} & -2.821223000 & -2.526536000 & 7.495442001 \\ \mathrm{C} & -2.644875000 & -3.825624000 & 7.801119001 \\ \mathrm{~N} & -1.526226000 & -4.301213001 & 7.121117001 \\ \mathrm{H} & 2.612908000 & -6.277113001 & -1.560818000 \\ \mathrm{H} & 0.101407000 & -7.349941001 & -1.079834000 \\ \mathrm{H} & 4.126634000 & -4.773256001 & -0.020136000 \\ \mathrm{H} & -1.939946000 & -5.481336001 & 0.499162000 \\ \mathrm{H} & 2.793520000 & -3.275180000 & 4.560337001 \\ \mathrm{H} & 0.376154000 & -0.637111000 & 2.176459000 \\ \mathrm{H} & 2.409458000 & 0.204619000 & 1.060253000 \\ \mathrm{H} & 4.814980001 & -2.419179000 & 3.453901000 \\ \mathrm{H} & 4.649311001 & -0.664134000 & 1.704902000 \\ \mathrm{H} & 0.603940000 & -4.317302001 & 5.223778001 \\ \mathrm{H} & -0.511905000 & -1.656820000 & 4.197121001 \\ \mathrm{H} & 3.141378000 & -3.375249000 & -0.531361000 \\ \mathrm{H} & 3.300445000 & -3.762528000 & 1.193681000 \\ \mathrm{H} & -1.236036000 & -5.811418001 & 2.088579000 \\ \mathrm{H} & -1.474258000 & -7.151451001 & 0.934661000 \\ \mathrm{H} & 1.137604000 & -2.843891000 & 6.010828001 \\ \mathrm{H} & -3.583697000 & -1.845184000 & 7.848287001 \\ \mathrm{H} & -3.235424000 & -4.451480001 & 8.456783001 \\ \mathrm{H} & -1.780358000 & -1.191346000 & 6.255332001 \\ \mathrm{H} & -1.271754000 & -5.274315001 & 7.147008001\end{array}$

$\mathrm{BCl}_{2}$ :

Total Energy (kcal/mol): -2007980.142 Enthalpy Correction (AU): 0.291039

Free Energy Correction (AU): 0.219711

Three lowest frequencies $\left(\mathrm{cm}^{-1}\right): 35.3,41.8,54.1$

$\begin{array}{lrrr}\mathrm{Cu} & 1.680331000 & -0.247483000 & 1.886696000 \\ \mathrm{C} & 2.400776000 & -0.855573000 & 0.040064000 \\ \mathrm{C} & 3.765594000 & -0.455801000 & 0.479090000 \\ \mathrm{C} & 4.260698001 & 0.845931000 & 0.328026000 \\ \mathrm{C} & 5.531701001 & 1.179524000 & 0.770294000 \\ \mathrm{C} & 5.875788001 & -1.069023000 & 1.518109000 \\ \mathrm{C} & 6.348557001 & 0.228292000 & 1.368524000 \\ \mathrm{C} & 4.601968001 & -1.403064000 & 1.085171000 \\ \mathrm{C} & 1.477205000 & 0.123201000 & 3.758296000 \\ \mathrm{~N} & 2.442162000 & 0.311831000 & 4.686876001 \\ \mathrm{C} & 1.899720000 & 0.704706000 & 5.893403001 \\ \mathrm{C} & 0.562757000 & 0.759307000 & 5.715613001 \\ \mathrm{~N} & 0.323238000 & 0.397827000 & 4.406421001 \\ \mathrm{C} & -0.987072000 & 0.399146000 & 3.781120000\end{array}$




$\begin{array}{lccc}\mathrm{C} & 3.864602000 & 0.190794000 & 4.430342001 \\ \mathrm{C} & 1.847840000 & -0.335072000 & -1.300618000 \\ \mathrm{~B} & 0.916182000 & 0.085030000 & -0.167701000 \\ \mathrm{Cl} & 0.819185000 & 1.873636000 & 0.359598000 \\ \mathrm{Cl} & -0.666643000 & -0.843527000 & 0.114336000 \\ \mathrm{H} & 5.890601001 & 2.198776000 & 0.640346000 \\ \mathrm{H} & 4.237292001 & -2.423137000 & 1.207537000 \\ \mathrm{H} & 2.231347000 & -1.931169000 & 0.147749000 \\ \mathrm{H} & 6.507339001 & -1.831641000 & 1.970527000 \\ \mathrm{H} & 7.348925001 & 0.492978000 & 1.703443000 \\ \mathrm{H} & 3.633572000 & 1.609260000 & -0.128512000 \\ \mathrm{H} & -0.236179000 & 1.012741000 & 6.397331001 \\ \mathrm{H} & -1.291435000 & 1.420335000 & 3.534516000 \\ \mathrm{H} & -1.719699000 & -0.048289000 & 4.457752001 \\ \mathrm{H} & -0.944892000 & -0.182462000 & 2.857746000 \\ \mathrm{H} & 4.015120000 & -0.333716000 & 3.483772000 \\ \mathrm{H} & 4.342108001 & -0.376255000 & 5.234016001 \\ \mathrm{H} & 4.328108001 & 1.179127000 & 4.358239001 \\ \mathrm{H} & 2.511022000 & 0.899443000 & 6.762631001 \\ \mathrm{H} & 2.479294000 & 0.422403000 & -1.764650000 \\ \mathrm{H} & 1.550097000 & -1.120552000 & -1.992644000\end{array}$

$\mathrm{BCl}_{2}-\mathrm{CO}_{2}$ :

Total Energy (kcal/mol): -2126278.917

Enthalpy Correction (AU): 191.9965717

Free Energy Correction (AU): 141.6483469

Three lowest frequencies $\left(\mathrm{cm}^{-1}\right)$ : -260.9, 15.1, 33.0

$\begin{array}{lrrr}\mathrm{Cu} & 0.645663000 & -3.538093000 & 2.476260000 \\ \mathrm{C} & 0.689227000 & -5.416406001 & 1.267589000 \\ \mathrm{O} & 1.711493000 & -5.240585001 & 0.699890000 \\ \mathrm{O} & -0.124680000 & -6.194901001 & 1.696081000 \\ \mathrm{C} & -0.781580000 & -3.595846000 & 1.066735000 \\ \mathrm{C} & -0.516426000 & -2.138461000 & 1.035561000 \\ \mathrm{C} & -0.789057000 & 0.125806000 & 1.885255000 \\ \mathrm{C} & 0.464463000 & -1.634662000 & 0.156262000 \\ \mathrm{C} & -1.135155000 & -1.218924000 & 1.900253000 \\ \mathrm{C} & 0.805302000 & -0.295411000 & 0.147813000 \\ \mathrm{C} & 0.182278000 & 0.598714000 & 1.015705000 \\ \mathrm{C} & 1.686906000 & -3.291553000 & 4.071913000 \\ \mathrm{~N} & 2.432654000 & -2.218851000 & 4.417303001 \\ \mathrm{C} & 3.009811000 & -2.395727000 & 5.657592001 \\ \mathrm{C} & 2.614876000 & -3.609787000 & 6.097383001 \\ \mathrm{~N} & 1.805271000 & -4.142107000 & 5.115410001 \\ \mathrm{C} & 1.161953000 & -5.441364001 & 5.203001001\end{array}$




$\begin{array}{rrrr}\text { C } & 2.569851000 & -1.020521000 & 3.610598000 \\ \mathrm{~B} & -2.123311000 & -5.688353001 & 1.807079000 \\ \mathrm{C} & -1.997085000 & -4.119151000 & 1.803123000 \\ \mathrm{Cl} & -2.517280000 & -6.527789001 & 3.347106000 \\ \mathrm{Cl} & -2.652406000 & -6.505144001 & 0.304114000 \\ \mathrm{H} & -1.298378000 & 0.814453000 & 2.557138000 \\ \mathrm{H} & 1.560070000 & 0.061199000 & -0.550703000 \\ \mathrm{H} & 0.443102000 & 1.654409000 & 1.000033000 \\ \mathrm{H} & 0.959531000 & -2.330544000 & -0.521441000 \\ \mathrm{H} & -1.912935000 & -1.561501000 & 2.579622000 \\ \mathrm{H} & 0.552633000 & -5.600987001 & 4.310850001 \\ \mathrm{H} & 0.513659000 & -5.481789001 & 6.082384001 \\ \mathrm{H} & 1.912515000 & -6.233650001 & 5.267504001 \\ \mathrm{H} & 2.835355000 & -4.142020000 & 7.011392001 \\ \mathrm{H} & 3.644618000 & -1.647017000 & 6.108913001 \\ \mathrm{H} & 3.627028000 & -0.771264000 & 3.486882000 \\ \mathrm{H} & 2.127129000 & -1.199750000 & 2.627542000 \\ \mathrm{H} & 2.048272000 & -0.181119000 & 4.079110000 \\ \mathrm{H} & -2.018452000 & -3.758129000 & 2.842314000 \\ \mathrm{H} & -2.928164000 & -3.741116000 & 1.339995000 \\ \mathrm{H} & -0.698372000 & -4.011096000 & 0.056330000\end{array}$

$\mathrm{BH}_{2}$ :

Total Energy (kcal/mol): -1431114.745

Enthalpy Correction (AU): 0.302768

Free Energy Correction (AU): 0.236922

Three lowest frequencies $\left(\mathrm{cm}^{-1}\right): 22.6,49.5,50.4$

$\begin{array}{lccc}\mathrm{H} & 1.92102 & -1.26500 & 2.00333 \\ \mathrm{C} & 2.14192 & -1.15070 & 0.95197 \\ \mathrm{C} & 3.27351 & -0.78265 & 0.31511 \\ \mathrm{H} & 4.24420 & -0.50028 & 0.69641 \\ \mathrm{~N} & 2.99794 & -0.82220 & -1.03656 \\ \mathrm{H} & 4.94655 & -0.70986 & -1.77863 \\ \mathrm{C} & 3.93143 & -0.44151 & -2.08161 \\ \mathrm{H} & 3.68336 & -0.97354 & -3.00332 \\ \mathrm{C} & 1.71794 & -1.19813 & -1.26430 \\ \mathrm{~N} & 1.20264 & -1.39818 & -0.02873 \\ \mathrm{C} & -0.15635 & -1.82972 & 0.22908 \\ \mathrm{H} & -0.16611 & -2.83648 & 0.65716 \\ \mathrm{H} & -0.64726 & -1.13856 & 0.91973 \\ \mathrm{H} & -0.70322 & -1.83756 & -0.71644 \\ \mathrm{Cu} & 0.81246 & -1.33877 & -2.94893 \\ \mathrm{C} & 0.52305 & -1.90260 & -4.96633 \\ \mathrm{H} & 0.53451 & -2.99132 & -4.87272\end{array}$




$\begin{array}{lrrr}\mathrm{C} & 1.86490 & -1.35340 & -5.28456 \\ \mathrm{C} & 2.07536 & 0.00070 & -5.58239 \\ \mathrm{C} & 3.34390 & 0.48465 & -5.86181 \\ \mathrm{C} & 2.98875 & -2.19167 & -5.28446 \\ \mathrm{H} & 2.85135 & -3.24948 & -5.05852 \\ \mathrm{C} & 4.25636 & -1.70726 & -5.56926 \\ \mathrm{C} & 4.44616 & -0.36165 & -5.85695 \\ \mathrm{H} & 5.43816 & 0.02039 & -6.08760 \\ \mathrm{H} & 5.10447 & -2.39024 & -5.57142 \\ \mathrm{H} & 1.22768 & 0.68380 & -5.58375 \\ \mathrm{C} & -0.68202 & -1.38353 & -5.73843 \\ \mathrm{H} & -0.43857 & -0.61394 & -6.47049 \\ \mathrm{H} & -1.31008 & -2.16543 & -6.16175 \\ \mathrm{~B} & -0.82134 & -1.02595 & -4.23480 \\ \mathrm{H} & -1.53878 & -1.68325 & -3.51517 \\ \mathrm{H} & -0.51812 & 0.10040 & -3.86565 \\ \mathrm{H} & 3.88228 & 0.63436 & -2.27314 \\ \mathrm{H} & 3.47267 & 1.54096 & -6.09245\end{array}$

\section{$\mathrm{BH}_{2}-\mathrm{CO}_{2}$ :}

Total Energy (kcal/mol): -1549410.7

Enthalpy Correction (AU): 0.31887

Free Energy Correction (AU): 0.247333

Three lowest frequencies $\left(\mathrm{cm}^{-1}\right):-217.3,29.5,40.8$

$\begin{array}{lrrr}\mathrm{Cu} & 0.630397000 & -3.326991000 & 2.778649000 \\ \mathrm{C} & 0.387728000 & -5.403763001 & 2.005481000 \\ \mathrm{O} & 1.420633000 & -5.330994001 & 1.381983000 \\ \mathrm{O} & -0.224733000 & -6.108633001 & 2.763470000 \\ \mathrm{C} & -0.888825000 & -3.940896000 & 1.362602000 \\ \mathrm{C} & -0.458422000 & -2.533423000 & 1.143482000 \\ \mathrm{C} & -0.605873000 & -0.140776000 & 1.601997000 \\ \mathrm{C} & 0.632335000 & -2.245763000 & 0.287781000 \\ \mathrm{C} & -1.051617000 & -1.438960000 & 1.810126000 \\ \mathrm{C} & 1.076208000 & -0.949333000 & 0.099948000 \\ \mathrm{C} & 0.457539000 & 0.116817000 & 0.749168000 \\ \mathrm{C} & 1.819957000 & -3.035347000 & 4.260874001 \\ \mathrm{~N} & 2.340940000 & -1.858125000 & 4.678614001 \\ \mathrm{C} & 3.206819000 & -2.043370000 & 5.735750001 \\ \mathrm{C} & 3.235786000 & -3.370954000 & 5.979567001 \\ \mathrm{~N} & 2.379472000 & -3.959518000 & 5.073792001 \\ \mathrm{C} & 2.185059000 & -5.394897001 & 4.946190001 \\ \mathrm{C} & 1.996544000 & -0.570579000 & 4.106633000 \\ \mathrm{~B} & -2.886313000 & -5.597361001 & 1.680668000 \\ \mathrm{C} & -2.243814000 & -4.181724000 & 2.001996000\end{array}$




$\begin{array}{rrrr}\mathrm{H} & -1.104041000 & 0.681401000 & 2.113802000 \\ \mathrm{H} & 1.910742000 & -0.764003000 & -0.573895000 \\ \mathrm{H} & 0.798005000 & 1.136212000 & 0.582092000 \\ \mathrm{H} & 1.118289000 & -3.074792000 & -0.224175000 \\ \mathrm{H} & -1.892637000 & -1.619098000 & 2.476288000 \\ \mathrm{H} & 1.192487000 & -5.598869001 & 4.540488001 \\ \mathrm{H} & 2.279876000 & -5.858005001 & 5.931227001 \\ \mathrm{H} & 2.927419000 & -5.820677001 & 4.265899001 \\ \mathrm{H} & 3.789118000 & -3.948817000 & 6.705488001 \\ \mathrm{H} & 3.718085000 & -1.220493000 & 6.213715001 \\ \mathrm{H} & 2.831961000 & 0.120287000 & 4.242567001 \\ \mathrm{H} & 1.798525000 & -0.686093000 & 3.038354000 \\ \mathrm{H} & 1.103234000 & -0.157242000 & 4.584864001 \\ \mathrm{H} & -2.196258000 & -4.035505000 & 3.092707000 \\ \mathrm{H} & -2.962491000 & -3.423858000 & 1.638516000 \\ \mathrm{H} & -3.412469000 & -6.398782001 & 2.727436000 \\ \mathrm{H} & -3.013789000 & -5.989378001 & 0.323543000 \\ \mathrm{H} & -0.775756000 & -4.476061001 & 0.413145000\end{array}$

$\mathrm{BPh}_{2}$ :

Total Energy (kcal/mol): -1720920.788

Enthalpy Correction (AU): 0.475772

Free Energy Correction (AU): 0.385121

Three lowest frequencies $\left(\mathrm{cm}^{-1}\right): 9.24,21.3,36.9$

$\begin{array}{llll}\mathrm{Cu} & -1.00187 & 0.04411 & -0.35473 \\ \mathrm{C} & 0.18039 & -1.49125 & -0.02902 \\ \mathrm{C} & -0.89355 & -2.48456 & 0.19992 \\ \mathrm{C} & -1.37585 & -2.82153 & 1.47506 \\ \mathrm{H} & -2.79144 & -3.92023 & 2.64917 \\ \mathrm{C} & -2.44886 & -3.68612 & 1.64173 \\ \mathrm{C} & -2.60186 & -3.96442 & -0.72547 \\ \mathrm{C} & -3.07864 & -4.26327 & 0.54807 \\ \mathrm{H} & -1.18245 & -2.86439 & -1.89849 \\ \mathrm{C} & -1.53776 & -3.09704 & -0.89318 \\ \mathrm{H} & 0.70003 & -1.73138 & -0.96856 \\ \mathrm{H} & -3.06534 & -4.41921 & -1.60034 \\ \mathrm{H} & -3.91297 & -4.94789 & 0.68320 \\ \mathrm{H} & -0.90124 & -2.39297 & 2.35607 \\ \mathrm{C} & -2.51141 & 1.22524 & -0.56204 \\ \mathrm{~N} & -3.80138 & 0.83592 & -0.41317 \\ \mathrm{C} & -4.66606 & 1.89651 & -0.58585 \\ \mathrm{C} & -3.90359 & 2.97715 & -0.85639\end{array}$




$\begin{array}{lrrr}\mathrm{H} & -4.17043 & 4.00281 & -1.06726 \\ \mathrm{~N} & -2.59233 & 2.54697 & -0.83778 \\ \mathrm{C} & -1.44937 & 3.39990 & -1.08853 \\ \mathrm{H} & -1.38518 & 4.18659 & -0.33156 \\ \mathrm{H} & -1.52486 & 3.85441 & -2.08099 \\ \mathrm{H} & -0.54263 & 2.79366 & -1.03727 \\ \mathrm{H} & -3.41684 & -1.21513 & -0.31514 \\ \mathrm{H} & -5.11403 & -0.77821 & -0.62587 \\ \mathrm{H} & -4.42231 & -0.58847 & 1.00816 \\ \mathrm{C} & -4.21532 & -0.51221 & -0.06328 \\ \mathrm{H} & -5.73778 & 1.78501 & -0.50486 \\ \mathrm{C} & 1.18080 & -1.28744 & 1.11777 \\ \mathrm{H} & 0.64201 & -0.94218 & 2.01331 \\ \mathrm{H} & 1.66669 & -2.23792 & 1.40340 \\ \mathrm{~B} & 2.19664 & -0.19314 & 0.64192 \\ \mathrm{C} & 1.84206 & 1.33377 & 0.78449 \\ \mathrm{C} & 3.55399 & -0.62035 & -0.00973 \\ \mathrm{C} & 4.68588 & 0.20769 & -0.00092 \\ \mathrm{C} & 5.89916 & -0.21057 & -0.52662 \\ \mathrm{C} & 6.00617 & -1.46806 & -1.10328 \\ \mathrm{C} & 4.90206 & -2.31054 & -1.13038 \\ \mathrm{C} & 3.70233 & -1.89563 & -0.57516 \\ \mathrm{H} & 4.62067 & 1.19630 & 0.45143 \\ \mathrm{H} & 6.76532 & 0.44728 & -0.48949 \\ \mathrm{H} & 6.95404 & -1.79690 & -1.52513 \\ \mathrm{H} & 4.98348 & -3.30035 & -1.57520 \\ \mathrm{H} & 2.85236 & -2.57683 & -0.58413 \\ \mathrm{C} & 2.26449 & 2.28365 & -0.15813 \\ \mathrm{C} & 1.98569 & 3.63488 & -0.00963 \\ \mathrm{C} & 1.28546 & 4.08018 & 1.10407 \\ \mathrm{C} & 0.84102 & 3.16273 & 2.04714 \\ \mathrm{C} & 1.10783 & 1.81174 & 1.87877 \\ \mathrm{H} & 2.82437 & 1.95040 & -1.03118 \\ \mathrm{H} & 2.33003 & 4.34697 & -0.75782 \\ \mathrm{H} & 1.08613 & 5.14241 & 1.23692 \\ \mathrm{H} & 0.28861 & 3.50308 & 2.92102 \\ \mathrm{H} & 0.75021 & 1.10671 & 2.62827\end{array}$

$\mathrm{BPh}_{2}-\mathrm{CO}_{2}$ :

Total Energy (kcal/mol): -1839234.245

Enthalpy Correction (AU): 0.491477

Free Energy Correction (AU): 0.40091

Three lowest frequencies $\left(\mathrm{cm}^{-1}\right)$ : $-206.6,31.3,36.2$
$\begin{array}{llll}\text { C } & 0.40491 & -0.54664 & -1.98524\end{array}$
$\begin{array}{llll}\text { C } & 1.22196 & -0.73941 & -0.86609\end{array}$
$\begin{array}{llll}\text { C } & 1.31228 & -2.04941 & -0.37316\end{array}$ 


$\begin{array}{lccc}\mathrm{C} & 0.58989 & -3.09238 & -0.93136 \\ \mathrm{C} & -0.23293 & -2.86507 & -2.02899 \\ \mathrm{C} & -0.31276 & -1.58894 & -2.56272 \\ \mathrm{~B} & 2.05418 & 0.45785 & -0.22015 \\ \mathrm{C} & 3.62912 & 0.34259 & -0.23546 \\ \mathrm{C} & 4.29371 & -0.51829 & -1.11364 \\ \mathrm{C} & 5.68035 & -0.58373 & -1.16226 \\ \mathrm{C} & 6.44048 & 0.20364 & -0.31143 \\ \mathrm{C} & 5.80615 & 1.06070 & 0.57973 \\ \mathrm{C} & 4.42326 & 1.13267 & 0.60512 \\ \mathrm{C} & 1.38167 & 1.90655 & -0.19056 \\ \mathrm{C} & 0.08515 & 2.01307 & 0.59748 \\ \mathrm{C} & -1.16321 & 2.53302 & -0.01341 \\ \mathrm{C} & -2.24473 & 2.86880 & 0.83064 \\ \mathrm{C} & -3.45712 & 3.29918 & 0.32688 \\ \mathrm{C} & -3.64518 & 3.42833 & -1.04686 \\ \mathrm{C} & -2.59314 & 3.12182 & -1.89648 \\ \mathrm{C} & -1.37790 & 2.67518 & -1.39473 \\ \mathrm{Cu} & -0.96257 & 0.28987 & 0.68759 \\ \mathrm{C} & 0.63736 & 0.32444 & 2.21965 \\ \mathrm{O} & -0.01835 & 0.37525 & 3.21015 \\ \mathrm{C} & -2.14403 & -1.24656 & 0.52492 \\ \mathrm{~N} & -2.12411 & -2.40405 & 1.22443 \\ \mathrm{C} & -3.04818 & -3.30069 & 0.73111 \\ \mathrm{C} & -3.67555 & -2.68449 & -0.29299 \\ \mathrm{H} & -3.23497 & 2.53186 & 1.55009 \\ \mathrm{H} & -3.10990 & -1.43163 & -0.40264 \\ \mathrm{C} & -1.18278 & -2.69720 & 2.28888 \\ \mathrm{C} & -3.53162 & -0.43371 & -1.36508 \\ \mathrm{O} & 1.71488 & 0.06200 & 1.74507 \\ \mathrm{H} & -2.71295 & 3.23751 & -2.97259 \\ \mathrm{H} & -4.26382 & 3.54887 & 1.01354 \\ \mathrm{H} & -4.59392 & 3.78068 & -1.44479 \\ \mathrm{H} & -2.10572 & 2.77364 & 1.90864 \\ \mathrm{H} & -0.57175 & 2.45913 & -2.09179 \\ \mathrm{H} & -0.22923 & -3.03604 & 1.86996 \\ \mathrm{H} & -1.59658 & -3.47834 & 2.93072 \\ \mathrm{H} & -1.01251 & -1.79929 & 2.88470 \\ \mathrm{H} & -3.17461 & -4.28727 & 1.15285 \\ \mathrm{H} & -4.47173 & -3.01571 & -0.94388 \\ \mathrm{H} & -4.63253 & -0.89239 & -2.35300 \\ \mathrm{H} & 1.23340 & 2.19483 & -1.24364 \\ \mathrm{H} & 2.10237 & 2.64693 & 0.18615 \\ \mathrm{H} & -1.15122 & -1.78338\end{array}$




$\begin{array}{lrrr}\mathrm{H} & 6.16919 & -1.25799 & -1.86323 \\ \mathrm{H} & 7.52719 & 0.15000 & -0.33955 \\ \mathrm{H} & 6.39676 & 1.67765 & 1.25476 \\ \mathrm{H} & 3.94232 & 1.80577 & 1.31438 \\ \mathrm{H} & 1.96338 & -2.24516 & 0.47891 \\ \mathrm{H} & 0.68014 & -4.09731 & -0.51941 \\ \mathrm{H} & -0.79794 & -3.68421 & -2.47035 \\ \mathrm{H} & -0.93183 & -1.39982 & -3.43880 \\ \mathrm{H} & 0.32741 & 0.44487 & -2.43030\end{array}$

